PROGRAMA DE DOCTORADO EN INVESTIGACIÓN TRANSDISCIPLINAR EN EDUCACIÓN

\author{
TESIS DOCTORAL
}

\title{
RESULTADOS DE UN PROGRAMA DE ESTIMULACIÓN TEMPRANA EN EL SEGUNDO CICLO DE EDUCACIÓN INFANTIL: UN ESTUDIO DE CASO EVALUATIVO
}

Presentada por Sofía García Herranz para optar al grado de Doctora por la Universidad de Valladolid

Dirigida por:

DR. D. VÍCTOR MANUEL LÓPEZ PASTOR

DR. D. ANDRÉS PALACIOS PICOS 



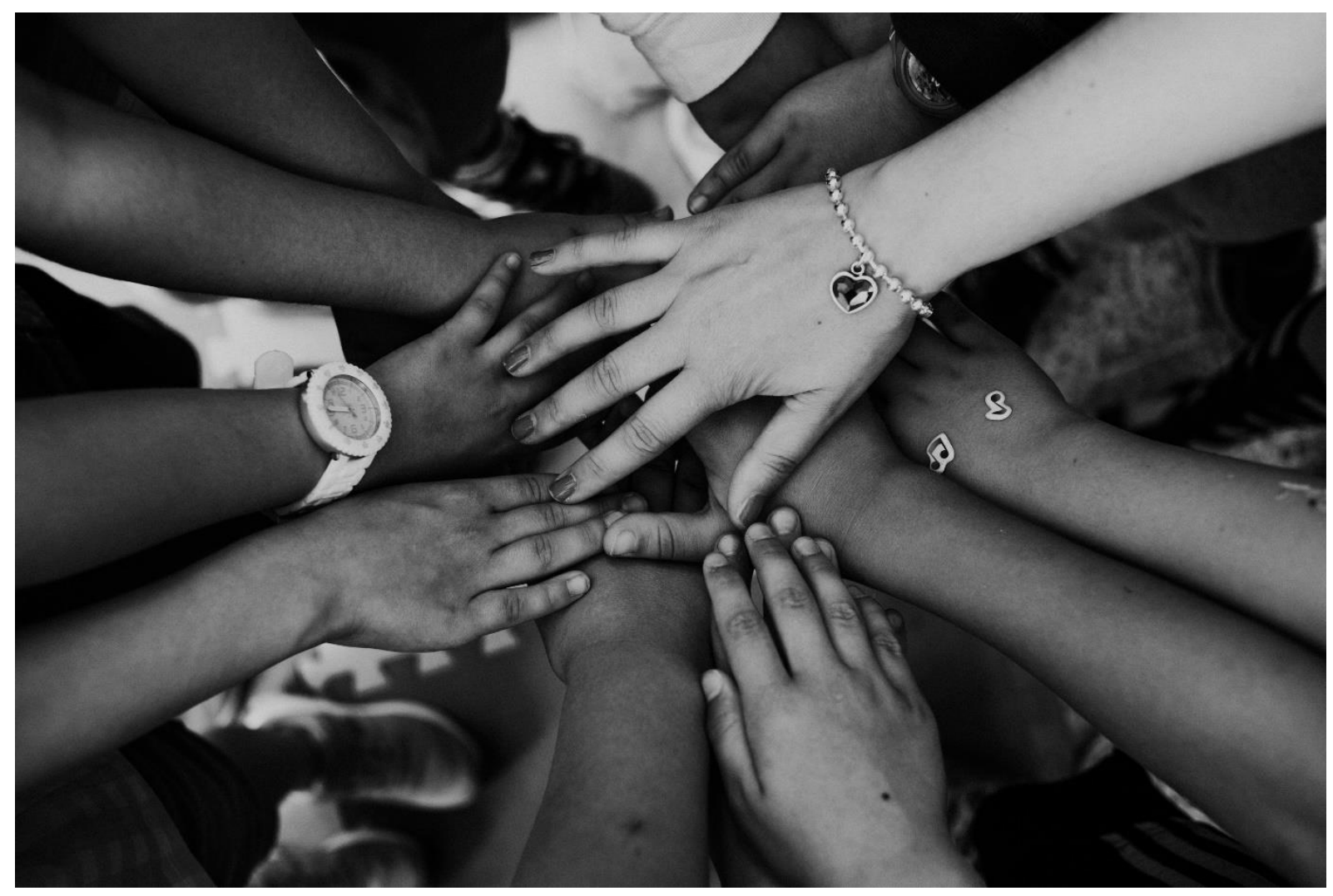

Si planificas para un aña, siembra triga.

Si planificas para una década, planta árboles.

Si planificas para una vida, EDUCA persanas.

(Kwan Tzu, 300 a.C.) 



\section{AGRADECIMIENTOS}

Todos los logros fueron antes proyectos, todos los proyectos fueron antes sueños... el logro de alcanzar este sueño de hacer mi tesis realidad, es consecuencia de muchas personas que han ocupado un puesto destacado en mí:

Sin duda, este proyecto no hubiera tomado forma sin el buen criterio de mis directores, Víctor y Andrés, por los que siento un profundo respeto y admiración. Gracias por vuestra paciencia, dedicación y motivación.

Gracias a mis pequeños, los verdaderos protagonistas de este sueño.

Gracias a mis compañeros del colegio de Cantimpalos y Torrecaballeros, por vuestro apoyo incondicional. Siempre arropada y mimada por vosotros, aprendiendo de los mejores.

Gracias a mis padres, Tere y Fernando, de los que aprendí que con esfuerzo todo se consigue, y muestra de ello lo veo cada día en mis hermanos, Sara y Víctor. Sin duda, una familia de luchadores. Especialmente a ti Sara, por todo tu esfuerzo, implicación y horas invertidas a mi lado.

Cuando cabeza y cuerpo no pueden, tira siempre la motivación, y esa motivación tiene nombre: Cati, Diana, Eva, Sara, Alicia, Noe, Aroa, María, Conchi, Cata, Cris e Isa; pilares en mi vida, hacéis posible lo imposible. Gracias de corazón.

Y por encima de todo, gracias a ti Luisen, el amor de mi vida.

A todos vosotros, mi mayor reconocimiento y gratitud. 



\section{İNDICE}

1.1 MOTIVOS POR LOS QUE HACER ESTA TESIS

1.2 OBJETO DE ESTUDIO 5

1.3 ESTRUCTURA Y CONTENIDO 5

2.MARCO TEÓRICO

2.1 ATENCIÓN TEMPRANA $\quad 8$

2.1.1 CONCEPTO DE ATENCIÓN TEMPRANA 8

2.1.2 HISTORIA Y EVOLUCIÓN DE LA AT 12

2.1.2.1 DÉCADA DE LOS AÑOS 60

2.1.2.2 DÉCADA DE LOS AÑOS 70 Y LOS $80 \quad 14$

2.1.2.3 DE LOS AÑOS 90 A LA ACTUALIDAD 17

2.1.3 ATENCIÓN TEMPRANA MULTINIVEL 18

2.1.3.1 SERVICIOS SANITARIOS 19

2.1.3.2 SERVICIOS EDUCATIVOS 20

2.1.3.3 SERVICIOS SOCIALES 22

2.1.4 LEGISLACIÓN SOBRE ATENCIÓN TEMPRANA 23

2.1.4.1 NORMATIVA INTERNACIONAL 23

2.1.4.2 NORMATIVA ESTATAL 24

2.1.4.3 NORMATIVA AUTONÓMICA EN CASTILLA Y LEÓN 30

2.2 NEUROCIENCIA Y EDUCACIÓN 32

2.3 NEUROCIENCIA COGNITIVA DEL DESARROLLO 37

2.4 BASES NEUROLÓGICAS DE LA ATENCIÓN TEMPRANA 39

2.4.1 PLASTICIDAD CEREBRAL 41

2.4.2 PERIODOS SENSIBLES 43

2.5 ESTIMULACIÓN TEMPRANA $\quad 46$

2.5.1 ESTIMULACIÓN TEMPRANA Y EL $2 \stackrel{0}{\text { CICLO DE EI }} 47$

2.5.1.1 INCLUSIÓN EN LAS AULAS DE EI 50

2.5.2 PROGRAMAS DE ESTIMULACIÓN TEMPRANA 53

2.5.2.1 PROGRAMAS DE INTERVENCIÓN PRENATAL $\quad 58$

2.5.2.2 PROGRAMAS DE INTERVENCIÓN SENSORIOMOTORA

2.5.2.3 PROGRAMAS DE INTERVENCIÓN CON NIÑOS CON DISCAPACIDAD INTELECTUAL 
2.5.2.4 PROGRAMAS DE FISIOTERAPIA NEUROLÓGICA INFANTIL 63

2.5.2.5 PROGRAMAS PARA NIÑOS CON TRASTORNOS DEL LENGUAJE 65

2.5.2.6 PROGRAMAS ALTERNATIVOS 65

2.6 MÉTODO DOMAN $\quad 68$

2.6.1 LOS INSTITUTOS DE DOMAN 69

2.6.2 ESCALA DE DESARROLLO

2.6.3 EXPERIENCIAS DEL MÉTODO DOMAN

2.6.3.1 PROGRAMA DE ESTIMULACIÓN BASADO EN BITS DE INTELIGENCIA

2.6.3.2 PROGRAMA DE ESTIMULACIÓN BASADO EN BITS DE IMÁGENES 76

2.6.3.3 PROGRAMA DE ESTIMULACIÓN VISUAL 77

2.6.3.4 PROGRAMA DE ESTIMULACIÓN PARA EL DESARROLLO DE LA CAPACIDAD LECTORA

2.6.3.5 PROGRAMA DE DESARROLLO DE LA CAPACIDAD MATEMÁTICA 79

2.6.3.6 PROGRAMA DE MOTRICIDAD $\quad 79$

2.6.3.7 PROGRAMA PSICOMOTOR DE BRAQUEACIÓN 80

2.7 EXPERIENCIAS PRÁTICAS CON PROGRAMAS DE ESTIMULACIÓN 80

3.METODOLOGÍA

\subsection{PROGRAMA DE ESTIMULACIÓN TEMPRANA PARA EL SEGUNDO CICLO DE EI 86}

3.1.1 JUSTIFICACIÓN

$\begin{array}{lll}3.1 .2 & \text { OBJETIVOS } & 87\end{array}$

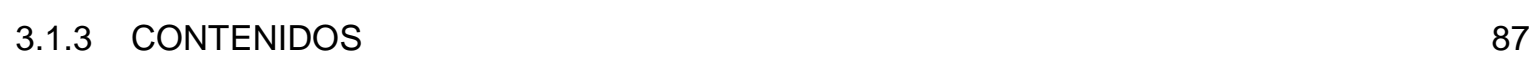

3.1.3.1 CONTENIDOS DEL ÁMBITO LECTO-ESCRITOR 87

3.1.3.2 CONTENIDOS DEL ÁMBITO LÓGICO-MATEMÁTICO 88

3.1.4 METODOLOGÍA Y RECURSOS EMPLEADOS 89

3.1.4.1 DESARROLLO DEL PROGRAMA DE ESTIMULACIÓN TEMPRANA 90

3.1.4.2 ACTIVIDADES DE APRENDIZAJE BÁSICAS 92

3.1.5 SISTEMA DE EVALUACIÓN FORMATIVA Y COMPARTIDA 107

\subsection{METODOLOGÍA DE INVESTIGACIÓN 112}

3.2.1 DISEÑO DE ESTUDIO 112

3.2.2 TÉCNICAS E INSTRUMENTOS DE OBTENCIÓN DE DATOS 115

$\begin{array}{lll}\text { 3.2.2.1 OBSERVACIÓN PARTICIPANTE } & 115\end{array}$

3.2.2.2 GRABACIONES DE VIDEOS 116

$\begin{array}{lll}3.2 .2 .3 & \text { FOTOGRAFÍAS } & 116\end{array}$

$\begin{array}{lll}\text { 3.2.2.4 DIARIO DE LA MAESTRA } & 117\end{array}$ 
3.2.2.5 BOLETINES INFORMATIVOS 117

3.2.3 ANÁLISIS DE DATOS 123

3.2.3.1 FICHA DE SEGUIMIENTO INDIVIDUAL 123

3.2.3.2 FICHA DE SEGUIMIENTO GRUPAL 131

3.2.4 CRITERIOS DE RIGOR CIENTÍFICO 139

3.2.4.1 CREDIBILIDAD 140

3.2.4.2 CONFIRMABILIDAD 141

3.2.4.3 TRANSFERIBILIDAD 142

3.2.4.4 DEPENDENCIA 142

3.2.5 CUESTIONES ÉTICO-METODOLÓGICAS 143

3.2.5.1 CONSENTIMIENTO 143

3.2.5.2 CONFIDENCIALIDAD 143

$\begin{array}{lll}3.2 .5 .3 & \text { ANONIMATO } & 144\end{array}$

3.2.5.4 HONESTIDAD Y SINCERIDAD DEL INVESTIGADOR 144

$\begin{array}{lll}3.2 .5 .5 & \text { COLABORACIÓN } & 144\end{array}$

3.2.5.6 IMPARCIALIDAD 144

3.2.5.7 RIGOR CIENTÍFICO 145

4.ANÁLISIS DE DATOS 147

4.1 TABLAS Y GRÁFICOS 148

4.1.1 TABLAS FSG CON DATOS DE ALUMNOS 150

4.1.2 TABLAS FSG CON SUMATORIOS 151

4.1.3 GRÁFICAS 152

4.1.3.1 GRÁFICAS DATOS DE ALUMNOS 152

4.1.3.2 GRÁFICAS SUMATORIO 152

4.2 INTERPRETACIÓN DE DATOS 153

4.2.1 CURSO ESCOLAR 2010/11 153

4.2.1.1 TABLAS Y GRÁFICOS DE LECTO-ESCRITURA 153

4.2.1.2 TABLAS Y GRÁFICOS DE LÓGICO-MATEMÁTICA 164

4.2.2 CURSO ESCOLAR 2011/12 173

4.2.2.1 TABLAS Y GRÁFICOS DE LECTO-ESCRITURA 173

4.2.2.2 TABLAS Y GRÁFICOS DE LÓGICO-MATEMÁTICAS 182

4.2.3 CURSO ESCOLAR 2012/13 192

4.2.3.1. TABLAS Y GRÁFICOS DE LECTO-ESCRITURA 192

4.2.3.1 TABLAS Y GRÁFICOS DE LÓGICO-MATEMÁTICA 200

5.DISCUSIÓN 209 
5.2 DISCUSIÓN DE RESULTADOS EN EL ÁMBITO LECTO-ESCRITOR 212

5.2.1 CURSO 2010/11: $3^{\circ}$ CURSO DEL 2 CICLO DE EI 212

5.2.2 CURSO 2011/12: $1^{\circ}$ CURSO DEL 2ํㅡㄴ CICLO DE EI 214

5.2.3 CURSO 2012/13: 2 CURSO DEL 2ํㅡㄴ CICLO DE EI 216

5.3 DISCUSIÓN DE RESULTADOS EN EL ÁMBITO LÓGICO-MATEMÁTICO 219

5.3.1 CURSO 2010/11: 3 CURSO DEL 2 CICLO DE EI 220

5.3.2 CURSO 2011/12: $1^{\circ}$ CURSO DEL 2을 CICLO DE EI 221

5.3.3 CURSO 2012/13: 2을 CURSO DEL 2 CICLO DE EI 223

6.CONCLUSIONES $\quad 227$

6.1 RESULTADOS CONSEGUIDOS 228

6.1.1 RESULTADOS ESPECÍFICO DEL ÁMBITO LECTO-ESCRITORE 228

6.1.2 RESULTADOS ESPECíCOS DEL ÁMBITO LÓGICO-MATEMÁTICO 229

6.1.3 RESULTADOS GENERALES 230

6.2 LIMITACIONES DEL ESTUDIO 231

6.3 PROSPECTIVA DE FUTURO 232

7.BIBLIOGRAFÍA 235

7.1 REFERENCIAS BIBLIOGRÁFICAS 236

$\begin{array}{lll}7.2 & \text { REFERENCIAS LEGISLATIVAS } & 248\end{array}$

\begin{tabular}{ll} 
8.ANEXOS & 251 \\
\hline
\end{tabular} 


\section{ÍNDICE DE FIGURAS}

FIGURA 2.1. ESCALA DEL DESARROLLO DE LA INTELIGENCIA DEL NIÑO DE DOMAN.............71

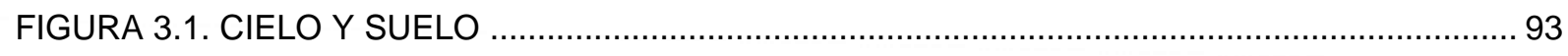

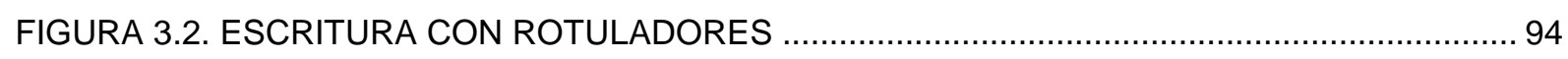

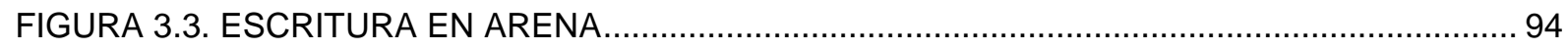

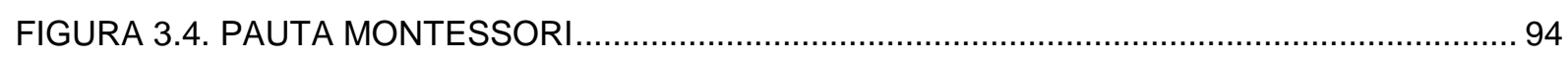

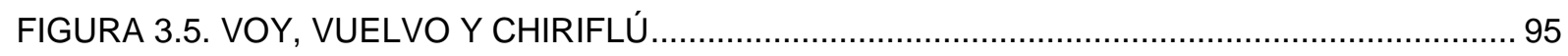

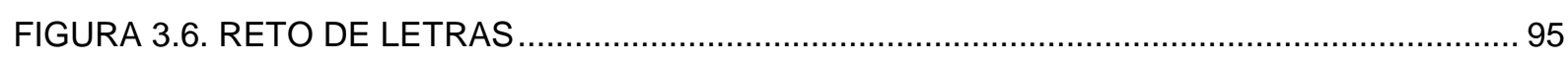

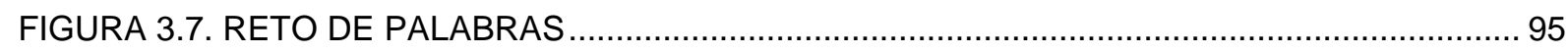

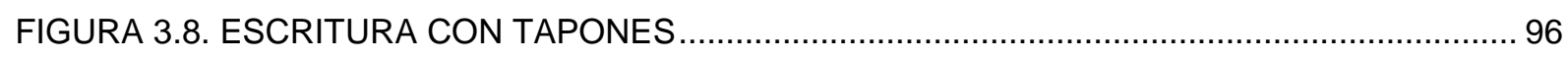

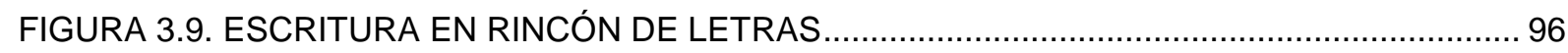

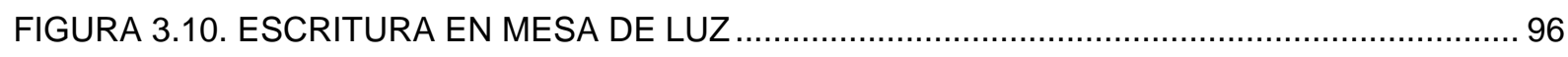

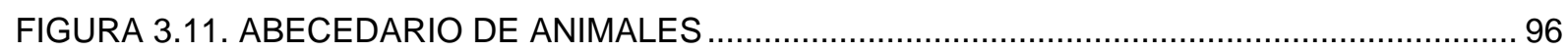

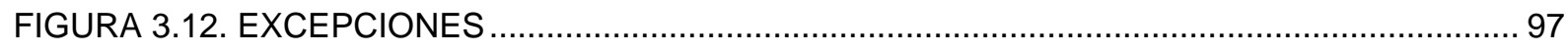

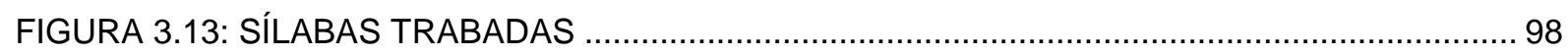

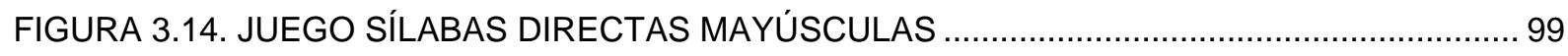

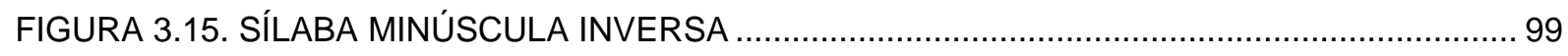

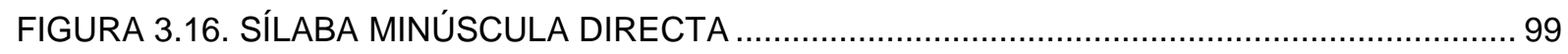

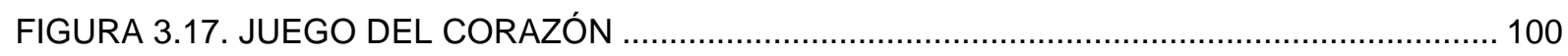

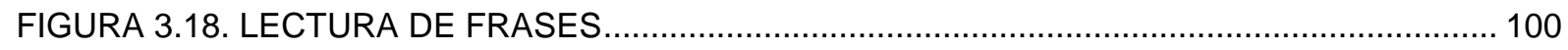

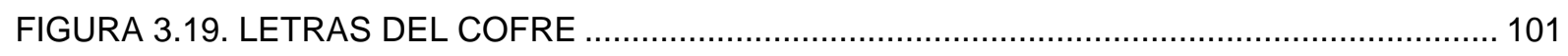

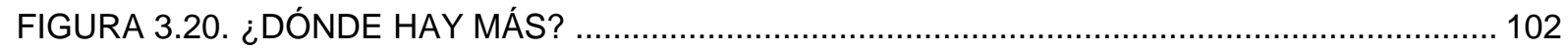

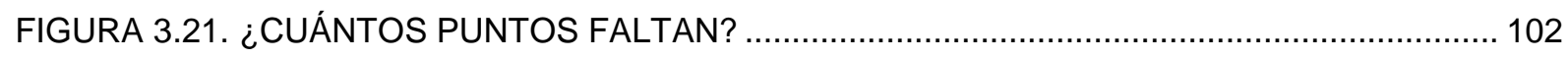

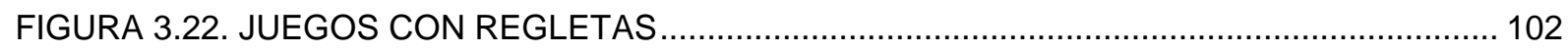

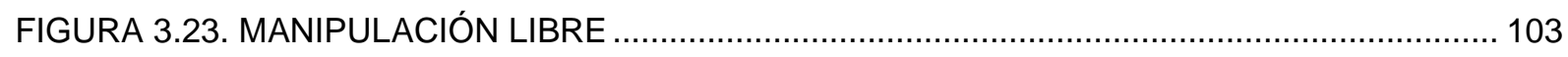

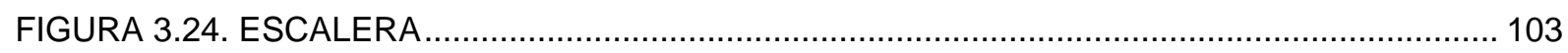

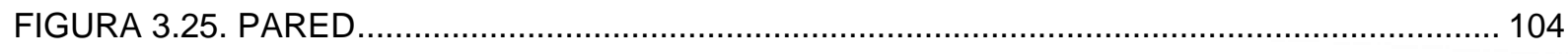

FIGURA 3.26. CREACIÓN DE NÚMEROS CON REGLETAS ......................................................... 104 


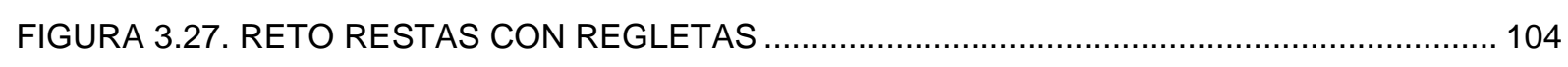

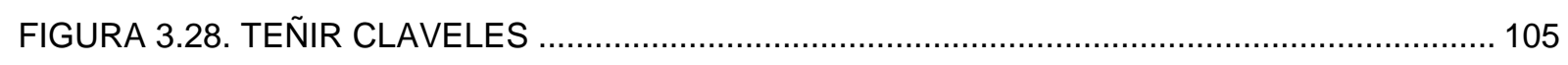

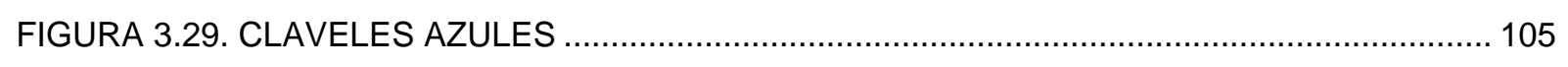

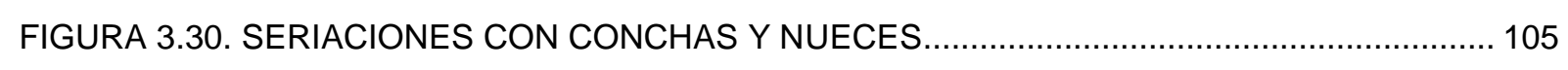

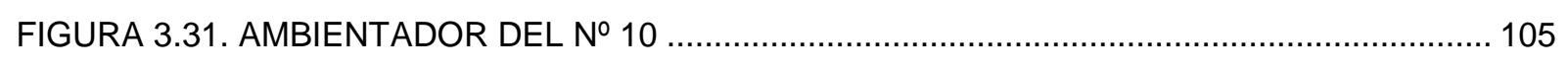

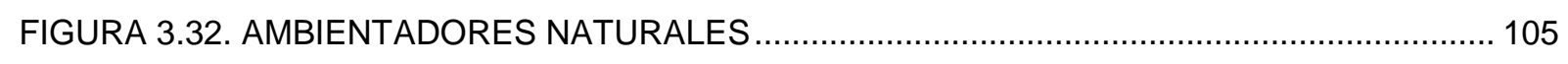

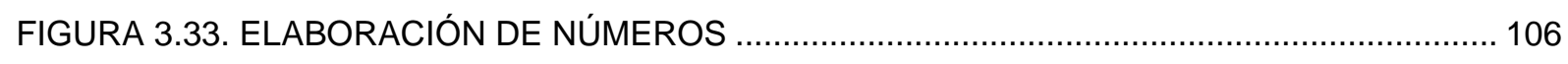

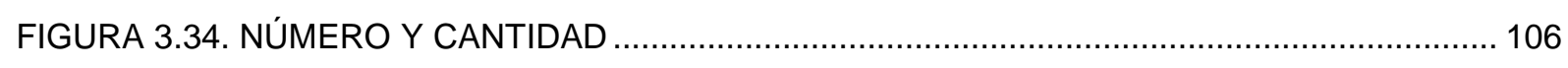

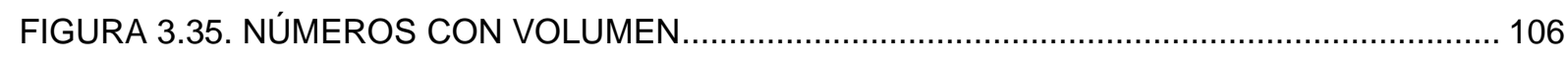

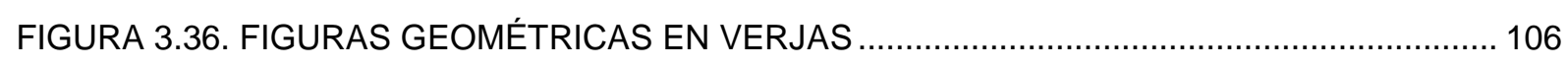

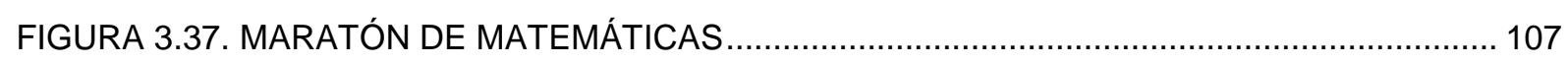

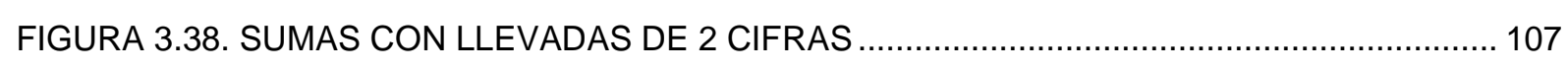

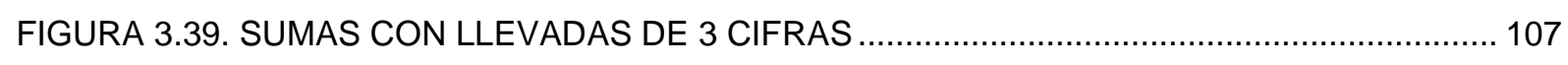

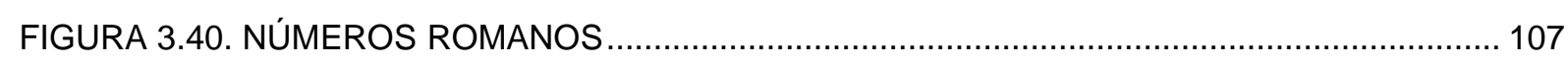

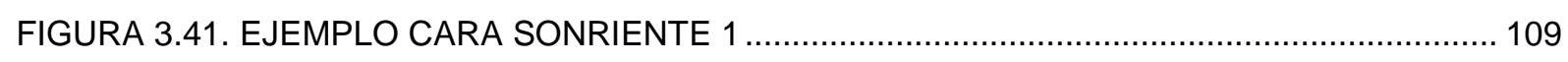

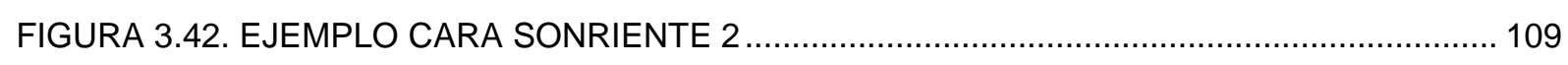

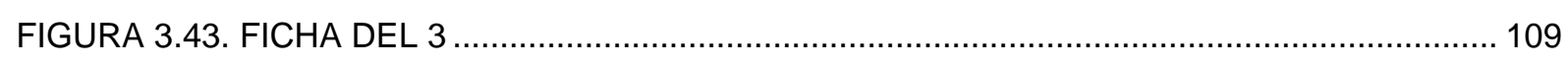

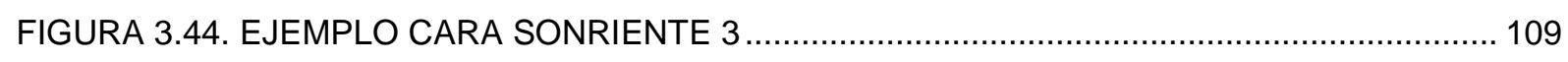

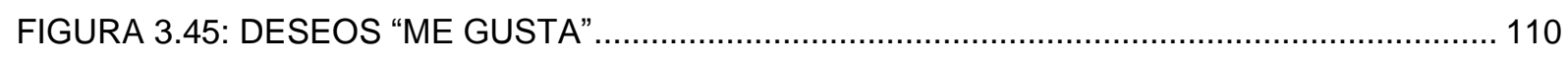

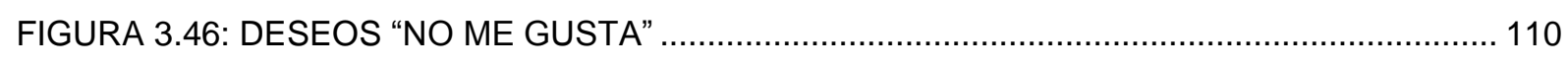

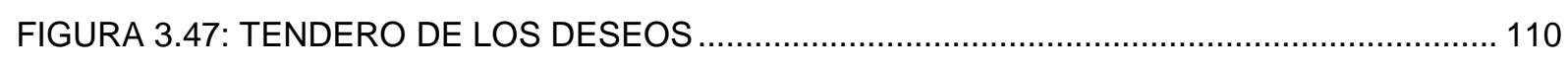

FIGURA 3.48: ACUERDO Y DESACUERDO DE CADA ALUMNO …......................................... 110

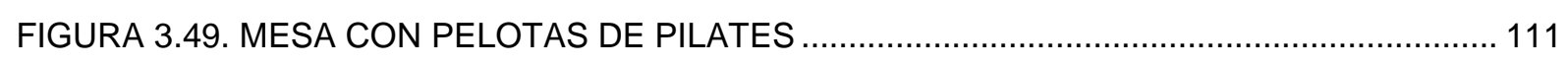

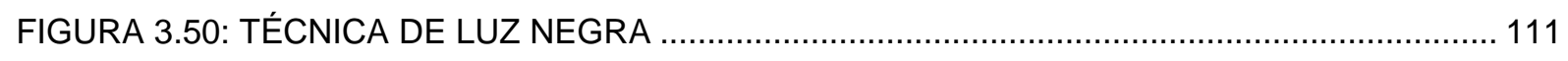

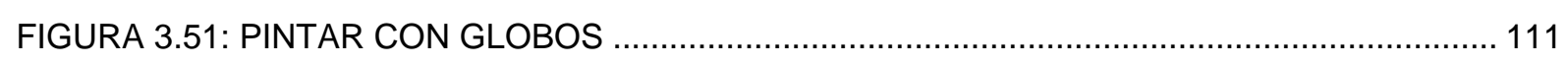

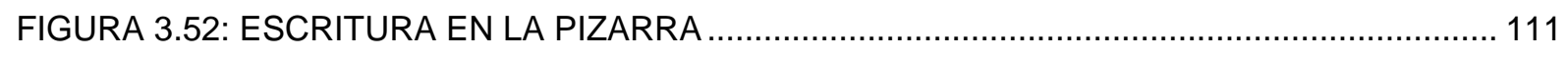

FIGURA 4.1. GRÁFICA DATOS ALUMNOS D.122 (\%): 3ํㅡㄴ LECTO-ESCRITURA (CURSO 2010/11)

FIGURA 4.2. GRÁFICA DATOS ALUMNOS BI (\%): 3ํ EI LECTO-ESCRITURA (CURSO 2010/11) 156 
FIGURA 4.3. GRÁFICA DATOS ALUMNOS PET (\%): 3ํㅡ EI LECTO-ESCRITURA (CURSO 2010/11)

FIGURA 4.4. GRÁFICA DATOS DE ALUMNOS COMPARATIVA INDICADORES LOGRO (\%): 3ㅌI

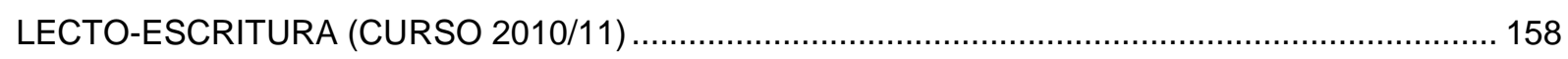

FIGURA 4.5. GRÁFICA SUMATORIO D.122 (\%): 3ํㅡ EI LECTO-ESCRITURA (CURSO 2010/11) ... 161 FIGURA 4.6. GRÁFICA SUMATORIO BI (\%): 3ํㅡㄹ EI LECTO-ESCRITURA (CURSO 2010/11) .......... 162 FIGURA 4.7. GRÁFICA SUMATORIA PET (\%): 3ํㅡㄹ LECTO-ESCRITURA (CURSO 2010/11) ....... 163 FIGURA 4.8. GRÁFICA SUMATORIO COMPARATIVA INDICADORES LOGRO (\%): 3ํㅡㄹ LIECTO ESCRITURA (CURSO 2010/11). 163 FIGURA 4.9. GRÁFICA DATOS DE ALUMNOS D.122 (\%): 3ํㅡ EI LÓGICO-MATEMÁTICA (CURSO 2010/11). 166

FIGURA 4.10. GRÁFICA DATOS DE ALUMNOS BI (\%): 3ํㅡ EI LÓGICO-MATEMÁTICA (CURSO 2010/11). 166

FIGURA 4.11. GRÁFICA DATOS DE ALUMNOS PET (\%): 3ํㅡ EI LÓGICO-MATEMÁTICA (CURSO 2010/11)

FIGURA 4.12. GRÁFICA DATOS DE ALUMNOS COMPARATIVA INDICADORES LOGRO (\%): $3^{\circ} \mathrm{EI}$ LÓGICO-MATEMÁTICA (CURSO 2010/11) 168

FIGURA 4.13. GRÁFICA SUMATORIOS D.122 (\%): 3 EI LÓGICO-MATEMÁTICA (CURSO 2010/11) 170

FIGURA 4.14. GRÁFICA SUMATORIOS BI (\%): 3ํ EI LÓGICO-MATEMÁTICA (CURSO 2010/11) 171 FIGURA 4.15. GRÁFICA SUMATORIOS PET (\%): 3 EI LÓGICO-MATEMÁTICA (CURSO 2010/11)

FIGURA 4.16. GRÁFICA SUMATORIO COMPARATIVA INDICADORES LOGRO (\%): 3ํㅡ EI LÓGICO MATEMÁTICAS (CURSO 2010/11)

FIGURA 4.17: GRÁFICA DATOS DE ALUMNOS D.122 (\%): 1 EI LECTO-ESCRITURA (CURSO 2011/12). 176

FIGURA 4.18. GRÁFICA DATOS DE ALUMNOS BI (\%): 1ํEI LECTO-ESCRITURA (CURSO 2011/12). 176

FIGURA 4.19. GRÁFICA DATOS DE ALUMNOS PET (\%): 1ํㅡ LECTO-ESCRITURA (CURSO 2011/12).

FIGURA 4.20. GRÁFICA DATOS DE ALUMNOS COMPARATIVA INDICADORES LOGRO (\%) LECTO ESCRITURA: $1^{\circ}$ EI (CURSO 2011/12) ...... 178 FIGURA 4.21.GRÁFICA SUMATORIO D.122 (\%) LECTO-ESCRITURA: 1ํㅡ EI (CURSO 2011/12) .. 180 
FIGURA 4.22. GRÁFICA SUMATORIO BI (\%) LECTO-ESCRITURA: 1 EI (CURSO 2011/12) ........ 181 FIGURA 4.23. GRÁFICA SUMATORIO PET (\%) LECTO-ESCRITURA: 1 EI (CURSO 2011/12) .... 181 FIGURA 4.24. GRÁFICA SUMATORIO COMPARATIVA INDICADORES LOGRO LECTOESCRITURA: 1ํㅡ (CURSO 2011/12) 182 FIGURA 4.25. GRÁFICA DATOS DE ALUMNOS D.122 (\%): 1ํㅡ EI LÓGICO-MATEMÁTICA (CURSO 2011/12) 185

FIGURA 4.26. GRÁFICA DATOS ALUMNOS BI (\%): 1ํ EI LÓGICO-MATEMÁTICA (CURSO 2011/12) 185

FIGURA 4.27. GRÁFICA DATOS ALUMNOS PET (\%): 1ํEI LÓGICO-MATEMÁTICA (CURSO 2011/12) 186

FIGURA 4.28. GRÁFICA DATOS DE ALUMNOS COMPARATIVA INDICADORES LOGRO (\%): 1ํI LÓGICO MATEMÁTICAS (CURSO 2010/11) 187 FIGURA 4.29. GRÁFICA SUMATORIO D.122 (\%): 1ํ EI LÓGICO-MATEMÁTICA (CURSO 2011/12) 189 FIGURA 4.30. GRÁFICA SUMATORIO D.BI (\%): 1ํ EI LÓGICO-MATEMÁTICA (CURSO 2011/12) 189 FIGURA 4.31. GRÁFICA SUMATORIO PET (\%): 1ํ EI LÓGICO-MATEMÁTICA (CURSO 2011/12) 190 FIGURA 4.32. GRÁFICA SUMATORIO COMPARATIVA INDICADORES LOGRO (\%): 1ํㅡ EI (CURSO $11 / 12)$ 191 


\section{ÍNDICE DE TABLAS}

TABLA 2.1. EVOLUCIÓN TERMINOLÓGICA DE LA AT 10

TABLA 2.2. EVOLUCIÓN DEL CONCEPTO DE AT 18

TABLA 2.3. NEUROCIENCIA: CONSIDERACIONES Y APLICACIÓN AL AULA 35

TABLA 2.4. PERIODOS SENSIBLES: CARACTERÍSTICAS Y RELEVANCIA EDUCATIVA 45

TABLA 2.5. OBJETIVOS GENERALES DEL 2 은 CICLO DE EI 48

TABLA 2.6. TIPOS DE BITS DE INTELIGENCIA

TABLA 3.1. CONTENIDOS DEL ÁMBITO LECTO-ESCRITOR 87

TABLA 3.2. CONTENIDOS DEL ÁMBITO LÓGICO-MATEMÁTICO 88

TABLA 3.3. RUTINAS DE TRABAJO DIARIAS 90

TABLA 3.4. DESARROLLO PROGRESIVO DEL PROGRAMA DE ESTIMULACIÓN TEMPRANA 91

TABLA 3.5. ACTIVIDAD: CIELO, SUELO Y CENTRO 94

TABLA 3.6. ACTIVIDAD: VOY, VUELVO Y CHIRIFLÚ 95

TABLA 3.7. ACTIVIDAD: RETOS 95

TABLA 3.8. ACTIVIDAD: ABECEDARIO DE LETRAS 96

TABLA 3.9. ACTIVIDAD: ¿CÓMO SUENA? 99

TABLA 3.10. ACTIVIDAD: JUEGO DEL CORAZÓN 100

TABLA 3.11. ACTIVIDAD: DESCUBRIMOS PALABRAS 100

TABLA 3.12. ACTIVIDAD: COFRE DE LETRAS 101

TABLA 3.13. ACTIVIDAD: PUNTOS ROJOS 101

TABLA 3.14. ACTIVIDAD: JUEGOS CON REGLETAS 102

TABLA 3.15. ACTIVIDAD: RETOS NUMÉRICOS 104

TABLA 3.16. EXPERIENCIAS MANIPULATIVAS DE LÓGICO-MATEMÁTICAS 105

TABLA 3.17. ME GUSTA, NO ME GUSTA.

TABLA 3.18. DESEOS Y CONSECUENCIA

TABLA 3.19. BOLETÍN INFORMATIVO DEL PRIMER CUSO DE EI (3 AÑOS) 118

TABLA 3.20. BOLETÍN INFORMATIVO DEL SEGUNDO CURSO DE EI (4 AÑOS) 119

TABLA 3.21. BOLETÍN INFORMATIVO DEL TERCER CURSO DE EI (5 AÑOS) 119 
TABLA 3.22. ÍTEMS BOLETINES INFORMATIVOS POR CURSO ESCOLAR Y ÁREA DE DESARROLLO

TABLA 3.23. OBJETIVOS GENERALES DE ETAPA A CONSEGUIR EN EL SEGUNDO CICLO DE

El.

TABLA 3.24. OBJETIVOS Y BLOQUES DE CONTENIDOS RELACIONADOS CON EL ÁMBITO LECTO ESCRITOR Y HABILIDADES LÓGICO MATEMÁTICAS.

TABLA 3.25. ÍTEMS DE LOS BOLETINES INFORMATIVOS DE LOS TRES CURSOS DEL 20 CICLO DE EI

TABLA 3.26. FICHA DE SEGUIMIENTO INDIVIDUAL CON ESCALA NUMÉRICA DEL 1ํ CURSO DE LECTOESCRITURA (3 AÑOS)

TABLA 3.27. FICHA DE SEGUIMIENTO INDIVIDUAL CON ESCALA NUMÉRICA DEL 2 CURSO DE LECTOESCRITURA (4 AÑOS)

TABLA 3.28. FICHA DE SEGUIMIENTO INDIVIDUAL CON ESCALA NUMÉRICA DEL 3 CURSO DE LECTOESCRITURA (5 AÑOS)

TABLA 3.29. FICHA DE SEGUIMIENTO INDIVIDUAL CON ESCALA NUMÉRICA DEL 1ํ CURSO DE LÓGICO-MATEMÁTICAS (3 AÑOS)

TABLA 3.30. FICHA DE SEGUIMIENTO INDIVIDUAL CON ESCALA NUMÉRICA DEL 2 CURSO DE LÓGICO-MATEMÁTICAS (4 AÑOS)

TABLA 3.31. FICHA DE SEGUIMIENTO INDIVIDUAL CON ESCALA NUMÉRICA DEL 3 CURSO DE LÓGICO-MATEMÁTICAS (5 AÑOS)

TABLA 3.32. FICHA DE SEGUIMIENTO GRUPAL CON ESCALA NUMÉRICA DEL $11^{\circ}$ CURSO EN LECTO ESCRITURA (3 AÑOS)

TABLA 3.33. FICHA DE SEGUIMIENTO GRUPAL CON ESCALA NUMÉRICA: 2º CURSO LECTOESCRITURA (4 AÑOS)

TABLA 3.34. FICHA DE SEGUIMIENTO GRUPAL CON ESCALA NUMÉRICA: 3 CURSO LECTOESCRITURA (5 AÑOS)

TABLA 3.35. FICHA DE SEGUIMIENTO GRUPAL CON ESCALA NUMÉRICA EN EL 1ํㅡㄴ CURO DE LÓGICO-MATEMÁTICAS (3 AÑOS)

TABLA 3.36. FICHA DE SEGUIMIENTO GRUPAL CON ESCALA NUMÉRICA EN EL $2{ }^{\circ}$ CURSO DE LÓGICO-MATEMÁTICAS (4 AÑOS)

TABLA 3.37. FICHA DE SEGUIMIENTO GRUPAL CON ESCALA NUMÉRICA EN EL 3 CURSO DE LÓGICO-MATEMÁTICAS (5 AÑOS) 
TABLA 4.3. CLAVE Y SIGNIFICADO

TABLA 4.4. CLAVE Y SIGNIFICADO

TABLA 4.5. FSG DATOS ALUMNOS LECTO-ESCRITURA: 3ํㅡ EI (CURSO 2010/11)

TABLA 4.6. FSG SUMATORIOS LECTO-ESCRITURA: 3ํㅡ EI (CURSO 2010/11)

TABLA 4.7. FSG DATOS ALUMNOS LÓGICO-MATEMÁTICA: 3ํㅡ EI (CURSO 2010/11)

TABLA 4.8. FSG SUMATORIOS LÓGICO-MATEMÁTICA: 3 EI (CURSO 2010/11)

TABLA 4.9. FSG DATOS ALUMNOS LECTO-ESCRITURA: 1ํㅡ EI (CURSO 2011/12)

TABLA 4.10. TABLA FSG SUMATORIO LECTO-ESCRITURA: 1ํ EI (CURSO 2011/12)

TABLA 4.11. FSG DATOS ALUMNOS LÓGICO-MATEMÁTICA: 1ํEI (CURSO 2011/2)

TABLA 4.12. FSG SUMATORIOS LÓGICO-MATEMÁTICA: 1ํ EI (CURSO 2011/12)

TABLA 4.13. FSG DATOS ALUMNOS LECTO-ESCRITURA: 2ํㅡㄹ (CURSO 2012/13)

TABLA 4.14. FSG SUMATORIOS LECTO-ESCRITURA: 2ํㅡㄴ (CURSO 2012/13)

TABLA 4.15. FSG DATOS ALUMNOS LÓGICO-MATEMÁTICA: 2ํㅡ EI (CURSO 2012/13)

TABLA 4.16. FSG SUMATORIOS LÓGICO-MATEMÁTICA: 2 EI (CURSO 2012/13)

TABLA 5.1. RESULTADOS PET: ÁMBITO LECTO-ESCRITOR, CURSO 2010/11 (3ํㅡ)

TABLA 5.2. RESULTADOS PET: ÁMBITO LECTO-ESCRITOR, CURSO 2011/12 (1ํㅡㄹ)

TABLA 5.3. RESULTADOS PET: ÁMBITO LECTO-ESCRITOR, CURSO 2012/13 (2ํㅡ)

TABLA 5.4. RESULTADOS PET: ÁMBITO LÓGICO-MATEMÁTICO, CURSO 2010/11 (3ํㅡㄹ)

TABLA 5.5. RESULTADOS PET: ÁMBITO LÓGICO-MATEMÁTICO, CURSO 2011/12 (1ํEI) 


\section{ACRÓNIMOS}

ACNEAE

AT

BI

BOE

BOCyL

CAT

CDIAT

D.122

EATAI

EI

FSG

FSI

GAT

IMSERSO

LOE

LOGSE

LOMCE

OGE

OMS
Alumno con necesidades específicas de apoyo educativo

Atención temprana

Boletín informativo

Boletín oficial del estado

Boletín oficial de Castilla y León

Centro de Atención Temprana

Centro de Desarrollo Infantil y Atención Temprana

Decreto $122 / 2007$

Equipo de Atención Temprana y apoyo a la integración

Educación Infantil

Ficha de seguimiento grupal

Ficha de seguimiento individual

Grupo de atención temprana

Instituto de Mayores y Servicios Sociales

Ley Orgánica de Educación

Ley Orgánica del Sistema Educativo

Ley Orgánica para la Mejora de la Calidad Educativa

Objetivo general de etapa

Organización Mundial de la Salud 
ONCE Organización Nacional de Ciegos Españoles

ONU Organización de las Naciones Unidas

PET Programa de estimulación temprana

SEREM Servicio de Recuperación y Rehabilitación de Minusválidos

SFX Síndrome frágil $X$

SN Sistema nervioso

SNC Sistema nervioso central

TIC Tecnología de la información y la comunicación

UNESCO Organización de las Naciones Unidas para la Educación, la Ciencia y la Cultura 


\section{RESUMEN}

El objeto de esta tesis es la evaluación de un programa de estimulación temprana, puesto en práctica en dos grupo de alumnos, a lo largo del segundo ciclo de Educación Infantil durante los cursos escolares 2010/11, 2011/2012 y 2012/13. Se busca evaluar los resultados obtenidos por el programa de estimulación temprana en los ámbitos lecto-escritor y lógicomatemático.

Metodológicamente, se trata de un estudio de caso evaluativo para el que hemos utilizado 5 técnicas de recogida de datos: observación participante, grabaciones de videos, fotografías, diarios de la maestra y los boletines informativos.

Para el análisis de los datos se han elaborado 48 fichas de seguimiento grupal, a partir de las cuales se han creado unas gráficas donde se recogen los principales hallazgos encontrados en relación al estudio permitiendo realizar una posterior discusión de los resultados.

Los principales resultados indican que el programa de estimulación permite: (1) un mayor desarrollo de la capacidad lectora y escritora en los alumnos, aprendiendo a leer y a escribir de una forma más natural y rápida y (2) un mayor desarrollo de la capacidad lógicomatemática en los niños, desarrollando operaciones numéricas y cálculo mental de una forma más natural y rápida.

La valoración del PET indica que el aprendizaje en el alumnado es mucho más alto que lo que establece la normativa y lo que suele ser habitual en estas edades; lo que pone de manifiesto diferentes ventajas: (1) a través del PET se desarrolla y potencia las capacidades, habilidades y destrezas de todos niños, convirtiéndose es una herramienta más al servicio del docente, de las familias y de los alumnos, que favorece el principio de inclusión; (2) el PET rompe con metodologías más tradicionales, favoreciendo un aprendizaje vivenciado, manipulativo y provocando que el alumno sea el principal responsable en su aprendizaje al formar parte activa del proceso; (3) los materiales utilizados en el PET son sencillos de diseñar y construir, permitiendo que cualquier docente pueda elaborar su propio programa de estimulación respetando los principios y fundamentos de la estimulación temprana; y (4) los buenos resultados obtenidos, favorecer la motivación de alumnos, padres y docente generando una mayor implicación y colaboración por parte de todos en el proceso de enseñanza-aprendizaje. 


\section{ABSTRACT}

The objective of this doctoral thesis is the evaluation of an early stimulation program which was implemented on two groups of students, along the second cycle of Childhood Education during the school years 2010/11, 2011/2012 and 2012/13. This thesis evaluates the results obtained for the early stimulation program in the reading-writing and logicalmathematical fields.

Methodologically, this is an evaluative case study to which 5 data collection techniques have been used: participatory observation, video recordings, photographs, teacher's diaries and newsletters.

For the data analysis, 48 group tracking cards have been prepared, and based on them, the graphics have been developed where the main findings regarding the study were included, The graphics allow a subsequent discussion of the results.

The main results indicate that the stimulation program allows: (1) a greater development of the reading and writing capacity in the students, learning to read and write in a more natural and faster way and (2) a greater development of the logic-mathematics capacity in children, developing numerical operations and mental calculation in a more natural and fastet way.

The assessment of the PET indicates that the learning in the students is much higher than established by the regulations and usual for these ages; and it shows several advantages: (1) through the PET, capabilities, abilities and skills of all children are developed, and become in another tool to be used by the teacher, families and students, and improving the inclusiviness principle; (2) the PET breaks with other more traditional methodologies, facilitating experienced and manipulative learning, and giving to the the student the main responsability into the learning due to being an active part of the process; (3) the materials used by the PET are simple to design and make, allowing to any teacher to develop their own stimulation program respecting the principles and foundations of early stimulation; and (4) the good results obtained, improving the motivation of students, parents and teachers, adressing to greater implication and collaboration of everyone involved in the teaching-learning process. 


\section{INTRODUCCIÓN}

Capítulo 1

1.1. Motivación

1.2. Objeto de estudio

1.3. Estructura y contenido 


\section{CAPITULO 1: INTRODUCCIÓN}

\subsection{MOTIVOS POR LOS QUE HACER ESTA TESIS}

Si contara las veces que personas allegadas a mí me preguntan ¿y por qué maestra de infantil? ¿Merece la pena aguantar lloros y rabietas, limpiar mocos, atar zapatos y estar todo el día agachada? La verdad, que la respuesta en sencilla: ser maestra de infantil es una vocación, un sueño, un proyecto de vida donde cada día tengo la oportunidad de observar atónita los grandes progresos de mis pequeños. Por ello, ser maestra de Educación Infantil es sencillamente un privilegio.

Como dijo Paulo Coelho "un niño siempre puede enseñar tres cosas a un adulto: a ponerse contento sin motivo, a estar siempre ocupado en algo y a saber exigir con todas sus fuerzas aquello que desea". Esta fuerza y vitalidad que los definen, hacen que la capacidad de los niños sea asombrosa, adquiriendo conocimientos casi sin esfuerzo, simplemente por curiosidad, por capacidad y por oportunidad.

Oportunidad en cuanto a que los maestros somos los encargados de ofrecer experiencias donde nuestros alumnos tengan libertad para hacer sus propias hipótesis para manipular, tocar, experimentar... en otras palabras, construir sus propios aprendizajes de forma significativa. Por tanto, y dando respuesta a la pregunta inicial, ser maestra de infantil es ser guía en la búsqueda de oportunidades de los niños, es ser diseñadora de retos y además, es ser fabricante de métodos y estrategias que provoquen conocimiento. Por esta razón, ser maestra implica un gran compromiso hacia mis alumnos y hacia la comunidad educativa. He aquí los motivos que justifican las razones del por qué hacer esta tesis:

El primer motivo que me ha llevado a realizar esta investigación es el compromiso como docente de dar a conocer mis hallazgos y contribuir a la creación de nuevos métodos de enseñanza-aprendizaje, ante la falta de experiencias prácticas en el ámbito de la estimulación temprana. Existe una queja extendida entre la comunidad educativa ante el desconocimiento de los fundamentos que sustentan la estimulación temprana, y ante la falta de información sobre técnicas y actividades concretas que permitan desarrollar la potencialidad de los alumnos. Por tanto, a través de mi investigación pretendo paliar esta limitación.

La segunda razón de peso que justifica mi investigación es proporcionar un manual que recoge actividades muy concretas, estructuradas y debidamente detalladas, que permitan a otros maestros mostrar una nueva forma de enseñar a leer, escribir e iniciarse en las habilidades matemáticas con los alumnos de Educación Infantil. Pero también, dar a conocer una propuesta de intervención en el aula fundamentada en el principio de inclusión, que 
permita potenciar las capacidades, habilidades y destrezas de todos y cada uno de los alumnos, independientemente de su nivel de desarrollo cognitivo, desventajas socioeducativa $u$ otras necesidades educativas tales como escolarización irregular o absentismo escolar. Un método de trabajo que rompe con metodologías más tradicionales y que apuesta por la individualización de la enseñanza.

\subsection{OBJETO DE ESTUDIO}

Una vez conocidas las motivaciones que me han llevado a la elaboración de la presente tesis doctoral, es conveniente definir el objeto de estudio; concretamente, este estudio posee un único objetivo de investigación: la evaluación de un programa de estimulación temprana, puesto en práctica en dos grupo de alumnos, a lo largo del segundo ciclo de Educación Infantil durante los cursos escolares 2010/11, 2011/2012 y 2012/13. Concretamente se busca evaluar los resultados obtenidos por el programa de estimulación temprana en los ámbitos lecto-escritor y lógico-matemático.

Por tanto, del objetivo principal de investigación, se desprenden dos objetivos más específicos:

(1) Evaluar los resultados obtenidos con un programa de estimulación temprana para el alumnado del $2^{\circ}$ ciclo de Educación Infantil en relación a la comprensión lecto-escritora.

(2) Evaluar los resultados obtenidos con un programa de estimulación temprana para el alumnado del $2^{\circ}$ ciclo de Educación Infantil en relación a la capacidad lógico-matemática.

\subsection{ESTRUCTURA Y CONTENIDO}

La tesis se estructura en 6 grandes bloques:

En este primer capítulo exponemos las motivaciones que nos han llevado a realizar la investigación, definiendo el objeto de estudio.

En el segundo capítulo desarrollamos el marco teórico que constituye la base que sustenta todo nuestro estudio. En él, recogemos los antecedentes históricos que abordan la atención temprana, para llegar a la conceptualización actual del término. Posteriormente nos adentraremos en el estudio de la neurociencia y su relación con el campo educativo, para llegar a definir y entender los fundamentos de la neurociencia cognitiva del desarrollo en la 


\section{CAPITULO 1: INTRODUCCIÓN}

etapa infantil, así como las bases neurológicas que delimitan la atención temprana. A continuación recogemos los aspectos más destacados que definen la importancia de la estimulación infantil en esta etapa educativa, exponiendo múltiples programas de estimulación en relación a los distintos ámbitos de desarrollo de los niños, hasta llegar al método Doman, que supone uno de los pilares que constituye el programa de estimulación temprana diseñado.

En el tercer capítulo mostramos los aspectos relacionados con la metodología. En la primera parte concretamos los objetivos, contenidos, metodología, recursos y el sistema de evaluación formativa y compartida utilizada en la aplicación del que programa de estimulación temprana en el ámbito lecto-escritor y lógico-matemático. En la segunda parte definimos la metodología propia de la investigación en relación al estudio de caso evaluativo, exponiendo las técnicas e instrumentos utilizados en la obtención de datos, así como el análisis de los datos realizados. Finalmente exponemos los criterios de rigor científico y las cuestiones éticometodológicas que avalan nuestro estudio.

En el cuarto capítulo mostramos los resultados de la investigación. Primeramente presentamos las tablas y gráficos donde se han recogido los datos del estudio; para posteriormente mostrar la interpretación de los datos obtenidos durante la investigación.

En el quinto capítulo presentamos la discusión de los resultados del objeto de estudio en el ámbito lecto-escritor y el ámbito lógico-matemático, organizados por cursos escolares, para llegar a una valoración global en cada uno de los ámbitos.

En el sexto capítulo detallamos los resultados específicos en cada ámbito de estudio para definir las fortalezas del PET. Asimismo, se incluyen las limitaciones encontradas en nuestra investigación y una prospectiva de futuro sobre posibles investigaciones para dar continuidad a nuestro estudio.

En el capítulo séptimo presentamos la bibliografía utilizada durante la consultada para la elaboración de la tesis doctoral.

Finalmente, aportamos los anexos donde se encuentran los diferentes videos utilizados para dar credibilidad a los resultados obtenidos tras la aplicación del programa de estimulación. 


\section{MARCO TEÓRICO}

Capítulo 2

2.1. Atención temprana

2.2. Neurociencia y educación

2.3. Neurociencia cognitiva del desarrollo

2.4. Estimulación temprana

2.5. Método Doman

2.6. Experiencias prácticas con programas de estimulación 


\section{CAPITULO 2: MARCO TEÓRICO}

En el presente capítulo se realizará una revisión del estado de la cuestión sobre las distintas cuestiones que afectan al objeto de estudio de la presente tesis doctoral. Comenzamos hablando de la evolución del término de atención temprana para llegar a la conceptualización actual. Seguidamente profundizaremos en el estudio de la neurociencia y las repercusiones que han tenido a nivel educativo, para comprender las aportaciones de este campo en el desarrollo cognitivo de los niños. Dada la importancia de la estimulación temprana en el periodo en el que se aplica nuestro PET, definimos los fundamentos y requisitos de este concepto para conocer diferentes programas de estimulación en relación a los ámbitos del desarrollo de la persona. Finalmente, presentamos una revisión del método Doman, analizando sus antecedentes y sus principales programas de estimulación referente clave en la elaboración del programa de estimulación temprana de nuestra investigación; para finalmente, llegar a conocer diferentes experiencias prácticas en relación a la estimulación temprana.

\subsection{ATENCIÓN TEMPRANA}

La atención temprana (en adelante AT) es un campo relativamente reciente pero con un rápido crecimiento que en unas pocas décadas se ha transformado en un área robusta de investigación, teoría y práctica.

\subsubsection{CONCEPTO DE ATENCIÓN TEMPRANA}

Los inicios de la AT se remontan a la segunda mitad de siglo, donde se comienza a hablar de AT como práctica intencionada que se aplica a sujetos que presentan algún tipo de déficit en su desarrollo; caracterizado por un marcado carácter asistencial, rehabilitador y compensatorio, sin tener en cuenta el carácter preventivo (Gutiez y Ruiz, 2012).

A partir de ese momento, se acepta por todos que la AT es un conjunto de actividades y de técnicas que tienen como objetivo el desarrollo de las capacidades de los niños en la primera infancia; lo que implica un abordaje interdisciplinar basado en la complementariedad, globalidad y unificación del proceso de detección, diagnóstico e intervención a los menores de 0 a 6 años con deficiencia o alteración del desarrollo (Gutiez y Ruiz, 2012); estas actividades contemplan al niño globalmente haciendo intervenir muy frecuentemente a la familia y al entorno. Se busca mejorar o prevenir los probables déficits en el desarrollo psicomotor de niños con riesgo de padecerlos tanto por causas orgánicas como biológicas o ambientales; creando un ambiente estimulante, adaptado a las capacidades de respuestas 
inmediatas del niño, para que estas vayan aumentando progresivamente y su evolución sea lo más parecida posible a la de un niño normal (Salvador, 1987).

Sin embargo, años después surge una nueva concepción del término AT, donde se considera como un método efectivo para combatir los efectos de la falta de estimulación experimentada de forma temprana en la vida, desechando la idea de que los primeros años de vida del niño no tienen importancia en el desarrollo. Es entonces cuando aparece una especialización disciplinar de los servicios y profesionales que atienden a este grupo, además de múltiples investigaciones que ponen de relieve la importancia de atender al desarrollo humano lo más tempranamente posible.

Este hecho hizo aflorar múltiples programas de atención en la primera infancia y el diseño de diferentes técnicas y terapias adecuadas a cada deficiencia (Vera y Pérez-López, 2009).

A partir de los años 70 el término más acuñado es el de estimulación precoz, tras iniciarse en España los programas de "estimulación precoz" cuando el SEREM (Servicio Social de Recuperación y Rehabilitación de Minusválidos Físicos y Psíquicos) destinó una serie de subvenciones para el desarrollo de estos programas. Por otro lado, este mismo organización impulsó la creación de equipos profesionales formados en la materia y creó la figura del estimulador precoz en todos los Centros Bases de España (Clemente, 2011). Un ejemplo de ello lo podemos encontrar en autores como Salvador (1987) quien defiende que la estimulación precoz supone promocionar unos determinados estímulos que van a facilitar el desarrollo global del niño para que llegue al máximo de sus potencialidades.

A finales de los años 90 encontramos autores que diferencian entre ambos conceptos, entre ellos destaca Candel (2007), quien delimita la estimulación precoz como "un tratamiento dirigido únicamente al niño" y la AT "como un conjunto de actuaciones dirigido al niño, la familia y a la comunidad" (Candel, 2007, p.10); vemos como la familia va ocupando un papel destacado que hasta el momento no tenía. Por primera vez, se plantean las necesidades y problemas de los niños desde un encuadre educativo en el que se implica a las familias; se busca como objetivo paliar la falta de estímulos y los problemas de aprendizaje de niños con deficiencias claras o simplemente de los niños incluidos en el grupo de los denominados de alto riesgo.

Esta evolución del concepto de AT se ha visto reflejada en varias máximas o implicaciones para la intervención ( Vera y Pérez-López, 2009): 


\section{CAPITULO 2: MARCO TEÓRICO}

- La intervención va dirigido tanto al niño como a sus entornos: familiar, sanitario, escolar y social.

- Es imprescindible una coordinación de todos los agentes educativos, sociales y sanitarios. Se requiere un tratamiento interdisciplinario.

- La AT va dirigida tano a niños con problemas en su desarrollo, niños con riesgo de padecerlas y a la población infantil en general.

- La intervención en AT implica valoración, detección, prevención y tratamiento en el caso que fuera necesario.

Como hemos visto, el término de AT ha ido evolucionando hasta llegar al término actual (ver tabla 2.1).

Tabla 2.1. Evolución terminológica de la AT

\begin{tabular}{|c|c|c|}
\hline AUTORES & AÑO & DEFINICIÓN \\
\hline Salvador & 1981 & $\begin{array}{l}\text { Prevenir o mejorar deficiencias en el desarrollo con niños con riesgo de } \\
\text { padecerlas }\end{array}$ \\
\hline Montenegro & 1981 & $\begin{array}{l}\text { Experiencias que el niño necesita para desarrollar al máximo su potencial } \\
\text { psicológico }\end{array}$ \\
\hline Ritcher & 1983 & Acciones ambientales ofrecidas aún antes del nacimiento \\
\hline Cabañas & 1992 & $\begin{array}{l}\text { Prevención de enfermedades en etapas tempranas y reparar sus } \\
\text { reminiscencias }\end{array}$ \\
\hline Guranlnikck & 1997 & Efectos positivos a largo plazo \\
\hline Sansalvador & 1998 & Proporciona determinados estímulos que facilitan el desarrollo del niño \\
\hline Candel & 1998 & Conjunto de actuaciones dirigidas al niño, la familia y la comunidad \\
\hline $\begin{array}{l}\text { Meisels y } \\
\text { Shonkoff }\end{array}$ & 2000 & Servicios multidisciplinares dirigidos a niños de $0-5$ años y sus familias \\
\hline Soriano & 2000 & Incluye prevención y estimulación \\
\hline GAP & 2000 & Conjunto de intervenciones dirigidas a población de 0-6 años, familia y entorno \\
\hline Guralnic & 2001 & $\begin{array}{l}\text { Sistema diseñado para apoyar patrones familiares de interacción que estimule } \\
\text { el desarrollo del niño }\end{array}$ \\
\hline $\begin{array}{l}\text { Agencia } \\
\text { Europea }\end{array}$ & 2005 & $\begin{array}{l}\text { Conjunto de actuaciones, en el entorno natural del niño, para niños pequeños } \\
\text { y sus familias }\end{array}$ \\
\hline $\begin{array}{l}\text { Samerroff y } \\
\text { Bronfenbrenn, }\end{array}$ & 2006 & $\begin{array}{l}\text { La intervención temprana incluye ambientes y contextos externos al niño: } \\
\text { familia, escuela y servicios de salud }\end{array}$ \\
\hline Brito y Pérez & 2006 & Actividades adecuadas a cada niño, situación y contexto \\
\hline Gutiez & 2010 & $\begin{array}{l}\text { tratamientos específicos que reciben los niños de } 0 \text { a } 6 \text { años que sufren una } \\
\text { discapacidad o tienen riesgo de padecerla }\end{array}$ \\
\hline UNICEF & 2013 & $\begin{array}{l}\text { Programas que dan apoyo a los niños diagnosticados con una discapacidad o } \\
\text { en riesgo de padecerlo, y cuyos objetivos se centran en el desarrollo personal, } \\
\text { la resiliencia, el fortalecimiento de aptitudes familiares y promover la inclusión } \\
\text { social de las familias y los niños }\end{array}$ \\
\hline
\end{tabular}

Elaboración propia a partir de García-Sánchez y Mendieta (1998), Clemente, (2011), Pérez, Martínez, Díaz, y Brito, (2012) y Orcaja, (2017). 
Siguiendo las aportaciones de Martínez, Fernández, y Chacón (2003) y el Libro Blanco de Atención Temprana (2000), de forma consensuada y desde un modelo global y multidisciplinar, podemos concretar el concepto de AT como:

"Conjunto de actuaciones planificadas que con carácter interdisciplinar dan respuesta a las necesidades transitorias o permanentes originadas por alteraciones en el desarrollo o por deficiencias durante los primeros años de vida, teniendo en cuenta a la familia y el contexto social donde el sujeto está ubicado" (Martínez, Fernández, y Chacón, 2003, p. 249).

"Pretende la potenciación máxima de las posibilidades psicofísicas e intelectuales del niño mediante la estimulación regulada y continuada, llevada a cabo en todas las áreas de desarrollo, pero sin forzar el curso normal y lógico de la maduración del sistema nervioso central” (Martínez, et al., 2003, p. 249).

"Conjunto de intervenciones, dirigidas a la población infantil de 0-6 años, a la familia y al entorno, que tienen por objetivo dar respuesta lo más pronto posible a las necesidades transitorias o permanentes que presentan los niños con trastornos en su desarrollo o que tienen el riesgo de padecerlos. Estas intervenciones, que deben considerar la globalidad del niño, han de ser planificadas por un equipo de profesionales de orientación interdisciplinar o transdisciplinar" (GAT, 2000, p. 12).

Por tanto, como exponen Gómez, Viguer y Cantero (2007), actualmente la AT está basada en dos supuestos fundamentales: el primero se refiere a las actividades interdisciplinares, donde los problemas a los que se enfrentan los niños con deficiencias o con vulnerabilidades específicas son potencialmente tan diversos que requieren un amplio rango de servicios para cubrir sus necesidades educativas y de bienestar; el segundo supuesto se refiere a la necesidad de desarrollar programas de intervención temprana en el contexto de la escuela y en la familia. Por tanto, se debe entender la AT como un servicio multidisciplinar encargado de proporcionados a los niños con deficiencia o evolutivamente vulnerables y sus familias, los programas recursos y técnicas necesarios (Shonkoff y Meisels, 1990).

Los aspectos esenciales que se buscan con la AT, se encuentran recogidos en los objetivos propuestos por El Libro Blanco de Atención Temprana; los resumimos en los siguientes: (1) reducir los efectos de la deficiencia; (2) optimizar el curso del desarrollo del niño; (3) aplicar medidas de compensación y adaptación a sus necesidades; (4) evitar o reducir la aparición de efectos secundarios; (5) atender a las necesidades de la familia y el entorno en el que vive el niño (6) considerar al niño como sujeto activo de la intervención (GAT, 2000).

Además, la AT incluye dos aspectos diferentes pero complementarios de gran importancia desde el punto de vista educativo: la prevención y estimulación que debe realizarse lo antes posible en la vida de un niño; y la intervención o acción educativa y rehabilitadora, que debe ponerse en marcha tan pronto como sea necesaria, en cuanto se detecta un problema, una dificultad o una deficiencia (Soriano, 2000). 


\section{CAPITULO 2: MARCO TEÓRICO}

Para finalizar, hemos de destacar los principios básicos que sustentan la AT en nuestro país, según la Agencia Europea (2005) que deben estar presentes y orientar cualquier actividad en relación a la prevención, tratamiento y rehabilitación de la población a la que va dirigida esta atención:

- Diálogo, participación e integración de todas las partes implicadas en el proceso, es decir, la familia, los profesionales y la sociedad.

- Gratuidad, universalidad e igualdad de oportunidades, lo que implica ofertar este servicio a toda la población que lo necesite.

- Interdisciplinariedad y alta cualificación profesional, como destaca Clemente (2011) la preparación de los profesionales que participan en la AT implica tanto la formación en una disciplina específica como en un marco conceptual común a todas ellas que debe tener su propio espacio de desarrollo a través de la reflexión y el trabajo en equipo.

- Coordinación entre todos los agentes implicados.

- Descentralización, apoyando a las iniciativas de comunidades, municipios y locales que pongan en marcha programas de AT.

- Sectorización, limitando el campo de actuación de los servicios para asegurando una respuesta adecuada a las demandas del niño.

\subsubsection{HISTORIA Y EVOLUCIÓN DE LA AT}

La AT surge a mediados del siglo pasado en un contexto de atención de niños con alguna deficiencia y a aquellos cuyas madres habían tenido problemas durante el embarazo y/o parto. Cuando se empezaron a comprobar los resultados que se tenían y los avances que lograban los niños, se pensó en la idea de comenzar a extender sus beneficios a los niños sanos para iniciar, lo antes posible, su estimulación. Como vemos, aunque en un principio se llama AT, cuando nació la terapia de estimulación era todo lo contrario: tardía (GonzálezGonzález, 2008). Ésta estaba reducida a unas actividades dirigidas a niños con severas limitaciones. Pronto los investigadores observaros que cuando la terapia era iniciada tarde los resultados eran pobres, por no decir nulos, mientras que cuando más temprano detectaban las limitaciones, los resultados eran mejores. Razón por la que se la denominó temprana, para hacer énfasis en la necesidad de iniciarla lo más rápido posible. 
Por tanto, la AT surgió inicialmente como un recurso terapéutico-educativo dirigido a ayudar a niños durante el primer ciclo de Educación Infantil (en adelante El) que padecían algún tipo de problema en su desarrollo, cuya principal finalidad era que pudieran alcanzar determinados objetivos que de otra manera, por sus propios medios, era improbable que pudieran conseguir. La creciente aceptación de la influencia decisiva que la experiencia temprana tiene en el desarrollo de las personas, hizo que los programas de AT pasasen a ser dirigidos exclusivamente a niños que crecía en condiciones de pobreza, con algún tipo de deficiencia o problemas de desarrollo, a generalizarse a todos aquellos que por diversas circunstancias, pudiese presentar problemas madurativos o de adaptación.

En un principio había un gran escepticismo entorno a la idea de la importancia de los primeros años para el desarrollo integral del individuo, pero poco a poco, y sobre todo a partir de los años 50 , fue creciente la aceptación de las teorías que resaltaban que la experiencia temprana ejercía una influencia decisiva en el desarrollo.

Candel (2007) señala tres factores fundamentales que contribuyen a su expansión: (1) la emergencia de doctrinas que, desde el campo de la Psicología, destacaron la importancia del medio ambiente para el desarrollo del niño; (2) la difusión de trabajos que insistieron en que las experiencias tempranas de los niños eran críticas para el desarrollo de una personalidad equilibrada y bien adaptada, resaltando la importancia de la relación madre-hijo en los primeros días de la vida de los niños y (3) los resultados de trabajos que demostraron un mayor nivel de plasticidad del sistema nervioso central.

La AT ha ido evolucionando a través de tres etapas (Gómez et. al , 2007): (a) sus inicio en Estados Unidos en la década de los años sesenta, acompañados de una importante expansión y proliferación de programas dirigidos a poblaciones de riesgo social; (b) su consolidación en los años setenta y ochenta ampliando su actuación a niños con necesidades especiales; y (c) por último, a partir de los noventa, se produce una reconceptualización de la intervención temprana y una reorganización de sus servicios.

\subsubsection{Década de los años 60}

La década de los 60 marca el inicio de la era moderna en la AT. Es una era de optimismo y de desarrollo de programas creativos. En Estados Unidos se da un fuerte apoyo público para invertir en servicios sociales y se emplean numerosos recursos para promover el logro de ambiciosas metas. En esta década se establece la guerra contra la pobreza (The war on poverty), con la dotación de gran cantidad de fondos y recursos para tratar de compensar las desigualdades sociales a las que están sometidos los niños y niñas que crecen en 


\section{CAPITULO 2: MARCO TEÓRICO}

ambientes pobres y desfavorecidos. La idea más extendida en este momento es que las experiencias tempranas son experiencias especiales que, no sólo suponen la base del desarrollo posterior, sino que además tienen un impacto desproporcionado en el curso del desarrollo.

En 1965 se pone en marcha el programa Head Start; este programa está basado en la creencia de que las experiencias de la primera infancia producen un impacto crucial en el desarrollo posterior (Pérez y Lorenzo, 2001). Fue concebido para combatir o contrarrestar las desventajas de los niños que crecen inmersos en la pobreza. Su creación fue un gran impulso, pues supuso un modelo en el campo de la intervención temprana que continúa vigente hasta la actualidad. A partir de 1965, alrededor del Head Start comenzó a desarrollarse una línea de investigación que se concretó en una gran variedad de proyectos.

Por otra parte, durante el mismo periodo de tiempo, en los centros médicos empezó a emerger una imagen más compleja sobre el niño y su desarrollo. No sólo estaba claro que el recién nacido entraba al mundo con un repertorio conductual mayor del que nunca se había pensado, sino que además, hubo un creciente reconocimiento de que durante los nueve meses de gestación el niño no está en un ambiente protegido de acontecimientos externos ni está influenciado exclusivamente por factores genéticos.

Así pues, empieza a ser más evidente que el único momento genético puro es el momento de la concepción, y que las influencias ambientales, tanto positivas como negativas, comienzan a funcionar nueve meses antes del nacimiento por conductas maternas tales como la ingestión de drogas o malos hábitos nutritivos. Junto a estas conductas, factores correlativos como la edad de la madre y la educación permiten designar unas categorías de riesgo que describen el estatus esperado del recién nacido.

Los nuevos conocimientos proveen un mayor poder predictivo concerniente al futuro curso del desarrollo y señalan la necesidad e implementar programas de optimización evolutiva que se dirijan a prevenir un desarrollo inadecuado y a promover el desarrollo óptimo.

\subsubsection{Década de los años 70 y los 80}

No es hasta la década de los 70 cuando se empieza a utilizar el término de estimulación, gracias a las aportaciones de grandes teóricos de la Medicina Rehabilitadora, la Fisioterapia, la Neurología infantil, la Psicología, la Pedagogía, etc. Entre ellos cabe destacar a Coriat, Waksman, y Thelesce (1970) y Bobath (1993) que aplicaron programas destinados a la habilitación y rehabilitación de funciones a nivel fundamentalmente motórico. 
Durante esta década se presta una atención creciente al estatus social y a los derechos legales de las personas que presentan algunas condiciones de discapacidad (Gliedman y Roth, 1980). La educación especial se convierte en la principal prioridad, y como consecuencia de ello, aumenta la demanda de profesionales de niños con necesidades especiales y comienza la especialización profesional en esta área de conocimiento (Hundert, 1994).

En cuanto a la investigación, resaltar que durante esta época gran parte de los estudios se centran en el tema de la evaluación de los efectos de la intervención. En esta línea, Lazar (1986) realiza un importante estudio sobre la persistencia de los efectos de la intervención en el que encuentra resultados que muestran el beneficio a largo plazo de los programas de intervención temprana.

A partir de los años 70 diferentes estudios se dirigen a determina si existe un periodo crítico de intervención, como señala White (1975) quien considera que todo lo que ocurre durante los primeros tres años de vida del niño es crucial y determinante, postura que también defiende Delacato (1990).

A nivel internacional, en el ámbito psicoeducativo destacan programas desarrollados por diferentes Universidades como el Proyecto Portage (Universidad de Wisconsin), el Proyecto Read (Universidad de Harvard) y el Proyecto Abecedaria (Universidad de Carolina). Además de estos programas aparecen otros dirigidos a poblaciones con características específicas como Hayden y Dimitriev (Universidad de Washington) para niños con Síndrome de Down, programas para personas con grave afectación cognitiva como el programa de Estimulación Basal o programas dirigidos a poblaciones de alto riesgo ambiental, como el proyecto Milwaukee.

En nuestro país, el origen de la AT a niños discapacidad o riesgo de tenerla, se sitúa en la década de los 70; en un contexto en el que existe una creciente sensibilidad de la sociedad ante las necesidades de los niños con problemas en su desarrollo y de sus familias; y una mayor confianza de los profesionales en poder ofrecer respuestas a estos niños y a sus familias, a partir de los avances en el conocimiento y en la experiencia en el campo de la Psicología, de la Medicina y de la Rehabilitación.

Alrededor de los años 70 surgieron instituciones españolas al servicio de la AT, como los Centros de Desarrollo Infantil y Atención Temprana (CDIAT), servicios autónomos cuyo objetivo era la atención a la población infantil de 0 a 6 años que presentaba trastornos en su desarrollo o que tenía riesgos de padecerlos. Estos centros eran de carácter interdisciplinar y 


\section{CAPITULO 2: MARCO TEÓRICO}

su creación y evolución ha sido paralela a otros servicios e instituciones que desde los ámbitos sanitario, social y educativo en las respectivas comunidades autónomas dan respuesta a esta población infantil y a sus familias.

Es también alrededor de los años 70-80 cuando se produce la expansión de asociaciones relacionadas con diferentes discapacidades (fundación ONCE, la Federación Española del Síndrome de Down, La Federación Española de Padres y Amigos de Sordos, etc.).

La implantación de la AT en nuestro país ha seguido una evolución muy diferente en cada comunidad autónoma. Se comenzó a crear asociaciones en la década de los 80 con el objetivo de perfeccionarse profesionalmente y también para alentar a las instituciones a implicarse en este ámbito. Por otro lado, también las familias se agrupan en asociaciones para atender lo más tempranamente posible las necesidades especiales de sus hijos.

Destacar que en la actualidad, la AT no tiene una normativa legal propia, y es abordada, como señala el Libro Blanco de Atención Temprana desde la sanidad, los servicios sociales y la educación.

Desde el ámbito sanitario, destacar el Plan Nacional de Prevención de la Subnormalidad en el año 1977, con el fin de controlar los niños de riesgo, así como la evolución de los niños que ya presentaban lesiones del sistema nervioso central, para poder detectar lo más precozmente anomalías en el desarrollo y poder orientar e iniciar el tratamiento oportuno.

Vista la importancia que tiene el entorno y las condiciones de adaptación cuando existe un déficit o discapacidad, los servicios sociales tenían una gran relevancia y un papel fundamental en el ámbito de la intervención temprana, tanto en las tareas de prevención como en las tareas de detección, diagnóstico e intervención. Desde los servicios sociales fueron tratadas la dimensión psicosocial y la atención a las familias.

En España, existe una red de Centros Base de INSERSO que se articula desde los servicios sociales y trabaja a través de programas personalizados cuyo objetivo es dar respuestas a las necesidades de integración social y autonómica de las personas con discapacidad. Los equipos de los Centros Base han dado un gran impulso a los programas de AT durante las dos últimas décadas. 


\subsubsection{De los años 90 a la actualidad}

En cuanto al periodo de los años 90 en adelante, Gómez et al. (2007, p.28) señalan que la característica básica es la consideración de que "los límites entre los ámbitos de bienestar social, salud mental y física, y educación temprana son cada vez menos claros, y cuanto más profundizamos en la comprensión de las complejidades del desarrollo temprano, más difícil es delimitarlo". Por este motivo se plantea la necesidad de una coordinación interinstitucional entre los diferentes ámbitos sanitario, social y educativo, de manera que el niño no reciba la intervención desde compartimentos estancos, sino que la transferencia de la información fluya entre ellos y todas las acciones que se desarrollen tengan como objeto el dar una respuesta integrada.

Una de las características de esta década, es que se centra la atención en la relación entre los padres de niños cuyo desarrollo era vulnerable y los proveedores de servicios de AT; esto dio lugar a la proliferación de programas dirigidos a padres.

En España, se forma el Grupo de Atención Temprana (GAT); la constitución de este grupo se produjo con la finalidad de elaborar el Libro Blanco de Atención Temprana, que fue publicado por el Real Patronato sobre Discapacidad en mayo de 2001. Este trabajo ha marcado un hito histórico en el ámbito de la intervención temprana en nuestro contexto. También en el año 2001 se constituye la Federación Estatal de Asociaciones de Profesionales de Atención Temprana. La Federación reúne profesionales de todo el estado con formación en los ámbitos sanitario, social y educativo. Por otra parte, también se forman grupos de trabajo que desde sus orígenes han trabajo en la organización y regulación en la Intervención Temprana como son el grupo de GENMA, el grupo PADI, GENSY, etc. Este movimiento asociativo en el sector de la intervención temprana llena el vacío institucional que todavía hoy existe en España, ya que no hay un marco normativo legal específico, ni un plan integral de atención temprana para todo el territorio estatal.

Es importante señalar que en España, en estos últimos años se han alcanzado muchos logros en el ámbito de la AT, entre los que cabe destacar la creación progresiva de una amplia red de servicios, el interés por la formación de los profesionales, la mejora de la calidad de la atención al niño y a sus familiares, etc. Sin embargo, también se han puesto en evidencia sus limitaciones, tanto en la teoría como en la práctica, entre las que se encuentran: la insuficiente cobertura de los servicios, las dificultades de coordinación, la ausencia de un marco normativo legal y un Plan Integral de la AT para todo el estado español. 


\section{CAPITULO 2: MARCO TEÓRICO}

La prevención y atención de los trastornos del desarrollo infantil temprano ha tenido diferentes respuestas a lo largo del tiempo, de acuerdo con las características científicas y asistenciales de cada momento. A medida que la AT se ha afianzado como recurso de atención a las necesidades de esta población, se han ido desarrollando diferentes iniciativas en relación con la organización de los servicios asistenciales, así como medidas relativas a la formación de los profesionales.

La evolución de los planteamientos científicos y de las necesidades asistenciales ha contribuido al desarrollo de los perfiles y de las competencias profesionales, pasando de un modelo meramente asistencial y centrado en la discapacidad del niño, a otro que asume el carácter integral de las actuaciones y que enfatiza los entornos del mismo (ver tabla 2.2).

Tabla 2.2. Evolución del concepto de AT

\begin{tabular}{|c|c|}
\hline ETAPAS & EVOLUCIÓN \\
\hline Años 60 & $\begin{array}{l}\text { - Inicios y expansión de la intervención temprana } \\
\text { - Guerra contra la pobreza } \\
\text { - Expansión de programas dirigidos a población de riesgo social } \\
\text { - Programas dirigidos a prevenir un desarrollo inadecuado }\end{array}$ \\
\hline Años 70 y 80 & $\begin{array}{l}\text { - Consolidación de la intervención temprana } \\
\text { - Compromiso hacia los niños con discapacidad } \\
\text { - Expansión de asociaciones relacionadas con discapacidad } \\
\text { - Relación entre la escuela infantil y AT }\end{array}$ \\
\hline $\begin{array}{l}\text { Años } 90 \text { hasta la } \\
\text { actualidad }\end{array}$ & $\begin{array}{l}\text { - Reconceptualización del concepto } \\
\text { - Proliferación de programas dirigidos a los padres } \\
\text { - Reorganización de los servicios de AT } \\
\text { - Formación de grupos de trabajo para la regulación de la AT }\end{array}$ \\
\hline
\end{tabular}

Fuente: elaboración propia a partir de Pérez y Brito, (2006)

\subsubsection{ATENCIÓN TEMPRANA MULTINIVEL}

El Libro Blanco de Atención Temprana (GAT, 2000), defiende que la desarrollo infantil es un proceso dinámico, sumamente complejo que se sustenta en la evolución biológica, psicológica y social, donde los primeros años de vida constituyen una etapa especialmente crítica ya que en ella se van a configurar y determinar las habilidades perceptivas, motrices, cognitivas, lingüísticas y sociales que posibilitarán una equilibrada integración con el mundo circundante. Este periodo del niño, constituye un periodo especialmente crítico puesto que se va a configurar sus habilidades y capacidades para favorecer su pleno desarrollo (Martinez, Fernández, y Chacón, 2003). 
Es por ello que la AT se aborda desde diferentes ámbitos profesionales: educación, sanidad y servicios sociales, con el objetivo de garantizar el principio de igualdad de oportunidades. La AT en la práctica, es un proceso en el que cada servicio ha de participar y colaborar para atender a la globalidad del niño (Gutiez y Ruiz, 2012). Por tanto, no se puede ver solo como una vertiente de rehabilitación, de intervención psicosocial o de la educación sino que debe formar parte de un proceso integral que tiene como fin último el desarrollo armónico de los niños integrados en su entorno (Redruello, 2004).

Como vemos, la variedad de perfiles profesionales que forma los servicios relacionados con la AT puede dividirse en tres:

\subsubsection{Servicios sanitarios}

Constituidos por médicos (rehabilitador, psiquiatra, neuropediatría, etc.), psicólogo, fisioterapeuta, logopeda y asistente social.

Diferenciamos tres niveles de prevención: (1) prevención primaria, cuyo objetivo es promover el bienestar de los niños y sus familias, en este nivel se incluye la asistencia sanitaria, el permiso de maternidad, adopciones y acogidas; (2) prevención secundaria, cuyo objetivo es detectar de forma precoz enfermedades, trastornos o situaciones de riesgo; y (3) prevención terciaria, comprenden aquellas actuaciones dirigidas a paliar situaciones de crisis biopsicosicial, como por ejemplo niños nacidos con discapacidad, niños con trastornos en el desarrollo, etc. interviniendo el equipo interdisciplinar sanitarios correspondiente.

Los servicios sanitarios con los que contamos en relación a la AT, son:

- Servicio de obstetricia: el obstetra realiza una prevención primaria, es el encargado de detectar y diagnosticar los factores de riesgo previos al embarazo, seguimiento y control en mujeres con embarazos de alto riesgo, etc.

- Servicio de neonatología: realizan una labor fundamental en prevención primaria y secundaria, ya que detectan factores del riesgo o indicadores de posibles deficiencias en el niño recién nacido y realizando la derivación a la institución correspondiente en el ámbito clínico, ecológico y social. La atención va dirigida tanto al recién nacido como a las familias, proporcionándoles los recursos necesarios.

- Pediatría de atención primaria: es el pediatra el que realiza labores de prevención primaria mediante la detección y coordinación con el resto de servicios que el niño precise. 


\section{CAPITULO 2: MARCO TEÓRICO}

\subsubsection{Servicios educativos}

Los servicios educativos están constituidos por pedagogos, psicólogos, fisioterapeutas, logopeda, maestro de pedagogía terapéutica, maestra de audición y lenguaje, maestro de educación especial y trabajador social. Puede realizar una intervención y seguimiento directo o indirecto, pero siempre de forma coordinada e informada a la familia.

La escuela se convierte en un importante contexto de intervención a través de medidas que permiten adaptar el currículo a las necesidades de cada alumno; cuenta con una serie de profesionales que hacen posible que se lleven a cabo estas medidas.

En relación con los servicios educativos, los maestros y educadores se convierten en los agentes de detección, ya que en esta etapa pueden observarse problemas en las distintas áreas del desarrollo; por tanto, como explican Gutiez y Ruiz (2012), la escuela infantil es un lugar privilegiado para realizar la prevención y la intervención en las dificultades del desarrollo, al tiempo que permite realizar una educación compensatoria en aquellos niños que pueden ver comprometido su desarrollo por carecer de estímulos socio-ambientales o familiares.

Desde este ámbito se aborda la intervención temprana en sus tres vertientes (prevención primaria, secundaria y terciaria): (1) desde la perspectiva de prevención primaria, las escuelas infantiles se convierten en un contexto en el que se realiza una tarea de prevención de posibles retrasos en el desarrollo, así como de compensación de posibles carencias; (2) a partir de la perspectiva de la prevención secundaria, una de las funciones a desempeñar por los profesionales de aula en colaboración con los equipos psicopedagógicos durante la etapa de El, es la detección de posibles necesidades educativas de los niños durante esta etapa; (3) en cuanto a la atención terciaria en la etapa, se considera que la escolarización de los alumnos con necesidades educativas especiales (en adelante ACNEAE) debe iniciarse en un contexto lo más normalizado posible, y solamente, de forma excepcional, en los casos en los que los servicios psicopedagógicos y las familias así lo consideren, estos alumnos se escolarizarán en centro de educación especial durante el segundo ciclo de El (36 años).

La relación entre los Centros de Desarrollo Infantil y de AT y la escuela infantil debe ir encaminada a proporcionar una atención educativa global, sistematizada y adecuada a la población infantil de 0 a 6 años, a contribuir a la reflexión y debate sobre propuestas organizativas y orientaciones en la escuela infantil, a apoyar, asesorar y formar tanto al maestro de apoyo como al profesor del aula ordinario, y fundamentalmente a apoyar y facilitar 
el proceso de integración y el desarrollo pleno de niños con necesidades educativas especiales (GAT, 2000).

Los principales escenarios en los que se desarrolla la AT en relación a al servicio educativo son:

- Las casas de niños: proporcionan una atención educativa a niños de 0-3 años. Sus funciones principales son atender educativamente a los niños, orientar a los padres y madres en el proceso formativo de sus hijos, facilitando espacios de reflexión y análisis de contenidos y experiencias propias de esta etapa de desarrollo y coordinarse con los servicios sociales, sanitarios y educativos de la comunidad para garantizar una atención plena e individualizad.

- Los equipos de AT: son los encargados de evaluar, coordinar, supervisar y facilitar el proceso que permite que los niños ACNEAE puedan acudir a las escuelas. La finalidad encomendada a estos equipo son evalúan al niño y elaboran el Dictamen de Escolarización, ofrecen un servicio interdisciplinar para abordar el desarrollo integral del niño sin perder la especificidad del papel de cada uno de los profesionales que van a intervenir en él (Gutiez y Ruiz, 2012). Un aspecto importante de los equipos de AT, es que se coordinan con los maestros de El en la elaboración de programas, objetivos, materiales y procedimientos adecuados para cada uno de estos alumnos.

- Centros de integración preferentes: existen centros de El en los cuales se integran niños con un tipo concreto de discapacidad (auditiva, motora, visual, etc.). De esta forma reciben la atención que precisan por personal especializado.

- Servicios sanitarios: están constituidos por los servicios de obstetricia, servicios de neonatología, unidades de seguimiento madurativo, pediatría, servicios de neuropediatría, servicios de rehabilitación infantil, servicios de salud mental, etc.

- Servicios sociales: el SEREM (servicio de rehabilitación de minusválidos) a través de sus Centros Base de valoración e intervención, crea en 1979 diferentes servicios sociales de AT. Estos son: (1) programas de promoción y bienestar social de las familias, cuyo objetivo es velar en los procesos de gestación, adopción, crianza y socialización; (2) programas de prevención dirigidos a contextos con dificultad o riesgo social, constituidos por programas de prevención primaria y secundaria que promueven un pleno desarrollo infantil en todos sus ámbitos del desarrollo; y (3) programas de intervención en Centros Base, toma como objetivo la intervención social desde los equipos de AT. 


\section{CAPITULO 2: MARCO TEÓRICO}

\subsubsection{Servicios sociales}

Intervienen pedagogos, psicólogos, médicos, fisioterapeutas, logopedas, asistente social, etc. Se realiza una intervención clínica de forma directa o indirecta con carácter ambulatorio.

Por su parte, los servicios sociales desarrollan distintas actuaciones en AT como son los programas de promoción y bienestar social con las familias, programas de prevención dirigidos a contextos con dificultad riesgo social y programas en intervención en Centros Base.

Los recursos con los que cuenta el ámbito de servicio social son:

- Los Centro Base, son dependencias del Centro Base cuyo trabajo consiste en detectar problemas o discapacidades en los niños de 0 a 6 años, realizar una valoración, un posterior diagnóstico, proporcionar las orientaciones pertinentes e indicar el tratamiento a seguir a las familias. Atienden a una población de 0-6 año que cumpla el requisito de tener concedida la calificación de minusvalía de al menos el 33\% (Gutiez y Ruiz, 2012).

- Centro de Atención Temprana (CAT): son centros que colaboran con los Centros Base y han impulsado enormemente la AT. Son centros subvencionados, que realizan labores terciarias mediante la detención, valoración e intervención terapéutica en niños con necesidades específicas o con riesgo de padecerlas y asesoramiento a las familias.

- Centros de Desarrollo Infantil y Atención Temprana (CDIAT): servicios de carácter interdisciplinar destinados a niños de 0 y 6 años que presentan alguna alteración en su desarrollo o tengan riesgo de padecerla. La función principal es la de potenciar al máximo las capacidades del niño para lograr una plena adaptación familiar, escolar y social. Este tipo de centro lo constituyen por profesionales especializados en el ámbito médico, educativo, psicológico y social. 


\subsubsection{LEGISLACIÓN SOBRE ATENCIÓN TEMPRANA}

La AT la podemos enmarcar dentro de la que ya existe sobre educación especial, y a partir de ahí ha ido encontrando un camino propio (Clemente, 2011), es por ello que se han realizado seleccionado las principales normas jurídicas en relación a la AT que se establecen a nivel internacional, europeo y estatal para terminar con una reseña a nuestra comunidad autonómica, Castilla y León.

El compendio legislativo que presentamos a continuación ha sido elaborado a partir del Libro Blanco de Atención Temprana (GAT, 2000), Redruello (2004), Clemente (2011) Robles y Sánchez (2013), y Cabrerizo, López, y Navarro (2013).

\subsubsection{Normativa internacional}

A nivel internacional, las principales leyes en relación a la AT son:

- Declaración de los Derechos del Niño, proclamada por la ONU el 20 de noviembre de 1959; establece en el principio V que el niño física o mentalmente impedido debe recibir el tratamiento, la educación y el cuidado especial que requiera en su caso particular.

- Resolución 29/35 de la XXIX Asamblea Mundial de la Salud, donde se aprueba en 1976 la Clasificación Internacional de la Organización Mundial de la Salud (OMS) donde se establecen las definiciones de deficiencia, discapacidad y minusvalía.

- Resolución 37/52 de la Asamblea General de las Naciones Unidas de 3 de diciembre de 1982, donde se aprueba el Programa de Acción Mundial para las Personas con Discapacidades y se concretan las medidas sobre prevención, rehabilitación e igualdad de oportunidades.

- En 1984 el Comité de Ministros del Consejo de Europa elabora una resolución sobre política coherente para la rehabilitación de las personas minusválidas; donde se reconoce la readaptación de las personas discapacitadas a través de la integración económica y social, para garantizar la dignidad humana y atenuar las dificultades que la sociedad plantea a las personas discapacitadas.

- Declaración de Luxor sobre los Derechos Humanos para enfermos mentales, el 17 de enero de 1989, de la Federación Mundial de la Salud Mental.

- Convención de las Naciones Unidas sobre los Derechos del Niño, aprobada el 20 de Noviembre de 1989 y ratificada por España el 30 de Noviembre de 1990; 


\section{CAPITULO 2: MARCO TEÓRICO}

la Convención a lo largo de sus 54 artículos, reconoce que los niños son individuos con derecho de pleno desarrollo físico, mental y social, y con derecho a expresar libremente sus opiniones.

- En 1992, se crea la Carta Europea de los Derechos del Niño, donde El Parlamento Europeo reconoce en esta Resolución la importancia que la infancia tiene como etapa de la vida de una persona, el papel de la familia en la satisfacción de las necesidades de los niños y el hecho de que tales necesidades engendran una serie de derechos para la infancia y, en consecuencia, obligaciones para la familia.

- Convenio de la protección del niño y la cooperación en materia de adopción en 1993; en este convenio se reconoce la necesidad de que el niño se desarrolle en un medio familiar armónico para su pleno desarrollo, se concretan medidas que permitan mantener al niño en su familia de origen y se reconoce las adopciones internacionales en el caso que fuera necesario.

- En 1995, la Declaración de Derechos del Deficiente Mental fue aprobada por la Asamblea General de las Naciones Unidas; donde las Naciones Unidas se compromete a adoptar medidas para promover niveles de vida más elevados; reafirmando su fe en los derechos humanos y las libertades fundamentales y en los principios de paz, de dignidad y valor de la persona humana y de justicia social.

- En 1995 se elabora la Guía Europea de la Buena Práctica, hacia la igualdad de oportunidades de las personas con discapacidad.

- En 1996 se establecen los principios de Buena Práctica en materia de Integración Educativa, cuyo objetivo general busca dotar a la comunidad educativa de una herramienta que mejore el aprendizaje y la participación de todos los niños y las niñas en los distintos ámbitos educativos.

- En 2002 se redacta la Carta Europea de los Derechos Fundamentales dedicando el artículo 24 a los derechos del menor, bajo los principios de dignidad, libertad, igualdad, solidaridad, ciudadanía y justicia.

\subsubsection{Normativa estatal}

Partimos de la Constitución Española de 1978 (BOE, 29 diciembre, 1978) como eje vertebrador de los servicios sociales, educativos y sanitarios, donde se defiende el progreso de la educación, cultura y de la economía para una digna calidad de vida. Los artículos más relevantes en relación a la AT son: 
$\checkmark$ Artículo 14: igualdad ante la ley.

$\checkmark$ Artículo 36: principios de normalización y de integración escolar.

$\checkmark$ Artículo 39: protección a la familia y a la infancia.

$\checkmark$ Artículo 41: régimen público de Seguridad Social que garantice la asistencia y prestaciones sociales suficientes ante situaciones de necesidad.

$\checkmark$ Artículo 43: reconoce el derecho a la protección de la salud.

$\checkmark$ Artículo 49: atención a los disminuidos físicos sensoriales y psíquicos.

Como ya hemos mencionado, el carácter interdisciplinar de la AT ha evolucionado de forma paralela a los ámbitos sanitario, social y educativo; es por ello, se ha hecho una subdivisión de la normativa existente en España referente a cada uno de los servicios.

\section{Normativa estatal en relación a los servicios educativos}

La legislación en España en el ámbito educativo, en relación a la AT, es de muy reciente creación; desde los años 70 hasta la actualidad se ha producido una proliferación de programas, nueva categorización de ACNEAE, recursos materiales, recursos personales, etc. dirigido a los alumnos de 0-6 años con o sin problemas en el desarrollo. Estos aspectos aparecen recogidos a través de la siguiente normativa estatal:

- Real Decreto 620/1981, de 5 de febrero, de régimen unificado de ayudas públicas a discapacitados (BOE, 6 de abril, 1981), donde se otorgan diferentes ayudas de carácter económico al sector de los disminuidos destinado al gasto de los servicios y atenciones que los disminuidos requieren y que no presta la propia administración central del estado ni la seguridad social, ni directamente ni mediante concierto a cargo de sus presupuestos.

- Real Decreto 1174/1983, de 27 de abril, sobre educación compensatoria (BOE, 27 de abril, 1983); recoge la educación compensatoria como garantía para conseguir unos niveles mínimos de prestación del servicio público educativo en todo el territorio español y para lograr la desaparición de las desigualdades.

- Real Decreto 334/1985, de 6 de marzo, de ordenación de la Educación Especial (BOE, 16 de marzo, 1985), ordenación de la Educación Especial y creación de los Equipos de Atención Temprana y Apoyo a la Integración (EATAI); para la atención educativa del sector de población escolar con Necesidades Educativas Especiales; este Real Decreto establecer la necesidad de intensificar el apoyo 


\section{CAPITULO 2: MARCO TEÓRICO}

psicopedagógico en los alumnos con necesidades educativas especiales a través de los Equipos compuestos por profesionales de distintas disciplinas

- Ley Orgánica 1/1991, de 3 de octubre, de Ordenación General del Sistema Educativo (LOGSE) (BOE, 4 de octubre, 1990), establece que las administraciones educativas proveerán los recursos necesarios para garantizar, en el proceso de aplicación de dicha ley, la creación de servicios especializados en los centros que impartan enseñanzas de régimen general, para favorecer la calidad y mejora de dicha enseñanza. Los artículos más destacados son:

$\checkmark$ Artículo 63: desarrollo de las acciones de carácter compensatorio a las personas que se encuentren en situaciones desfavorables.

$\checkmark$ Artículo 64: actuación preventiva y compensatoria garantizando las condiciones más favorables para la escolarización de todos los niños cuyas condiciones personales supongan una desigualdad.

$\checkmark$ Artículo 66: becas y ayudas dirigidas al estudio.

$\checkmark$ Artículo 67: programas específicos de este carácter compensatorio.

- Real Decreto 1330/1991, de 6 de septiembre, por el que se establecen los aspectos básicos del currículo de la Educación Infantil (BOE, 7 de septiembre, 1991), donde se estipula que la Educación Infantil ha de propiciar en los niños experiencias que estimulen su desarrollo personal completo, contribuyendo de manera eficaz a compensar todo tipo de desigualdades; entre otras, algunas de las carencias que tienen su origen en las diferencias del entorno social, cultural y económico, sin que ello signifique dejar de reconocer las diferencias psicológicas de los niños, que han de ser educativamente atendidas.

- Orden de 9 de diciembre de 1992, del Ministerio de Educación y Ciencia, por la que se regulan la estructura y funciones de los Equipos de Orientación Educativa y Psicopedagógica (BOE, 18 de febrero, 1992), se dicta que los Equipos de carácter interdisciplinar prestarán un servicio de asesoramiento y apoyo al sistema escolar en sus diferentes niveles; estos Equipos estarán Psicólogos, Pedagogos, Trabajadores sociales y Maestros especialistas en audición y lenguaje.

- Real Decreto 696/1995, de 28 de abril, de ordenación de la educación de los alumnos con necesidades educativas especiales (BOE, 2 de junio, 1995), donde se establecen un conjunto de medidas dirigidas a la progresiva transformación del sistema educativo con objeto de garantizar que los alumnos con necesidades especiales puedan alcanzar, en el máximo grado posible, los objetivos educativos 
establecidos con carácter general y conseguir de esta manera una mayor calidad de vida en los ámbitos personal, social y laboral.

- Orden, de 14 de febrero de 1996 por la que se regula el procedimiento para la realización de la evaluación y el dictamen de escolarización y se establecen los criterios para la escolarización de los alumnos con necesidades educativas especiales (BOE, 23 de febrero, 1996), donde se recogen los criterios para escolarizar a estos alumnos y las medidas y apoyos que deberán ser aplicadas.

- Ley Orgánica 10/2002, del 23 de diciembre, de Calidad de la Educación (LOCE) (BOE, 24 de diciembre, 2003), busca como objetivo fundamental una educación de calidad y equidad para todos.

- Real Decreto 828/2003, por el que se establecen los aspectos educativos básicos en Educación Preescolar (BOE, 1 de julio, 2003), donde se establece que los alumnos con necesidades educativas especiales, transitorias o permanentes, precisan en este período básico de su vida de una atención temprana e individualizada, contando con una respuesta apropiada y adaptada de carácter preventivo y compensador por las distintas Administraciones.

- Ley Orgánica de Educación (LOE), de 3 de mayo (BOE, 4 de mayo, 2006), a fin de garantizar la equidad, el título II aborda los grupos de alumnos que requieren una atención educativa diferente a la ordinaria por presentar alguna necesidad específica de apoyo educativo, y establece los recursos precisos para acometer esta tarea con el objetivo de lograr su plena inclusión e integración; incluyendo el tratamiento educativo de alumnos que requieren determinados apoyos y atenciones específicas derivadas de circunstancias sociales, de discapacidad física, psíquica o sensorial o que manifiesten trastornos graves de conducta; además se recogen las medidas aplicadas a los alumnos con altas capacidades intelectuales y los que se han integrado tarde en el sistema educativo español. Esta ley aboga por el principio de inclusión, entendiendo que únicamente de ese modo se garantiza el desarrollo de todos es a través de la equidad puesto que la atención a la diversidad es una necesidad que abarca a todas las etapas educativas y a todos los alumnos, se trata de contemplar la diversidad de los alumnos como un principio y no como una medida que corresponde a las necesidades de unos pocos.

- Real Decreto 132/2010, de 12 de febrero, por el que se establecen los requisitos mínimos de los centros que impartan las enseñanzas del segundo ciclo de la Educación Infantil, la Educación Primaria y la Educación Secundaria (BOE, 12 de 


\section{CAPITULO 2: MARCO TEÓRICO}

marzo, 2010), en este Real Decreto se recogen los requisitos mínimos referidos a titulación académica del profesorado, relación numérica alumno-profesor, instalaciones docentes y deportivas, y número de puestos escolares, para impartir enseñanzas con garantía de calidad.

- Ley Orgánica 8/2013, de 9 de diciembre, para la mejora de la calidad educativa, (LOMCE) (BOE, 10 de diciembre, 2013), en esta ley se constata el hecho de que todos y cada uno de los alumnos serán objeto de una atención en la búsqueda de desarrollo del talento, que convierta la educación en el principal instrumento de movilidad social, ayude a superar barreras económicas y sociales y genere aspiraciones y ambiciones realizables para todos. Toma especial importancia el reconocimiento de la diversidad entre el alumnado; se defiende una educación de calidad como soporte de la igualdad y de justicia social para garantiza la igualdad de oportunidades y hacer efectiva la posibilidad de que cada alumno desarrolle el máximo de sus potencialidades.

\section{Normativa estatal en relación a los servicios sociales}

En relación al ámbito social, la normativa referente a la AT la encontramos en siguiente normativa:

- Ley Orgánica 1/1996, de 15 de enero, de Protección Jurídica del Menor, de modificación parcial del Código Civil y de la Ley de Enjuiciamiento Civil (BOE, 17 de enero, 1996), a través de esta ley se introduce la adopción como un elemento de plena integración familiar, la configuración del acogimiento familiar como una nueva institución de protección del menor, la generalización del interés superior del menor como principio inspirador y el incremento de las facultades del Ministerio Fiscal en relación con los menores, así como de sus correlativas obligaciones. Sus artículos más destacado en relación a la AT son:

$\checkmark$ Artículos 2: la protección del derecho a la vida, supervivencia y desarrollo del menor y la satisfacción de sus necesidades básicas, tanto materiales, físicas y educativas como emocionales y afectivas.

$\checkmark$ Artículo 3: la necesidad de garantizar su igualdad y no discriminación por su especial vulnerabilidad, ya sea por la carencia de entorno familiar, sufrir maltrato, su discapacidad, su orientación e identidad sexual, su condición de refugiado, solicitante de asilo o protección subsidiaria, su pertenencia a una minoría étnica, o cualquier otra característica o circunstancia relevante. 
$\checkmark$ Artículo 11: se impulsarán políticas compensatorias dirigidas a corregir las desigualdades sociales.

$\checkmark$ Artículo 17: actuaciones en situaciones de riesgo, garantizando los derechos del menor y orientando a disminuir los indicadores de riesgo y dificultad, promoviendo medidas para su protección y preservación del entorno familiar.

- Real Decreto 1971/1999, de 23 de diciembre, de procedimiento para el reconocimiento, declaración y calificación del grado de minusvalía (BOE, 26 de enero, 2000), este Real Decreto desarrollar la normativa que regula el reconocimiento, declaración y calificación del grado de minusvalía en el ámbito de los Servicios Sociales y de la Seguridad Social, actualizando los baremos vigentes establecidos con anterioridad.

- Ley 51/2003, de 2 de diciembre, de igualdad de oportunidades, no discriminación y accesibilidad universal de las personas con discapacidad (BOE, 3 de diciembre, 2003), esta ley defiende que las personas con discapacidad constituyen un sector de población heterogéneo, pero todas tienen en común que, en mayor o menor medida, precisan de garantías suplementarias para vivir con plenitud de derechos o para participar en igualdad de condiciones que el resto de ciudadanos en la vida económica, social y cultural del país.

\section{Normativa estatal en relación a los servicios sanitarios}

Dentro del ámbito sanitario podemos destacar las siguientes leyes:

- Ley 41/2002, de 14 de noviembre, básica reguladora de la autonomía del paciente y de derechos y obligaciones en materia de información y documentación clínica (BOE, 15 de noviembre, 2002), la presente Ley completa las previsiones que la Ley General de Sanidad enunció como principios generales; refuerza y da un trato especial al derecho a la autonomía del paciente. Se estipula la regulación sobre instrucciones previas que contempla los deseos del paciente expresados con anterioridad dentro del ámbito del consentimiento informado. Asimismo, la Ley trata con profundidad todo lo referente a la documentación clínica generada en los centros asistenciales, subrayando especialmente la consideración y la concreción de los derechos de los usuarios.

- Ley 16/2003, de 28 de mayo, de cohesión y calidad del Sistema Nacional de Salud (BOE, 29 de mayo, 2003), esta ley establece acciones de coordinación y 


\section{CAPITULO 2: MARCO TEÓRICO}

cooperación de las Administraciones públicas sanitarias como medio para asegurar a los ciudadanos el derecho a la protección de la salud, con el objetivo común de garantizar la equidad, la calidad y la participación social en el Sistema Nacional de Salud: equidad, calidad y participación ciudadana.

\subsubsection{Normativa autonómica en Castilla y León}

Los servicios que dan respuesta a la AT en Castilla y León son: servicios sanitarios, servicios educativos, servicios sociales y otros servicios (ONCE). Respecto a los servicios educativos, existen 11 equipos psicopedagógicos de AT (uno por provincia y tres en Valladolid); en relación a los servicios sociales, existen 9 Centros Base (uno en cada provincia), 2 servicios municipales de AT (ambos ubicados en Burgos) y servicios de AT de diferentes asociaciones (Síndrome de Down, ASPACE, etc.); también existen 2 equipos de AT de la ONCE (en Salamanca y Valladolid) los cuales realizan una atención domiciliara con niños de 0-3 años y atención en el $2^{\circ}$ ciclo de El, en las escuelas; existen asociaciones que poseen servicios de AT y funcionan de forma autónoma.

Hemos seleccionado normativa referente a los servicios sociales y servicios educativos en Castillo y León:

\section{Normativa estatal en relación a los servicios sociales}

- Instrucción 02/05/2005, por la que se regula el Programa de AT en los Centros Base de la Gerencia de Servicios Sociales de la Consejería de Familia e Igualdad de Oportunidades de la Comunidad de Castilla y León; en esta orden se establece que la edad estipulada en Catilla y León para recibir AT es de 0 a 3 años y de 3 a 6 años en niños no escolarizados.

\section{Normativa estatal en relación a los servicios educativos}

- Decreto 122/2007, de 27 de diciembre, por el que se establece el currículo del segundo ciclo de la Educación Infantil en la Comunidad de Castilla y León (BOCyL, 2 de enero, 2007), señala en su artículo 7 que la Consejería competente en materia de educación establecerá los procedimientos que permitan identificar aquellas características que puedan tener incidencia en la evolución escolar de los niños y niñas, y facilitará la coordinación de cuantos sectores intervengan en la atención de este alumnado. Asimismo determina que la Consejería competente en materia de educación arbitrará las medidas necesarias para aquellos alumnos que precisen una atención educativa diferente a la ordinaria, por presentar necesidades 
educativas especiales, por dificultades específicas de aprendizaje, por sus altas capacidades intelectuales, o por condiciones personales.

- Orden EDU/1152/2010, de 3 de agosto, por la que se regula la respuesta educativa al alumnado con necesidad específica de apoyo educativo escolarizado en el segundo ciclo de Educación Infantil, Educación Primaria, Educación Secundaria Obligatoria, Bachillerato y Enseñanzas de Educación Especial, en los centros docentes de la Comunidad de Castilla y León (BOCyL, 13 de agosto, 2010), la presente Orden pretende regular y desarrollar los aspectos relativos a la ordenación y a la organización de la respuesta educativa al alumnado con necesidad específica de apoyo educativo, bajo los principios de calidad y equidad educativa.

- Instrucciones de 9 de julio de 2015 de la Dirección General de Innovación Educativa y Formación del Profesorado, por la que se establece el procedimiento de recogida de tratamiento de los datos relativos al alumnado con necesidades educativas específicas de apoyo educativo escolarizados en centros docentes de Castilla y León, en su anexo I se establece los distintos grupos especificando su tipología y categoría.

- Acuerdo 29/2017, de 15 de junio, de la Junta de Castilla y León, por el que se aprueba el II Plan de Atención a la Diversidad en la Educación de Castilla y León 2017-2022, desde la perspectiva de la inclusión educativa este acuerdo destaca la necesidad de ofrecer oportunidades reales de aprendizaje a todo el alumnado, en diferentes contextos educativos, y en especial a la población escolar más vulnerable y con mayor riesgo de exclusión social y/o educativa. Por tanto, los objetivos marcados en este acuerdo son: promoción de la cultura inclusiva en los centros educativos, mejora de los procesos de prevención, detección e intervención temprana de las necesidades educativas del alumnado, fomento de procesos de participación de la familia y la sociedad en los centros educativos, refuerzo y apoyo a líneas de investigación, innovación y evaluación pedagógica como estrategia que estimule el desarrollo de prácticas eficaces e inclusivas e impulse la mejora de las competencias profesionales docentes como parte de un sistema educativo de calidad e impulso de la igualdad, la cultura de la no violencia y respeto a todas las personas.

- Instrucción del 24 de agosto de 2017 de la Dirección General de Innovación y Equidad Educativa por la que se modifica la instrucción 9 de julio de 2015 de la Dirección General de Innovación Educativa y Formación del Profesorado, por la 


\section{CAPITULO 2: MARCO TEÓRICO}

que se establece el procedimiento de recogida de tratamiento de los datos relativos al alumnado con necesidades educativas específicas de apoyo educativo escolarizados en centros docentes de Castilla y León, donde se extrae del grupo de ACNEAE a los alumnos con TDAH creándose un nuevo grupo en la categoría ya existente.

\subsection{NEUROCIENCIA Y EDUCACIÓN}

Durante las últimas décadas, el estudio del sistema nervioso y sus aportaciones, demuestran la importancia de unir neurociencia y educación. Esta cooperación, idea principal que plantea Marina (2012), debe animar a los pedagogos a aprender de los neurocientíficos lo que sea útil para mejorar los planteamientos metodológicos en los centros escolares; y los neurocientíficos, deben validar y sacar información de los métodos aplicados en las aulas día a día por los educadores. Estas aportaciones deben ser recíprocas, en esta línea Marina (2012) expone como la educación debe proponer una parte de la agenda investigadora de la neurociencia. Como venimos explicando, los neurocientíficos investigan el cerebro y su funcionalidad, identificando cómo actúan tanto las neuronas individuales como las estructuras formadas por grupos pequeños o grandes de neuronas. Pero la neurociencia ha dado un paso más al intentar comprender el cerebro. Esta tarea debe ser un trabajo interdisciplinario, combinando enfoques y disciplinas, de modo que se produzcan nuevas perspectivas más potentes para su aplicabilidad en el ámbito educativo: la neuroeducación.

Debemos actualizar los sistemas de enseñanza, contribuyendo a que los aprendizajes de los alumnos sean más efectivos. El aprendizaje no es sólo acumular conocimientos; nos encontramos en una etapa clave para sentar las bases. Aportaciones de la neurociencia permitirán mejorar el sistema de enseñanza a fin de lograr un mejor aprendizaje y diseñar programas de enseñanza específicos de acuerdo con el currículum escolar. Aportaciones que permitan entender por qué determinados entornos educativos funcionan y otros no; en qué estamos fallando.

Sabemos que el proceso de desarrollo cerebral comienza en el útero materno y sigue durante las diferentes etapas del ciclo vital. Herencia genética y entorno se van entrelazando y definen la calidad de las personas. Las primeras reflexiones acerca de la importancia de considerar los aportes de las neurociencias en el ámbito educativo según Campos (2010), son:

Las instituciones educativas representan un ámbito de enorme influencia en el proceso de desarrollo cerebral ya que nuestros alumnos y alumnas pasan un promedio de 14 años y 
miles de horas en un aula. Las experiencias a las cuales están expuestos los alumnos y alumnas en el aula pueden estar armonizados o no con los sistemas naturales de aprendizaje y de memoria del cerebro, lo que va a reflejar directamente en el desarrollo del potencial cerebral. Para Campos (2010) el maestro es un agente significativo en la confluencia de la teoría y la práctica y por ello, su formación, capacitación y competencia para la innovación facilitarán la unión entre las Neurociencias y la educación.

Diferentes autores (Granier, 2000; Regidor, 2003; Uriarte, 2013) exponen que la calidad de la educación está directamente relacionada con la calidad del educado; la formación inicial del docente y el hecho de que éste siga formándose continuamente es de gran relevancia; además pone de relieve la escasez de educadores calificados en el ámbito de la neuroeducación.

El fortalecimiento de la calidad de la educación, es el sexto objetivo de la EPT (educación para todos) (UNESCO, 2006). En este sentido, Campos expone que sólo "cuando tengamos educadores de calidad, mejores propuestas curriculares, nuevas y eficientes prácticas pedagógicas, un ambiente emocionalmente positivo en los colegios, entre tantos otros factores, se logrará una educación de calidad“ (Campos, 2010, p.3).

Al analizar los informes mundiales en lo que se refiere al alto porcentaje de niños, niñas y adolescentes que no presentan las competencias, capacidades y habilidades básicas con relación a la lectura, escritura y cálculo, el índice de reprobación en los grados de primaria o la deserción escolar, llegamos a inferir que la brecha entre los resultados proyectados y los resultados reales de las reformas educativas se debe a que se ha propuesto una transformación sin antes entender que esta transformación viene desde adentro, de las estructuras mentales no sólo del educando sino principalmente del educador.

El cerebro, durante la niñez y la adolescencia sufre cambios importantes relacionados con las conexiones neuronales (tanto entre neuronas cercanas como entre grupos de neuronas situadas a larga distancia); es una etapa en la que la neurona desarrolla una gran cantidad de conexiones. Si el docente dirige bien esta explosión de conexiones estará modelando, dirigiendo y reorganizando el cerebro en torno a un proceso educativo de calidad; como indica Ortiz (2009) se estará esculpiendo el cerebro de los niños para el logro de una verdadera obra de arte.

Como se ha expuesto, experiencia y aprendizaje son factores claves para modelar el cerebro. La experiencia proporcionada en el ámbito educativo modela el cerebro a través de múltiples sinapsis; las conexiones poco utilizas van desapareciendo y toman fuerza las 


\section{CAPITULO 2: MARCO TEÓRICO}

sinapsis más activas. La educación lo hace de una forma intencionada y dirigida. Los docentes debemos conocer las implicaciones de esta circunstancia, para desarrollar al máximo las potencialidades de nuestros alumnos. Debemos aprovechar de forma consciente las posibilidades que el cerebro nos brinda, puesto que las capacidades cognitivas están programadas genéticamente sólo como potencialidad, y es a través de la interacción entre aprendizaje y educación como se desarrollan (De La Barrera y Donolo, 2009).

Durante los primeros 15 años es cuando las asociaciones de neuronas se deciden, y durante ese periodo se va configurando una red de células nerviosas. Es precisamente en la etapa escolar (de 3 a 12 años) cuando el cerebro se alimenta, en mayor medida, de estímulos a través de los órganos de los sentidos. Cada cerebro es único, irrepetible, aunque su anatomía y funcionalidad sean diferentes entre una persona y otra, además está programado para aprender. Cada cerebro capta el aprendizaje de una forma concreta; por ello, los docentes debemos conocer cómo se produce el aprendizaje en el cerebro, qué experiencias pueden mejorar o perjudicar en el aprendizaje de nuestros alumnos. A la hora de diseñar nuestras programaciones de aula o elaborar planes, programas o proyectos a nivel de ciclo (en El), internivel (en Educación Primaria) o a nivel de centro, debemos incorporar aquellas metodologías o estrategias que proporcionen al alumno diferentes oportunidades para provocar conocimiento de una manera natural y desarrollando todo el potencial de cada alumno.

Sabemos que el cerebro no utiliza una única forma de aprender o una única ruta de aprendizaje. Es necesario propiciar diferentes estrategias y experiencias. Gardner (2016) aporta luz en relación a cómo el cerebro humano necesita de las múltiples inteligencias para dar lugar a un aprendizaje significativo. Explica, en su teoría, que el cerebro no cuenta con sólo un tipo de inteligencia, sino con varias inteligencias que están interconectadas entre sí pero que a la vez pueden trabajar de manera independiente y tener un nivel individual de desarrollo. Estas aportaciones llevadas al ámbito de la educación, pueden ofrecernos herramientas para proporcionar distintos tipos de enseñanzas. Necesitamos una educación donde los alumnos aprendan de forma integral y globalizada, y no parcelada por materias o asignaturas. Debemos ofrecer estrategias educativas para que los alumnos utilicen diferentes recursos que les permite aprender a aprender; desarrollen competencias que les sirva para desenvolverse en la vida; capacidades que hagan despertar en ellos los recursos necesarios para desentrañar misterios, afrontar retos y superar obstáculos.

Toda esta información que tenemos sobre el cerebro humano, órgano responsable del aprendizaje, se ha visto incrementada debido al desarrollo de las nuevas técnicas de visualización cerebral. Como consecuencia, aparece una nueva disciplina en la que 
convergen los conocimientos generados por la neurociencia, la educación y la psicología. Éstas, nos aportan información muy valiosa sobre el proceso de enseñanza y aprendizaje. La neuroeducación consiste en aprovechar los conocimientos sobre el funcionamiento cerebral para enseñar y aprender mejor (véase tabla 2.3).

Tabla 2.3. Neurociencia: consideraciones y aplicación al aula

\begin{tabular}{|l|l|}
\hline CONSIDERACIONES & APLICACIÓN EN EL AULA \\
\hline $\begin{array}{l}\text { El cerebro humano es extraordinariamente plástico. } \\
\text { Adapta su actividad y cambia su estructura a lo largo } \\
\text { de toda la vida; siendo más eficaz en los primeros años } \\
\text { de vida (periodo sensible para el aprendizaje). Esta } \\
\text { plasticidad cerebral posibilita la mejora del alumno a } \\
\text { través de la experiencia; fortaleciendo o debilitando las } \\
\text { sinapsis que conectan las neuronas. }\end{array}$ & $\begin{array}{l}\text { La aplicación de programas de estimulación } \\
\text { temprana permite que exista un mejor aprendizaje. }\end{array}$ \\
\hline $\begin{array}{l}\text { Las emociones mantienen la curiosidad, nos sirven } \\
\text { para comunicarnos y son imprescindibles en los } \\
\text { procesos de razonamiento y toma de decisiones. Los } \\
\text { procesos emocionales y los cognitivos son } \\
\text { inseparables (Damasio, 2011) }\end{array}$ & $\begin{array}{l}\text { Desde el aula, se debe favorecer climas } \\
\text { alumnocionales positivos y seguros para nuestros }\end{array}$ \\
\hline $\begin{array}{l}\text { La neurociencia resalta la importancia de hacer del } \\
\text { aprendizaje una experiencia positiva y agradable. }\end{array}$ & $\begin{array}{l}\text { Utilizar estrategias y metodologías activas que } \\
\text { fomenten la creatividad, provoquen conocimiento a } \\
\text { través de la experimentación, manipulación y } \\
\text { actividad del alumno. }\end{array}$ \\
\hline $\begin{array}{l}\text { La práctica regular de la actividad física (principalmente } \\
\text { el ejercicio aeróbico) promueve la neuroplasticidad y la } \\
\text { neurogénesis en el hipocampo, facilitando la memoria } \\
\text { de largo plazo y un aprendizaje más eficiente (Ảberg et } \\
\text { al., 2009). }\end{array}$ & $\begin{array}{l}\text { Desde los centros deben potenciarse las sesiones } \\
\text { de psicomotricidad y las actividades al aire libre. }\end{array}$ \\
\hline $\begin{array}{l}\text { El cerebro conecta la nueva información con la ya } \\
\text { conocida, por lo que aprendemos mejor y más } \\
\text { rápidamente cuando relacionamos la información } \\
\text { novedosa con los conocimientos ya adquiridos. }\end{array}$ & $\begin{array}{l}\text { Para optimizar el aprendizaje, el cerebro necesita la } \\
\text { repetición de todo aquello que tiene que asimilar. } \\
\text { Los niños deben aprender jugando. }\end{array}$ \\
\hline
\end{tabular}

Elaboración propia a partir de Ortiz (2009)

El alumno debe ser el protagonista de su propio aprendizaje. Debe aprender haciendo, actuando, por ensayo y error. Y si además planteamos actividades que despierten su interés, motivadoras, en un clima emocional adecuado favorecernos un aprendizaje duradero.

Como docentes no debemos planificar y programar clases donde sólo se trabaje con uno o varios estilos de aprendizaje, priorizando la ruta visual, auditivo, lingüístico o lógico. El cerebro aprende con diferentes estilos. La plasticidad y capacidad del cerebro para aprender a través de distintos estilos, hace necesario el uso de un abanico de propuestas, ideas y experiencias que den lugar al proceso de enseñanza y aprendizaje. Por tanto, para que el cerebro forme una buena ruta para el aprendizaje, necesita entornos adecuados y enriquecidos, recursos multisesoriales, el cuerpo, un ambiente adecuado, motivación, etc. Si además, ofrecemos estos estímulos en los periodos sensibles para que se dé un correcto aprendizaje, estaremos contribuyendo a la formación integral de nuestros alumnos. Sin 


\section{CAPITULO 2: MARCO TEÓRICO}

olvidar, materiales y espacios concretos, estrategias educativas adaptadas a las necesidades y ritmos de nuestros alumnos, actividades variadas y adaptadas al contexto, etc. nos permitirá que el nuevo aprendizaje sea adquirido de forma significa y se desarrolle nuevas conexiones sinápticas.

Las aportaciones que nos trae la neuroeducación, muestran sus grandes posibilidades en el campo educativo. Ahora sabemos que todos tenemos un cerebro plástico, apto para aprender y favorecido por unos periodos sensibles. Esta ciencia, hace que los docentes entendamos las particularidades del sistema nervioso y del cerebro y, a la vez, relacione este conocimiento con el comportamiento de sus alumnos. No obstante, para hablar de calidad educativa, los docentes debemos integrar propuestas innovadoras a nuestra forma de trabajar. Por tal razón, "es de vital importancia implementar en nuestras aulas nuevos componentes que abran camino a un nuevo modelo de práctica pedagógica, un modelo que considere la armonía entre el cerebro, el aprendizaje y el desarrollo humano" (Campos, 2010, p.13).

Un requisito necesario en nuestras aulas, es que todo agente educativo conozca y entienda cómo aprende el cerebro del niño, cómo procesa la información, cómo controla las emociones, los sentimientos, los estados conductuales, o cómo es frágil frente a determinados estímulos. Desde el punto de vista educativo, el conocimiento de esta ciencia es necesaria para la innovación y transformación de los planteamientos educativos actuales y para el fortalecimiento de una educación de calidad. Por tanto, conocer el cerebro y el sistema nervioso, abre grandes posibilidades para los educadores y aquellos agentes buscan promover el desarrollo del ser humano; sacando así el máximo partido a sus potencialidades; de esta forma la neuroeducación puede contribuir considerablemente a disminuir la brecha entre las investigaciones neurocientíficas y la práctica pedagógica (Campos, 2010).

En esta misma línea, Marina (2012) señala que debemos propiciar verdaderas oportunidades de entendimiento de la propuesta de aprendizaje que certifique que los alumnos lo estén incorporando de forma adecuada. Los docentes no podemos limitarnos a clases donde se explica la lección y el alumno realiza una serie de ejercicios; necesitamos que los estudiantes reflexionen, aprendan de los aciertos y errores, exista feed-back entre docentes y alumnos, se dé lugar a discusiones grupales, grupos interactivos, debates, tertulias dialógicas, se propongan proyectos de investigación a partir de las inquietudes del alumnado... en definitiva, promover un estilo de aprendizaje donde se utilicen el mayor número de rutas sensoriales y donde haya cabida a todas las múltiples inteligencias. 
Uno de los objetivos de la neurociencia en el campo de la educación, es la posibilidad de modificar y modelar las estructuras cerebrales que subyacen a los diferentes procesos de aprendizaje. Como sugiere Ortiz (2009) es necesario sensibilizar a maestros y educadores sobre la trascendencia que tienen sus enseñanzas en el modelo estructural del cerebro del niño, sobre la gran capacidad que tiene el cerebro para reorganizar redes neuronales, para utilizar diferentes áreas compensatorias de otras hipofuncionantes, para colonizar áreas no diseñadas genéticamente para un determinado proceso y si conseguimos ir de la mano en la organización de programas educativos, podríamos lograr entre todos mejorar enormemente la dinámica cerebral y la capacidad de aprendizaje de nuestros alumnos (Ortiz, 2009, p.31).

Así, la idea presentada por las investigaciones actuales en relación con la construcción de una ciencia del aprendizaje y la educación se puede sintetizar en dos ideas claves: (1) la necesidad de que los educadores utilicen los hallazgos y evidencias de la neurociencia cognitiva para su práctica generándose novedades y conocimiento científico relevante, para la educación en general a través de un diálogo fluido y en colaboración con los investigadores; y (2) favorecer los descubrimientos de los hallazgos para que puedan ser difundidos entre los educadores, colaborando en la generación de evidencias y de descubrimientos neurocientíficos que pueda relacionarse con la educación favoreciendo la construcción y revisión de nuevos conocimientos.

Por tanto, los maestros debemos convertirnos en mediaros y guías que favorezcan experiencias. El cerebro está preparado para archivar lo aprendido en las aulas en sus sistemas de memoria; para que esas conexiones sinápticas sean fuertes y creen una red de conexión neuronal potentes, es necesario repasar los conocimientos en determinados momentos, con una intensidad, frecuencia y duración concreta, para consolidar los aprendizajes. Todo lo expuesto justifica la importancia de llevar a cabo PET bien diseñados y programados, ajustados a las necesidades de nuestros alumnos.

Por tanto, integrar neurociencia cognitiva y educación, es hablar de nuevas posibilidades educativas; todas las personas que formamos parte de la vida de los alumnos durante estos años, necesitamos de una alfabetización en neuroeducación. Formarnos investigar en este ámbito, posibilitará comprender mejor cerebro.

\subsection{NEUROCIENCIA COGNITIVA DEL DESARROLLO}

Entender cómo aprende el cerebro permite vislumbrar nuevas estrategias metodológicas en las aulas. La neurociencia cognitiva del desarrollo nos ofrece las claves para descubrir el potencial del ser humano. 


\section{CAPITULO 2: MARCO TEÓRICO}

Esta ciencia se centra en el estudio del sistema nervioso; entendido éste, como el sistema a través del cual el ser humano recibe información acerca de su entorno a través de sus distintos órganos sensoriales, procesa dicha información y emite respuestas a ello (Tortosa y Reiriz, 2010). La neurociencia se enfoca en conocer la estructura, la función, el desarrollo, la genética, la bioquímica, la fisiología y la patología del sistema nervioso y se centra en el estudio de la conducta y el aprendizaje tanto en condiciones normales como patológicas (Marina, 2012).

Esta ciencia explica cómo actúan millones de células nerviosas individuales en el encéfalo para producir la conducta y cómo, a su vez, estas células están influidas por el medioambiente, incluyendo la conducta de otros individuos (Kandel, Schwartz, Jessell, y Herreros, 1997).

El desarrollo del potencial humano está directamente relacionado con el desarrollo y maduración del sistema nervioso central y del cerebro; tomando gran protagonismo la influencia ejercida por el medio ambiente. La neurociencia, que en los últimos años vienen revelando grandes misterios del cerebro y su funcionamiento, aportan al campo educativo conocimientos importantísimos acerca de las bases neurales del aprendizaje, de la memoria, de las emociones y de muchas otras funciones cerebrales que son, día a día, estimuladas y fortalecidas en el aula (Campos, 2010).

Los procesos de aprendizaje y el ambiente van modelando el cerebro a través de sinapsis; estos puntos de conexión entre neuronas son los encargados de que vayan desapareciendo las conexiones poco utilizadas y que tomen fuerza las que son más activas (Salvador, 1987). Una red neuronal se forma con la conexión entre varias neuronas. El niño es capaz de crear un millón de sinapsis por segundo, la generación de sinapsis ocurre en tiempos diferentes en las diversas áreas de la corteza cerebral (Kandel et al., 1997).

El bebé desarrolla el doble de sinapsis que un adulto; tiene un cerebro privilegiado. Por esta razón, la experiencia va sometiendo al cerebro a una poda eficaz, este proceso consiste en eliminar las conexiones neuronales que menos se utilizan para reforzar las que más se usan. Como afirma Marina (2011, p.11) "talla su cerebro como un jardinero talla sus setos". Este mismo autor sostiene que el bebé nace preparado para construirse a sí mismo de acuerdo con la experiencia. El aprendizaje se consolida mediante la producción de sinapsis, de enlaces entre neuronas. Las estructuras cerebrales se desarrollan en diferentes tiempos y existen periodos en los que son especialmente sensibles a la estimulación del medio ambiental (Korzeniowski, 2011); la experiencia dada al alumno, moldea el desarrollo anatómico y funcional del cerebro. 
La mielinización provoca que los impulsos nerviosos se conduzcan con mayor velocidad, facilitando la comunicación entre neuronas. Durante la niñez, hay mayor número de neuronas y conexiones que en la edad adulta, no obstante, no todas las conexiones son eficientes, por lo que la poda es importante para eliminar las conexiones que no son funcionales y este proceso es continuo desde los 5 hasta los 16 años. Por tanto, aunque el cerebro humano alcanza el $90 \%$ del tamaño adulto a los cinco años, estos cambios progresivos y regresivos aseguran que aquellas conexiones que se conservan entre las neuronas, sean las más eficientes para recibir y analizar la información que llega al cerebro (Flores y Ostrosky, 2008).

Uno de los periodos más importantes del desarrollo del cerebro se da desde la etapa prenatal hasta cumplir los 5-6 años de vida (Regidor, 2003; Benarós et al. 2010; Álvarez, 2010). Durante esta etapa, el aprendizaje y la estimulación juegan un papel decisivo en el número y fuerza de las conexiones neuronales establecidas. A través de la experiencia, algunas conexiones serán eliminadas y otras fortalecidas. Los docentes, especialmente los maestros de El, ocupamos un papel destacado en este periodo de la vida del niño.

En los niños más pequeños, las zonas subcorticales del sistema nervioso central ejercen una poderosa influencia en su forma de aprender, de comportarse, de comunicarse, de sentir y de pensar. El movimiento, la impulsividad, la exploración, el juego, la falta de control emocional, entre otras, son características esenciales de la primera infancia, que se van encauzando "a medida que las zonas corticales, y principalmente la corteza prefrontal van limitando la acción de las zonas subcorticales" (Campos, 2010, p.10). Este largo proceso, está relacionado con la mielinización de las fibras nerviosas. Las experiencias, el entorno familiar y social, las condiciones de vida, salud y educación que van perfilando al desarrollo desde la primera infancia. De ahí, la comparación hecha por Real al comparar al cerebro como un libro con las páginas en blanco "capaz de llegar a ser una auténtica obra maestra o un simple bestseller" (2003, p.19).

\subsection{BASES NEUROLÓGICAS DE LA ATENCIÓN TEMPRANA}

El sistema nervioso (SN) es una red compleja de estructuras especializadas que tienen como misión controlar y regular el funcionamiento de los diversos órganos y sistemas, coordinando su interrelación y la relación del organismo con el medio externo. Está constituido por el sistema nerviosos central (SNC) que lo forman el encéfalo y la médula espinal; y el sistema nervioso periférico (SNP) que lo configuran todos los tejidos nervioso (Tortosa y Reiriz, 2010). 


\section{CAPITULO 2: MARCO TEÓRICO}

El encéfalo es la parte del SNC contenida en el cráneo y comprende el cerebro, el cerebelo y el tronco encefálico; por su parte, la médula espinal está situada en el interior del canal vertebral y se conecta con el encéfalo a través del agujero occipital del cráneo.

Las principales funciones del SNC son: percibir los estímulos que no llegan a través de los sentidos, transmitir los impulsos nerviosos sensitivos a los centros de elaboración, producción de impulsos y transmisión de estos impulsos a los músculos correspondientes. A través del SNC se perciben emociones, sentimientos y recuerdos.

Como hemos señalado, en el encéfalo se encuentra el cerebro, el cual consta de la corteza cerebral (capa superficial de sustancia gris), la sustancia blanca (axones cuya misión es transmitir impulsos nerviosos) y los núcleos estriados (controlan la función motora, enviando impulsos a la corteza cerebral, hipotálamo y tronco cerebral). El cerebro está dividido en dos hemisferios cerebrales, derecho e izquierdo; cada parte está especializada en funciones diferente; así, el hemisferio derecho se encarga de las habilidades musicales, la conducta emocional, percepción espacial, reconocimiento del cuerpo, etc. y el hemisferio izquierdo se encuentra más relacionado con la parte del lenguaje.

Todas las regiones sensoriales y motoras del cerebro están conectadas entre sí desde un punto de vista funcional mediante fibras; podemos diferenciar tres áreas funcionales del cerebro (Martinez et al., 2003): (1) áreas sensoriales, encargado de recibir sensaciones de los distintos receptores sensoriales; (2) áreas motoras, entre las áreas más importantes encontramos el área motora primaria (controla la contracción voluntaria de grupos musculares específicos, como los del pulgar, labios, lengua, etc.), el área de Broca (controla los músculos del habla) y área de Wernicke (se encarga de la comprensión del lenguaje); y (3) áreas de asociación, desarrollan funciones más complejas como son la memoria y las emociones-

A nivel funcional, apuntar que el SN consta de neuronas sensitivas y neuronas motoras, que controlen la mayor parte de funciones de regulación del cuerpo. Las neuronas se comunican entre sí a través de impulsos nerviosos que se generan en el inicio del axón y se propaga del axón hasta las terminaciones sinápticas.

Tortosa y Reiriz (2010) explican cómo durante la etapa embrionaria y hasta los 24 meses de edad, se crean nuevas neuronas y sinapsis en nuestro cerebro de forma continua y a un ritmo sorprendente; alcanzando hasta 40.000 nuevas sinapsis nuevas cada segundo; al finalizar este proceso, los bebés poseen muchas más neuronas y sinapsis de las que no son funcionalmente necesarias; es en este momento cuando comienza la etapa de destrucción de las sinapsis que no se usan o poda neuronal y el fortalecimiento de las que sí 
son usadas, proporcionando conexiones neuronales más veloces y eficaces. A través de esta poda neuronal, es como se eliminan las sinapsis adicionales incrementando la eficacia de la red neuronal creada en el cerebro. Este incremento neuronal que se produce de forma exponencial durante los primeros 6 años de vida, está determinado por la proliferación de las conexiones sinápticas entre las neuronas y la mielinización de fibras nerviosas.

El número de sinapsis que se producen en bebés y en niños es aproximadamente el doble que en adultos, lo que permite a los bebés aprender rápidamente nuevas tareas a medida que crecen y se desarrollan.

\subsubsection{PLASTICIDAD CEREBRAL}

La plasticidad cerebral es la capacidad que tiene la estructura cerebral para modificarse con el aprendizaje. El cerebro cambia significativamente a través de la vida en respuesta a las experiencias aprendidas. Según López (2009) la plasticidad cerebral es la flexibilidad del cerebro en respuesta a las exigencias medioambientales; en esta misma línea Ortiz (2009) expone que la plasticidad sináptica tiene lugar a lo largo del desarrollo y el aprendizaje y por tanto, la educación y la experiencia convierten cada cerebro en una obra única.

Las conexiones entre neuronas se crean cada vez que llega un estímulo al cerebro. No toda la información recibida llega a estimular, debe ser procesada. Para que una información se convierta en estímulo, debe despertar interés en el niño, aunque sea de forma inconsciente.

El cerebro humano se reorganiza a sí mismo continuamente a partir de inputs. Ese proceso, denominado neuroplasticidad, continúa a través de toda la vida pero es especialmente rápido en los primeros años. Las experiencias que tenga en niño en casa o en la escuela va a influir en la construcción de los circuitos neuronales que determinan lo que el cerebro va a aprender (Marina, 2012). Plasticidad es flexibilidad y adaptabilidad, por ello, como docentes debemos conocer lo que el cerebro puede hacer y no solo tolerar; buscamos una forma de plantear la educación acorde con el potencial de nuestro alumnado.

Reidor (2003) indica, que durante los doces primeros meses de vida, el cerebro del bebé crece más rápidamente que nunca, convirtiéndose en un órgano privilegiado con unas posibilidades qué va más allá de cuanto se puede imaginar. El bebé nace preparado para construirse a sí mismo de acuerdo con la experiencia; es por ello, que el aprendizaje se 


\section{CAPITULO 2: MARCO TEÓRICO}

consolida mediante la producción de sinapsis, de enlaces entre neuronas. El niño produce un millón de sinapsis por segundo.

El cerebro es el único órgano del cuerpo humano que tiene la capacidad de aprender y a la vez enseñarse a sí mismo (Antunes, 2014). Además, su enorme capacidad plástica le permite reorganizarse y reaprender de una forma espectacular, continuamente. Con aproximadamente 100 mil millones de células nerviosas llamadas neuronas, el cerebro va armando una red de conexiones desde la etapa prenatal y conformando un cableado único en cada ser humano, donde las experiencias juegan un rol fundamental. Este gran sistema de comunicación entre las neuronas sinapsis, es lo que permite que el cerebro aprenda.

La estimulación ambiental conseguirá una dirección concreta mediante el posterior podado (de forma cuantitativa en relación al número de sinapsis o cualitativa, en base a la calidad de las conexiones). La enseñanza en este tramo educativo es de suma importancia pues ofrece la oportunidad de definir aquella dirección en la que el cerebro va a mejorar sus conexiones con diferentes áreas cerebrales fortaleciendo unas y debilitando otras.

Algunos de los aspectos importantes en el desarrollo cerebral según Ortiz (2009) que los educadores debemos conocer son: (1) conocer la existencia de dos líneas diferentes en los procesos de maduración; una corresponde a la materia gris y la otra a la materia blanca. La materia gris tiene su gran incremento en áreas prefrontales entre los 4-12 años, la materia blanca aumenta paulatinamente desde la infancia a la juventud y (2) saber que el desarrollo cerebral que se produce en las distintas regiones cerebrales, maduran en distintos momentos temporales. Existen periodos sensibles al aprendizaje. Por ello, los procesos de enseñanza aprendizaje deben tener en cuenta este aspecto a la hora de introducir en el currículo educativo distintas materias o asignaturas.

De estas aportaciones, subyacen una serie de consideraciones que docentes debemos tener en cuenta: ambiente y genética. En una clase no todos los alumnos interaccionan igual, asimilan la información de la misma forma ni aprenden igual, a pesar de que el maestro, los recursos, los materiales, métodos de trabajo... sean iguales para todos. El ambiente es determinante para el desarrollo del cerebro. La genética, la cual es una gran fuente explicativa de la capacidad de integración de los procesos cerebro ambiente. El tiempo, frecuencia y tipo de estimulación, así como los periodos de descanso serán claves para un buen desarrollo del cerebro en esta etapa infantil. Un ambiente rico en estímulos es básico para un buen desarrollo cerebral. 
Lo más importante para un educador, es entender la neurociencia como una forma de conocer el cerebro de forma más amplia: cómo es, cómo aprende, cómo procesa, registra, conserva y evoca una información, para que a partir de este conocimiento pueda mejorar las propuestas y experiencias de aprendizaje que se dan en el aula.

En palabras de Campos:

Si los que lideran los sistemas educativos llegaran a comprender que los educadores, a través de su planificación de aula, de sus actitudes, de sus palabras y de sus emociones ejercen una enorme influencia en el desarrollo del cerebro de los alumnos y alumnas, y por ende en la forma en que aprenden, quedaría sin necesidad de justificar el por qué vincular los estudios de las neurociencias al contexto pedagógico. (2010, p. 5).

Por tanto, además de hablar de la gran plasticidad cerebral que se produce a lo largo de los primeros 6 años de vida, debemos dedicar unas líneas a identificar los periodos sensibles del desarrollo cerebral, durante los cuales el organismo es especialmente susceptible a la estimulación de su entorno.

\subsubsection{PERIODOS SENSIBLES}

El desarrollo de las funciones ejecutivas del cerebro se extiende desde el primer año de vida hasta la adolescencia (Romine y Reynolds, 2005). Dentro de este periodo existe lo que se conoce como períodos sensibles. Definidos como "ventanas de tiempo en las cuales la plasticidad cerebral está incrementada, posibilitando que el funcionamiento ejecutivo sea promovido por la experiencia" (Korzeniowski, 2011, p.3).

El cerebro es físicamente modificado a través del reforzamiento, debilitamiento y eliminación de conexiones entre neuronas y el crecimiento de otras nuevas. Los patrones de plasticidad son diferentes dependiendo de la edad.

Korzeniowsk (2011), explica la existencia de periodos sensibles donde la plasticidad del cerebro es mayor y susceptible de favorecer aprendizaje de una manera más rápida y sencilla que en otro momento. Estos períodos coinciden con la etapa de escolarización, por lo que resulta interesante analizar la relación entre estos periodos sensibles y el aprendizaje escolar. Los estímulos los puede recibir durante toda su vida, pero el niño, por su propia naturaleza, cuenta con estos periodos sensitivos, en los que está sorprendentemente predispuesto a aprender. Ciertos estímulos, oportunos en el tiempo, favorecen el aprendizaje y el desarrollo de capacidades en el niño. Durante la infancia se dan mayor número de posibilidades en dichos periodos, consecuencia del desarrollo masivo de la arborización neuronal. Este desarrollo neuronal de determinadas áreas cerebrales permitirá de forma 


\section{CAPITULO 2: MARCO TEÓRICO}

natural acceder a la estimulación de los procesos estimulares asociados a dichas áreas y podrá justificar el mejor aprendizaje posterior en ellas. Por ello, los periodos sensibles tendrán una gran relevancia en el ámbito educativo.

El proceso de desarrollo del cerebro se lleva a cabo por ciclos, y no de forma lineal; Ortiz (2009), habla de la existencia de periodo sensible, cuando se da un desarrollo masivo de conexiones neuronales que coincidirían con el tiempo de desarrollo en el que se puede conseguir un mejor resultado en la estimulación; se dan en mayor medida en los primeros años de vida, incluso en el periodo prenatal. Tienen la finalidad de conseguir un cableado neuronal estable que favorece los procesos básicos de adaptación al medio ambiente y genera los mecanismos más complejos que se llevarán a cabo posteriormente.

Una revisión de los períodos sensibles en la literatura permite afirmar que el período de mayor crecimiento ocurre entre los 3 y 8 años de edad (López, 2009). También, se observa un incremento, aunque más moderado, entre los 9 y 12 años y algunos autores consignan un último período entre los 15 y 19 años (Romine y Reynolds, 2005).

Durante estos periodos sensibles se producen una serie de hechos significativo (Pineda, 2000): (1) en el primer periodo, la evolución de la función reguladora del lenguaje interno y la maduración progresiva de las zonas prefrontales, crean entre los 3 y 8 años, un período sensible en el desarrollo de la adquisición de las funciones ejecutivas; en este lapso, las habilidades de planificación y organización se desarrollan rápidamente, los niños manifiestan conductas estratégicas y habilidades de razonamiento más organizadas y eficientes; comienzan a dirigir su comportamiento en forma autónoma, mostrando una mayor independencia de las instrucciones adultas, aunque aún presentan cierto grado de descontrol e impulsividad; (2) entre los 12 y 14 años de edad, algunas funciones ejecutivas como el control inhibitorio alcanzan su techo en el desarrollo, pero otras como la flexibilidad cognitiva, la resolución de problemas y la memoria de trabajo continúan evolucionando; (3) y durante los 15 y 19 años, existe un tercer periodo sensible, donde se da un de intenso desarrollo.

Diferentes autores (Pineda, 2000; Romine y Reynolds, 2005; Tarcisio, 2012) señalan que el mejor periodo para aprender a hablar idiomas de forma fluida y sin acento es antes de los 10 años de edad. Las personas que aprenden un segundo o tercer idioma después de este tiempo casi siempre tendrán acento; sin embargo, no se suelen ofrecer rutinariamente idiomas hasta la escuela secundaria, y algunos estudiantes pueden llegar a la universidad antes de entrar en contacto con ellos. Los hallazgos son semejantes para las matemáticas, la música, la visión y el lenguaje. 
Los periodos sensibles no son rígidos e inflexibles; son periodos que comprenden los cambios sutiles en las habilidades del cerebro que estarían influenciadas por experiencias que ocurren durante la vida (Tarcisio, 2012).

La inteligencia de los niños se desarrolla con un patrón específico, con un brote de crecimiento que empieza en el cerebro durante las edades de 3 a 6 años. Entre 6 y 13 años, el patrón de maduración se traslada rápidamente del frente hacia atrás, hacia las áreas del cerebro que se especializan en las habilidades del idioma. Hay un marcado corte en el crecimiento de las áreas del idioma del cerebro después de los 13 años. Aproximadamente entre los 13 y los 15 años, cerca del $50 \%$ del tejido del cerebro que controla las habilidades motoras resulta eliminado (Biddle, Good, Goodson, y Bayo, 2000).

Según Ortiz (2009), los periodos sensibles tienen: (a) un momento determinado; (b) un tipo de estimulación determinada; (c) suelen suceder en la misma época en todos los individuos; (d) se necesitan pocos estímulos para desencadenar sinapsis que den lugar al aprendizaje; (e) no se necesita ningún otro estimulo que ayude a la formación del cableado y (f) no es necesaria la acumulación temporal de estímulos.

Este mismo autor, sostiene la existencia de tres grandes periodos sensibles de desarrollo cerebral de interés para los sistemas educativos (véase tabla 2.4).

Tabla 2.4. Periodos sensibles: características y relevancia educativa

\begin{tabular}{|c|c|}
\hline CARACTERÍSTICAS & RELEVANCIA EDUCATIVA \\
\hline \multicolumn{2}{|l|}{ Primer periodo sensible (de 3 a 6-7 años) } \\
\hline $\begin{array}{l}\text { - Gran conexión neuronal entre áreas corticales cercanas. } \\
\text { - Gran maduración de las estructuras que permiten una gran } \\
\text { posibilidad de comunicación e interacción con el medio } \\
\text { amiente. } \\
\text { - Interacción constante con el ambiente. } \\
\text { - Gran capacidad de percepción y observación y gran } \\
\text { comunicación no verbal y emocional. } \\
\text { - Gran número de conexiones neuronales que desarrolla, } \\
\text { hasta el punto que existe un proceso de podado para llevar a } \\
\text { cabo comportamientos ordenados en la adaptación del niño } \\
\text { al medio ambiente }\end{array}$ & $\begin{array}{l}\text { - En esta etapa la estimulación para el niño } \\
\text { es fundamental. } \\
\text { - La información en esta etapa debe ser } \\
\text { concisa, clara, debe prevalecer un ambiente } \\
\text { lleno de movimientos, colores, riqueza } \\
\text { estimular novedosa, participación, juegos, } \\
\text { música, conductas cercanas a las actividades } \\
\text { de la vida diaria, un entorno emocional, social } \\
\text { y familiar establece. }\end{array}$ \\
\hline \multicolumn{2}{|l|}{ Segundo periodo sensible (de 12 a 14 años) } \\
\hline $\begin{array}{l}\text { - Etapa de gran armonización en el desarrollo global del } \\
\text { cerebro. } \\
\text { - Etapa en la que los periodos sensibles conocimientos } \\
\text { culturales, propios de la enseñanza escolar se encuentran } \\
\text { muy desarrollados. } \\
\text { - La estimulación ambiental, la repetición y la selección de } \\
\text { conocimientos serán básica para el futuro conocimiento de } \\
\text { los niños. }\end{array}$ & $\begin{array}{l}\text { - Etapa clave en la educación por su } \\
\text { incidencia en los procesos de destrezas } \\
\text { académicas, es la época donde mayor } \\
\text { impacto tiene todos los procesos, } \\
\text { aprendizajes y adaptaciones escolares. } \\
\text { - Etapa donde la educación perfilará el futuro } \\
\text { de los niños. }\end{array}$ \\
\hline
\end{tabular}




\begin{tabular}{|l|l|}
\hline - Etapa de gran desarrollo neurohormonal. La sustancia & - Etapa de desarrollo individual de gran \\
blanca presenta un mayor desarrollo en esta época de la & curiosidad y de experiencias nuevas. \\
vida; esto permite la conexiona entre áreas cerebrales & - El cerebro se activa con gran velocidad y \\
distantes, lo que contribuirá a un gran desarrollo y & amplitud en los aprendizajes nuevos y \\
perfeccionamiento de las funciones cognitivas y de la & disminuye en los repetitivos. Pero en cambio, \\
adaptabilidad social, ética y moral, dada la complejidad de & con la repetición aumenta la capacidad de \\
redes neuronales necesarias para llevar a cabo estor & archivo, memorización y recuerdo. \\
procesos tan complejos del ser humano. & - Existe un gran aumento de la sustancia \\
- La maduración del córtex prefrontal, permitirá acceder a las & blanca, que tiene la capacidad de conexionar \\
funciones más complejas (razonamiento, lógica, funciones & muchas áreas cerebrales; dando lugar a \\
ejecutivas, atención...) y regular las conductas sociales. & comportamientos nuevos, incluido los \\
& emocionales y relacionados con el sexo.
\end{tabular}

Fuente: elaboración propia a partir de Neurociencia y Educación (Ortiz, 2009)

\subsection{ESTIMULACIÓN TEMPRANA}

En general, el fundamento de la AT aparece ligado al término estimulación temprana debido a la gran importancia que tienen los primeros años de vida para los niños y del papel que desempeña el ambiente en ese desarrollo (Guerrero, Guralnick y Bennett, 2001); como vemos, la AT tienen por objetivo dar respuesta, lo más pronto posible, a las necesidades transitorias o permanentes que presentan los niños con trastornos en su desarrollo o que tienen riesgo de padecerlos; sin embargo, la estimulación temprana va dirigida a estimular lo más tempranamente posible a todos los niños sin que ello suponga un tratamiento rehabilitador; se busca desarrollar las potencialidades de todo el alumnado.

Las primeras investigaciones en el plano neuropsicológico realizadas por Hebb (2009), junto con otras que hacía relación a la determinación de nuestra capacidad intelectual en los primeros cuatro años de vida (Bloom, 1964), y los estudios de Bowlby (1993) que insistían en la primacía de la experiencia tempranas y en las consecuencias a largo plazo de estas experiencias, consiguieron captar la atención de las diferentes disciplinas científicas para el estudio de programas de estimulación en los primeros años de la infancia, favoreciendo así un desarrollo óptimo en los niños.

La estimulación temprana supuso un nuevo enfoque más global, riguroso y sistemático en el que se engloban avances científicos recientes, desde las distintitas disciplinas (Pedagogía, rehabilitación, Psicología evolutiva, El, etc.), y donde se plantea las necesidades de los niños pequeños desde un encuadre educativo y no desde el meramente rehabilitador o compensador de desigualdades.

Por tanto, a través de la estimulación temprana se busca favorecer un desarrollo óptimo y pleno a toda la población infantil, sin que suponga un requisito imprescindible poseer alguna discapacidad. Es una estimulación dirigida a toda la población infantil sin excepción. 


\subsubsection{ESTIMULACIÓN TEMPRANA Y EL 2은 CLO DE EI}

Es momento de hablar de estimulación temprana en relación al ámbito educativo, dada su relación directa con el objetivo de la presente investigación. Por tanto, en adelante hablaremos de la importancia de la estimulación temprana en alumnos de 3 a 6 años, dentro del contexto educativo.

Como hemos visto anteriormente, la estimulación temprana denota en su sentido estricto "un fin terapéutico y preventivo y que aplicado al ámbito de la educación ordinaria, connota muchas veces un sentido de adelantamiento o de aceleración de las capacidades infantiles" (Rivas, 2004, p.23). Algunos maestros pueden considerar que el término "temprano" tiene una connotación de adelantamiento de sus capacidades antes de que el alumno esté preparado; en este caso se está confundiendo el término temprano con prematuro (que aún falta cierta maduración y coordinación que es necesaria para la ejecución de algo). Por tanto, al referirnos a estimulación temprana se hará alusión a potenciar las capacidades del niño respetando su ritmo biológico a través de una estimulación regulada y continuada (Rivas, 2004) y por medio de unos programas definidos, como el que se muestra en esta investigación. Buscamos potenciar las capacidades del alumnado, en el momento más adecuado con un aprovechamiento óptimo del aprendizaje.

Por ello, se debe descartar la idea de estimulación temprana con connotación de aceleración, y acuñar el término en relación a un desarrollo más completo y mejor de las capacidades individuales de cada niño dentro de sus posibilidades.

Aclarado este término, hablaremos de la El como una de las mejores épocas para iniciar la estimulación temprana.

Es evidente la coincidencia existente entre los períodos de edad de los sujetos a los que van dirigidas la El y la estimulación temprana. La El se divide en dos ciclos (el primero abarca de los 0 a los 3 años de edad; y el segundo de los 3 a los 6 años) y uno de los mejores periodos para iniciar la estimulación infantil, dada la enorme plasticidad celebrar caracterizada en los niños a esta edad, es en este mismo periodo.

Por tanto, al tener como sujetos de estudio a los miembros del mismo grupo poblacional (alumnos con edades comprendidas de 3 a 6 años), exista una interrelación que no podemos obviar y debe ser aprovechado; pues como señala Estalayo y Vega (2001) nadie quiere ni puede aprender, tanto ni tan bien, como los niños menores de 6 años. 


\section{CAPITULO 2: MARCO TEÓRICO}

Sin embargo, la coincidencia no se da sólo en la edad, sino en los propios objetivos que persiguen tanto la estimulación temprana como la El. Para comprobarlo, basta con examinar los Objetivos Generales que el Currículo de El en nuestra comunidad autónoma recoge; éstos los podemos encontrar en el Decreto 122/2007 (BOE, 2 de enero, 2008) en su artículo 4 (ver tabla 2.5).

Tabla 2.5. Objetivos Generales del $2^{\circ}$ ciclo de EI

\begin{tabular}{|l|}
\hline OBJETIVOS GENERALES $2^{\circ}$ CICLO DE EI \\
\hline $\begin{array}{l}\text { a) Conocer su propio cuerpo y el de los otros, sus posibilidades de acción y aprender a respetar las } \\
\text { diferencias. }\end{array}$ \\
\hline b) Construir una imagen positiva y ajustada de sí mismo y desarrollar sus capacidades afectivas \\
\hline c) Adquirir progresivamente autonomía en sus actividades habituales. \\
\hline d) Observar y explorar su entorno familiar, natural y social. \\
\hline $\begin{array}{l}\text { e) Relacionarse con los demás y adquirir progresivamente pautas elementales de convivencia y } \\
\text { relación social, con especial atención a la igualdad entre niñas y niños, así como ejercitarse en la } \\
\text { resolución pacífica de conflictos }\end{array}$ \\
\hline f) Desarrollar habilidades comunicativas en diferentes lenguajes y formas de expresión. \\
\hline $\begin{array}{l}\text { g) Iniciarse en las habilidades lógico-matemáticas, en la lecto-escritura y en el movimiento, el gesto y el } \\
\text { ritmo. }\end{array}$ \\
\hline
\end{tabular}

Elaboración propia a partir del Decreto 122/2007 (BOE, 2 de enero, 2008)

El currículo de El establece como finalidad contribuir al desarrollo físico, afectivo, social e intelectual de los niños y las niñas (BOE, 4 de enero, 2007); se busca que desde la educación se atienda de forma global a todo el alumnado, atendiendo de forma progresiva al desarrollo afectivo, al movimiento y los hábitos de control corporal, a las manifestaciones de la comunicación y del lenguaje, a las pautas elementales de convivencia y relación social, así como al descubrimiento de las características físicas y sociales del medio.

Por tanto, los niños a los que el maestro de El educa son los que comprenden los años más importantes y relevantes en cuanto a estimulación se trata; y es por ello, el momento calve y más idónea para comenzar una cuidadosa estimulación. En este sentido, Guillén (2010) defiende que el maestro de infantil ocupa un lugar privilegiado como agente en dicha atención, ya que su contacto diario durante el curso con esos niños, y su labor docente con ellos, le permite detectar cualquier deficiencia en el desarrollo por mínima que ésta sea (en el caso que hubiera) y si a esto añadimos su contacto con la familia, propiciará una y el entorno social del alumno podrá potenciar las capacidades del alumnado intervención de gran calidad.

Como venimos apuntando, es evidente la gran importancia que tiene la AT para evitar problemas ya existentes, además de proporcionar estímulos muy positivos en el desarrollo evolutivo del niño. La El reviste una especial trascendencia ya que los primeros años de vida 
son determinantes para un desarrollo físico y psicológico armonioso del niño, así como para la formación de las facultades intelectuales y el desarrollo de la personalidad; es decir, para el desarrollo pleno del alumnado en todos sus ámbitos: afectivo, cognitivo, social e intelectual. La educación a estas edades tiene un marcado carácter preventivo y compensador, debido a la importancia que tiene la intervención temprana para evitar problemas en el desarrollo, en toda la población infantil en general y especialmente en aquellos niños que presentan necesidades educativas especiales.

Los problemas en el proceso de integración suelen aparecer cuando no hay una intervención temprana previa al ingreso en la escuela infantil, y cuando al aumentar la edad y el nivel educativo, las exigencias escolares son mayores. En general, los ACNEAE que acuden a la escuela en la edad de 0-3 años, lo hacen por recomendación de los equipos psicopedagógicos, o de los centros de desarrollo infantil y de AT, que valoran positivamente las posibilidades que ofrece la escuela para el desarrollo del niño aunque continúe con los programas de intervención temprana ya iniciados. Hay que tener en cuenta que los centros de El, por sus objetivos y por la especial atención que se otorga a los aspectos afectivos y sociales son lugares idóneos para conseguir que todos los alumnos implicados en el proceso de enseñanza-aprendizaje desarrollen al máximo sus capacidades.

Por todo ello, se hace necesario e imprescindible la coordinación entre todas las instancias que intervienen con los ACNEAE así como con el alumnado de ambientes desfavorecidos, inmigrantes o de minorías étnicas o simplemente con aquellos niños que se encuentran en una edad idónea para que la estimulación sea más efectiva; en pocas palabras, la relación entre la escuela Infantil y la estimulación temprana son transcendentales. La El y la AT comparten muchas características que legitiman el valor de la escuela infantil como marco privilegiado para la atención de todos los niños y especialmente para aquellos con dificultades en su desarrollo. En este escenario, el maestro de El se convierte en una pieza clave: asiste, cuida y atiende el proceso de desarrollo de sus niños, sean cuales sean sus características y las necesidades de los mismos.

Vidal (2007) explica como la AT y unos programas de estimulación temprana (en adelante PET) debidamente diseñados son necesarios para la población infantil, dada las especiales características durante este periodo en el que se van a producir las adquisiciones básicas del desarrollo y que, en determinados casos, no se logran por la estimulación natural espontánea, ya sea por las circunstancias que rodean al niño (ambiente, nivel económico, afecto, etc.) o por que el niño no puede aprovechar adecuadamente esos estímulos del medio (cuando hay patologías implantadas o alto riesgo de padecerlas). 


\section{CAPITULO 2: MARCO TEÓRICO}

Por todo lo anteriormente expuesto, defendemos que la El y la AT no sólo constituyen un mecanismo de compensación de desigualdades a través de unos programas de estimulación, sino que se constituye como el contexto más idóneo para proporcionar a todos y cada uno de los niños la posibilidad de ofrecer una estimulación de calidad. No debemos olvidar que esta etapa abarca un periodo crucial donde tiene lugar un desarrollo cerebral más rápido e importante, y es durante este periodo donde una buena estimulación, por parte del maestro en las aulas, es decisiva.

\subsubsection{Inclusión en las aulas de El}

Los centros escolares se caracterizan por la gran diversidad del alumnado, esta circunstancia supone un reto importante para atender a todos los niños de la etapa infantil.

Durante los últimos años, las diferentes leyes, reales decretos y decretos se hacen eco de la importancia de la inclusión en el aula, tal es así, que hemos asistido a un importante cambio conceptual donde se defiende una escuela inclusiva que atienda a la diversidad de todo el alumnado, y no dirigirla, de forma exclusiva, a los ACNEAE.

La actual ley orgánica de educación (LOMCE) ha incluido, como una de sus novedades más destacadas, la educación inclusiva como proyecto que trata de construir una educación basada en la equidad, que garantice la igualdad de oportunidades para el pleno desarrollo del personalidad a través de la inclusión educativa, la igualdad de derechos y oportunidades que ayuden a superar cualquier discriminación y la accesibilidad universal a la educación, y que actúe como elemento compensador de las desigualdades personales, culturales económicas y sociales, con especial atención a las que derivan de cualquier tipo de discapacidad.

En la misma línea Calvo (2005) defiende la educación inclusiva como el derecho de todo alumno a adquirir un aprendizaje profundo (entendiendo por tal la aproximación a la comprensión de la realidad que se vive), además del derecho de cada alumno a recibir una educación acorde con sus necesidades individuales de aprendizaje y con los potenciales que manifiesta. Como vemos, el término inclusión hace referencia a reducir los procesos de exclusión social en los que se ven insertos muchos alumnos, bien por estar en una situación de desventaja sociocultural o por sus características particulares (Araque y Barrio, 2010); pero además, al hablar de inclusión no sólo hacemos referencia a la integración escolar o a dar respuesta a las necesidades de los ACNEAE, va un paso más allá, dirigiendo su atención de forma personalizada y dando una respuesta educativa a todos y cada uno de los alumnos que forman parte de nuestras aulas. Por tanto, la idea de inclusión no sólo implica atender la 
diversidad, supone una atención dirigida a todo el alumnado procurándole todas las medidas (tanto ordinarias como específicas de atención educativa) que sean requeridas.

El principio de atención a la diversidad está basado en la obligación de los Estados y sus sistemas educativos a garantizar a todos el derecho a la educación (Blanco, 2006); reconociendo la diversidad de sus necesidades, combatiendo las desigualdades y adoptando un modelo educativo abierto y flexible que permita el acceso, la permanencia escolar de todo el alumnado, sin excepción, así como resultados escolares aceptables (UNESCO, 2006).

Desde la LOE (BOE, 4 de mayo, 2006) la atención a la diversidad se aborda contemplando una serie de medidas ordinarias y específicas; estas medidas son concretadas en la comunidad de Castilla y León en el º ciclo de El, a través de la orden 1152/2010 (BOE, 6 de mayo, 2010). En ambas normativas se diferencian el tipo de medidas dirigidas a los alumnos, en base a sus necesidades: (a) las medidas ordinarias y (b) medidas específicas.

(a) Medidas ordinarias de atención educativa: van dirigida a todo el alumnado, independientemente de si pertenece a algún grupo de ACNEAE, y conforman aquellas estregáis organizativas y metodológicas que faciliten la adecuación del currículo a sus características individuales y al contexto sociocultural de los centro docentes, con objeto de proporcionar una atención individualizada en el proceso de enseñanza y aprendizaje sin modificar los objetivos generales de cada una de las etapas educativas. Entre las medidas ordinarias de atención educativa en relación al $2^{\circ}$ ciclo de El, se encuentran (BOE, 6 de mayo, 2010): la acción tutorial que posibilite una adecuada respuesta a las características del alumnado a nivel escolar, personal y social, y la actuación sistemática en los procesos de intervención; estrategias de enseñanza, apoyos, agrupamientos flexibles y medidas de refuerzo y ampliación que sean necesarias; las adaptaciones curriculares que afecten a la metodología, organización, adecuación de actividades temporalización, adaptación de técnicas, tiempos e instrumentos de evaluación; enriquecimiento curricular para los alumnos con altas capacidades intelectuales; los planes de acogida dirigido al alumnado de integración tardía en el sistema educativo; y la aplicación de medidas de prevención y control de absentismo escolar.

(b) Medidas específicas de atención educativa: son todos aquellos programas, actuaciones y estrategias de carácter organizativo y curricular que precise el ACNEAE que no haya obtenido respuesta a través de las medidas ordinarias anteriores. Entre las medidas específicas encontramos: adaptaciones curriculares significativas previa evaluación psicopedagógica; la permanecía excepcional en el $2^{\circ}$ ciclo de El; los programas específico de apoyo, refuerzo y acompañamiento para el alumnado de integración tardía en el sistema 


\section{CAPITULO 2: MARCO TEÓRICO}

educativo o para el alumnado en situación de desventaja socioeducativa, además de las actuaciones propiciadas por el maestro de compensatoria; la adaptación lingüística y social, incluida la atención en aulas específicas de apoyo, para el alumnado de integración tardía en el sistema educativo cuya lengua materna sea distinta del castellano y presente graves carencias lingüísticas en esta lengua; la atención educativa al alumnado enfermo para aquellas situaciones de hospitalización o de convalecencia domiciliada; la atención en el aula por parte del maestro de audición y lenguaje para aquellos alumnos que previo informe psicopedagógico, requiera este recurso personal; y de igual manera, la atención en el aula por parte del maestro de pedagogía terapéutica, dirigida a la atención de alumnos con problemas cognitivos.

Como vemos, estas medidas favorecen la inclusión de nuestro alumnado, permitiendo un desarrollo pleno de cada alumno, desde la globalidad del desarrollo.

En los últimos años, es notoria la tendencia que ha tomado el ámbito educativo basándose en el principio de inclusión y normalización, asegurando la no discriminación y dando una respuesta de calidad a todo el alumnado de infantil, en base a sus características personales y no, a posibles problemas en el desarrollo.

Es por ello, que desde las aulas se debe tener en cuenta al grupo-clase entendiendo la diferencia como algo natural e inherente al ser humano, buscando una mejora dirigida a todos. Para conseguir este cambio conceptual, y hacer de la inclusión la base de la educación, debe existir una reestructuración de los programas diseñados por los centros (GonzálezGonzález, 2008)

Tal es así, que recientemente la junta de Castilla y León ha diseñado el II Plan de Atención a la Diversidad (BOCyL, 19 de junio, 2017); este plan es el referente en materia de atención a la diversidad en nuestra comunidad, y supone el marco estratégico para las actuaciones de la Administración educativa desde una visión inclusiva de la educación. Pretende fortalecer a los centros educativos para atender a todo el alumnado, personalizando la oferta educativa, ya que cada alumnado aprende de una manera distinta, y por tanto, todos son diferentes y a cada uno hay que ayudarle a desarrollar sus potencialidades, sus inteligencias o talentos.

Las líneas de actuación de este plan están dirigidas a:

- La promoción de la cultura inclusiva en los centros educativos, incorporando metodologías activas, nuevas organizaciones y evaluaciones educativas, así como la flexibilización del sistema educativo. 
- La mejora de los procesos de prevención detección e intervención temprana, permitiendo mejorar la coordinación entre las distintas administraciones, el trabajo cooperativo de los distintos profesionales que intervienen con la Consejería de Educación, y con el propósito de ser lo más preventivas posible ante las necesidades educativas que puedan surgir en la vida escolar del alumnado.

- El fomento de los procesos de participación de la familia y la sociedad en los centros educativos.

- El refuerzo y apoyo a líneas de investigación innovación y evaluación pedagógica, como estrategia que estimula el desarrollo de prácticas eficaces inclusivas e impulse la mejora de las competencias profesionales docentes como parte de un sistema educativo de calidad.

En definitiva, apostar por la inclusión educativa en las aulas de El implica entender que cada alumno es único y por tanto, requiere de un estilo concreto de enseñanza, de unos recursos específicos y de una atención individualizada. Para ello, debemos utilizar metodologías activas que permitan un aprendizaje significativo y duradero por medio de experiencias sensitivas y manipulativas. De igual manera, el conocer cómo se organiza el cerebro, ser consciente de los momentos más sensibles y propicios para el aprendizaje, y en consecuencia, diseñar PET que den respuesta a todas estas necesidades, permitirá hablar de educación de calidad.

\subsubsection{PROGRAMAS DE ESTIMULACIÓN TEMPRANA}

La comprensión acerca de la estructura y funcionamiento del cerebro proporciona al docente la base para diseñar un nuevo estilo de enseñanza- aprendizaje, una nueva forma de plantear los conocimientos. Entender las posibilidades que nos ofrece comprender el funcionamiento del cerebro, permitirá conocer los requisitos necesarios para diseñar PET en las escuelas y potenciar el desarrollo de nuestros alumnos.

La colaboración neurociencia y educación debe estar presente en las aulas. El aprendizaje supone estímulos, experiencias y por tanto, cambios en las conexiones neuronales y en el cerebro del alumno. El poder que tiene la educación en este aspecto es asombroso, debemos aprovecharlo y fortalecer las potencialidades de los programas de estimulación.

Marina (2011) habla de la "gran oportunidad" que ofrece la plasticidad cerebral. Plasticidad que permite el modelado, la modificación y la reparación de las conexiones 


\section{CAPITULO 2: MARCO TEÓRICO}

neuronales. Esta propiedad puede ayudar a la recuperación de funciones perdidas mediante la estimulación y el ejercicio del sistema afectado, ya que como apunta Regidor (2003) los primeros años de vida son el mejor momento para que las neuronas sean activadas 0 estimuladas; más tarde, aún sería posible perfeccionar esas conexiones entre neuronas y esos circuitos ya creados, pero resulta mucho más difícil.

La capacidad del cerebro para guardar información es ilimitada y maleable. El cerebro tiene diferentes sistemas de memoria, que pueden almacenar desde una pequeña cantidad de datos hasta un número ilimitado de ellos. La memoria es una de las funciones más complejas del cerebro y que es diariamente estimulada en el aula. Saber cómo se da el proceso de adquisición, almacenamiento y evocación permitirá al maestro elaborar propuestas de aprendizaje con frecuencia, intensidad y duración más adecuadas. La habilidad de adquirir, formar, conservar y recordar la información depende de factores endógenos y exógenos, de las experiencias y de la metodología de aprendizaje utilizada por el educador, por este motivo unos programas de estimulación debidamente diseñados, pueden reportar grandes beneficios para nuestros alumnos.

Los primeros seis años de vida se caracterizan por un alto grado de plasticidad neuronal (Santoyo, 2010). La consecución progresiva de hitos en este desarrollo va permitiendo la aparición y mejora de nuevas habilidades; por ejemplo, es necesario que el niño aprenda a sujetar la cabeza, controlando la musculatura del cuello, para que pueda dirigir la vista, lo que refuerza la motivación para la marcha o el contacto visual como elemento socializador (Candel, 2007).

Como ya se ha visto anteriormente surge en sus orígenes de la evidencia de que, a través de la generación de un ambiente rico en estímulos de diverso tipo, podemos intervenir positivamente en la adquisición de funciones o capacidades que se han visto mermadas por problemas acaecidos a lo largo del desarrollo o en problemas surgidos a lo largo de la maduración de las mismas. Desde la neurología, Livingston, Katona, Roch, Guilhaume y Rive (2004) fundamenta lo que denomina neurorehabilitación o rehabilitación temprana en la plasticidad del cerebro en los primeros meses de vida, en base a la activación y aprovechamiento funcional de todas las estructuras del Sistema Nervioso Central (SNC), que conserven su funcionalidad normal e incluso de aquellas que presentan funciones incompletas en relación con el daño cerebral (Millán y Mulas, 2009).

Las lesiones tempranas de las estructuras nerviosas o la privación de la estimulación sensorial procedente del ambiente pueden afectar la maduración neuropsicológica, por lo que aprovechar la plasticidad neuronal en estadios precoces es decisivo para optimizar el 
desarrollo posterior. Así, la eficacia de PET se basa, por una parte, en la precocidad de la intervención, y por otra, en la consecución de un diagnóstico precoz de los problemas o patologías que van a derivar en patología de neurodesarrollo posterior, y cuya presencia define las poblaciones de riesgo subsidiarias de aplicación de programas de atención temprana (Rodríguez, 1993). El diagnóstico precoz permite iniciar un trabajo de forma temprana y por tanto más eficaz, puesto que la capacidad de asimilar e integrar nuevas experiencias es mucho mayor en etapas precoces del desarrollo, gracias a la posibilidad de aumentar las interconexiones neuronales, en respuesta a ambientes enriquecidos con estímulos debidamente programados. Por ello, la aplicación de los programas de trabajo con el niño no es arbitraria, sino que cumple dos condiciones: es sistemática, en cuanto a la adecuación del programa a su edad de desarrollo y a las expectativas reales que determinemos para cada niño en particular, y es secuencial, puesto que cada etapa superada es punto de apoyo necesario para iniciar la siguiente (Estalayo y Vega, 2001).

La plasticidad de las estructuradas nerviosas es un hecho evidente y es la base teórica que respalda la intervención con PET. Es evidente que muchos niños afectados por patologías neurológicas logran un desarrollo aceptable a pesar de la existencia de factores de riesgo y mal pronóstico asociados a su patología. En muchas ocasiones, el daño estructural apreciable en la neuroimagen o los resultados de los test predictivos iniciales no necesariamente se relacionan con el resultado y pronóstico final. Existe evidencia acerca de la influencia que sobre la plasticidad cerebral tiene la estimulación, pero no se conoce exactamente qué ocurre en el cerebro humano. Están implicados en la plasticidad cerebral tanto factores externos (la calidad de la rehabilitación y trabajo ofertado, etc.), como factores propios de la ecología del niño (percepción de su enfermedad y ambiente familiar que lo rodea, factores demográficos, etc.) (Leeber y Rijke, 2003).

Como señala el Libro Blanco de La Atención Temprana (2000) el SN se encuentra en la primera infancia en una etapa de maduración y de importante plasticidad; la situación de maduración condiciona una mayor vulnerabilidad frente a las condiciones adversas del medio y las agresiones, por lo que cualquier causa que provoque una alteración en la normal adquisición de los hitos que son propios de los primeros estadios evolutivos puede poner en peligro el desarrollo armónico posterior, pero la plasticidad también dota al Sistema Nervioso de una mayor capacidad de recuperación y reorganización orgánica y funcional, que decrece de forma muy importante en los años posteriores.

La estimulación temprana es un método pedagógico basado en teorías científicas y en estudio de neurólogos de todo el mundo. Su razón de ser es que ciertos estímulos, oportunos en el tiempo, favorecen el aprendizaje y el desarrollo de las capacidades del niño (Estalayo y 


\section{CAPITULO 2: MARCO TEÓRICO}

Vega, 2001). Se trata de un aprendizaje temprano, y no precoz. Precoz significa que tiene lugar antes de la capacidad natural del niño esté lo suficientemente desarrollada. Sin embargo, "un aprendizaje temprano es, simplemente, el que se adelanta en el tiempo porque el proceso de ese niño en concreto está siendo más ágil y estimulado de lo habitual" (Regidor, 2003, p.18).

La estimulación temprana tiene por objetivo aprovechar esta capacidad de aprendizaje y adaptabilidad del cerebro en beneficio del niño. Mediante diferentes ejercicios y juegos su intención es la de proporcionar una serie de estímulos repetitivos, de manera que se potencien aquellas funciones cerebrales que a la larga resultan de mayor interés. El objetivo primordial de la estimulación temprana es ayudar en el proceso de formación de la estructura cerebral humana, proporcionando estímulos adecuada y oportunamente, para permitirle al individuo alcanzar un desarrollo con gran variedad de posibilidades.

El efecto que tiene la experiencia temprana sobre el desarrollo y la conectividad cerebral sugiere la necesidad de reflexionar sobre este aspecto. Los programas de intervención que entrenan a los educadores para que aporten un medio ambiente estimulante y cálido desde la infancia hasta la niñez han demostrado tener efectos positivos sobre el desarrollo cognoscitivo, emocional, físico y social de los niños (Maureira, 2010).

Del nacimiento a los seis años de vida, el tamaño del cerebro humano se desarrolla de forma extraordinaria. El bebé se transforma deprisa, aprende mucho y cada día nos sorprende con nuevos descubrimientos. Las modificaciones de su cuerpo y de su mente nunca dejan de sorprender. Hoy se sabe que el cerebro humano, igual que los músculos del cuerpo, responde de forma muy positiva a programas de estimulación temprana, en los que se invierten solo unos minutos diarios, y se logran progresos y asimilaciones fundamentales para la vida del niño, tenidos por inimaginables tiempo atrás (Antunes, 2014). Durante este periodo, el enriquecimiento del cerebro es consecuencia directa de las conexiones que se efectúan entre las neuronas. Los cinco sentidos (vista, odio, tacto, gusto y olfato) sirven de canal o de vía de entrada para que los estímulos lleguen a las neuronas y descarguen en ella pequeñas dosis de carga positiva. Se trata de ir entrenando su cerebro para crear numerosas potencialidades. Ante estos estímulos, las neuronas reaccionan creando circuito por la que canalizar la información que llega a través de los sentidos. Preparando al cerebro, para un desarrollo y aprendizaje óptimo.

En otras palabras, la capacidad cerebral dependerá en gran medida, de que el niño reciba los estímulos necesarios para una maduración adecuada. Todo sentido precisa una cantidad mínima de estimulación para que pueda ser procesado; es lo que se denomina 
umbral mínimo y puede definirse como la intensidad mínima de estímulos que se requiere para producir para producir una respuesta específica. Durante los primeros años de vida, "nuestra misión es ofrecerle estímulos y oportunidades para que pueda, en el futuro, abordar, cualquier aprendizaje con rapidez, facilidad y deleite" (Regidor, 2003, p.39).

Algunos de los motivos que justifican la necesidad de diseñar programas de estimulación temprana son: (a) la primera infancia es el periodo donde se producen incrementos espectaculares en el número de conexiones entre neuronas; (b) existen periodos críticos en los que la experiencia determina el desarrollo del cerebro y (c) existencia de periodos sensibles que indican una mayor flexibilidad en el aprendizaje (Marina 2011, p.18).

Bricker (1991) apoya y fundamenta la necesidad de crear y aplicar programas de estimulación temprana para el desarrollo integral del niño.

Estos argumentos podrían ser resumidos en los siguientes:

- Los PET ayudan a las familias de los niños deficientes o de riesgo, al menos en tres aspectos: ajuste del niño; instrucción y manejo del niño y obtención de diversos apoyos (servicios sociales, sanitarios, etc.); es importante incluir a los padres desde el principio en el programa de estimulación temprana antes de que éstos desarrollen relaciones negativas con sus hijos.

- Los PET tiene una faceta preventiva, no sólo para los niños con alto riesgo, sino también para los niños deficientes, pues permite, de alguna manera, frenar el deterioro progresivo de sus niveles de desarrollo, evitando que los niños presenten alteraciones más graves en distintos aspectos de su desarrollo, permitiendo a la vez a las familias, comportamientos más realistas que beneficien al niño.

- La rentabilidad económica, factor de tremenda importancia, y del que puede concluirse, a través de trabajos realizados en otros países, el bajo costo y la alta rentabilidad personal y familiar de los programas de estimulación temprana. El carácter fundamentalmente preventivo de la Atención temprana, puede hacer ahorrar gran cantidad de dinero que debe invertirse en programas posteriores de tipo terapéutico que tratan de subsanar los problemas que ya no se han desarrollado, y que son, evidentemente mucho más costosos.

A continuación, pasamos a realizar una breve descripción de aquellos programas de estimulación temprana PET dirigidos a la etapa de EI ( 0 a 6 años). Todos los programas que se presentan a continuación se fundamentan en que una intervención temprana es la mejor 


\section{CAPITULO 2: MARCO TEÓRICO}

garantía de éxito; cualquier niño con cualquier trastorno es subsidiario de mejora; y la necesidad de entornos estimuladores que promueva aprendizajes concretos (Rivas, 2004).

\subsubsection{Programas de intervención prenatal}

La estimulación prenatal es concebida para potenciar las capacidades cognitivas del futuro niños e implica que sus padres tengan la voluntad de dedicar cada día un tiempo a realizar el programa de estimulación, ya que el tiempo requerido por los ejercicios de cualquier programa conduce a favorecer e intensificar la vinculación afectiva prenatal, siendo esta una de las bases más sólidas para el desarrollo de unas buenas relaciones padres-hijos dentro de un clima de armonía familiar (Bautista, 2014).

Durante el segundo trimestre de gestación todos los órganos sensoriales del feto han empezado a funcionar; y es a lo largo de este trimestre, cuando el no nacido demuestra, con cambios en sus constantes fisiológicas o con ciertas conductas motrices, que es capaz de detectar y discriminar determinados estímulos y mostrar hacia ellos interés, agrado, relajación excitación, etc. (Gómez et al., 2007) de ahí la necesidad de aplicar estos programas antes del nacimiento.

Por tanto, pasamos a describir los programas de estimulación prenatal más representativos basándonos en las aportaciones de Gómez et al. (2007) y Vidal (2007).

- Programa comienzo del corazón-comienzo del amor, diseñado por Marnie en 1990, su objetivo es concienciar a los padres de que durante la gestación el no nacido ya debe formar parte de sus vidas y enseñarles a comunicarse con él, instrumentalizando la consecución de metas a través de la relajación, el goce, la concentración mental, la actividad (masaje, conversación, música, cuentos, diario, dibujo, sueños, interacción sexual, preparativos) y la formación (lecturas, vídeos, madres con experiencia, profesionales).

- Programa comienzos vinculados, diseñado por Sallenbach en 1993, su objetivo es fortalecer la vinculación entre los padres y el no nacido a través de los sentimientos, la música y el aprendizaje, abarcando cinco áreas de intervención: social, lingüística, visual, auditiva y musical.

- Currículum cardiaco, diseñado por Logan en 1991, su objetivo es incrementar el desarrollo neuronal del cerebro durante el periodo fetal por medio de la estimulación del mismo con patrones sonoros que se adapten al entorno sonoro natural del no nacido. 
- Currículo prenatal de música y sonido, diseñado por Whitwell en 1992, su objetivo es armonizar cuerpo, corazón, mente, alma y espíritu por medio de la música, el movimiento, la poesía y el color en las parejas que están esperando un hijo; este programa incluye técnicas de relajación, visualizaciones guiadas, ejercicios para comunicarse y aproximarse afectivamente al feto, armonización del entorno, ejercicios de composición de canciones prenatales, actividades de canto y de improvisación musical con instrumentos y elaboración de cintas grabadas con música para ser utilizad en el parto y el nacimiento. Se trabajan las relaciones interpersonales con los miembros de la familia: padres y hermanos; una vez nacido el bebé, se continúa la labor educativa y de apoyo emocional a los padres.

- Programa educativo multifactorial, diseñado por Manrique en 1989, su objetivo es combinar la educación de los futuros padres con la estimulación de su hijo durante los primeros años de vida del niño; se imparten a los padres 13 lecciones de dos horas de duración una vez por semana sobre estimulación, relajación, salud, nutrición, comunicación con el feto, etc. Durante los seis primeros años de vida del niño, las actividades de estimulación continúan al igual que los juegos lingüísticos y la información sobre salud y nutrición.

- Programa primer comienzo, diseñado por Plaza y Alonso en 1987, su objetivo es potenciar el desarrollo intelectual y contribuir al bienestar físico y emocional a través de la estimulación musical del feto mediante sonidos. Utiliza un tono y una intensidad de sonidos adecuados, así como un ritmo entre 65-80 de pulsación (similar al de la madre), silencios y sonido único del violín, de tal forma que el niño recibe unos estímulos sonoros a los que reacciona. Este programa incluye ocho cintas con música de violín; se ha seleccionado este instrumento por su riqueza de armónicos, además alcanza la altura tonal semejante a la que las madres y otros adultos emplean al hablar cuando se dirigen a un bebé.

- Programa de estimulación infantil prenatal, diseñada por Panthauraamphorn en 1993, su objetivo es crear un programa de actuación durante los primeros meses de gestación para reforzar el vínculo prenatal entre la madre y el futuro niño; existe un ritual con baños y masaje abdominal, ejercicios de respiración, relajación, sentarse en una mecedora, ver fotos, escuchar música tailandesa. A las 20 semanas el programa incluye 20 minutos de sesiones usando una cinta en la que el padre llama al bebé por su nombre, le habla y le pone una música suave. EI programa incluye sonidos de la naturaleza y de campanas, masaje con las manos, experiencias con agua fría y caliente, etc. 


\section{CAPITULO 2: MARCO TEÓRICO}

- Programa prenatal de valores positivos, diseñado por Manashakti en 1975, impregnado de valores culturales y espirituales de las religiones orientales se encuentra dentro de un programa educativo más amplio que acoge a sujetos desde la infancia hasta los 28 años de edad. Dicho programa pretende educar al feto a través del yoga prenatal con la ayuda de la música y la terapia del color. El objetivo principal del programa es aceptar al bebé con buenos pensamientos, dar sanskar (buenos valores) al feto, mejorar la salud emocional de los padres, aumentar la participación activa del padre durante el embarazo, aumentar el valor y la confianza para trabajar en la madre.

- Sistema de armonización intrauterina, diseñado por Verny y Wintraub en 1992 , tiene como meta desarrollar y enriquecer la comunicación entre los padres y el bebé creando una atmosfera de amor y seguridad para la futura madre y su hijo. El programa se desarrolla a medida que transcurre el embarazo, indicándose mes a mes cuáles son ejercicios y técnicas que deben ponerse en práctica, su temporalización, materiales y personas que deben participar. Los ejercicios más representativos son: escuchar música durante el embarazo, realizar técnica de relajación, escribir un diario, escoger pensamientos positivos de forma consciente para introducirlos en la conciencia y así producir los resultados deseados, trabajar con los sueños, el dibujo, el juego con arcilla, etc.

- Prenatal University, diseñado por Van de Car y Lehrer en 1986, la finalidad es proporcionar seguridad al feto y de esta manera influir positivamente en el desarrollo de su personalidad, ya que al hablarle, cantarle, leerle un cuento y acariciarle a través del vientre se estimulan sus sentidos. Este programa incide directamente sobre determinadas áreas: estimulación prenatal, nutrición, creación de un entorno intrauterino y extrauterino adecuado, potenciación de vinculación familiar por medio de la reducción del estrés, el aprendizaje del rol parental y las actividades lúdicas.

\subsubsection{Programas de intervención sensoriomotora}

Con la implementación de estos programas se buscan dar respuesta a las necesidades educativas que puedan presentar los alumnos, creando estrategias que estimulen sus capacidades sensoriales para favorecer un desarrollo óptimo. La intervención debe ser sistematizada y adaptada al niño, incidiendo principalmente en las áreas sensitivas y motoras; debe ser valorada y modificada a lo largo del proceso de intervención y aplicada por 
especialistas o educadores, fomentando la participación de personas cercanas al niño, como es la familia.

Presentamos los programas más conocidos en la intervención sensoriomotora según las aportaciones realizadas por Gómez et al., (2007).

- Programa ARYET, diseñado por un equipo de expertos en el desarrollo infantil en el año 1988, consiste en una guía práctica y sencilla para aquellas personas que se inician en la atención temprana. Está estructurado para realizar un entrenamiento sistemático de las habilidades del niño durante los dos primeros años de vida.

- Programa de intervención temprana para niños con Síndrome de Down, creado por Hanson en 1979, establece una secuencia del desarrollo en el niño con síndrome de Down además de un procedimiento de actuación práctico para llevar a cabo en las primeras prácticas educativas. Los objetivos que persigue este programa se resumir en: identificar lo antes posible a los niños cuyo desarrollo está atrasado; identificar y evaluar las dificultades evolutivas de dichos niños; potenciar las habilidades latentes que tienen y dar a estos niños la oportunidad de desarrollarse e interactuar con un ambiente adecuado.

- Proyecto Portage, guía metodológica diseñada por Portage en 1967, cuyo objetivo es la evaluación y programación de actividades que aseguren que niños y niñas ingresen a la escuela con las habilidades necesarias para alcanzar el éxito en el aprendizaje. Esta guía facilita un profesor quien enseña a los padres en sus propios hogares.

Tan importante como seleccionar el programa que mejor se adecue al niño, es realizar una valoración inicial para proporcionar los recursos idóneos; en lo referente a la intervención sensoriomotora son dos las escalas más utilizadas para determinar el grado de intervención:

- Escala de observación del desarrollo, elaborada por Secadas en 1988, realiza escala para estudiar el desarrollo de los niños en los primeros años de su evolución. La escala de observación del desarrollo es un instrumento para uso de padres y educadores que permite diagnosticar el estado de desarrollo en que se encuentran los niños en el momento de la exploración, así como describir los procesos y secuencias temporales.

- Escala Haizea-Llevant, instrumento diseñado en 1991, el objetivo de esta escala es facilitar la valoración del desarrollo infantil a fin de detectar precozmente 


\section{CAPITULO 2: MARCO TEÓRICO}

aquellas dificultades en las que esté indicada una evaluación más completa y especializada. La mera valoración del desarrollo puede, sin embargo, no ser suficiente para identificar ciertas alteraciones, por lo que se incluyen en la escala unos signos de alerta, cuya presencia en cualquier edad o a partir de edades concretas indica la posibilidad de alteraciones.

\subsubsection{Programas de intervención con niños con discapacidad intelectual}

Los programas de intervención con niños con discapacidad intelectual están dirigidos a mejorar o recuperar el déficit existente en las capacidades cognitivas (Ginarte, 2002); estos programas se basan en la idea de que el funcionamiento cognitivo puede mejorarse estimulando el sistema cognitivo de forma general. Para ello es necesaria de una evaluación inicial que ofrezca una descripción detallada de las funciones o habilidades perdidas y de las áreas que se mantienen conservadas, de tal forma que los programas de tratamiento puedan diseñarse para que demanden al cerebro el uso de los procesos dañados; esto permite determinar y analizar los déficit sobre los cuales se va a intervenir, qué estrategias emplea el sujeto para resolver la tarea, y las capacidades con las que contamos para aplicar el programa de intervención.

Algunos de los programas más conocidos en este ámbito según Gómez et al., (2007) y ASPACE (2001) son los que presentamos a continuación.

- Todo un mundo de sensaciones, programa diseñado por Fodor, García-Castellón y Morán en 2002, su objetivo es estimular el desarrollo del bebé durante su primer año de vida. Presentan una secuencia de estimulación de los sentidos y de psicomotricidad infantil clara y muy bien estructurada, además explican una serie de pautas en función de las necesidades educativas que tendrá el bebé a medida que vaya evolucionando; estas pautas son un referente claro para saber qué debe hacerse en cada momento.

- Currículo Carolina, programa elaborado por un grupo de expertos de la universidad de Carolina del Norte en 1994, su objetivo es facilitar estrategias de intervención adecuadas para niños pequeños con necesidades específicas de apoyo educativo. Proporcionan ayuda a las personas que se dedican a la intervención temprana, familiares de niños con limitaciones y otras personas dedicadas al cuidado de niños con necesidades especiales. El Currículo Carolina está formado por 26 secuencias de desarrollo que abarcan 5 áreas: cognición, comunicación, adaptación social, motricidad fina y motricidad gruesa. Cada ítem o actividad incluida en cada área, 
debe ser adquirida por el niño a una determinada edad, por ello están numerados según el orden en el que deben ser aprendidos.

- Programa de intervención en el área cognitiva para niños con síndrome de Down, diseñado por Motos y Candel en 1999, está dirigido a niños síndromes de Down de 0 a 24 meses. Se divide en cuatro secuencias de tres meses para el primer año y dos secuencias para el segundo año, con la gran diferencia que en el primero el programa está pensado para intervenir en el área motora, y en este caso las intervenciones están pensadas para favorecer el área cognitiva.

- Programa para la intervención en niños con trastornos generalizados del desarrollo, diseñado por Tortosa-Nicolás en 2003, el objetivo es facilitar a todos los profesionales, docentes y terapeutas el uso de las TIC con alumnos con trastorno generalizado del desarrollo en relación con la interacción social, la comunicación y habilidades de autonomía entre otros. Este programa sigue una serie de principios: estimular la exploración de objetos, realizar juegos circulares de interacción centrados en el cuerpo, estimular al niño en un ambiente muy estructurado, utilizar el aprendizaje sin error (el cual consiste en no atender a los errores, adaptar los objetos al nivel evolutivo del niño y asegurar la adquisición previa de los objetivos de conducta que se pretenden enseñar), seguir el encadenamiento hacia atrás (descomponer la secuencia de aprendizaje, en objetivos de conducta muy delimitado), utilizar el entrenamiento o la enseñanza incidental, es decir, estar alerta a posibles iniciativas del niño y reforzarlas de forma positiva, responder consistentemente ante conductas comunicativas, no prestar atención a las rabietas y actuar impidiendo su refuerzo.

\subsubsection{Programas de fisioterapia neurológica infantil}

Para poner en práctica este tipo de programas es importante que el fisioterapeuta mantenga una comunicación efectiva con el equipo interdisciplinario, aplicando estrategias y técnicas terapéuticas de intervención idóneas para cada paciente. La intervención fisioterapéutica en neurología no se basa en guías o protocolos detallados sobre cómo debe ser la aplicación de una determinada estrategia, sino que parte de considerar los fundamentos teóricos, sus principales características y del conocimiento del neurodesarrollo, la neurofisiología, biomecánica, reeducación muscular y el aprendizaje motor (González, 2005). Para aplicar este tipo de programas es necesario identificar el nivel de habilidad del niño para diseñar el objetivo de la intervención utilizando estrategias adecuadas a sus necesidades. 


\section{CAPITULO 2: MARCO TEÓRICO}

Señalamos a continuación los métodos terapéuticos más conocidos en este ámbito en base a las publicaciones de Gómez et al. (2007) y ASPACE (2001).

- Método Petö, diseñado por Petö en 2000, donde se propone la estimulación global de funciones en orden a conseguir objetivos funcionales prácticos, con la participación activa del propio paciente en su proceso de recuperación. El trabajo se realiza por grupos entre 5 y 12 pacientes, pero las tareas se adaptan a la situación y necesidades propias de cada paciente.

- El principio Vojta, método terapéutico diseñado por Votja entre 1950 y 1970, también conocido como locomoción refleja, que permite activar patrones motores normales en pacientes con alteraciones motoras neurológicas o con déficits posturales ortopédicos. El método consiste en la aplicación de estímulos propioceptivos en periostio, fascias y tejido muscular en unos puntos muy concretos y partiendo de posturas muy determinadas, que desencadenan de forma refleja patrones de locomoción programados genéticamente en el cerebro, provocando un efecto corrector de la motricidad anormal al ser activados de forma sistemática.

- Técnica terapéutica de Le Métayer, diseñado por Bobath en 1950, este tratamiento desarrolla una serie de técnicas que tienen como objetivo inhibir los patrones de la actividad refleja anormal, facilitando patrones motores normales, como preparación a las actividades funcionales.

- Método Rood, diseñado por Rood en 1956, este método se basa en la fisiología, de cómo las unidades motoras juegan un papel en el control de la postura y el movimiento; $y$ de que forma la entrada aferente puede ejercer una influencia en el sistema nervioso central.

- Reaprendizaje motor orientado a la tarea, diseñado por Carr y Shepherd en 1980, su objetivo es el reaprendizaje de determinadas tareas motrices específicas. Enseñar al paciente estrategias eficaces para conseguir realizar un movimiento funcional, por tanto el paciente toma un papel activo en el proceso de rehabilitación.

- Método Pohl, este programa diseñado en los años 80, intenta concienciar al cerebro de los movimientos que realizan los músculos y articulaciones; se consigue con movilizaciones activas (incluso pasivas) al principio de un músculo proximal, luego va aumentando el movimiento distalmente hasta que se incluye la totalidad del miembro. Se comienza con una primera fase de relajación para que el cerebro 
tenga poca información de sus músculos y articulaciones, así en la segunda fase se realizan las contracciones y la información llega más fácilmente al cerebro.

\subsubsection{Programas para niños con trastornos del lenguaje}

La detección temprana de un trastorno del lenguaje en una condición para que el programa se inicie en el momento oportuno y sea más eficaz (Gómez et al., 2007), aunque no es hasta los 3 años cuando se puede detectar; en estos primeros años la plasticidad cerebral es máxima y es conveniente aprovechar esta oportunidad para mejorar los aspectos del procesamiento del lenguaje alterados. Como en los casos anteriores, es conveniente realizar una evaluación inicial para saber de dónde partir y que programas, objetivos y estrategias aplicar; una vez hallados los resultados de la evaluación se establecen unos objetivos en base al tipo de intervención que se vaya a realizar. Algunos de los programas más utilizados en este campo según Gómez et al. (2007), ASPACE (2001) y Vidal (2007) son:

- Programa de ejercitación del cerebro, diseñado por Merzenich y su equipo en 2003, es un programa de un mes de duración orientado a promover competencias de lectura para niños con trastornos disléxicos de edad escolar (8 a 12 años), basado en el entrenamiento de diferentes procesamientos fonológicos. Con este programa se busca mejoras en el desempeño a nivel de la producción oral y de la lectura.

- Programa McCandliss, diseñado por McCandliss en 2003, es un programa de intervención de cuatro meses de duración, también orientado a mejorar las competencias de lectura de niños disléxicos de edad escolar, pero en base al entrenamiento de habilidades atencionales de decodificación. Con este programa se busca mejoras a nivel de las habilidades de control atencional, la comprensión lectora y el procesamiento fonológico.

- Software Klingberg, diseñado por Klingberg en 2009, consiste en un programa computarizado de entrenamiento de memoria de trabajo para niños de 7 a 15 años con trastornos por déficit de atención con hiperactividad. Los resultados permitieron verificar un aumento significativo en la cantidad de información que los niños pueden mantener durante la realización de una tarea.

\subsubsection{Programas alternativos}

- Técnica Tomatis, diseñado por Tomatis en los años 50, es una técnica de estimulación auditiva; consiste en escuchar música o sonido a través del oído 


\section{CAPITULO 2: MARCO TEÓRICO}

electrónico (complejo simulador del oído humano); se reeducan los músculos del oído medio, se restituyen las frecuencias perdidas y se restablece el buen funcionamiento del sistema nervioso; de este modo podemos recuperar la capacidad de escucha y aportar energía al cerebro y al cuerpo.

- Hipoterapia, actividad rehabilitadora a través de la monta terapéutica; su utilización data desde el año 460 a.C donde Hipócrates utilizó la monta terapéutica como la mejor terapia para combatir el insomnio y mejorar la tonicidad muscular (López y Dario, 2015). Consiste en aprovechar los movimientos tridimensionales del caballo para estimular los músculos y articulaciones. Además, el contacto con el caballo, aporta facetas terapéuticas a niveles cognitivos, comunicativos y de personalidad.

- Método Padovan, diseñado por Padovan en los años 70, este método trabaja los ejercicios tradicionales que provienen del método Doman (1997) de reorganización neurofuncional; éstos ayudan al niño en su conjunto, muchos de los problemas que padecen niños con dificultades de lenguaje, pues dichas dificultades vienen a menudo asociadas a otras y a casos de autismo, lesión cerebral, trisomía, déficit de atención con o sin hiperactividad, dislexia, etc. Estos ejercicios tratan de imitar a la naturaleza en la evolución del desarrollo del niño, por lo que se trabajan movimientos que hace el bebé de forma natural, realizándolos continuada e intensivamente para lograr vencer posibles lagunas o desajustes surgidos durante el desarrollo.

- Método Foltra, diseñado por Devesa en los años 40, consiste en llevar a cabo un tratamiento rehabilitador específico de cada caso, médico, fisioterápico, psicológico y logopédico hasta conseguir el máximo posible en la recuperación del paciente con daño neurológico adquirido, central o periférico y su reintegración en la sociedad, sin que el tiempo de tratamiento y dedicación diaria a éste o la disponibilidad económica individual sean un factor limitante o condicionante.

- Terapia de movimientos rítmicos y reflejos primitivos, diseñado por Blomberg en 1986, consiste en la realización repetitiva de movimientos rítmicos que implican todo el cuerpo. Se llevan a cabo sobre el suelo y se basan principalmente en la imitación de los movimientos propios realizados por los bebés de forma natural durante su crecimiento y desarrollo. A través de la estimulación sensorial y del movimiento principalmente, las zonas más básicas y primitivas del cerebro (las que reciben esta estimulación de forma más directa) se activan y se van desarrollando. A su vez van estimulando y conectándose con otras zonas más evolucionadas. Para que el cerebro esté maduro, no sólo es necesario que todas las zonas estén 
estimuladas y activas, sino que estén interconectadas unas con otras funcionando de forma conjunta; si falla esta interconexión y la correcta activación de todas las zonas cerebrales, pueden surgir problemas tanto físicos como cognitivos, de aprendizaje, emocionales o de relación.

- Hidroterapia, diseñada por Sebastián Kneipp en el S.XIX, consiste en una actividad física en la que se utiliza el agua de forma terapéutica, bien por su efecto térmico o por sus propiedades mecánicas, como el ser un medio que amortigua los impactos de los ejercicios realizados en él. De este modo, se contrarresta el efecto perjudicial ejercido por la gravedad, que se impone en la mayoría de los deportes practicados de forma habitual en el suelo, siendo ésta la principal ventaja obtenida en el medio acuático.

- Musicoterapia, la música como terapia data del año 1.500 a.C.; la música con fines terapéuticos tiene importantes beneficios sobre los aspectos emocionales y motivacionales, la salud física, las funciones cognitivas y sensoriomotoras, así como las habilidades sociales y de comunicación. Las sesiones de musicoterapia pueden recibirse de manera individual o en grupo, dependiendo de las necesidades específicas de la persona. El programa de tratamiento consta de elementos y ejercicios muy variados (improvisación musical, escuchar y cantar canciones, discusión lírica, tocar instrumentos, etc.) que se adaptarán a las características y aptitudes de cada persona.

- Método Collis, creado por Collis en 1997, este método utiliza todo tipo posible de estímulos externos; se suministran al cerebro informaciones de forma masiva (táctil, auditiva, visual) para que éste las ordene. Así se adquiere un esquema motor acorde a la edad del niño e instruyendo a los padres para que también lo lleven a cabo. Collis, tiende a considerar la actividad neuronal como un todo afirmando la existencia de un trastorno combinado por alteración del desarrollo mental, los reflejos postulares y el tono muscular. Busca, desde las edades más precoces, una seguridad postural que sirva como base de coordinación muscular.

- Método Point, diseñado por Point en 2006, el método se ha descrito como una estrategia educativa y como un método de estimulación social, sensoriomotora, cognitiva y artística, dirigido a niños entre los cero y seis años. Este método tiene como objetivo propiciar el desarrollo de inteligencias múltiples y los procesos de aprendizaje temprano con el fin de garantizar éxito escolar. Además, plantea el aprendizaje natural de una segunda lengua (inglés) y afirma que el bilingüismo aumenta la fluidez y la flexibilidad del pensamiento al utilizar la educación 


\section{CAPITULO 2: MARCO TEÓRICO}

psicomotriz y la estimulación musical para favorecer el desarrollo de la personalidad y mejorar la inteligencia.

- Método Bebé Políglota, diseñado por Granés-Morales en los años 80, el método Bebé Políglota se refiere a un programa de estimulación dirigido a niños y niñas menores de siete años. Pretende facilitar el aprendizaje de cinco o más idiomas utilizando estímulos audiovisuales, que incluyen el sonido de locutores nativos hablando cada uno de los idiomas mientras se realizan actividades lúdicas.

\subsection{MÉTODO DOMAN}

Doman fue un médico e investigador estadounidense fundador de los Institutos para el Desarrollo del Potencial Humano en Filadelfia (EEUU) y más conocido como el padre de la metodología de los bits de inteligencia. Comenzó a interesarse hace más de 60 años por el desarrollo cognitivo temprano en los bebés cuando trataba a niños con lesiones cerebrales. Progresivamente fue extendiendo sus experiencias y sus trabajos al entorno de los niños sanos, al aplicar programas similares a los utilizados en niños con lesión cerebral. En aquellos años, a los niños con lesiones cerebrales se les consideraban incurables puesto que sus incapacidades eran consecuencia de la muerte de neuronas. Doman y su equipo mantuvieron que si bien las neuronas muertas no pueden recuperarse, las vivas pueden desarrollarse y establecer conexiones entre ellas de tal forma que asuman las funciones que debían desempeñar las muertas (Estalayo y Vega, 2001). Esto les llevó a cuestionarse lo que estaba pasando con los niños sanos y comenzaron a aplicar sus propios métodos a estos niños, desde los primeros meses de vida, obteniendo unos resultados muy esperanzadores.

Al acabar la segunda Guerra Mundial, Doman, regresó a Filadelfia tras haber ganado muchas condecoraciones en el campo de la batalla. Por este motivo la Asociación de Fisioterapeutas de la ciudad celebró un banquete en su honor y cada uno le cedió uno de sus pacientes. Este gesto, permitió a Doman abrir su propia consulta y trabajar con 31 enfermos, que tenían una característica común, todos habían sufrido una lesión cerebral. La posterior colaboración con su antiguo maestro, el neurólogo Temple Fay, y la creación pionera de un centro de rehabilitación junto con el mismo Dr. Fay, su hermano Robert y un equipo de profesionales, le permitió comprobar hasta qué pronto eran ineficaces los múltiples métodos empleados y vanos los esfuerzos de siete largos años, cuando se trataba de rehabilitar a un niño con lesión cerebral. Doman y su equipo sometió a un severo análisis clínico sus estudios universitarios y sus prácticas médicas. Uno de los resultados más transcendentales fue el hallazgo de que la lesión cerebral se halla en el cerebro y, por consiguiente, deben emplearse 
procedimientos que permitan acceder a él si se pretenden conseguir o restablecer las funciones neurológicas.

\subsubsection{LOS INSTITUTOS DE DOMAN}

Doman creó Los Institutos para el Desarrollo del Potencial Humano, una fundación dedicada al tratamiento de los niños con cualquier grado de lesión cerebral. Muy gradualmente, fueron hallando métodos de acceso al cerebro, incluso a los más dañados, restableciendo la vista, el oído, el tacto, el movimiento, el lenguaje, etc. Los objetivos se fueron volviendo cada vez más ambiciosos, hasta el punto de no renunciar a unas funciones neurológicas perfectas (Estalayo y Vega, 2007). Se comprobó la permanencia en el lesionado de una gran inteligencia potencial y se elaboraron programas eficaces para las áreas intelectuales y escolares.

Siguiendo de forma inconsciente el principio de la imposibilidad de restaurar un cerebro lesionado, se excluyó de sus cuidados a los pacientes con síndrome de Down. Veras, estrecho colaborador de Doman, comprobó y demostró a Doman que también valía la pena luchar por aquellos niños con lesión cerebral o anomalías genéticas, pues el pronóstico era muy esperanzador. A partir de ese momento lo admitieron en el centro, donde los logros obtenidos fueron muy numerosos.

A medida que se fue comprendiendo en Los Institutos el proceso del desarrollo cerebral y los requisitos para lograrlo en caso de lesionados cerebrales, fue tomando cuerpo la idea de que cada niño requería una atención intensa y personalizada. Se comprendió que el tiempo era uno de los enemigos del paciente, pues su paso solía significar un mayor retraso a no ser que se lograra acelerar el ritmo de desarrollo. Finalmente, se tomó una decisión, en adelante no contarían con pacientes internos ni ofrecerían asistencia ambulatoria, se propusieron capacitar a los padres de los niños y confiarles la realización doméstica de un programa intensivo elaborado para un periodo de varios meses hasta la consecución de metas precisas en varias áreas neurológicas, "nadie podría prestar a los niños ni más ni mejor atención que los propios padres" (Doman, 2008, p.51). Por otra parte, los profesionales, liberados de las tareas cotidianas, podrían ampliar su radio de acción a muchos más niños y, como consecuencia, la investigación clínica recibiría un gran impulso.

Un perfeccionamiento continuo de la metodología para llevar a cabo este plan desembocó en un curso de una semana en el que los padres adquirieron un conocimiento teórico-práctico de lo esencial sobre el cerebro, las leyes de su crecimiento, la naturaleza de la lesión cerebral y un sistema para la evaluación y programación con métodos contrastados. 


\section{CAPITULO 2: MARCO TEÓRICO}

Esta formación es complementada en cursillos periódicos cada vez que se llevaba al niño a realizarle una revisión de sus progresos. Poco a poco, los padres se fueron convirtiendo en los mejores rehabilitadores neurológicos de sus hijos; pudiendo ofrecer así, un tratamiento intensivo y la aplicación de métodos neurológicos y no sintomáticos, con resultados variables, pero en todo caso, muy superiores a los habituales.

El tratamiento de las lesiones cerebrales que proponen Los Institutos fundados por Doman, constituyeron una auténtica revolución; de cuyos beneficios no debería verse privado ningún niño que se halle en estado de coma, que sufra una lesión severa o leve o cuyo imperfecto desarrollo neurológico sea la causa de muchos síntomas, como las dificultades para leer, la pobre comprensión oral, el estrabismo, la dislexia, la hiperactividad, la deficiente lateralidad, la inadaptación, la falta de atención, la falta de coordinación o sociabilidad, etc. (Estalayo y Vega 2001, p.17).

La creación de métodos especiales de lectura y matemáticas y del popular programa de los bits de inteligencia dio a los lesionados cerebrales acceso a los contenidos de los programas escolares. Los buenos resultados que se consiguieron con ellos hicieron pensar a Doman en los niños sanos que fracasaban a diario en la escuela y fundó un centro de educación para niños de 0 a 14 años. Para dar a conocer sus hallazgos a todos los niños del mundo, Doman escribió varios libros (Doman, 1986, 1998, 2008, 2009) y organizó cursos para padres y educadores. Han logrado diseñar protocolo y programas de estimulación eficaces, para el desarrollo armónico de la inteligencia de los niños.

Es a través de este trabajo como llega a una de sus ideas más conocidas "los niños son capaces de aprender cualquier cosa, especialmente poseen una capacidad asombrosa para el aprendizaje durante los primeros seis meses, superior a la del resto de su vida" (Doman, 2008, p.36). Este autor denomina a este periodo de tiempo la génesis del genio, e indica que cuanto más pequeño es un niño, más fácil es el aprendizaje.

Como mantienen Estalayo y Vega (2001) desde el punto de vista científico (neurológico) la educación consiste en el establecimiento de conexiones neurológicas que son las que determinan la inteligencia y posibilitan el conocimiento "cuantas más conexiones consiga realizar el cerebro más inteligente será (porqué podrá realizar más funciones) y más posibilidades de acumular conocimientos tendrá porque para aprender usamos esas redes neuronales creadas en los 7 primeros años de nuestra vida" (2001, p.78).

\subsubsection{ESCALA DE DESARROLLO}

El perfil o escala de desarrollo de Doman (ver figura 2.1), que se tiene como referencia para la evaluación del desarrollo infantil y para diseñar programas de estimulación, señala las funciones propias de los diversos estratos cerebrales. 


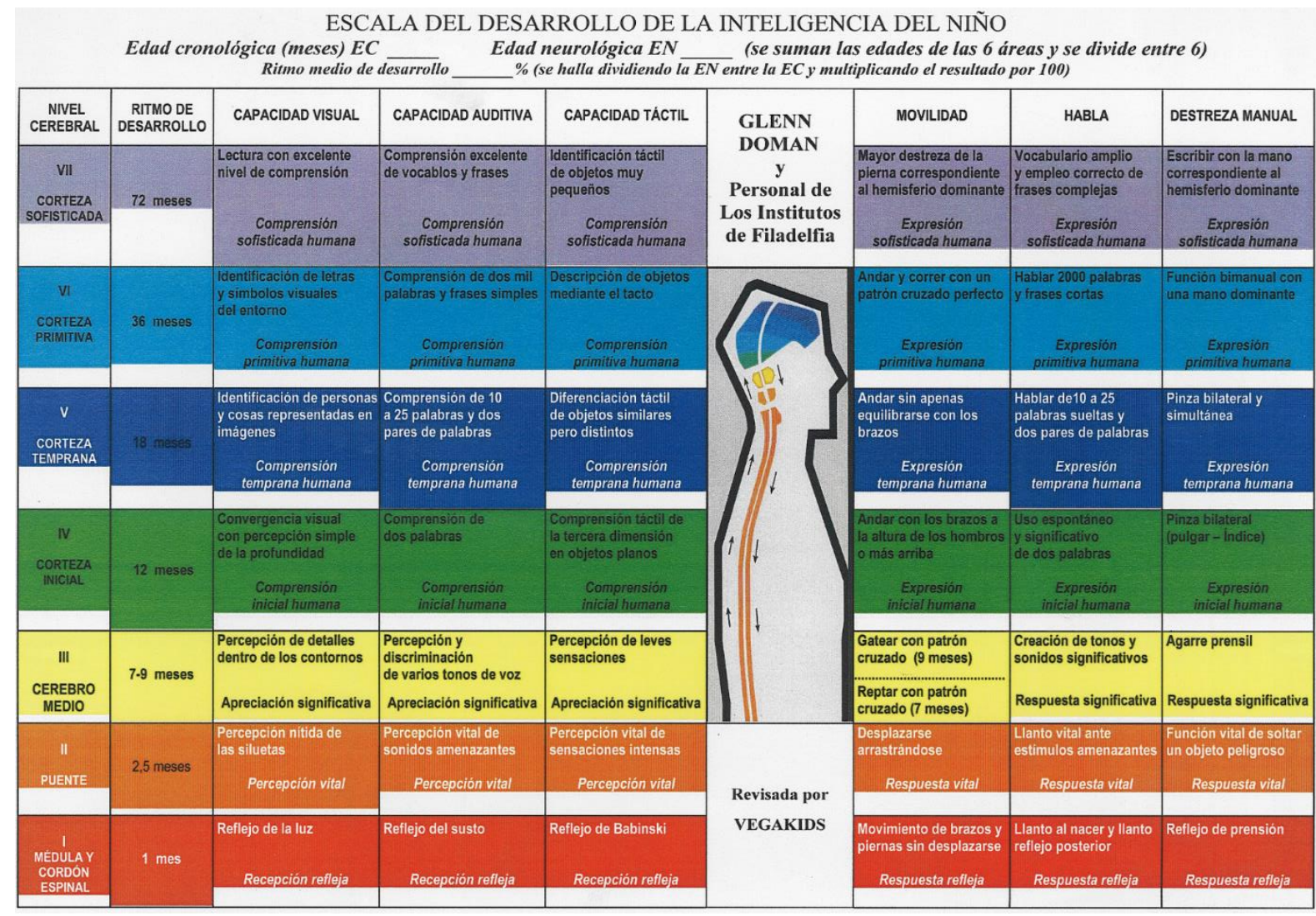

Figura 2.1. Escala del desarrollo de la inteligencia del niño de Doman

De esta forma es posible trabajar de forma sistemática y ordenada y conocer los objetivos del niño en cada una de las áreas neurológicas a partir del nivel ya alcanzado. Una auténtica evaluación del desarrollo neurológico del niño requiere un buen conocimiento de su proceso, de las áreas principales, de los diversos niveles y de las funciones específicas de cada uno de ellos.

El origen de la escala fueron numerosos datos relativos a más de doce mil niños, con los cuales se fue precisando cada vez más el perfil o escala del desarrollo que había ideado Doman en 1960 como instrumento de evaluación, diagnóstico funcional y tratamiento (Estalayo y Vega, 2007). Comparando con otras escalas de desarrollo, como la de Denver la escala de desarrollo destaca por su sencillez, orden y claridad; sólo indica cuarenta y dos funciones, mientras el test de Denver, por ejemplo, supera el centenar. Este hecho responde a la intención de centrarse en lo esencial, recogiendo en la escala de desarrollo sólo las funciones que constituyen el funcionamiento indispensable para la adquisición de funciones neurológicas superiores.

Otra diferencia es que en el perfil de Doman, se expresa gráficamente que esas funciones son meras habilidades, sino el reflejo del desarrollo de sucesivos estratos cerebrales, de cuyo grado de perfección dependen la adquisición y la calidad de los niveles 


\section{CAPITULO 2: MARCO TEÓRICO}

más altos. El Perfil abarca desde el nacimiento a los seis años de edad. Se distinguen en él seis áreas del desarrollo y, en cada una de ellas, siete niveles. En éstos se señalan las funciones que les son propias, el estrato cerebral responsable de las mismas y la edad media en que suelen estar perfeccionadas (véase figura 2.1).

Teniendo delante el cuadro del Desarrollo Neurológico de Los Institutos de Doman, no resulta complicado evaluar a un niño. Basta ir comprobando en él de forma sistemática la presencia de las funciones que corresponden a los diversos estratos del sistema nervioso central, en cada una de las áreas hasta llegar al nivel cuya función no tenga el niño o la tenga en una medida insuficiente. Esto es lo más importante, pues permite valorar el ritmo de desarrollo del niño, formular un diagnóstico funcional si no es el adecuado, y elegir el programa que necesita para avivar el proceso de su desarrollo.

Se distinguen claramente las áreas y funciones sensoriales de las que son motoras. Las áreas sensoriales, susceptibles de ser estimuladas, son los cincos sentidos. Los principales programas de estimulación se centran en las vías visual y auditiva. Las áreas motoras consideradas son la movilidad, el lenguaje y la destreza manual. La primera y la tercera contribuyen, junto con el equilibrio, lo que Doman llama la Inteligencia Física. El área de la movilidad es la clave o el motor de desarrollo de la inteligencia en todas sus expresiones, teniendo una incidencia determinante en las áreas restantes.

En cada área se distinguen siete niveles de evolución neurológica, de desarrollo de estructuras anatómicas y de conquista de funciones sucesivamente más elevadas. Las primeras funciones neurológicas, aunque elementales y reflejas, constituyen el fundamento de cada área. Los segundos niveles son percepciones o respuestas vitales, pues tienen la misión de salvaguardar la integridad o la vida del individuo. Con ellos, la naturaleza señala la importancia de favorecer la pronta adquisición del desarrollo cerebral. Los terceros niveles encierran los programas neurológicos propios de los cuadrúpedos y, mediante su perfeccionamiento, el niño se acerca al umbral de la humanidad. Los últimos cuatro niveles son corticales y constan de funciones exclusivas de la especie humana. En cinco de las áreas, la función más alta guarda relación con el lenguaje oral (área auditiva y del lenguaje) y escrito (área visual, táctil y manual) y la sexta área (la de la movilidad) es el secreto para logar un buen dominio del lenguaje.

El Perfil o Escala de desarrollo del niño es el marco de los PET. En él, se hallará siempre de referencia específico para los principios, técnicas y los programas. 
Como ya hemos mencionado anteriormente, de las seis áreas mencionadas, tres son vías sensoriales y tres, motoras. Las vías sensoriales son la visual, auditiva y táctil, cuyo gradual desarrollo permite llevar al cerebro informaciones cada vez más precisas sobre el mundo exterior. Las vías motoras que se señalan, son la movilidad, el lenguaje y la destreza manual. Se encargan de procesar las órdenes del cerebro para regular las relaciones del individuo con el mundo exterior y con las demás personas. Su eficiencia depende por completo de las funciones sensoriales pues, sin la información que se recibe gracias a ellas, no podrían desarrollarse ni expresare.

El ritmo medio de desarrollo indicado en el Perfil no corresponde necesariamente a la normalidad, aunque así suele interpretarse. En opinión de Doman y Doman (1998), ese ritmo es inferior al propio del proceso neurológico, aunque es el más común. Corresponde al desarrollo que se alcanza en un ambiente creado por el desconocimiento parcial, el azar y la intuición. Un medio regulado por el conocimiento, la atención sistemática y los procedimientos más eficaces, puede acelerar el ritmo y augurar el éxito, que, de otro modo, no está garantizado.

En palabras de Estalayo y Vega (2001):

La mayoría de padres y muchos educadores no saben que es posible y conveniente hacer algo análogo para que los niños tengan una vigorosa vida cerebral y un armónico desarrollo neurológico, del que va a depender su supervivencia, el éxito escolar y social y su felicidad. (Estalayo y Vega (2001, p.13).

A partir de esta escala de desarrollo no resulta complicado evaluar a un niño. Basta con ir comprobando en él de forma sistemática la presencia de las funciones que corresponden a los diversos estratos del sistema nervioso central, empezando por el ínfimo, que es el de la médula espinal, en cada una de las áreas hasta llegar al nivel cuya función no tenga el niño o la tenga en una medida insuficiente. Este dato es fundamental, pues permite valorar el ritmo de desarrollo del niño, formular un diagnóstico funcional si no es el adecuado, y elegir el programa que necesita para avivar el proceso de su desarrollo.

Como puede verse en el cuadro anterior, la columna temporal revelará la edad neurológica que le corresponde al bebé en cada una de las áreas. Si el paciente coincide con su edad cronológica, sabremos que el ritmo es aceptable, pero también que convendría acelerarlo para que se aproxime a uno más apropiado a la fisiología cerebral. Si por el contrario, es inferior la conveniencia se convierte en una necesidad tanto más urgente cuanto mayor sea la diferencia entre la edad cronológica y la neurológica, y tanto más razonable será también pensar en la presencia de una lesión cerebral y no sólo de un retraso neurológico. 


\section{CAPITULO 2: MARCO TEÓRICO}

Para hallar la edad cronológica en los Institutos de Doman, se suma las edades neurológicas de las seis áreas y se divide la suma entre seis, de este modo se hallará la edad neurológica media. La suma de los diversos niveles neurológicos que alcance el niño en esas seis áreas, constituyen el grado de su inteligencia efectiva. La razón entre la edad neurológica y la cronológica del niño es igual al ritmo medio, que suele expresarse en porcentajes multiplicándolo por 100 .

No debemos olvidar que el primer paso en la evaluación del desarrollo neurológico es la recogida de datos. Estos pueden ser obtenidos a través de dos vías. Los obtenidos mediante la observación directa y la comprobación personal del experto que hace la evaluación y las informaciones aportada por los padres.

\subsubsection{EXPERIENCIAS DEL MÉTODO DOMAN}

De todo lo anterior se deduce que el potencial humano que hay en cada niño es enorme y cuanto mayor sea la estimulación mayor será la oportunidad de desarrollo del niño. Por eso, Estalayo y Vega (2007) mantienen que mientras menor es la edad del niño, mayor es su potencial y más fácil establecer conexiones neuronales y aumentar la complejidad de dichos circuitos.

Esta metodología de intervención se basa en aprovechar al máximo las posibilidades del niño, siendo fundamental el momento temprano en que se comienza, ya que más adelante no será tan fácil como cuando el niño es pequeño; como afirma (Doman, 1986, p.89) "la capacidad de almacenar datos concretos es inversamente proporcional a la edad" y "es más fácil enseñar a un niño de dos año a tener unos conocimientos enciclopédicos que enseñárselo a un niño de siete años".

\subsubsection{Programa de estimulación basado en bits de inteligencia}

El material principal utilizado para llevar a cabo los programas creados por Doman y su equipo son los bits de inteligencia; "un bit de inteligencia es todo dato concreto que se almacena en el cerebro del niño para la formación de su banco de datos" (Estalayo y Vega, 2007, p.37); por tanto, se trata de una información concreta, clara y novedosa que pueda percibir el niño a través de las distintas vías sensoriales; algunos ejemplos de bits son: una nota musical, una palabra escrita, una sensación táctil, una información gustativo, una fotografía, etc. Doman utiliza principalmente tres tipos de bits de inteligencia para aplicar los diferentes programas de estimulación: (a) bits de palabras, (b) bits de imágenes y (c) bits de números (ver tabla 2.6). 
Tabla 2.6. Tipos de bits de inteligencia

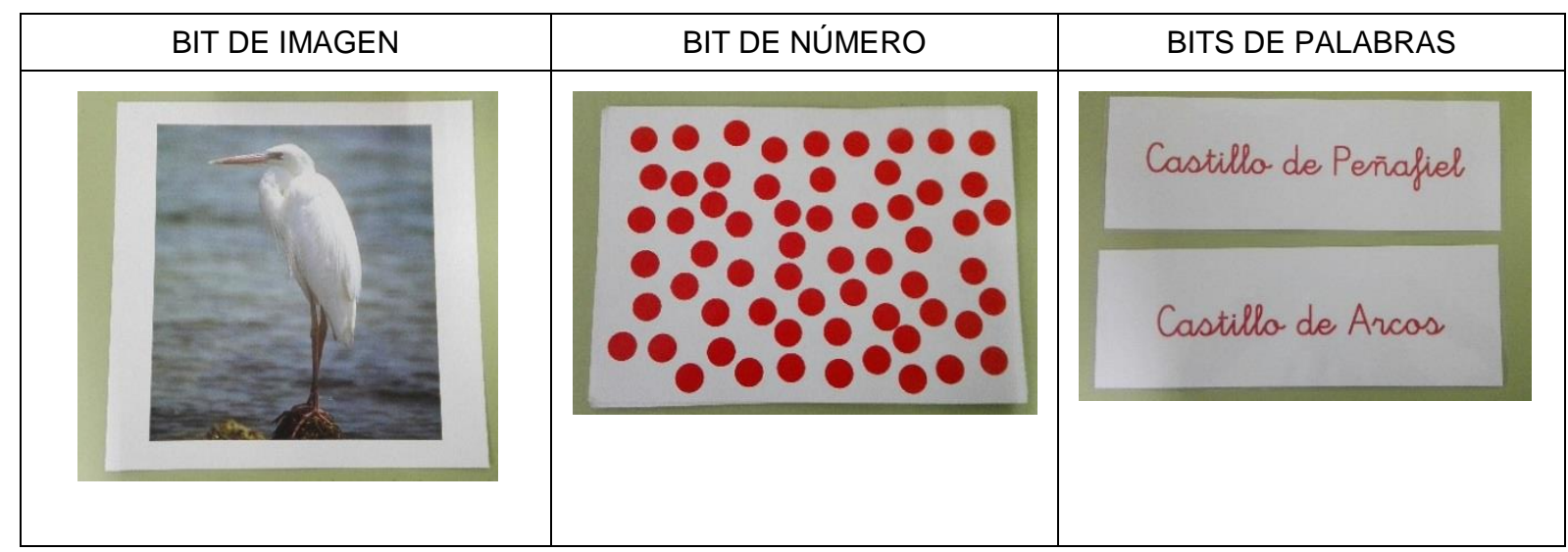

Elaboración propia a partir de Estalayo y Vega (2007)

- (a) Bits de imágenes: son representaciones gráficas de objetos o seres vivos en cuyo reverso se indica su nombre; el material gráfico se monta sobre un soporte rígido, con el fin de poder manejarlo fácilmente y evitar que lleguen a la retina del niño imágenes ondulantes y borrosas o confusas a causa de la flexibilidad del soporte de la imagen; por tanto, el material ideal es una cartulina rígida o cartoncillo de color blanco (para que resalte más la imagen). En el dorso de un Bit de inteligencia se escribe el título para leerlo en el momento de presentarlo en las sesiones de estimulación; se aconseja ponerlo en la parte superior de la lámina, de este modo se puede leer al mismo tiempo que se comprueba la atención e interés de los niños. Los bits de imágenes se organizan por categorías, cada categoría están constituido por 10 bits de imágenes.

- (b) Bits de palabras: se elaboran con cartulinas blancas de dina A3 cortadas por la mitad. A la hora de elaborar el material se ha debe tener en cuenta que las palabras escritas en la cartulina tengan una letra grande y clara, de trazo grueso (como arial black o letra escolar) y color llamativo (roja). Se trata de estimular el área visual del niño para desarrollar la capacidad lectora.

- (c) Bits de números: para elaborar este material se necesita 100 cartulinas blancas y rígidas de $30 \times 30$ (Dina A3), en las que se fijan pegatinas de círculos rojos (gomets) de $2 \mathrm{~cm}$ de diámetro, desde 1 hasta 100 (en total 5050). Cada cartulina constituye un bit matemático, de esta forma el bit matemático 37 estará constituido por 37 gomets pegados en la cartulina sin caer en la tentación de formar figuras regulares que el niño pueda identificar.

Estalayo y Vega (2007) defienden que para poner en marcha los diferentes programas de estimulación utilizando como recurso los bits de inteligencia, se requiere el conocimiento 


\section{CAPITULO 2: MARCO TEÓRICO}

de los siguientes fundamentos: (1) aplicar los programas lo más tempranamente posible, el niño el niño necesita recibir estímulos desde el nacimiento para que sean más eficaces; (2) realizar una estimulación sistemática, puesto que es más productivo seguir un plan sistemático y de forma diaria; (3) estimulación abundante, ya que en esta edad los niños demuestran una enorme curiosidad y facilidad de aprender consecuencia de su plasticidad cerebral; y (4) estimulación de calidad, se precisan estímulos que lleguen con fuerza, rápidos e intensos (se recomienda presentar cada bits a una velocidad de un segundo y tres veces al día).

De igual manera, es necesario conocer los requisitos que deben adoptarse a la hora de aplicar el programa con los bits de inteligencia:

- Es imprescindible que el tamaño, calidad y montaje de los bits sea excelente.

- Colocar a todos los alumnos para que depongan de una buena visibilidad.

- El puesto de los niños debe variar de una sesión a otra.

- En el momento de aplicar el programa debe existir un silencio total y mucha atención.

- El maestro debe situarse siempre frente a los alumnos en la mediana del grupo.

- Los bits se presentan a una distancia de 2 metros entre el maestro y los alumnos.

- Cada categoría de bits de inteligencia consta de 10 bits.

- El programa de estimulación se presenta 3 veces al día durante 5 días consecutivos (de lunes a viernes), después se retiran sin comprobar que los hayan aprendido, sólo se anuncia la categoría nueva y se dicen los nombres de los bits uno tras otro a medida que se presentan.

- Cada estímulo dura un segundo y las sesiones deben ser siempre muy breves.

Una vez conocidos los fundamentos y requisitos necesarios para aplicar los bits de inteligencia, pasamos a describir los distintos programas diseñados por Doman y su equipo en los Institutos para el Desarrollo del Potencial Humano.

\subsubsection{Programa de estimulación basado en bits de imágenes}

El objetivo de este programa es responder a la curiosidad del niño, desarrollar el hábito y la capacidad de atención y crear un archivo visual a través de los bits de imágenes (Estalayo y Vega, 2001). 
Para ello se selección una categoría de 5 bits de imágenes; se presentan tres veces al día, a intervalos largos, durante 5 días consecutivos a un ritmo de 1 bit por segundo. Cuando se domine la técnica y se puedan pasar los bits con soltura, se aumenta poco a poco el número de categorías. Llegados a este punto, se introducen todas las categorías el mismo día o se procura que todos los días haya una categoría nueva.

\subsubsection{Programa de estimulación visual}

El objetivo de este programa es favorecer la agudeza visual del niño desde el nacimiento. Está constituido por 5 fases; no debe pasarse a la fase siguiente sin haber superado la anterior:

- Fase inicial: se puede iniciar la primera fase desde el momento del nacimiento. Para ello es necesario un cuarto blanco que pueda ser oscurecido (al apagar la luz). Se enciende una luz intensa durante un segundo, seguido por cinco segundos de oscuridad y así sucesivamente durante 1 minuto 15 veces al día.

- Segunda fase: el objetivo es que el niño distinga el perfil de los objetos. Se coloca un gran damero con escaques en la pared, se toma al bebé en brazos y se enciende las luces un segundo y así sucesivamente durante un minuto 15 veces al día. Se ilumina el damero con luz intensa. Con 20-30 días será suficiente; a partir de ahí se presenta al bebé estímulos del mismos tipo que representen formas variadas como siluetes de objetos, animales, plantas, etc. Durante 3 semanas se enseñan las mismas siluetas durante 3 o 4 segundos. Cada día de la semana una distinta, 10 veces al día. En cada una de las 10 sesiones de cada día se enseña una misma silueta nueva y otra antigua. En la $5^{\circ}$ semana se pasan las últimas 7 siluetas que no se han mostrado aún y las 7 nuevas de la semana anterior.

- Tercera fase: el objetivo es acelerar la capacidad visual del bebé para que distinga detalles dentro de un contorno. Se preparan 10 figuras geométricas de $15 \mathrm{~cm}$ en 6-10 colores; se fijan en los escaques del damero y tomando al niño, se le van mostrando las figuras mientras se le dice el nombre de la figura geométrica y el color. Se hacen 3 sesiones diarias mostrando 2 o 3 figuras.

- Cuarto fase: la finalidad es acelerar la convergencia visual, que permitirá al niño apreciar la tercera dimensión y la distancia de los objetos. Esta fase consiste en favorecer que el niño se mueva de forma ilimitada a través del gateo. 


\section{CAPITULO 2: MARCO TEÓRICO}

\subsubsection{Programa de estimulación para el desarrollo de la capacidad lectora}

Este programa está constituido por una serie de etapas. Existen tres premisas en que se basa el programa: comenzar en una edad temprana (se recomienda al año de edad), utilizar bits de palabras que contengan letra grande y clara de color llamativo (son preferibles palabras escrita en arial black o letra escolar) y presentar las palabras de forma rápida para que el niño no pierda interés.

- Primera etapa: palabras sueltas. Se presentan palabras sueltas 3 veces al día durante 5 días consecutivos a estímulo por segundo. Al finalizar, se retira el material y se sustituye por otros 5 carteles nuevos. Se sigue esta mecánica hasta un máximo de 5 categorías diferentes y un total de 25 palabras.

- Segunda etapa: pares de palabras. Cuando se ha pasado un número suficiente de palaras sueltas, se pasan 3 categorías de 3 pares de palabras ya vistas. Es importante introducir adjetivos, colores y verbos para constituir pares de palabras, como por ejemplo: casa blanca.

- Tercera etapa: frases de tres o más palabras. Cuando los niños han visto muchos pares de palabras, se introduce de forma gradual y sucesivamente frases de tres, cuatro o cinco palabras sin dejar de usar también palabras sueltas.

- Cuarta etapa: el primer libro. En una cartulina se escribe una frase corta y sencilla con palabras ya conocidas por el niño. Con un total de 5 páginas se elabora un libro iniciando al niño a la lectura autónoma.

- Quinta etapa: lectura independiente. Para llegar a esta etapa el niño debe poseer un vocabulario de 30 a 50 palabras conocidas; con estas palabras se escribe un texto de unos 6 capítulos de 6 hojas cada uno. Se escriben unas pocas palabras en cada página y basta una ilustración después de cada capítulo. El primer día que se aplica el programa, se lee dos veces el primer capítulo; el segundo día, se hace lo mismo con el segundo, pero omitiendo la palabra clave del relato. El tercer día, se saltan dos palabras importantes del siguiente capítulo; en días sucesivos, se leen los capítulos $4^{\circ}$ y $5^{\circ}$ omitiendo 3 y 4 palabras respectivamente. El sexto día bastará abrir el último texto e ir pasando las páginas a un ritmo similar al de otros días, para que el niño lea sin ninguna ayuda. 


\subsubsection{Programa de desarrollo de la capacidad matemática}

El material básico para llevar a cabo el programa son los bits numéricos, para elaborar los bits son necesarias 100 cartulinas blancas en las que se fijan círculos rojos de $2 \mathrm{~cm}$ de diámetro, desde 1 hasta 100. Este programa consta de 3 fases:

- Primera fase: conjuntos. Durante los 5 primeros días, se le presentan al niño los bits numéricos del 1 al 10, 3 veces al día, a un segundo por estimulo (cada bit). Las dos primeras veces en orden de menor a mayor y la tercera vez, en desorden. El sexto día se retiran los dos bits numéricos más bajos (1 y 2) se sustituyen por el 11 y el 12. A partir del $7^{\circ}$ día, se retiran a diario los dos bits numéricos más bajos y se sustituyen por los dos números que siguen al más alto presentado el día anterior. Esta fase concluye una vez que se llega al 100.

- Segunda fase: operaciones aritméticas constituidas por sumas, restas, multiplicaciones y divisiones. Para ello se les dice la operación y se muestra el resultado con los bits numéricos, conviene no mezclar operaciones y no superar el minuto y medio diario a la hora de llevar a cabo el programa.

- Tercera fase: símbolos y operaciones aritméticas con símbolos. Se preparan 101 cartulinas blancas y pequeñas y se escriben en ellos las grafías del 0 al 100 . Durante los tres primero días se presentan los símbolos o grafías del 0 al 10 en tres sesiones diarias cada una; a partir del 4º día se hace los mismo del 11 al 20. Con el resto de números se aumentará el ritmo, de modo que se verán todos los símbolos en 10 días. Finalizado esta etapa, se les presentan operaciones simples y mixtas con números simbólicos, escribiendo la operación por un lado de la cartulina y el resultado por el otro.

\subsubsection{Programa de motricidad}

Estalayo y Vega (2007) indican que el grado madurativo que se alcanza a través de este programa, es fruto de la distancia recorrida en cada etapa o fase, la cual depende de la oportunidad que se dé al bebé de moverse. Existen tres fases, donde toma relevancia el tipo de pista que se utilice y la meta a conseguir (que es la distancia de garantía para pasar a la etapa siguiente):

- Primera fase: arrastre y reptar. Se necesita una pista dura y deslizante, con forma acanalada de unos 35-40 cm de ancho y $2 \mathrm{~m}$ de largo, colocada a modo de tobogán 


\section{CAPITULO 2: MARCO TEÓRICO}

para facilitar el inicio del proceso. La meta es que el bebé se arrastre 5 metros al día y que repte con patrón cruzado 45 metros diarios a los 7 meses.

- Segunda fase: gateo. Se necesita una pista de moqueta, de unos $50 \mathrm{~cm}$ de ancho y lo más larga posible. El bebé llevará pantalón con rodillera acolchada. La meta es que el niño haga $350 \mathrm{~m}$ diarios a los 9 meses.

- Tercera fase: carrera. El niño debe correr desde los 18 meses cada vez más hasta llegar a $5 \mathrm{~km}$ a los 4 años.

\subsubsection{Programa psicomotor de braqueación}

Para llevar a cabo este programa de estimulación motriz, en necesario disponer de una escalera horizontal, con los travesaños a una distancia proporcional a la estatura del niño y poner una colchoneta debajo (Uriarte, 2013).

A través de este programa se trabaja el córtex superior y la convergencia ocular cercana, además ayuda a fortalecer los dedos y prepara para la escritura al favorecer la seguridad en el trazo y la coordinación óculo-manual (Estalayo y Vega, 2007).

El programa consta de diferentes 4 fases que consisten en: (a) el niño debe ser capaz de quedarse colgado durante 15 segundos de forma independiente, aguantando su propio peso; (b) comenzar a balancearse agarrando con las dos manos un mismo barrote; (c) dirigir la mano al siguiente barrote y seguir el patrón cruzado, desplazándose a lo largo de la barrera de braqueación; y (d) para finalmente realizar el ejercicio con soltura.

\subsection{EXPERIENCIAS PRÁTICAS CON PROGRAMAS DE ESTIMULACIÓN}

Es un hecho constatado por la comunidad educativa que la estimulación temprana reporta grandes beneficios en el desarrollo del niño (González, 2008; Sánchez-Raya, Martínez-Gual, Elvira, Salas, y Cívico, 2015; Albornoz y Guzmán, 2016). Sin embargo, en la actualidad es un área poco explorada que cuenta con escasas publicaciones con experiencias prácticas. La comunidad educativa necesita conocer más a fondo los fundamentos y requisitos necesarios propios de la estimulación; no obstante, la falta de información en este campo provoca importantes limitaciones. Los propios profesores plantean que no hay un tiempo previsto en el currículo o material idóneo para llevar a cabo los programas de estimulación temprana (Vizuete, 2014), esto se debe a la escasa información y manuales explicativos que 
den respuesta a estos interrogantes. Además, la gran mayoría están dirigidos a niños con problemas en el desarrollo (alumnos ACNEAE); siendo insuficientes los estudios dirigidos a la población infantil en general.

Por tanto, se ha realizado una revisión de diferentes experiencias estimulación temprana aplicadas en el ámbito educativo, sanitario y social.

Higgins, McLaughlin, Derby, y Long (2012) han constatado como a través de diferentes programas de estimulación incrementan el rendimiento y la adquisición de nuevo vocabulario en alumnos con trastornos del espectro autista (TEA). En la misma línea, Sánchez-Raya, Martínez-Gual, Elvira, Salas, y Cívico (2015) abordan la intervención temprana en niños de 0 a 6 años con este mismo trastorno; los resultados obtenidos muestran que la intervención temprana constituye un importante predictor en la recuperación funcional de estos menores.

Galeote, Soto, Sebastián, Rey, y Checa, (2012) presentan los buenos resultados obtenidos tras la aplicación de un programa de estimulación lingüística con niños Síndrome de Down, mostrando los progresos encontrados en relación al aumento de vocabulario y la mejor comprensión, producción oral y producción gestual de los menores.

Morales y Rincón, (2016) realizan un estudio sobre la importancia de la estimulación motriz en niños de 5 y 6 años; comparando la madurez neuropsicológica entre un grupo control que no presenta conductas de gateo, frente a otro grupo experimental que si lo muestra. El gateo es el primer movimiento armónico que implica el uso de la cabeza y las extremidades, además permite establecer conexiones neuronales entre ambos hemisferios del cerebro y favorece la agudeza visual. En este caso, y tras la aplicación del programa de estimulación motriz, se evidencian mejores resultados en el grupo experimental.

En la investigación dirigida por Robles y Sánchez, (2013) se examina la respuesta al tratamiento de un programa de estimulación infantil temprano, a través de un estudio de caso único en el que se realiza un seguimiento de los logros conseguidos por dos niños varones con Síndrome del X frágil (SFX) con mutación completa; los resultados del estudio muestran los buenos resultado en las áreas del lenguaje, cognitiva y motriz tras la aplicación del programa.

Moreno, García, Godoy, y Suárez (2011) presentan un estudio de caso único de un niño de 10 años con graves problemas en el lenguaje. En la investigación se muestra los buenos resultados obtenidos en las áreas de expresión y comprensión, tras la aplicación de del programa de estimulación lingüística. 


\section{CAPITULO 2: MARCO TEÓRICO}

Moreno-Torres, Cid, Santana, y Ramos (2011) estudian la evolución de un grupo de 10 niños sordos menores de 2 años con implante coclear, con el objetivo es comprobar en qué medida el desarrollo de los alumnos se ve afectado por el grado de estimulación temprana recibida. Los resultados revelan que el grado de estimulación fue el único factor que se correlacionó con el desarrollo lingüístico tras 12 meses de aplicación; confirmando la gran importancia de la estimulación recibida en la rehabilitación de estos niños.

Figueroa, Campoverde, y Calle (2015) exponen los resultados positivos tras la creación e implementación de una sala multisensorial para la estimulación cognitiva de niños menores de 6 años con discapacidad.

Millá (2016) analiza la evolución que experimentaron los niños con prematuridad y bajo peso al nacer al aplicarle programas de estimulación en un Centro de Desarrollo Infantil y Atención Temprana (CDIAT). Con esta investigación se estudia la mejora del desarrollo evolutivo de estos niños mediante la AT. Los resultados muestran como los niños que finalizan la intervención a los 18 meses presentaban menor número de patologías asociadas; respecto a su posterior escolarización, la mayoría de niños son escolarizados en centros educativos ordinarios, más de la mitad no necesitaron apoyos y un alto porcentaje de alumnos tuvieron un curso evolutivo normalizado.

En relación a los estudios dirigidos alumnos sin problemas en su desarrollo encontramos a Tellano et al. (2016), quienes muestran los hallazgos tras aplicar un programa de estimulación lingüística en alumnos de 3 años, donde los menores adquieren un mayor vocabulario y conocimiento de la estructura del texto; experimentando una evolución significativa en el conocimiento metalingüístico (especialmente en relación a la lectura) y las habilidades lingüísticas (estructuras gramaticales). A la luz de estos resultados, estos autores demuestran que mediante la programa de estimulación permite la organización de la información de forma jerárquica, estableciendo relaciones significativas entre diferentes conceptos, desencadenando en una mejora significativa en relación a las de comprensión y expresión oral.

En la misma línea, la investigación realizada por Albornoz y Guzmán (2016) tiene como objetivo analizar la eficacia de un programa de estimulación temprana en el desarrollo cognitivo de los niños de 3 años de edad. Una de las conclusiones a las que se llega, es que la repetición sistemática promueve el reforzamiento de áreas específicas en el cerebro como el desarrollo del lenguaje, el área sensorial y el área motriz; permitiendo una mejor adaptación de los sujetos investigados al contexto social donde se hallan. 
Por otro lado (L'Ecuyer, 2015) desacredita los fundamentos de la estimulación temprana en el ámbito educativos en relación al método Doman; las principales razones que le llevan a estas conclusiones son: (1) que el método carece de evidencias empíricas que demuestran la eficacia del método Doman en niños con lesiones cerebrales; y (2) que a fecha de hoy, no existan estudios que verifiquen la eficacia del método en el ámbito escolar. Contrastando estas afirmaciones, encontramos varias investigaciones que refutan los planteamientos de este estudio:

En relación a niños ACNEAE, encontramos los estudios de Campillo y Díez (2010) donde muestran diferentes experiencias promovidas por la ONCE en menores con discapacidad visual, constatando la eficacia de programas de estimulación cognitiva a través de bits de inteligencia del método Doman.

Asimismo, encontramos diferentes investigaciones que ponen de manifiesto los resultados alcanzados por los alumnos en los que se les ha aplicado programas diseñados a partir de los fundamentos del método Doman, utilizando los bits de inteligencia como principal recurso (Gómez, 2009; García-Herranz, 2012; Uriarte, 2013, Moya y García, 2014):

(1) El propósito del estudio dirigido por Gómez (2009) se centra en elaborar y desarrollar un programa educativo a través de los bits de inteligencia como prevención de posibles problemas de aprendizaje en los alumnos de El. Los resultados muestran que los bits de inteligencia es un buen recurso para prevenir dificultades en el aprendizaje de los menores al permite atender a la diversidad en Educación Infantil, sin que se hagan notables las diferencias socio-culturales, cognitivas y emocionales de los mismos.

(2) García-Herranz (2012) muestra los buenos resultados obtenidos en el área lectoescritora, lógico-matemática y del conocimiento del entorno, tras aplicar un programa de estimulación cognitiva a alumnos en el $2^{\circ}$ ciclo de El.

(3) Uriarte (2013) recoge en su libro los logros alcanzados por sus alumnos del $1^{\circ}$ y $2^{\circ}$ ciclo de El tras aplicar el método Doman en sus clases. Alguno de los resultados obtenidos, es la facilidad que tienen sus alumnos para aprender a leer, escribir y realizar operaciones matemáticas.

(4) Moya y García (2014) exponen la necesidad de elaborar un programa educativo mediante bits de inteligencia como prevención de posibles dificultades de aprendizaje en el alumnado de El tras los resultados hallados. Los objetivos planteados para la investigación fueron detectar las dificultades que pueden surgir 


\section{CAPITULO 2: MARCO TEÓRICO}

en las aulas de El en relación a su desarrollo madurativo; elaborar una propuesta de intervención en el aula a través de los bits de inteligencia; determinar el proceso de aplicación de los bits de inteligencia; y analizar los resultados que se derivan tras la puesta en práctica del programa de estimulación. Los resultados hallados demostraron que la aplicación de los bits de inteligencia en el aula son un buen recurso para la prevención de dificultades de aprendizaje ya que pueden ser aplicados de forma sencilla en todas las aulas de El, dando respuesta a los objetivos de atención a la diversidad que recoge la legislación; además el método permite el desarrollo de los procesos cognitivos básicos (atención, percepción y memoria), la adquisición de normas y conductas, un aumento de vocabulario, de expresiones, de conocimientos, y de reflexiones, permitiendo la mejora de las habilidades lingüísticas y de las estrategias de pensamiento.

En conclusión, la escasa bibliografía impide a los maestros contar con manuales que recojan propuestas concretas de intervención en el aula, reproduciéndose año tras año metodologías más tradicionales que no dan respuesta al principio de inclusión, siendo la atención a la diversidad una necesidad que comprende a todos los escolares y no únicamente a los alumnos con necesidades educativas. 


\title{
3. METODOLOGÍA
}

\author{
Capítulo 3
}

3.1. Programa de estimulación temprana para el 2 ㅇ ciclo de El

3.2. Metodología de investigación 


\subsection{PROGRAMA DE ESTIMULACIÓN TEMPRANA PARA EL SEGUNDO CICLO DE EI}

\subsubsection{JUSTIFICACIÓN}

Mi primer contacto con la estimulación temprana fue de manera causal. Durante mi segundo año como maestra de $\mathrm{El}$, en el curso 2008/09, comencé a formarme de la mano de Vega y Estalayo, autores destacados en materia de neurocognición (Estalayo y Vega, 2001, 2007), fueron los causantes de despertar en mí una gran curiosidad por este campo. Gracias a sus contribuciones, diseñé mi propio PET, poniéndolo en práctica de manera experimental durante ese mismo curso. Gracias a los resultados comprobé que los maestros de El nos encontramos en una situación privilegiada frente a docentes de otros tramos educativos: (1) debido al gran potencial que poseen los alumnos durante los seis primeros años de vida; la etapa de El es el momento clave en el que las ventanas sensoriales de los alumnos están abiertas de par en par (Redruello, 2004); y (2) su curiosidad innata, que hace que todo despierte interés en ellos.

Día a día constataba como mis alumnos aprendían de manera rápida y sencilla, era increíble los progresos conseguidos conforme pasaba el tiempo al proponer nuevos juegos, utilizando diferentes bits y retos; tanto compañeros como padres observaban asombrados la evolución de los niños. Para a mí era toda una revolución, mientras que para ellos un juego más con el que disfrutaban.

Estos resultados no podían ser de manera casual, por lo que comencé a investigar e indagar más de lleno en el mundo de la neuroestimulación. Las conclusiones a las que llegué fueron que: (1) los escolares de El participantes en el estudio se encuentran en un momento crucial del desarrollo; la plasticidad del cerebro es mayor y susceptible de favorecer aprendizaje de una manera más rápida y sencilla que en otros momentos. Como expone López-Reyes (2009) ciertos estímulos, oportunos en el tiempo, favorecen el aprendizaje y el desarrollo de sinapsis entre neuronas; y (2) entender como aprende el cerebro, nos permite como maestros vislumbrar estrategias metodológicas claves para una enseñanza de calidad.

Debemos tomar conciencia de la importancia que tiene el que como docentes conozcamos el funcionamiento del cerebro y del sistema nervioso de los niños; esto nos permitirá diseñar herramientas educativas claves para sentar las bases de una educación óptima, desarrollando al máximo las potencialidades de nuestros alumnos. La neurociencia 
puede ayudarnos a diseñar programas de enseñanza específicos de acuerdo con el currículum escolar, además de apostar por la innovación y transformación de los planteamientos educativos actuales para el fortalecimiento de una educación de calidad.

Todos estos argumentos refuerzan los motivos que me han llevado a desarrollar mi propio PET y mostrar los resultados hallados. Como docente considero imprescindible meditar sobre el diseño de un PET que dé respuesta a las necesidades y curiosidades de mis alumnos, para provocar las mejores condiciones donde puedan aprendan de forma rápida y temprana. Y es aquí donde presento mi PET diseñado para favorecer el desarrollo de la capacidad lectora, escritora y matemática, mostrando a la comunidad educativa los resultados obtenidos fruto de una investigación de 3 años de duración.

\subsubsection{OBJETIVOS}

Los objetivos del PET son: (1) comprobar si el programa aplicado permite un mayor desarrollo de la capacidad lectora, aprender a leer de una forma más natural y rápida, en menos tiempo de lo que viene siendo habitual con otros métodos de lectoescritura; y (2) comprobar si el programa aplicado permite un mayor desarrollo de la capacidad lógicomatemática de una forma más natural y rápida, en aspectos como, por ejemplo, identificar números de dos cifras, sumar con llevadas sin utilizar dedos, comprensión de la suma y resta, etc.

\subsubsection{CONTENIDOS}

\subsubsection{Contenidos del ámbito lecto-escritor}

En la tabla 3.1 se detallan los contenidos educativos que el el Decreto 122/2007 (BOE, 2 de enero, 2007) fija para el ámbito lecto-escritor, en cada uno de los cursos del segundo ciclo de El.

Tabla 3.1. Contenidos del ámbito lecto-escritor

\begin{tabular}{|l|l|l|}
\hline $1^{\circ}$ curso & $2^{\circ}$ curso & $3^{\circ}$ curso \\
\hline $\begin{array}{l}\text { Correcta dirección en el trazo y } \\
\text { posición adecuada al escribir en } \\
\text { mayúscula }\end{array}$ & $\begin{array}{l}\text { Correcta dirección en el trazo y } \\
\text { posición adecuada al escribir en } \\
\text { mayúscula }\end{array}$ & $\begin{array}{l}\text { Correcta dirección en el trazo y } \\
\text { posición adecuada al escribir } \\
\text { mayúscula y minúscula }\end{array}$ \\
\hline $\begin{array}{l}\text { Discriminación auditivamente } \\
\text { de las vocales }\end{array}$ & $\begin{array}{l}\text { Discriminación auditiva de } \\
\text { vocales y algunas consonantes }\end{array}$ & $\begin{array}{l}\text { Discriminación auditiva todas los } \\
\text { letras del abecedario }\end{array}$ \\
\hline
\end{tabular}




\begin{tabular}{|l|l|l|}
\hline $\begin{array}{l}\text { Discrimina visualmente las } \\
\text { vocales en mayúscula }\end{array}$ & $\begin{array}{l}\text { Discrimina visualmente de } \\
\text { vocales algunos consonantes en } \\
\text { mayúscula }\end{array}$ & $\begin{array}{l}\text { Discriminación visual de todas las } \\
\text { letras del abecedario (mayúscula y } \\
\text { minúscula) }\end{array}$ \\
\hline $\begin{array}{l}\text { Iniciarse en la lectura de su } \\
\text { nombre, objetos y palabras } \\
\text { significativas en mayúscula }\end{array}$ & $\begin{array}{l}\text { Iniciarse en la lectura de palabras } \\
\text { sencillas en mayúscula }\end{array}$ & $\begin{array}{l}\text { Lee y comprende palabras y frases } \\
\text { sencillas en mayúscula y minúscula }\end{array}$ \\
\hline $\begin{array}{l}\text { Iniciarse en la escritura de su } \\
\text { nombre, objetos y palabras } \\
\text { significativas en mayúscula }\end{array}$ & $\begin{array}{l}\text { Iniciarse en la escritura de } \\
\text { palabras sencillas en mayúscula }\end{array}$ & $\begin{array}{l}\text { Escribe y comprende palabras y } \\
\text { frases sencillas en mayúscula y } \\
\text { minúscula }\end{array}$ \\
\hline & & $\begin{array}{l}\text { Producción de diferentes mensajes } \\
\text { con sus palabras preferidas y } \\
\text { representación gráfica de los fonemas } \\
\text { que las componen }\end{array}$ \\
\hline & $\begin{array}{l}\text { Descubre la utilidad del texto escrito a } \\
\text { través de la práctica de la lectura } \\
\text { comprensiva }\end{array}$ \\
\hline
\end{tabular}

\subsubsection{Contenidos del ámbito lógico-matemático}

En la tabla 3.2., se recogen los contenidos educativos que el Decreto 122/2007 (BOE, 2 de enero, 2007) establece para el ámbito lógico-matemático en cada uno de los cursos del segundo ciclo de El.

Tabla 3.2. Contenidos del ámbito lógico-matemático

\begin{tabular}{|c|c|c|}
\hline $1^{\circ}$ curso & $2^{\circ}$ curso & $3^{\circ}$ curso \\
\hline $\begin{array}{l}\text { Utiliza la serie numérica del } 1 \text { al } 3 \\
\text { para cuantificar }\end{array}$ & $\begin{array}{l}\text { Utiliza la serie numérica para } \\
\text { cuantificar y realizar la grafía del } 1 \\
\text { al } 7\end{array}$ & $\begin{array}{l}\text { Utiliza la serie numérica del } 1 \text { al } \\
9 \text { para cuantificar }\end{array}$ \\
\hline Realiza la grafía del 1,2 y 3 & $\begin{array}{l}\text { Realiza la grafía del 1, 2, 3, 4, 5, } 6 \\
\text { y } 7\end{array}$ & $\begin{array}{l}\text { Realiza la grafía del } 1,2,3,4,5 \text {, } \\
6,7,8 \text { y } 9\end{array}$ \\
\hline $\begin{array}{l}\text { Ordena objetos de una colección y } \\
\text { expresa su lugar en la serie del } 1 \text { al } \\
3\end{array}$ & $\begin{array}{l}\text { Ordena objetos de una colección y } \\
\text { expresa su lugar en la serie del } 1 \\
\text { al } 7\end{array}$ & $\begin{array}{l}\text { Ordena objetos de una } \\
\text { colección y expresa su lugar en } \\
\text { la serie del } 1 \text { al } 9\end{array}$ \\
\hline Iniciación a la suma & $\begin{array}{l}\text { Resuelve sencillas operaciones de } \\
\text { dos sumandos hasta el } 7\end{array}$ & $\begin{array}{l}\text { Realiza operaciones más } \\
\text { complejas que impliquen sumar } \\
\text { hasta el } 9\end{array}$ \\
\hline Iniciación a la resta & $\begin{array}{l}\text { Resuelve sencillas operaciones de } \\
\text { restar sin rebasar el } 7\end{array}$ & $\begin{array}{l}\text { Realiza operaciones más } \\
\text { complejas que impliquen restar } \\
\text { sin rebasar el } 9\end{array}$ \\
\hline \multirow[t]{2}{*}{$\begin{array}{l}\text { Resuelve operaciones muy sencillas } \\
\text { que impliquen sumar, restar, } \\
\text { expresar diferencias y repartir }\end{array}$} & $\begin{array}{l}\text { Resuelve problemas que impliquen } \\
\text { sumar, restar, expresar diferencias } \\
\text { y repartir hasta el } 7\end{array}$ & $\begin{array}{l}\text { Resuelve problemas que } \\
\text { impliquen sumar, restar, } \\
\text { expresar diferencias y repartir } \\
\text { hasta el } 9\end{array}$ \\
\hline & & $\begin{array}{l}\text { Identifica monedas de nuestro } \\
\text { actual sistema monetario }\end{array}$ \\
\hline
\end{tabular}




\subsubsection{METODOLOGÍA Y RECURSOS EMPLEADOS}

A la hora de hablar de metodología en El no podemos referirnos a un único tipo; en esta etapa educativa no existen métodos únicos. Por eso no tiene sentido hablar de una metodología concreta para este tramo escolar; buscamos responder a una intencionalidad educativa, en un contexto concreto y en un grupo de alumnos con unas necesidades propias. El planteamiento didáctico de esta experiencia está adecuado a unos principios metodológicos extraídos del Decreto 122/2007 y de la experiencia de (García-Herranz, 2012) que se exponen a continuación:

- Partir del nivel de desarrollo de cada alumno para adaptarnos a sus necesidades propias; de esta manera se planifica y medita sobre la elección de los bits de imágenes y palabras y/o recursos materiales que deben ser seleccionadas en base a su nivel real de desarrollo.

- Conocer del nivel real de aprendizaje de cada uno de ellos, planteando unos objetivos adaptados a su ritmo y necesidades. La facilidad que tienen los alumnos para aprender es tan grande y rápida, que durante la experiencia surge momentos en los que se debe ampliar o reforzar determinados contenidos a través del PET o variando la dificultad de los juegos planteados.

- Tener en cuenta el principio de globalización; todos los contenidos planteados en el programa de estimulación temprana se hallan íntimamente relacionados dado el carácter globalizador que caracteriza a este tramo educativo. Por ello todos los aspectos trabajados durante la experiencia son planteados desde la globalidad de la acción y de los aprendizajes.

- Favorecer un clima de confianza y afecto, para que los alumnos aprendan a relacionarse e integrarse con sus compañeros, el maestro, la comunidad educativa y el entorno en que se desenvuelven, mejorando en independencia y autonomía.

- Creación de normas de convivencias claras, favoreciendo en todo momento actitudes de respeto. Es importante establecer unas normas que proporcionen seguridad tanto a los niños como a las personas que forman parte del aula.

- Utilizar el juego como el principal recurso educativo en el aula; según Uriarte (2013, p.25) "el juego debería considerarse el acto más serio en el niño". El juego es una herramienta que provocar conocimiento.

- Promover que el alumno sea el protagonista de su propio aprendizaje a través de la manipulación y experimentación, dando respuesta al principio de actividad. En 
este sentido, algunos materiales claves para que los alumnos alcancen aprendizajes significativos son: regletas, bits de números, bits de palabras, bits de imágenes, puzles, palillos, mesa de luz, pizarra y abecedarios plastificados.

- Suscitar aprendizajes que partan de sus intereses y motivaciones, siempre cercanos al contexto en el que se desenvuelven. Los bits de inteligencia responden a categorías que despiertan interés en el alumnado como por ejemplo: razas de gato, minerales, planetas,...

- Utilizar una metodología vivencial, que conduzca al alumno a descubrir los aprendizajes a través de la manipulación y la experimentación; una metodología que brinde oportunidades, que provoque aprendizajes significativos y que desarrollo en ellos las competencias que les permitan aprender a aprender (de Díaz et al., 2006).

\subsubsection{Desarrollo del programa de estimulación temprana}

En este apartado vamos a presentar la forma normal de trabajar en el aula; las rutinas que suelen seguirse de forma cotidiana; lo mostramos en la tabla 3.3.

Tabla 3.3. Rutinas de trabajo diarias

\begin{tabular}{|c|c|}
\hline RUTINA DE TRABAJO & JUSTIFICACIÓN \\
\hline $\begin{array}{l}\text { Hay dos momentos a lo largo de la jornada escolar en } \\
\text { el que los niños están más alerta y atentos: nada más } \\
\text { llegar por las mañanas y después del recreo. Son en } \\
\text { estos momentos, donde ubico el PET. }\end{array}$ & $\begin{array}{l}\text { Es muy importante recapacitar sobre el momento } \\
\text { ideal en el que poner en marcha las sesiones del } \\
\text { PET. Atendiendo a la curva de atención y fatiga, } \\
\text { existen momentos a lo largo del día en el que los } \\
\text { alumnos están más concentrados. }\end{array}$ \\
\hline $\begin{array}{l}\text { El rincón de la alfombra, cuenta con una alfombra } \\
\text { amplia en forma de rectángulo y una pizarra. Los } \\
\text { alumnos se sientan en el borde del tapete, dejando } \\
\text { libre el lado más cercano a la pizarra. En mi caso, me } \\
\text { coloco frente a ellos en una silla pequeña, en la } \\
\text { mediana del grupo para tener un buen contacto visual; } \\
\text { procuro colocar a aquel niño que tiende más a } \\
\text { distraerse o es más movido frente a mí; siempre } \\
\text { procurando que el puesto del resto de niños varíe de } \\
\text { una sesión a otra. }\end{array}$ & $\begin{array}{l}\text { La distancia apropiada entre el docente y el alumno } \\
\text { debe ser de } 2 \text { metros; consiguiendo una buena } \\
\text { visibilidad. Además es recomendable procurar el uso } \\
\text { de luz natural en vez de artificial. }\end{array}$ \\
\hline $\begin{array}{l}\text { Cada mañana al sonar el timbre, recojo a los niños de } \\
\text { la fila y rápidamente, me coloco en una silla en la } \\
\text { mediana de la alfombra; siempre espero sentada y en } \\
\text { silencio, con los bits preparados. Los padres saben que } \\
\text { es el momento del PET y tienen la prudencia de no } \\
\text { interrumpir ni consultarme nada en las entradas. }\end{array}$ & $\begin{array}{l}\text { Necesitamos un entorno que esté libre de } \\
\text { distracciones. El lugar donde se aplica el PET es el } \\
\text { denominado por los alumnos "rincón de la alfombra", } \\
\text { es el rincón más alejado de la puerta y libre de ruidos } \\
\text { y distracciones. }\end{array}$ \\
\hline $\begin{array}{l}\text { Nada más entrar en el aula seguimos el mismo ritual: } \\
\text { los alumnos se ponen el babi, colocan el almuerzo en } \\
\text { su sitio y se sientan en el borde de la alfombra en } \\
\text { silencio. Saben que es el momento de los bits y hasta } \\
\text { que no estemos todos en silencio total, sentados como }\end{array}$ & $\begin{array}{l}\text { Para conseguir interiorizar esta rutina en los niños, } \\
\text { utilicé desde el primer día el refuerzo positivo a través } \\
\text { de un gomet: a aquel niño que se colocase } \\
\text { correctamente bajo las premisas explicadas, obtenía } \\
\text { una pegatina. En pocos días se consiguió que todo el }\end{array}$ \\
\hline
\end{tabular}




\begin{tabular}{|l|l|}
\hline $\begin{array}{l}\text { indios, con el "culete en el borde de la alfombra" y muy } \\
\text { atentos, no podemos comenzar. }\end{array}$ & $\begin{array}{l}\text { alumnado, de forma rápida, estuviera sentado, en } \\
\text { silencio y listo para comenzar. }\end{array}$ \\
\hline $\begin{array}{l}\text { Elaboro bits de imágenes atractivos para los niños. Los } \\
\text { propios padres colaborar, elaborando diferentes } \\
\text { categorías. }\end{array}$ & $\begin{array}{l}\text { Los bits deben ser lo suficientemente intensos para } \\
\text { atraer la atención del niño: bits de imágenes grandes, } \\
\text { novedosas, muy claras y definidas; un tono de voz } \\
\text { fuerte. }\end{array}$ \\
\hline $\begin{array}{l}\text { Los bits los presento de forma rápida (cada bit lo } \\
\text { muestro en } 1 \text { segundo) y subiendo ligeramente el tono } \\
\text { de voz, de esta manera consigo captar la atención del } \\
\text { grupo y evito distracciones. }\end{array}$ & $\begin{array}{l}\text { "Los estímulos cortos son más efectivos, } \\
\text { especialmente los estímulos visuales" (Estalayo y } \\
\text { rápidos. }\end{array}$ \\
\hline $\begin{array}{l}\text { Todas las semanas dejo prog estímulos deben ser breves y } \\
\text { imágenes y palabras que presentaré cada lunes. }\end{array}$ \\
$\begin{array}{l}\text { Procuro que las categorías estén relacionadas con los } \\
\text { centros de interés que se estemos trabajando en cada } \\
\text { momento del curso. }\end{array}$
\end{tabular}

Como hemos visto, el PET se lleva a cabo dos veces al día, en cada sesión se utilizan 30 bits: 10 bits de imágenes y 10 bits de palabras que se cambian cada lunes, y 10 bits de números, que se cambian diariamente. La primera vez que se realiza el PET no se presentan todas las categorías a la vez, se realiza de forma progresiva, mostramos un posible ejemplo en la tabla 3.4.

Tabla 3.4. Desarrollo progresivo del programa de estimulación temprana

\begin{tabular}{|c|c|c|}
\hline SEMANAS & CATEGORÍAS DE BITS & DESARROLLO \\
\hline $1^{a}$ semana & $\begin{array}{l}-10 \text { bits de imágenes } \\
\text { (planetas) }\end{array}$ & $\begin{array}{l}\text {-Se presenta la primera categoría de bits de imágenes, por } \\
\text { ejemplo: planetas. }\end{array}$ \\
\hline $2^{a}$ semana & $\begin{array}{l}\text { - } 10 \text { bits de imágenes } \\
\text { (polígonos) } \\
-10 \text { bits de palabras } \\
\text { (planetas) }\end{array}$ & $\begin{array}{l}\text {-Añadimos una categoría nueva de bits de imágenes; por ejemplo: } \\
\text { polígonos. } \\
\text {-Incorporamos una nueva categoría de palabras, que corresponde } \\
\text { con los bits de imágenes de la semana anterior. }\end{array}$ \\
\hline $3^{\mathrm{a}}$ semana & $\begin{array}{l}-10 \text { bits de imágenes } \\
\text { (premios nobeles de } \\
\text { literatura) } \\
-10 \text { bits de palabras } \\
\text { (polígonos) } \\
-10 \text { bits números (del } 1 \\
\text { al } 10 \text { ) }\end{array}$ & $\begin{array}{l}\text {-Añadimos una categoría nueva de bits de imágenes; por ejemplo: } \\
\text { premios nobeles de literatura. } \\
\text {-Incorporamos una nueva categoría de palabras, que corresponde } \\
\text { con los bits de imágenes de la semana anterior. } \\
\text {-Introducimos la primera categoría de bits de números: números } \\
\text { del } 1 \text { al 10. Los dos primero días, se presentan en orden } \\
\text { ascendente, el resto en desorden. }\end{array}$ \\
\hline $4^{\mathrm{a}}$ semana & $\begin{array}{l}-10 \text { bits de imágenes } \\
\text { (huesos de las } \\
\text { extremidades) }\end{array}$ & $\begin{array}{l}\text {-Añadimos una categoría nueva de bits de imágenes: huesos de } \\
\text { las extremidades. }\end{array}$ \\
\hline
\end{tabular}




\begin{tabular}{|l|l|l|}
\hline & $\begin{array}{l}-10 \text { bits de palabras } \\
\text { (premios nobeles de } \\
\text { literatura) }\end{array}$ & $\begin{array}{l}\text {-Incorporamos una nueva categoría de palabras, que corresponde } \\
\text { con los bits de imágenes de la semana anterior }\end{array}$ \\
$\begin{array}{l}-10 \text { bits de números } \\
\text { (quito el no 1 y 2, y } \\
\text { añado el no 11 y 12) }\end{array}$ & $\begin{array}{l}\text {-A partir del lunes de la 40 semana, se retiran los dos números más } \\
\text { bajos y se sustituyen por los dos siguientes. Se retiran el } 1 \text { y el } 2 \text { y } \\
\text { se sustituyen por el 11 y el 12. En adelante se retiran a diario los } \\
\text { dos números más bajos y se sustituyen por los dos números que } \\
\text { siguen al más alto presentado el día anterior. }\end{array}$ \\
\hline En adelante & $\begin{array}{l}-10 \text { bits de imágenes } \\
-10 \text { bits de palabras } \\
-10 \text { bits de números }\end{array}$ & $\begin{array}{l}\text {-Cada lunes presentamos una categoría nueva de imágenes, una } \\
\text { categoría nueva de palabras que corresponden con las imágenes } \\
\text { de la semana anterior y los } 10 \text { bis de números correspondientes de } \\
\text { ese día. }\end{array}$ \\
\hline
\end{tabular}

En síntesis, aclarar, que los bits se presentan de forma rápida: a un segundo; pocas veces: dos veces al día; y con entusiasmo: utilizando un tono de voz ligeramente más alto. Siempre se baraja de una sesión a otra. Cada lunes se cambian las categorías de bits de imágenes y palabras; y la de números, de forma diaria. Además, se sigue el mismo orden para presentar las categorías en cada sesión: (1) mostramos las imágenes; (2) mostramos las palabras; (3) mostramos los puntos que forman los bits de números y (4) por último, se da la vuelta a los bits de números mostrando la grafía del número escrita en el reverso. Este proceso dura entre 1-2 minutos (véase anexo 5: $1^{\circ} \mathrm{El}$, 3ำ trimestre (I)). Al final de cada curso académico, en 40 semanas; los alumnos habrán visto y eschuchado 120 categorias de bits, un total de 1200 estímulos. Al terminar el 2o ciclo de El, habrán visto, escuchado y leido aproximadamente 4800 bits de inteligencia.

\subsubsection{Actividades de aprendizaje básicas}

En la etapa de El los niños necesitas tener unas rutinas muy marcadas que les de seguridad y autonomía, más que en cualquier otra. Esta es la base que justifica la necesidad de organizar el día a día por momentos y no por asignaturas, como viene siendo habitual en el resto de tramos educativos. Por ello, debemos reflexionar sobre aquellos momentos en los que los niños poseen mayor concentración y el rendimiento escolar es mayor; aseguramos un mejor aprendizaje. Por este motivo, ubicamos las actividades de aprendizaje en relación a la lecto-escritura y la lógico-matemática en dichos períodos. Estos tiempos corresponden a las dos asambleas diarias, que tienen lugar al inicio del día y después del recreo.

El procedimiento que se sigue a diario es siempre el mismo, aspecto clave para que los alumnos anticipen lo que va a suceder, otorgándoles seguridad. Una vez mostrados los bits, seguidamente se realizan las actividades de aprendizaje básicas. Cada una de ellas tienes un momento específico, en la primera asamblea se llevan a cabo las actividades relacionas con la lectura y escritura, y las actividades de lógico matemáticas se realizan durante la segunda asamblea del día. Estas actividades, al igual que los bits, se realizan en 
la alfombra de manera grupal con todo el alumnado. Las distintas actividades van variando en base al interés que despierten en los alumnos y los objetivos propuestos a conseguir con ellas; por esta razón, no podemos hablar de periodos fijos de duración de cada actividad.

Pasamos a continuación a describir las distintas actividades.

\section{Actividades de aprendizaje básicas de lecto-escritura}

En las siguientes tablas, detallamos las actividades dirigidas a reforzar el aprendizaje de la escritura y posteriormente el de la lectura. En cada tabla se especificará: el procedimiento utilizado para el desarrollo de la actividad acompañado de una o varias imágenes, facilitando una mejor comprensión; el material utilizado; y en caso que fuera necesario, la progresión de las fases a seguir en dicha actividad.

Antes de explicar la batería de actividades utilizadas exclusivamente para el aprendizaje de la escritura, es necesario entender las pautas generales que siguen los alumnos a la hora de escribir. Existen pautas diferentes para la escritura de letras en mayúsculas y la escritura de letras en minúscula:

1) En relación a la escritura de letras mayúscula, delimitaremos el espacio con dos líneas horizontales para que los alumnos tengan una referencia espacial. Por esta razón, utilizaremos siempre dos líneas denominadas cielo y suelo (véase figura 3.1.) que atraviesen de forma horizontal todo lo largo de la pizarra, folio o soporte que se esté utilizando. El motivo de comenzar escribiendo letras es mayúscula, tiene que ver con la mayor dificultad que implica los trazos curvos (minúscula) con respecto a las líneas (mayúscula).

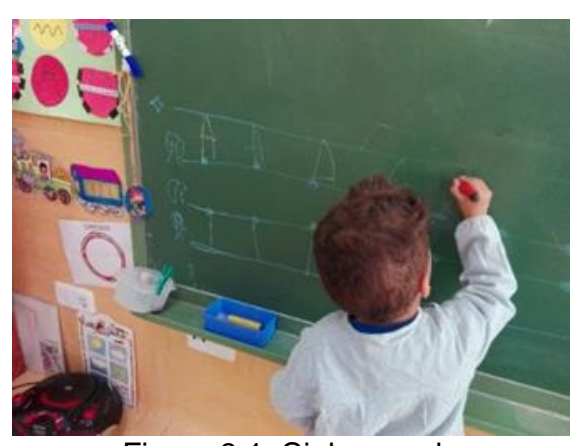

Figura 3.1. Cielo y suelo

Es importante, una vez iniciada la escritura en mayúscula, favorecer experiencias y situaciones donde los alumnos puedan escribir su nombre y palabras relacionadas con su entorno más cercano. Por ello, la actividad de cierra del PET durante la primera asamblea consiste en realizar retos (véase actividad retos). Pronto incorporan la escritura como parte 


\section{CAPITULO 3: METODOLOGÍA}

de un juego más en el rincón de letras, también contamos con la mesa de luz para reforzar el aprendizaje de la escritura "utilizando rotuladores o recipiente transparente con arena para realizar la grafía de letras y números" (véanse figuras 3.2 y 3.3).

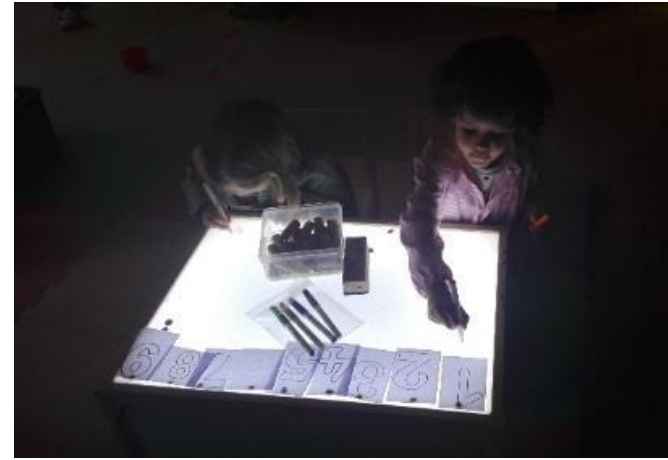

Figura 3.2. Escritura con rotuladores

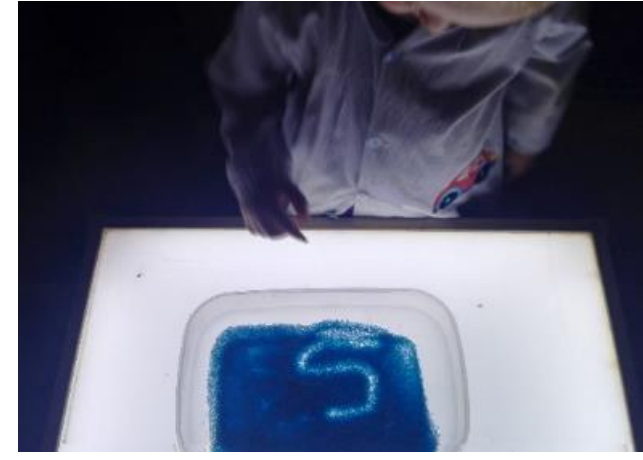

Figura 3.3. Escritura en arena

2) Para iniciar la escritura de letras en minúscula es necesario contar con suficientes experiencias como para poder dar este salto de una grafía a otra; normalmente esto ocurre en el segundo curso del segundo ciclo de El. Es fundamental favorecer experiencias motivadoras utilizando diferentes espacios y soportes potenciadores de aprendizaje, como puede ser la pizarra, el arenero, las ventanas de clase, el suelo del pasillo o del aula, la pizarra, la mesa de luz, etc. "Cuántos más sentidos intervengan en cualquier experiencia de aprendizaje, mejor es la calidad del mismo" (Uriarte, 2013, p.20).

Existen dos pautas que los niños aprenden durante el proceso: (a) todas las letras tienen dos manos, para poder agarrarse entre ellas; (b) las letras pueden llegar al cielo, al suelo, al centro o al cielo y al suelo (véase tabla 3.5).

Tabla 3.5. Actividad: cielo, suelo y centro

\begin{tabular}{|c|c|}
\hline PROCEDIMIENTO & IMÁGEN \\
\hline $\begin{array}{l}\text { El objetivo es que lo niños a través del juego, ubiquen la posición } \\
\text { espacial de cada letra en minúscula dentro de las } 4 \text { líneas de la } \\
\text { pauta. Cada letra se corresponde con un gesto, en base al lugar } \\
\text { que ocupa dentro de las líneas. Diferenciamos } 4 \text { gestos diferentes: } \\
\text { a) apuntar con el dedo hacia arriba en aquellas letras que su grafía } \\
\text { llega al cielo o toquen la primera línea de la pauta: "b, d, h, k, l, Il t"; } \\
\text { b) apuntar con el dedo hacia abajo en las letras cuya grafía toquen } \\
\text { el suelo o la última línea de la pauta: "g, j, p, q“; c) poner las dos } \\
\text { manos en paralelo, una sobre la otra, haciendo alusión a aquellas } \\
\text { letras que queden entre la segunda y tercera línea de la pauta: "a, } \\
\text { c, e, i, m, n, ñ o, r, s, u, v, w, x, z"; y d) apuntar con un dedo hacia } \\
\text { arriba y con el de la otra mano hacia abajo, para hacer alusión a la } \\
\text { única letra que toca tanto el cielo como el cielo, es decir, la primera } \\
\text { y última línea de la pauta de escritura: "f". La actividad consiste en } \\
\text { recitar el abecedario acompañado de los gestos correspondientes; } \\
\text { con este ejercicio ayudamos al alumno a ubicar espacialmente las }\end{array}$ & 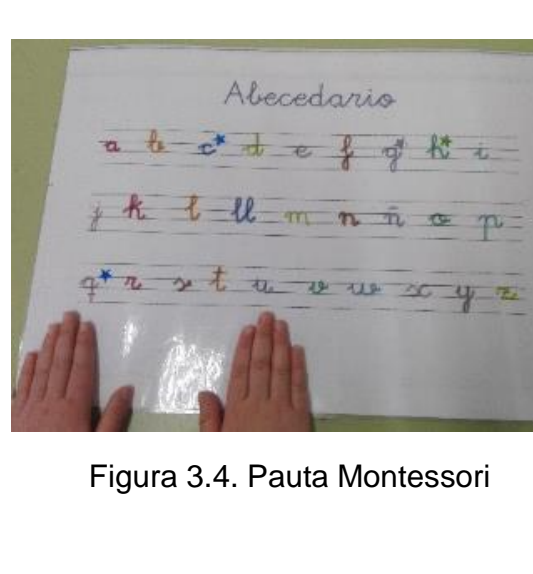 \\
\hline
\end{tabular}


CAPITULO 3: METODOLOGÍA

letras, actividad que favorece una correcta escritura sin cometer

fallos comunes tales como no diferenciarse la "e" de la "l".

MATERIAL

Abecedario plastificado, con las letras en minúscula y pauta Montessori: pauta de escritura que tiene 4 líneas horizontales que delimita el espacio de las letras para poder guiar a los niños en la escritura.

Tabla 3.6. Actividad: voy, vuelvo y chiriflú

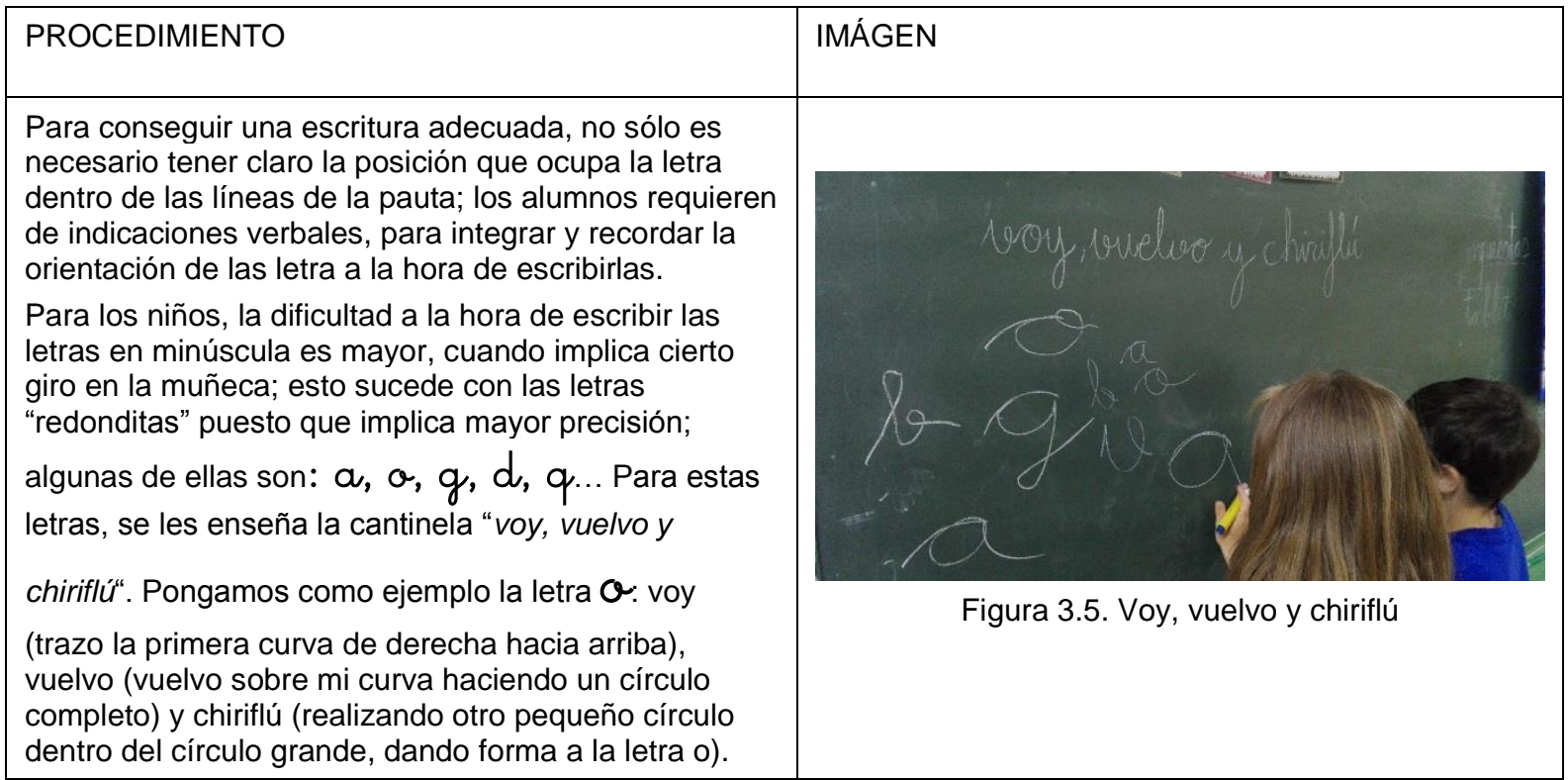

Tabla 3.7. Actividad: retos

\begin{tabular}{|l|l|}
\hline PROCEDIMIENTO & IMÁGENES \\
\hline $\begin{array}{l}\text { Dependiendo de la edad y el } \\
\text { momento escolar en que se } \\
\text { encuentren los alumnos, los } \\
\text { retos pueden ser: escribir letras } \\
\text { en mayúscula utilizando las dos } \\
\text { líneas horizontales, escribir } \\
\text { letras en minúscula siguiendo la } \\
\text { pauta Montessori, escribir el } \\
\text { nombre, palabras sencillas, } \\
\text { palabras más complejas e } \\
\text { incluso frases. Cuando los niños } \\
\text { son más mayores, un posible } \\
\text { reto es dar respuesta a } \\
\text { preguntas o cuestiones escritas } \\
\text { en la pizarra (que han leído } \\
\text { previamente) como pude verse } \\
\text { en la figura 3.7. }\end{array}$ & \\
\hline MATERIAL & \\
\hline
\end{tabular}

Pizarra, tiza, borrador, regletas, folios, pinturas... 


\section{CAPITULO 3: METODOLOGÍA}

La evolución va paralela a sus inquietudes y gusto por la escritura, que lo muestran a diario especialmente en el rincón de las letras (en la alfombra), donde disponen de todo tipo de material: letras plastificadas, pizarra, tizas, borrador, bits de palabras, caja mágica de las letras, blu-tack, mesa de luz, etc. Por este motivo, no se sigue ningún método de lectoescritura comprado o elaborado; sino que se busca aprendizajes que partan de los intereses de los alumnos y donde se utilicen el mayor número de sentidos, a través de experiencias significativas y motivadoras. Algunos ejemplos son: construir el abecedario, palabras o frases a partir de tapones con goma-eva (figura 3.8); escritura de palabras y frases en el rincón de las letras (figura 3.9) y reforzar la grafía de letras trabajadas y escritura libre con rotuladores de colores sobre la mesa de luz (ver figura 3.10).

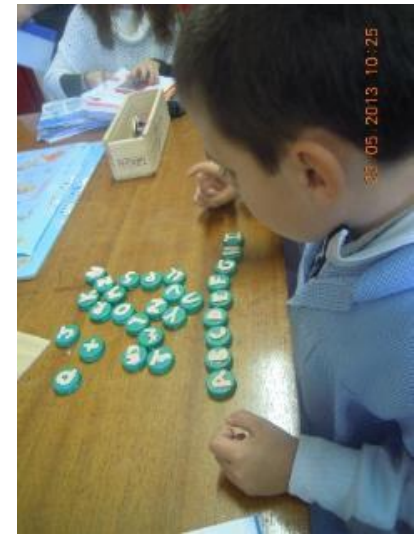

Figura 3.8. Escritura con tapones

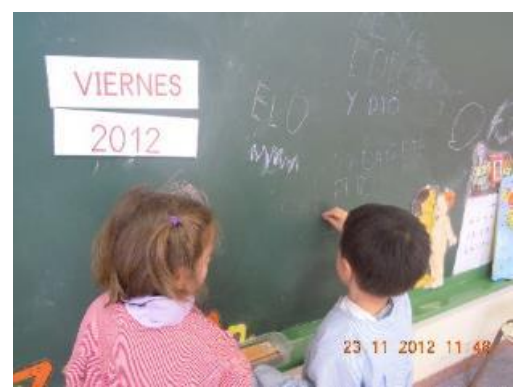

Figura 3.9. Escritura en rincón de letras

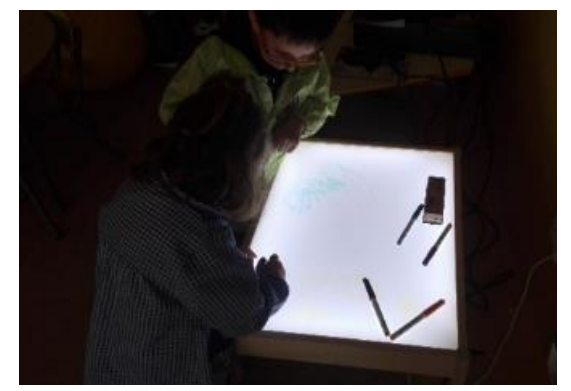

Figura 3.10. Escritura en mesa de luz

Tabla 3.8. Actividad: abecedario de letras

\begin{tabular}{|l|l|}
\hline PROCEDIMIENTO \\
\hline Antes de comenzar con esta actividad, es \\
imprescindible que los alumnos identifique y \\
reconozcan las vocales. Aclarar que el abecedario \\
se compones de 5 vocales y 22 consonantes; 4 de \\
las consonantes son denominadas excepciones y \\
están marcadas con gomets o pegatinas de \\
estrellas (figura 3.12); el motivo es que al juntar \\
cada una de estas letras con las vocales su sonido \\
no sigue el mismos criterio que con el resto, como \\
veremos posteriormente. \\
Esta actividad se presenta inmediatamente \\
después de llevar a cabo PET, en la primera \\
asamblea. Se siguen los mismos principios \\
seguidos durante el programa: estímulos rápidos, \\
intensos y de calidad. Cada imagen se presenta \\
con un tono de voz alto (para llamar la atención del \\
oyente), de forma rápida (a un segundo por \\
imagen) y barajando de una sesión a otra, para que \\
los alumnos no memoricen la letra en base a su \\
posición. Es imprescindible, que los alumnos estén \\
en silencio y sólo una vez presentado todas las \\
imágenes, se vuelve a barajar y sean ellos quien \\
digan el nombre de cada letra y animal "a de abeja, \\
t de tiburón, r de ratón...”. Esta actividad aumenta
\end{tabular}


CAPITULO 3: METODOLOGÍA

\begin{tabular}{|l|l|l|}
\hline $\begin{array}{l}\text { de dificultad conforme se van pasando por las } \\
\text { distintas fases. }\end{array}$ & \\
\hline MATERIAL & Figura 3.12. Excepciones \\
\hline Abecedario plastificado de papel donde cada letra corresponde a un animal. \\
\hline
\end{tabular}




\section{PROGRESIÓN}

Se recomienda seguir la siguiente progresión; tomando la precaución de no pasar a la fase siguiente sin haber superado la anterior:

1-Identificar y asociar cada letra con su animal: presentamos todas las letras del abecedario a modo de bits: a de abeja, m de morsa, h de hipopótamo,..; en aproximadamente dos o tres semanas, la mayoría de alumnos identificará y asociarán todas las letras con el nombre del animal.

2-Asociar el sonido de cada consonante con cada una de las vocales (sílabas directas): la finalidad de esta fase es que los alumnos aprendan el sonido de cada sílaba al juntar una consonante con su vocal. Al finalizar esta etapa, los escolares reconocerán sílabas directas.

En esta fase retiramos vocales y excepciones, sólo se usarán las consonantes. Como si de bits se trataran, se muestra el sonido de la consonante al juntar con cada una de las vocales: "ma, me, mi, mo, mu; ta, te, ti, to, tu; sa, se, si, so, su; la, le, li, lo, lu,..."

En pocos días, la mayoría de alumnos son capaces de reconocer los sonidos de cada consonante asociados a las vocales, es en este momento cuando comenzamos la lectura de palabras en la pizarra; se utilizan palabras de 2 o 3 sílabas directas como máximo, p.e. mesa, rosa, tomate...

3-Asociar el sonido de las excepciones con cada vocal: para que los alumnos identifiquen las excepciones (véase figura 3), cada imagen contiene unos gomets; este sistema facilita que reconozcan rápidamente la excepción y además, asocien el tamaño y tipo de gomets con el sonido de esa letra al juntarla con las vocales.

Las letras "G y C" poseen pegatinas circulares de dos tamaños: a) grandes asociadas con sonido fuerte "ge y gi" y "ca, co y cu"; y b) pequeños asociadas a sonidos débiles "ga, go y gu" y "ce y ci". Por tanto, la letra "G" sonará: ga, go, gu, ge y gi; y la letra "C": ca, co, cu, ce y ci. La letra "H" posee una estrella para que recuerden que es "mudita" y su sonido es el mismo que la vocal a la que acompaña. Por último la letra "Q", posee dos pegatinas con forma de estrellas que los alumnos identificarán con los sonidos "que y qui".

4-Asociar el sonido de cada vocal al unirla a una consonante (sílabas inversas): pretendemos que los niños identifiquen y reconozcan el sonido de silabas inversas. Para esta fase retiramos las vocales y la letra "Q", usaremos el resto de las consonantes. Mostramos la imagen de la constante acompañado del sonido correspondiente a trabajar: "am, em, im, om, um; at, et, it, ot, ut; as, es, is, os, us; al, el, il, ol, ul,...". Con las excepciones: "ag, og, ug, eg, ig; ac, oc, uc, ec, ic; ah, oh, uh, eh, ih"

En relación a la lectura grupal, pronto veremos una evolución notable, pudiendo incrementar la dificultad de las palabras e incluso comenzar con la lectura de frases sencillas del tipo: "el niño toma sopa" (sílabas directas e inversas).

5-Identificar las letras en minúscula: el objetivo de esta fase es reconocer e identificar las letras del abecedario en minúscula. Retiramos el abecedario de animales, e introducimos en nuevo abecedario con letras en minúsculas (véase figura 3.15 y 3.16). Se sigue el mismo procedimiento, ir mostrando cada letra acompañado del sonido de las vocales, un día con sílabas directas al siguiente con sílabas inversas. En apenas dos semanas el control de las letras en minúscula será pleno; mientras tanto seguiremos jugando con las letras, formando palabras y frases en la pizarra.

6-Sílabas trabadas: para terminar, retiramos el abecedario e introducimos bits de letras trabadas. En total, son doce bits: bl, br, cl, cr, pl, pr, gl, gr, dr, tr, fl y fr. Se sigue la misma dinámica que en la fase 2

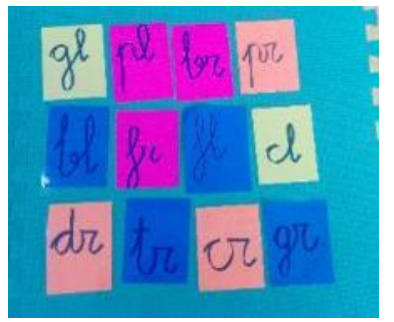

Figura 3.13: sílabas trabadas 
Tabla 3.9. Actividad: ¿cómo suena?

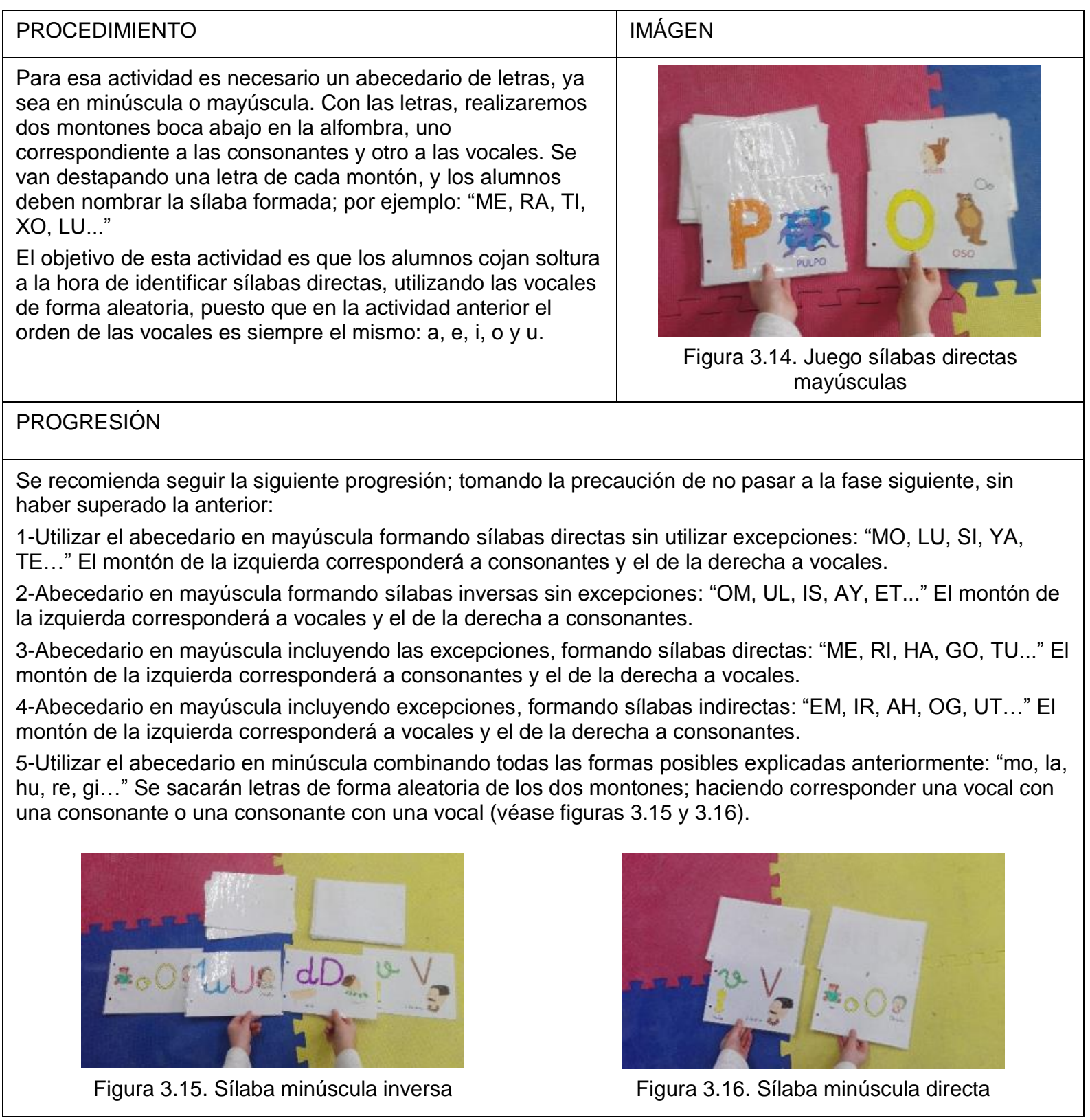




\section{CAPITULO 3: METODOLOGÍA}

Tabla 3.10. Actividad: juego del corazón

\begin{tabular}{|c|c|}
\hline PROCEDIMIENTO & IMÁGEN \\
\hline $\begin{array}{l}\text { Esta actividad se realiza en la pizarra. Pegamos con blu-tack las } \\
\text { cinco vocales formando una columna, procurando que el orden } \\
\text { de las vocales sea distinto de un día para otro. Elegimos } 5 \\
\text { consonantes, que iremos pasando de una en una a lo largo de } \\
\text { toda la columna de vocales; cada niño deberá decir la sílaba } \\
\text { directa que se forma al juntar la consonante con la vocal que le } \\
\text { haya tocado; si acierta, se dibujará un corazón al lado de su } \\
\text { vocal. } \\
\text { Al finalizar la actividad, tendremos un número concretos de } \\
\text { corazones dibujados en la pizarra, en base al número de aciertos } \\
\text { de cada uno de los niños. Contamos entre todos los corazones y } \\
\text { lo apuntamos en la esquina de la pizarra; de esta manera, en la } \\
\text { sesión siguiente veremos si hemos mejorado conseguido más } \\
\text { corazones que el día anterior. } \\
\text { Como en el caso anterior, la dificultad variará en base a los } \\
\text { objetivos propuestos. Se recomienda seguir la progresión de la } \\
\text { actividad anterior. }\end{array}$ & Figura 3.17. juego del corazón \\
\hline \multicolumn{2}{|l|}{ MATERIAL } \\
\hline Pizarra, tizas, borrador, blu-tack y un abecedario. & \\
\hline
\end{tabular}

Tabla 3.11. Actividad: descubrimos palabras

\begin{tabular}{|l|l|l|}
\hline PROCEDIMIENTO & IMÁGEN \\
\hline $\begin{array}{l}\text { Esta actividad está dirigida exclusivamente al } \\
\text { maquinista y al vagón de cola. En nuestra aula, } \\
\text { contamos con dos responsables cada día: maquinista y } \\
\text { vagón de cola. Ambos alumnos tienen papeles muy } \\
\text { destacados, otorgándoles parte del protagonismo } \\
\text { diario. Sus responsabilidades no se limitan únicamente } \\
\begin{array}{l}\text { a repartir material, situarse en un lugar concreto en la } \\
\text { fila o pasar lista, además tienen una misión: descubrir } \\
\text { palabras o frases. Para ello se les formula las } \\
\text { siguientes cuestiones: “iqué prefieres, palabra o frase? } \\
\text { ¿Mayúscula o minúscula? ¿Cómo de larga quieres que } \\
\text { sea tú palabra o frase?"; dependiendo de la edad y } \\
\text { momento en que se encuentren, se decantarán por } \\
\text { lecturas más sencillas o complejas. }\end{array}\end{array}$ \\
$\begin{array}{l}\text { MATERIAL } \\
\text { Pizarra, tiza y borrador. }\end{array}$
\end{tabular}


Tabla 3.12. Actividad: cofre de letras

\begin{tabular}{|l|l|}
\hline PROCEDIMIENTO & IMÁGEN \\
Únicamente pondremos en marcha esta actividad cuando \\
objetivo es reforzar el reconocimiento e identificación de las \\
letras en minúscula. Jugaremos con el factor sorpresa, para \\
ello utilizaremos un cofre de madera lleno de letras \\
plastificadas en minúscula. Cada día, el encargado sacará \\
del cofre dos letras al azar, si los alumnos identifican la \\
letra se pegarán encima de la pizarra, en caso contrario, se \\
guardarán para la próxima ocasión. Seguidamente, \\
dedicaremos unos minutos a hablar sobre todo lo que \\
sepamos sobre esas letras: si tienen barriga, si llegan al \\
cielo, al suelo o al centro, si conocemos palabras que \\
lleven esa letra...
\end{tabular}

\section{Actividades de aprendizaje básicas en relación a la lógico-matemática}

Exponemos en las siguientes tablas, las actividades básicas para el desarrollo de las capacidades lógico matemáticas. Como en el caso anterior, en cada tabla se detalla: el procedimiento utilizado para el desarrollo de la actividad acompañado de una o varias imágenes, facilitando una mejor comprensión; el material utilizado; y en el caso que fuera necesario, la progresión de las fases a seguir en dicha actividad.

Tabla 3.13. Actividad: puntos rojos

\section{PROCEDIMIENTO}

Todos los días, después de los bits, dedicamos unos minutos a jugar con los bits de números. Para poner en marcha la actividad, se muestran dos bits numéricos y se formulan preguntas del tipo: ¿Qué número es más grande: 75 o 7? ¿Cuántos puntos le faltan a 75 para ser como 77? ¿Qué pasa si al 58 le quito dos puntitos? ¿Y si le añado 3 ? Esta actividad permite muchas variantes, conforme los alumnos van avanzando se puede plantear interrogantes más complejos (véase figura 3.21).

Puntualizar, que es una actividad muy intuitiva, puesto que antes de formular cualquier interrogante se muestran los bits de números (véase figura 3.20); los niños rápidamente establecen relaciones entre números de forma autónoma. Existe un aprendizaje muy rápido y potente a través del ensayo error. 


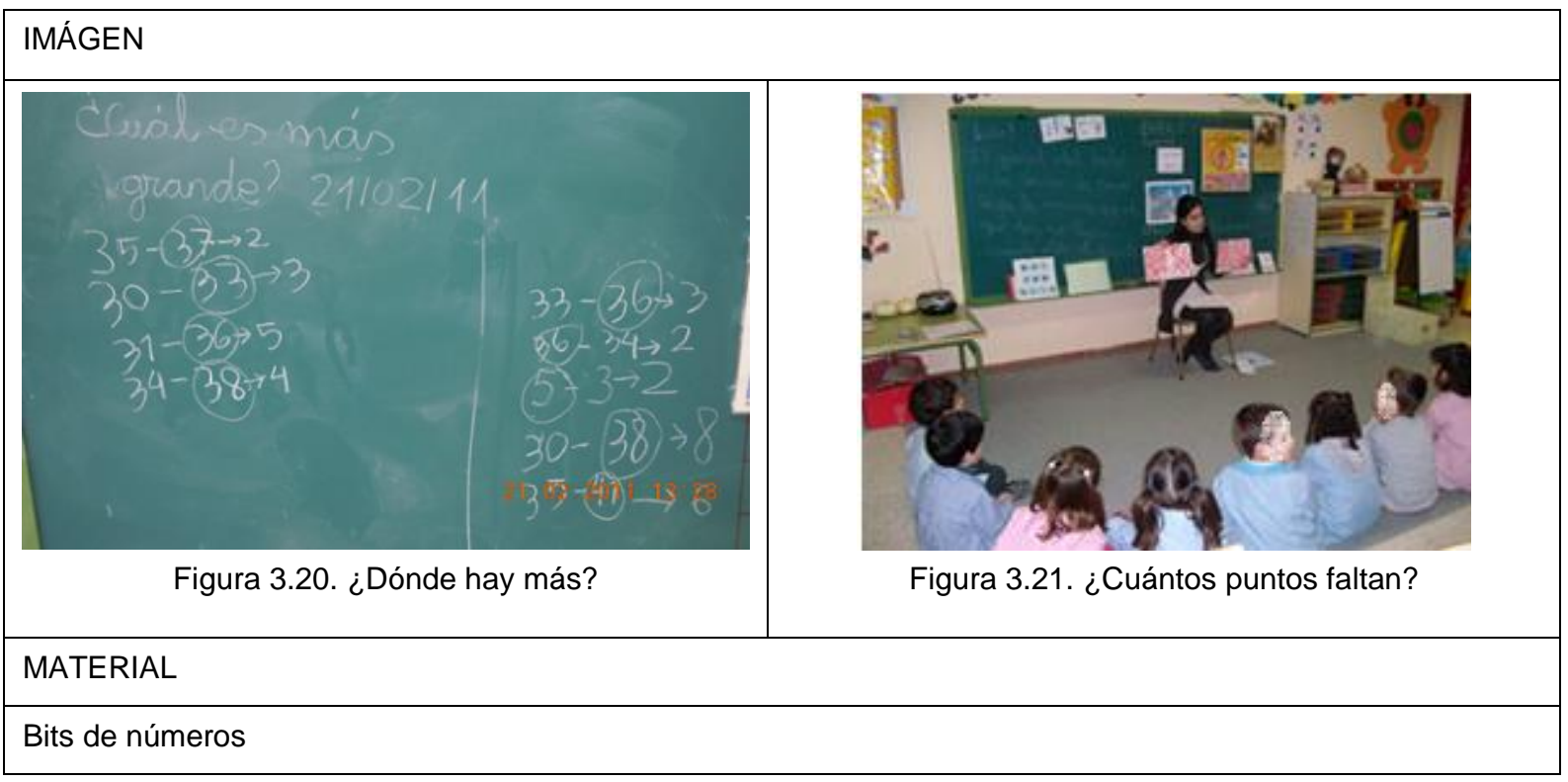

Tabla 3.14. Actividad: juegos con regletas

\begin{tabular}{|c|c|}
\hline PROCEDIMIENTO & IMÁGEN \\
\hline $\begin{array}{l}\text { Diariamente en la segunda asamblea, } \\
\text { dedicamos } 20 \text { minutos después de mostrar los } \\
\text { bits, a realizar diferentes juegos con las } \\
\text { regletas (ver anexo 1, ver anexo } 3 \text { y ver anexo } \\
\text { 5) }\end{array}$ & Figura 3.22. Juegos con regletas \\
\hline \multicolumn{2}{|l|}{ MATERIAL } \\
\hline \multicolumn{2}{|c|}{$\begin{array}{l}\text { Las regletas de Cuisenaire, están formadas por una serie de primas de madera o plástico, de nueve colores } \\
\text { con distinta longitud, que guardan entre si relaciones en cuanto al número, color y longitud. Cada una de las } \\
\text { diez regletas se le asocia con un número y color, en base a su longitud. La regleta que representa la unidad, y } \\
\text { por tanto el número uno, es de color blanco o color madera, y es un cubito que mide } 1 \mathrm{~cm} \text { de arista, es decir, } 1 \\
\text { cm cúbico. La regleta que representa al número dos, es de color rojo, y mide el equivalente a dos unidades } \\
\text { juntas, es decir, es un prisma de } 1 \times 1 \times 2 \mathrm{~cm} \text {. La regleta que representa el número } 3 \text {, es de color verde claro, y } \\
\text { mide el equivalente a tres unidades juntas. Esta misma situación, se repite con cada una de las } 10 \text { regletas, } \\
\text { asociando los siguientes colores en relación al número: } 4 \text { rosa, } 5 \text { amarillo, } 6 \text { verde oscura, } 7 \text { negra, } 8 \text { marrón, } \\
9 \text { azul y por último, la regleta número } 10 \text { es naranja, y es la más grande de todas. }\end{array}$} \\
\hline \multicolumn{2}{|l|}{ PROCEDIMIENTO } \\
\hline \multicolumn{2}{|c|}{$\begin{array}{l}\text { El manejo de las regletas en el aula requiere tiempo y constancia, debemos ir pasando por una serie de fases } \\
\text { para reforzar la etapa anterior y así, poder pasar al siguiente; un posible modo de proceder es el siguiente: }\end{array}$} \\
\hline \multicolumn{2}{|c|}{$\begin{array}{l}\text { 1-Manipulación libre: al presentar el material por primera vez, debe existir un tiempo de experimentación; } \\
\text { favoreciendo un primer contacto de forma lúdica dejándoles que manipulen libremente (véase figura 3.23); } \\
\text { resulta interesante la creación de un rincón de regletas en el aula. En este rincón, los alumnos poseen tantas } \\
\text { cajas como mesas hay en el aula, para que puedan experimentar y llevar a cabo lo aprendido en la asamblea; } \\
\text { lo interesante de este rincón, es que a través del juego y de forma espontánea, establecen relaciones, } \\
\text { aprendiendo de forma espontánea: qué regleta es más larga, cuánto necesita una regleta para ser como otra } \\
\text { dada, que número se forma al sumar dos regletas y por tanto al sumarle una más el resultado es... }\end{array}$} \\
\hline & \\
\hline
\end{tabular}


grupo clase preguntas del tipo “¿después del uno, cuál va? ¿Y luego? ¿De qué color es la regleta del numero...?".

3-Creación de escaleras: al colocar una regleta al lado de la otra, comenzando por el uno y terminando por el diez; se da lugar a la creación de una escalera. A través de esta actividad, se favorece el conteo del 1 al 10 , comprender qué número es más grande por su longitud, más pequeño, etc. (véase figura 3.26).

4-Creación de paredes: una vez realizada la escalera, es siguiente paso es colocar sobre cada una de las regletas otra cuya suma sea igual a diez (véase figura 3.25). Comenzamos colocando encima del 1 la regleta del 9; encima del 2 la regleta del 8 ; encima del 3 la regleta del $7 ; \ldots$ es una manera lúdica, rápida y fácil de descomponer el diez (los amigos del diez).

5-¿Cuántos caben?: se les muestra una regleta determina y buscamos otras más pequeñas que quepan encima; por ejemplo buscar qué regletas caben encima del 4 (cuatro unos, dos doses, un tres y un uno, el cinco no porque queda un cachito fuera, etc.). Este será el paso previo para iniciarles en la suma.

6-Llegados a este punto, es momento de iniciar la suma, para ello se les da la indicación verbal "que sumar es juntar", y siempre que iniciemos este tipo de juegos en la asamblea de forma grupal, recordamos la frase. Es importante no limitarse a sumas de dos sumando, como por ejemplo 1+1, desde el inicio de la experiencia realizamos sumas de dos, tres, cuatro, cinco,... sumando, sin ser el resultado mayor de diez.

7-Conteo: es fundamental paralelamente al uso de las regletas, favorecer juegos de conteo, contar de 2 en 2 , de 10 en 10 y de 5 en 5 (dependiendo de la edad de los alumnos y el momento en el que se encuentre, se puede aumentar la dificultad). Reforzaremos especialmente el contar de 10 en 10 a través de las regletas; para ello se van colocando regletas naranjas (del 10) una al lado de la otra mientras contamos: $10,20,30 \ldots$

8-Creación de números mayores de 10: tras haber tenido suficiente experiencias en relación a sumas menores de 10 y conteo de 10 en 10, es momento de crear a través de las regletas, número grandes. Por ejemplo, 79: los alumnos van contando 10, 20, 30, 40, 50, 60 y 70 mientras colocan las regletas del 10 una al lado de la otra y por último, se añade la regleta del 9. Para ellos es un juego fácil y divertido, para el docente, una manera sencilla y rápida de que los alumnos aprendan (véase figura 3.26).

9-Favorecer el cálculo mental: les preguntaremos aquellas sumas que recuerden; normalmente recordarán sumas del tipo: $2+2 ; 5+5 ; 1+1 ; \ldots$ "Entonces, si le sumamos uno más ¿qué pasa?, y si ¿le sumamos dos más? ¿Qué sumas que den diez recordáis?" A través de este tipo de experiencias se va favoreciendo el cálculo mental.

10-Iniciación a la resta: "restar es quitar", una breve premisa que les ayuda a recordar el concepto de resta. Se les recuerda que para poder restar, la regleta de abajo debe ser igual o más grande que la de arriba. Al darles una regleta, por ejemplo la del 4 y quitarle 1 (se pone la regleta del 1 encima de la del 4), queda un hueco que deben rellenar con otra; el propiciar experiencias de ensayo error les permite aprender, porque no sólo descubren que en ese hueco cabe un 3 , sino que ven que un 5 es muy grande y por tanto necesitan otra más pequeña.

11-Resta con llevadas: dado un número grande como pueda ser el 51, se pone encima el número que queremos restar, como por ejemplo el 22; los niños rellenan el hueco que queda siguiendo la indicación de poner primero tantos dieces como quepan (en este caso 2 dieces) junto con la regleta falte (la del 9). Para ellos es muy sencillo, puesto que ven que el 51 está formado por 5 dieces y 1 uno; y el 22 está formado por 2 dieces y 1 dos; por tanto encima caben otros 2 dieces y 1 nueve; el resultado será 29.

Favorecer múltiples experiencias diarias con las regletas, a través de la manipulación y el ensayo error, permite a los alumnos aprender de forma sencilla, rápida y divertida.

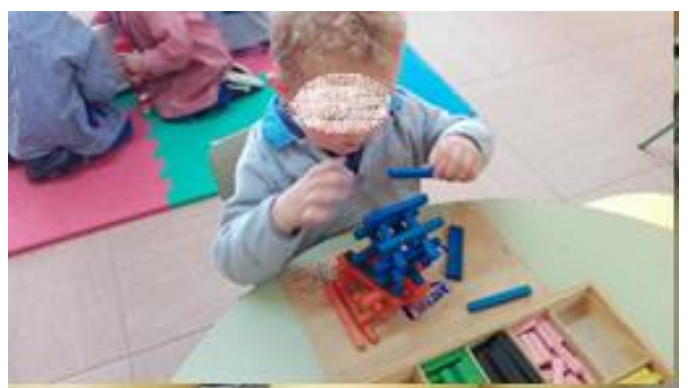

Figura 3.23. Manipulación libre

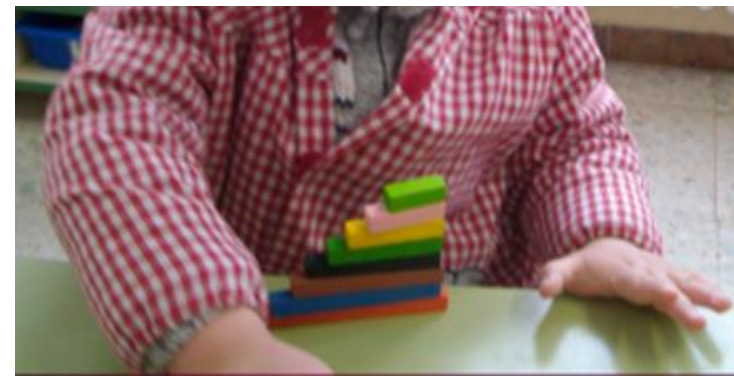

Figura 3.24. Escalera 


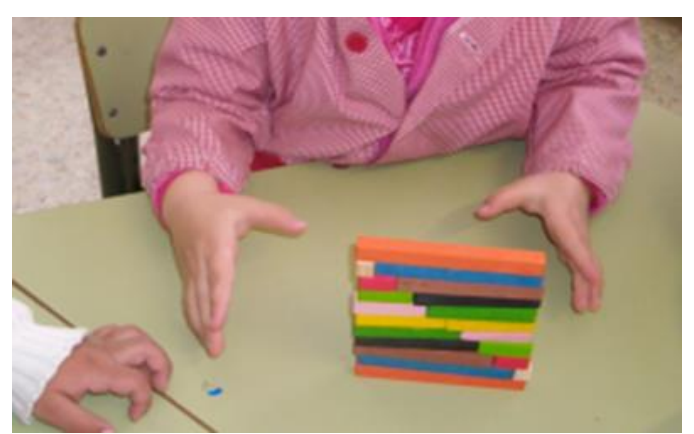

Figura 3.25. Pared

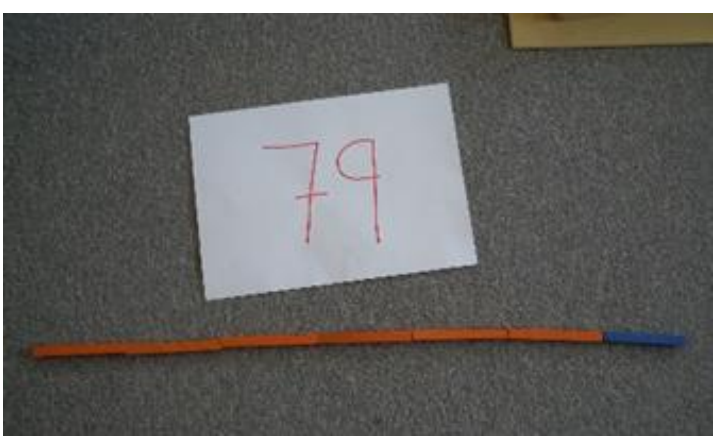

Figura 3.26. Creación de números con regletas

Tabla 3.15. Actividad: retos numéricos

\begin{tabular}{|c|c|}
\hline DECRIPCIÓN DE LA ACTIVIDAD & IMÁGEN \\
\hline $\begin{array}{l}\text { La actividad final del PET consiste en plantear retos } \\
\text { matemáticos. Para ello se plantean interrogantes que los } \\
\text { alumnos deben resolver; normalmente se hace una } \\
\text { ronda, planteando una cuestión a cada uno de los } \\
\text { alumnos, adaptando el reto al nivel de cada persona. } \\
\text { Algunos ejemplos son: averiguar sumas y restas } \\
\text { utilizando regletas, solucionar problemas sencillos que } \\
\text { impliquen sumas o restas, descubrir cuantos puntos le } \\
\text { falta a un número para ser igual que otro, mostrar la } \\
\text { imagen de un número de entre } 1 \text { y } 12 \text { cifras que el } \\
\text { alumno debe descodificar. }\end{array}$ & 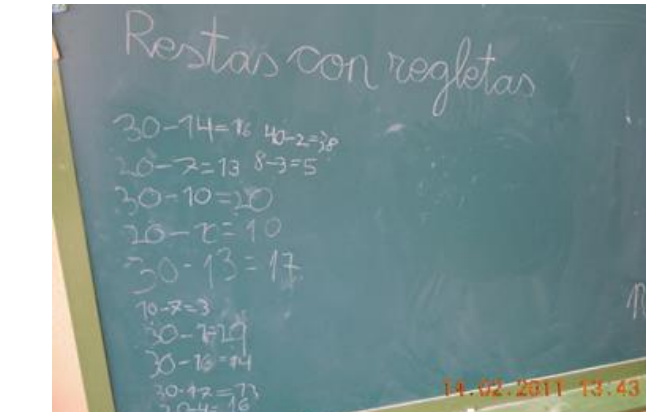 \\
\hline & Figura 3.27. Reto restas con regletas \\
\hline
\end{tabular}

La duración de la segunda sesión de cada día del PET es aproximadamente de 45-50 minutos. El procedimiento seguido de una sesión a otra es muy similar: comenzamos mostrando los bits, jugamos unos minutos con los puntos rojos (se hace una ronda de preguntas entre todos los niños del aula), dedicamos 20 minutos a juegos con regletas, planteamos un reto matemático y siempre se dedica unos minutos finales a dos actividades: conteo y cálculo mental.

1) Conteo: todos los días contamos de 2 en 2, de 5 en 5 y de 10 en 10. En base al curso en el que nos encontremos, vamos aumentando la dificultad. Por ejemplo, en 3 o curso de El, contamos de 2 en 2, de 3 en 3, de 4 en 4, de 5 en 5 y de 10 en 10 hacia delante y hacia atrás.

2) Cálculo mental: para iniciar esta actividad, pedimos a los niños que recuerden sumas que han hecho anteriormente con regletas $(2+2=4,1+1=2,5+5=10 \ldots)$ a partir de aquí vemos que sucede si sumamos uno más a un número, si sumamos dos, si le quitamos uno, etc. Estas reflexiones junto con las experiencias llevadas en la alfombra a través 
de las actividades diarias y el conteo hacen que los alumnos muestren gran facilidad a la hora de realizar operaciones mentales, como demuestran a través del juego del 100 (véase anexo 2, anexo 3 y anexo 9).

Como en el caso de la lectura y escritura, no contamos con un cuadernillo de una editorial concreta donde se realizan operaciones matemáticas, grafía de números, asociaciones entre número y cantidad, etc. Yo misma, elaboraba las fichas de acuerdo con la evolución y necesidades de los alumnos. Sin embargo, los alumnos a través de experiencias manipulativas y vivenciadas han ido integrando de forma significativa los conceptos propuestos para cada curso escolar. En la tabla 3.16 mostramos diferentes ejemplos:

Tabla 3.16. Experiencias manipulativas de lógico-matemáticas

\begin{tabular}{|c|c|c|}
\hline Concepto matemático: color & & \\
\hline $\begin{array}{l}\text { Favorecer experiencias manipulativas } \\
\text { donde intervengan el mayor número de } \\
\text { sentidos, provoca en los niños } \\
\text { aprendizajes significativos. En las } \\
\text { imágenes se muestra como alumnos de } \\
4 \text { años, refuerzan la adquisición de los } \\
\text { colores primarios tiñendo claveles con } \\
\text { colorante alimentario. Esta misma } \\
\text { actividad se puede llevar a cabo, } \\
\text { mezclando dos de los colores para } \\
\text { crear otro color secundario: verde, } \\
\text { naranja o morado. }\end{array}$ & Figura 3.28. Teñir claveles & Figura 3.29. Claveles azules \\
\hline
\end{tabular}

Concepto matemático: clasificaciones, seriaciones y secuencias.

Mediante través de materiales reales del entorno, promover experiencias donde los alumnos puedan clasificar, seriar y secuenciar.

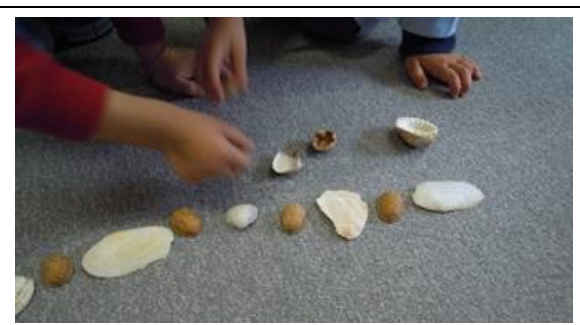

Figura 3.30. Seriaciones con conchas y nueces

Concepto matemático: grafía de la serie numérica

A través de la manipulación de objetos, como puede ser una naranja y clavo alimentario, no sólo trabajamos la grafía de los números sino que elaboramos ambientados naturales para el aula. Experiencias potencialmente valiosas, que promueven en los niños nuevos aprendizajes o reforzar los que ya poseían.

Ellos mismos elaboran sus propios números, que posteriormente podrán manipular para realizar secuencias, clasificaciones, realización de

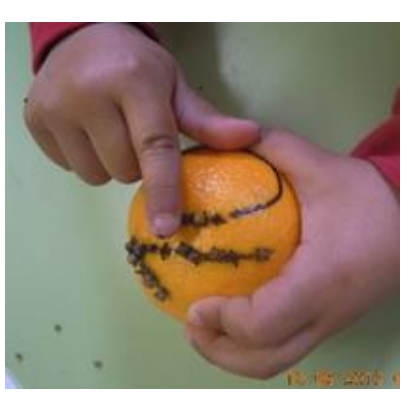

Figura 3.31. Ambientador del nํ 10

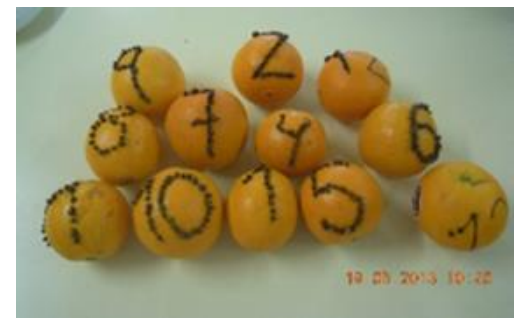

Figura 3.32. Ambientadores naturales 


\begin{tabular}{|c|c|}
\hline $\begin{array}{l}\text { operaciones aritméticas como } \\
\text { sumas, restas, repartir en partes } \\
\text { iguales, }, . .\end{array}$ & \\
\hline \multicolumn{2}{|c|}{ Concepto matemático: grafía de números y asociación concepto-cantidad } \\
\hline $\begin{array}{l}\text { A través de elementos altamente } \\
\text { motivadores, como es la mesa de } \\
\text { luz, se busca provocar situaciones } \\
\text { didácticas para que el alumno } \\
\text { aprenda. Este material permite } \\
\text { muchas variantes al poder incorporar } \\
\text { numerosos elementos para su uso: } \\
\text { corchos, recipientes con arena, } \\
\text { rotuladores borrables, cucharas } \\
\text { traslucidas,... múltiples posibilidades } \\
\text { que hace que a través de la } \\
\text { manipulación se genere procesos de } \\
\text { aprendizaje. }\end{array}$ & $\begin{array}{l}\text { Figura 3.33. Elaboración de Figura 3.34. Número y cantidad } \\
\text { números }\end{array}$ \\
\hline \multicolumn{2}{|l|}{ Concepto matemático: volumen } \\
\hline $\begin{array}{l}\text { Para realizar estas actividades } \\
\text { necesitamos espuma de afeitar, cola } \\
\text { y colorante alimenticio. Mezclamos } \\
\text { estos elementos y se introducen en } \\
\text { una manga pastelera. Con esta } \\
\text { mezcla, los alumnos realizan la } \\
\text { grafía del número además de } \\
\text { reforzar el color que se esté } \\
\text { trabajando en ese momento. } \\
\text { Utilizar materiales poco comunes en } \\
\text { la práctica educativa, como es } \\
\text { espuma de afeitar, llama } \\
\text { enormemente la atención de los } \\
\text { alumnos. }\end{array}$ & 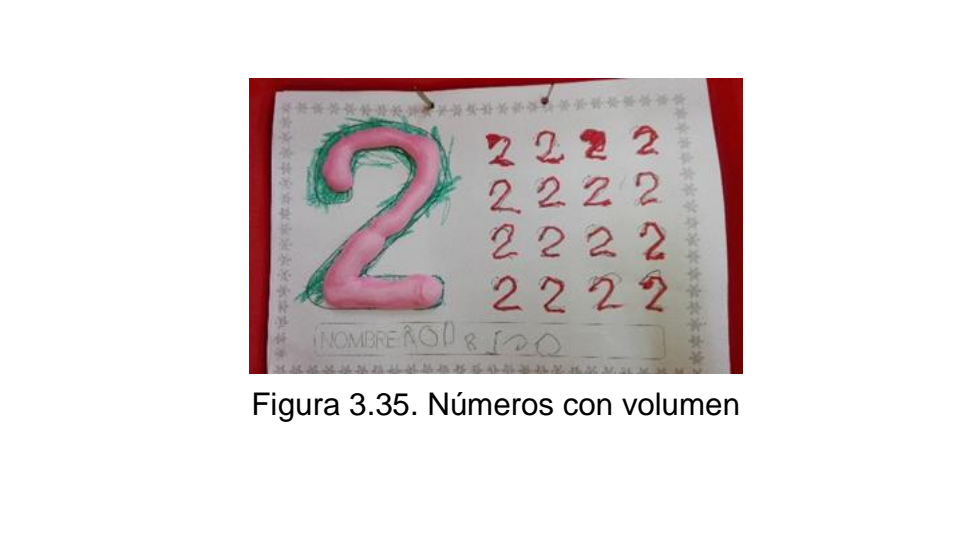 \\
\hline \multicolumn{2}{|c|}{ Conceptos matemáticos: figuras geométricas } \\
\hline $\begin{array}{l}\text { En los centros, existen números } \\
\text { espacios potenciadores de } \\
\text { aprendizaje. Como muestra la } \\
\text { imagen, las propias verjas del patio } \\
\text { puede convertirse en un buen aliado } \\
\text { para este fin: descubrir las figuras } \\
\text { geométricas que se esconden en } \\
\text { ellas (rombos, cuadrados, } \\
\text { rectángulos y triángulos). }\end{array}$ & Figura 3.36. Figuras geométricas en verjas \\
\hline
\end{tabular}

El juego es la principal herramienta con la que cuento para generar aprendizaje: permite que mis alumnos comprender mejor los conceptos mediante su manipulación, refuerza los ya adquiridos, sirve de trampolín para descubrir el mundo que les rodeas, las propiedades de los objetos y todo ello le lleva a reforzar automatismos y consolidar contenidos. Según Piaget (1985, p.20) "los juegos ayudan a construir una amplia red de dispositivos que permiten al niño la asimilación total de la realidad, incorporarla para revivirla, dominarla, comprenderla y compensarla". Fruto de ello y el PET puede verse plasmado en producciones diarias de los propios alumnos: (1) figura 3.37: maratón de matemáticas, alumno de 3ํㅜ curso de El, muestra gran destreza con el cálculo, realizando operaciones que impliquen sumas con llevadas y restas sin utilizar ningún soporte material; (2) en la figura 3.38: alumna 
de 3ํㅡㄴ curso de El, realiza sumas con llevadas de dos cifras; (3) figura 3.39: sumas con llevadas de tres cifras y descodificación de números romanos a números cardinales de 1 y 2 cifras; y (4) figura 3.40:descodificación de números romanos en números cardinales de hasta 4 cifras.

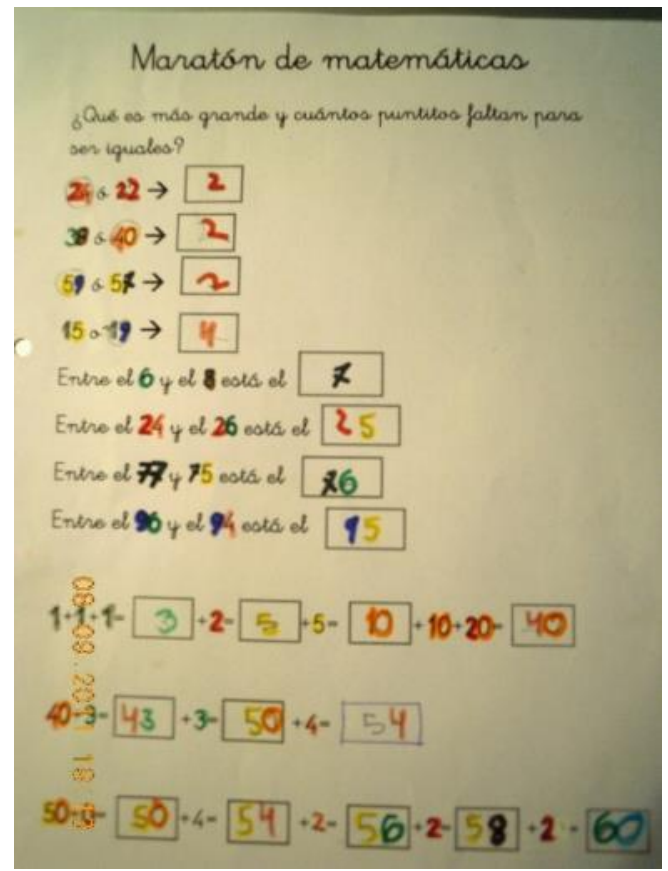

Figura 3.37. Maratón de matemáticas

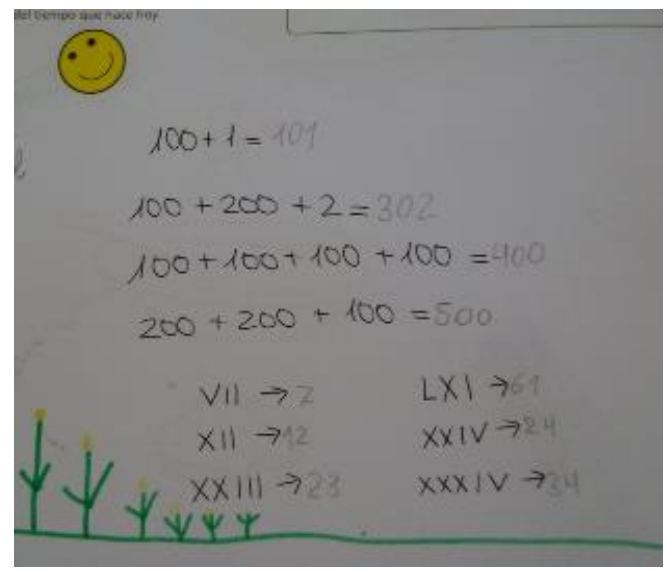

Figura 3.39. Sumas con llevadas de 3 cifras

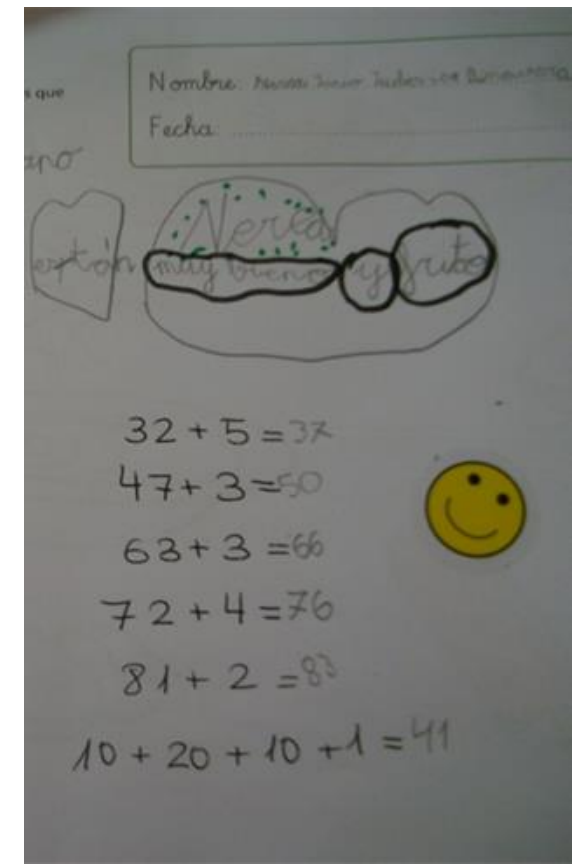

Figura 3.38. Sumas con llevadas de 2 cifras

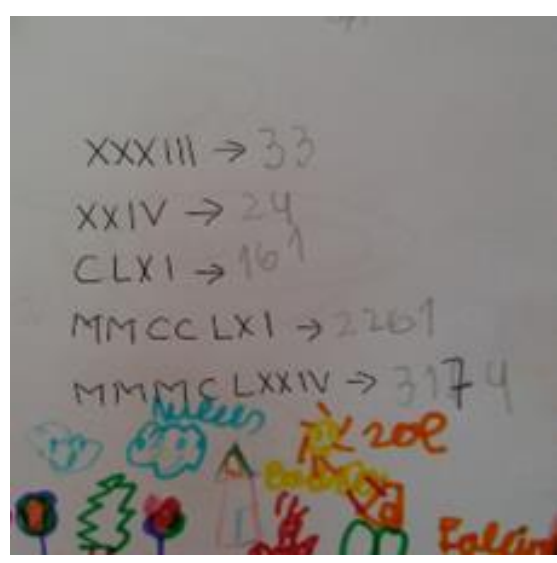

Figura 3.40. Números romanos

\subsubsection{SISTEMA DE EVALUACIÓN FORMATIVA Y COMPARTIDA}

En este apartado vamos a presentar el sistema de evaluación utilizado en el PET. EI sistema de evaluación pretende ser una herramienta al servicio del proceso de enseñanza aprendizaje, que genere aprendizaje en sí mismo y no ser utilizado como una medio de calificación (García-Herranz y López, 2015). Según el Decreto 122/2007 (BOE, 2 de enero, 


\section{CAPITULO 3: METODOLOGÍA}

2007) la evaluación cumple "una función reguladora del proceso de enseñanza-aprendizaje porque aporta información relevante sobre el mismo, facilita al profesorado la toma de decisiones para una práctica docente adecuada y posibilita a los niños iniciarse en el autoevaluación y a aprender a aprender". Dentro de esta proyecto, la evaluación formativa y compartida cobra un papel fundamental como regulador de los procesos de aprendizaje del alumnado, pero también como regulador de todo el proceso de enseñanza-aprendizaje que se lleva a cabo en el aula y como sistema clave en el proceso de mejora de la calidad docente (tradicionalmente se tiende a evaluar únicamente el proceso de aprendizaje de los alumnos, en menor medida el proceso de enseñanza de los docentes y prácticamente en ningún caso el proceso de enseñanza-aprendizaje).

Este sistema es acorde con la forma de trabajar diaria, dando un sentido completo a todo el proceso; por ello la utilización de procesos de evaluación formativa y compartida debe ser coherente con la metodología utilizada (López, 2009); como bien describe Santos (2003, p.16) “dime qué y cómo evalúas y te diré qué y cómo enseñas".

A lo largo de toda la experiencia planteo la evaluación en mi aula dando a los alumnos la oportunidad de elegir la forma de elaborar sus producciones (fichas, actividad en mesa, trabajos, etc.): (a) sencilla, realizando la tarea lo mejor posible; (b) más compleja, realizar la tarea lo mejor posible y por el reverso de ésta demostrar sus conocimientos adquiridos durante el PET, realizando de forma adicional otras tareas que ellos deciden para conseguir una valiosa cara sonriente. En las siguientes imágenes puede observarse varios ejemplos de tareas adicionales realizadas en el reverso de las fichas: (1) en las figuras 3.41 y 3.42 mostramos como dos alumnos de $2^{\circ}$ curso de El realizan propuestas diferente para una misma ficha y así conseguir una cara sonriente, en la figura 3.41 un alumno decide realizar un dibujo en relación al eje motivador que se está trabajando en ese momento (medios de transporte) y repasa con rotulador los números utilizando los colores de la regletas; en la figura 3.42 otra alumna decide realizar una serie utilizando tres colores, dibujar un medio de transporte escribiendo la palabra "avión" y repasar los números acorde con los colores de las regletas; (2) en el segundo caso mostramos una propuesta de una alumna de $1^{\circ}$ curso de El (ver figuras 3.43 y 3.44 ), la cual decide escribir palabras relacionadas con el eje motivador que se está trabajando en ese momento (el circo) de forma autónoma, destacar que hasta el momento no se había trabajado en el aula la escritura de palabras sencillas, aspecto importante para entender como este sistema de evaluación genera aprendizaje: iniciación a la escritura de forma autónoma. 


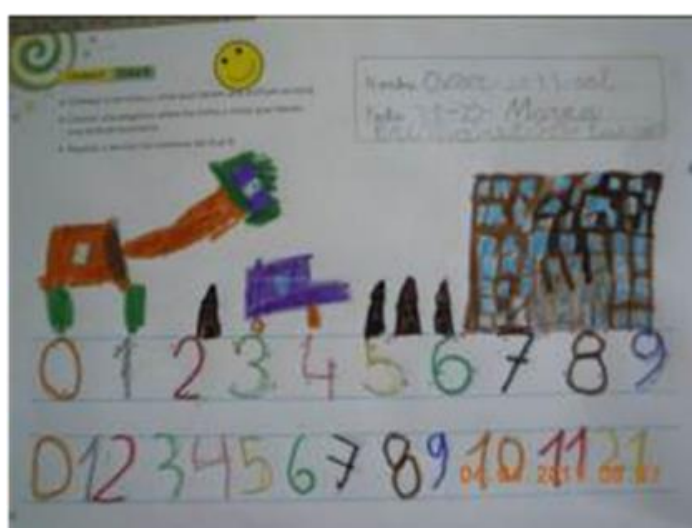

Figura 3.41. Ejemplo cara sonriente 1

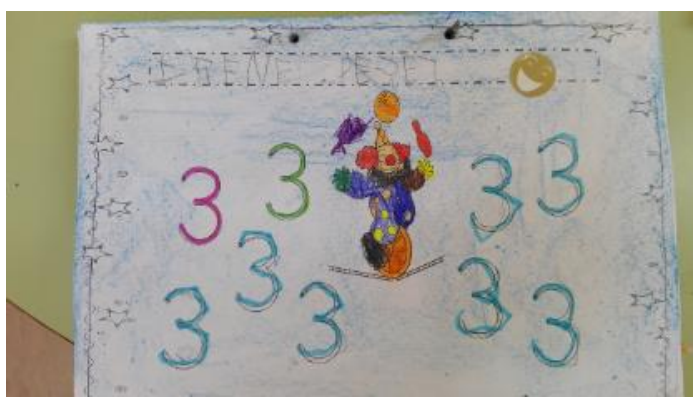

Figura 3.43. Ficha del 3

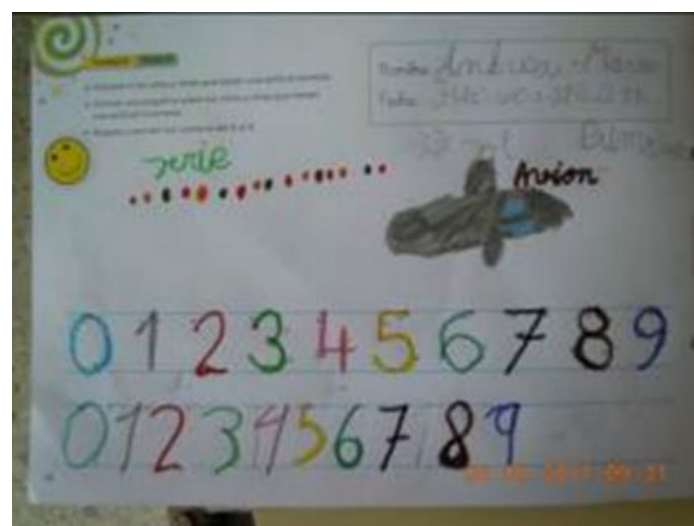

Figura 3.42. Ejemplo cara sonriente 2

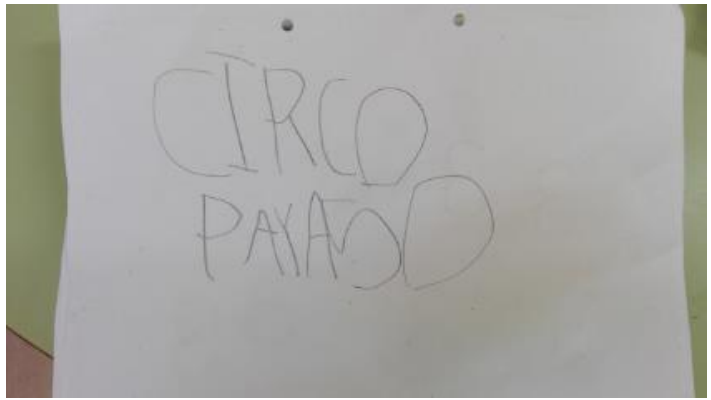

Figura 3.44. Ejemplo cara sonriente 3

En la primera asamblea de cada día explico la ficha a realizar y los propios alumnos son quienes eligen que opción seguir (sencilla o compleja). De la misma manera, a lo largo de la segunda y última asamblea, dialogamos sobre lo acontecido y explico las razones que me han llevado a otorgar la cara sonriente; en el caso contrario razonamos de qué manera podría haberse conseguido, aportando feed-back sobre cómo mejorar. Previamente, en la primera reunión con las familias, los padres fueron informados sobre la propuesta; la experiencia fue acogida con gran aceptación y ganas de ponerla en práctica también desde casa. El hecho de que los propios padres conozcan la dinámica seguida en clase es un aspecto positivo ya que motiva a los niños a involucrarse más en la iniciativa.

Durante esta experiencia diseñe una nueva actividad denominada "el tendero de los deseos" puesta en práctica al finalizar cada unidad didáctica o proyecto, la cual me permitía evaluar los resultados conseguidos durante la aplicación de la evaluación formativa y compartida.

Para llevar a cabo esta actividad los alumnos (1) cuentan con un número considerable de pinzas con sus nombres escritas en ellas; (2) dependiendo de la edad de los escolares se les plantean que dibujen (ver figura 3.45 y 3.45 ) o escriban (ver figura 3.47) aquellos "deseos" donde expliquen qué actividad, ficha, momento a lo largo del día... les ha gustado más o, por el contrario, les ha gustado menos; (3) una vez escrito los deseos y expuestos de forma dialogada en la asamblea grupal cada alumno pondrá una pinza en aquellos deseos con los 


\section{CAPITULO 3: METODOLOGÍA}

que estén de acuerdo (ver figuras 3.47 y 3.48). Según el número de pinzas que haya en cada deseo podremos ver el grado de acuerdo y desacuerdo de la clase, lo que supone una información muy valiosa de aquellos aspectos que han resultado aceptados y valorados, o por el contrario no han sido aceptados de la manera esperada. Esta actividad nos da la oportunidad de cambiar aquellas experiencias, materiales o dinámicas que no cuentan con la aceptación de los alumnos y de la misma manera, seguir afianzando y consolidando aquellos otros que cuentan con un número significativo de pinzas y por tanto de la aceptación de la clase (feedback).

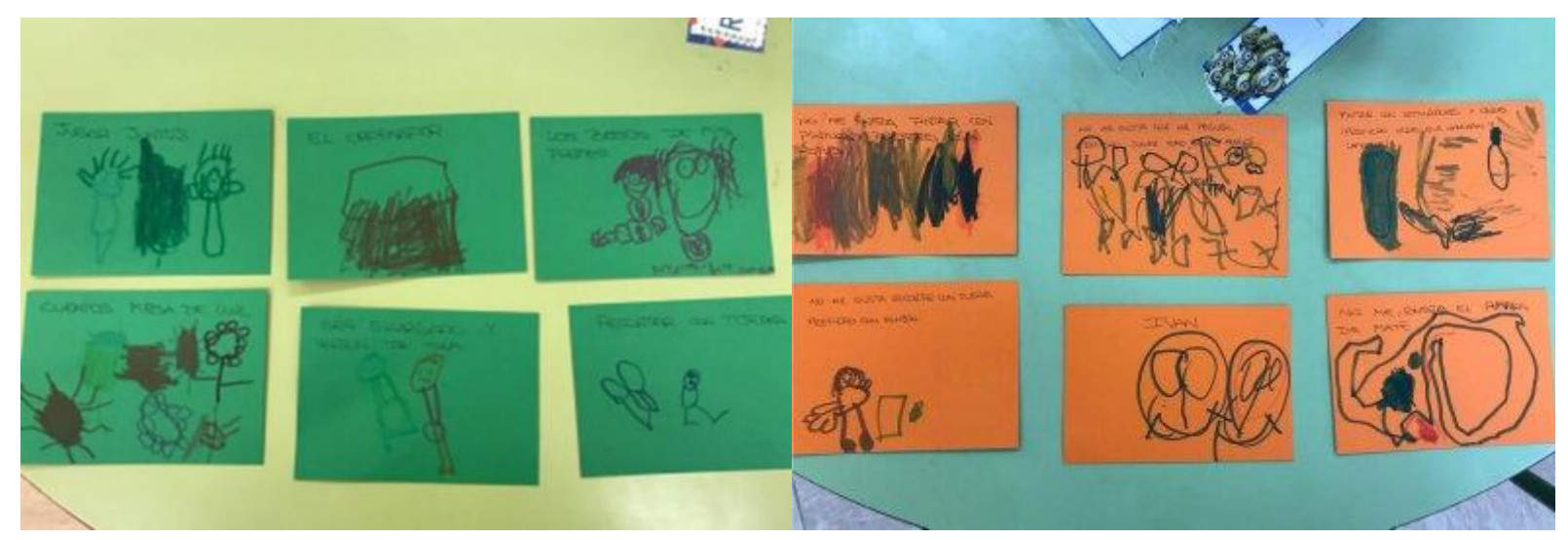

Figura 3.45: deseos "me gusta"

Figura 3.46: deseos "no me gusta"

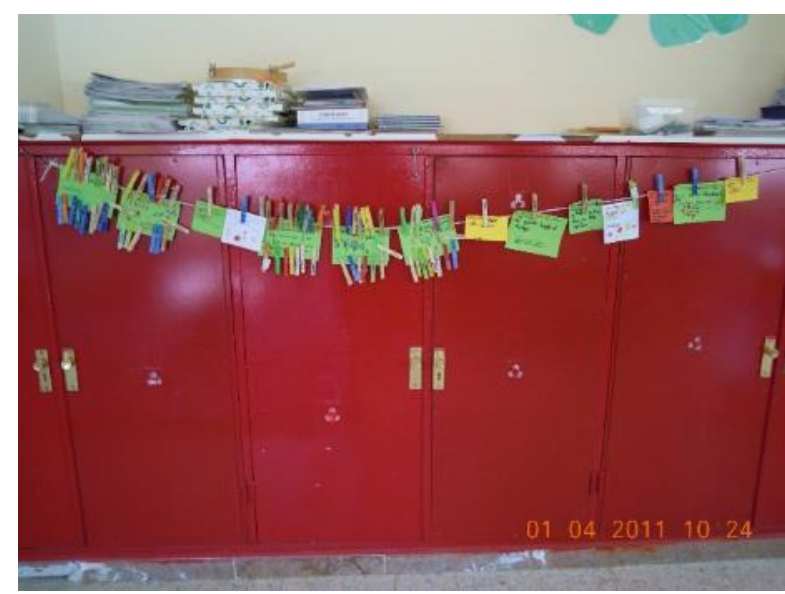

Figura 3.47: tendero de los deseos

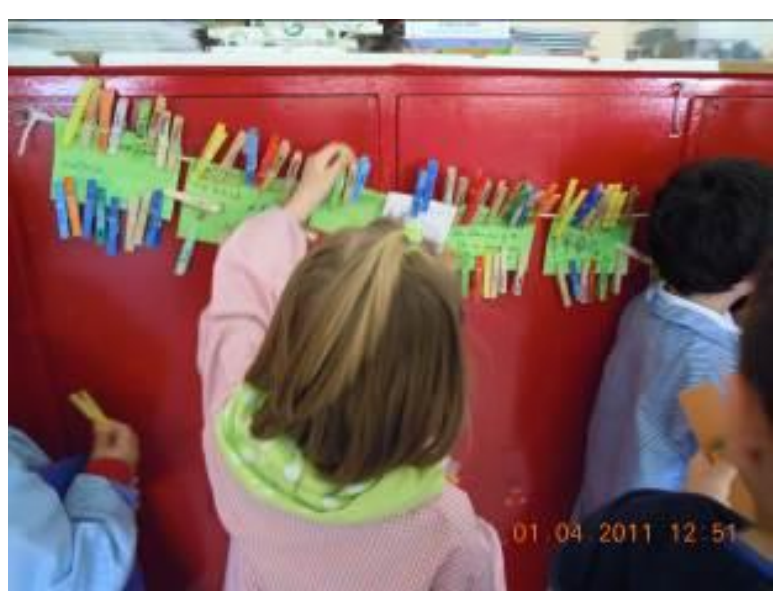

Figura 3.48: acuerdo y desacuerdo de cada alumno

Como se muestra en las figuras 47 y 48 , existen deseos que: (1) cuentan con una o dos pinzas y por tanto la información que nos proporcionan no es valiosa lo que implica, que esa información no es tenida en cuenta; y (2) deseos con un gran número de pinzas que muestran el grado de acuerdo y desacuerdo de toda la clase, siendo un dato representativo a valorar. Esta actividad me ha permitido reorganizar mi propia práctica docente y el proceso de enseñanza aprendizaje; según la información obtenida he reorientando el día a día cambiando aspectos poco valorados por otros más motivantes y por el contario, afianzando aquellos que han sido aceptados con agrado (ejemplo de ello se muestra en la tabla 3.17). 
Tabla 3.17. Me gusta, no me gusta.

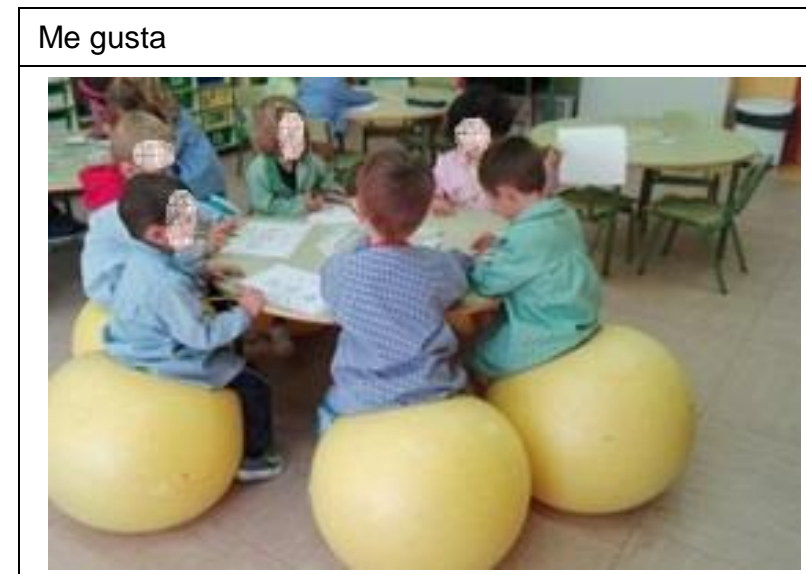

Figura 3.49. mesa con pelotas de Pilates

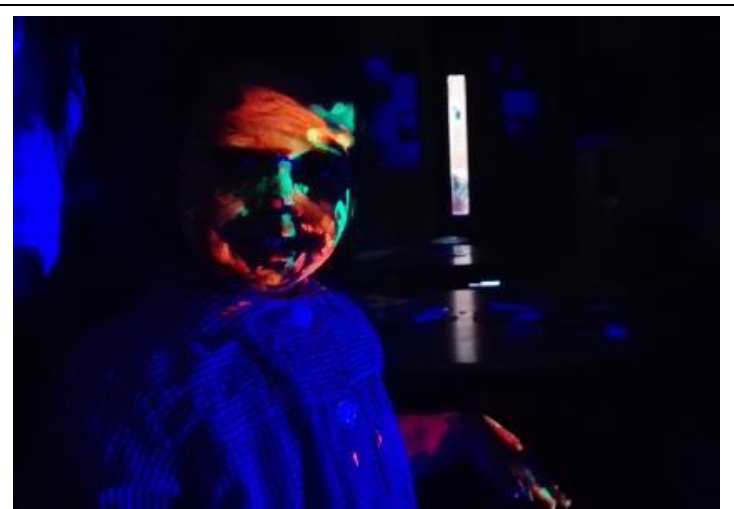

Figura 3.50: técnica de luz negra

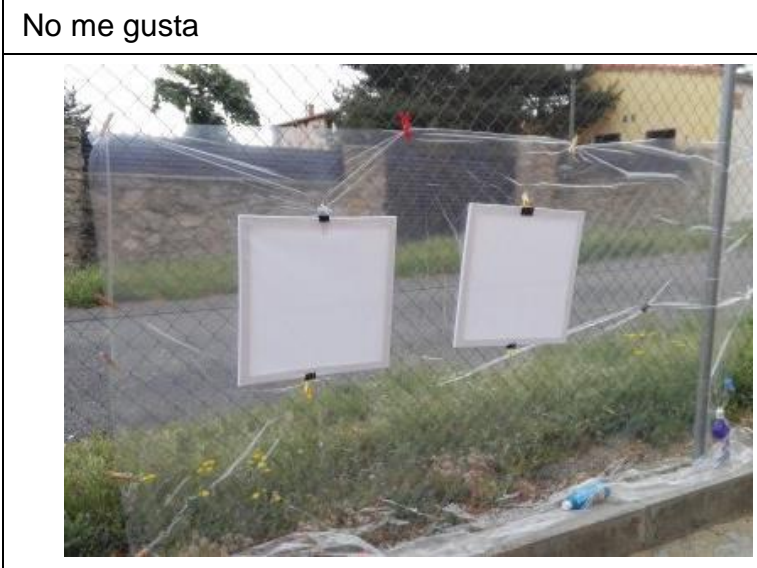

Figura 3.51: pintar con globos

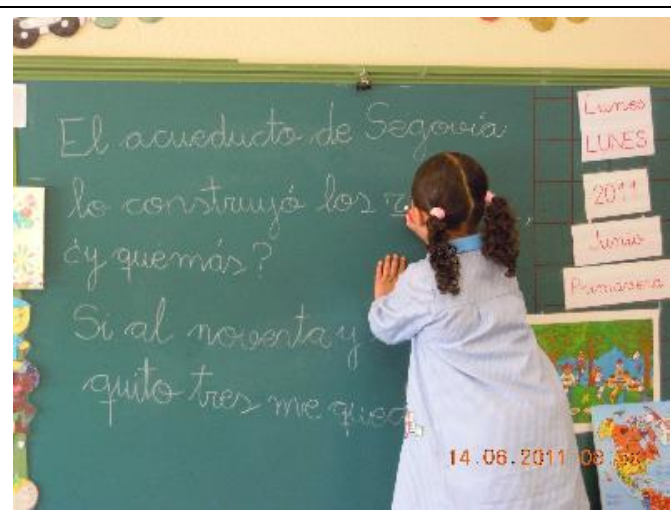

Figura 3.52: escritura en la pizarra

En la tabla 3.18 podemos ver en la consecuencia práctica que han tenido los deseos de los alumnos durante los últimos cursos.

Tabla 3.18. Deseos y consecuencia

\begin{tabular}{|c|c|}
\hline Deseo & Consecuencia \\
\hline $\begin{array}{l}\text { Alumna de } 1^{\circ} \text { de } \mathrm{El} \text {; explicación de su dibujo en la } \\
\text { asamblea: "me encanta sentarme en la pelota de } \\
\text { Pilates y quiero una pelota para mi sola" (ver figura } \\
3.45 \text { ) }\end{array}$ & $\begin{array}{l}\text { Reorganización del mobiliario: la información de este } \\
\text { deseo hizo que al finalizar el trimestre, todos los } \\
\text { alumnos contaran con pelotas de Pilates en vez de } \\
\text { sillas; inicialmente una única mesa contaba con } \\
\text { pelotas que iban rotando de forma semanal. }\end{array}$ \\
\hline $\begin{array}{l}\text { Alumna de } 1^{\circ} \text { de El; explicación de su dibujo en la } \\
\text { asamblea: "deseo pintarme y mancharme mucho la } \\
\text { cara y los brazos" (ver figura } 3.45 \text { ) }\end{array}$ & $\begin{array}{l}\text { Mayor número de actividades de expresión corporal: } \\
\text { aprendieron números, letras, conceptos espaciales, } \\
\text { canciones, adivinanzas, etc. a través de experiencias } \\
\text { con luz negra, cuentos motores y canciones motrices. }\end{array}$ \\
\hline $\begin{array}{l}\text { Alumno de } 2^{\circ} \text { de } \mathrm{El}: \text { "no me gusta esperar tanto para } \\
\text { usar la mesa de luz" (ver figura } 3.46 \text { ) }\end{array}$ & $\begin{array}{l}\text { Creación de un nuevo rincón: la mesa de luz dejó de } \\
\text { ser un recurso utilizado de forma puntual para } \\
\text { actividades muy concretas y se incorporó como un } \\
\text { rincón de juego más (véase figura 3.34). }\end{array}$ \\
\hline $\begin{array}{l}\text { Alumno de } 3^{\circ} \text { de } \mathrm{El} \text { : "no me gusta estar siempre en } \\
\text { clase, quiero hacer cosas fuera" (ver figura 3.46) }\end{array}$ & $\begin{array}{l}\text { Programar mayor número de actividades fuera del } \\
\text { aula: algunos ejemplos fueron descubrir colores } \\
\text { secundarios estallando globos de pintura en lienzos } \\
\text { colocados en el patio (ver figura 3.51); descubrir las }\end{array}$ \\
\hline
\end{tabular}




\begin{tabular}{|l|l|}
\hline & $\begin{array}{l}\text { figuras geométricas de las verjas del patio (ver figura } \\
3.36) \text {, aumentar el número de salidas al entorno, etc. }\end{array}$ \\
\hline $\begin{array}{l}\text { Alumna de } 3^{\circ} \text { de El: "no quiero hacer tantas fichas en } \\
\text { el cuaderno, prefiero en la pizarra" }\end{array}$ & $\begin{array}{l}\text { Incorporar retos diarios: a raíz de este deseo, se } \\
\text { comenzó con la iniciativa de realizar en el PET retos } \\
\text { matemáticos (ver figura 3.27) y retos de palabras (ver } \\
\text { figura 3.7 y 3.52). }\end{array}$ \\
\hline
\end{tabular}

En conclusión, este sistema de evaluación permite que: (1) los niños mejoren y evolucionen significativamente en su proceso de aprendizaje y además que desarrollen importantes actitudes: “...el trabajo autónomo, la capacidad de superación personal y su dedicación a la tarea son actitudes que se están dando en el aula desde que inicié la experiencia. Es increíble los logros conseguidos hasta el momento" (diario de aula 23/05/11); (2) el enorme potencial educativo que posee este tipo de experiencia se ve reforzado por la responsabilidad que adquieren los alumnos al aprender a elegir desde el inicio: "el ofrecerles dos vías de aprendizaje me está dando muy buenos resultados, por primera vez consigo que ellos decidan realmente lo que quieren hacer al ser conscientes de lo que su decisión conlleva" (diario de aula 11/04/11); (3) el ser escuchados y sentir valoradas sus propuesta hizo que poco a poco despertara en ellos un compromiso y dedicación hacia sus tareas, el gusto por superarse un poquito más cada día. Así lo mostraban no sólo en sus tareas individuales, sino incluso a la hora de jugar por rincones: "Claudia se ha puesto a practicar con las regletas en el rincón de las mates, afán de superación" (diario de aula 12/05/11); (4) aumento de la autonomía en la realización de las tareas de mesa: "gran autonomía por parte de todos a la hora de realizar la tarea individual; y (5) hoy Tomás será encargado, todos sus compañeros así lo han decidido por conseguir todos los días una cara sonriente" (diario de aula 11/04/11).

De forma personal, como docente, este sistema de evaluación formativa y compartida me ha permitido evolucionar a nivel profesional, ampliar y mejorar mi formación y entender la evaluación como un instrumento para generar conocimientos y aprendizaje.

\subsection{METODOLOGÍA DE INVESTIGACIÓN}

\subsubsection{DISEÑO DE ESTUDIO}

El estudio de casos (EC) es un método de investigación cualitativa de gran relevancia para el desarrollo de las ciencias sociales. Existen autores que en el campo educativo han sentado las bases teóricas y prácticas del método (Yin ,1989; Stake,2007; Stenhouse, 1998). Constituye un campo privilegiado para comprender en profundidad la realidad social y educativa. Walker (2002) expone que los EC se han usado como recurso para enseñar a los 
nuevos maestros como evolucionan los estudiantes cuando se aplica un sistema de enseñanza o una técnica de estudio específica.

Yin (1989) destaca la importancia de contextualizar el objeto de investigación, al entender que un EC consiste "en una descripción y análisis detallados de unidades sociales o entidades educativas únicas" (1989, p.65); para Stake "es el estudio de la particularidad y de la complejidad de un caso singular, para llegar a comprender su actividad es circunstancias concretas" (2007, p. 24). En esta misma línea, Álvarez y San Fabián defienden que mediante este método, se recogen de forma descriptiva distintos tipos de informaciones cualitativas, que no aparecen reflejadas en números sino en palabras, "lo esencial en esta metodología es poner de relieve incidentes clave, en términos descriptivos, mediante el uso de entrevistas, notas de campo, observaciones, grabaciones de vídeo, documentos" (Álvarez y San Fabián, 2000, p.3). Por último, Simons llama la atención sobre la tradición de la investigación de la ciencia social, definiendo el EC como "estrategia de intervención exhaustiva, que incorpora sistemas específicos de recogida y análisis de datos para investigar los fenómenos en contextos auténticos" (Simons, 2011, p.41).

Basándonos en las aportaciones hechas por Álvarez y San Fabián (2000), encontramos una serie de características comunes que definen el EC: (1) realizan una definición contextualizada del objeto de estudio, (2) son estudios donde el investigador ha de observar la realidad con una visión objetiva, (3) reflejan la particularidad de cada situación, (4) se centran en las relaciones y las interacciones, (5) el investigador permanece en el campo de estudio de forma prolongada, (6) se dan procesos de negociación entre el investigador y los participantes, (7) este tipo de método implica múltiple fuente de datos y el análisis de los mismos de forma global e interrelacionada, (8) los resultados surgen principalmente del trabajo de campo, lo que implica una descripción minuciosa del proceso investigador seguido.

Por otra parte, Pérez (1994) expone que el estudio de casos plantea las siguientes potencialidades educativas: (1) adquisición de experiencia en el diagnóstico de problemas concretos, (2) una comprensión más completa y realista de la realidad, (3) desarrollo de la capacidad de análisis y de síntesis, (4) integración e interrelación de conocimientos y vivencias y (5) motivación.

Para habar de tipos de EC, encontraremos diferentes clasificaciones en base al autor que tomemos de referencia. Atendiendo a la finalidad del estudio de la investigación, tanto Stake (2007) como Álvarez y San Fabián (2000) hablan de tres modalidades: (1) estudio intrínseco de caso: es cuando el objeto de estudio nos viene dado, tiene valor en sí mismo y nos permite aprender sobre ese caso en particular; la finalidad de este EC es comprender otra 


\section{CAPITULO 3: METODOLOGÍA}

cosa; en este supuesto no se elige al caso porque sea representativo de otros casos, o porque ilustre un determinado problema o rasgo, sino porque el caso en sí es de interés, son "casos con especificidades propias, que tienen un valor en sí mismos y pretenden alcanzar una mejor comprensión del caso concreto a estudiar" (Álvarez y San Fabián, 2000, p.6-7); (2) EC instrumental: el objetivo que se busca es someter a prueba una teoría concreta, como por ejemplo EC colectivo a través del cual se estudian varios casos para fundamentar la generalidad de una teoría o estudio; en este tipo de EC la finalidad es "examinar el EC para profundizar en un tema o afinar una teoría, de tal modo que el caso juega un papel secundario, de apoyo, para llegar a la formulación de afirmaciones sobre el objeto de estudio"; y (3) EC colectivo: nos referimos a este tipo de EC cuando el interés se centra en la indagación de un fenómeno o población en lugar de un caso concreto; es decir, el objeto a estudiar se centra en el estudio intensivo de varios casos, por ello se realiza cuando el interés de la investigación "se centra en un fenómeno, población o condición general seleccionando para ello varios casos que se han de estudiar intensivamente"..

A estos tres tipos se pueden añadir los que señala Stenhouse (1985), Guba y Lincon (1985), Perez-Serrano (2014) y Simons (2011): (1) EC etnográfico: este tipo de estudio de caso "utiliza métodos cualitativos y se ocupa de interpreta el caso en relación una teoría o unas teorías de la cultura" (Simons, 2011, p.44), involucra el estudio profundo de una entidad singular. Se utilizan como técnicas principales la observación participante y la entrevista; por tanto es necesario llevar a cabo registros, obteniendo resultados concretos; (2) EC investigación acción: el foco está en generar un cambio permitiendo transformar intencionalmente la realidad; los profesores son incentivados a cuestionar sus propias ideas y teorías educativas, sus propias prácticas y sus propios contextos como objetos de análisis y crítica; (3) EC evaluativo: implica la evaluación de programas o proyecto que forman el caso; por tanto existe una descripción y explicación para llegar a emitir juicios sobre la realidad del objeto de estudio que constituyan la base para tomar decisiones; y (4) EC educativo: está diseñado para mejorar la comprensión de la acción educativa. Su propósito es enriquecer el pensamiento y el discurso de los educadores mediante la documentación sistemática y reflexiva de la experiencia; por ello las acciones del investigador se traducen en evidencias.

Centrándonos en nuestra investigación, nos encontramos ante un PET cuyo objetivo es determinar el grado de eficacia del método y establecer el nivel de mejora real de los alumnos participantes en la experiencia. Debemos realizar una descripción del PET, una explicación de lo observado para emitir un juicio y evaluar el programa para observar los progresos reales de los alumnos en relación aldesarrollo de la capacidad lectora, escritora y matemática. En nuestro caso se trata de un EC evaluativo puesto que se observa para 
evaluar, se evalúa para decidir y se decide para actuar. La acción será sometida a evaluación, para una nueva toma de decisiones de mejora.

\subsubsection{TÉCNICAS E INSTRUMENTOS DE OBTENCIÓN DE DATOS}

\subsubsection{Observación participante}

Existe una considerable variedad de técnicas e instrumentos que pueden utilizar en un EC; la observación participante (OP) es una de las técnicas más utilizadas en metodologías de investigación cuantitativa para recoger datos (Martínez, 2007); esta técnica permite incrementar la validez de la investigación mediante observaciones que puedan ayudar al investigador a tener una mejor comprensión del contexto y el fenómeno en estudio (Kawulich, 2005). La OP se entiende como "forma condensada, capaz de lograr la objetividad por medio de una observación próxima, y de captar a la vez los significados que dan los sujetos de estudio a su comportamiento. (...) Proporciona descripciones, es decir, discurso propio del investigado" (Álvarez, 2008, p.7). El investigador, al cuestionarse la realidad que está observando en su aula necesita un registro escrito sobre la situación en la que se encuentra inmerso; autores como Kawulich (2005) y Munck y Sobo (1998), revelan varias ventajas al usar la OP frente a otros métodos de recolección de datos en los EC evaluativos: (1) permite recoger distintos tipos de datos tanto cualitativos como cuantitativos a través de diferentes instrumentos, (2) reduce la incidencia reactiva de las personas observadas; (3) ayuda al investigador a plantearse preguntas que son relevantes para la investigación; (4) otorga al investigador una mejor comprensión de lo que está ocurriendo, y otorga credibilidad a las interpretaciones; (5) a veces es la única forma de recoger los datos correctos para lo que uno está estudiando; (6) permite una descripción ricamente detallada, permitiendo describir comportamientos, intenciones, situaciones... además de facilitar oportunidades para ver o participar en eventos no programados; y (7) mejora la calidad de la recolección e interpretación de datos, generando nuevas hipótesis de investigación.

Como vemos, la OB debe ser usada como para dar validez y credibilidad, permitiendo recolectar datos que ayuden al investigador a tener una mejor comprensión del objeto de estudio. No obstante, la validez es mayor con el uso de estrategias adicionales usadas con la OP: (1) grabaciones de video, (2) fotografías, (3) diarios de maestra y (4) boletines informativos. 


\section{CAPITULO 3: METODOLOGÍA}

\subsubsection{Grabaciones de videos}

La grabación de videos es una herramienta que permite al investigador realizar observaciones sistemáticas del comportamiento que tiene lugar en el aula para capar aspectos y manifestaciones concretas de lo que queremos estudiar (López-Arenas y Cabrero, 1990); García y Benítez (2004, p.4) apuntan que este instrumento es una "eficaz herramienta para realizar investigaciones en el aula, facilita la presentación de un mismo tema desde diferentes enfoques metodológicos expositivo, sistémico, aprendizaje por descubrimiento...".

La introducción del video en el aula de forma ocasional, puede producir modificaciones sustanciales en el escenario donde se desarrolla el estudio; convirtiéndose en elemento de distracción. No obstante, si se hace un uso generalizado y continuada en el tiempo, se convierte en una herramienta más para recopilar datos (Bravo, 2000). La grabación tiene una serie de ventajas: (1) asegura la precisión contribuyendo a la veracidad de la toma de datos; (2) nos evita tener que anotarlo todo; y (3) permite comprobar lo que vemos o recordamos, pudiendo comprobar los datos obtenidos en la grabación con los sacados de las notas tomadas en los diarios (Simons, 2011a)

Con objeto de medir la incidencia del PET en los alumnos durante los 3 años académicos en los que duró la investigación, se realizaron de forma periódica diferentes grabaciones a lo largo del curso: (1) al inicio de cada curso académico, para tener una referencia de los conocimientos iniciales poseídos por cada alumno; (2) al finalizar cada uno de los trimestres y (3) en momentos puntuales para dejar evidencias de aspectos relevantes que fueran surgiendo en algún momento del curso (véase anexo 2).De este modo se obtuvieron datos de la evolución de cada alumno por cada curso escolar adecuados para obtener material visual del aula, para establecer diagnósticos permitiendo observar con detalle episodios de la enseñanza.

\subsubsection{Fotografías}

Esta herramienta permite documentar trabajos conjuntamente con la información actual, ilustrando las situaciones y dando vida a la información verbal (Aragón, 2010). La fotografía permite recordar momentos importantes a lo largo de la investigación y servir de ilustración de aspectos que no se describen con facilidad (Kawulich, 2005). Durante toda la investigación se tomaron fotografías de hechos relevantes que pueden aportar datos interesantes. 


\subsubsection{Diario de la maestra}

El diario de la maestra es otra de las herramienta de investigación que permite registrar experiencias educativas con la intención de ser analizadas y compartidas (Smyth, 1991). Para Zabalza (2004) los diarios de clase "son los documentos en los que profesores y profesoras recogen sus impresiones sobre lo que está sucediendo en sus clases" (p. 15). Esta herramienta nos permite recoger datos sobre los acontecimientos que se producen diariamente en el aula, posibilitando una posterior reflexión de lo acontecido. Es una herramienta muy útil para promover la práctica reflexiva, ya que se caracteriza por: (1) tener una continuidad en el tiempo; (2) recoge aspectos destacables en opinión del investigador; y (3) permite organizar la práctica docente, describir las tareas de enseñanza y aprendizaje y destacando hechos relevantes propios del alumno o el profesor (Zabalza, 2004).

Es una técnica de recogida de datos sencilla y útil, ya que permite registrar datos precisos, no es necesario anotar todo lo que sucede diariamente, pero sí lo más relevante que se ampliará posteriormente sin dejar transcurrir mucho tiempo; siendo un aval para la validez de la investigación (Martínez, 2000). Por ello dedicaba unos minutos al terminar las clases a registrar aquellos acontecimientos sucedidos a lo largo del día y hacer una pequeña reflexión de los acontecimientos más relevantes ocurridos. Este instrumento de recogida de datos me permitió mirar con perspectiva el propio modo de actuar en la clase con el alumnado, la evolución del PET, aquellos bits de imágenes que suscitaron más interés en el alumnado o, por el contrario, resultaron poco atractivos o demasiado complejos, impresiones personales acerca del progreso de los alumnos, frustraciones, preocupaciones, dificultades encontradas a la hora de aplicar el PET, avances, resultados, etc. En definitiva, pude ir registrando datos relevantes durante cada curso escolar que duró la investigación realizar un seguimiento minucioso de los avances conseguidos y como apoyo para la reflexión diaria.

\subsubsection{Boletines informativos}

Para finalizar, se ha utilizado como herramienta de investigación los boletines informativos $(\mathrm{Bl})$; en el $\mathrm{Bl}$ se registran los objetivos didácticos alcanzados por un alumno en cada uno de los tres trimestres de un curso escolar concreto. Los ítems utilizados son $\mathrm{P}$ (en progreso) cuando el objetivo aún no ha sido alcanzado y $\mathrm{C}$ (conseguido) cuando un objetivo dado ha sido alcanzado con éxito. Como vemos en las tablas (ver tablas de la 3.19 a la 3.22), se muestra la evolución de cada niño en relación a las áreas del currículo: conocimiento de sí mismo y autonomía personal, conocimiento del entorno y lenguajes: comunicación y 
representación; obteniendo una valiosa fuente de información que será analizada posteriormente en relación a los objetivos propuestos para el PET.

Tabla 3.19. Boletín informativo del primer cuso de El (3 años)

\section{COONOCIMIENTO DE SI MISMO Y AUTTONOMIIA} PERSONAI

Muestra autonomía en las tareas cotidiana:

$>$ Respeta los tiempos de trabajo descanso juego

$>$ Controla sus emociones

$>$ Conoce y nombra las partes del cuerpo

Desarrolla la coordinación óculo-manual

$>$ Realiza los trabajos con orden y limpieza

$>$ Acaba sus tareas

$>$ Adquiere hábitos

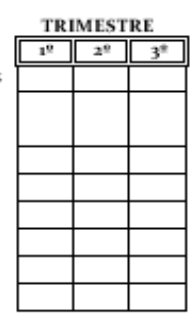

INGLES

$>$ Saluda y se despide en inglés

$>$ Comprende y responde a instrucciones básicas

$>$ Conoce el vocabulario trabajado en clase

$>$ Disfruta escuchando los cuentos, chants y canciones

Escucha y participa en clase

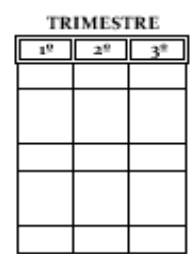

\section{LENGULA]ES COMUNICACIÓN Y Y} REPRESENTACIÓN

Comprende los mensajes que le comunican otras personas

$>$ Expresa emociones, sentimientos y necesidades

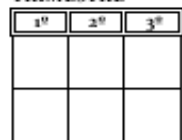

Pronuncia con claridad palabras de su vocabulario básico

$>$ Lee e interpreta imágenes

Memoriza y reproduce canciones, cuentos, poesias,

Disfruta con la representación plástica

Explora las propiedades sonoras del cuerpo y de los objetos

Coordina movimientos corporales básicos

Participa activamente en las

dramatizaciones

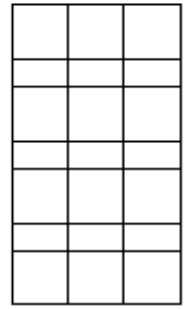

\section{CONOKCIMIENTO DEL ENTORNO}

Muestra interés y curiosidad por lo que le rodea

$>$ Participa en las actividades propuestas

Se relaciona con sus compañeros

> Se orienta en los espacios cotidianos

Utiliza adecuadamente los objetos de la escuela

Comparte y cuida el material

$>$ Respeta las normas

Resuelve los conflictos sin agresividad

Conoce los conceptos básicos trabajados

Reconoce las formas básicas

Reconoce los números 1,2,3,y asocia su cantidad

Clasifica por colores, tamaños y formas

Conoce los colores trabajados

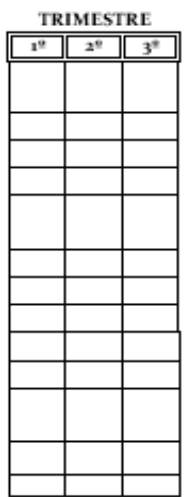


Tabla 3.20. Boletín informativo del segundo curso de El (4 años)

\section{CONOCIMMENTO DE SI MUSMO $Y$} AUTIONOMUA PIERSONAL

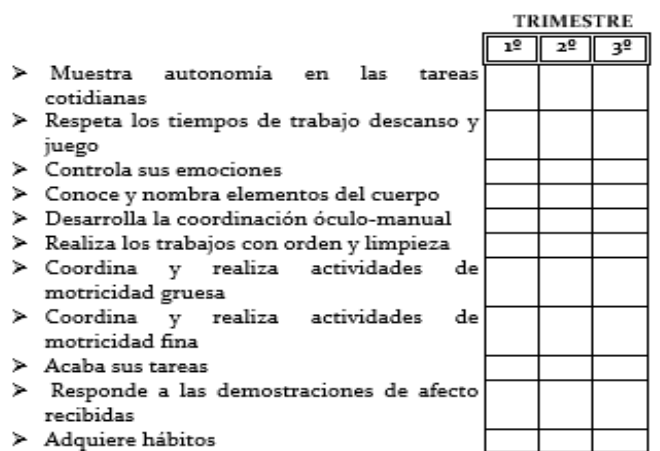

\section{CONOCIMIENTO DEIL ENTYORNO}

Muestra interés y curiosidad por lo que le

$>$ Participa en las actividades propuestas

> Se relaciona con sus compañeros

Se orienta en los espacios cotidianos

Utiliza adecuadamente los objetos de la

escuela

Comparte y cuida el material

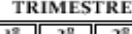

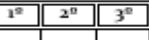

$>$ Respeta las normas

Resuelve los conflictos sin agresividad

$>$ Reconoce las formas básicas

Clasifica por colores, tamaños y formas

Conoce y escribe los números del 1 al 6

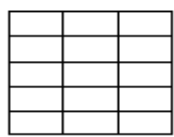

LENGUA IES: COMUNICACION Y REFPRIESENTIACIÓN

Comprende los mensajes que le comunican \begin{tabular}{|lll}
$1^{a}$ & $2^{a}$ & $3^{a}$ \\
\hline
\end{tabular} otras personas

Expresa emociones, sentimientos y necesidades

Pronunia con claridad palabras de vocabulario básico

Participa en conversaciones de grupo

Participa en conversaciones de grupo

Lee e interpreta imágenes y códigos

Realiza grafias con la direccionalidad correcta

Identifica las vocales

Memoriza y reproduce canciones, cuentos, poesias,

$>$ Conoce los colores

$>$ Disfruta con la representación plástica

$>$ Explora las propiedades sonoras del cuerpo, los objetos y algunos instrumentos

Escucha cuentos con interés

$>$ Participa activamente en las dramatizaciones

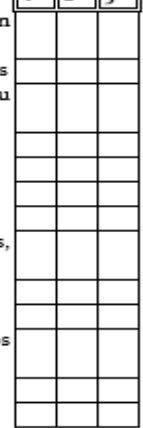

Tabla 3.21. Boletín informativo del tercer curso de El (5 años)

\section{CONOCIMIENTO DE SI MISMO Y} AUTTONOMIA PERSONAI

$>$ Muestra autonomía en las tareas cotidianas

$>$ Respeta los tiempos de trabajo descanso y juego

$>$ Controla sus emociones

$>$ Conoce y nombra elementos del cuerpo

$>$ Desarrolla la coordinación óculo-manual

$>$ Realiza los trabajos con orden y limpieza

$>$ Coordina y realiza actividades motricidad gruesa

$>$ Coordina y realiza actividades motricidad fina

$>$ Acaba las tareas propuestas

$>$ Responde a las demostraciones de afecto recibidas

$>$ Adquiere hábitos

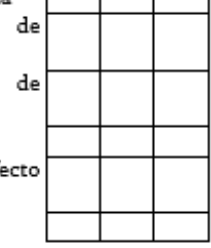

\section{CONOCIMUENTO DEL ENTORNO}

$>$ Muestra interés y curiosidad por lo que rodea

$>$ Se relaciona con sus compañeros

$>$ Tiene autonomía en los recorridos habituales

$>$ Participa con agrado en las actividades propuestas

$>$ Utiliza adecuadamente los objetos de escuela

$>$ Comparte y cuida el material

$>$ Respeta las normas

$>$ Resuelve los conflictos sin agresividad

$>$ Comprende los conceptos básicos
$>$ Clasifica por colores, tamaños $\mathrm{y}$ formas

Conoce y escribe los números del 1 al

$>$ Asocia número y cantidad

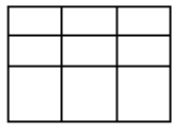

\section{LENGUAIES ${ }_{n}$ COMUNICACIÓN $\mathbf{Y}$}

\section{REPRESENTACIÓN}

TRIMESTRE

$>$ Escucha con interés

$>$ Comprende los mensajes que le comunican otras personas

$>$ Expresa emociones, sentimientos y necesidades

$>$ Pronuncia con claridad palabras de vocabulario básico

$>$ Participa en conversaciones de grupo

$>$ Lee e interpreta imágenes y códigos

Realiza grafias con la direccionalidad correcta

$>$ Discrimina sonidos $y$ fonemas

$>$ Reconoce las letras trabajadas

Lee y comprende palabras

> Memoriza y reproduce canciones, cuentos, poesías,...

$>$ Se expresa mediante la representación plástica

> Participa en actividades de expresión corporal,

ritmo,

> Participa en dramatizaciones

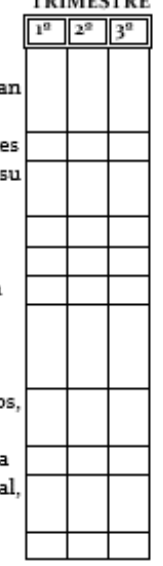




\section{CAPITULO 3: METODOLOGÍA}

Cada centro determina los ítems que los alumnos deben superar para alcanzar los objetivos propuestos por curso escolar. En nuestro caso, el ciclo de El del centro donde se realizó la investigación tenía estipulado una serie de ítems por cada uno de los tres cursos escolares que conforman el $2^{\circ}$ ciclo de $\mathrm{El}$ y en cada una de las tres áreas de experiencia. A lo largo de la tabla 3.22 puede verse que ítems debe lograrse en cada curso escolar en relación al área I (conocimiento de sí mismo y autonomía personal), área II (conocimiento del entorno) y área III (lenguajes: comunicación y representación). 
CAPITULO 3: METODOLOGÍA

Tabla 3.22. Ítems boletines informativos por curso escolar y área de desarrollo

\begin{tabular}{|c|c|c|c|}
\hline & $1^{\circ}$ curso & $2^{\circ}$ curso & $3^{\circ}$ curso \\
\hline 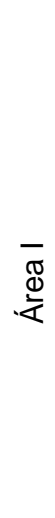 & $\begin{array}{l}\text { - Muestra autonomía en las tareas cotidianas } \\
\text { - Respeta tiempos de trabajo, descanso y juego } \\
\text { - Controla sus emociones } \\
\text { - Conoce y nombra las partes del cuerpo } \\
\text { - Desarrolla la coordinación óculo manual } \\
\text { - Realiza los trabajos con orden y limpieza } \\
\text { - Acaba sus tareas } \\
\text { - Adquiere hábitos }\end{array}$ & $\begin{array}{l}\text { - Muestra autonomía en las tareas cotidianas } \\
\text { - Respeta tiempos de trabajo, descanso y juego } \\
\text { - Controla sus emociones } \\
\text { - Conoce y nombra elementos del cuerpo } \\
\text { - Desarrolla la coordinación óculo manual } \\
\text { - Realiza los trabajos con orden y limpieza } \\
\text { - Coordina y realiza actividades motricidad gruesa } \\
\text { - Coordina y realiza actividades de motricidad fina } \\
\text { - Acaba sus tareas } \\
\text { - Responde a las demostraciones de afecto } \\
\text { - Adquiere hábitos }\end{array}$ & $\begin{array}{l}\text { - Muestra autonomía en las tareas cotidianas } \\
\text { - Respeta tiempos de trabajo, descanso y juego } \\
\text { - Controla sus emociones } \\
\text { - Conoce y nombra elementos del cuerpo } \\
\text { - Desarrolla la coordinación óculo manual } \\
\text { - Realiza los trabajos con orden y limpieza } \\
\text { - Coordina y realiza actividades motricidad gruesa } \\
\text { - Coordina y realiza actividades de motricidad fina } \\
\text { - Acaba las tareas propuestas } \\
\text { - Responde a las demostraciones de afecto } \\
\text { - Adquiere hábitos }\end{array}$ \\
\hline 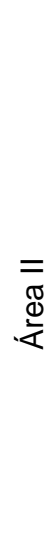 & $\begin{array}{l}\text { - Muestra interés y curiosidad por lo que le rodea } \\
\text { - Participa en las actividades propuestas } \\
\text { - Se relaciona con sus compañeros } \\
\text { - Se orienta en los espacios cotidianos } \\
\text { - Utiliza adecuadamente los objetos de la escuela } \\
\text { - Comparte y cuida el material } \\
\text { - Respeta las normas } \\
\text { - Resuelve los conflictos sin agresividad } \\
\text { - Conoce los conceptos básicos trabajados } \\
\text { - Reconoce números } 1,2,3 \text { y asocia a su cantidad } \\
\text { - Clasifica por colores, tamaños y formas } \\
\text { - Conoce los colores trabajados }\end{array}$ & $\begin{array}{l}\text { - Participa en las actividades propuestas } \\
\text { - Se relaciona con sus compañeros } \\
\text { - Se orienta en los espacios cotidianos } \\
\text { - Utiliza adecuadamente los objetos de la escuela } \\
\text { - Comparte y cuida el material } \\
\text { - Respeta las normas } \\
\text { - Resuelve los conflictos sin agresividad } \\
\text { - Reconoce las formas básicas } \\
\text { - Clasifica por colores, tamaños y formas } \\
\text { - Conoce y escribe los números del } 1 \text { al } 6\end{array}$ & $\begin{array}{l}\text { - Muestra interés y curiosidad por lo que le rodea } \\
\text { - Se relaciona con sus compañeros } \\
\text { - Tiene autonomía en los recorridos habituales } \\
\text { - Participa con agrado en las actividades } \\
\text { - Utiliza adecuadamente los objetos de la escuela } \\
\text { - Comparte y cuida el material } \\
\text { - Respeta las normas } \\
\text { - Resuelve los conflictos sin agresividad } \\
\text { - Comprende los conceptos básicos } \\
\text { - Clasifica por colores, tamaños y formas } \\
\text { - Conoce y escribe los números del } 1 \text { al } 9 \\
\text { - Asocia número y cantidad }\end{array}$ \\
\hline
\end{tabular}




\section{CAPITULO 3: METODOLOGÍA}

\begin{tabular}{|c|c|c|c|}
\hline $\begin{array}{l}\equiv \\
\equiv \\
\text { 这 }\end{array}$ & $\begin{array}{l}\text { - Comprende los mensajes que le comunican otras } \\
\text { personas } \\
\text { - Expresa emociones, sentimientos y necesidades } \\
\text { - Pronuncia con claridad palabras de su vocabulario } \\
\text { básico } \\
\text { - Lee e interpreta imágenes } \\
\text { - Memoriza y reproduce canciones, cuentos, } \\
\text { poesías... } \\
\text { - Disfruta con las representaciones plásticas } \\
\text { - Explora las propiedades sonoras del cuerpo y de los } \\
\text { objetos } \\
\text { - Coordina movimientos corporales básicos } \\
\text { - Participa activamente en las dramatizaciones }\end{array}$ & $\begin{array}{l}\text { - Comprende los mensajes que le comunican otras } \\
\text { personas } \\
\text { - Expresa emociones, sentimientos y -necesidades } \\
\text { - Pronuncia con claridad palabras de su vocabulario } \\
\text { - Lee e interpreta imágenes y códigos } \\
\text { - Realiza grafías en la direccionalidad correcta } \\
\text { - Identifica las vocales } \\
\text { - Memoriza y reproduce canciones, cuentos, } \\
\text { poesías... } \\
\text { - Conoce los colores } \\
\text { - Disfruta con las representaciones plásticas } \\
\text { - Explora las propiedades sonoras del cuerpo y de } \\
\text { los objetos } \\
\text { - Escucha cuentos con interés } \\
\text { - Participa activamente en las dramatizaciones }\end{array}$ & $\begin{array}{l}\text { - Escucha con interés } \\
\text { - Comprende los mensajes que le comunican } \\
\text { - Expresa emociones, sentimientos y necesidades } \\
\text { - Pronuncia con claridad palabras de su vocabulario } \\
\text { básico } \\
\text { - Participa en conversaciones en grupo } \\
\text { - Lee e interpreta imágenes y códigos } \\
\text { - Realiza grafías en la direccionalidad correcta } \\
\text { - Discrimina sonidos y fonemas } \\
\text { - Reconoce las letras trabajadas } \\
\text { - Lee y comprende palabras } \\
\text { - Memoriza y reproduce canciones, cuentos, poesías... } \\
\text { - Se expresa mediante la representación plástica } \\
\text { - Participa en actividades de expresión corporal, ritmo... } \\
\text { - Participa activamente en las dramatizaciones }\end{array}$ \\
\hline
\end{tabular}




\subsubsection{ANÁLISIS DE DATOS}

A continuación, explicamos los dos modelos de fichas utilizados para analizar los datos recogidos a lo largo de la investigación: ficha de seguimiento individual y ficha de seguimiento grupal.

\subsubsection{Ficha de seguimiento individual}

La ficha de seguimiento individual (FSI) está diseñada para recoger el seguimiento de un único alumno a lo largo de todo el curso escolar. En total se han elaborado 6 FSI, 3 correspondientes al ámbito lecto-escritor y otras 3 dirigidas a las habilidades lógico-matemáticas de cada uno de los tres cursos escolares del segundo ciclo de El (tablas de la 3.26 a la 3.31). Para su elaboración se han tenido en cuenta varios aspectos: (a) indicadores de logro; (b), una temporalización; (c) escala numérica utilizada y (d) observaciones, que explicaremos a continuación.

a) Indicadores de logro: diferenciando entre tres tipos: (1) Decreto 122/2007, por el que se establece el currículo en el segundo ciclo de El en la comunidad de Castilla y León (D 122); (2) boletín informativo correspondiente a cada uno de los cursos y ámbitos (BI); y (3) iniciales del Programa de Estimulación Temprana (PET).

b) Temporalización: diferenciando 4 periodos, al inicio del curso escolar (I) y al final de cada uno de los tres trimestres $(1,2,3)$.

c) Escala numérica: existen unos códigos de valoración de forma que en las columnas con espacios en blanco se pone directamente el código numérico del 0 al 4 ; donde 0 : totalmente en desacuerdo, 1: en desacuerdo, 2: ni de acuerdo ni en desacuerdo, 3 : de acuerdo y 4 : totalmente de acuerdo

d) Observaciones: esta columna extra permite al docente añadir comentarios específicos si en algún momento lo considera necesario.

Para determinar los indicadores de logro propuestos en las diferentes tablas se ha realizado una revisión de la legislación correspondiente al segundo ciclo de El. Tanto LOE (ley orgánica de educación 2/2006, de 3 de mayo), como el Real Decreto 1630/2006, por el que se establecen las enseñanzas mínimas en el 2 c ciclo de El a nivel nacional (BOE, 4 de enero, 2006) y el Decreto 122/2007 (BOE, 2 de enero, 2007), establecer 7 capacidades que los alumnos han de alcanzar al finalizar la etapa de EI Se denominan objetivos generales de etapa (OGE) y son el referente general (ver tabla 3.23) de los cuales partiremos para analizar los objetivos didácticos de las áreas del currículo y los contenidos que están directamente relacionados con lecto escritura y lógicomatemáticas (áreas II y III del currículo). 


\section{CAPITULO 3: METODOLOGÍA}

Tabla 3.23. Objetivos generales de etapa a conseguir en el segundo ciclo de El.

\begin{tabular}{|c|c|c|}
\hline Currículum oficial & Artículo & Objetivos generales de etapa \\
\hline $\begin{array}{l}\text { Ley Orgánica 2/2006 de } 3 \text { de mayo, de } \\
\text { educación }\end{array}$ & 13 & $\begin{array}{l}\text { La El contribuirá a desarrollar en las niñas y niños las } \\
\text { capacidades que les permitan: } \\
\text { a-Conocer su propio cuerpo y el de los otros, sus posibilidades } \\
\text { de acción y aprender a respetar las diferencias. }\end{array}$ \\
\hline \multirow[t]{2}{*}{$\begin{array}{l}\text { Real Decreto } 1630 \text { de } 29 \text { de diciembre, } \\
\text { por el que se establece las enseñanzas } \\
\text { mínimas en el segundo ciclo de El }\end{array}$} & \multirow[t]{2}{*}{3} & $\begin{array}{l}\text { de acción y aprender a respetar las diferencias. } \\
\text { b-Construir una imagen positiva y ajustada de sí mismo y } \\
\text { desarrollar sus capacidades afectivas. }\end{array}$ \\
\hline & & $\begin{array}{l}\text { c-Adquirir progresivamente autonomía en sus actividades } \\
\text { habituales. }\end{array}$ \\
\hline \multirow[t]{4}{*}{$\begin{array}{l}\text { Decreto } 122 / 2007 \text { de } 27 \text { de diciembre, } \\
\text { por el que se establece el currículo del } \\
\text { segundo ciclo de la El en la comunidad } \\
\text { de Castilla y León }\end{array}$} & \multirow[t]{4}{*}{4} & $\begin{array}{l}\text { d-Relacionarse con los demás y adquirir progresivamente pautas } \\
\text { elementales de convivencia y relación social, con especial } \\
\text { atención a la igualdad entre niñas y niños, así como ejercitarse } \\
\text { en la resolución pacífica de conflictos. }\end{array}$ \\
\hline & & $\begin{array}{l}\text { e-Relacionarse con los demás y adquirir progresivamente pautas } \\
\text { elementales de convivencia y relación social, con especial } \\
\text { atención a la igualdad entre niñas y niños, así como ejercitarse } \\
\text { en la resolución pacífica de conflictos }\end{array}$ \\
\hline & & $\begin{array}{l}\text { f-Desarrollar habilidades comunicativas en diferentes lenguajes y } \\
\text { formas de expresión. }\end{array}$ \\
\hline & & $\begin{array}{l}\text { g-Iniciarse en las habilidades lógico-matemáticas, en la lecto- } \\
\text { escritura y en el movimiento, el gesto y el ritmo. }\end{array}$ \\
\hline
\end{tabular}

De los siete OGE recogidos por las diferentes leyes, observamos que únicamente los dos últimos ( $\mathrm{f}$ y $\mathrm{g}$ ) están relacionados directamente con la lecto-escritura y la lógico-matemáticas. Teniendo claro los dos objetivos generales de partida, debemos concretar aún más y hacer un análisis más específico de los objetivos de área y bloques de contenidos claramente relacionado con el ámbito lecto-escritor y la competencia matemática en Castilla y León, y así determinar los indicadores de logro que formarán parte en las columnas de las fichas de seguimiento individual y fichas de seguimiento grupal (ver tabla 3.24). 
Tabla 3.24. Objetivos y bloques de contenidos relacionados con el ámbito lecto escritor y habilidades lógico matemáticas.

\begin{tabular}{|c|c|c|}
\hline Áreas & Objetivos & Bloques de contenidos \\
\hline $\begin{array}{l}\text { Área II: } \\
\text { Conocimie } \\
\text { nto del } \\
\text { entorno }\end{array}$ & $\begin{array}{l}\text {-Iniciarse en el concepto de } \\
\text { cantidad, en la expresión } \\
\text { numérica y en las operaciones } \\
\text { aritméticas, a través de la } \\
\text { manipulación y la } \\
\text { experimentación. }\end{array}$ & $\begin{array}{l}\text {-Aproximación a la serie numérica mediante la adición de la unidad y } \\
\text { expresión de forma oral y gráfica de la misma. } \\
\text {-Utilización de la serie numérica para contar elementos de la } \\
\text { realidad y expresión gráfica de cantidades pequeñas. } \\
\text {-Composición y descomposición de números mediante la utilización } \\
\text { de diversos materiales y expresión verbal y gráfica de los resultados } \\
\text { obtenidos. } \\
\text {-Realización de operaciones aritméticas, a través de la manipulación } \\
\text { de objetos, que impliquen juntar, quitar, repartir, completar... } \\
\text {-Identificación de situaciones de la vida cotidiana que requieren el } \\
\text { uso de los primeros números ordinales. } \\
\text {-Identificación de algunos instrumentos de medida. Aproximación a } \\
\text { su uso. } \\
\text {-Estimación intuitiva y medida del tiempo. Ubicación temporal de } \\
\text { actividades de la vida cotidiana. } \\
\text {-Reconocimiento de algunas monedas e iniciación a su uso. }\end{array}$ \\
\hline Áreas & Objetivos & Bloques de contenidos \\
\hline $\begin{array}{l}\text { Área III: } \\
\text { Lenguajes: } \\
\text { Comunicac } \\
\text { ión y } \\
\text { representa } \\
\text { ción }\end{array}$ & $\begin{array}{l}\text {-Iniciarse en la lectura } \\
\text { comprensiva de palabras y } \\
\text { textos sencillos y motivadores, } \\
\text { utilizando una entonación y } \\
\text { ritmo adecuados. } \\
\text {-Descubrir la funcionalidad del } \\
\text { texto escrito. } \\
\text {-Identificar las palabras dentro } \\
\text { de la frase y discriminar auditiva } \\
\text { y visualmente los fonemas de } \\
\text { una palabra, en mayúscula y en } \\
\text { minúscula. } \\
\text {-Iniciarse en la escritura de } \\
\text { palabras o frases significativas } \\
\text { aplicando una correcta dirección } \\
\text { en el trazo y posición adecuada } \\
\text { al escribir. }\end{array}$ & $\begin{array}{l}\text {-Uso gradualmente autónomo de diferentes soportes para el } \\
\text { aprendizaje de la escritura comprensiva (juegos manipulativos, } \\
\text { mensajes visuales, fotos, carteles, ilustraciones acompañadas de un } \\
\text { texto escrito que los identifique, rótulos, etiquetas, láminas, libros, } \\
\text { periódicos, revistas, etc.). } \\
\text {-Utilización de juegos de abecedarios y palabras para componer } \\
\text { vocabulario y frases sencillas usuales y significativas. }\end{array}$ \\
\hline
\end{tabular}

En la tabla 3.25 detallamos los ítems extraídos de los boletines informativos del centro para los tres cursos $\left(1^{\circ}, 2^{\circ}\right.$ y $3^{\circ}$ del segundo ciclo de El). Los boletines fueron acordados por el grupo de maestras y utilizados durante los años escolares de 2010/11 al 2012/13, en que se llevó a cabo la investigación. 
Tabla 3.25. Ítems de los boletines informativos de los tres cursos del 2 ํㅜ ciclo de El

\begin{tabular}{|c|c|c|c|}
\hline & $1^{\circ}$ Curso & $2^{\circ}$ Curso & $3^{\circ}$ Curso \\
\hline 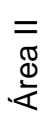 & $\begin{array}{l}\text {-Reconoce los números } \\
1,2,3 \text { y asocia a su } \\
\text { cantidad }\end{array}$ & $\begin{array}{l}\text {-Conoce y escribe los números } \\
\text { del } 1 \text { al } 6\end{array}$ & $\begin{array}{l}\text {-Conoce y escribe los números del } 1 \text { al } 9 \\
\text {-Asocia número y cantidad }\end{array}$ \\
\hline 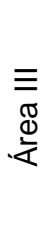 & $\begin{array}{l}\text {-Lee e interpreta } \\
\text { imágenes }\end{array}$ & $\begin{array}{l}\text {-Lee e interpreta imágenes y } \\
\text { códigos } \\
\text {-Realiza grafías en la } \\
\text { direccionalidad correcta } \\
\text {-Identifica las vocales }\end{array}$ & $\begin{array}{l}\text {-Lee e interpreta imágenes y códigos } \\
\text {-Realiza grafías en la direccionalidad correcta } \\
\text {-Discrimina sonidos y fonemas } \\
\text {-Reconoce las letras trabajadas } \\
\text {-Lee y comprende palabras }\end{array}$ \\
\hline
\end{tabular}

Tabla 3.26. Ficha de seguimiento individual con escala numérica del $1^{\circ}$ curso de lectoescritura (3 años)

\begin{tabular}{|c|c|c|c|c|c|c|}
\hline \multirow{2}{*}{\multicolumn{2}{|c|}{$\begin{array}{l}\text { Curso escolar:: } \\
\text { Indicadores de logro }\end{array}$}} & \multicolumn{5}{|c|}{$\begin{array}{l}\text { Escala numérica: }(4) \text { totalmente de } \\
\text { acuerdo/(3) de acuerdo/(2)ni acuerdo ni } \\
\text { desacuerdo/(1) en desacuerdo/(0) } \\
\text { totalmente en desacuerdo }\end{array}$} \\
\hline & & 1 & $1^{\circ}$ & $2^{\circ}$ & $3^{\circ}$ & Observaciones \\
\hline \multirow{3}{*}{$\begin{array}{l}\text { Correcta } \\
\text { direccionalidad } \\
\text { del trazo }\end{array}$} & $\begin{array}{l}\text { D.122: Correcta dirección en el trazo y posición } \\
\text { adecuada al escribir en mayúscula }\end{array}$ & & & & & \\
\hline & BI: Realiza grafías en la direccionalidad correcta & & & & & \\
\hline & $\begin{array}{l}\text { PET: Correcta dirección en el trazo y posición } \\
\text { adecuada al escribir en mayúscula }\end{array}$ & & & & & \\
\hline \multirow{3}{*}{$\begin{array}{l}\text { Discrimina } \\
\text { auditivamente } \\
\text { letras }\end{array}$} & $\begin{array}{l}\text { D.122: Discriminación auditivamente de las } \\
\text { vocales }\end{array}$ & & & & & \\
\hline & BI: Lee e interpreta imágenes & & & & & \\
\hline & $\begin{array}{l}\text { PET: Discrimina auditivamente todas las letras del } \\
\text { abecedario }\end{array}$ & & & & & \\
\hline \multirow{3}{*}{$\begin{array}{l}\text { Identifica } \\
\text { fonemas }\end{array}$} & D. 122: Identifica algún fonema & & & & & \\
\hline & BI: No se contempla & & & & & \\
\hline & PET: Identifica todas las letras del abecedario & & & & & \\
\hline \multirow{3}{*}{$\begin{array}{l}\text { Discrimina } \\
\text { visualmente } \\
\text { fonemas }\end{array}$} & $\begin{array}{l}\text { D. 122: Discrimina visualmente las vocales en } \\
\text { mayúscula }\end{array}$ & & & & & \\
\hline & BI: No se contempla & & & & & \\
\hline & $\begin{array}{l}\text { PET: Discrimina visualmente todas las letras en } \\
\text { mayúscula del abecedario }\end{array}$ & & & & & \\
\hline \multirow{3}{*}{$\begin{array}{l}\text { Lectura } \\
\text { sencillas de } \\
\text { palabras }\end{array}$} & $\begin{array}{l}\text { D. 122: Iniciarse en la lectura a través de su } \\
\text { nombre, objetos y palabras significativas }\end{array}$ & & & & & \\
\hline & BI: Lee e interpreta imágenes & & & & & \\
\hline & PET: Lee palabras & & & & & \\
\hline
\end{tabular}


Tabla 3.27. Ficha de seguimiento individual con escala numérica del $2^{\circ}$ curso de lectoescritura (4 años)

\begin{tabular}{|c|c|c|c|c|c|c|}
\hline Curso escolar:: & Alumno: & \multicolumn{5}{|c|}{$\begin{array}{l}\text { Escala numérica: (4) totalmente de acuerdo/(3) de } \\
\text { acuerdo/(2)ni acuerdo ni desacuerdo/(1) en } \\
\text { desacuerdo/(0) totalmente en desacuerdo }\end{array}$} \\
\hline \multicolumn{2}{|l|}{ Indicadores de logro } & I & $1^{\circ}$ & $2^{\circ}$ & $3^{\circ}$ & Observaciones \\
\hline \multirow[t]{3}{*}{$\begin{array}{l}\text { Correcta } \\
\text { direccionalidad }\end{array}$} & $\begin{array}{l}\text { D.122: Correcta dirección en el } \\
\text { trazo y posición adecuada al } \\
\text { escribir en mayúscula }\end{array}$ & & & & & \\
\hline & $\begin{array}{l}\text { BI: Realiza grafías en la } \\
\text { direccionalidad correcta }\end{array}$ & & & & & \\
\hline & $\begin{array}{l}\text { PET: Correcta dirección en el } \\
\text { trazo y posición adecuada al } \\
\text { escribir en mayúscula y minúscula }\end{array}$ & & & & & \\
\hline \multirow{3}{*}{$\begin{array}{l}\text { Discrimina } \\
\text { auditivamente } \\
\text { fonemas }\end{array}$} & $\begin{array}{l}\text { D.122: Discriminación auditiva de } \\
\text { vocales y algunas consonantes }\end{array}$ & & & & & \\
\hline & BI: Identifica las vocales & & & & & \\
\hline & $\begin{array}{l}\text { PET: Discrimina auditivamente } \\
\text { todas las letras del abecedario }\end{array}$ & & & & & \\
\hline \multirow[t]{3}{*}{$\begin{array}{l}\text { Discrimina } \\
\text { visualmente } \\
\text { fonemas }\end{array}$} & $\begin{array}{l}\text { D.122: Discriminación visual de } \\
\text { vocales y algunas consonantes en } \\
\text { mayúscula }\end{array}$ & & & & & \\
\hline & BI: Identifica las vocales & & & & & \\
\hline & $\begin{array}{l}\text { PET: Discrimina visualmente } \\
\text { todas las letras del abecedario }\end{array}$ & & & & & \\
\hline \multirow{3}{*}{$\begin{array}{l}\text { Lectura de palabras } \\
\text { sencillas }\end{array}$} & $\begin{array}{l}\text { D.122: Iniciarse en la lectura de } \\
\text { palabras sencillas en mayúscula }\end{array}$ & & & & & \\
\hline & $\begin{array}{l}\text { BI: Lee e interpreta imágenes y } \\
\text { códigos }\end{array}$ & & & & & \\
\hline & $\begin{array}{l}\text { PET: Lectura y comprensión de } \\
\text { frases más complejas en } \\
\text { mayúscula y minúscula }\end{array}$ & & & & & \\
\hline \multirow{3}{*}{$\begin{array}{l}\text { Escritura de } \\
\text { palabras sencillas }\end{array}$} & $\begin{array}{l}\text { D.122: Iniciarse en la escritura de } \\
\text { palabras sencillas en mayúscula }\end{array}$ & & & & & \\
\hline & $\begin{array}{l}\text { BI: Lee e interpreta imágenes y } \\
\text { códigos }\end{array}$ & & & & & \\
\hline & $\begin{array}{l}\text { PET: Escritura y comprensión de } \\
\text { frases más complejas en } \\
\text { mayúscula y minúscula }\end{array}$ & & & & & \\
\hline
\end{tabular}




\section{CAPITULO 3: METODOLOGÍA}

Tabla 3.28. Ficha de seguimiento individual con escala numérica del $3^{\circ}$ curso de lectoescritura (5 años)

\begin{tabular}{|c|c|c|c|c|c|c|}
\hline Curso escolar:: & Alumno: & \multicolumn{5}{|c|}{$\begin{array}{l}\text { Escala numérica: (4) totalmente de acuerdo/(3) de } \\
\text { acuerdo/(2)ni acuerdo ni desacuerdo/(1) en } \\
\text { desacuerdo/(0) totalmente en desacuerdo }\end{array}$} \\
\hline \multicolumn{2}{|l|}{ Indicadores de logro } & I & $1^{0}$ & $2^{\circ}$ & $3^{\circ}$ & Observaciones \\
\hline \multirow[t]{3}{*}{$\begin{array}{l}\text { Correcta } \\
\text { direccionalidad }\end{array}$} & $\begin{array}{l}\text { D.122: Correcta dirección en el trazo y } \\
\text { posición adecuada al escribir mayúscula } \\
\text { y minúscula }\end{array}$ & & & & & \\
\hline & $\begin{array}{l}\text { BI: Realiza grafías en la direccionalidad } \\
\text { correcta }\end{array}$ & & & & & \\
\hline & $\begin{array}{l}\text { PET: Correcta dirección en el trazo y } \\
\text { posición adecuada al escribir en } \\
\text { mayúscula y minúscula }\end{array}$ & & & & & \\
\hline \multirow{3}{*}{$\begin{array}{l}\text { Discrimina } \\
\text { auditivamente } \\
\text { fonemas }\end{array}$} & $\begin{array}{l}\text { D. 122: Discriminación auditiva de todas } \\
\text { las letras del abecedario }\end{array}$ & & & & & \\
\hline & BI: Discrimina sonidos y fonemas & & & & & \\
\hline & $\begin{array}{l}\text { PET: Discrimina auditivamente de todas } \\
\text { las letras del abecedario }\end{array}$ & & & & & \\
\hline \multirow[t]{3}{*}{$\begin{array}{l}\text { Discrimina } \\
\text { visualmente } \\
\text { fonemas }\end{array}$} & $\begin{array}{l}\text { D. 122: Discriminación visual de todos } \\
\text { las letras del abecedario (mayúscula y } \\
\text { minúscula) }\end{array}$ & & & & & \\
\hline & BI: Reconoce las letras trabajadas & & & & & \\
\hline & $\begin{array}{l}\text { PET: Discrimina visualmente todos los } \\
\text { letras del abecedario (mayúscula y } \\
\text { minúscula) }\end{array}$ & & & & & \\
\hline \multirow[t]{3}{*}{$\begin{array}{l}\text { Lectura y } \\
\text { comprensión de } \\
\text { palabras }\end{array}$} & $\begin{array}{l}\text { D. 122: Lee y comprende palabras y } \\
\text { frases sencillas en mayúscula y } \\
\text { minúscula }\end{array}$ & & & & & \\
\hline & BI: Lee y comprende palabras & & & & & \\
\hline & $\begin{array}{l}\text { PET: Lee y comprende textos que } \\
\text { impliquen sílabas directas, inversas y } \\
\text { trabadas }\end{array}$ & & & & & \\
\hline \multirow[t]{3}{*}{ Escritura de frases } & $\begin{array}{l}\text { D. 122: Escribe y comprende palabras y } \\
\text { frases sencillas en mayúscula y } \\
\text { minúscula }\end{array}$ & & & & & \\
\hline & BI: No se corresponde & & & & & \\
\hline & PET: Escritura de textos & & & & & \\
\hline \multirow[t]{3}{*}{$\begin{array}{l}\text { Producción de } \\
\text { mensajes sencillos }\end{array}$} & $\begin{array}{l}\text { D. 122: Producción de diferentes } \\
\text { mensajes con sus palabras preferidas y } \\
\text { representación gráfica de los fonemas } \\
\text { que las componen }\end{array}$ & & & & & \\
\hline & BI: No se corresponden & & & & & \\
\hline & $\begin{array}{l}\text { PET: Producción de textos más } \\
\text { complejos escritos con sus palabras } \\
\text { preferidas y representación gráfica de } \\
\text { los fonemas que las componen }\end{array}$ & & & & & \\
\hline \multirow[t]{2}{*}{ Uso del texto } & $\begin{array}{l}\text { D. 122: Descubre la utilidad del texto } \\
\text { escrito a través de la práctica de la } \\
\text { lectura comprensiva }\end{array}$ & & & & & \\
\hline & $\mathrm{BI}$ : Reconoce las letras trabajadas & & & & & \\
\hline
\end{tabular}




\begin{tabular}{|l|l|l|l|l|l|l|}
\hline & $\begin{array}{l}\text { PET: Descubre la utilidad del texto } \\
\text { escrito con una lectura fluida y } \\
\text { comprensiva }\end{array}$ & & & & \\
\hline
\end{tabular}

Tabla 3.29. Ficha de seguimiento individual con escala numérica del 1ํ curso de lógico-matemáticas (3 años)

\begin{tabular}{|c|c|c|c|c|c|c|}
\hline Curso escolar:: & Alumno: & \multicolumn{5}{|c|}{$\begin{array}{l}\text { Escala numérica: (4) totalmente de acuerdo/(3) de } \\
\text { acuerdo/(2)ni acuerdo ni desacuerdo/(1) en desacuerdo/(0) } \\
\text { totalmente en desacuerdo }\end{array}$} \\
\hline \multicolumn{2}{|c|}{ Indicadores de logro } & 1 & $1^{0}$ & $2^{\circ}$ & $3^{\circ}$ & Observaciones \\
\hline \multirow{3}{*}{$\begin{array}{l}\text { Utiliza la serie } \\
\text { numérica }\end{array}$} & $\begin{array}{l}\text { D. } 122 \text { : Utiliza la serie numérica del } \\
1 \text { al } 3 \text { para cuantificar }\end{array}$ & & & & & \\
\hline & $\begin{array}{l}\text { Bl: Asocia cantidades de los } \\
\text { números } 1,2 \text { y } 3\end{array}$ & & & & & \\
\hline & $\begin{array}{l}\text { PET: Utiliza la serie numérica del } 1 \\
\text { al } 20 \text { para cuantificar }\end{array}$ & & & & & \\
\hline \multirow{3}{*}{$\begin{array}{l}\text { Grafía de los } \\
\text { números }\end{array}$} & D. 122: Realiza la grafía del 1, 2 y 3 & & & & & \\
\hline & BI: Reconoce los números 1,2 y 3 & & & & & \\
\hline & PET: Realiza la grafía del 1 al 20 & & & & & \\
\hline \multirow[t]{3}{*}{$\begin{array}{l}\text { Lugar en la } \\
\text { serie }\end{array}$} & $\begin{array}{l}\text { D. 122: Ordena objetos de una } \\
\text { colección y expresa su lugar en la } \\
\text { serie del } 1 \text { al } 3\end{array}$ & & & & & \\
\hline & BI: No se contempla & & & & & \\
\hline & $\begin{array}{l}\text { PET: Ordena objetos de una } \\
\text { colección y expresa su lugar en la } \\
\text { serie del } 1 \text { al } 20\end{array}$ & & & & & \\
\hline \multirow{3}{*}{$\begin{array}{l}\text { Iniciación a la } \\
\text { suma }\end{array}$} & D. 122: Iniciación a la suma & & & & & \\
\hline & BI: No se contempla & & & & & \\
\hline & $\begin{array}{l}\text { PET: Realiza sumas con llevadas } \\
\text { hasta el } 20\end{array}$ & & & & & \\
\hline \multirow{3}{*}{$\begin{array}{l}\text { Iniciación a la } \\
\text { resta }\end{array}$} & D. 122: Iniciación a la resta & & & & & \\
\hline & BI: No se contempla & & & & & \\
\hline & $\begin{array}{l}\text { PET: Realiza restas con llevadas sin } \\
\text { rebasar el } 20\end{array}$ & & & & & \\
\hline \multirow[t]{3}{*}{$\begin{array}{l}\text { Operaciones } \\
\text { combinadas }\end{array}$} & $\begin{array}{l}\text { D. 122: Resuelve operaciones muy } \\
\text { sencillas que impliquen sumar, } \\
\text { restar, expresar diferencias y repartir }\end{array}$ & & & & & \\
\hline & $\mathrm{BI}$ : No se contempla & & & & & \\
\hline & $\begin{array}{l}\text { PET: Cálculo mental con } \\
\text { operaciones combinadas hasta el } 20\end{array}$ & & & & & \\
\hline
\end{tabular}




\section{CAPITULO 3: METODOLOGÍA}

Tabla 3.30. Ficha de seguimiento individual con escala numérica del $2^{\circ}$ curso de lógico-matemáticas (4 años)

\begin{tabular}{|c|c|c|c|c|c|c|}
\hline Curso escolar:: & Alumno: & \multicolumn{5}{|c|}{$\begin{array}{l}\text { Escala numérica: (4) totalmente de acuerdo/(3) de } \\
\text { acuerdo/(2)ni acuerdo ni desacuerdo/(1) en desacuerdo/(0) } \\
\text { totalmente en desacuerdo }\end{array}$} \\
\hline \multicolumn{2}{|c|}{ Indicadores de logro } & I & $1^{0}$ & $2^{\circ}$ & $3^{0}$ & Observaciones \\
\hline \multirow[t]{3}{*}{$\begin{array}{l}\text { Utiliza la serie } \\
\text { numérica }\end{array}$} & $\begin{array}{l}\text { D.122: Utiliza la serie numérica para } \\
\text { cuantificar y realiza la grafía del } 1 \text { al } \\
7\end{array}$ & & & & & \\
\hline & Bl: Conoce los números del 1 al 7 & & & & & \\
\hline & $\begin{array}{l}\text { PET: Utiliza y conoce los números } \\
\text { hasta el } 100\end{array}$ & & & & & \\
\hline \multirow{3}{*}{$\begin{array}{l}\text { Grafía de los } \\
\text { números }\end{array}$} & $\begin{array}{l}\text { D. } 122 \text { :Realiza la grafía del } 1,2,3,4 \text {, } \\
5,6 \text { y } 7\end{array}$ & & & & & \\
\hline & BI: Escribe los números del 1 al 6 & & & & & \\
\hline & $\begin{array}{l}\text { PET: Realiza la grafía de los } \\
\text { números hasta el } 100\end{array}$ & & & & & \\
\hline \multirow[t]{3}{*}{$\begin{array}{l}\text { Lugar en la } \\
\text { serie }\end{array}$} & $\begin{array}{l}\text { D. } 122 \text { : Ordena objetos de una } \\
\text { colección y expresa su lugar en la } \\
\text { serie del } 1 \text { al } 7\end{array}$ & & & & & \\
\hline & BI: No se contempla & & & & & \\
\hline & $\begin{array}{l}\text { PET: Ordena objetos de una } \\
\text { colección y expresa su lugar en la } \\
\text { serie del } 1 \text { al } 100\end{array}$ & & & & & \\
\hline \multirow[t]{3}{*}{$\begin{array}{l}\text { Operaciones } \\
\text { con sumas }\end{array}$} & $\begin{array}{l}\text { D.122: Resuelve sencillas } \\
\text { operaciones de dos sumandos hasta } \\
\text { el } 7\end{array}$ & & & & & \\
\hline & BI: No se contempla & & & & & \\
\hline & $\begin{array}{l}\text { PET: Resuelve sumas con llevadas } \\
\text { hasta el } 100\end{array}$ & & & & & \\
\hline \multirow[t]{3}{*}{$\begin{array}{l}\text { Operaciones } \\
\text { con restas }\end{array}$} & $\begin{array}{l}\text { D.122: Resuelve sencillas } \\
\text { operaciones de restar sin rebasar el } \\
7\end{array}$ & & & & & \\
\hline & BI: No se contempla & & & & & \\
\hline & $\begin{array}{l}\text { PET: Resuelve restas con llevadas } \\
\text { sin rebasar el } 100\end{array}$ & & & & & \\
\hline \multirow[t]{3}{*}{$\begin{array}{l}\text { Operaciones } \\
\text { combinadas }\end{array}$} & $\begin{array}{l}\text { D. 122: Resuelve problemas que } \\
\text { impliquen sumar, restar, expresar } \\
\text { diferencias y repartir hasta el } 7\end{array}$ & & & & & \\
\hline & BI: No se contempla & & & & & \\
\hline & $\begin{array}{l}\text { PET: Cálculo mental con } \\
\text { operaciones combinadas hasta el } \\
100\end{array}$ & & & & & \\
\hline
\end{tabular}


Tabla 3.31. Ficha de seguimiento individual con escala numérica del $3^{\circ}$ curso de lógico-matemáticas (5 años)

\begin{tabular}{|c|c|c|c|c|c|c|}
\hline Curso escolar:: & Alumno: & \multicolumn{5}{|c|}{$\begin{array}{l}\text { Escala numérica: (4) totalmente de acuerdo/(3) de } \\
\text { acuerdo/(2)ni acuerdo ni desacuerdo/(1) en desacuerdo/(0) } \\
\text { totalmente en desacuerdo }\end{array}$} \\
\hline \multicolumn{2}{|c|}{ Indicadores de logro } & 1 & $1^{\circ}$ & $2^{\circ}$ & $3^{\circ}$ & Observaciones \\
\hline \multirow[t]{3}{*}{$\begin{array}{l}\text { Utiliza la serie } \\
\text { numérica }\end{array}$} & $\begin{array}{l}\text { D. } 122 \text { : Utiliza la serie numérica del } \\
1 \text { al } 9 \text { para cuantificar }\end{array}$ & & & & & \\
\hline & BI: Conoce los números del 1 al 9 & & & & & \\
\hline & $\begin{array}{l}\text { PET: } 122 \text { Utiliza la serie numérica } \\
\text { hasta el } 1.000\end{array}$ & & & & & \\
\hline \multirow[t]{3}{*}{$\begin{array}{l}\text { Grafía de los } \\
\text { números }\end{array}$} & $\begin{array}{l}\text { D.122: Realiza la grafía del } 1,2,3 \text {, } \\
4,5,6,7,8 \text { y } 9\end{array}$ & & & & & \\
\hline & BI: Escribe los números del 1 al 9 & & & & & \\
\hline & $\begin{array}{l}\text { PET: Realiza la grafía hasta el } \\
1.000\end{array}$ & & & & & \\
\hline \multirow[t]{3}{*}{$\begin{array}{l}\text { Lugar en la } \\
\text { serie }\end{array}$} & $\begin{array}{l}\text { D. } 122 \text { : Ordena objetos de una } \\
\text { colección y expresa su lugar en la } \\
\text { serie del } 1 \text { al } 9\end{array}$ & & & & & \\
\hline & $\begin{array}{l}\text { Bl: Asocia número-cantidad del } 1 \text { al } \\
9\end{array}$ & & & & & \\
\hline & $\begin{array}{l}\text { PET: Ordena objetos de una } \\
\text { colección y expresa su lugar en la } \\
\text { serie del } 1 \text { al } 1.000\end{array}$ & & & & & \\
\hline \multirow[t]{3}{*}{$\begin{array}{l}\text { Operaciones } \\
\text { con sumas }\end{array}$} & $\begin{array}{l}\text { D. 122: Realiza operaciones más } \\
\text { complejas que implique sumar } \\
\text { hasta el } 9\end{array}$ & & & & & \\
\hline & BI: No se contempla & & & & & \\
\hline & $\begin{array}{l}\text { PET: Realiza sumas con llevadas } \\
\text { complejas hasta el } 1.000\end{array}$ & & & & & \\
\hline \multirow[t]{3}{*}{$\begin{array}{l}\text { Operaciones } \\
\text { con restas }\end{array}$} & $\begin{array}{l}\text { D. } 122 \text { : Realiza operaciones más } \\
\text { complejas que impliquen restar sin } \\
\text { rebasar el } 9\end{array}$ & & & & & \\
\hline & BI: No se contempla & & & & & \\
\hline & $\begin{array}{l}\text { PET: Realiza restas con llevadas } \\
\text { complejas mayores de } 100\end{array}$ & & & & & \\
\hline \multirow[t]{3}{*}{$\begin{array}{l}\text { Operaciones } \\
\text { combinadas }\end{array}$} & $\begin{array}{l}\text { D. 122: Resuelve operaciones que } \\
\text { impliquen sumar, restar, expresar } \\
\text { diferencias y repartir hasta el } 9\end{array}$ & & & & & \\
\hline & BI: No se contempla & & & & & \\
\hline & $\begin{array}{l}\text { PET: Cálculo mental con } \\
\text { operaciones combinadas hasta el } \\
1.000\end{array}$ & & & & & \\
\hline
\end{tabular}

\subsubsection{Ficha de seguimiento grupal}

La base de la ficha de seguimiento grupal (FSG) es la misma que la de las FSI, con la diferencia de que está diseñada para poder recoger el seguimiento de todos los alumnos del mismo 


\section{CAPITULO 3: METODOLOGÍA}

grupo clase en dos hojas; en la primera hoja se recogen los datos de los 8 primeros sujetos de una clase y en la segunda de los 8 restantes. En total se han elaborado 6 FSG, 3 correspondientes al ámbito lecto-escritor y otras 3 dirigidas a las habilidades lógico matemáticas de cada uno de los tres cursos escolares del segundo ciclo de E.I. (ver tablas de la 3.32 a la 3.37.). Para su elaboración se han tenido en cuenta varios aspectos: (a) una escala numérica; (b), una temporalización; (c) observaciones e (d) indicadores de logro, que explicaremos a continuación.

a) Escala numérica: los códigos numéricos de valoración son los utilizados para las fichas se seguimiento grupal, es decir, del 0 al 4; donde 0 es: totalmente en desacuerdo, 1: en desacuerdo, 2: ni de acuerdo ni en desacuerdo, 3: de acuerdo y 4: totalmente de acuerdo

b) Temporalización: cada uno de los sujetos comprende 4 columnas donde se diferencia 4 periodos, correspondientes al inicio del curso escolar y al final de cada uno de los tres trimestres; he aquí la diferencia con respecto a las fichas de seguimiento grupal.

c) Observaciones: al igual que en los casos anteriores se ha incorporado una columna extra que permite al docente añadir comentarios específicos si en algún momento lo considera necesario.

d) Indicadores de logro: son los mismos que en el caso anterior, es decir: (1) Decreto $122 / 2007$ por el que se establece el currículo en el segundo ciclo de El en la comunidad de Castilla y León (D. 122); (2) boletín informativo correspondiente a cada uno de los cursos y ámbitos (BI) y (3) Programa de Estimulación Temprana (PET). 
Tabla 3.32. Ficha de seguimiento grupal con escala numérica del $1^{\circ}$ curso en lecto escritura ( 3 años)

\begin{tabular}{|c|c|c|c|c|c|c|c|c|c|c|c|c|c|c|c|c|c|c|c|c|c|c|c|c|c|c|c|c|c|}
\hline \begin{tabular}{|l} 
Curso \\
escolar:
\end{tabular} & Alumno: & 501 & 51 & 502 & & 503 & & 504 & & 505 & & 506 & & 507 & & 508 & & & 509 & 510 & 10 & 511 & 11 & 512 & & 513 & 13 & & when \\
\hline & Indikadoreses de begro & 1192 & \begin{tabular}{|l|l|}
20 & $\mathrm{~F}$ \\
\end{tabular} & \begin{tabular}{|l|l|l|}
1 & 28 \\
18
\end{tabular} & $27 \mathrm{~F}$ & \begin{tabular}{|l|l|l|}
1 & 12 & 20 \\
\end{tabular} & \begin{tabular}{l|l}
22 & $F$
\end{tabular} & \begin{tabular}{|l|l|l|}
1 & 1028 & 28 \\
\end{tabular} & F & \begin{tabular}{|l|l|}
18 & 28 \\
\end{tabular} & \begin{tabular}{l|l}
20 & $\mathrm{~F}$
\end{tabular} & \begin{tabular}{|l|l|l|}
1 & 18 & 28 \\
\end{tabular} & $F$ & \begin{tabular}{|l|l|l|}
1 & 12 & 28 \\
\end{tabular} & \begin{tabular}{l|l|l|l|l|l|l|l}
2 & $F$
\end{tabular} & \begin{tabular}{|l|l|l|}
18 & 28 \\
\end{tabular} & 207 & & \begin{tabular}{|l|l|l|l|l|}
28 & $F$ \\
\end{tabular} & \begin{tabular}{|l|l|l|l|}
1 & 18 & 2 \\
\end{tabular} & \begin{tabular}{|l|l|}
28 & $F$ \\
\end{tabular} & \begin{tabular}{|l|l|l|l|l|}
1 & 19 & 2 \\
\end{tabular} & \begin{tabular}{l|l|l|}
27 & $F$ \\
\end{tabular} & \begin{tabular}{|l|l|l|}
1 & 18 & 20 \\
\end{tabular} & \begin{tabular}{l|l}
27 & $\mathrm{~F}$
\end{tabular} & & \begin{tabular}{|l|l|}
28 & $\mathrm{~F}$ \\
\end{tabular} & & 28 \\
\hline & 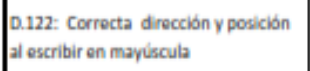 & & & & & & & & & & & & & & & & & & & & & & & & & & & & \\
\hline & 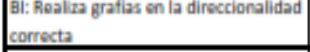 & & & & & & & & & & & & & & & & & & & & & & & & & & & & \\
\hline & 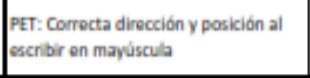 & & & & & & & & & & & & & & & & & & & & & & & & & & & & \\
\hline 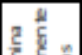 & 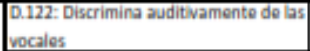 & & & & & & & & & & & & & & & & & & & & & & & & & & & & \\
\hline & Bi: Loe e interpretati imagenes & & & & & & & & & & & & & & & & & & & & & & & $T$ & & & & & \\
\hline 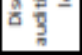 & 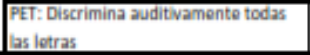 & & & & & & & & & & & & & & & & & & & & & & & & & & & & \\
\hline & 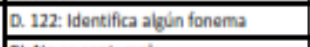 & & & & & & & & & & & & & & & & & & & & & & & & & & & & \\
\hline & 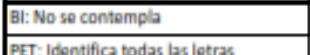 & & & & & & & & & & & & & & & & & & & & & & & & & & & & 1 \\
\hline 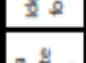 & 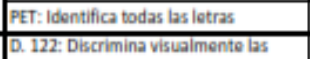 & & & & & & & & & & & & & & & & - & & L & & & L & & 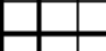 & & & & & \\
\hline & 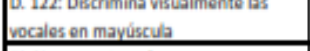 & & & & & & & & & & & & & & & & & & & & & & & & & & & & \\
\hline & Bi: No so contempla & & & & & & & & & & & & & & & & & & & & & & & & & & & & \\
\hline & 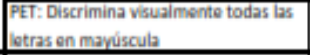 & & & & & & & & & & & & & & & & & & & & & & & & & & & & \\
\hline 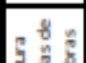 & $\begin{array}{l}\text { D. 122: Iniciarse en Il lactura do } \\
\text { palabras en maviscula }\end{array}$ & & & & & & & & & & & & & & & & & & & & & & & & & & & & \\
\hline$\underline{y}$ & Bi: Loe e interprecta imagenes & & & & & & & & & & & & & & & & & & & & & & & & & & & & \\
\hline & PET:Loop palabras & & & & & & & & & & & & & & & & & & & & & & & & & & & & \\
\hline 然 & 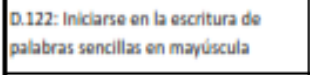 & & & & & & & & & & & & & & & & & & & & & & & & & & & & \\
\hline \begin{tabular}{|l|l|}
8 \\
8 \\
3 \\
3
\end{tabular} & Bl: Leo e interpreta imasgenesy yodiligos & & & & & & & & & & & & & & & & & & & & & & & & & & & & \\
\hline 这 & 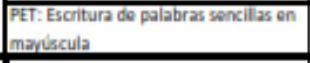 & & & & & & & & & & & & & & & & & & & & & & & & & & & & \\
\hline & Sunmatorio D. 122 & & & & & & & & & & & & & & & & & & & & & & & & & & & & \\
\hline & Sumstorio al & & & & & & & & & & & & & & & & & & & & & & & & & & & & \\
\hline & Eumatorio PET & & & & & & & & & & & & & & & & & & & & & & & & & & & & \\
\hline
\end{tabular}


CAPITULO 3: METODOLOGÍA

Tabla 3.33. Ficha de seguimiento grupal con escala numérica: $2^{\circ}$ curso lectoescritura (4 años)

\begin{tabular}{|c|c|c|c|c|c|c|c|c|c|c|c|c|c|c|c|c|c|c|c|c|c|c|c|c|c|c|c|c|c|c|c|c|c|c|c|c|c|c|c|c|c|c|c|c|c|c|c|c|c|c|c|c|c|}
\hline \multirow[t]{2}{*}{\begin{tabular}{|c|} 
Curso \\
escolar: \\
\end{tabular}} & \multirow{2}{*}{\begin{tabular}{|l} 
Alumno: \\
Indicadores de logro \\
\end{tabular}} & \multicolumn{4}{|c|}{501} & \multicolumn{3}{|c|}{502} & \multicolumn{4}{|c|}{503} & \multicolumn{3}{|c|}{504} & \multicolumn{4}{|c|}{505} & \multicolumn{3}{|c|}{506} & \multicolumn{4}{|c|}{507} & \multicolumn{3}{|c|}{508} & \multicolumn{3}{|c|}{509} & \multicolumn{4}{|c|}{$\$ 10$} & & 511 & & & 51 & & & & $\$ 13$ & & & $\$ 14$ & & & $\begin{array}{l}\text { SUMAT } \\
\text { GRUF }\end{array}$ & $\begin{array}{l}\text { TORIO } \\
\text { PAL }\end{array}$ & \\
\hline & & 1 & $10: 2$ & $2^{\circ}$ & $\mathrm{F}$ & 119 & 29 & F & 1 & 19 & $22^{\circ}$ & $\mathrm{F}$ & $1 \mid 1$ & 29 & F & 1 & 19 & $2^{9}$ & $f$ & 119 & 29 & F & 1 & 19 & $2^{\circ}$ & & 19 & 29 & $\mathrm{~F}$ & 1 & 19 & $22^{\circ} \mathrm{F}$ & 1 & 19 & $29^{\circ}$ & $\mathrm{F}$ & 1 & 192 & F & 1 & 19 & 29 & $\mathrm{~F}$ & 119 & 29 & $F$ & 1 & \begin{tabular}{|l|l|l|}
102 & 2
\end{tabular} & 29 F & 1 & 19 & 29 & f \\
\hline 总 & $\begin{array}{l}\text { D.122: Correcta dirección en el trazo } \\
\text { y posición adecuada al escribir en } \\
\text { mayúscula a }\end{array}$ & & & & & & & & & & & & & & & & & & & & & & & & & & & & & & & & & & & & & & & & & & & & & & & & & & & & \\
\hline 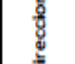 & \begin{tabular}{|l|} 
Bl: Realiza grafilas en la \\
direccionalidad correcta
\end{tabular} & & & & & & & & & & & & & & & & & & & & & & & & & & & & & & & & & & & & & & & & & & & & & & & & & & & & \\
\hline 今 & $\begin{array}{l}\text { PET: Correcta direcclón en el trazo y } \\
\text { posición adecuada al escribit en } \\
\text { mayúscula y minúscula }\end{array}$ & & & & & & & & & & & & & & & & & & & & & & & & & & & & & & & & & & & & & & & & & & & & & & & & & & & & \\
\hline t & $\begin{array}{l}\text { D.122: Discriminación auditiva de } \\
\text { vocales y algunas consonantes }\end{array}$ & & & & & & & & & & & & & & & & & & & & & & & & & & & & & & & & & & & & & & & & & & & & & & & & & & & & \\
\hline & B: Identifica las wocales & & & & & & & & & & & & & & & & & & & & & & & & & & & & & & & & & & & & & & & & & & & & & & & & & & & & \\
\hline 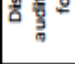 & $\begin{array}{l}\text { PET: Discrimina auditivamente todas } \\
\text { las letras del abecedario }\end{array}$ & & & & & & & & & & & & & & & & & & & & & & & & & & & & & & & & & & & & & & & & & & & & & & & & & & & & \\
\hline है & $\begin{array}{l}\text { D.122: Discriminación visual de } \\
\text { vocales y algunas consonantes en } \\
\text { mayúscula }\end{array}$ & & & & & & & & & & & & & & & & & & & & & & & & & & & & & & & & & & & & & & & & & & & & & & & & & & & & \\
\hline$\frac{\pi}{3}$ & B: Identifica las vocales & & & & & & & & & & & & & & & & & & & & & & & & & & & & & & & & & & & & & & & & & & & & & & & & & & & & \\
\hline $8 \frac{40}{2}$ & $\begin{array}{l}\begin{array}{l}\text { PET: Discrimina visualmente todas las } \\
\text { letras del abecedario }\end{array} \\
\end{array}$ & & & & & & & & & & & & & & & & & & & & & & & & & & & & & & & & & & & & & & & & & & & & & & & & & & & & \\
\hline 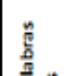 & $\begin{array}{l}\text { D.122: Iniciarse en la lectura de } \\
\text { palabras sencillas en mayúscula }\end{array}$ & & & & & & & & & & & & & & & & & & & & & & & & & & & & & & & & & & & & & & & & & & & & & & & & & & & & \\
\hline 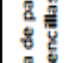 & $\begin{array}{l}\text { Bi: Lee e interpreta imágenes y } \\
\text { códigos }\end{array}$ & & & & & & & & & & & & & & & & & & & & & & & & & & & & & & & & & & & & & & & & & & & & & & & & & & & & \\
\hline 造 & $\begin{array}{l}\text { PEt: Lectura y comprensión de frases } \\
\text { más complejas en mayúsculay } \\
\text { minúscula }\end{array}$ & & & & & & & & & & & & & & & & & & & & & & & & & & & & & & & & & & & & & & & & & & & & & & & & & & & & \\
\hline $\int_{\substack{a \\
0}}^{a}$ & $\begin{array}{l}\text { D.122: Iniciarse en la escritura de } \\
\text { palabras sencillas en mayúscula }\end{array}$ & & & & & & & & & & & & & & & & & & & & & & & & & & & & & & & & & & & & & & & & & & & & & & & & & & & & \\
\hline 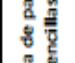 & $\begin{array}{l}\text { Bl: Lee e interpreta imágenes y } \\
\text { códigos }\end{array}$ & & & & & & & & & & & & & & & & & & & & & & & & & & & & & & & & & & & & & & & & & & & & & & & & & & & & \\
\hline 至 & $\begin{array}{l}\text { PEt: Escritura y comprensión de } \\
\text { frases más complejas en mayúscula y } \\
\text { minúscula }\end{array}$ & & & & & & & & & & & & & & & & & & & & & & & & & & & & & & & & & & & & & & & & & & & & & & & & & & & & \\
\hline & Sumatorio D. 122 & & & & & & & & & & & & & & & & & & & & & & & & & & & & & & & & & & & & & & & & & & & & & & & & & & & & \\
\hline & Sumatorio BI & & & & & & & & & & & & & & & & & & & & & & & & & & & & & & & & & & & & & & & & & & & & & & & & & & & & \\
\hline & Sumatorio PET & & & & & & & & & & & & & & & & & & & & & & & & & & & & & & & & & & & & & & & & & & & & & & & & & & & & \\
\hline
\end{tabular}


CAPITULO 3: METODOLOGÍA

Tabla 3.34. Ficha de seguimiento grupal con escala numérica: $3^{\circ}$ curso lectoescritura (5 años)

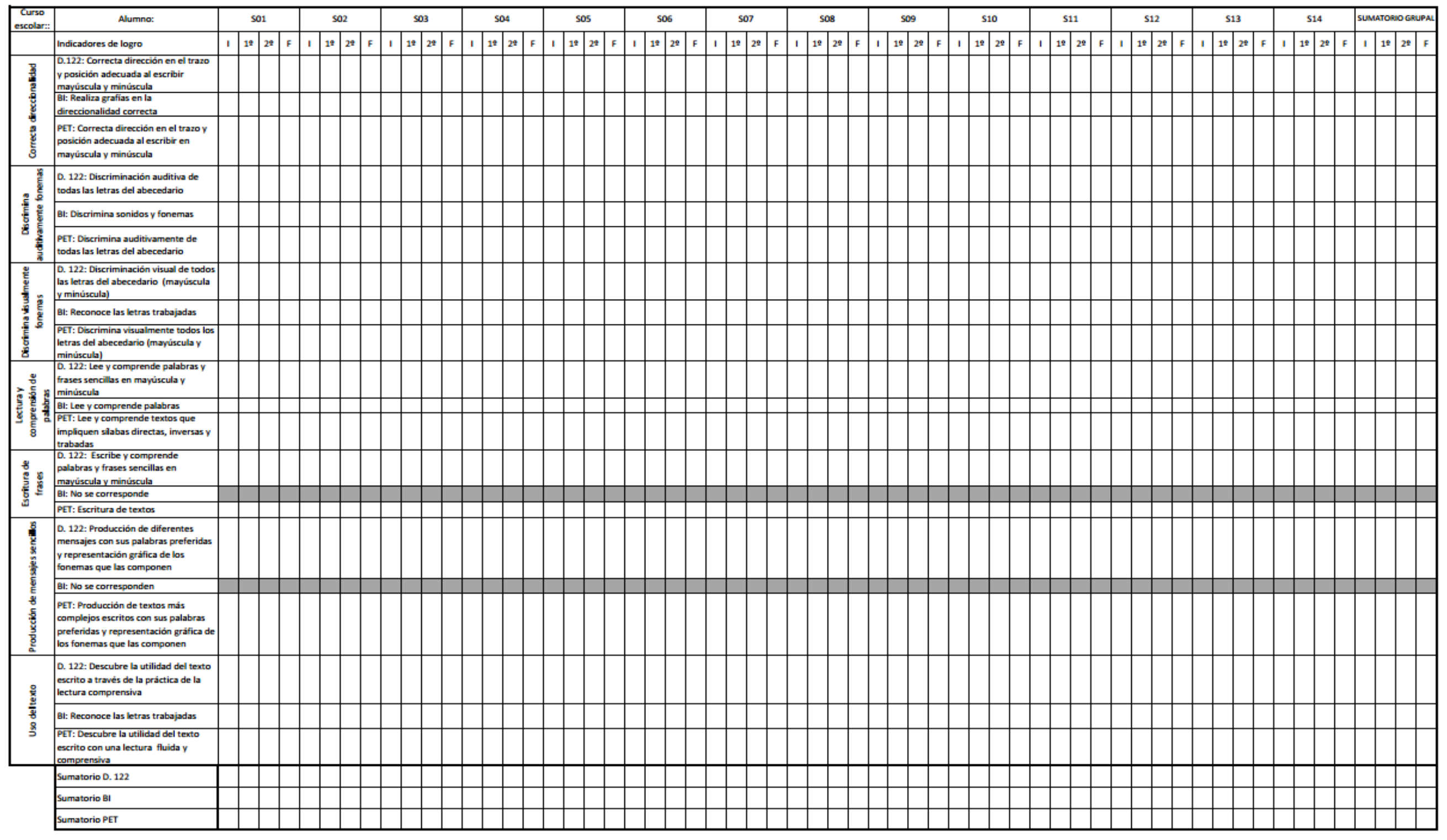


CAPITULO 3: METODOLOGÍA

Tabla 3.35. Ficha de seguimiento grupal con escala numérica en el 1ํㅜ curso de lógico-matemáticas (3 años)

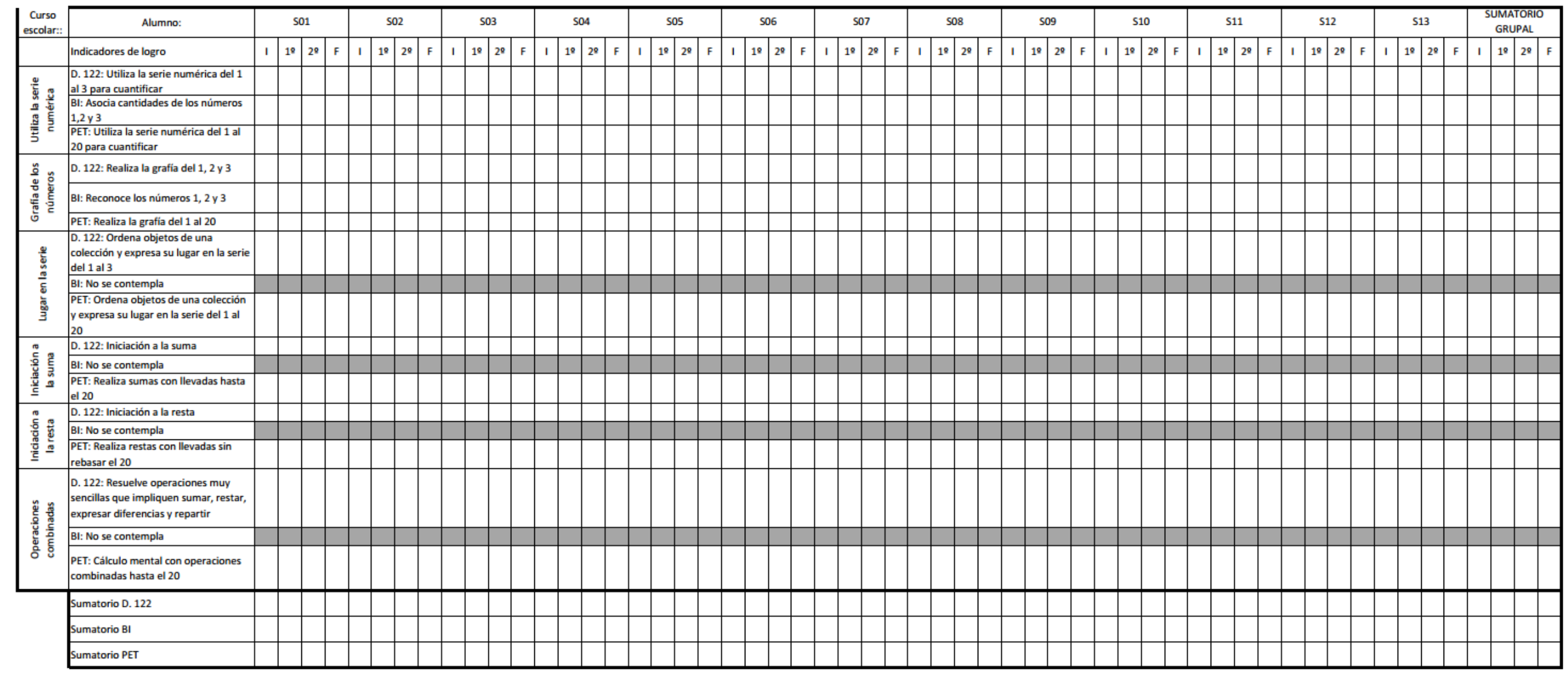


CAPITULO 3: METODOLOGÍA

Tabla 3.36. Ficha de seguimiento grupal con escala numérica en el $2^{\circ}$ curso de lógico-matemáticas (4 años)

\begin{tabular}{|c|c|c|c|c|c|c|c|c|c|c|c|c|c|c|c|c|c|c|c|c|c|c|c|c|c|c|c|c|c|c|c|c|c|c|c|c|c|c|c|c|c|c|c|c|c|c|c|c|c|c|c|c|c|c|c|}
\hline \multirow{2}{*}{$\begin{array}{c}\text { Curso } \\
\text { escolar:: }\end{array}$} & \multirow{2}{*}{\begin{tabular}{|l|} 
Alumno: \\
Indicadores de logro
\end{tabular}} & \multicolumn{4}{|c|}{501} & \multicolumn{4}{|c|}{502} & \multicolumn{3}{|c|}{503} & \multicolumn{4}{|c|}{504} & \multicolumn{4}{|c|}{505} & \multicolumn{4}{|c|}{506} & \multicolumn{3}{|c|}{507} & \multicolumn{4}{|c|}{508} & \multicolumn{3}{|c|}{509} & & st & 10 & & & s11 & & & & 512 & & & $\$ 13$ & & & s1 & 14 & & & $\begin{array}{l}\text { ATOR } \\
\text { RUPAL }\end{array}$ & \\
\hline & & 1 & 19 & 29 & $\mathrm{~F}$ & 1 & 192 & 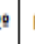 & $f$ & 1 & 29 & F & 1 & $1^{0}$ & 29 & $\mathbf{F}$ & 1 & 19 & 29 & $F$ & 1 & 19 & 29 & $\mathrm{~F}$ & 1 & 19 & $29 \mathrm{~F}$ & 1 & 19 & 29 & $\mathrm{~F}$ & 1 & 2 & F & 1 & 19 & 29 & $\mathrm{~F}$ & 1 & 192 & $29 \%$ & 1 & 119 & 29 & $\mathrm{~F}$ & $1:$ & 192 & F & 1 & 19 & $20^{\circ}$ & $\mathrm{F}$ & 11 & 29 & r \\
\hline 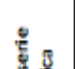 & $\begin{array}{l}\text { D. 122: Utiliza la serie numérica } \\
\text { cuantificary y realiza la grafía del } 1 \text { al } 7\end{array}$ & & & & & & & & & & & & & & & & & & & & & & & & & & & & & & & & & & & & & & & & & & & & & & & & & & & & & & \\
\hline है & B: Conoce los números del 1 al 7 & & & & & & & & & & & & & & & & & & & & & & & & & & & & & & & & & & & & & & & & & & & & & & & & & & & & & & \\
\hline 5 & \begin{tabular}{|l|} 
PET: Conoce yutiliza los números del \\
1 al 100
\end{tabular} & & & & & & & & & & & & & & & & & & & & & & & & & & & & & & & & & & & & & & & & & & & & & & & & & & & & & & \\
\hline " & D. 122: Realiza la grafia del 1 al 7 & & & & & & & & & & & & & & & & & & & & & & & & & & & & & & & & & & & & & & & & & & & & & & & & & & & & & & \\
\hline 8 & Bl: Escribe los números del 1 al 6 & & & & & & & & & & & & & & & & & & & & & & & & & & & & & & & & & & & & & & & & & & & & & & & & & & & & & & \\
\hline 5 & \begin{tabular}{|l|} 
PET: Realiza la grafila de los números \\
hasta el 100
\end{tabular} & & & & & & & & & & & & & & & & & & & & & & & & & & & & & & & & & & & & & & & & & & & & & & & & & & & & & & \\
\hline 㐘 & $\begin{array}{l}\text { D. 122: Ordena objetos de una } \\
\text { colecclón y expresa su lugar en la } \\
\text { serie del } 1 \text { al } 7\end{array}$ & & & & & & & & & & & & & & & & & & & & & & & & & & & & & & & & & & & & & & & & & & & & & & & & & & & & & & \\
\hline$\frac{3}{4}$ & Bl: No se contempla & & & & & & & & & & & & & & & & & & & & & & & & & & & & & & & & & & & & & & & & & & & & & & & & & & & & & & \\
\hline 产 & \begin{tabular}{|l|}
$\begin{array}{l}\text { PET: Ordena objetos de una colecclón } \\
\text { vexpresa su lugar en la serie del } 1 \text { al } \\
100\end{array}$ \\
\end{tabular} & & & & & & & & & & & & & & & & & & & & & & & & & & & & & & & & & & & & & & & & & & & & & & & & & & & & & & \\
\hline $\begin{array}{l}5 \\
8 \\
8\end{array}$ & \begin{tabular}{|l|} 
D. 122: Realliza sencillas operaciones \\
de dos sumandos hasta el7
\end{tabular} & & & & & & & & & & & & & & & & & & & & & & & & & & & & & & & & & & & & & & & & & & & & & & & & & & & & & & \\
\hline 8 & Bi: No se contempla & & & & & & & & & & & & & & & & & & & & & & & & & & & & & & & & & & & & & & & & & & & & & & & & & & & & & & \\
\hline 8 & $\begin{array}{l}\text { PEt: Realiza sumas con llevadas hasta } \\
\text { el } 100\end{array}$ & & & & & & & & & & & & & & & & & & & & & & & & & & & & & & & & & & & & & & & & & & & & & & & & & & & & & & \\
\hline 8 & \begin{tabular}{|l|} 
D. 122: Realiza sencillas operaciones \\
de restar sin rebasar el 7
\end{tabular} & & & & & & & & & & & & & & & & & & & & & & & & & & & & & & & & & & & & & & & & & & & & & & & & & & & & & & \\
\hline 尊 & B: No se contempla & & & & & & & & & & & & & & & & & & & & & & & & & & & & & & & & & & & & & & & & & & & & & & & & & & & & & & \\
\hline 8 & $\begin{array}{l}\text { PET: Realiza restas con llevadas sin } \\
\text { rebasar el } 100\end{array}$ & & & & & & & & & & & & & & & & & & & & & & & & & & & & & & & & & & & & & & & & & & & & & & & & & & & & & & \\
\hline & Sumatorio D. 122 & & & & & & & & & & & & & & & & & & & & & & & & & & & & & & & & & & & & & & & & & & & & & & & & & & & & & & \\
\hline & Sumatorio BI & & & & & & & & & & & & & & & & & & & & & & & & & & & & & & & & & & & & & & & & & & & & & & & & & & & & & & \\
\hline & Sumatorio PET & & & & & & & & & & & & & & & & & & & & & & & & & & & & & & & & & & & & & & & & & & & & & & & & & & & & & & \\
\hline
\end{tabular}


CAPITULO 3: METODOLOGÍA

Tabla 3.37. Ficha de seguimiento grupal con escala numérica en el 3ํㅜㄴ curso de lógico-matemáticas (5 años)

\begin{tabular}{|c|c|c|c|c|c|c|c|c|c|c|c|c|c|c|c|c|c|c|c|c|c|c|c|c|c|c|c|c|c|c|c|c|c|c|c|c|c|c|c|c|c|c|c|c|c|c|c|c|c|c|c|c|}
\hline \multirow{2}{*}{ 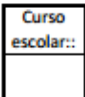 } & \multirow{2}{*}{\begin{tabular}{|c|} 
Alumno: \\
Indicadores de logro \\
\end{tabular}} & \multicolumn{4}{|c|}{501} & \multicolumn{3}{|c|}{502} & \multicolumn{3}{|c|}{503} & \multicolumn{4}{|c|}{504} & \multicolumn{4}{|c|}{505} & \multicolumn{3}{|c|}{506} & \multicolumn{3}{|c|}{507} & \multicolumn{3}{|c|}{508} & \multicolumn{3}{|c|}{509} & & s1 & & & & s11 & & & s12 & & & s1 & & & & \$14 & & & $\overline{\text { LATOR }}$ & IO GRU: & \\
\hline & & 1 & 19 & 29 & $\mathrm{~F}$ & \begin{tabular}{l|l}
1 & 1 \\
\end{tabular} & 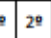 & F & 1 & \begin{tabular}{|l|l|l|l|}
19 &
\end{tabular} & 20 & \begin{tabular}{l|l}
$\mathrm{F}$ & $\mathrm{I}$ \\
$\mathrm{a}$
\end{tabular} & 19 & 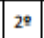 & $F$ & \begin{tabular}{|l|l}
1 & 1 \\
\end{tabular} & 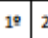 & $22^{\circ} \mathrm{F}$ & $=1$ & 19 & $22^{\circ}$ & $\mathrm{F}$ & \begin{tabular}{l|l}
1 & 19
\end{tabular} & 20 & $\mathrm{~F}$ & 1 & \begin{tabular}{|l|l|}
19 & 2 \\
\end{tabular} & 29 & 1 & 192 & $22^{2} \mathrm{~F}$ & 1 & 19 & 29 & \begin{tabular}{l|l}
$\mathrm{F}$ & $\mathrm{I}$
\end{tabular} & \begin{tabular}{l|l}
1 & 19 \\
\end{tabular} & 29 & $\mathrm{~F}$ & 10 & 1929 & $9 F$ & 1 & 10 & $22^{\circ}$ & $\mathrm{F}$ & 11 & 1920 & F & & 19 & 20 & $\mathrm{~F}$ \\
\hline Utiliza la & $\begin{array}{l}\text { D. } 122 \text { : Utiliza la serie numérica del } 1 \\
\text { al } 19 \text { para cuantificar } \\
\end{array}$ & & & & & & & & & & & & & & & & & & & & & & & & & & & & & & & & & & & & & & & & & & & & & & & & & & & \\
\hline \begin{tabular}{|c|} 
serie \\
numérica
\end{tabular} & Bl: Conoce los números del 1 al 9 & & & & & & & & & & & & & & & & & & & & & & & & & & & & & & & & & & & & & & & & & & & & & & & & & & & \\
\hline & $\begin{array}{l}\text { PET: } 122 \text { Utiliza la serie numérica } \\
\text { hasta el } 1.000\end{array}$ & & & & & & & & & & & & & & & & & & & & & & & & & & & & & & & & & & & & & & & & & & & & & & & & & & & \\
\hline Grafia de & $\begin{array}{l}\text { D.122: Realiza la grafila del 1, 2, 3, } 4 \text {, } \\
5,6,7,8 \mathrm{y} 9\end{array}$ & & & & & & & & & & & & & & & & & & & & & & & & & & & & & & & & & & & & & & & & & & & & & & & & & & & \\
\hline \begin{tabular}{|c|c|c|} 
los \\
números
\end{tabular} & B1: Escribe los números del 1 al 9 & & & & & & & & & & & & & & & & & & & & & & & & & & & & & & & & & & & & & & & & & & & & & & & & & & & \\
\hline & PET: Realiza la grafia hasta el 1.000 & & & & & & & & & & & & & & & & & & & & & & & & & & & & & & & & & & & & & & & & & & & & & & & & & & & \\
\hline & $\begin{array}{l}\text { D. 122: Ordena objetos de una } \\
\text { colección yexpresa su lugar en la } \\
\text { serie del } 1 \text { al } 9 \\
\end{array}$ & & & & & & & & & & & & & & & & & & & & & & & & & & & & & & & & & & & & & & & & & & & & & & & & & & & \\
\hline Lugar en & Bl: Asocia número-cantidad del 1 al 9 & & & & & & & & & & & & & & & & & & & & & & & & & & & & & & & & & & & & & & & & & & & & & & & & & & & \\
\hline & $\begin{array}{l}\text { PET: Ordena objetos de una colección } \\
\text { vexpresa su lugar en la serie del } 1 \text { al } \\
1.000\end{array}$ & & & & & & & & & & & & & & & & & & & & & & & & & & & & & & & & & & & & & & & & & & & & & & & & & & & \\
\hline |operacio & $\begin{array}{l}\text { D. 122: Realiza operaciones más } \\
\text { complejas que implique sumar hasta } \\
\text { el } 9\end{array}$ & & & & & & & & & & & & & & & & & & & & & & & & & & & & & & & & & & & & & & & & & & & & & & & & & & & \\
\hline & Bi: No se contempla & & & & & & & & & & & & & & & & & & & & & & & & & & & & & & & & & & & & & & & & & & & & & & & & & & & \\
\hline sumas & $\begin{array}{l}\text { PET: Realliza sumas con llevadas } \\
\text { complejas hasta el } 1.000\end{array}$ & & & & & & & & & & & & & & & & & & & & & & & & & & & & & & & & & & & & & & & & & & & & & & & & & & & \\
\hline cio & $\begin{array}{l}\text { D. 122: Realiza operaciones más } \\
\text { complejas que impliquen restar sin } \\
\text { rebasar el } 9\end{array}$ & & & & & & & & & & & & & & & & & & & & & & & & & & & & & & & & & & & & & & & & & & & & & & & & & & & \\
\hline$\left[\begin{array}{c}\text { nesescon } \\
\text { restas }\end{array}\right]$. & Bl: No se contempla & & & & & & & & & & & & & & & & & & & & & & & & & & & & & & & & & & & & & & & & & & & & & & & & & & & \\
\hline & $\begin{array}{l}\text { PET: Realiza restas con llevadas } \\
\text { complejas mayores de } 100\end{array}$ & & & & & & & & & & & & & & & & & & & & & & & & & & & & & & & & & & & & & & & & & & & & & & & & & & & \\
\hline $\begin{array}{c}\text { Operacio } \\
\text { nes }\end{array}$ & $\begin{array}{l}\text { D. 122: Resuelve operaciones que } \\
\text { impliquen sumar, restar, expresar } \\
\text { differencias y repartir hasta el } 9\end{array}$ & & & & & & & & & & & & & & & & & & & & & & & & & & & & & & & & & & & & & & & & & & & & & & & & & & & \\
\hline & Bl: No se contempla & & & & & & & & & & & & & & & & & & & & & & & & & & & & & & & & & & & & & & & & & & & & & & & & & & & \\
\hline & $\begin{array}{l}\text { PET: Cákculo mental con operaciones } \\
\text { combinadas hasta el } 1.000\end{array}$ & & & & & & & & & & & & & & & & & & & & & & & & & & & & & & & & & & & & & & & & & & & & & & & & & & & \\
\hline & Sumatorio D. 122 & & & & & & & & & & & & & & & & & & & & & & & & & & & & & & & & & & & & & & & & & & & & & & & & & & & \\
\hline & Sumatorio B1 & & & & & & & & & & & & & & & & & & & & & & & & & & & & & & & & & & & & & & & & & & & & & & & & & & & \\
\hline & Sumatorio PET & & & & & & & & & & & & & & & & & & & & & & & & & & & & & & & & & & & & & & & & & & & & & & & & & & & \\
\hline & Sumatorio & & & & & & & & & & & & & & & & & & & & & & & & & & & & & & & & & & & & & & & & & & & & & & & & & & & \\
\hline
\end{tabular}




\subsubsection{CRITERIOS DE RIGOR CIENTÍFICO}

Hacer una investigación implica utilizar diferentes métodos, técnicas e instrumentos para la construcción del conocimiento científico; "esto significa un compromiso con la calidad del tipo de conocimiento que se produce" (Diaz, Mendoza, y Porras, 2011, p.2). En este apartado pretendemos demostrar la fiabilidad y validez científica de esta investigación para garantizar la calidad del estudio. Por tanto, debemos reflexionar sobre la forma de interpretar los datos analizados y describir tanto la fiabilidad y la validez, como los respectivos criterios que hemos utilizado para demostrar su verificación.

En las investigaciones cualitativas, el EC permite vislumbrar su alcance como "herramienta metodológica que permita realizar investigaciones que cumplan con el rigor científico adecuado, ofreciendo validez y confiabilidad en sus resultados" (Diaz et al., 2011, p.21). En este sentido, la credibilidad de las conclusiones obtenidas en este EC evaluativo deben detallar los medios a utilizar para demostrar la rigurosidad que lo caracteriza como tal. Como describe Magaly (2007, p.2) "es necesario describir los recursos y procedimientos que se utilizarán tanto para la recogida de la información como para su transformación en datos durante el análisis".

En esta línea, Velasco y De Rada señala que "el investigador no debe confiarse sólo en las técnicas sino que debe presentar los resultados a los participantes para que den conformidad a lo interpretado" (1997, p.3); además defiende que ha de seguirse unos criterios de credibilidad "permitiendo que el informe de investigación sea riguroso, creíble y confiable para poder transferir derivaciones del estudio" (Velasco y De Rada, 1997, p.13).

Los criterios que permiten asegurar el rigor y la calidad científica de los estudios cualitativos han sido definidos por diferentes autores (Guba y Lincoln, 1981; Guba, 1981; Velasco y De Rada, 1997). Por ello pasamos a describir los criterios de rigor científico utilizado a lo largo de la presente investigación, ya que "la calidad y objetividad de una investigación científica se mide mediante los criterios de validez y fiabilidad de sus resultados" (Martínez, 2006, p.12).

Noreña, Alcaraz-Moreno, Rojas, y Rebolledo-Malpica (2012) definen el concepto de validez y fiabilidad (p.4 y 5). La validez es: "el grado en que un instrumento de mide lo que realmente pretende o quiere medir; es decir, lo que en ocasiones se denomina exactitud"; y la fiabilidad se refiere: "a la consistencia interna de la medida, es decir, la fiabilidad de una medida analiza si ésta se halla libre de errores aleatorios y, en consecuencia, proporciona resultados estables y consistentes". 


\section{CAPITULO 3: METODOLOGÍA}

Guba (1981) define 4 criterios de rigor científico que utilizaremos para demostrar la calidad en nuestro estudio.

\subsubsection{Credibilidad}

Según Guba (1981) este criterio permite aumentar la probabilidad de que los resultados obtenidos sean creíbles justificándolo con estancias largas en el campo de estudio, observación persistente y triangulando métodos y fuentes, mediante actividades que proporcionen una comprobación externa, utilizando una adecuada contratación referencial y realizando actividades que faciliten prueba directa sobre los resultados por parte de los informantes. En este sentido, este criterio "se refiere a cómo los resultados de un estudio son verdaderos para las personas que fueron estudiadas y para quienes lo han experimentado o han estado en contacto con el fenómeno investigado" (Noreña et al., 2012, p.5). Por ello es interesante que el investigador no sólo describa, sino que interprete su propio comportamiento en base a las experiencias de los sujetos de la investigación. Estas interpretaciones deben ser plasmadas a través de las técnicas e instrumentos utilizados en la recogida de datos.

Para otorgar credibilidad al estudio se utilizó como técnica principal la triangulación, por ser la técnica de validación más empleada. Esta técnica consiste en "la puesta en relación de las perspectivas de los diferentes agentes implicados en la investigación, incluido el investigador" (Álvarez y San Fabián, 2012, p.10).

Por su parte (Arias, 2000) define tres tipos de triangulación: (a) de métodos: cotejando los datos obtenidos a través de una técnica con otra; (b) de sujetos: para ello se compara los puntos de vista de los miembros de la comunidad estudiada; y (c) de espacios y tiempo: cotejando los resultados obtenidos en diferentes espacios y momentos a lo largo de la investigación.

En nuestro caso, se han llevado a cabo las siguientes estrategias de triangulación para otorgar credibilidad al estudio: (1) triangulación de métodos, se ha hecho un acopio de las notas de campo surgido durante los tres años que duró la investigación, a través de todos mis diarios como maestra, donde registré datos relevante sobre mis alumnos y tome nota de mis impresiones, hallazgos, errores y aciertos acometidos por mí como investigadora; además llevé a cabo grabaciones periódicas y recopilé la información relativa a los boletines de notas trimestrales de cada uno de los sujetos participantes en la investigación; (2) triangulación de sujetos, durante todo el proceso he ido exponiendo los diferentes hallazgos a miembros de la comunidad científica educativa a través de ponencias, comunicaciones, artículos e incluso debates, permitiendo a diferentes compañeros exponer su opinión, formular dudas, críticas y 
expresar propuestas de mejora; y, (3) triangulación de espacios y tiempo: el PET se aplicó durante un tiempo prolongado, tres cursos escolares, en dos promociones de alumnos diferentes, observando y registrando la consistencia de los resultados en los distintos momentos y espacios de la investigación.

Además, con la finalidad de otorgar la mayor credibilidad posible, se ha realizado una revisión bibliográfica exhaustiva a través de artículos, libros, tesis y otras investigaciones relacionas con el tema de estudio.

Por último, hemos tratado de aportar credibilidad a la investigación mediante la adecuación referencial (comprobando los datos registrados mediante las diferentes técnicas) y mediante la coherencia estructural del estudio (buscando la sincronización y consistencia al interpretar los diferentes datos).

\subsubsection{Confirmabilidad}

Se refiere a la forma en la cual un investigador puede seguir la pista de lo que hizo otro, garantizando la veracidad de las descripciones realizadas por los sujetos investigados (Guba y Lincoln, 1981). Diaz et al. (2011) exponen que la confirmabilidad tiene por objeto "asegurarse de que un investigador, siguiendo los mismos procedimientos descritos por otro investigador anterior y conduciendo el mismo estudio, puede llegar a los mismos resultados y conclusiones" (p.19).

Para asegurase la confirmabilidad de nuestro estudio hemos utilizado diferentes instrumentos explicados en el criterio anterior (diarios de maestra, filmaciones periódicas, fotografías de aspectos relevantes y $\mathrm{BI}$ trimestrales); además se han recogiendo reflexiones textuales de los alumno, junto con mis propias impresiones, reflexiones, inseguridad, sensaciones, pensamientos e intuiciones como investigadora durante toda el proceso. En relación a la escritura de los resultados se ha elaborado contrastándola con la bibliografía existente en relación al tema de estudio, respetando la citación de las fuentes; asimismo, he tenido en cuenta los hallazgos obtenidos por otros investigadores relacionados con mi tema de estudio. Durante todo el proceso he cuidado minuciosamente la veracidad de los datos reflejados en las tablas grupales e individuales, además de velar bien los asuntos de rigor de la investigación mediante mi propia reflexividad, tomando conciencia de la influencia que puedo llegar a tomar con mis planteamientos; por ello, en todo momento, he tomado una conciencia autocrítica, abstrayéndome de mis propias creencias, otorgando la mayor neutralidad posible en la actividad investigadora. 


\section{CAPITULO 3: METODOLOGÍA}

\subsubsection{Transferibilidad}

La transferibilidad consiste en poder transferir los resultados de la investigación a otros contextos diferentes: "da cuenta de la posibilidad de ampliar los resultados del estudio a otras poblaciones" (Magaly, 2007, p.23). Para proporcionar transferibilidad a la investigación se debe recogen abundantes datos descriptivos y desarrollar descripciones minuciosas (Guba 1981).

Para lograr alcanzar la transferencia la investigación se ha llevado a cabo una descripción exhaustiva de las características del centro y contexto donde se ha llevado la investigación y de los alumnos participantes en el estudio; describiendo aspectos relevantes de cada sujeto, en cada curso escolar. De esta manera, podemos ver como los resultados obtenidos tras la aplicación del PET a los alumnos de 3, 4 y 5 años no son generalizables sino transferibles a otros centros y contextos similares. Ejemplo de esta transferibilidad, es ver como otros docentes de EI, han puesto en práctica el PET observando resultados similares a los expuestos en las conclusiones.

\subsubsection{Dependencia}

La dependencia hace referencia a la estabilidad de los datos. Para Magaly, (2007, p.9): "se trata de verificar la sistematización en la recolección y el análisis cualitativo". Guba (1981) defiende que para favorecerla se deben utilizar métodos solapados que puedan complementarse y suplir mutuamente las deficiencias; así como la réplica paso a paso, a través de observadores externos, que revises la investigación y contrasten sus conclusiones de manera continuada a lo largo de todo el proceso que dure la investigación. Por su parte Ruiz (2012) explica que existe aspectos que garantizan la dependencia de la investigación: (a) fijar de entrada un plan flexible que permita efectuar cambios y documentarlos detalladamente; (b) recurrir a técnicas de triangulación de sujetos, de situaciones y de técnicas de recogida de información; y (c) utilizar agentes externos a la investigación que examinen, como expertos, la calidad de la recogida e interpretación de los datos.

En nuestra investigación hemos empleado el término que Guba denomina "métodos solapados" (2008, p.160), es un tipo de triangulación mediante el cual se puede emplear distintos métodos a la vez, con el objetivo de superar insuficiencias de los métodos por separado. En este caso, al recopilar los datos a través de diferentes métodos, hemos llegado a resultados similares, como muestran las gráficas de las figuras 4.4, 4.12. 4.20, 4.28. 4.36 y4.44; donde se ve los objetivos alcanzados por todos los sujetos en relación a los distintos tipos de indicadores de logro (D. 122, BI y PET) de este modo reforzamos la estabilidad de la 
investigación. Por otro lado, otra cuestión a la que se ha prestado un cuidado especial, es a la realización de la "réplica paso a paso" (Guba, 2008, p.160). Para ello nos hemos valido de los alumnos en prácticas y la maestra de apoyo, que han podido seguir la evolución de los resultados en todo momento. En el propio diario puede verse reflejado, la evolución de los resultados siendo tanto los alumnos en prácticas o la maestra de apoyo los encargados de aplicar el PET, además de dejar constancia de la réplica en las memorias realizadas por las tres alumnas de prácticas que estuvieron durante periodos largos de la investigación. Como ya hemos comentados en los casos anteriores, hemos establecido una "una pista de revisión" (Guba, 2008) a través de las anotaciones y registro en los diarios de la maestra, permitiendo una explicación progresiva del proceso. De la misma manera, hemos contado con agentes externos a la investigación, los cuales nos ha dado su opinión y hecho aportaciones; permitiendo revisión externa.

\subsubsection{CUESTIONES ÉTICO-METODOLÓGICAS}

La confianza mutua es clave para unas buenas relaciones en el campo, pero no deben darse por supuestas; deben crearse en el proceso de realización de la investigación. Una vez que estamos en el aula donde vamos a realizar la investigación deberemos "crear relaciones y establecer condiciones de confianza con las personas que vamos a estudiar" (Simons, 2011, p.146). Para tal fin es necesario cumplir unas cuestiones ético-metodológicas que garanticen la calidad, ética y equidad del estudio. En nuestra investigación se han tenido en cuenta 7 cuestiones ético-metodológicas.

\subsubsection{Consentimiento}

La forma tradicional de obtener un consentimiento informado es pedir que los participantes firmen un impreso antes de tomar parte en la investigación. En nuestro caso, al ser los alumnos menores de edad, son los padres los que firman la autorización. Durante la primera reunión grupal, celebrada a principios de septiembre de cada curso escolar, se informa a las familias de todo el proceso a llevar a cabo y se proporciona el permiso de consentimiento informado. De la misma manera, antes de iniciar la investigación se pide permiso al equipo directivo.

\subsubsection{Confidencialidad}

Garantizar la confidencialidad es un principio común al iniciar la investigación. Toda la información proporcionada en el estudio debe ser confidencial, utilizando siempre el 


\section{CAPITULO 3: METODOLOGÍA}

anonimato "tanto con respecto al exterior, los sujetos y las instituciones serán citadas con un seudónimo" (Vázquez y Angulo, 2003, p.23). Nadie externo a quien realice el estudio de caso, deberá conocer quién ha proporcionado la información.

\subsubsection{Anonimato}

El uso de seudónimos, cambiar los nombres de las persona o de las instituciones, es un principio habitual en los EC para mantener el anonimato de las sujetos y ofrecer una garantía de protección y privacidad (Simons, 2011b), evitando que los alumnos participantes en la experiencia puedan ser reconocidos. Por este motivo, se han utilizado nombres ficticios para referirnos a los alumnos participantes en la investigación.

\subsubsection{Honestidad y sinceridad del investigador}

Debemos presentar toda la información de forma apropiada, completa y veraz "asumiendo responsabilidades y reconociendo tanto los errores como los aciertos cuando haya tenido lugar" (Hamodi, 2014, p.168). Los diarios han sido un buen instrumento para recoger indicios acerca de estas cuestiones y reflexionar sobre ello.

\subsubsection{Colaboración}

"Nadie está obligado a participar y proporcionar información" (Vázquez y Angulo, 2003, p.23) lo que significa que la decisión de aceptar ser grabado u observado ha de ser negociado y hablado con cada sujeto que participa directamente. En nuestro caso, se elaboró un consentimiento escrito que fue firmado por los padres durante la primera reunión grupal realizada al inicio de los cursos 2010-11, 2011-12 y 2012-13 en los que desarrolló el estudio.

\subsubsection{Imparcialidad}

El EC pretende constituirse en un ámbito en que se respeten los puntos de vista, las apreciaciones y las valoraciones de todos los sujetos participantes en la investigación (Vázquez y Angulo, 2003). No se trata de ponderar unas sobre otras, ni mostrarse más participativo de una que de otras, sino de mostrar esas valoraciones de una manera imparcial y equitativa. 


\subsubsection{Rigor científico}

Esta investigación se ha realizado respetando las normas establecidas por la Comunidad Científica Internacional, siguiendo los pasos fijados por el método científico. De igual manera, se han realizado las revisiones necesarias para constatar el cumplimiento de las normas de estilo y escritura establecidas. 
CAPITULO 3: METODOLOGÍA 


\section{ANÁLISIS DE DATOS}

Capítulo 4

4.1. Tablas y gráficos

4.2. Interpretación de datos 


\section{CAPITULO 4: ANÁLISIS DE DATOS}

Las tablas incluidas en este capítulo reflejan todos los datos obtenidos en la investigación. Se han desarrollado gráficas asociadas a cada tabla para facilitar el análisis e interpretación de los datos.

\subsection{TABLAS Y GRÁFICOS}

Existen dos tipos de tablas que recogen los datos obtenidos de las FSG: (1) FSG que recogen los datos obtenidos por cada grupo de alumnos (FSG datos de alumnos); y, (2) FSG que recogen los sumatorios totales y porcentuales por clase (FSG sumatorios). En cada uno de los tres cursos escolares encontramos 4 tablas (a) y 8 gráficas (b).

(a)-Tablas: cada ámbito investigado (lecto-escritura y lógico-matemática) tiene dos FSG, en la primera aparecen los datos obtenidos por todo el alumnado del grupoclase y en la segunda los sumatorios totales y porcentuales de cada ámbito.

(b)-Gráficas: cada ámbito investigado (lecto-escritura y lógico-matemática) tiene cuatro gráficas; tres de ellas recogen los datos de los alumnos en relación a los indicadores de logro (D.122, BI y PET) y la cuarta gráfica realiza una comparativa entre los sumatorios totales y porcentuales de los indicadores anteriormente descritos.

En la tabla 4.1 puede verse todas las tablas y gráficas obtenidas, organizadas por curso escolar.

Tabla 4.1. Tablas y gráficas de los años 2010 al 2013

\begin{tabular}{|c|c|}
\hline \multicolumn{2}{|l|}{ Curso $2010 / 11$ (3ํㅡ El) } \\
\hline \multirow{4}{*}{$\begin{array}{l}\text { FSG datos alumnos lecto- } \\
\text { escritura: } 3^{\circ} \mathrm{EI} \text { (curso } \\
\text { 2010/11) }\end{array}$} & Gráfica datos de alumnos D.122 (\%): 3ํㅡ El lecto-escritura (curso 2010/11) \\
\hline & Gráfica datos de alumnos $\mathrm{BI}$ (\%): 3ํㅡㄹ lecto-escritura (curso 2010/11) \\
\hline & Gráfica datos de alumnos PET (\%): 3 El lecto-escritura (3 EI, curso 2010/11) \\
\hline & $\begin{array}{l}\text { Gráfica datos de alumnos comparativa indicadores logro (\%): 3ํㅡ lecto- } \\
\text { escritura (curso 2010/11) }\end{array}$ \\
\hline \multirow{4}{*}{$\begin{array}{l}\text { FSG sumatorios lecto- } \\
\text { escritura: } 3^{\circ} \mathrm{El} \text { (curso } \\
\text { 2010/11) }\end{array}$} & Gráfica sumatorio D.122 (\%): 3ํㅡ El lecto-escritura (curso 2010/11) \\
\hline & Gráfica sumatorio BI (\%): 3o El lecto-escritura (curso 2010/11) \\
\hline & Gráfica sumatorio PET (\%): 3ํㅡ El lecto-escritura (curso 2010/11) \\
\hline & $\begin{array}{l}\text { Gráfica sumatorio comparativa indicadores logro (\%): 3 El lecto escritura } \\
\text { (curso 2010/11) }\end{array}$ \\
\hline \multirow{4}{*}{$\begin{array}{l}\text { FSG datos alumnos lógico- } \\
\text { matemática: 3ํㅡI (curso } \\
\text { 2010/11) }\end{array}$} & Gráfica datos de alumnos D.122 (\%): 3 El lógico-matemática (curso 2010/11) \\
\hline & Gráfica datos de alumnos $\mathrm{BI}$ (\%): 3ํE El lógico-matemática (curso 2010/11) \\
\hline & Gráfica datos de alumnos PET (\%): 3ํE lógico-matemática (curso 2010/11) \\
\hline & $\begin{array}{l}\text { Gráfica datos de alumnos comparativa indicadores logro (\%): 3ํㅡ El lógico- } \\
\text { matemática (curso 2010/11) }\end{array}$ \\
\hline & Gráfica sumatorios D.122 (\%): 3ํㅡ El lógico-matemática (curso 2010/11) \\
\hline
\end{tabular}




\begin{tabular}{|c|c|}
\hline \multirow{3}{*}{$\begin{array}{l}\text { FSG sumatorios lógico- } \\
\text { matemática: 3ํE (curso } \\
\text { 2010/11) }\end{array}$} & Gráfica sumatorios BI (\%): 3ํㅡ El lógico-matemática (curso 2010/11) \\
\hline & Gráfica sumatorios PET (\%): 3ํE El lógico-matemática (curso 2010/11) \\
\hline & $\begin{array}{l}\text { Gráfica sumatorio comparativa indicadores logro (\%): 3ํE lógico matemáticas } \\
\text { (curso 2010/11) }\end{array}$ \\
\hline \multicolumn{2}{|l|}{ Curso 2011/12 (1ํㅡㄹ) } \\
\hline \multirow{4}{*}{$\begin{array}{l}\text { FSG datos alumnos lecto- } \\
\text { escritura: } 1^{\circ} \mathrm{EI} \text { (curso } \\
\text { 2011/12) }\end{array}$} & Gráfica datos de alumnos D.122 (\%): 1ํEl lecto-escritura (curso 2011/12) \\
\hline & Gráfica datos de alumnos BI (\%): 1ํE lecto-escritura (curso 2011/12) \\
\hline & Gráfica datos de alumnos PET (\%): 1ํㅡ El lecto-escritura 1ํ EI (curso 2011/12) \\
\hline & $\begin{array}{l}\text { Gráfica datos de alumnos comparativa indicadores logro (\%): 1ํㅡ El lecto- } \\
\text { escritura (curso 2011/12) }\end{array}$ \\
\hline \multirow{4}{*}{$\begin{array}{l}\text { FSG sumatorios lecto- } \\
\text { escritura: 1ํ EI (curso } \\
\text { 2011/12) }\end{array}$} & Gráfica sumatorio D.122 (\%): 1ํㅡ El lecto-escritura (curso 2011/12) \\
\hline & Gráfica sumatorio BI (\%): 1ํEl lecto-escritura (curso 2011/12) \\
\hline & Gráfica sumatorio PET (\%): 1ํEI lecto-escritura (curso 2011/12) \\
\hline & Gráfica sumatorio comparativa indicadores logro (\%): 1 El (curso 2011/12) \\
\hline \multirow{4}{*}{$\begin{array}{l}\text { FSG datos alumnos lógico- } \\
\text { matemática: 1 El (curso } \\
\text { 2011/12) }\end{array}$} & Gráfica datos de alumnos D.122 (\%): 1 El lógico-matemática (curso 2011/12) \\
\hline & Gráfica datos de alumnos BI (\%): 1 El lógico-matemática (curso 2011/12) \\
\hline & Gráfica datos de alumnos PET (\%): 1 El lógico-matemática (curso 2011/12) \\
\hline & $\begin{array}{l}\text { Gráfica datos de alumnos comparativa indicadores logro (\%): 1 El lógico } \\
\text { matemáticas (curso 2010/11) }\end{array}$ \\
\hline \multirow{4}{*}{$\begin{array}{l}\text { FSG sumatorios lógico- } \\
\text { matemática: 1ํㅡ (curso } \\
\text { 2011/12) }\end{array}$} & Gráfica sumatorio D.122 (\%): 1 El lógico-matemática (curso 2011/12) \\
\hline & Gráfica sumatorio BI (\%): 1 El lógico matemática (curso 2011/12) \\
\hline & Gráfica sumatorio PET (\%): 1ํEI lógico-matemática (curso 2011/12) \\
\hline & Gráfica sumatorio comparativa indicadores logro (\%): 1ํE (curso 2011/12) \\
\hline \multicolumn{2}{|l|}{ Curso 2012/13 (2 El) } \\
\hline \multirow{4}{*}{$\begin{array}{l}\text { FSG datos alumnos lecto- } \\
\text { escritura: } 2^{\circ} \text { El (curso } \\
\text { 2012/13) }\end{array}$} & Gráfica datos de alumnos D.122 (\%): 2º El lecto-escritura (curso 2012/13) \\
\hline & Gráfica datos de alumnos BI (\%): º El lecto-escritura (curso 2012/13) \\
\hline & Gráfica datos de alumnos PET (\%): 2 El lecto-escritura (curso 2012/13) \\
\hline & $\begin{array}{l}\text { Gráfica datos de alumnos comparativa indicadores logro (\%): } 2^{\circ} \text { El lecto- } \\
\text { escritura (curso 2012/13) }\end{array}$ \\
\hline \multirow{4}{*}{$\begin{array}{l}\text { FSG sumatorios lecto- } \\
\text { escritura: } 2^{\circ} \text { EI (curso } \\
2012 / 13 \text { ) }\end{array}$} & Gráfica sumatorio D.122 (\%): 2º El lecto-escritura (curso 2012/13) \\
\hline & Gráfica sumatorio BI (\%): 2 El lecto-escritura (curso 2012/13) \\
\hline & Gráfica sumatorio PET (\%): 2º lecto-escritura (curso 2012/13) \\
\hline & Gráfica sumatorio comparativa indicadores logro (\%): 2ํㅡ El (curso 2012/13) \\
\hline \multirow{4}{*}{$\begin{array}{l}\text { FSG datos alumnos lógico- } \\
\text { matemática: 2o El (curso } \\
\text { 2012/13) }\end{array}$} & Gráfica datos de alumnos D.122 (\%): 2º El lógico-matemática (curso 2012/13) \\
\hline & Gráfica datos de alumnos BI (\%): º El lógico-matemática (curso 2012/13) \\
\hline & Gráfica datos de alumnos PET (\%): º El lógico-matemática (curso 2012/13) \\
\hline & $\begin{array}{l}\text { Gráfica datos de alumnos comparativa indicadores logro (\%): ํㅡㄹ lógico- } \\
\text { matemática (curso 2012/13) }\end{array}$ \\
\hline \multirow{4}{*}{$\begin{array}{l}\text { FSG sumatorios lógico- } \\
\text { matemática: } 2^{\circ} \text { El (curso } \\
2012 / 13 \text { ) }\end{array}$} & Gráfica sumatorio D.122 (\%): 2º El lógico-matemática (curso 2012/13) \\
\hline & Gráfica sumatorio BI (\%): 2 El lógico matemática (curso 2012/13) \\
\hline & Gráfica sumatorio PET (\%): 2º El lógico-matemática (curso 2012/13) \\
\hline & Gráfica sumatorio comparativa indicadores logro (\%): 2ํㅡ El (curso 2012/13) \\
\hline
\end{tabular}


A continuación, explicaremos los aspectos genéricos de todas las tablas y gráficas y posteriormente analizaremos los datos obtenidos en cada una de ellas en los distintos cursos escolares.

\subsubsection{TABLAS FSG CON DATOS DE ALUMNOS}

Cada tabla de FSG con datos de los alumnos está constituida por una serie de filas. La primera fila indica los sujetos participantes en la investigación durante un curso escolar; para preservar su anonimato y confidencialidad han sido enumerados sucesivamente. La segunda fila indica los cuatro periodos en los que se ha evaluado a cada alumno (ver tabla 4.2).

Tabla 4.2. Clave y significado

\begin{tabular}{|l|l|}
\hline Clave & Significado \\
\hline $\mathrm{I}$ & Inicio del curso \\
\hline $1^{\circ}$ & Final del primer trimestre \\
\hline $2^{0}$ & Final del segundo trimestre \\
\hline $\mathrm{F}$ & Final del curso \\
\hline
\end{tabular}

El siguiente grupo de líneas nos indican la valoración que ha conseguido cada alumno en cada periodo. Cada fila corresponde a un tipo de indicadores de logro evaluado. Estos se agrupan por objetivos didácticos, que a su vez se divide en tres indicadores de logro en base a su procedencia (ver tabla 4.3).

Tabla 4.3. Clave y significado

\begin{tabular}{|c|c|}
\hline Clave & Significado \\
\hline D.122 & $\begin{array}{l}\text { El currículo oficial de Castilla y León (Decreto } 122 / 2007) \text {, marca unos objetivos generales que } \\
\text { deben ser alanzados a lo largo del segundo ciclo de El; no vienen definidos por cursos, no } \\
\text { obstante, han sido concretados para cada uno de los niveles }\left(1^{\circ}, 2^{\circ} \text { y } 3^{\circ}\right) \text {. }\end{array}$ \\
\hline $\mathrm{BI}$ & $\begin{array}{l}\text { Corresponde a los objetivos que se esperan que cada alumno alcance al terminar el curso } \\
\text { escolar. Éstos vienen definidos por el centro a través de los boletines informativos (BI). }\end{array}$ \\
\hline PET & $\begin{array}{l}\text { Siglas correspondientes al programa de estimulación temprana, puesto en práctica a lo largo del } \\
\text { curso escolar donde se han definido unos objetivos más ambiciosos que los que marca la ley. }\end{array}$ \\
\hline
\end{tabular}

Aclarar que se ha seguido una escala Linkert; esta escala es una herramienta de medición que nos permite medir el grado de consecución de cada sujeto. Para ello se han dado una escala de valoración que asigna valores entre 0 y 4 ; siendo: (0) totalmente en 
desacuerdo, (1) en desacuerdo, (2) ni acuerdo ni desacuerdo, (3) de acuerdo y (4) totalmente de acuerdo.

Finalmente, los datos obtenidos por cada indicador de logro se recogen en las últimas filas de forma total y porcentual. Se han agrupado según la procedencia del indicador (véase tabla 4.4).

Tabla 4.4. Clave y significado

\begin{tabular}{|l|l|}
\hline Clave & Significado \\
\hline $\begin{array}{l}\text { Sumatorio } \\
\text { D.122 }\end{array}$ & $\begin{array}{l}\text { Se han recogido para cada alumno y periodo evaluado todos los valores correspondientes al } \\
\text { D.122 de cada uno de los objetivos, por tanto nos movemos en valores comprendidos entre } 0 \text { y el } \\
\text { máximo indicado en la explicación de cada tabla. }\end{array}$ \\
\hline $\begin{array}{l}\text { Sumatorio } \\
\mathrm{BI}\end{array}$ & $\begin{array}{l}\text { Se han recogido para cada alumno y periodo evaluado todos los valores correspondientes al BI } \\
\text { de cada uno de los objetivos; a diferencia del caso anterior hay objetivos didácticos que no tienen } \\
\text { indicador Bl asociado, por los que los valores comprendidos varían. El valor máximo posible será } \\
\text { indicado en la explicación particular de cada tabla. }\end{array}$ \\
\hline $\begin{array}{l}\text { Sumatorio } \\
\text { PET }\end{array}$ & $\begin{array}{l}\text { Se han recogido para cada alumno y periodo evaluado todos los valores correspondientes a PET } \\
\text { de los objetivos. Como en el primer caso nos movemos en valores comprendidos entre 0 y el } \\
\text { máximo indicado en la explicación de cada tabla. }\end{array}$ \\
\hline
\end{tabular}

En las tres filas siguientes se muestran los valores anteriores en términos porcentuales. El valor 0 corresponde al $0 \%$ en la escala porcentual, y los valores máximos corresponde al $100 \%$. En la última fila encontramos el sumatorio total de cada uno de los sujetos durante los diferentes periodos escolares, pasado a valores porcentuales para facilitar la interpretación y comprensión de los datos registrados en la gráfica correspondiente.

\subsubsection{TABLAS FSG CON SUMATORIOS}

La información está organizada de forma análoga a las FSG con datos de alumnos, con la salvedad de que en estas tablas las columnas recogen la suma de los valores obtenidos por toda la clase. Los valores se muestran en 4 periodos (I, $1^{\circ}, 2^{\circ}$ y $F$ ) de forma total y porcentual. Igualmente que en el caso anterior, las últimas filas reflejan los datos obtenidos por toda la clase, agrupados por la procedencia de los indicadores (D.122, BI y PET) y de forma total.

Los datos totales comprenden valores entre 0 y el máximo que dependerá del número de sujetos de la clase; es decir, si hay 10 alumnos el valor máximo será 40 . Este valor se indicará en el análisis particular de cada tabla. 


\section{CAPITULO 4: ANÁLISIS DE DATOS}

\subsubsection{GRÁFICAS}

Se han desarrollado gráficas para analizar los resultados de las distintas FSG. Para ello se han utilizado los valores porcentuales, puesto que son más fácilmente comparables entre los diferentes tipos de indicadores. Encontramos un total de 8 gráficas referentes a lectoescritura y 8 en relación a la lógico-matemática.

Para facilitar el análisis se ha seguido un código de colores, asociando a cada tipo de indicador un color concreto: (1) indicador de logro D.122: color azul; (2) indicador de logro BI: color rojo; (3) indicador de logro PET: color verde.

\subsubsection{Gráficas datos de alumnos}

Encontramos dos tipos de gráficas que recogen los datos obtenidos en los indicadores de logro total de la clase (a) las gráficas con datos de alumnos de cada uno de los indicadores de logro y (b) las gráficas de datos de alumnos que compara los tres indicadores.

a) Gráficas datos de alumnos (D.122, BI y PET): cada gráfica indica el grado de consecución del indicador de logro en cada periodo evaluado alcanzado por cada uno de los alumnos de una misma clase, de esta forma se refleja la evolución de cada sujeto en cada uno de los indicadores. Existen tres gráficas para lecto-escritura y tres para lógicomatemática.

b) Gráficas datos de alumnos comparativa indicadores de logro: incluye los valores hallados en valores porcentuales por las gráficas anteriores; de esta forma se puede comparar la evolución de todos los alumnos de la clase en cada tipo de indicador. Contamos con una única grafica sumatorio total tanto en lecto-escritura como en lógico-matemática.

\subsubsection{Gráficas sumatorio}

Como en el caso anterior, encontramos dos tipos de gráficas que recogen los datos obtenidos por los sumatorios totales de cada uno de los indicadores de logro; con la salvedad que en estas gráficas no se especifica la evolución de cada uno de los sujetos del aula, sino que se muestra los valores hallados por el grupo clase en cada periodo evaluado.

Los dos tipos de gráficas son: (a) gráficas sumatorio de cada uno de los indicadores de logro y (b) las gráficas sumatorio que compara las gráficas sumatorios anteriores. 
a) Gráficas sumatorio de los indicadores de logro (D.122, BI y PET): cada gráfica indica el grado de consecución del indicador de logro en cada periodo evaluado alcanzado por la totalidad de la clase, de esta forma se refleja la evolución del grupo en cada uno de los indicadores. Existen tres gráficas para lecto-escritura y tres para lógico-matemática.

b) Gráficas sumatorio comparativa indicadores de logro: incluye los valores hallados en valores porcentuales por las gráficas anteriores; de esta forma se puede comparar la evolución de la clase en cada tipo de indicador. Contamos con una única grafica sumatorio total en lecto-escritura y otra en lógico-matemática.

\subsection{INTERPRETACIÓN DE DATOS}

\subsubsection{CURSO ESCOLAR 2010/11}

Durante este curso escolar, los 14 alumnos se encuentran en el $3^{\circ}$ curso del $2^{\circ}$ ciclo de El (5-6 años), de los cuales la mitad son niños y la otra mitad niñas. El ritmo general del aula es bueno, alumnos trabajadores y con buenas aptitudes, es un grupo muy movido que precisa de normas muy marcadas para regular su comportamiento. Existen unas relaciones afectivas fuertes entre todos los alumnos, puesto que es un grupo que lleva desde $1^{\circ}$ de El juntos, siempre conmigo de tutora.

Dos de los alumnos poseen necesidades específicas de apoyo educativo (ACNEAE): el sujeto 13 posee un trastorno de la comunicación y del lenguaje no significativo y el sujeto 14 es un alumno con necesidades de compensatoria educativa. Por ello, el sujeto 13 es apoyado por el maestro de audición y lenguaje durante tres sesiones semanales fuera del aula y el sujeto 14 recibe apoyo por parte del especialista de compensatoria durante dos sesiones semanales dentro y fuera del aula.

\subsubsection{Tablas y gráficos de lecto-escritura}

En la tabla 4.5 se han recogido los datos obtenidos para el curso 2010/11 en relación al ámbito lecto-escritor. En la primera columna se especifican los 7 objetivos didácticos de referencia para cada alumno durante ese curso escolar. A lo largo de la segunda columna, se concretan los objetivos a alcanzar en cada indicador de logro (D.122, BI y PET); puntualizar que en el caso de $\mathrm{Bl}$ existen dos objetivos que no contemplan este indicador (escritura de frases y producción de mensajes sencillos), por tanto, los valores hallados se moverán en un rango comprendido entre $0-20$, siendo 0 el valor mínimo y 20 el valor máximo; el resto de 
CAPITULO 4: ANÁLISIS DE DATOS

indicadores de logro (D. 122 y BI) están presentes en todos los objetivos didácticos de la tabla; se moverán en un rango de 0-28, siendo 0 el valor mínimo y 28 el valor máximo. Finalmente, en el resto de columnas se recogen los datos obtenidos por los 14 sujetos participantes en la investigación durante los 4 periodos de referencia (principio de curso y final de los tres trimestres). 
Tabla 4.5. FSG datos alumnos lecto-escritura: 3으 El (curso 2010/11)

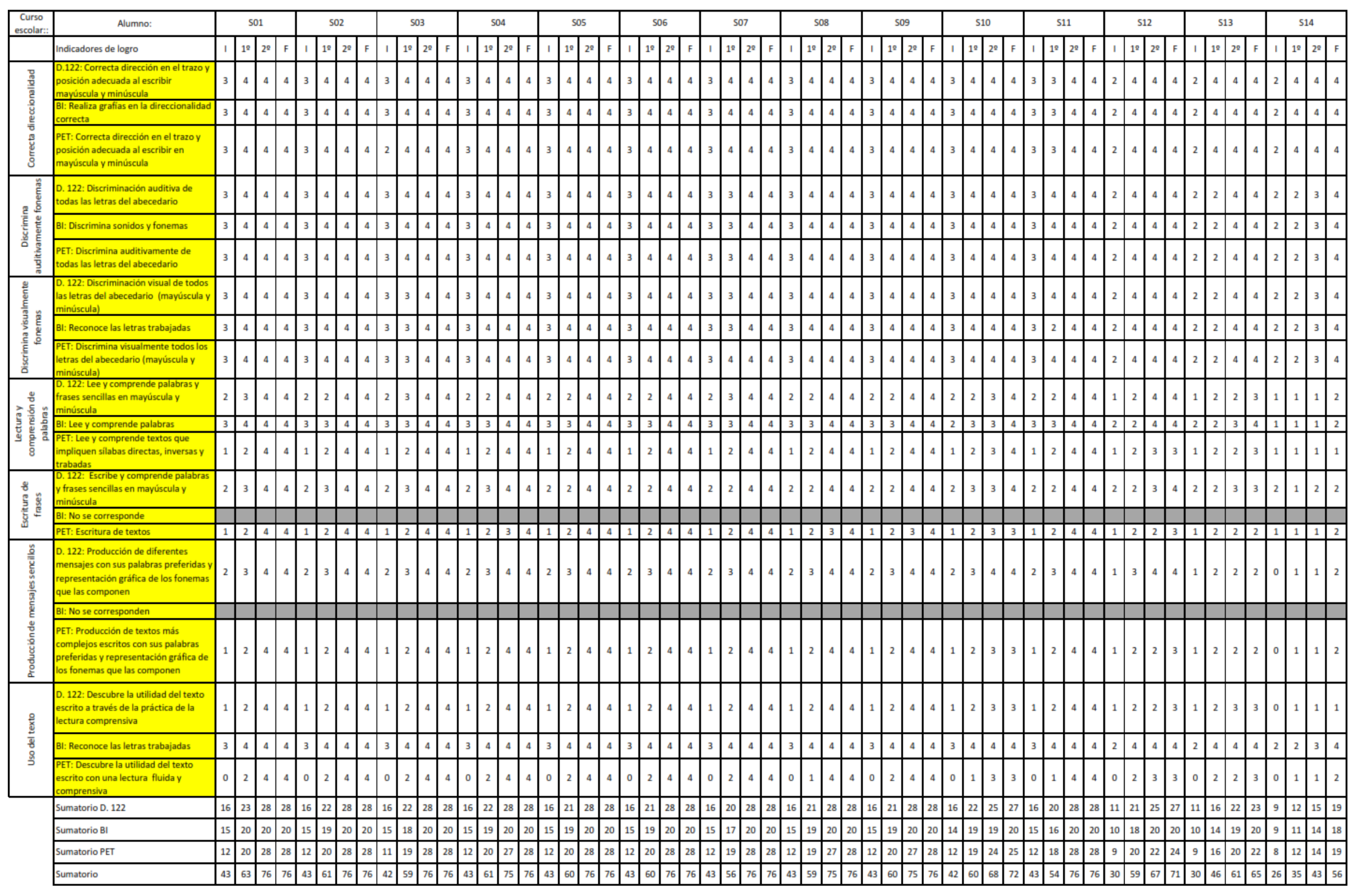


A partir de los datos de la tabla 4.5 se han elaborado 4 gráficas para facilitar su interpretación (figuras 4.1, 4.2, 4.3 y 4.4).

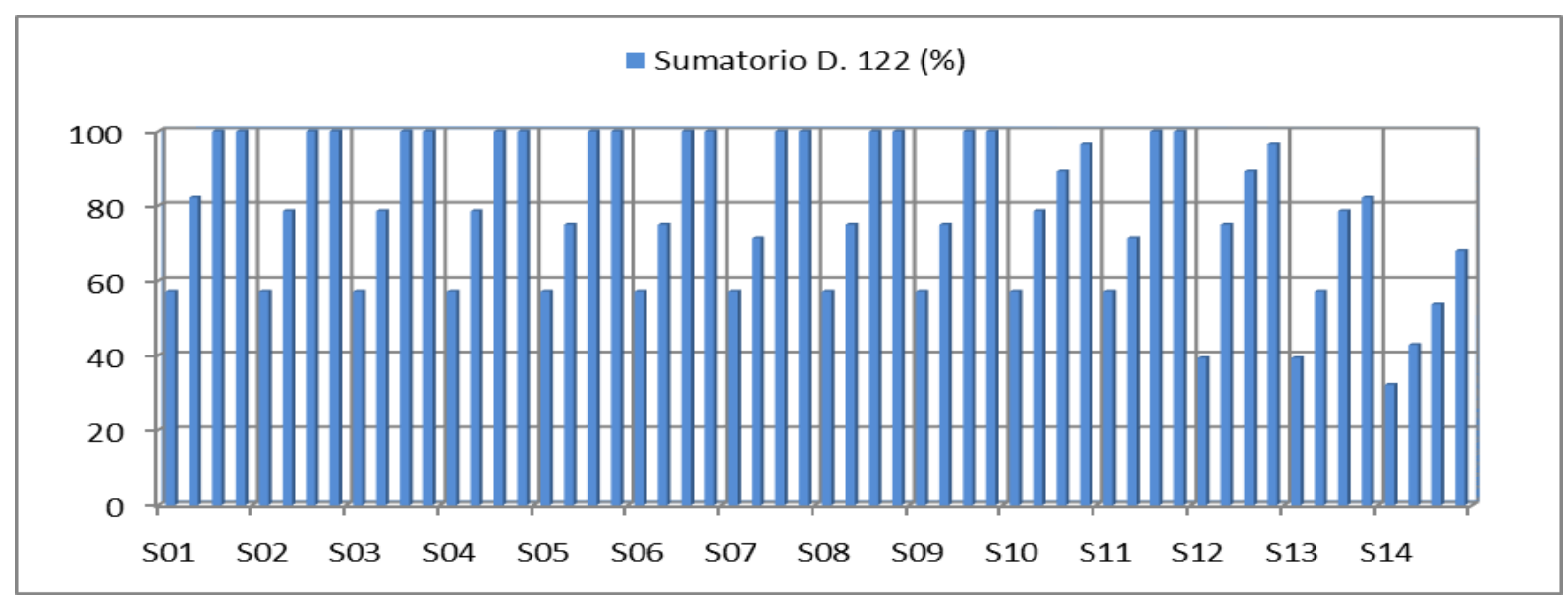

Figura 4.1. Gráfica datos alumnos D.122 (\%): 3ํㅡ El lecto-escritura (curso 2010/11)

Como se observa en la figura 4.1 los sujetos poseen un nivel inicial de partida muy alto, 10 de los 14 sujetos parten con un $57 \%$ de los objetivos conseguidos en el tramo inicial propuestos por el indicador D.122; el resto de alumnos se mueven en valores comprendidos entre el 30-40\%. Estos 10 sujetos alcanzan el valor total en la escala en el segundo trimestre; respecto a los otros 4 alumnos restantes que no consiguen alcanzar el $100 \%$ de los objetivos establecidos, dos de ellos se quedan muy cerca de conseguirlo (alcanzan un valor del 96\%) y los otros dos sujetos (sujeto 13 y sujeto 14 ) alcanzan el $82 \%$ y $68 \%$ de la puntuación total ya que son alumnos con necesidades específica de apoyo educativo que requieren más tiempo y medidas más específicas en su día a día que el resto de alumnado.

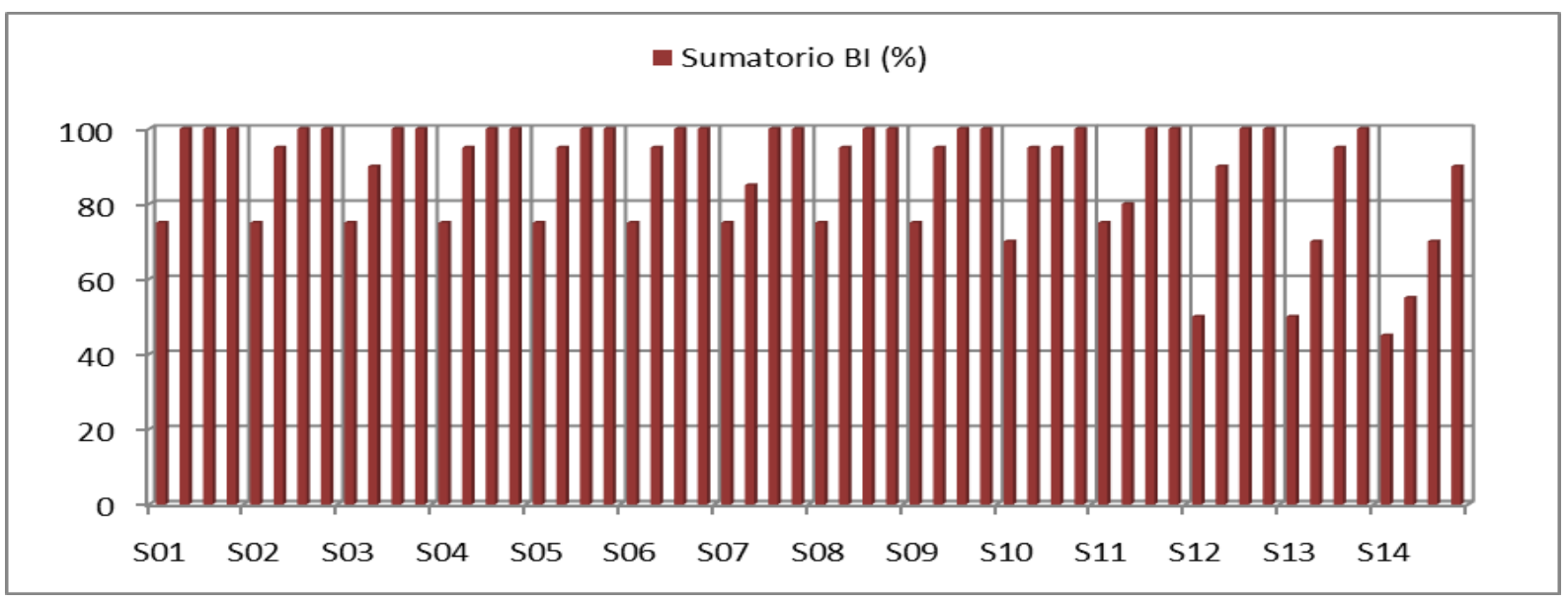

Figura 4.2. Gráfica datos alumnos BI (\%): 3ํㅡㄹ lecto-escritura (curso 2010/11)

El nivel inicial de partida que muestra la figura 4.2 es incluso mayor que la figura anterior, de los 14 integrantes del aula 11 sujetos parten con valores iguales o superiores al $70 \%$ y los 3 restantes se mueven con valores comprendidos entre el $45-50 \%$. En este caso, 


\section{CAPITULO 4: ANÁLISIS DE DATOS}

los objetivos marcados por el indicador BI son alcanzados por todos los alumnos, excepto por el sujeto con necesidades de compensatoria educativa. El sujeto 01 consigue los objetivos propuestos al finalizar el primer trimestre y 9 sujetos más se quedan a escasos puntos de conseguirlo (alcanzan valores comprendidos entre el 90-95\%); 10 sujetos alcanzan los objetivos en el segundo trimestre y únicamente el S14 no consigue los objetivos programados, sin embargo alcanza una puntuación total en la escala del $90 \%$.

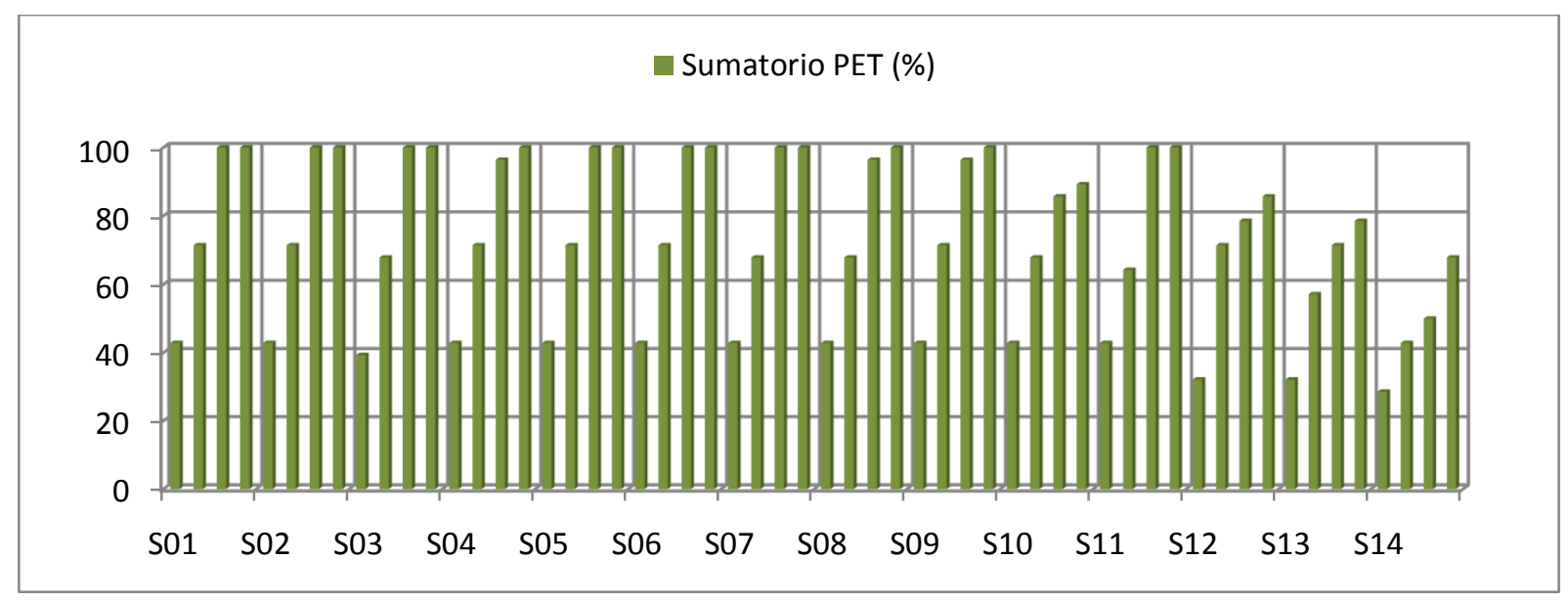

Figura 4.3. Gráfica datos alumnos PET (\%): 3ํㅡ El lecto-escritura (curso 2010/11)

En la figura 4.3 se muestra el nivel inicial de partida del PET en relación a la lectoescritura, alcanzando valores comprendidos entre el 30-40\%. Observamos que 11 de los 14 alumnos han alcanzado en su totalidad todos los objetivos marcados, incluso 10 de ellos lo han conseguido antes del tiempo esperado (durante el $2^{\circ}$ trimestre). Por otro lado, existen 4 alumnos que no alcanzan la totalidad de los objetivos propuestos por el indicador PET; sin embargo, 3 de ellos lograron niveles muy altos (alcanzando valores iguales y superiores al $80 \%$ ), siendo el sujeto 14 (alumno ACNEAE) quien consigue un $68 \%$ total del valore en la escala.

La siguiente gráfica (ver figura 4.4) nos permite ver la evolución de todos los alumnos en cada uno de los de indicadores de logro, comparando la respuesta de cada alumno en cada indicador en relación a la lecto-escritura durante el curso escolar 2010/11. 


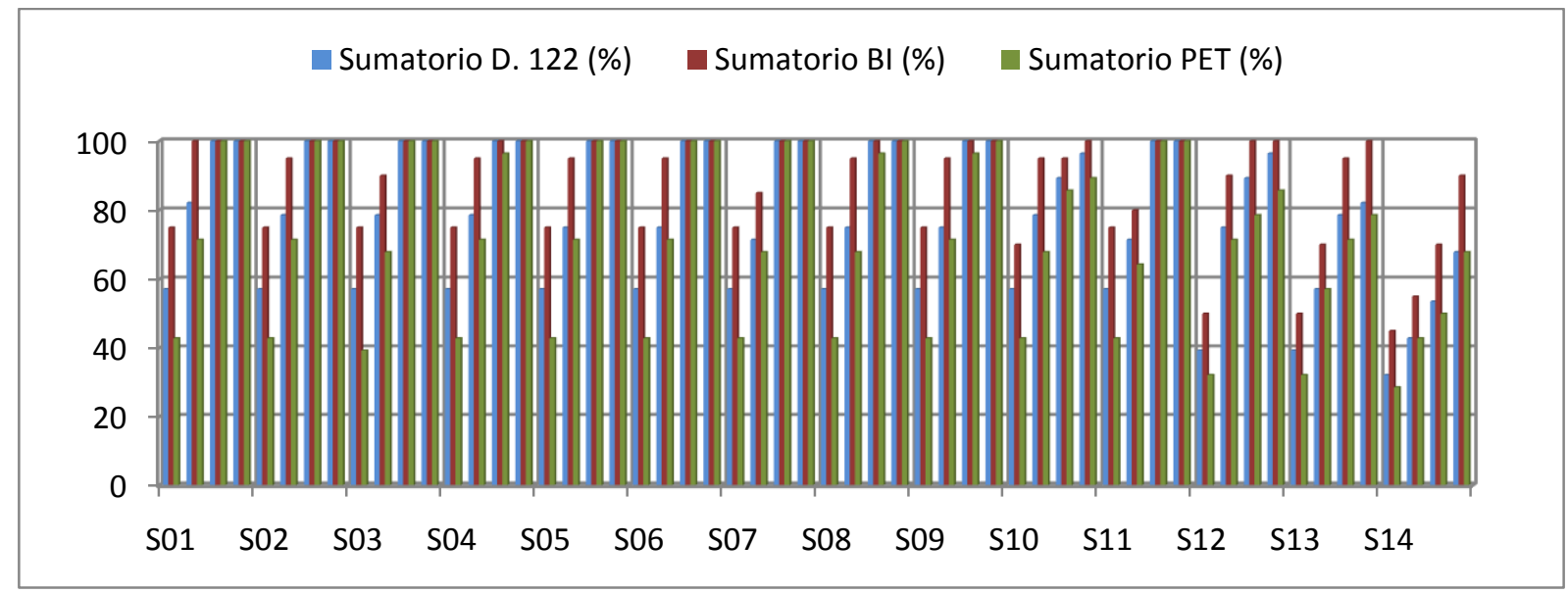

Figura 4.4. Gráfica datos de alumnos comparativa indicadores logro (\%): 3 ํ El lecto-escritura (curso 2010/11)

Hay que tener en cuenta que los objetivos propuestos por PET son mucho más exigentes que el de resto de indicadores, factor determinante en la interpretación de los datos. Como se observa en la gráfica 4.4 , todos los alumnos parten de un valor inicial por encima de los 30 puntos en la escala (entre $45-55 \%$ en el indicador D.122, entre $40-75 \%$ en el indicador $\mathrm{BI}$ y entre $30-40 \%$ en el indicador PET) esto indica un nivel medio-alto en el ritmo general del aula. Existe una evolución constante en todos los periodos evaluados, registrándose mayor avance en el primer trimestre.

7 de los 14 sujetos consiguen los objetivos propuestos por los tres indicadores al finalizar el segundo trimestre y otros 3 se quedan muy cerca de conseguirlo (alcanzan el valor máximo en los indicadores $\mathrm{D} .122$ y $\mathrm{BI}$ y obtienen un valor del $96 \%$ en el indicador PET) alcanzando la puntuación máxima de la escala en el tercer trimestres. De los 4 sujetos restantes el sujeto 10 y el sujeto 12 alcanzan el $100 \%$ en el indicador $\mathrm{BI}$ y consiguen valores por encima del 95\% en el resto de indicadores. En cuanto a los sujeto 13 y sujeto 14, alumnos ACNEAE, el sujeto 13 alcanza valores más altos que el sujeto 14 consiguiendo el $100 \%$ en la consecución de los objetivos propuestos por el BI obteniendo valores próximos o superiores al $80 \%$ en el resto de indicadores; sin embargo el sujeto 14 es el único alumno que no consigue alcanzar el valor máximo en ningún indicador, registrándose una consecución mayor de los objetivos programados por el indicador $\mathrm{BI}$ (del 90\%).

Una vez explicada la tabla 4.5 y las 4 gráficas asociadas a esta tabla, pasamos a interpretar los valores hallados por la tabla 4.6 y sus gráficas correspondientes. En la tabla 4.6 se muestran los valores obtenidos a nivel grupal de toda la clase en los tres tipos de indicadores, en relación a los 7 objetivos didácticos de referencia para el ámbito lecto-escritor en el curso 2010/11. En las últimas filas encontramos los sumatorios de cada indicador (D. 122, $\mathrm{BI}$ y PET) en los 4 periodos evaluados (inicio del curso, primer trimestre, segundo trimestre y final de curso). 


\section{CAPITULO 4: ANÁLISIS DE DATOS}

Dado que contamos con 14 alumnos y el valor más alto de la escala es 4 , el valor máximo que se puede alcanzar en cada indicador será 56 . Por tanto, nos moveremos en un rango entre $0-56$, correspondiendo 56 al $100 \%$ del valor porcentual. 


\section{CAPITULO 4: ANÁLISIS DE DATOS}

Tabla 4.6. FSG sumatorios lecto-escritura: 3ํㅡ El (curso 2010/11)

\begin{tabular}{|c|c|c|c|c|c|c|c|c|c|}
\hline \multirow{2}{*}{$\begin{array}{c}\text { Curso } \\
\text { escolar:: }\end{array}$} & Alumno: & \multicolumn{4}{|c|}{ SUMATORIO GRUPAL } & \multicolumn{4}{|c|}{ SUMATORIO GRUPAL (\%) } \\
\hline & Indicadores de logro & 1 & $1^{2}$ & $2^{2}$ & $\mathbf{F}$ & $\mathbf{I}$ & 12 & $2^{2}$ & $\mathrm{~F}$ \\
\hline \multirow{3}{*}{ 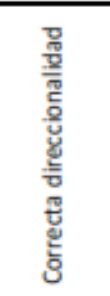 } & $\begin{array}{l}\text { D.122: Correcta dirección en el trazo y } \\
\text { posición adecuada al escribir } \\
\text { mayúscula y minúscula }\end{array}$ & 39 & 55 & 56 & 56 & $69,6 \%$ & $98,2 \%$ & $100,0 \%$ & $100,0 \%$ \\
\hline & $\begin{array}{l}\text { Bl: Realiza grafias en la direccionalidad } \\
\text { correcta }\end{array}$ & 39 & 55 & 56 & 56 & $69,6 \%$ & $98,2 \%$ & $100,0 \%$ & $100,0 \%$ \\
\hline & $\begin{array}{l}\text { PET: Correcta dirección en el trazo y } \\
\text { posición adecuada al escribir en } \\
\text { mayúscula y minúscula }\end{array}$ & 38 & 55 & 56 & 56 & $67,9 \%$ & $98,2 \%$ & $100,0 \%$ & $100,0 \%$ \\
\hline \multirow{3}{*}{ 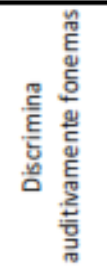 } & $\begin{array}{l}\text { D. 122: Discriminación auditiva de } \\
\text { todas las letras del abecedario }\end{array}$ & 39 & 51 & 55 & 56 & $69,6 \%$ & $91,1 \%$ & $98,2 \%$ & $100,0 \%$ \\
\hline & BI: Discrimina sonidos y fonemas & 39 & 51 & 55 & 56 & $69,6 \%$ & $91,1 \%$ & $98,2 \%$ & $100,0 \%$ \\
\hline & $\begin{array}{l}\text { PET: Discrimina auditivamente de } \\
\text { todas las letras del abecedario }\end{array}$ & 39 & 51 & 55 & 56 & $69,6 \%$ & $91,1 \%$ & $98,2 \%$ & $100,0 \%$ \\
\hline \multirow{3}{*}{ 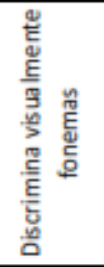 } & $\begin{array}{l}\text { D. 122: Discriminación visual de todos } \\
\text { las letras del abecedario (mayúscula y } \\
\text { minúscula) }\end{array}$ & 39 & 50 & 55 & 56 & $69,6 \%$ & $89,3 \%$ & $98,2 \%$ & $100,0 \%$ \\
\hline & BI: Reconoce las letras trabajadas & 39 & 48 & 55 & 56 & $69,6 \%$ & $85,7 \%$ & $98,2 \%$ & $100,0 \%$ \\
\hline & $\begin{array}{l}\text { PET: Discrimina visualmente todos los } \\
\text { letras del abecedario (mayúscula y } \\
\text { minúscula) }\end{array}$ & 39 & 51 & 55 & 56 & $69,6 \%$ & $91,1 \%$ & $98,2 \%$ & $100,0 \%$ \\
\hline \multirow{3}{*}{ 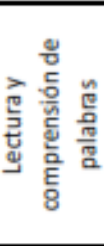 } & $\begin{array}{l}\text { D. 122: Lee y comprende palabras y } \\
\text { frases sencillas en mayúscula y } \\
\text { minúscula }\end{array}$ & 25 & 30 & 50 & 53 & $44,6 \%$ & $53,6 \%$ & $89,3 \%$ & $94,6 \%$ \\
\hline & BI: Lee y comprende palabras & 37 & 39 & 51 & 54 & $66,1 \%$ & $69,6 \%$ & $91,1 \%$ & $96,4 \%$ \\
\hline & $\begin{array}{l}\text { PET: Lee y comprende textos que } \\
\text { impliquen sílabas directas, inversas y } \\
\text { trabadas }\end{array}$ & 14 & 27 & 49 & 51 & $25,0 \%$ & $48,2 \%$ & $87,5 \%$ & $91,1 \%$ \\
\hline \multirow{3}{*}{ 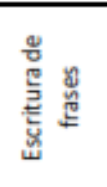 } & $\begin{array}{l}\text { D. 122: Escribe y comprende palabras } \\
\text { y frases sencillas en mayúscula y } \\
\text { minúscula }\end{array}$ & 28 & 32 & 51 & 53 & $50,0 \%$ & $57,1 \%$ & $91,1 \%$ & $94,6 \%$ \\
\hline & BI: No se corresponde & & & & & & & & \\
\hline & PET: Escritura de textos & 14 & 27 & 45 & 50 & $25,0 \%$ & $48,2 \%$ & $80,4 \%$ & $89,3 \%$ \\
\hline \multirow{3}{*}{ 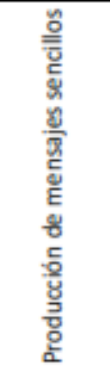 } & $\begin{array}{l}\text { D. 122: Producción de diferentes } \\
\text { mensajes con sus palabras preferidas y } \\
\text { representación gráfica de los fonemas } \\
\text { que las componen }\end{array}$ & 24 & 39 & 51 & 52 & $42,9 \%$ & $69,6 \%$ & $91,1 \%$ & $92,9 \%$ \\
\hline & BI: No se corresponden & & & & & & & & \\
\hline & $\begin{array}{l}\text { PET: Producción de textos más } \\
\text { complejos escritos con sus palabras } \\
\text { preferidas y representación gráfica de } \\
\text { los fonemas que las componen }\end{array}$ & 13 & 27 & 48 & 50 & $23,2 \%$ & $48,2 \%$ & $85,7 \%$ & $89,3 \%$ \\
\hline \multirow{7}{*}{ 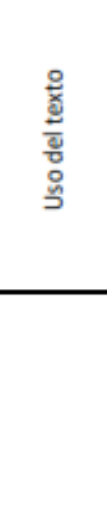 } & $\begin{array}{l}\text { D. 122: Descubre la utilidad del texto } \\
\text { escrito a través de la práctica de la } \\
\text { lectura comprensiva }\end{array}$ & 13 & 27 & 49 & 50 & $23,2 \%$ & $48,2 \%$ & $87,5 \%$ & $89,3 \%$ \\
\hline & BI: Reconoce las letras trabajadas & 39 & 54 & 55 & 56 & $69,6 \%$ & $96,4 \%$ & $98,2 \%$ & $100,0 \%$ \\
\hline & $\begin{array}{l}\text { PET: Descubre la utilidad del texto } \\
\text { escrito con una lectura fluida y } \\
\text { comprensiva }\end{array}$ & 0 & 24 & 49 & 51 & $0,0 \%$ & $42,9 \%$ & $87,5 \%$ & $91,1 \%$ \\
\hline & Sumatorio D. 122 & 207 & 284 & 367 & 376 & $52,8 \%$ & $72,4 \%$ & $93,6 \%$ & $95,9 \%$ \\
\hline & Sumatorio BI & 193 & 247 & 272 & 278 & $68,9 \%$ & $88,2 \%$ & $97,1 \%$ & $99,3 \%$ \\
\hline & Sumatorio PET & 157 & 262 & 357 & 370 & $40,1 \%$ & $66,8 \%$ & $91,1 \%$ & $94,4 \%$ \\
\hline & Sumatorio & 557 & 793 & 996 & 1024 & $52,3 \%$ & $74,5 \%$ & $93,6 \%$ & $96,2 \%$ \\
\hline
\end{tabular}




\section{CAPITULO 4: ANÁLISIS DE DATOS}

Asociada a la tabla 4.6 se han elaborado 4 gráficas para facilitar la interpretación de los datos; éstas pueden verse en las figuras $4.5,4.6,4.7$ y 4.8 .

En la siguiente gráfica (ver figura 4.5) podemos ver los valore porcentuales hallados por toda la clase en relación al D.122.

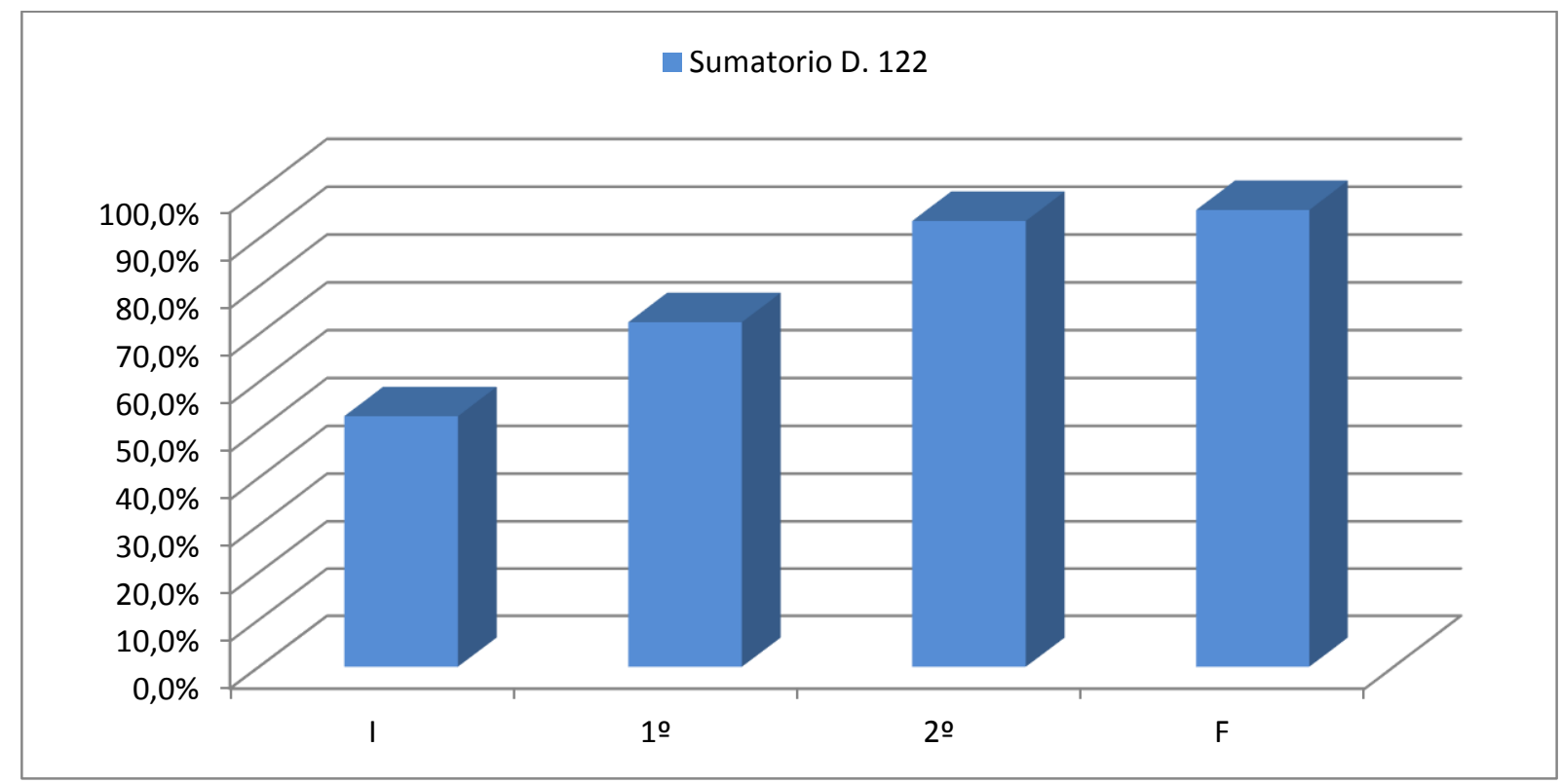

Figura 4.5. Gráfica sumatorio D.122 (\%): 3ํㅡ El lecto-escritura (curso 2010/11)

Como se observa en la gráfica, se parte de un valor inicial por encima del $50 \%$ de la puntuación total en la escala, experimentando una evolución constante hasta el $2^{\circ}$ trimestre donde se produce una evolución más lenta ya que se alcanza un valor del 93,6\% del valor total, llegando al 95,9\% en el último tramo evaluado; lo que implica que casi la totalidad del grupo ha conseguido los objetivos propuestos por el D. 122.

En la siguiente gráfica (véase figura 4.6) podemos observar la evolución obtenida por toda la clase en relación al indicador BI. 


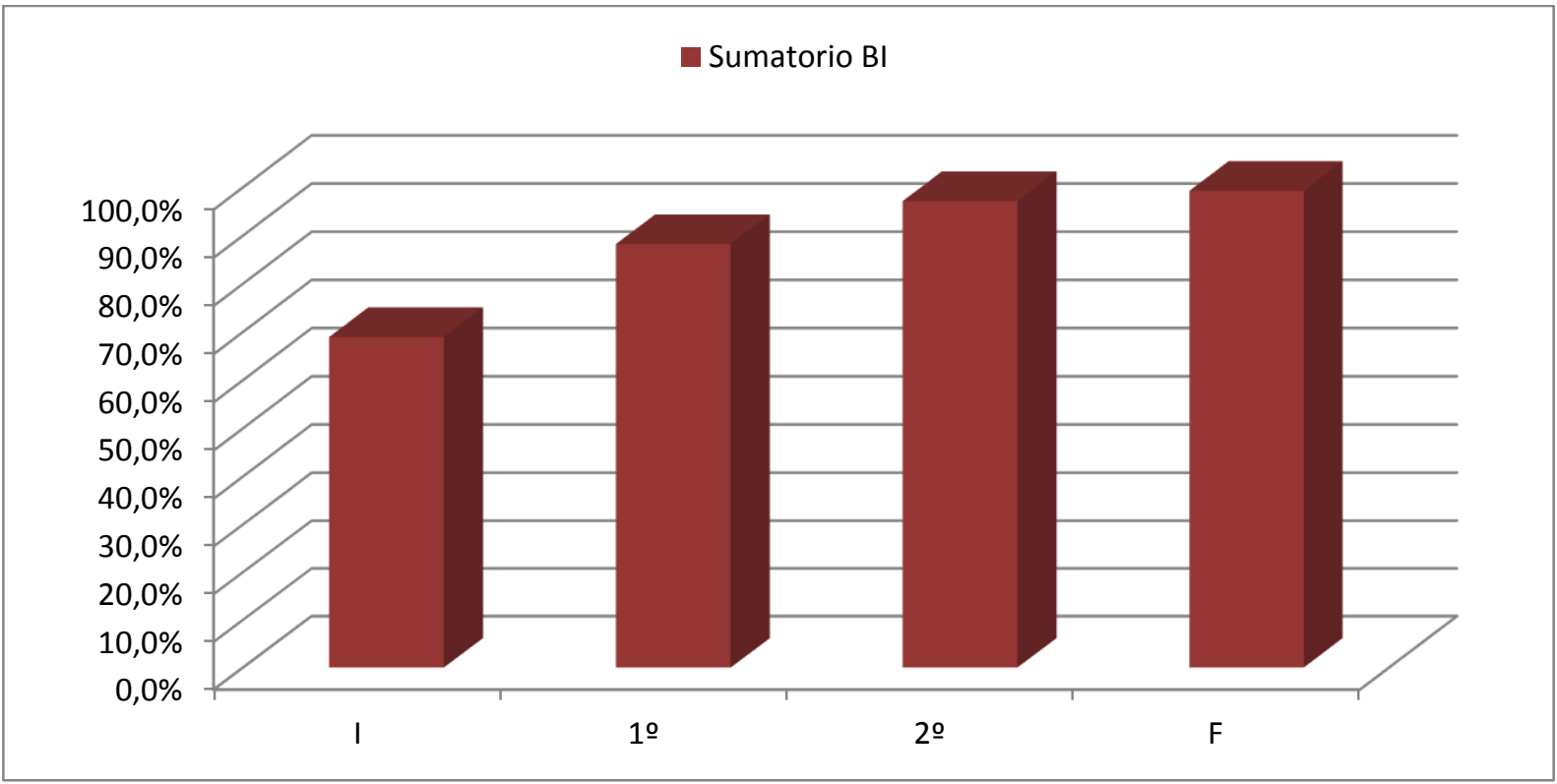

Figura 4.6. Gráfica sumatorio BI (\%): 3ํEl lecto-escritura (curso 2010/11)

Puede observarse una evolución muy similar a la vista en la figura anterior. Partimos de un valor inicial aún más alto que en el caso anterior (del 68,9\%) y existe una evolución significativa hasta el final del $2^{\circ}$ trimestre; después la evolución con respecto al final de curso es muy baja, debido a que la clase alcanza valores muy altos en la consecución de los objetivos en el segundo trimestre. En este caso, la clase alcanza un 97,1\% de los objetivos propuestos por el D.122 en el segundo trimestre, consiguiendo un 99,3\% de puntuación total al finalizar el curso.

En la siguiente gráfica (véase figura 4.7), mostramos los datos obtenidos por toda la clase en relación al indicador PET.

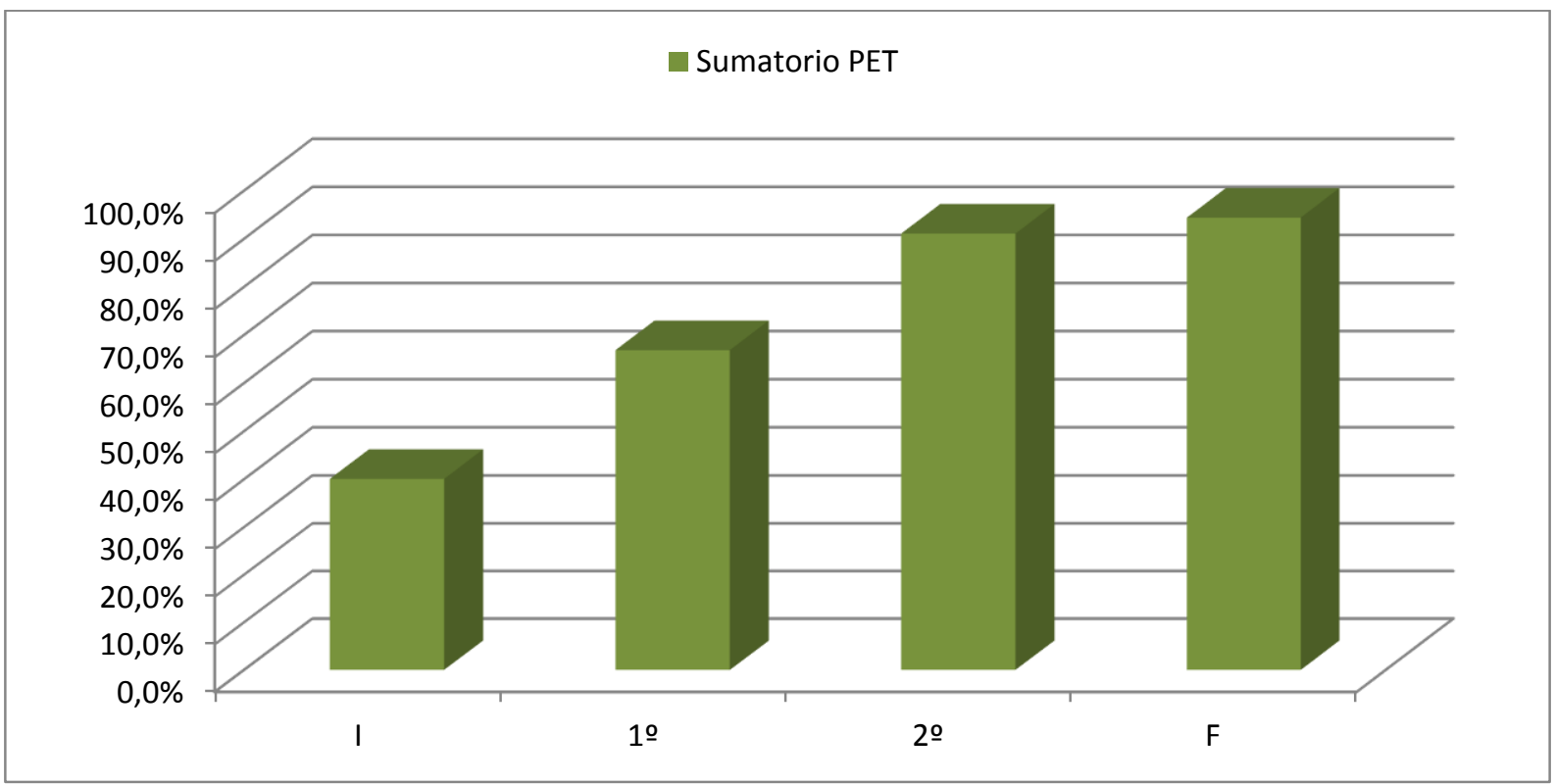




\section{CAPITULO 4: ANÁLISIS DE DATOS}

Figura 4.7. Gráfica sumatoria PET (\%): 3 El lecto-escritura (curso 2010/11)

La evolución inicial es similar a las figuras 4.5 y 4.6; partimos de un valor inicial del $40 \%$, existe una evolución constante hasta el segundo trimestre, donde se produce un crecimiento más lento en la consecución de los objetivos. Los valores hallados en el primer trimestre alcanzan una puntuación del $66,8 \%$, del $91,1 \%$ en el segundo trimestre y del $94,4 \%$ al finalizar el curso.

Finalmente, en la figura 4.8 mostramos la evolución conseguida por todos los alumnos, realizando una comparativa de los tres indicadores de logro de lecto-escritura a lo largo del curso 2010/11.

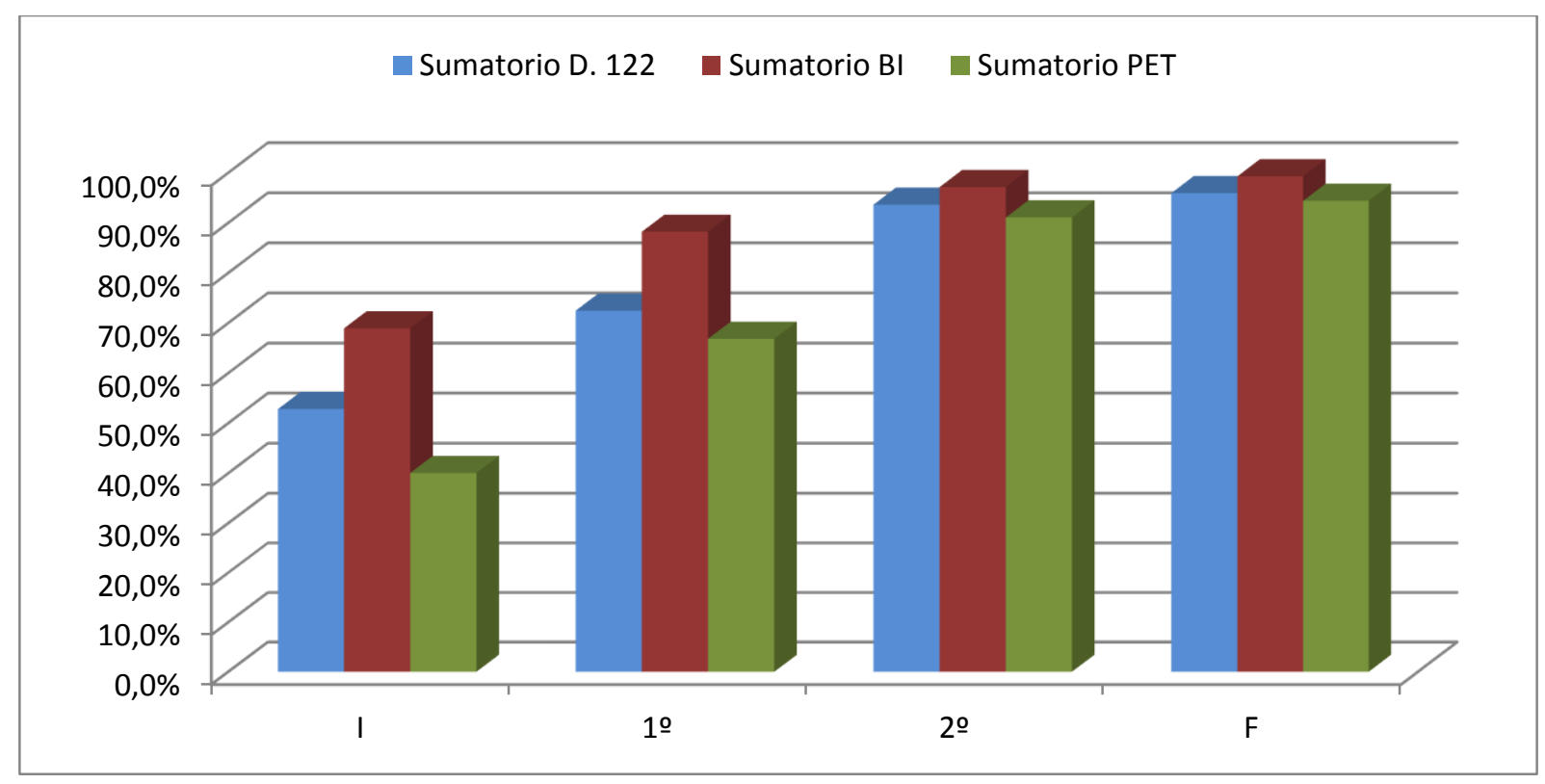

Figura 4.8. Gráfica sumatorio comparativa indicadores logro (\%): 3 El lecto escritura (curso 2010/11)

La gráfica muestra como el indicador $\mathrm{BI}$ y D.122 parten de valores altos, lo que revela un nivel alto de partida en el grupo. Todos los indicadores de logro experimentan una evolución significativa en el primer y segundo trimestre, y una evolución más lenta en el último periodo; como ya se ha explicado esta situación se debe a los valores hallados por los indicadores en el segundo trimestre que están muy cerca de alcanzar la máxima puntuación en la tabla.

El indicador BI y D.122 alcanzando valores más altos en el primer y segundo trimestre que el indicador PET; sin embargo, a lo largo del segundo trimestre la diferencia entre los tres indicadores de logro no es tan evidente (95,9\% D.122, 98,6\% BI y 87,9\% en PET).

Al finalizar el curso, la totalidad de la clase ha alcanzado valores muy altos en los tres indicadores. Estos datos muestran que el nivel general de la clase al finalizar el curso es muy 


\section{CAPITULO 4: ANÁLISIS DE DATOS}

alto en referencia a lo que marca y exige la ley, superado con éxito objetivos mucho más exigentes que los que vienen marcados por la junta de Castilla y León, como, por ejemplo, leer y comprender textos complejos que impliquen sílabas directas, inversas y trabadas o escritura en minúscula de textos complejos (ver vídeo $3^{\circ}$ curso: $3^{\circ}$ trimestre II).

\subsubsection{Tablas y gráficos de lógico-matemática}

En la tabla 4.7 se muestran los datos obtenidos para el curso 2010/11 en relación al ámbito lógico-matemático. En la primera columna se especifican los 6 objetivos didácticos de referencia para cada alumno durante ese curso escolar. A lo largo de la segunda columna, se concretan los objetivos a alcanzar en cada indicador de logro (D.122, BI y PET); puntualizar que en el caso de $\mathrm{Bl}$ existen tres objetivos que no contemplan este indicador (operaciones con sumas, operaciones con restas y operaciones combinadas), por tanto, los valores hallados se moverán en un rango comprendido entre $0-12$, siendo 0 el valor mínimo y 12 el valor máximo; el resto de indicadores de logro (D. 122 y BI) están presentes en todos los objetivos didácticos de la tabla; se moverán en un rango de $0-24$, siendo 0 el valor mínimo y 24 el valor máximo. Finalmente, en el resto de columnas se recogen los datos obtenidos por los 14 sujetos participantes en la investigación durante los 4 periodos de referencia (principio de curso y final de los tres trimestres). 
Tabla 4.7. FSG datos alumnos lógico-matemática: $3^{\circ}$ El (curso 2010/11)

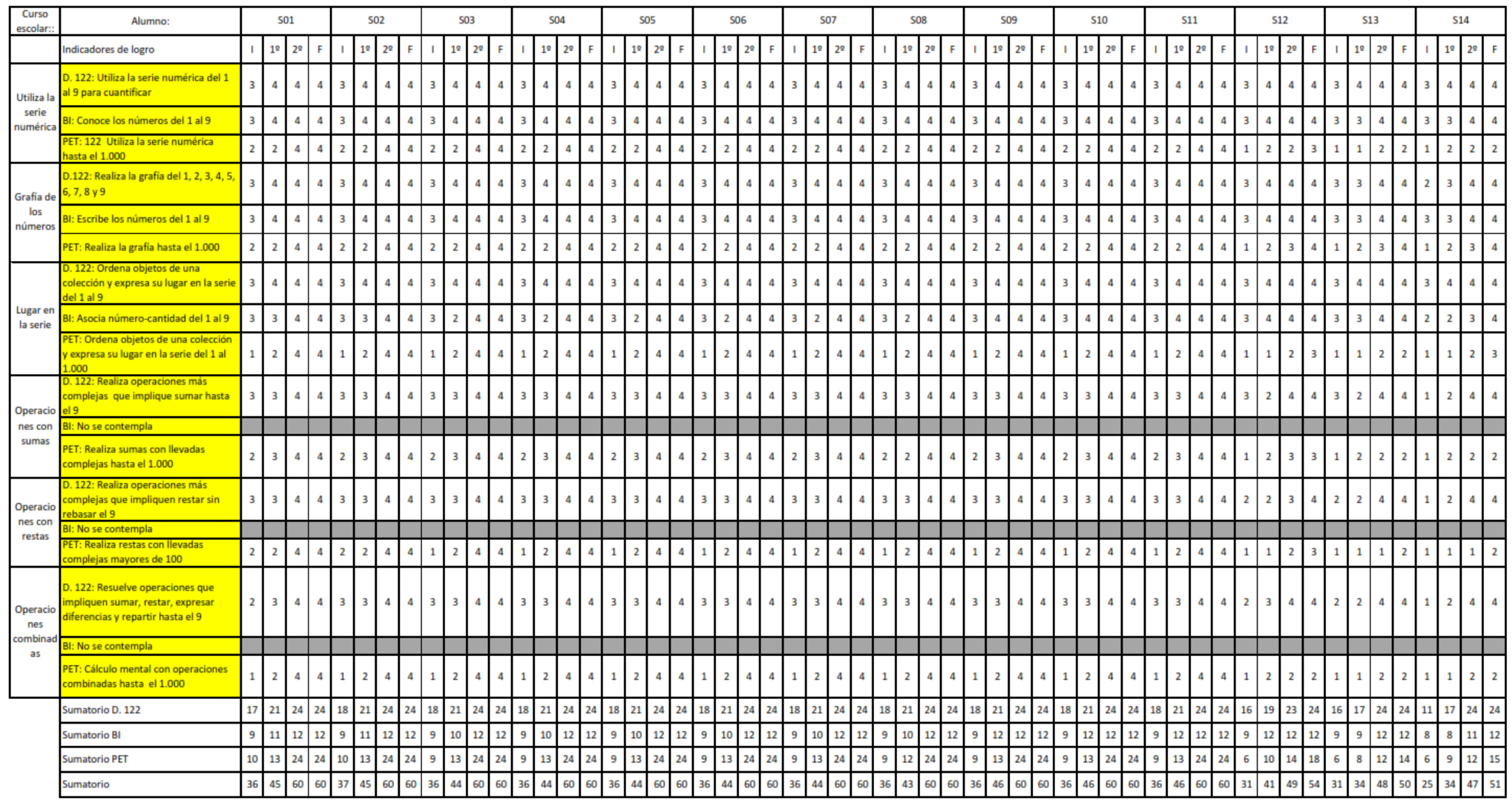


En relación a la tabla 4.7 se han elaborado 4 gráficas para facilitar su interpretación (figuras 4.9, 4.10, 4.11 y 4.12 ).

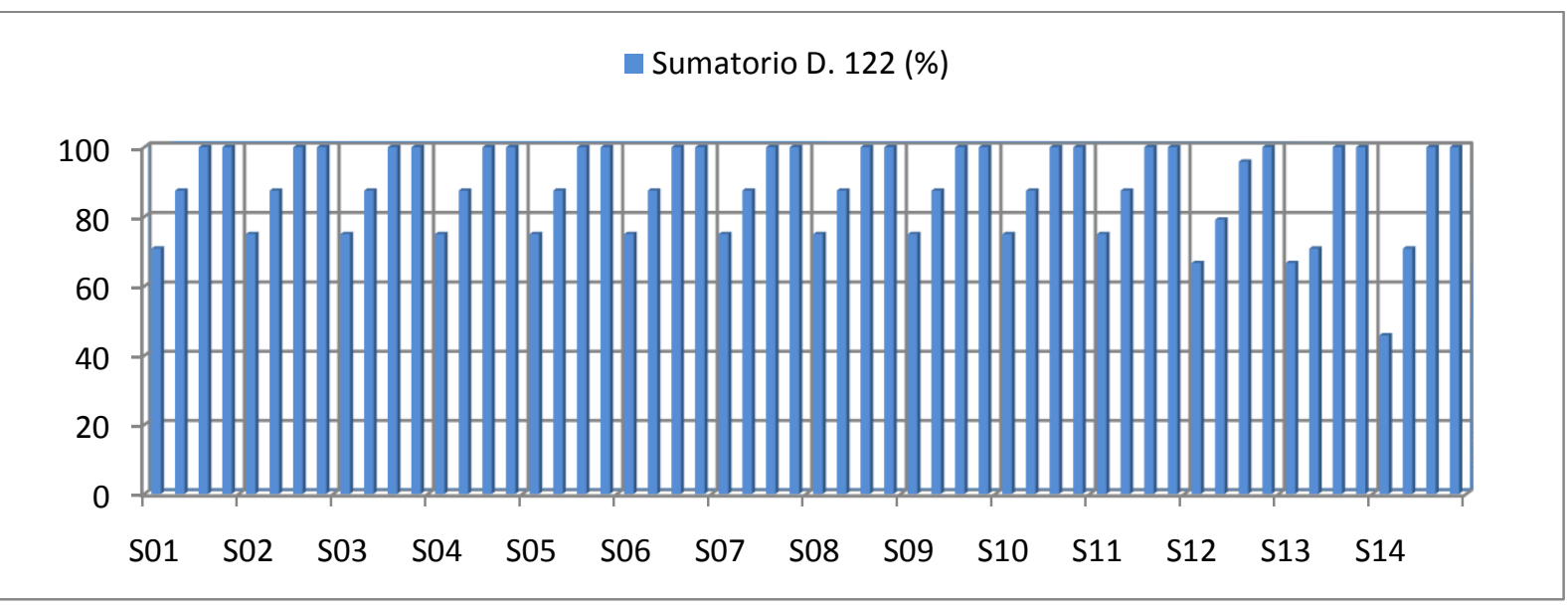

Figura 4.9. Gráfica datos de alumnos D.122 (\%): 3ํ El lógico-matemática (curso 2010/11)

Como se observa en la figura 4.9, los sujetos poseen un nivel inicial de partida muy alto; toda el aula, excepto el sujeto 14, parte con un nivel superior al $65 \%$ de los objetivos programados por el indicador D.122, mientras que el sujeto 14 parte de un valor inicial del $46 \%$. Durante el primer trimestre se registra una evolución mayor que en resto de periodos evaluados, consiguiendo valores comprendidos entre el 70-88\%. En el segundo trimestre todos los alumnos consiguen la puntuación máxima en la escala, excepto el sujeto 12, que alcanza un $96 \%$ de puntuación total. Al finalizar el curso, la totalidad de la clase alcanzan todos los objetivos propuestos por el indicador D.122 en el ámbito lógico-matemático.

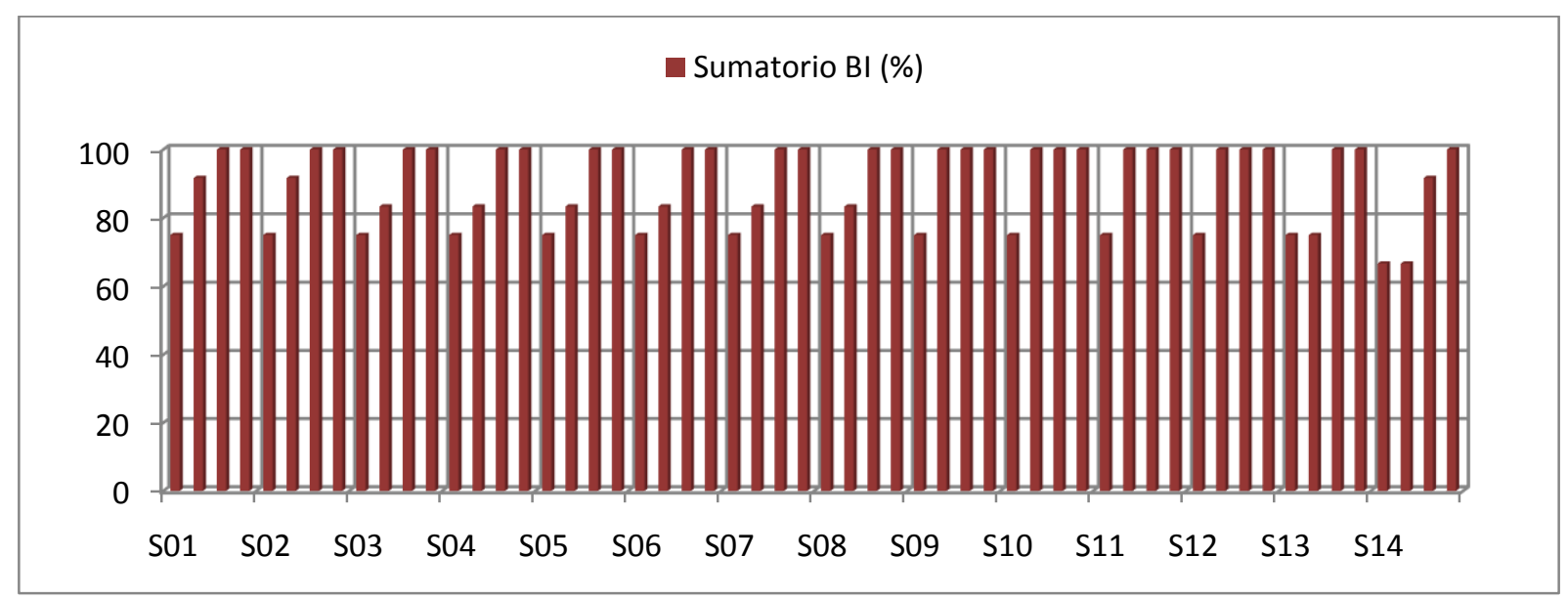

Figura 4.10. Gráfica datos de alumnos BI (\%): 3 El lógico-matemática (curso 2010/11)

En nivel inicial de partida que muestra la figura 4.10 es incluso mayor que la figura anterior, todos los alumnos parten con valores muy similares que se hallan entre el $67-75 \%$. A lo largo del $1^{\circ}$ trimestre 4 sujetos alcanza la puntuación máxima en el indicador $\mathrm{BI}$, quedándose los sujeto 01 y sujeto 02 muy cerca de conseguirlo (con un 92\%). En este 
trimestre los ACNEAE no experimentan ningún avance. En el segundo trimestre todos los sujetos, excepto sujeto 14, alcanzan el $100 \%$ de la puntuación total en la escala. Al finalizar el curso todos los alumnos alcanzan los objetivos propuestos por el indicador BI.

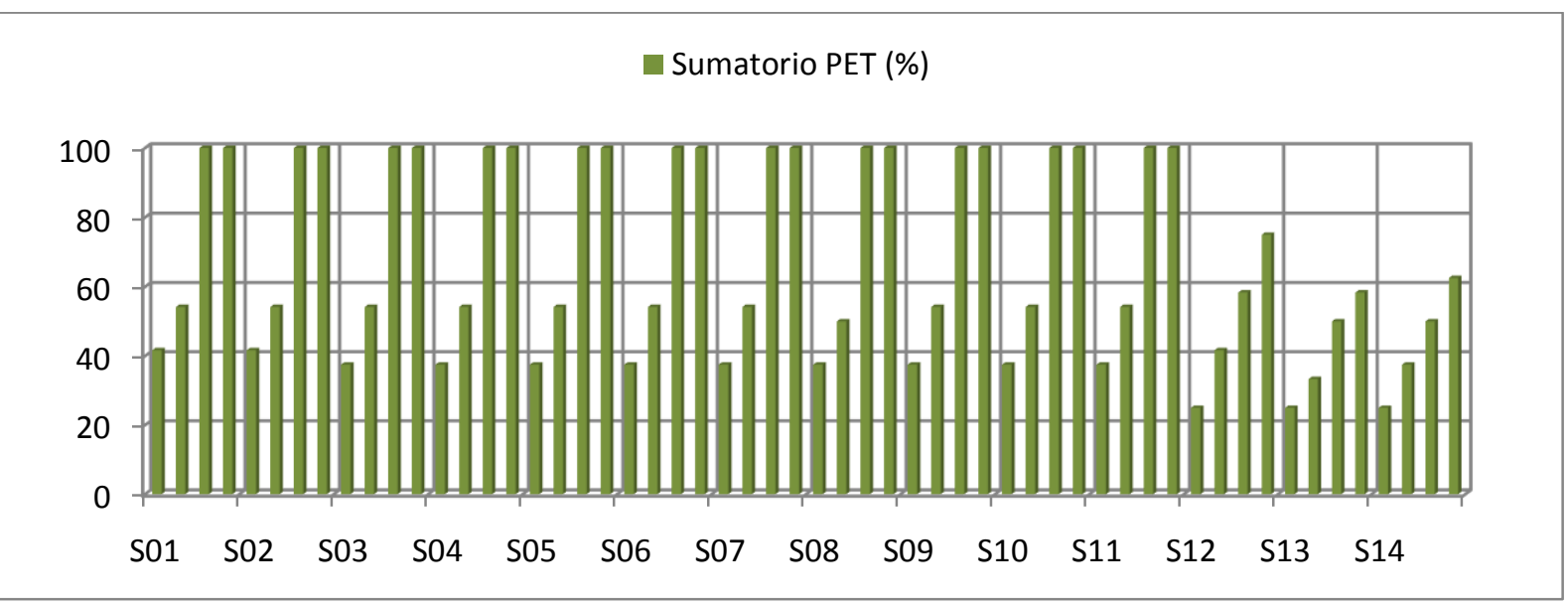

Figura 4.11. Gráfica datos de alumnos PET (\%): 3ํㅡ El lógico-matemática (curso 2010/11)

En la figura 4.11 podemos ver como el nivel inicial de partida del grupo en relación al indicador PET es más bajo que el resto de indicadores. El grupo parte con un nivel comprendido entre el 25 y el $42 \%$ de la puntuación total. En el primer trimestre se observa una evolución importante, siendo más evidente a lo largo del segundo trimestre; durante el primer trimestre el nivel de la clase es bastante homogéneo, alcanzando valores comprendidos entre el 38 y el 54\%. En el segundo trimestre 11 sujetos alcanzan el valor máximo de la escala. Durante el último trimestre los sujetos 12, 13 y 14 no alcanzan la puntuación máxima en la consecución de los objetivos, obteniendo como resultados los siguientes valores: $75 \%, 58 \%$ y $63 \%$, siendo los dos últimos sujetos los alumnos que precisan mayor apoyo (ACNEAE).

La siguiente gráfica (ver figura 4.12) nos permite comparar la evolución de todos los alumnos en cada indicador de logro, comparando los valores hallados por cada alumno en relación al ámbito lógico-matemática durante el curso escolar 2010/11. 


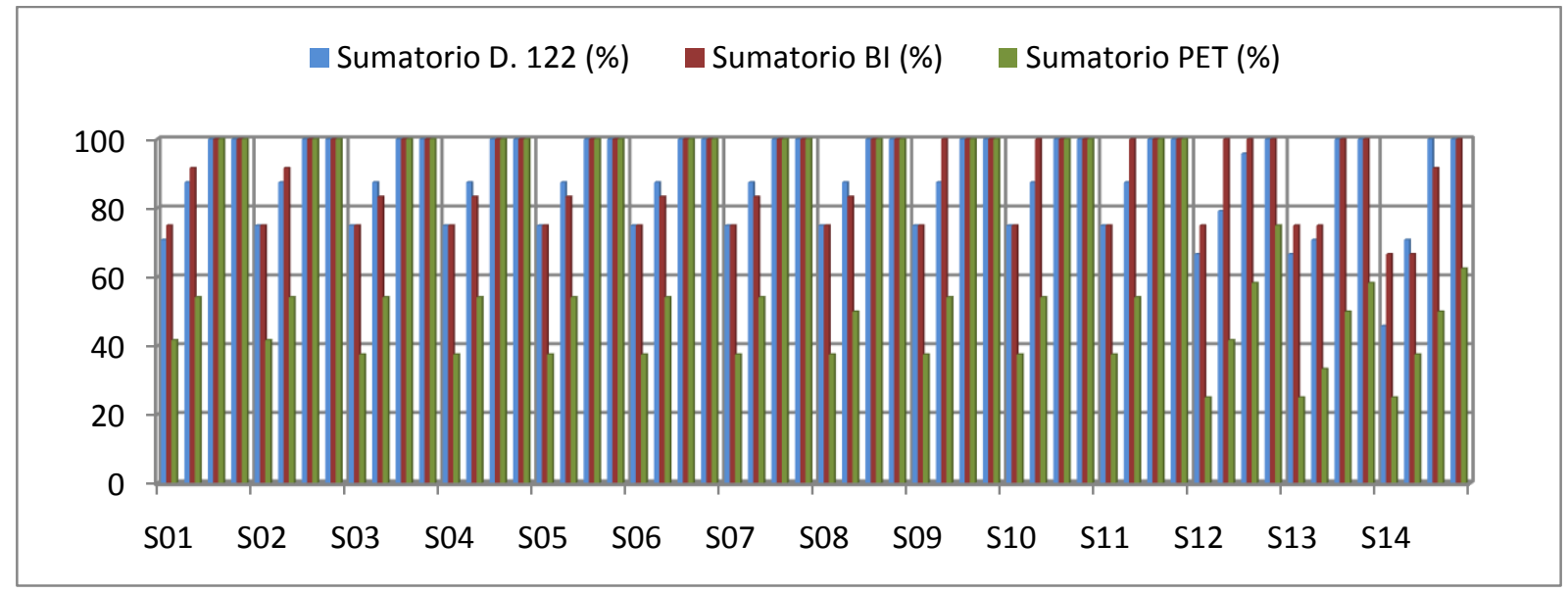

Figura 4.12. Gráfica datos de alumnos comparativa indicadores logro (\%): 3o El lógico-matemática (curso 2010/11)

Debemos tener presente que los objetivos propuestos por PET son mucho más exigentes que el de resto de indicadores, factor determinante en la interpretación de los datos. Como vemos en figura 4.12, el nivel medio del grupo es medio-alto; sin embargo, se perciben dos ritmos diferenciados: los sujetos $01,02,03,04,05,06,07,08,09,10$ y 11 parten de un nivel más alto que los sujetos 12,13 y 14, y consiguen la totalidad de los objetivos propuestos por los tres indicadores en el segundo trimestre. Los sujetos 12, 13 y 14 consiguen la puntuación máxima de los indicadores de logro D.122 y Bl en el tercer trimestre, mientras que alcanzan valores medios y altos con referencia al indicador PET (75\%, 58\% y $66 \%)$.

Una vez explicada la tabla 4.7 y las 4 gráficas asociadas a esta tabla, pasamos a interpretar los valores hallados por la tabla 4.8 y sus gráficas correspondientes. En la 4.8 se muestran los valores obtenidos a nivel grupal de toda la clase en los tres tipos de indicadores, en relación a los 6 objetivos didácticos de referencia para el ámbito lógico-matemático. En las últimas filas encontramos los sumatorios de cada indicador (D. 122, BI y PET) en los 4 periodos evaluados (inicio del curso, primer trimestre, segundo trimestre y final de curso). Al igual que en el ámbito lecto-escritor, contamos con 14 alumnos; por tanto, dado que el valor más alto de la escala es 4 , el valor máximo que se puede alcanzar en cada indicador será 56. Por tanto, nos moveremos en un rango entre $0-56$, correspondiendo 56 al $100 \%$ del valor porcentual. 
Tabla 4.8. FSG sumatorios lógico-matemática: 3ํㅡ El (curso 2010/11)

\begin{tabular}{|c|c|c|c|c|c|c|c|c|c|}
\hline \multirow{2}{*}{$\begin{array}{c}\text { Curso } \\
\text { escolar:: }\end{array}$} & Alumno: & \multicolumn{4}{|c|}{ SUMATORIO GRUPAL } & \multicolumn{4}{|c|}{ SUMATORIO GRUPAL (\%) } \\
\hline & Indicadores de logro & 1 & $1^{9}$ & $2^{2}$ & $\mathrm{~F}$ & 1 & 19 & $2^{2}$ & $\mathrm{~F}$ \\
\hline \multirow{3}{*}{$\begin{array}{l}\text { Utiliza la } \\
\text { serie } \\
\text { numérica }\end{array}$} & $\begin{array}{l}\text { D. 122: Utiliza la serie numérica del } 1 \\
\text { al } 9 \text { para cuantificar }\end{array}$ & 42 & 56 & 56 & 56 & $75,0 \%$ & $100,0 \%$ & $100,0 \%$ & $100,0 \%$ \\
\hline & Bl: Conoce los números del 1 al 9 & 42 & 54 & 56 & 56 & $75,0 \%$ & $96,4 \%$ & $100,0 \%$ & $100,0 \%$ \\
\hline & $\begin{array}{l}\text { PET: } 122 \text { Utiliza la serie numérica } \\
\text { hasta el } 1.000\end{array}$ & 25 & 27 & 50 & 51 & $44,6 \%$ & $48,2 \%$ & $89,3 \%$ & $91,1 \%$ \\
\hline \multirow{3}{*}{$\begin{array}{l}\text { Grafía de } \\
\text { los } \\
\text { números }\end{array}$} & $\begin{array}{l}\text { D.122: Realiza la grafía del } 1,2,3,4,5 \text {, } \\
6,7,8 \text { y } 9\end{array}$ & 41 & 54 & 56 & 56 & $73,2 \%$ & $96,4 \%$ & $100,0 \%$ & $100,0 \%$ \\
\hline & Bl: Escribe los números del 1 al 9 & 42 & 54 & 56 & 56 & $75,0 \%$ & $96,4 \%$ & $100,0 \%$ & $100,0 \%$ \\
\hline & PET: Realiza la grafia hasta el 1.000 & 25 & 28 & 53 & 56 & $44,6 \%$ & $50,0 \%$ & $94,6 \%$ & $100,0 \%$ \\
\hline \multirow{3}{*}{$\begin{array}{l}\text { Lugar en } \\
\text { la serie }\end{array}$} & $\begin{array}{l}\text { D. 122: Ordena objetos de una } \\
\text { colección y expresa su lugar en la serie } \\
\text { del } 1 \text { al } 9\end{array}$ & 42 & 56 & 56 & 56 & $75,0 \%$ & $100,0 \%$ & $100,0 \%$ & $100,0 \%$ \\
\hline & BI: Asocia número-cantidad del 1 al 9 & 41 & 39 & 55 & 56 & $73,2 \%$ & $69,6 \%$ & $98,2 \%$ & $100,0 \%$ \\
\hline & $\begin{array}{l}\text { PET: Ordena objetos de una colección } \\
\text { y expresa su lugar en la serie del } 1 \text { al } \\
1.000\end{array}$ & 14 & 25 & 50 & 52 & $25,0 \%$ & $44,6 \%$ & $89,3 \%$ & $92,9 \%$ \\
\hline \multirow{3}{*}{$\begin{array}{l}\text { Operacio } \\
\text { nes con } \\
\text { sumas }\end{array}$} & $\begin{array}{l}\text { D. 122: Realiza operaciones más } \\
\text { complejas que implique sumar hasta } \\
\text { el } 9\end{array}$ & 40 & 39 & 56 & 56 & $71,4 \%$ & $69,6 \%$ & $100,0 \%$ & $100,0 \%$ \\
\hline & BI: No se contempla & & & & & & & & \\
\hline & $\begin{array}{l}\text { PET: Realiza sumas con llevadas } \\
\text { complejas hasta el } 1.000\end{array}$ & 25 & 38 & 51 & 51 & $44,6 \%$ & $67,9 \%$ & $91,1 \%$ & $91,1 \%$ \\
\hline \multirow{3}{*}{$\begin{array}{l}\text { Operacio } \\
\text { nes con } \\
\text { restas }\end{array}$} & $\begin{array}{l}\text { D. 122: Realiza operaciones más } \\
\text { complejas que impliquen restar sin } \\
\text { rebasar el } 9\end{array}$ & 38 & 39 & 55 & 56 & $67,9 \%$ & $69,6 \%$ & $98,2 \%$ & $100,0 \%$ \\
\hline & BI: No se contempla & & & & & & & & \\
\hline & $\begin{array}{l}\text { PET: Realiza restas con llevadas } \\
\text { complejas mayores de } 100\end{array}$ & 16 & 25 & 48 & 51 & $28,6 \%$ & $44,6 \%$ & $85,7 \%$ & $91,1 \%$ \\
\hline \multirow{7}{*}{$\begin{array}{c}\text { Operacio } \\
\text { nes } \\
\text { combinad } \\
\text { as }\end{array}$} & $\begin{array}{l}\text { D. 122: Resuelve operaciones que } \\
\text { impliquen sumar, restar, expresar } \\
\text { diferencias y repartir hasta el } 9\end{array}$ & 37 & 40 & 56 & 56 & $66,1 \%$ & $71,4 \%$ & $100,0 \%$ & $100,0 \%$ \\
\hline & BI: No se contempla & & & & & & & & \\
\hline & $\begin{array}{l}\text { PET: Cálculo mental con operaciones } \\
\text { combinadas hasta el } 1.000\end{array}$ & 14 & 26 & 50 & 50 & $25,0 \%$ & $46,4 \%$ & $89,3 \%$ & $89,3 \%$ \\
\hline & Sumatorio D. 122 & 240 & 284 & 335 & 336 & $71,4 \%$ & $84,5 \%$ & $99,7 \%$ & $100,0 \%$ \\
\hline & Sumatorio BI & 125 & 147 & 167 & 168 & $74,4 \%$ & $87,5 \%$ & $99,4 \%$ & $100,0 \%$ \\
\hline & Sumatorio PET & 119 & 169 & 302 & 311 & $35,4 \%$ & $50,3 \%$ & $89,9 \%$ & $92,6 \%$ \\
\hline & Sumatorio & 484 & 600 & 804 & 815 & $57,6 \%$ & $71,4 \%$ & $95,7 \%$ & $97,0 \%$ \\
\hline
\end{tabular}




\section{CAPITULO 4: ANÁLISIS DE DATOS}

Asociada a la tabla 4.8 se han elaborado 4 gráficas para facilitar la interpretación de los datos; éstas pueden verse en las figuras $4.13,4.14,4.15$ y 4.16 .

Comenzamos con la figura 4.13, donde se recogen los valores porcentuales hallados por toda la clase en relación a los objetivos lógico-matemáticos del D.122.

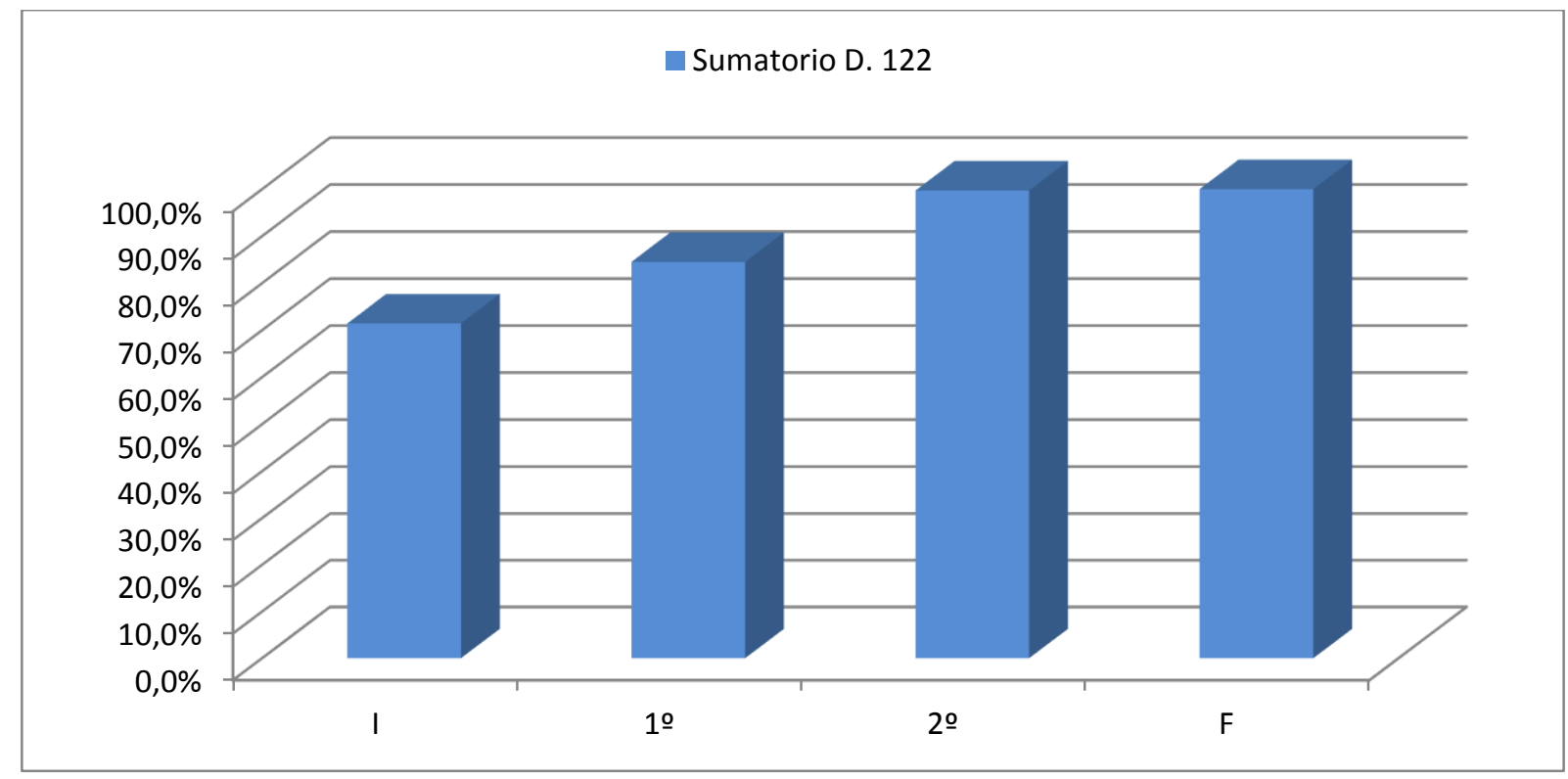

Figura 4.13. Gráfica sumatorios D.122 (\%): 3ํE El lógico-matemática (curso 2010/11)

Como se observa en la figura, los alumnos parten de un nivel inicial del $71,4 \%$, experimentando una buena evolución a lo largo del primer y segundo trimestre (se pasa de un $84,5 \%$ a un $99,7 \%$ ), y una leve mejora durante el periodo final del curso, consiguiendo $\mathrm{EL}$ $100 \%$ de la puntuación total en la escala. Por tanto, los objetivos alcanzados por la clase son máximos, indicando un alto nivel del grupo en relación a los objetivos exigidos por el D.122.

En la siguiente gráfica (véase figura 4.14) podemos observar la evolución obtenida por toda la clase en relación al indicador BI. 


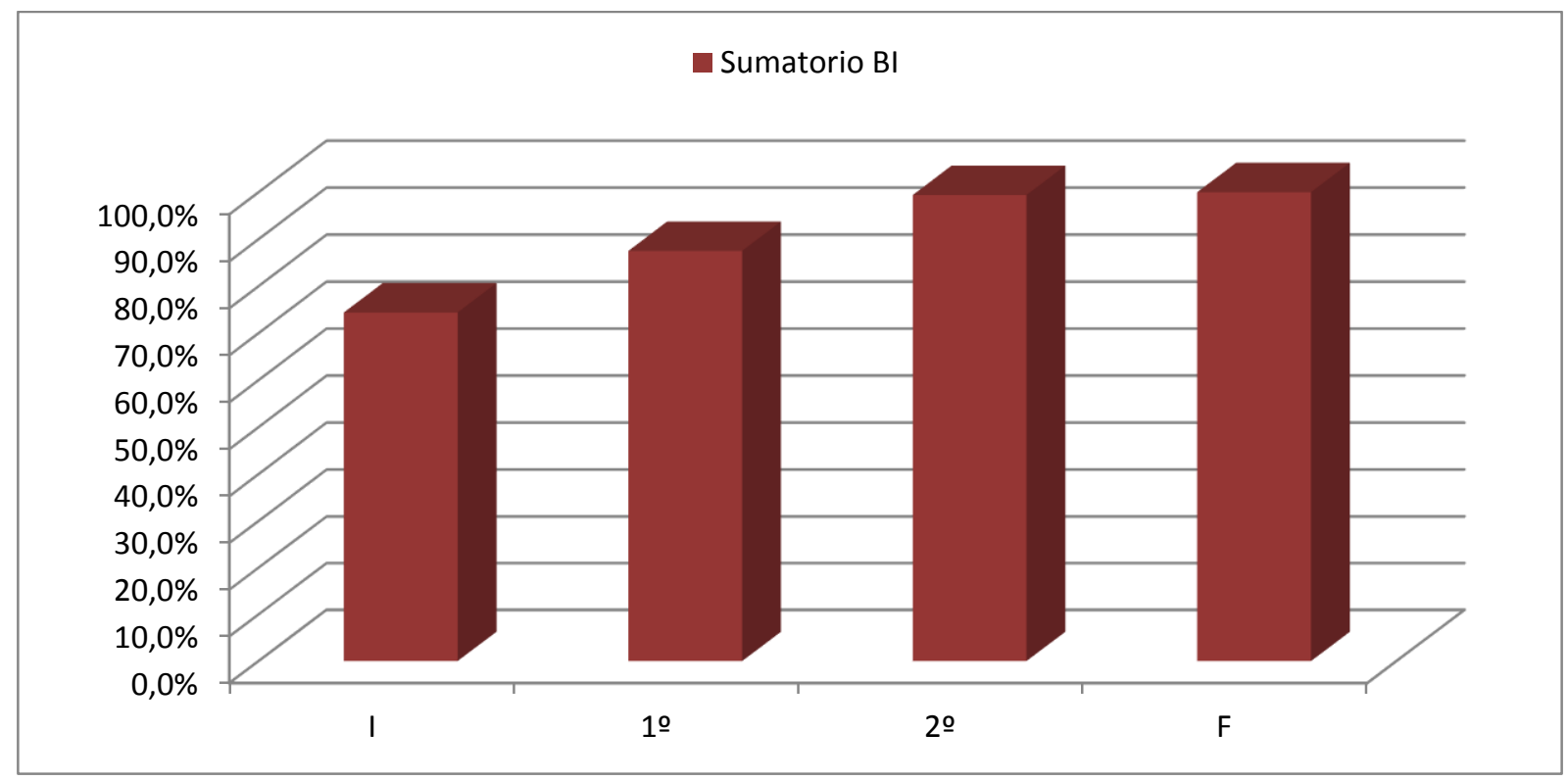

Figura 4.14. Gráfica sumatorios BI (\%): 3 El lógico-matemática (curso 2010/11)

En relación al indicador $\mathrm{BI}$ se observarse una evolución muy similar a la vista en la figura anterior. En este caso el grupo de alumnos parte un valor inicial del $74,4 \%$ de la puntuación total de la escala, experimentando la mayor evolución del inicio del curso al primer trimestre (pasamos del 74,4\% al 87,5\%). Durante los siguientes trimestres la evolución es continua aunque no tan rápida como sucedía en el trimestre anterior (obteniendo un $87,5 \%$ en el segundo trimestre y un $99,4 \%$ en el tercero). De nuevo, los valores hallados por el grupo al finalizar el curso son máximos (del 100\%) alcanzan valores totales en la consecución de los objetivos propuestos por el BI.

En la siguiente gráfica (véase figura 4.15), recogemos los datos obtenidos por toda la clase en relación al indicador PET. 


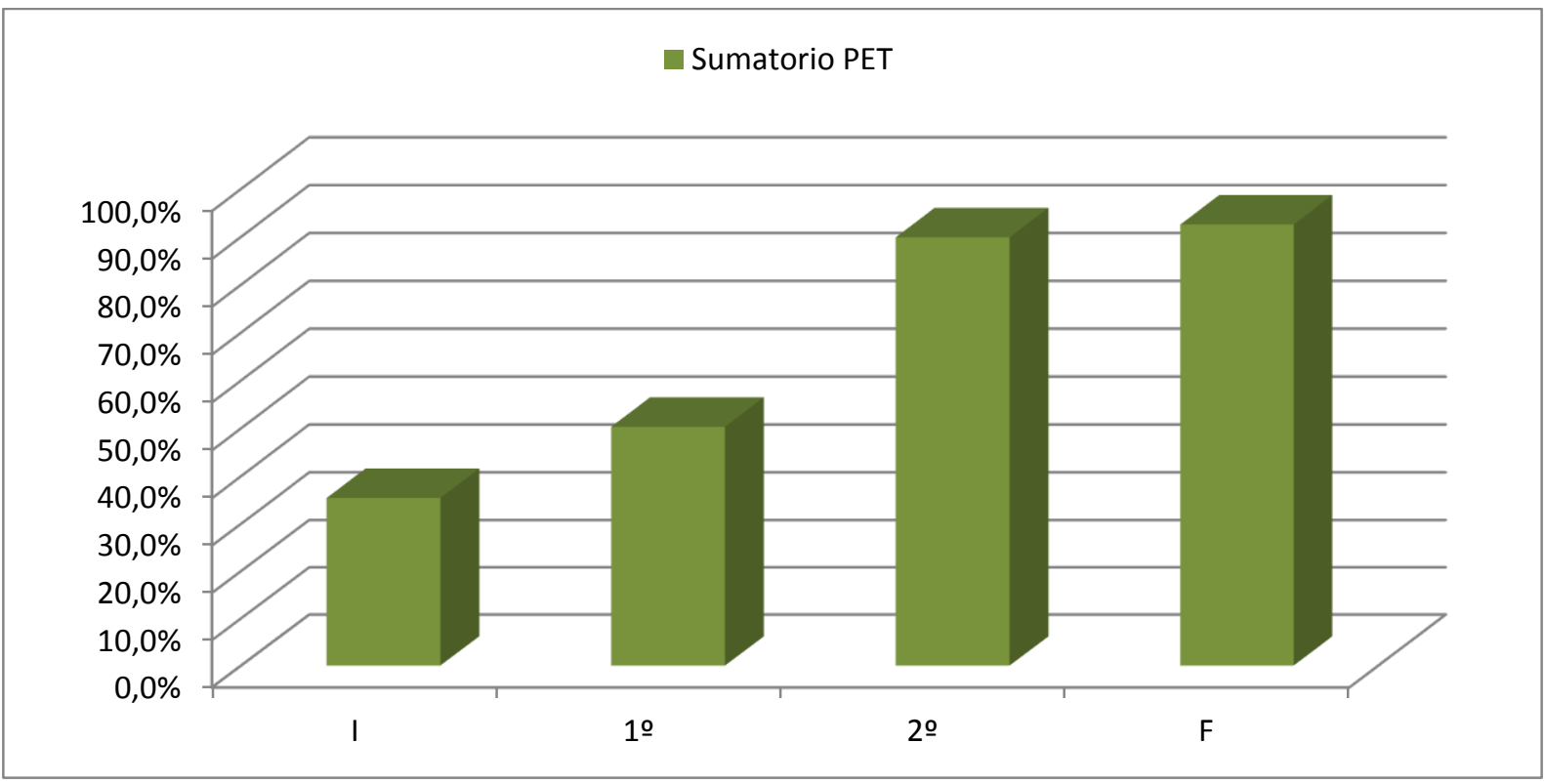

Figura 4.15. Gráfica sumatorios PET (\%): 3ํEl lógico-matemática (curso 2010/11)

La evolución inicial es similar a las figuras 4.14 y 4.15, sin embargo partimos de un valor inicial inferior a las gráficas anteriores en la puntuación total de la escala (35,4\%). La evolución más significativa se da durante el segundo trimestre (pasamos de un 50,03\% a un $89,9 \%$ ), produciéndose una mejora más leve a lo largo del siguiente trimestre (se pasa de un $89,9 \%$ en el segundo trimestre a un $89,9 \%$ al finalizar el curso). Dado que los objetivos de este indicador son mucho más complejos, se puede considerar que el grupo clase ha alcanzado un nivel muy alto en su aprendizaje lógico-matemático.

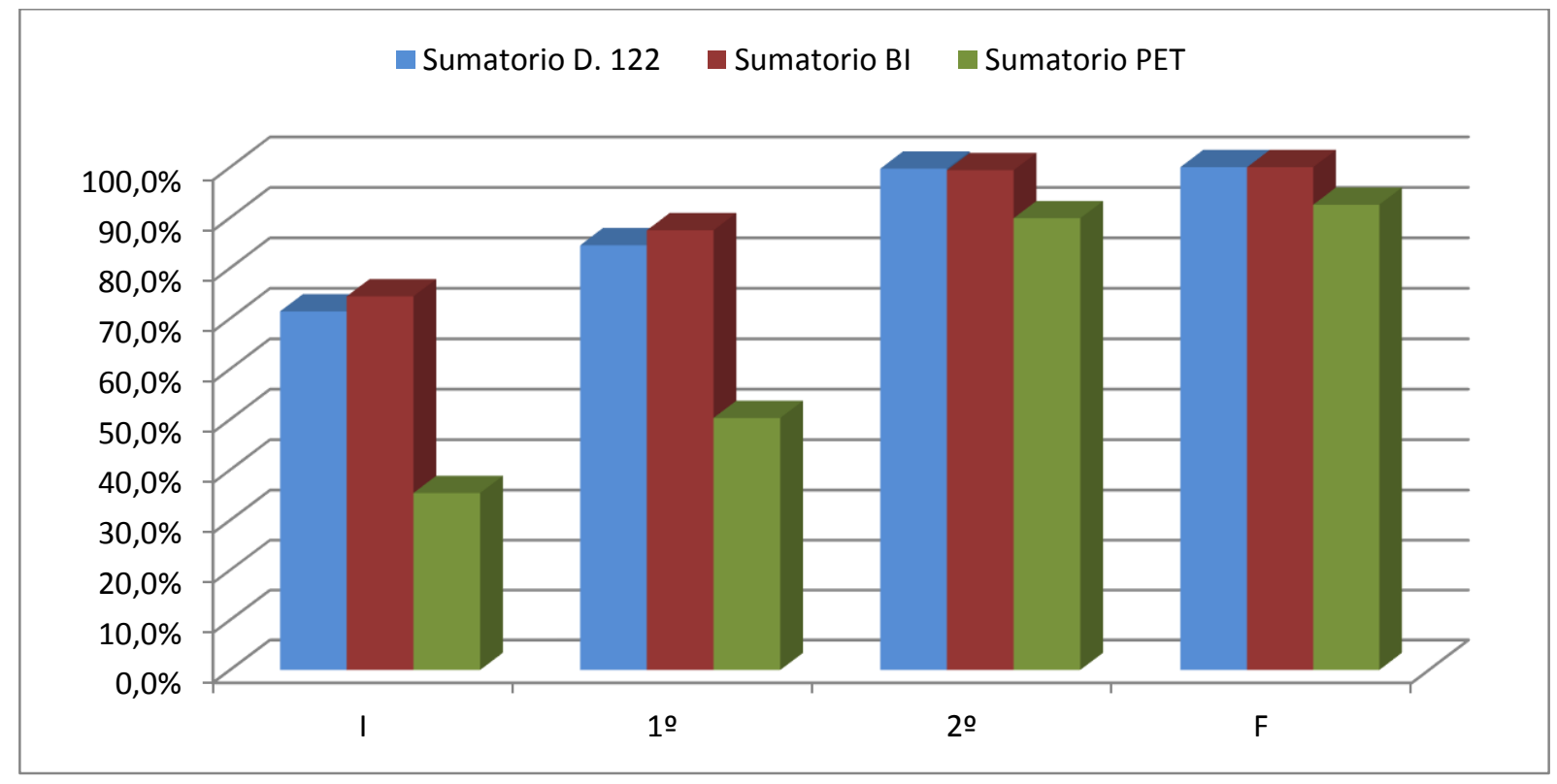

Figura 4.16. Gráfica sumatorio comparativa indicadores logro (\%): 3ํEl lógico matemáticas (curso 2010/11) 
En la gráfica se observa como el nivel de partida de la clase es muy alto en relación a los indicadores D.122 y BI. En los tres indicadores se observa que el grupo de alumnos ha alcanzado valores muy altos en el segundo trimestre, produciéndose una mejora más lenta al finalizar el curso al conseguir los valores máximos propuestos por los indicadores D.122 y BI.

Al finalizar el curso, los valores alcanzados por los tres indicadores son similares, obteniendo valores máximos en los indicadores D.122 y BI (100\%) frente al indicador PET $(92,6 \%)$. Estos datos indican que el nivel general de la clase es muy alto en relación a lo que marca el currículo oficial de El y el boletín oficial del trimestre. Dado que los objetivos propuestos por el PET son mucho más exigentes e implican un nivel mucho más alto que los de los otros dos indicadores, el haber obtenido el grupo un grado de consecución general del $92,6 \%$ muestra un aprendizaje bastante mayor de lo que indican los estándares del Curriculum oficial para este curso, alcanzando objetivos como: destreza en el cálculo mental, realizar operaciones que impliquen sumas y restas de dos y tres cifras, identificar y realizar la grafía de números complejos hasta el mil, etc. (ver video $3^{\circ}$ curso: $2^{\circ}$ trimestre I, video $3^{\circ}$ curso: $3^{\circ}$ trimestre I y video $3^{\circ}$ curso: $3^{\circ}$ trimestre II).

\subsubsection{CURSO ESCOLAR 2011/12}

Durante este curso escolar soy tutora de un nuevo grupo de alumnos de $1^{\circ}$ curso del $2^{\circ}$ ciclo de El; este grupo está constituido por 13 alumnos de los cuales únicamente 4 son niñas. En el aula existen dos ritmos de trabajo claramente diferenciados: encontramos alumnos con un ritmo de aprendizaje rápido y otros alumnos con un ritmo de aprendizaje más lento condicionado por la barrera idiomática, inmadurez en su desarrollo y problemas de atención. Se trata de un grupo muy movido, que precisa de normas muy marcadas para regular su comportamiento.

Dos de los alumnos poseen desconocimiento del idioma (sujeto 06 y sujeto 07 ); además, el sujeto 06 es un alumno absentista que falta al aula una media de 2-3 días por semana. El sujeto 03 presenta graves problemas de atención, impulsividad y muestra conductas desafiantes.

\subsubsection{Tablas y gráficos de lecto-escritura}

En la tabla 4.9 se han recogido los datos obtenidos para el curso 2011/12 en relación al ámbito lecto-escritor. En la primera columna se especifican los 6 objetivos didácticos de referencia para cada alumno durante ese curso escolar. A lo largo de la segunda columna, se concretan los objetivos a alcanzar en cada indicador de logro (D.122, BI y PET); puntualizar 


\section{CAPITULO 4: ANÁLISIS DE DATOS}

que en el caso de $\mathrm{Bl}$ existen dos objetivos que no contemplan este indicador (identifica fonemas y discrimina visualmente fonemas), por tanto, los valores hallados se moverán en un rango comprendido entre $0-16$, siendo 0 el valor mínimo y 16 el valor máximo; el resto de indicadores de logro (D. 122 y BI) están presentes en todos los objetivos didácticos de la tabla; se moverán en un rango de 0-24, siendo 0 el valor mínimo y 24 el valor máximo. Finalmente, en el resto de columnas se recogen los datos obtenidos por los 13 sujetos participantes en la investigación durante los 4 periodos de referencia (principio de curso y final de los tres trimestres). 
Tabla 4.9. FSG datos alumnos lecto-escritura: $1^{\circ}$ EI (curso 2011/12)

\begin{tabular}{|c|c|c|c|c|c|c|c|c|c|c|c|c|c|c|c|c|c|c|c|c|c|c|c|c|c|c|c|c|c|c|c|c|c|c|c|c|c|c|c|c|c|c|c|c|}
\hline & lumno: & & 501 & & & & & & & 503 & & & 504 & & & & & & & & & & s07 & & & 508 & & & & & & & & & & s11 & & & 512 & & & s13 & & \\
\hline & Indicadores de logro & & & 2 & & & & & & & & & & & & & 22 & & & & F & & & & & & & & & $2^{2}$ & & & $22^{2}$ & & & & F & & & $\begin{array}{ll}22^{2} & \mathrm{~F} \\
\end{array}$ & & & \begin{tabular}{l|l}
28 & $F$ \\
\end{tabular} & \\
\hline & D.122: Correcta dirección y posición & 0 & & 4 & & & 4 & & 0 & 4 & & & & & & & 4 & & 0 & & & 01 & 4 & & 0 & & 4 & 0 & & & & & 4 & & 0 & & & & 4 & & & 4 & & 4 \\
\hline & Bli:R & & & 4 & 4 & & 4 & & & 2 & 4 & & 2 & 4 & & 2 & & & 0 & & & 0 & 2 & 4 & 0 & 3 & 4 & 0 & & $|4|$ & & & 4 & & & & & & & & & 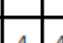 & & \\
\hline & & & & & & & & & & & & & & & & & & & & & & & & & & & & & & & -1 & & & & & & & & & & & 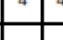 & & \\
\hline & $\begin{array}{l}\text { PEEcci } \\
\text { escribir }\end{array}$ & 0 & 2 & 4 & 4 & 3 & 4 & $4 \mid$ & 0 & 4 & & & & & & & 4 & 4 & 1 & & I & 1 & \begin{tabular}{l|l}
2 & 4 \\
\end{tabular} & 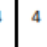 & 0 & & $4^{4}$ & 0 & & 4 & 4 & 0 & & & 0 & 4 & & & 4 & & & 4 & & ${ }^{4}$ \\
\hline & 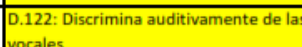 & & & 4 & 4 & & 4 & & 0 & & & & 4 & 4 & & & 4 & & 0 & & 3 & 0 & 4 & the & 0 & 4 & 4 & 4 & & 3 & 4 & & & & 0 & 4 & 4 & & 4 & & & 4 & & 4 \\
\hline & 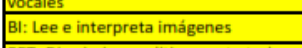 & 0 & & 3 & 40 & 3 & 4 & 4 & 0 & & 4 & 0 & 2 & 3 & & 4 & 4 & 4 & 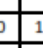 & & 2 & 0 & $2 \sqrt[3]{3}$ & 4 & & 2 & 3 & 40 & & 3 & 4 & 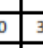 & & 4 & 0 & 3 存 & 4 & & 3 & \begin{tabular}{l|l}
4 & 4 \\
\end{tabular} & & \begin{tabular}{|c|c|}
3 & \\
\end{tabular} & \begin{tabular}{l|l}
4 & 4 \\
4
\end{tabular} & 4 \\
\hline & 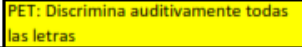 & 0 & 2 & 2 & \begin{tabular}{l|c}
3 & 0 \\
\end{tabular} & 3 & 4 & 4 & 0 & 12 & 3 & 0 & 2 & 3 & 4 & 3 & 4 & 4 & 0 & 1 & 2 & 0 & 2 & 4 & 0 & 3 & 4 & 4 & 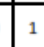 & 2 & 3 & 0 & 4 & 4 & 0 & 3 & 4 & & 3 & \begin{tabular}{l|l}
4 & 4 \\
4
\end{tabular} & & 3 & & 4 \\
\hline & D. 122: Iden & & & 4 & & 4 & & & 0 & & & & & 4 & & 4 & 4 & \begin{tabular}{c|c}
4 \\
\end{tabular} & 01 & 1 & 2 & 4 & 3 & 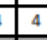 & $\overline{0}$ & 4 & & & $\frac{2}{2}$ & 3 & 4 & 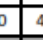 & & 4 & 0 & 4 & 4 & & 4 & & & 4 & & \\
\hline & \begin{tabular}{|l|l|l|} 
B: No se contempla \\
PET: Identifica todas las letras
\end{tabular} & 0 & 2 & 3 & $\frac{10}{30}$ & $t_{3}$ & 4 & $|4|$ & 0 & 3 & $\left.\right|_{4}$ & 0 & 1 & $\frac{1}{2}$ & 30 & $\left.\right|_{3}$ & 4 & 4 & $t_{1}$ & 1 & 2 & 0 & $\frac{1}{2} 3$ & 4 & \begin{tabular}{|l|l|l}
0 \\
\end{tabular} & 3 & $\frac{1}{4}$ & 40 & $\int_{2}$ & 3 & 3 & $t_{2}$ & $\mid 4$ & $4 \mid$ & 0 & $\frac{1}{2}$ & $T_{4}$ & $\mid$ & 2 & & & $\frac{1}{2}$ & & 4 \\
\hline & $\begin{array}{l}\text { D. } 122 \text { : Discrimina visu } \\
\text { vocales men maviscula }\end{array}$ & 0 & 4 & 4 & 4 & 4 & 4 & 4 & 0 & 3 & 4 & 0 & & 4 & 40 & 4 & 4 & 4 & 1 & 2 & 3 & 0 & 4 & 4 & 0 & ${ }_{4}$ & 4 & 4 & 2 & \begin{tabular}{|l|}
4 \\
\end{tabular} & 4 & 0 & 4 & 4 & 0 & 4 & 4 & & 4 & \begin{tabular}{l|l}
4 & 4 \\
4
\end{tabular} & & 4 & & 4 \\
\hline & 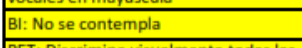 & & & & & & & & & & & & & & & & & 4 & 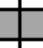 & 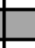 & & & 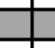 & 1 & & $\square$ & & & & 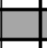 & & & & & & - & 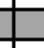 & & - & - & & 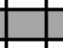 & & \\
\hline & $\begin{array}{l}\text { criminin visual } \\
\text { maxuscsula }\end{array}$ & 0 & & 3 & \begin{tabular}{l|l}
3 & 0 \\
\end{tabular} & & 4 & 4 & $\circ$ & & & 0 & 1 & 2 & & 3 & 4 & 4 & 1 & & 2 & 0 & ${ }_{4}$ & 4 & 0 & 4 & 4 & ${ }_{4}$ & 12 & 2 & 3 & o & & & & 4 & 4 & & 4 & & & 4 & & 4 \\
\hline & 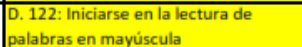 & 0 & & 2 & & & 4 & & 0 & & 2 & t & & 2 & & 4 & 4 & \begin{tabular}{l|}
4 \\
\end{tabular} & 1 & & 1 & 0 & 2 & 4 & & 2 & & & & 2 & 3 & 0 & & & & 3 & ${ }_{4}^{4}$ & & 3 & & & 3 & & 4 \\
\hline & genes & & & 3 & 4 & & 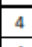 & & 0 & & & & 2 & t & 3 & 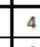 & 4 & \begin{tabular}{l|l}
4 & -1 \\
4
\end{tabular} & 0 & 1 & 2 & 0 & - & 4 & & 2 & & 4 & & 3 & 4 & & & 4 & & $\sqrt{3}$ & 4 & & 3 & 4 & & 3 & & 4 \\
\hline & & & & & & & 4 & & & & & & & 21 & & 14 & & & & 1 & $t^{1}$ & & & 4 & 0 & 2 & & & & & & & & & & & & & & & & & & \\
\hline & 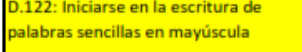 & 0 & & 3 & 4 & & 4 & ${ }^{4}$ & 0 & & & 0 & & & & & ${ }^{4}$ & 4 & $\circ$ & & 2 & 0 & 2 & & 0 & & 3 & & & 3 & 4 & 0 & & & 0 & 3 & 4 & & 3 & 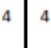 & & 3 & & ${ }^{4}$ \\
\hline & Bi: Lee e interpreta inágenes y código, & 0 & & 3 & \begin{tabular}{l|l}
40 \\
4
\end{tabular} & & 4 & & 0 & & & & & 3 & & 4 & 4 & & 01 & & 2 & 0 & 2 & 4 & 0 & 2 & 3 & & T & 3 & 4 & 0 & & & & 3 & 4 & & 3 & \begin{tabular}{l|l}
4 & 4 \\
\end{tabular} & & 3 & & 4 \\
\hline & \begin{tabular}{|l|} 
PET: Escritura \\
maviscrala
\end{tabular} & 0 & & 3 & 40 & & 4 & & 0 & & & 0 & & 3 & & 3 & 4 & 4 & 0 & & 2 & 0 & 2 & & & 2 & & & & & 4 & & & & & 3 & 4 & & 3 & \begin{tabular}{l|l}
4 & 4
\end{tabular} & & 3 & 4 & 4 \\
\hline & Sumatorio D. 122 & 0 & & 21 & $23 \mathrm{C}$ & 21 & 24 & 24 & 0 & & 22 & 0 & 15 & 21 & 2 & 21 & 24 & 24 & 0.6 & 8 & 13 & 0 & $17 \sqrt{2}-3 x-1$ & 24 & 0 & 19 & 22 & 4 & t & \begin{tabular}{|l|}
19 \\
\end{tabular} & 23 & 0 & & 24 & 0 & 212 & 24 & & 221 & $\begin{array}{l}24 \\
224\end{array}$ & & 22 & \begin{tabular}{l|l}
24 & 24
\end{tabular} & 24 \\
\hline & $\begin{array}{l}\text { matorio BI } \\
\end{array}$ & 0 & & & $16 \mathrm{C}$ & 12 & & & 0 & & & & 8 & & & & 16 & 16 & 04 & & 8 & 0 & & & 0 & & & & & \begin{tabular}{|l|l|}
13 \\
\end{tabular} & & 0 & & & & & & & & \begin{tabular}{l|l}
6 & 16 \\
\end{tabular} & & \begin{tabular}{|l|}
13 \\
\end{tabular} & \begin{tabular}{l|l}
16 & 16
\end{tabular} & 16 \\
\hline & & & & & & & & & & & & & & & & & & & & & & & & & & & & & & & & & & & & & & & & & & & & \\
\hline
\end{tabular}


A partir de los datos de la tabla 4.9 se han elaborado 4 gráficas para facilitar su interpretación (figuras 4.17, 4.18, 4.19 y 4.20).

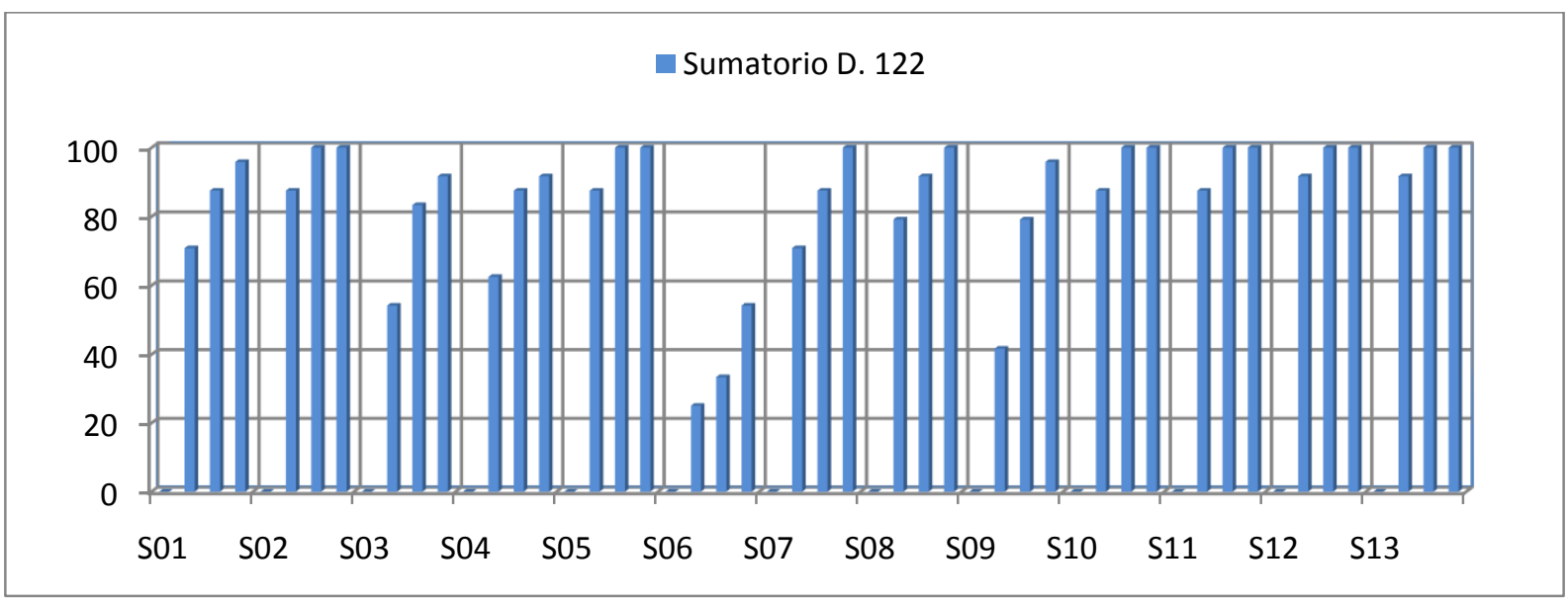

Figura 4.17: Gráfica datos de alumnos D.122 (\%): 1ํEl lecto-escritura (curso 2011/12)

Como puede observarse en la figura 4.17 , todos los sujetos parten del valor 0 en la evaluación inicial, debido a que no tenían conseguido los objetivos didácticos propuestos, aunque muchos han asistido a la guardería antes de ir al colegio. En general, se observa un gran aprendizaje durante el primer periodo y una mejora continua en todos los sujetos durante el segundo trimestre, en el que 6 de los 13 sujetos ya han alcanzado la valoración máxima. Otros 2 sujetos alcanzan dicha valoración en el tercer trimestre y todos menos uno alcanza valores muy altos en la consecución de los objetivos programados en el D.122. Sólo un alumno alcanza poco más del $50 \%$ de la puntuación en la escala, debido a su falta de asistencia continuada y la barrera idiomática.

En la siguiente gráfica (véase figura 4.18) podemos observar la evolución obtenida de todos los alumnos en relación al indicador $\mathrm{BI}$.

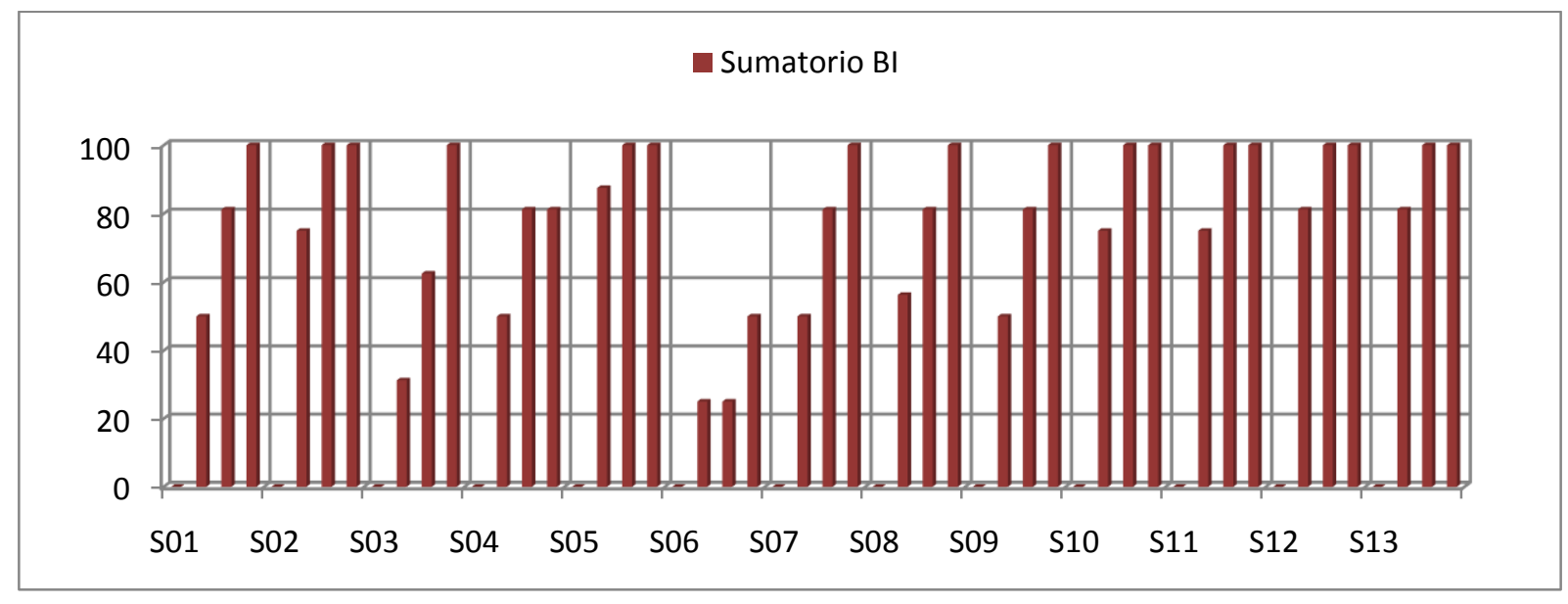

Figura 4.18. Gráfica datos de alumnos BI (\%): 1ํㅡㄹ lecto-escritura (curso 2011/12) 
Como muestra la figura 4.18, de nuevo, los alumnos parten del valor 0 en la evaluación inicial. En general se muestra una evolución muy rápida durante el primer trimestre; no obstante, el grado de consecución de los objetivos no ha mejorado tan rápidamente como sucedía en la figura 4.17; en este caso el valor máximo alcanzando por el grupo es de un $80 \%$ frente al $90 \%$ del caso anterior. Durante el segundo trimestre todos los alumnos muestran evolución, excepto el sujeto 06 consecuencias de su falta de asistencia continuada. Casi la totalidad de los alumnos han alcanzado los objetivos programados en el $\mathrm{Bl}$, incluso 5 de los de ellos lo han conseguido a lo largo del segundo trimestre; de los dos alumnos que no han alcanzado el valor máximo, uno de ellos se ha quedado muy cerca de conseguirlo (80\%) y el otro alumno, sujeto 06 , alcanza poco más del $50 \%$ de la puntuación de la escala.

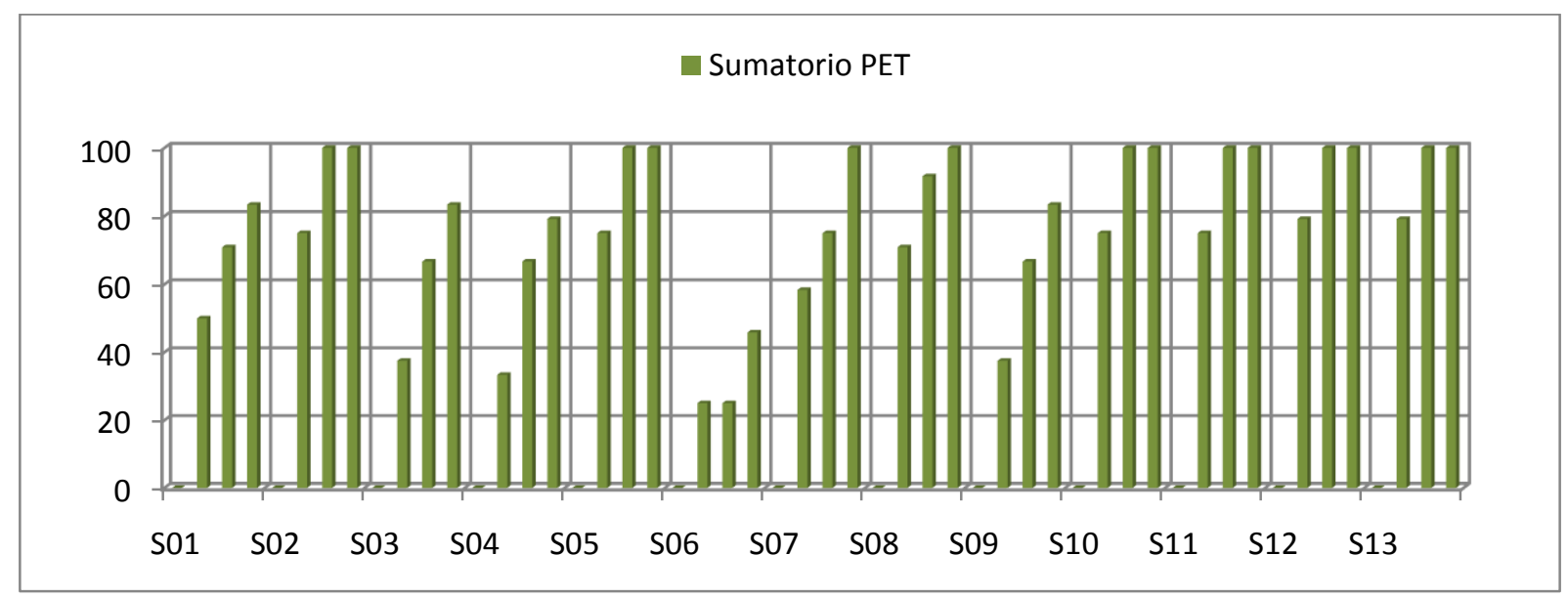

Figura 4.19. Gráfica datos de alumnos PET (\%): 1ํㅡㄴ lecto-escritura (curso 2011/12)

De nuevo, la figura 4.19 muestra como los alumnos parten del valor 0 en la evaluación inicial registrándose una evolución muy rápida durante el primer trimestre; el grado de consecución de los objetivos propuestos por el PET durante el primer trimestre es del 80\%, como sucedía en la figura 4.18. Durante el segundo trimestre hay una evolución en todos los alumnos, excepto el sujeto 06 debido a su falta asistencia continuada. De los 13 alumnos, 8 han alcanzado los objetivos programados por el PET, y 4 de ellos lo consiguieron a lo largo del segundo trimestre. Recalcar que en este caso son 5 los sujetos que no han alcanzado los valores máximos; todos ellos alcanzaros valores iguales o superiores al $80 \%$, excepto el sujeto 06, que se alcanzó un valor del $46 \%$ de la puntuación total de la escala.

La siguiente gráfica (ver figura 4.20) nos permite ver la evolución de todos los alumnos en cada uno de los de indicadores de logro, comparando la respuesta de cada alumno en cada indicador en relación a la lecto-escritura durante todo el curso escolar. 


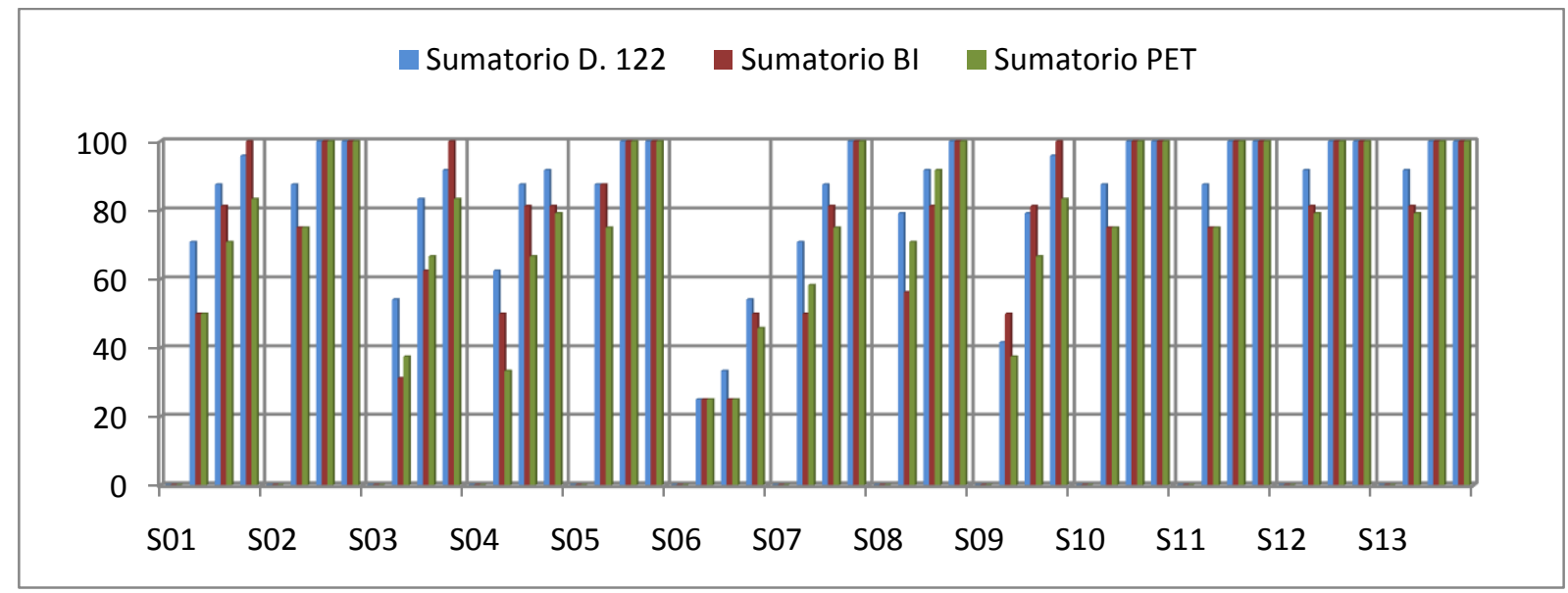

Figura 4.20. Gráfica datos de alumnos comparativa indicadores logro (\%) lecto escritura: 1ํ El (curso 2011/12)

Hay que tener en cuenta que los objetivos propuestos por PET son mucho más exigentes que el de resto de indicadores, factor a tener en cuenta en la interpretación de los datos. Como se observa en la gráfica 4.20 , todos los alumnos parten de un valor 0 y experimentan una evolución notable a lo largo del primer trimestre, siendo el indicador D.122 el que sufre un crecimiento más rápido. De forma general, todo el grupo experimenta una evolución paulatina a lo largo de los tres trimestres, excepto el sujeto 06.

De los 13 sujetos, 6 consiguen los objetivos propuestos por los tres indicadores al finalizar el segundo trimestre y otros 2 lo hacen en el tercero. De los 5 restantes el sujeto 01 , sujeto 03 y sujeto 05 , alcanzan el $100 \%$ de los objetivos propuestos por el indicador BI, incluso el sujeto 05 alcanza el $100 \%$ del indicador D.122, quedándose los otros dos sujetos muy cerca de conseguirlo (se registran valores mayores al 90\%); en el caso del indicador PET los valores hallados por estos sujetos están por encima del $80 \%$ en los tres casos.

Los sujetos 04 y 06 son los dos únicos alumnos que no han alcanzado los valores máximos propuestos por los tres indicadores; ambos alumnos poseen barrera idiomática y uno de ellos es un alumno con alta tasa de absentismo, factores determinantes en su evolución. El sujeto 04 consigue valores muy altos, obteniendo un $90 \%$ de puntuación total en el indicador D.122, valores por encima del $80 \%$ en $\mathrm{BI}$ y un $79 \%$ en PET. Por último, el suejto 06 muestra muy poca evolución durante el primer y segundo trimestre, es en el último tramo donde se registra un progreso más alto, consiguiendo 46 puntos en el indicador PET, 50 puntos en el indicador BI y 54 puntos en el indicador D.122.

Una vez explicada la tabla 4.9 y las 4 gráficas asociadas a esta tabla, pasamos a interpretar los valores hallados por la tabla 4.10 y sus gráficas correspondientes. En la tabla 4.10 se muestran los valores obtenidos a nivel grupal de toda la clase en los tres tipos de indicadores, en relación a los 6 objetivos didácticos de referencia para el ámbito lecto-escritor. 
En las últimas filas encontramos los sumatorios de cada indicador (D. 122, BI y PET) en los 4 periodos evaluados (inicio del curso, primer trimestre, segundo trimestre y final de curso).

Dado que contamos con 13 alumnos y el valor más alto de la escala es 4, el valor máximo que se puede alcanzar en cada indicador será 52. Por tanto, nos moveremos en un rango entre $0-52$, correspondiendo 52 al $100 \%$ del valor porcentual.

Tabla 4.10. Tabla FSG sumatorio lecto-escritura: $1^{\circ}$ EI (curso 2011/12)

\begin{tabular}{|c|c|c|c|c|c|c|c|c|c|}
\hline \multirow{2}{*}{$\begin{array}{c}\text { Curso } \\
\text { escolar:: }\end{array}$} & \multirow{2}{*}{\begin{tabular}{|l} 
Alumno: \\
Indicadores de logro
\end{tabular}} & \multicolumn{4}{|c|}{ SUMATORIO GRUPAL } & \multicolumn{4}{|c|}{ SUMATORIO GRUPAL (\%) } \\
\hline & & 1 & $1^{2}$ & $2^{2}$ & $\mathrm{~F}$ & 1 & 19 & $2^{9}$ & $\mathrm{~F}$ \\
\hline \multirow{3}{*}{ 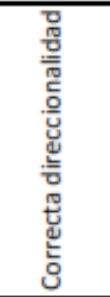 } & $\begin{array}{l}\text { D.122: Correcta dirección y posición al } \\
\text { escribir en mayúscula }\end{array}$ & 0 & 33 & 49 & 50 & $0,0 \%$ & $63,5 \%$ & $94,2 \%$ & $96,2 \%$ \\
\hline & $\begin{array}{l}\text { B: Realiza grafias en la direccionalidad } \\
\text { correcta }\end{array}$ & 0 & 33 & 49 & 50 & $0,0 \%$ & $63,5 \%$ & $94,2 \%$ & $96,2 \%$ \\
\hline & $\begin{array}{l}\text { PET: Correcta dirección y posición al } \\
\text { escribir en mayúscula }\end{array}$ & 0 & 33 & 49 & 50 & $0,0 \%$ & $63,5 \%$ & $94,2 \%$ & $96,2 \%$ \\
\hline \multirow{3}{*}{ 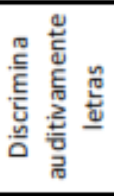 } & $\begin{array}{l}\text { D.122: Discrimina auditivamente de las } \\
\text { vocales }\end{array}$ & 0 & 46 & 49 & 51 & $0,0 \%$ & $88,5 \%$ & $94,2 \%$ & $98,1 \%$ \\
\hline & BI: Lee e interpreta imágenes & 0 & 31 & 42 & 49 & $0,0 \%$ & $59,6 \%$ & $80,8 \%$ & $94,2 \%$ \\
\hline & $\begin{array}{l}\text { PET: Discrimina auditivamente todas } \\
\text { las letras }\end{array}$ & 0 & 30 & 41 & 47 & $0,0 \%$ & $57,7 \%$ & $78,8 \%$ & $90,4 \%$ \\
\hline \multirow{3}{*}{ 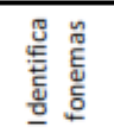 } & D. 122: Identifica algún fonema & 0 & 43 & 48 & 50 & $0,0 \%$ & $82,7 \%$ & $92,3 \%$ & $96,2 \%$ \\
\hline & BI: No se contempla & & & & & & & & \\
\hline & PET: Identifica todas las letras & 0 & 28 & 43 & 47 & $0,0 \%$ & $53,8 \%$ & $82,7 \%$ & $90,4 \%$ \\
\hline \multirow{3}{*}{ 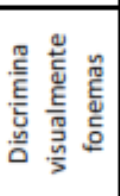 } & $\begin{array}{l}\text { D. 122: Discrimina visualmente las } \\
\text { vocales en mayúscula }\end{array}$ & 0 & 46 & 49 & 51 & $0,0 \%$ & $88,5 \%$ & $94,2 \%$ & $98,1 \%$ \\
\hline & BI: No se contempla & & & & & & & & \\
\hline & $\begin{array}{l}\text { PET: Discrimina visualmente todas las } \\
\text { letras en mayúscula }\end{array}$ & 0 & 37 & 42 & 45 & $0,0 \%$ & $71,2 \%$ & $80,8 \%$ & $86,5 \%$ \\
\hline \multirow{3}{*}{ 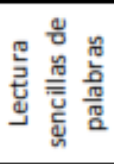 } & $\begin{array}{l}\text { D. 122: Iniciarse en la lectura de } \\
\text { palabras en mayúscula }\end{array}$ & 0 & 29 & 39 & 43 & $0,0 \%$ & $55,8 \%$ & $75,0 \%$ & $82,7 \%$ \\
\hline & BI: Lee e interpreta imágenes & 0 & 31 & 42 & 49 & $0,0 \%$ & $59,6 \%$ & $80,8 \%$ & $94,2 \%$ \\
\hline & PET: Lee palabras & 0 & 29 & 38 & 43 & $0,0 \%$ & $55,8 \%$ & $73,1 \%$ & $82,7 \%$ \\
\hline \multirow{6}{*}{ 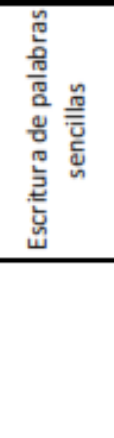 } & $\begin{array}{l}\text { D.122: Iniciarse en la escritura de } \\
\text { palabras sencillas en mayúscula }\end{array}$ & 0 & 28 & 42 & 50 & $0,0 \%$ & $53,8 \%$ & $80,8 \%$ & $96,2 \%$ \\
\hline & BI: Lee e interpreta imágenes y códigos & 0 & 31 & 42 & 49 & $0,0 \%$ & $59,6 \%$ & $80,8 \%$ & $94,2 \%$ \\
\hline & $\begin{array}{l}\text { PET: Escritura de palabras sencillas en } \\
\text { mayúscula }\end{array}$ & 0 & 28 & 42 & 50 & $0,0 \%$ & $53,8 \%$ & $80,8 \%$ & $96,2 \%$ \\
\hline & Sumatorio D. 122 & 0 & 225 & 276 & 295 & $0,0 \%$ & $72,1 \%$ & $88,5 \%$ & $94,6 \%$ \\
\hline & Sumatorio BI & 0 & 126 & 175 & 197 & $0,0 \%$ & $60,6 \%$ & $84,1 \%$ & $94,7 \%$ \\
\hline & Sumatorio PET & 0 & 185 & 255 & 282 & $0,0 \%$ & $59,3 \%$ & $81,7 \%$ & $90,4 \%$ \\
\hline
\end{tabular}

Asociada a la tabla 4.10 se han elaborado 4 gráficas para facilitar la interpretación de los datos; éstas pueden verse en las figuras 4.21, 4.22, 4.23 y 4.24 . 


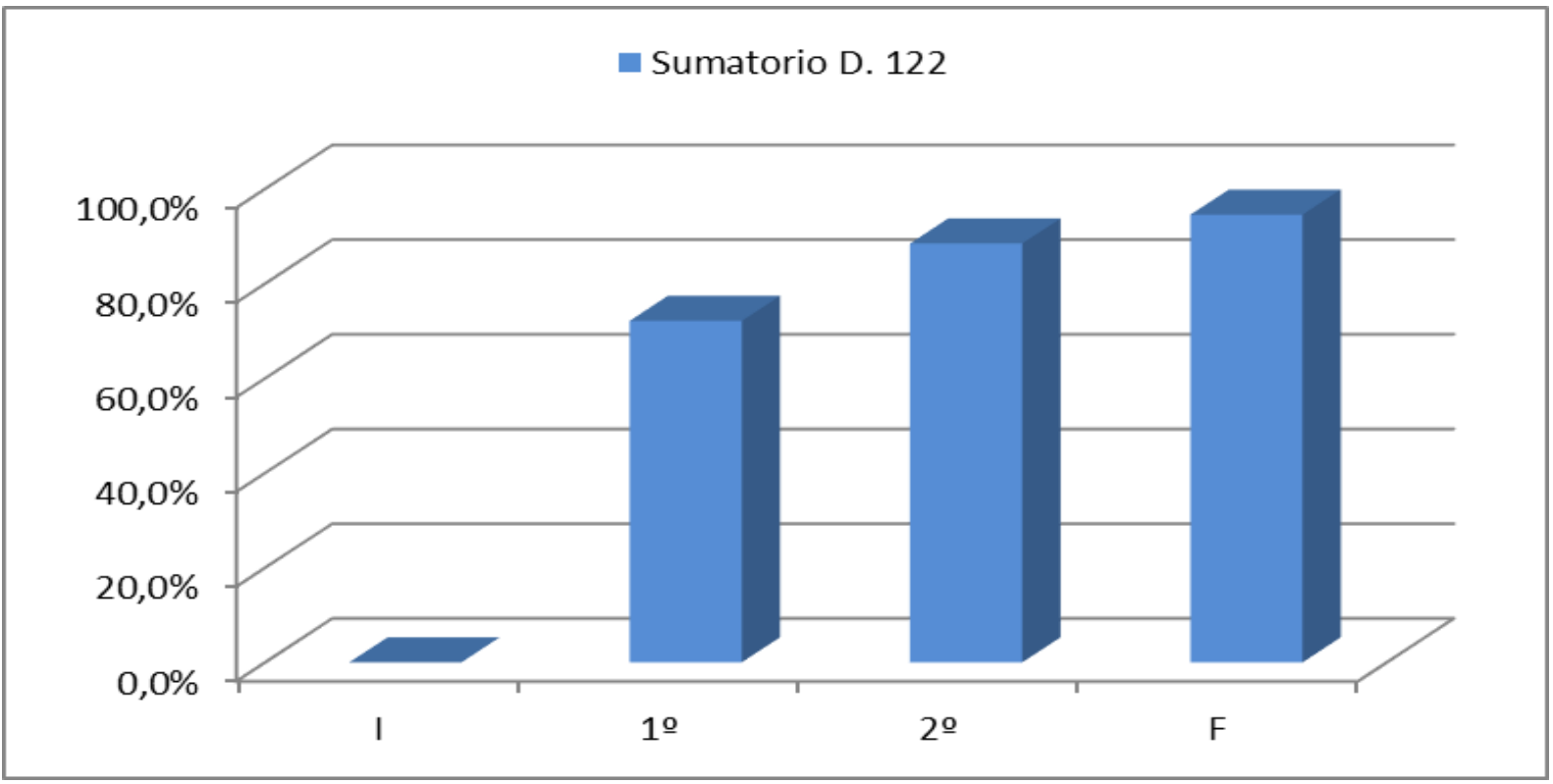

Figura 4.21.Gráfica sumatorio D.122 (\%) lecto-escritura: 1ํㅡl (curso 2011/12)

Con la gráfica 4.21 podemos ver los valore porcentuales hallados por toda la clase en relación al D.122. Como se observa, todos los alumnos parten del valor 0, experimentando una evolución considerable durante el primer trimestre; alcanzando un valor superior al $70 \%$ al final de éste. A lo largo del segundo y tercer trimestre existe evolución, aunque de forma más paulatina. Los datos totales porcentuales alcanzados en el segundo trimestre están muy cerca del $90 \%$, consiguiendo un $95 \%$ de valor total al finalizar el curso; lo que implica, que casi la totalidad del grupo ha conseguido los objetivos propuestos por el D. 122.

En la siguiente gráfica (figura 4.22) podemos observar la evolución obtenida por toda la clase en relación al indicador $\mathrm{Bl}$.

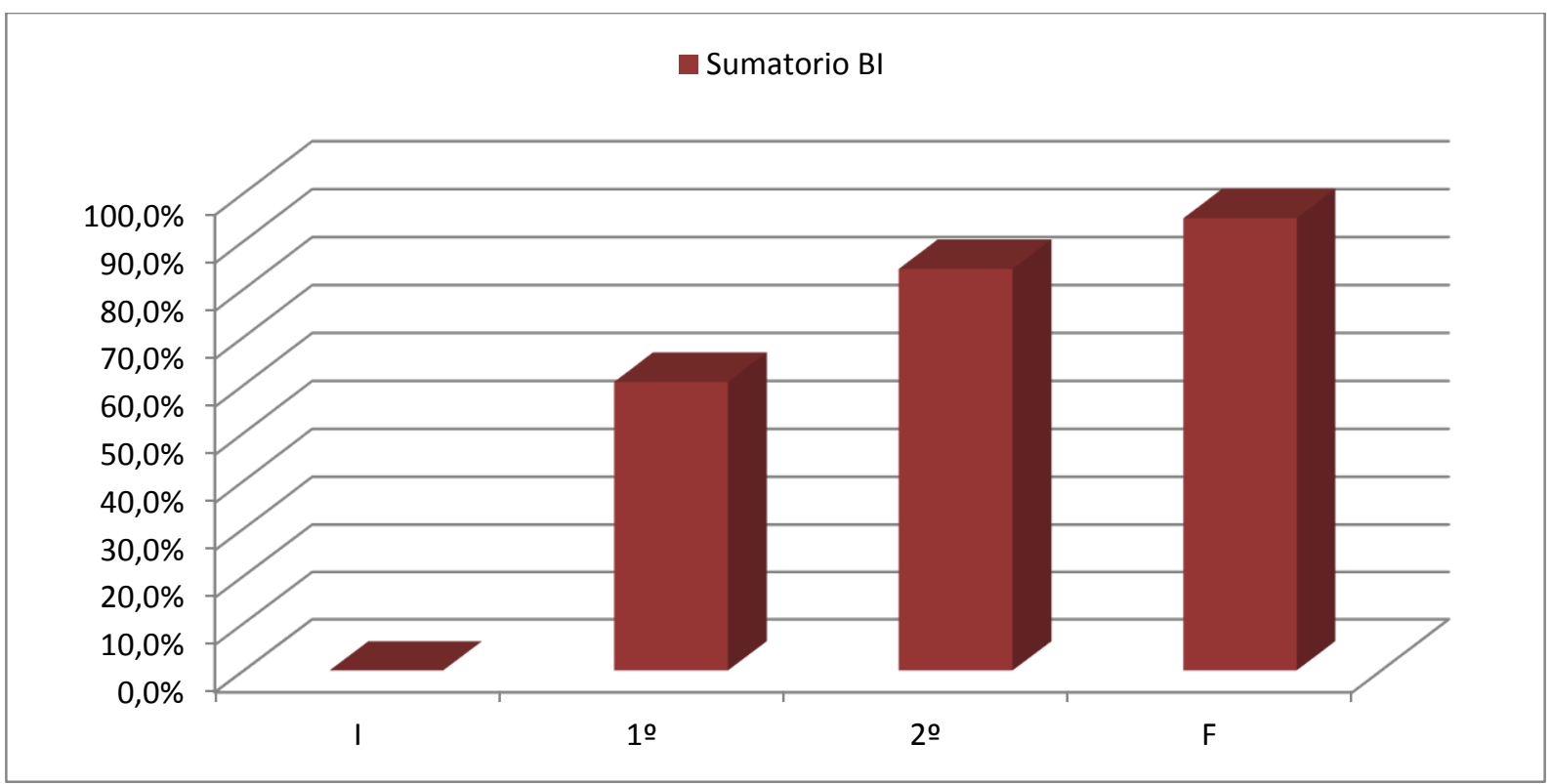


Figura 4.22. Gráfica sumatorio BI (\%) lecto-escritura: 1ํㅡ EI (curso 2011/12)

En la figura puede observarse una evolución muy similar a la vista en la figura anterior. Nuevamente, partimos de un valor inicial 0 , lo que implica un avance muy rápido en el primer trimestre, ralentizándose a lo largo de los otros trimestres. En este caso, la clase ha estado muy cerca de alcanzar un $90 \%$ de los objetivos propuestos por el D.122 en el segundo trimestre, consiguiendo un $95 \%$ de puntuación total al finalizar el curso.

En la figura 4.23 mostramos los datos obtenidos por toda la clase en relación al indicador PET.

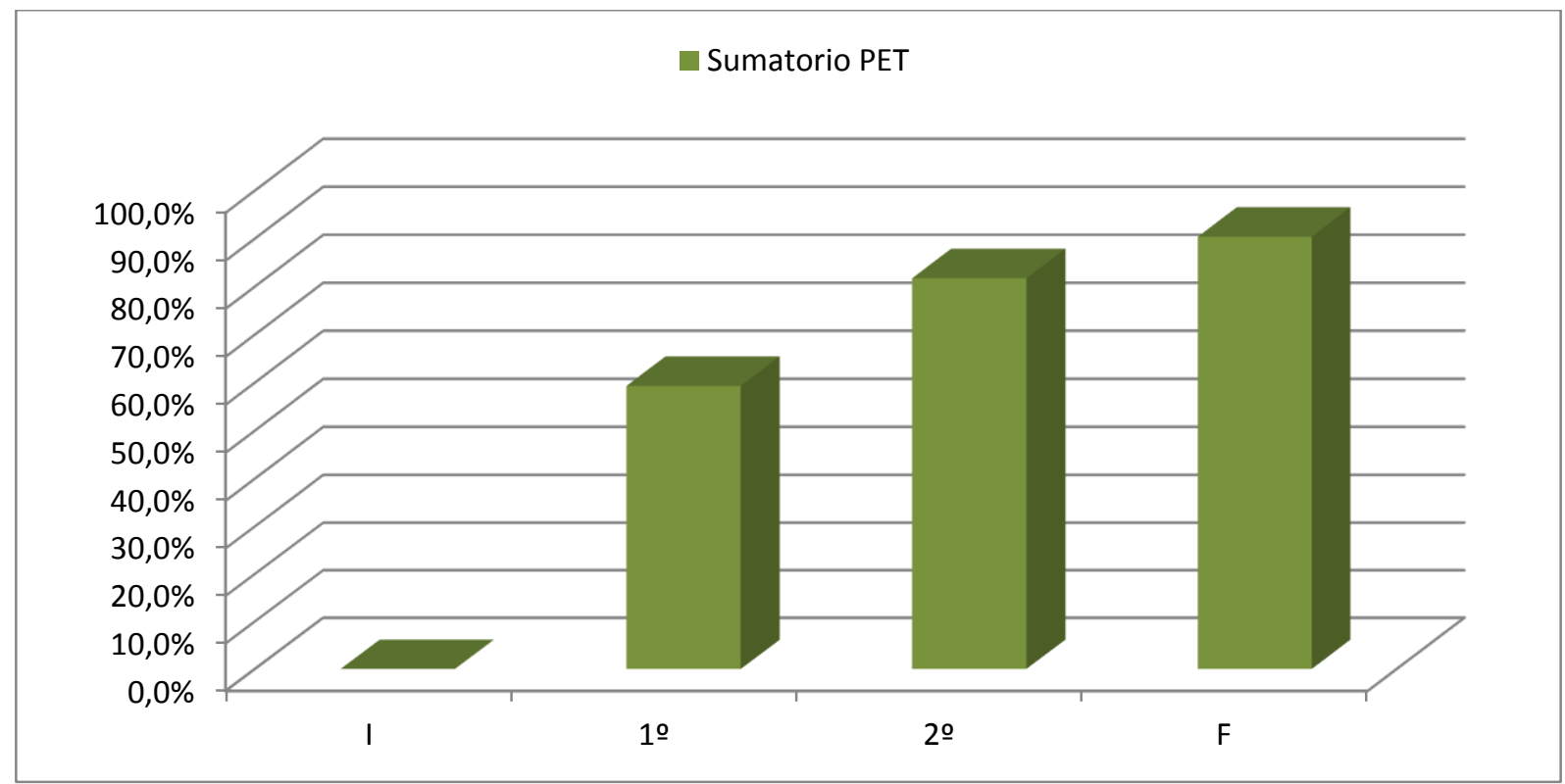

Figura 4.23. Gráfica sumatorio PET (\%) lecto-escritura: 1ํ EI (curso 2011/12)

La evolución inicial en la figura 4.23 es similar a las figuras 4.21 y 4.22 ; partimos del valor inicial 0 lo que implica un avance significativo en el primer trimestre. La evolución es constante a lo largo de todo el curso, siendo los progresos más lentos en los dos últimos tramos. Los valores hallados en el primer trimestre alcanzaron una puntuación del $59,3 \%$, del $81,7 \%$ en el segundo trimestre y del $90,4 \%$ al finalizar el curso.

Finalmente, en la siguiente gráfica (figura 4.24) mostramos la evolución conseguida por todos los alumnos, realizando una comparativa de los tres indicadores a lo largo del curso 2011/12. 


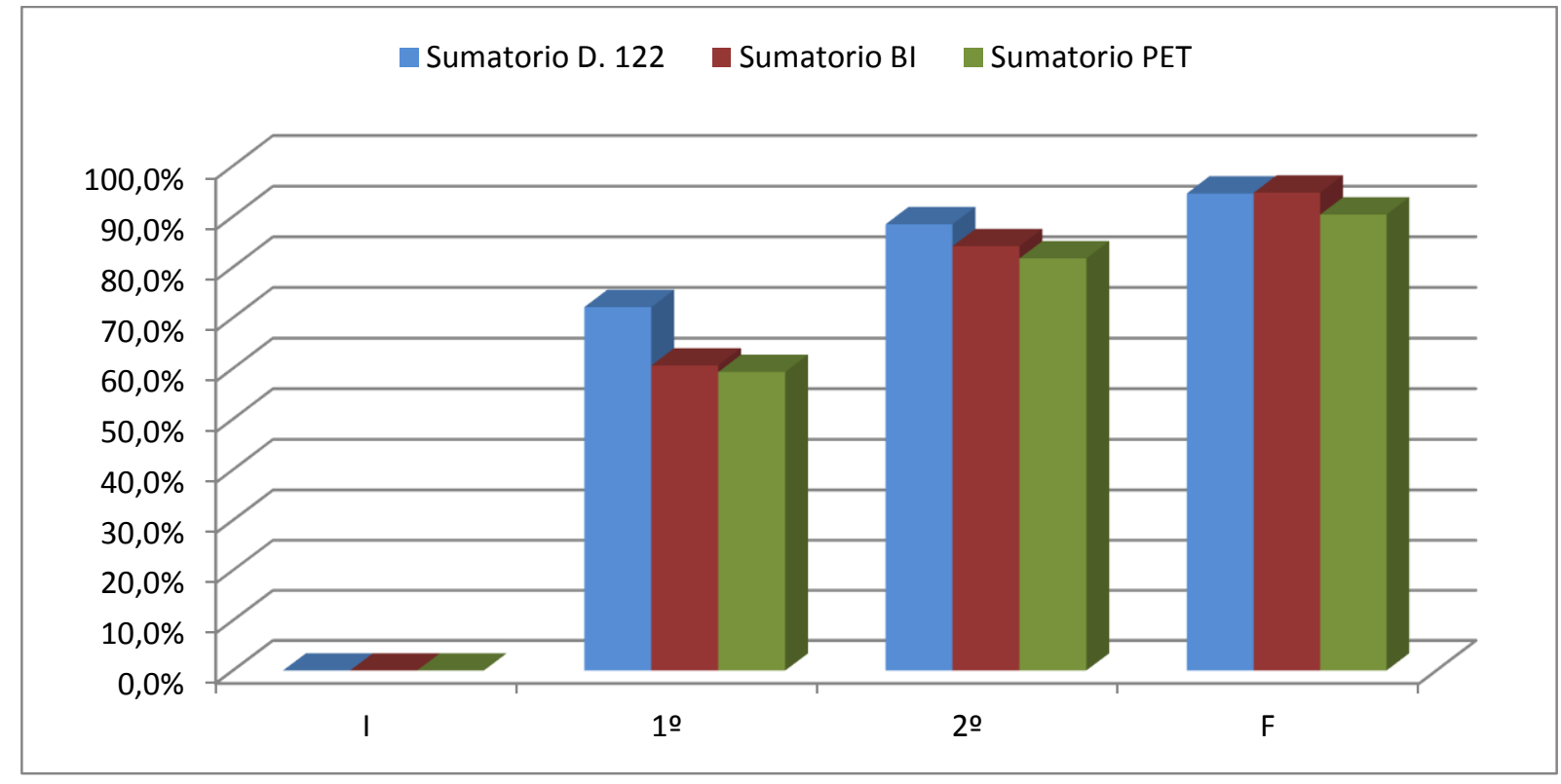

Figura 4.24. Gráfica sumatorio comparativa indicadores logro lecto-escritura: 1ํㅡ EI (curso 2011/12)

En la gráfica todos los indicadores parten del valor 0 , esto implica que todos los indicadores de logro experimentan una evolución muy rápida en el primer trimestre; esta evolución aunque más lenta es contante a lo largo de todo el curso, siendo el indicador D.122 el que consigue los valores más altos en el primer y segundo trimestre. A lo largo del segundo trimestre, la diferencia entre los tres indicadores es de 3 y 4 puntos $(81 \%$ D. $122,84 \%$ Bl y $88 \%$ en PET).

Al finalizar el curso, la totalidad de la clase ha alcanzado valores muy altos en el D.122 y BI, quedándose muy cerca de estos valores el PET (90,4\%). Estos datos indican que el nivel general de la clase es muy alto en referencia a lo que marca y exige la ley para este curso escolar, y además, un porcentaje altísimo de sujetos participantes en la investigación, ha superado con éxito objetivos mucho más exigentes que los que marca la junta de Castilla y León, como son: reconocimiento de todas las letras del abecedario, lectura fluida en cuentos con letra en minúscula, escritura de frases, etc. (ver anexo 1, anexo 4, anexo 5, anexo 6, anexo 7 , anexo 9 y anexo 10).

\subsubsection{Tablas y gráficos de lógico-matemáticas}

En la tabla 4.11 se muestran los datos obtenidos para el curso 2011/12 en relación al ámbito lógico-matemático. En la primera columna se especifican los 6 objetivos didácticos de referencia para cada alumno durante ese curso escolar. A lo largo de la segunda columna, se concretan los objetivos a alcanzar en cada indicador de logro (D.122, BI y PET); puntualizar que en el caso de $\mathrm{BI}$ existen cuatro objetivos que no contemplan este indicador (lugar en la 
serie, iniciación a la suma, iniciación a la resta y operaciones con monedas), por tanto, los valores hallados se moverán en un rango comprendido entre $0-8$, siendo 0 el valor mínimo y 8 el valor máximo; el resto de indicadores de logro (D. 122 y BI) están presentes en todos los objetivos didácticos de la tabla; se moverán en un rango de 0-24, siendo 0 el valor mínimo y 24 el valor máximo. Finalmente, en el resto de columnas se recogen los datos obtenidos por los 13 sujetos participantes en la investigación durante los 4 periodos de referencia (principio de curso y final de los tres trimestres). 
Tabla 4.11. FSG datos alumnos lógico-matemática: 1ํㅡ El (curso 2011/2)

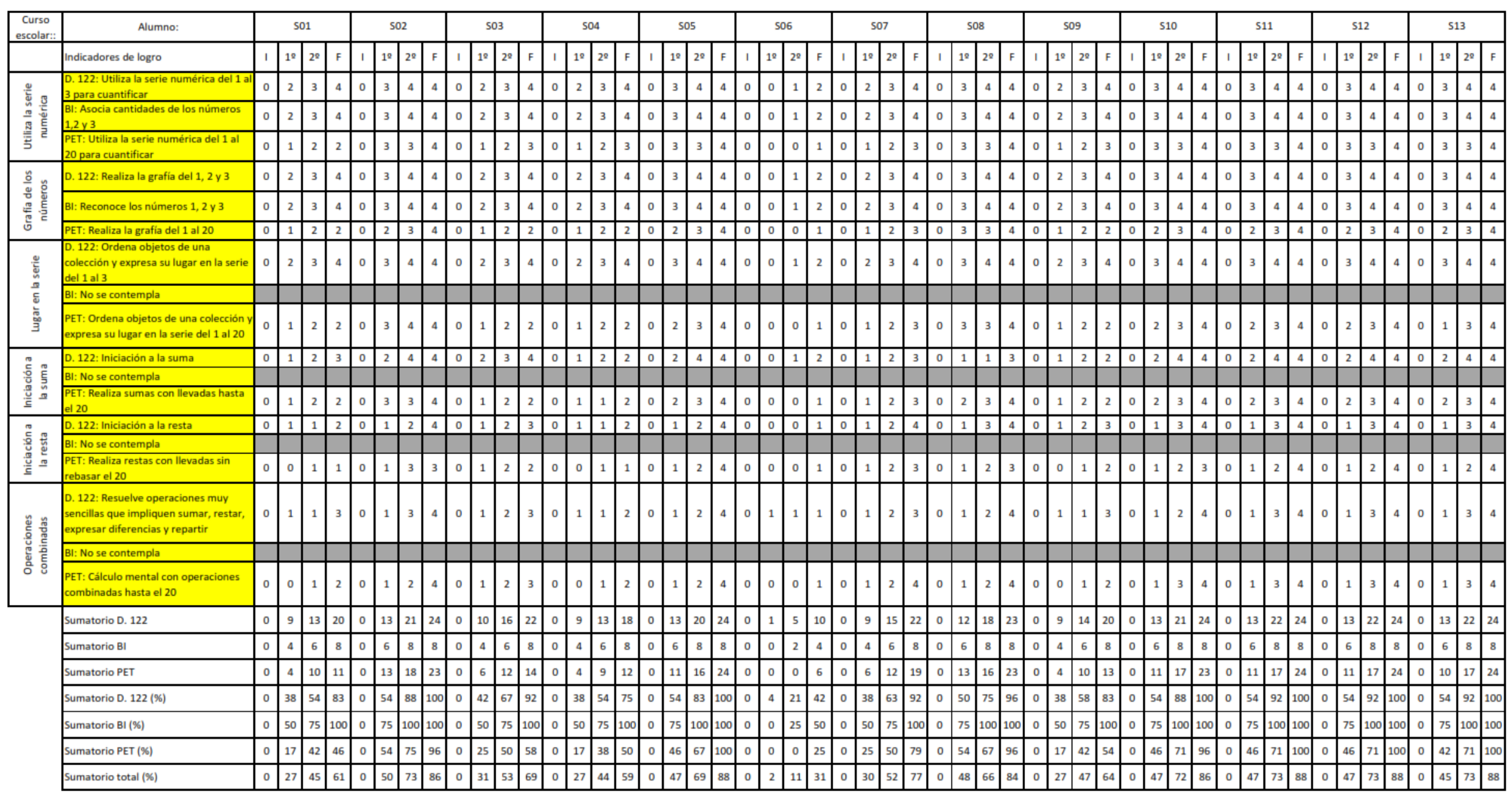


En relación a la tabla 4.11 se han elaborado 4 gráficas para facilitar su interpretación (figuras $4.25,4.26,4.27$ y 4.28 ).

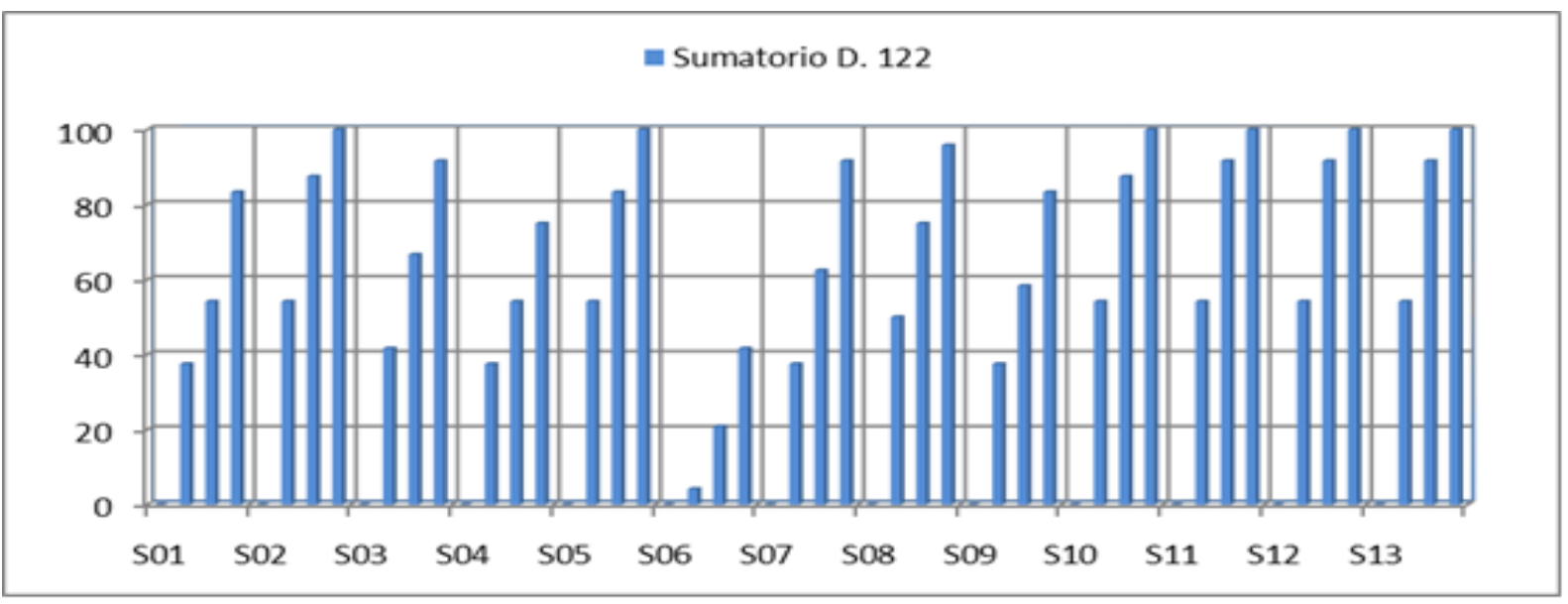

Figura 4.25. Gráfica datos de alumnos D.122 (\%): 1ํEl lógico-matemática (curso 2011/12)

Como puede observarse en la figura 4.25, todos los sujetos parten del valor 0 en la evaluación inicial, debido a que no tenían conseguido los objetivos didácticos propuestos, aunque muchos han asistido a la guardería antes de ir al colegio. En general, se observa un gran aprendizaje durante el primer periodo y una mejora continua en todos los sujetos durante el segundo y tercer trimestre, en este caso, a diferencia de anterior ámbito investigado (lectoescritura) no hay ningún sujeto que haya alcanzado la valoración máxima en segundo trimestre. 6 de 13 sujetos alcanzan el 100\% de los objetivos programados por el D.122 en el tercer trimestre, de los 7 restantes los sujetos 03, 08 y 09 consiguen valores por encima del 90\% (92\%, 92\% y 96\%) quedándose éste último muy cerca de conseguir el valor máximo; el sujeto 01 alcanza un $83 \%$, sin embargo los alumnos que presentan barrera idiomática alcanzan valores del $75 \%$ y del $42 \%$, recordar que éste último es un alumno absentista que falta al aula una media de 2-3 días por semana lo que impide que su evolución sea mayor.

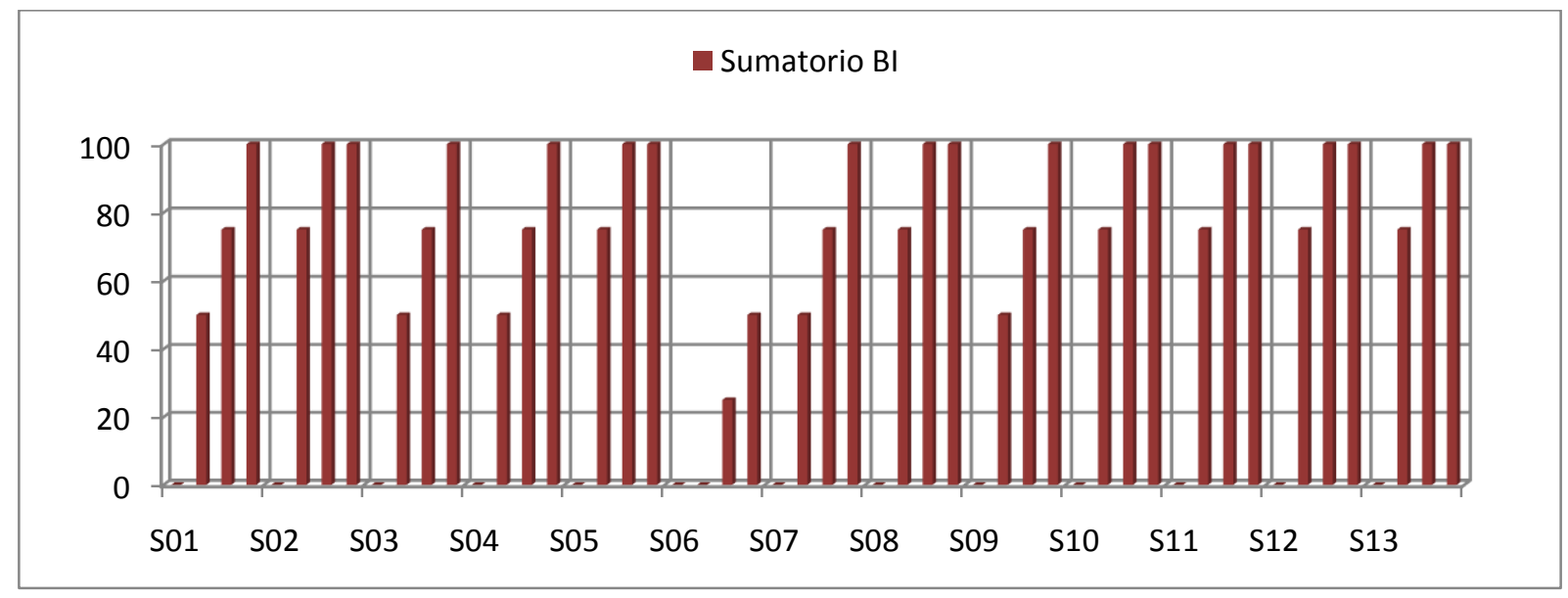

Figura 4.26. Gráfica datos alumnos BI (\%): 1ํㅡ El lógico-matemática (curso 2011/12) 
Como muestra la figura 4.26, de nuevo, los alumnos parten del valor 0 en el indicador $\mathrm{BI}$ en la evaluación inicial. En general se muestra una evolución muy rápida durante todo el curso, especialmente durante el primer y segundo trimestre. La totalidad de los alumnos han alcanzado los objetivos programados en el $\mathrm{BI}$, excepto el sujeto 06 que consigue el $50 \%$ de la puntuación en la escala; 7 de los sujetos han conseguido alcanzar los objetivos programados por $\mathrm{BI}$ en el segundo trimestre, consiguiendo los 5 restantes valores superiores al $75 \%$ en este trimestre.

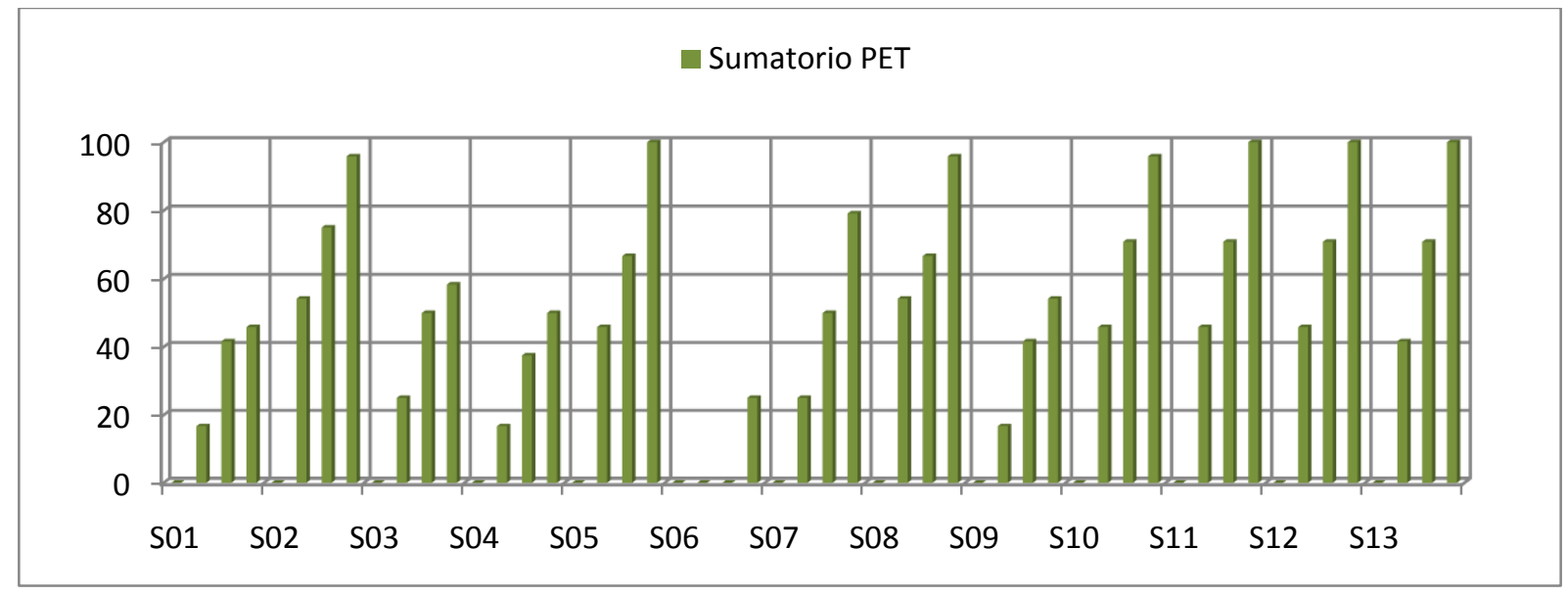

Figura 4.27. Gráfica datos alumnos PET (\%): 1ํE El lógico-matemática (curso 2011/12)

Como se muestra en la figura 4.27, los alumnos parten del valor 0 en la evaluación inicial en el indicador PET registrándose una evolución muy rápida durante el primer trimestre; excepto el sujeto 06, que no muestra evolución hasta el final de curso. Durante el segundo trimestre hay una evolución en todos los alumnos, excepto el sujeto 06 , debido a su falta asistencia continuada. De los 13 alumnos, 3 se han quedado muy cerca de conseguir la puntuación máxima obteniendo valores del 96\%. Son 6 los sujetos que no han alcanzado los valores máximos, obteniendo valores comprendidos entre el $80-79 \%$. El sujeto 06 no muestra ninguna evolución hasta el último trimestre, donde consigue alcanzar el $25 \%$ de la puntuación total de la escala, consecuencia de su falta de asistencia prolongada durante ese trimestre.

La figura 4.28 nos permite observar la evolución de todos los alumnos durante todo el curso escolar en cada uno de los tres indicadores de logro sobre lecto-escritura. 


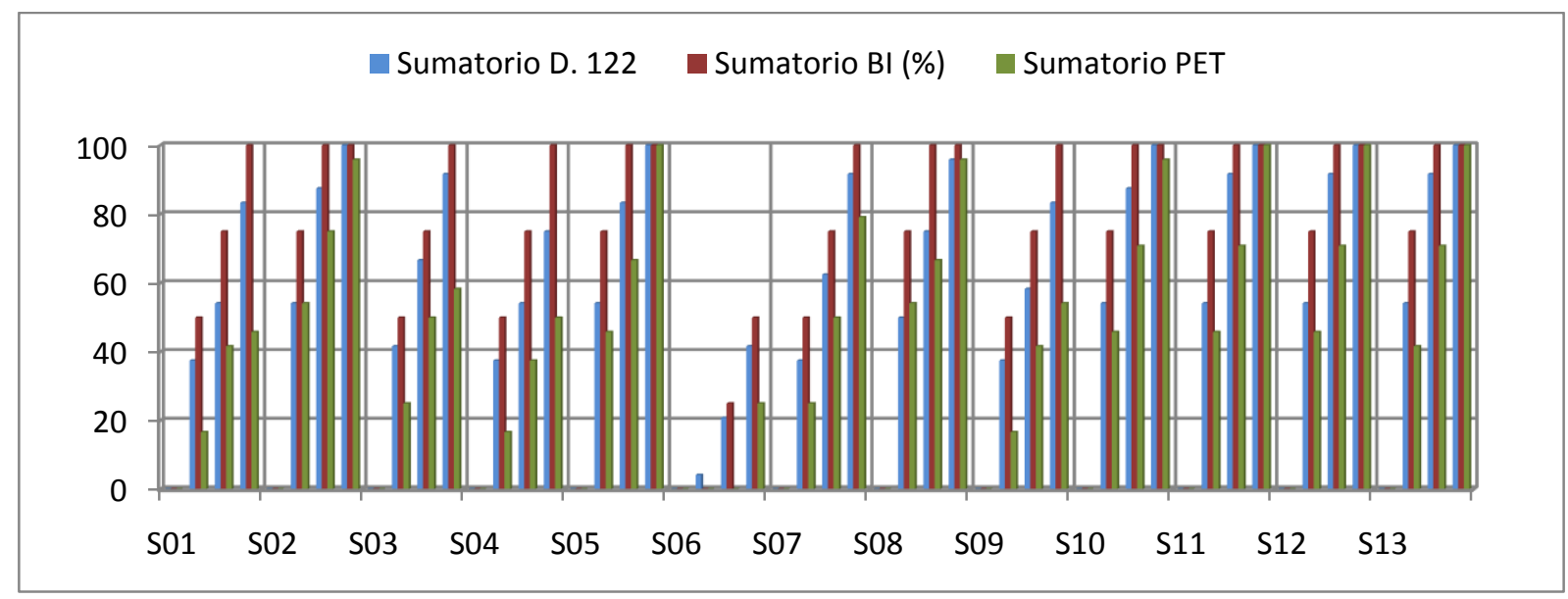

Figura 4.28. Gráfica datos de alumnos comparativa indicadores logro (\%): 1ํㅡl lógico matemáticas (curso 2010/11)

Como ya hemos explicado anteriormente, hay que tener en cuenta que los objetivos propuestos por PET son mucho más exigentes que los otros dos. Como se observa en la gráfica, todos los alumnos parten de un valor 0 en los tres indicadores y experimentan una evolución notable a lo largo del primer trimestre, siendo el indicador $\mathrm{BI}$ el que sufre un crecimiento más rápido. De forma general, todo el grupo experimenta una evolución paulatina a lo largo de los tres trimestres, excepto el sujeto 06 por las razones ya indicadas anteriormente.

De los 13 sujetos, 4 consiguen los objetivos propuestos por los tres indicadores al finalizar el curso escolar, mientras que existen otros 3 sujetos que se quedan muy cerca de conseguirlo (sujeto 02 , sujeto 08 y sujeto 10 ), alcanzando valores máximos en el indicador $\mathrm{BI}$ y D.122 y valores iguales o superiores al 95\% en el PET. De los 7 sujetos restantes. Los sujetos $01,03,04,05$ y 09 alcanzan el $100 \%$ de los objetivos propuestos por el indicador $\mathrm{BI}$, valores superiores al $75 \%$ en el indicador D.122 y valores cercanos al $50 \%$ en el indicador PET. El sujeto 06 no muestra una evolución tan significativa como el resto de alumnos, mostrando apenas evolución en el indicador PET y logrando una puntuación del $50 \%$ en el indicador $\mathrm{BI}$ y del $42 \%$ en el indicador $\mathrm{D} .122$ consecuencia de faltar al aula de forma asidua.

En la figura 4.12 se muestran los valores obtenidos a nivel grupal de toda la clase en los tres tipos de indicadores, en relación a los 6 objetivos didácticos de referencia para el ámbito lógico-matemático. En las últimas filas encontramos los sumatorios de cada indicador (D. 122, BI y PET) en los 4 periodos evaluados (inicio del curso, primer trimestre, segundo trimestre y final de curso). Al igual que en el ámbito lecto-escritor contamos con 13 alumnos; dado que el valor más alto de la escala es 4 , el valor máximo que se puede alcanzar en cada indicador será 52. Por tanto, nos moveremos en un rango entre 0-52, correspondiendo 52 al $100 \%$ del valor porcentual. 


\section{CAPITULO 4: ANÁLISIS DE DATOS}

Tabla 4.12. FSG sumatorios lógico-matemática: 1ํE (curso 2011/12)

\begin{tabular}{|c|c|c|c|c|c|c|c|c|c|}
\hline \multirow{2}{*}{$\begin{array}{l}\text { Curso } \\
\text { escolar:: }\end{array}$} & \multirow{2}{*}{\begin{tabular}{|l} 
Alumno: \\
Indicadores de logro
\end{tabular}} & \multicolumn{4}{|c|}{ SUMATORIO GRUPAL } & \multicolumn{4}{|c|}{ SUMATORIO GRUPAL (\%) } \\
\hline & & 1 & 12 & $2^{2}$ & $\mathrm{~F}$ & 1 & 19 & $2^{2}$ & $\mathrm{~F}$ \\
\hline \multirow{3}{*}{ 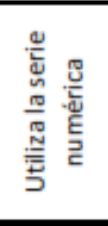 } & $\begin{array}{l}\text { D. 122: Utiliza la serie numérica del } 1 \text { al } \\
3 \text { para cuantificar }\end{array}$ & 0 & 31 & 44 & 50 & $0,0 \%$ & $59,6 \%$ & $84,6 \%$ & $96,2 \%$ \\
\hline & $\begin{array}{l}\text { Bl: Asocia cantidades de los números } \\
1,2 \text { y } 3\end{array}$ & 0 & 31 & 44 & 50 & $0,0 \%$ & $59,6 \%$ & $84,6 \%$ & $96,2 \%$ \\
\hline & $\begin{array}{l}\text { PET: Utiliza la serie numérica del } 1 \text { al } 20 \\
\text { para cuantificar }\end{array}$ & 0 & 26 & 31 & 43 & $0,0 \%$ & $50,0 \%$ & $59,6 \%$ & $82,7 \%$ \\
\hline \multirow{3}{*}{ 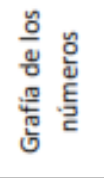 } & D. 122: Realiza la grafía del 1,2 y 3 & 0 & 31 & 44 & 50 & $0,0 \%$ & $59,6 \%$ & $84,6 \%$ & $96,2 \%$ \\
\hline & BI: Reconoce los números 1,2 y 3 & 0 & 31 & 44 & 50 & $0,0 \%$ & $59,6 \%$ & $84,6 \%$ & $96,2 \%$ \\
\hline & PET: Realiza la grafia del 1 al 20 & 0 & 20 & 31 & 40 & $0,0 \%$ & $38,5 \%$ & $59,6 \%$ & $76,9 \%$ \\
\hline \multirow{3}{*}{ 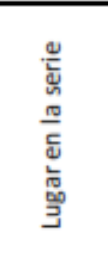 } & \begin{tabular}{|l|} 
D. 122 : Ordena objetos de una \\
colección y expresa su lugar en la serie \\
del 1 al 3 \\
\end{tabular} & 0 & 31 & 44 & 50 & $0,0 \%$ & $59,6 \%$ & $84,6 \%$ & $96,2 \%$ \\
\hline & Bl: No se contempla & & & & & & & & \\
\hline & $\begin{array}{l}\text { PET: Ordena objetos de una colección y } \\
\text { expresa su lugar en la serie del } 1 \text { al } 20\end{array}$ & 0 & 20 & 32 & 40 & $0,0 \%$ & $38,5 \%$ & $61,5 \%$ & $76,9 \%$ \\
\hline \multirow{3}{*}{ 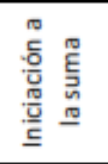 } & D. 122: Iniciación a la suma & 0 & 19 & 37 & 43 & $0,0 \%$ & $36,5 \%$ & $71,2 \%$ & $82,7 \%$ \\
\hline & BI: No se contempla & & & & & & & & \\
\hline & $\begin{array}{l}\text { PET: Realiza sumas con llevadas hasta } \\
\text { el } 20\end{array}$ & 0 & 20 & 30 & 40 & $0,0 \%$ & $38,5 \%$ & $57,7 \%$ & $76,9 \%$ \\
\hline \multirow{3}{*}{ 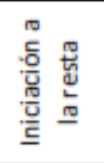 } & D. 122: Iniciación a la resta & 0 & 12 & 27 & 43 & $0,0 \%$ & $23,1 \%$ & $51,9 \%$ & $82,7 \%$ \\
\hline & BI: No se contempla & & & & & & & & \\
\hline & $\begin{array}{l}\text { PET: Realiza restas con llevadas sin } \\
\text { rebasar el } 20\end{array}$ & 0 & 9 & 22 & 35 & $0,0 \%$ & $17,3 \%$ & $42,3 \%$ & $67,3 \%$ \\
\hline \multirow{6}{*}{ 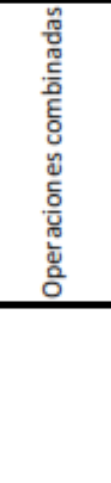 } & $\begin{array}{l}\text { D. 122: Resuelve operaciones muy } \\
\text { sencillas que impliquen sumar, restar, } \\
\text { expresar diferencias y repartir }\end{array}$ & 0 & 13 & 26 & 43 & $0,0 \%$ & $25,0 \%$ & $50,0 \%$ & $82,7 \%$ \\
\hline & BI: No se contempla & & & & & & & & \\
\hline & $\begin{array}{l}\text { PET: Cálculo mental con operaciones } \\
\text { combinadas hasta el } 20\end{array}$ & 0 & 9 & 25 & 42 & $0,0 \%$ & $17,3 \%$ & $48,1 \%$ & $80,8 \%$ \\
\hline & Sumatorio D. 122 & 0 & 137 & 222 & 279 & $0,0 \%$ & $43,9 \%$ & $71,2 \%$ & $89,4 \%$ \\
\hline & Sumatorio BI & 0 & 62 & 88 & 100 & $0,0 \%$ & $59,6 \%$ & $84,6 \%$ & $96,2 \%$ \\
\hline & Sumatorio PET & 0 & 104 & 171 & 240 & $0,0 \%$ & $33,3 \%$ & $54,8 \%$ & $76,9 \%$ \\
\hline
\end{tabular}

Asociada a la tabla 4.12 se han elaborado 4 gráficas para facilitar la interpretación de los datos, que pueden verse en las figuras $4.29,4.30,4.31$ y 4.32 .

En la figura 4.29, se recogen los valores porcentuales hallados por toda la clase en relación a los objetivos lógico-matemáticos del indicador D.122. 


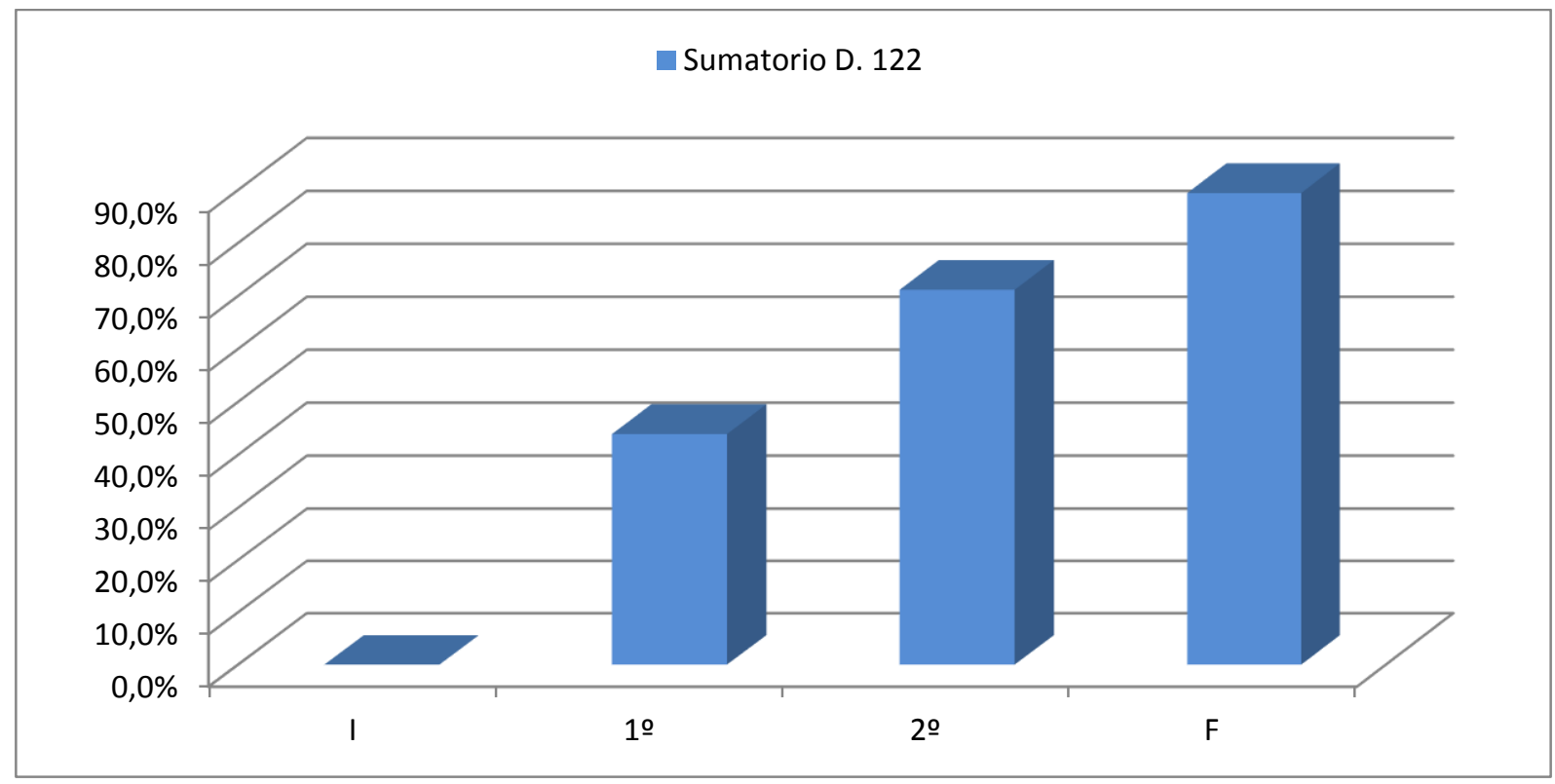

Figura 4.29. Gráfica sumatorio D.122 (\%): 1ํEl lógico-matemática (curso 2011/12)

Como se observa en la figura, todos los alumnos parten del valor 0 , experimentando una evolución considerable durante el primer trimestre; alcanzando un valor superior al $40 \%$ al final de éste. A lo largo del segundo y tercer trimestre existe mejora, aunque de forma más paulatina. Los datos totales porcentuales alcanzados en el segundo trimestre están por encima del $70 \%$, consiguiendo un $89 \%$ de valor total al finalizar el curso; lo que implica, que un porcentaje muy alto del grupo ha conseguido los objetivos propuestos por el D. 122.

En la figura 4.6 podemos observar la evolución obtenida por toda la clase en relación al indicador BI.

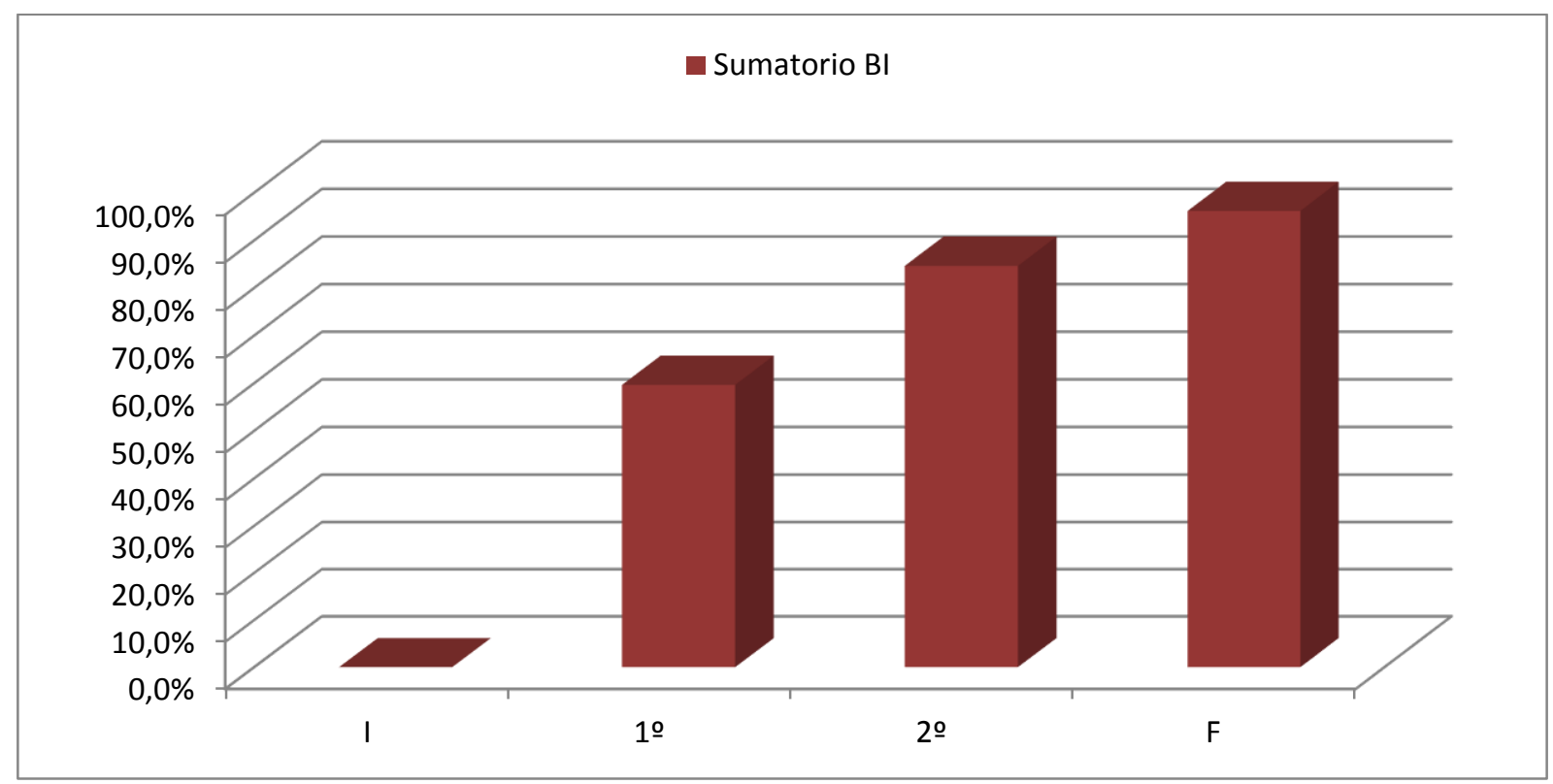

Figura 4.30. Gráfica sumatorio D.BI (\%): 1ํㅡ El lógico-matemática (curso 2011/12) 


\section{CAPITULO 4: ANÁLISIS DE DATOS}

Puede observarse una evolución muy similar a la vista en la figura anterior. Nuevamente partimos de un valor inicial 0 , lo que implica un avance muy rápido en el primer trimestre, ralentizándose a lo largo de los otros trimestres. En este caso, la clase ha estado muy cerca de alcanzar un $90 \%$ de los objetivos propuestos por el indicador D.122 en el segundo trimestre, consiguiendo un $96 \%$ de puntuación total al finalizar el curso. Por tanto, casi la totalidad del grupo ha alcanzado los objetivos lógico-matemáticos propuestos por los boletines informativos propuestos por el ciclo de El.

En la figura 4.31 recogemos los datos obtenidos por toda la clase en relación al indicador PET.

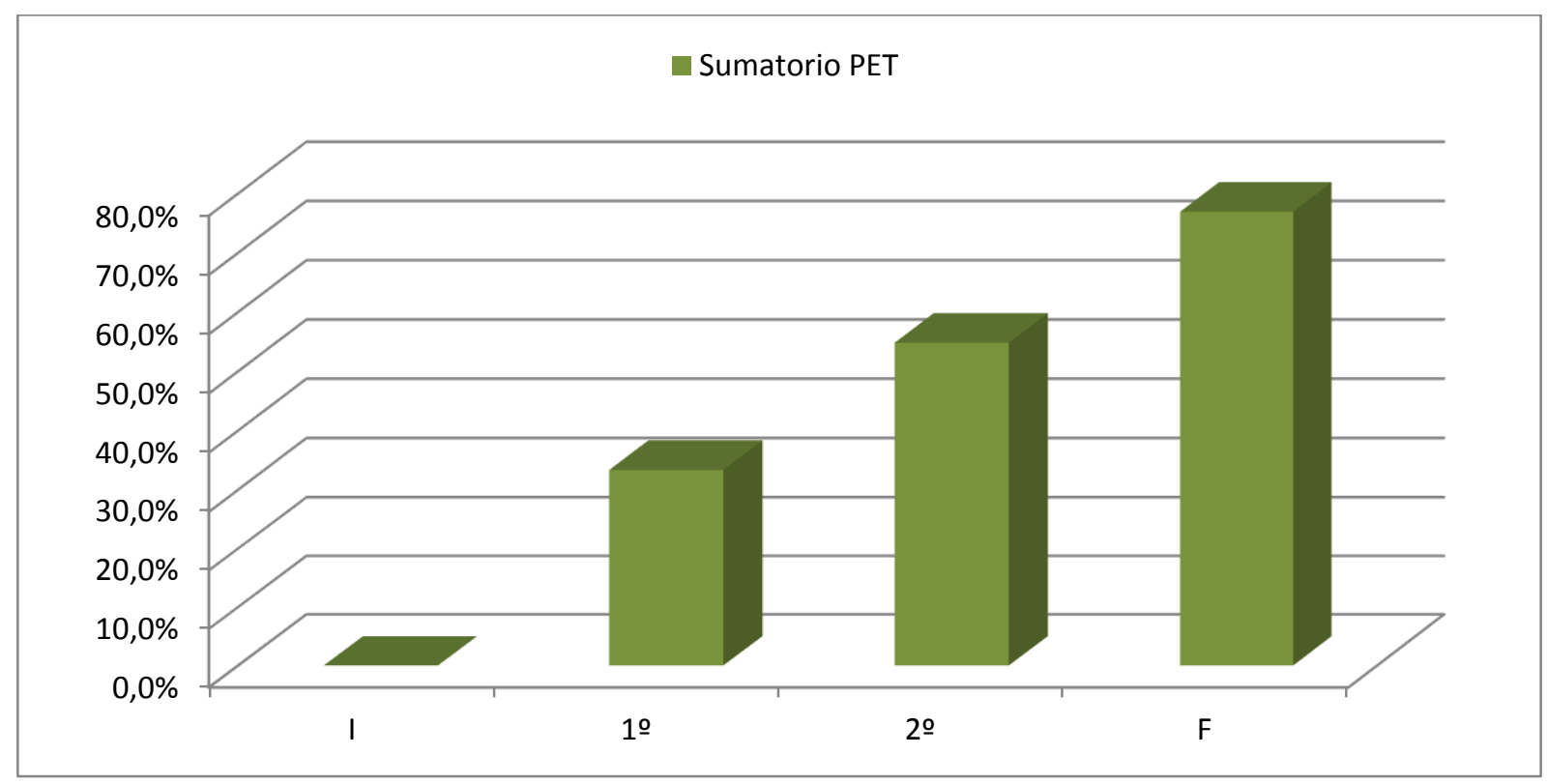

Figura 4.31. Gráfica sumatorio PET (\%): 1ํ El lógico-matemática (curso 2011/12)

La evolución inicial es similar a las figuras 4.29 y 4.30; partimos del valor inicial 0 lo que implica un avance significativo en el primer trimestre. La evolución es constante a lo largo de todo el curso, siendo los progresos más lentos en los dos últimos tramos. Los valores hallados en el primer trimestre alcanzaron una puntuación del $53,3 \%$, del $54,8 \%$ en el segundo trimestre y del $76,9 \%$ al finalizar el curso. Lo que implica que un porcentaje considerable de alumnos ha alcanzado los objetivos propuesto por este indicador; aunque en menor medida que en los indicadores BI y D.122, aspecto importante a considerar dada la complejidad de los objetivos programados en este indicador.

Finalmente, en la figura 4.32 mostramos la evolución conseguida por todo el grupo de alumnos, realizando una comparativa de los tres indicadores de logro de lógico-matemáticas a lo largo del curso 2011/12. 


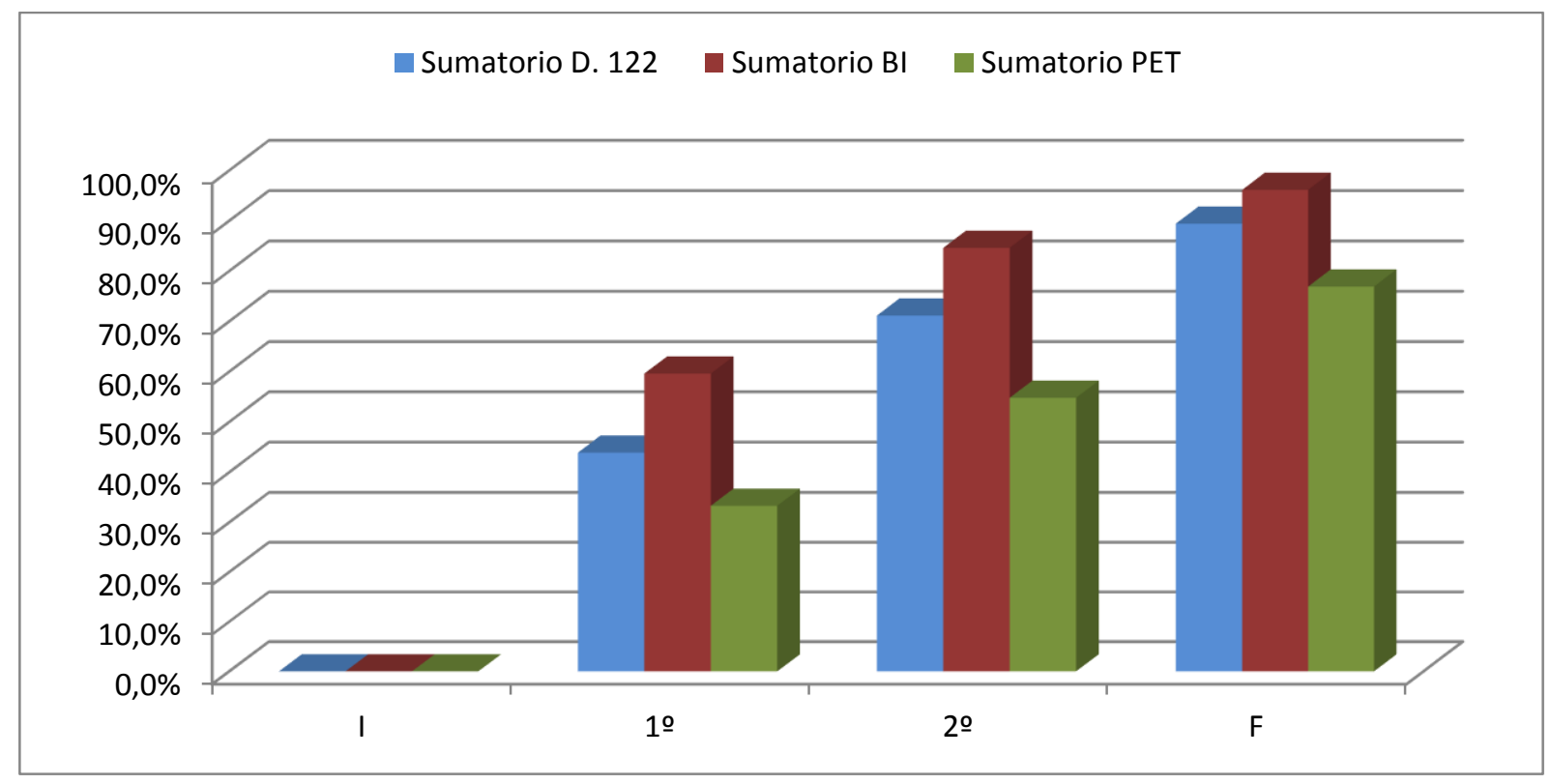

Figura 4.32. Gráfica sumatorio comparativa indicadores logro (\%): 1ํㅡ El (curso 11/12)

Los tres indicadores parten del valor 0 experimentando una evolución muy rápida en el primer trimestre; esta evolución, aunque más lenta es contante a lo largo de todo el curso, siendo el indicador $\mathrm{Bl}$ el que consigue los valores más altos en el primer, segundo y tercer trimestre. Al finalizar el curso, la totalidad de la clase ha alcanzado valores muy altos en el indicador $\mathrm{BI}$ (del 96,2\%), quedándose muy cerca de estos valores el indicador D.122 (90\%) y algo más alejado el indicador PET (77\%). Estos datos muestran que el nivel general de la clase es muy alto en referencia a lo que exige el ciclo de El del centro donde se realiza la investigación; además un porcentaje muy alto de sujetos han alcanzados valores por encima del $90 \%$ en referencia al decreto de la comunidad de Castilla y León, lo que implica un nivel muy alto a nivel general del grupo. Dado que los objetivos propuestos por el PET son mucho más exigentes e implican un nivel mucho más alto que los de los otros dos indicadores, el haber obtenido el grupo un grado de consecución general mayor del 75\% muestra un aprendizaje bastante mayor de lo que indican los estándares del Curriculum oficial para este curso, alcanzando objetivos como: reconocer números hasta el 100, identificar cuál es más grande y cuál más pequeño, realizar sumas y restas con regletas de dos cifras, etc. (ver video $1^{\circ}$ curso: $2^{\circ}$ trimestre I y video $1^{\circ}$ curso: $3^{\circ}$ trimestre). 


\subsubsection{CURSO ESCOLAR 2012/13}

En este curso escolar seguimos la investigación con el mismo grupo de alumnos que el curso pasado, con la salvedad que para este curso una de las alumnas abandona el aula por cambio de domicilio y entran dos alumnos nuevos, el sujeto 13 y el sujeto 14 .

Contamos con un total de 14 alumnos que se encuentran en el $2^{\circ}$ curso del $2^{\circ}$ ciclo de El (4-5 años), de los cuales únicamente 3 son niñas. Como sucedía en el curso pasado, sigue existiendo dos ritmos de trabajo diferenciados, e incluso un tercer nivel, con la llegada de los dos alumnos nuevos que muestran un nivel más bajo al del resto (sujeto 13 y sujeto 14). Es preciso incidir en el cumplimiento de unas normas muy marcadas para regular el comportamiento del aula.

A diferencia del curso pasado, la barrera idiomática del sujeto 06 es cada vez menor y casi inexistente en el sujeto 07 . El sujeto 06 sigue faltando de forma periódica al aula, iniciándose el protocolo de absentismo durante ese curso escolar para intentar mitigar sus ausencias periódicas. El sujeto 03 sigue mostrando problemas importantes de atención, impulsividad y conductas desafiantes.

En relación a los alumnos nuevos, el sujeto 13 ha estado escolarizado anteriormente en otro centro escolar, se encuentra en una situación familiar inestable y muestra dificultades para la interacción social, obsesiones con el tema de los animales, expresiones de habla extrañas y problemas de precisión en la motricidad gruesa y fina, además de torpeza al andar y correr. En cuanto al sujeto 14, también ha estado matriculado anteriormente en otro centro y cuenta con una situación familiar inestable, es un niño muy tranquilo, introvertido e inseguro.

\subsubsection{Tablas y gráficos de lecto-escritura}

En la tabla 4.13 se han recogido los datos obtenidos para el curso 2012/13 en relación al ámbito lecto-escritor. En la primera columna se especifican los 5 objetivos didácticos de referencia para cada alumno durante ese curso escolar. A lo largo de la segunda columna, se concretan los objetivos a alcanzar en cada indicador de logro (D.122, BI y PET); los valores hallados se moverán en un rango comprendido entre 0-20, siendo 0 el valor mínimo y 20 el valor máximo. Finalmente, en el resto de columnas se recogen los datos obtenidos por los 14 sujetos participantes en la investigación durante los 4 periodos de referencia (principio de curso y final de los tres trimestres). 
Tabla 4.13. FSG datos alumnos lecto-escritura: $2^{\circ}$ EI (curso 2012/13)

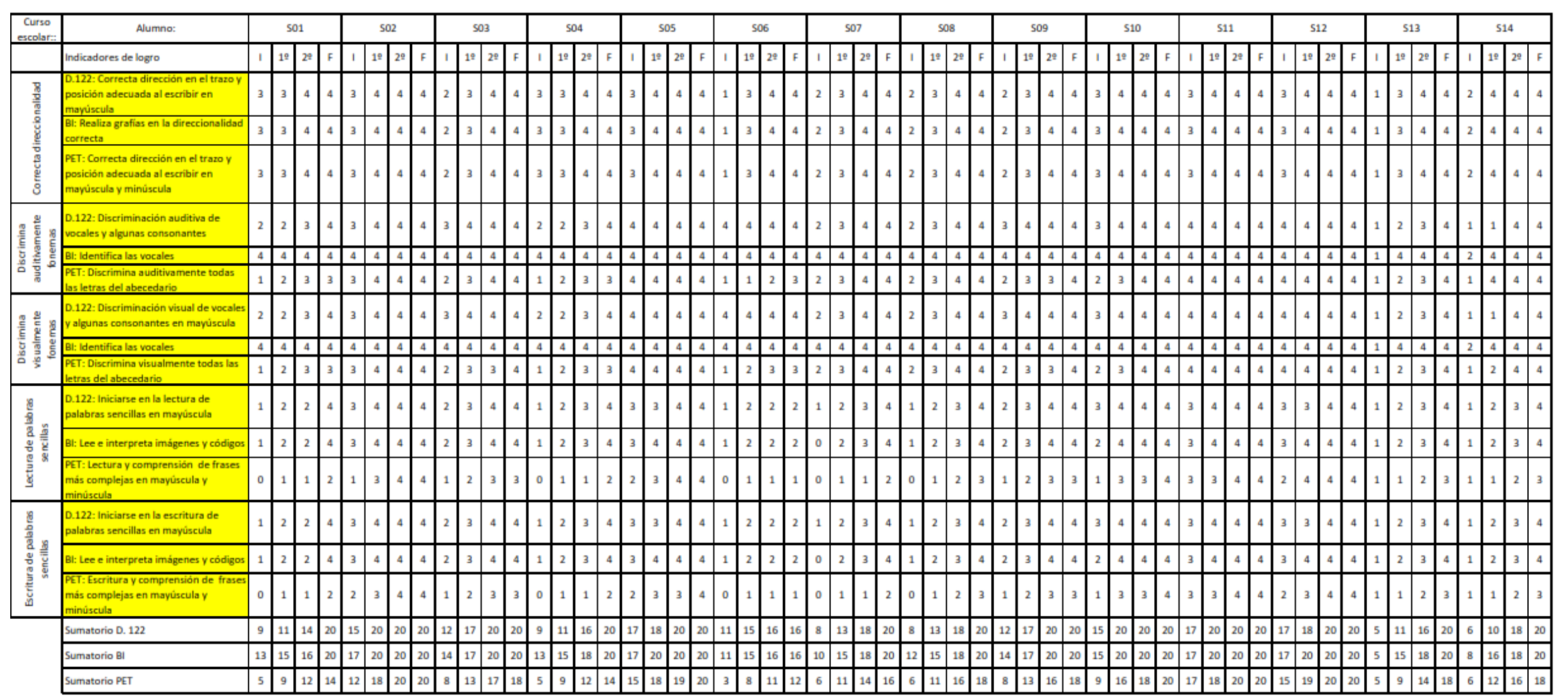


A partir de los datos de la tabla 4.13 se han elaborado 4 gráficas para facilitar su interpretación (figuras 4.33, 4.34, 4.35 y 4.36).

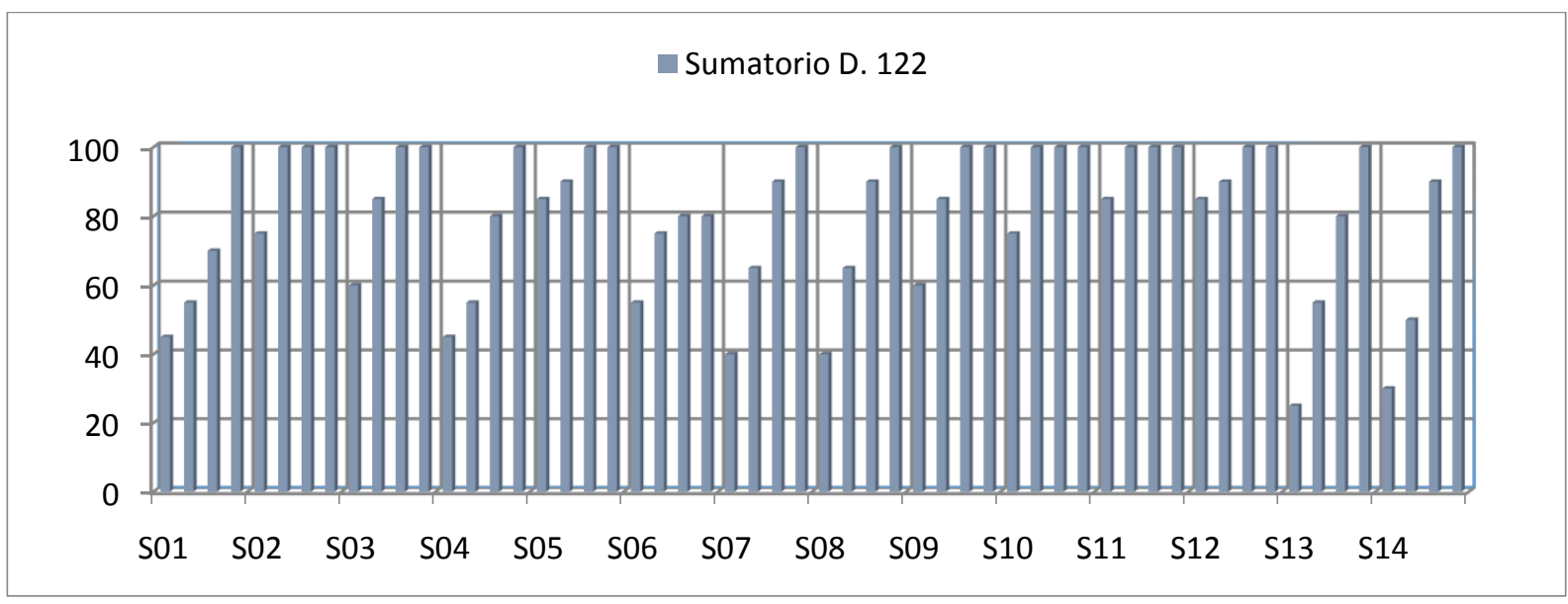

Figura 4.33. Gráfica datos de alumnos D.122 (\%): 2º El lecto-escritura (curso 2012/13)

Como vemos en la figura 4.33, el ritmo inicial de partida de la clase en relación al indicador D.122 se mueve en un rango comprendido entre 40-85\%; sin embargo, los dos alumnos nuevos (sujeto 13 y 14) parten con un nivel inicial inferior al resto de compañeros (del $25 \%$ y el $30 \%$ ). La totalidad del grupo, excepto el sujeto 06 , alcanzan el $100 \%$ de los objetivos programados por el D.122; de los 13 alumnos, 3 lo consiguen en el $1^{\circ}$ trimestre, 4 en el segundo y 6 al finalizar el curso. Como sucedía en el curso pasado, el sujeto 06 no alcanza la puntuación total de la escala debido a su falta de asistencia continuada. Los alumnos nuevos evolucionan muy rápidamente durante todo el curso, alcanzando el $100 \%$ de los objetivos en el $3^{\circ}$ trimestre. El avance más significativo se produce al finalizar el $2^{\circ}$ trimestre (mejorando un $35 \%$ el sujeto 13 y un $40 \%$ el sujeto 14 ).

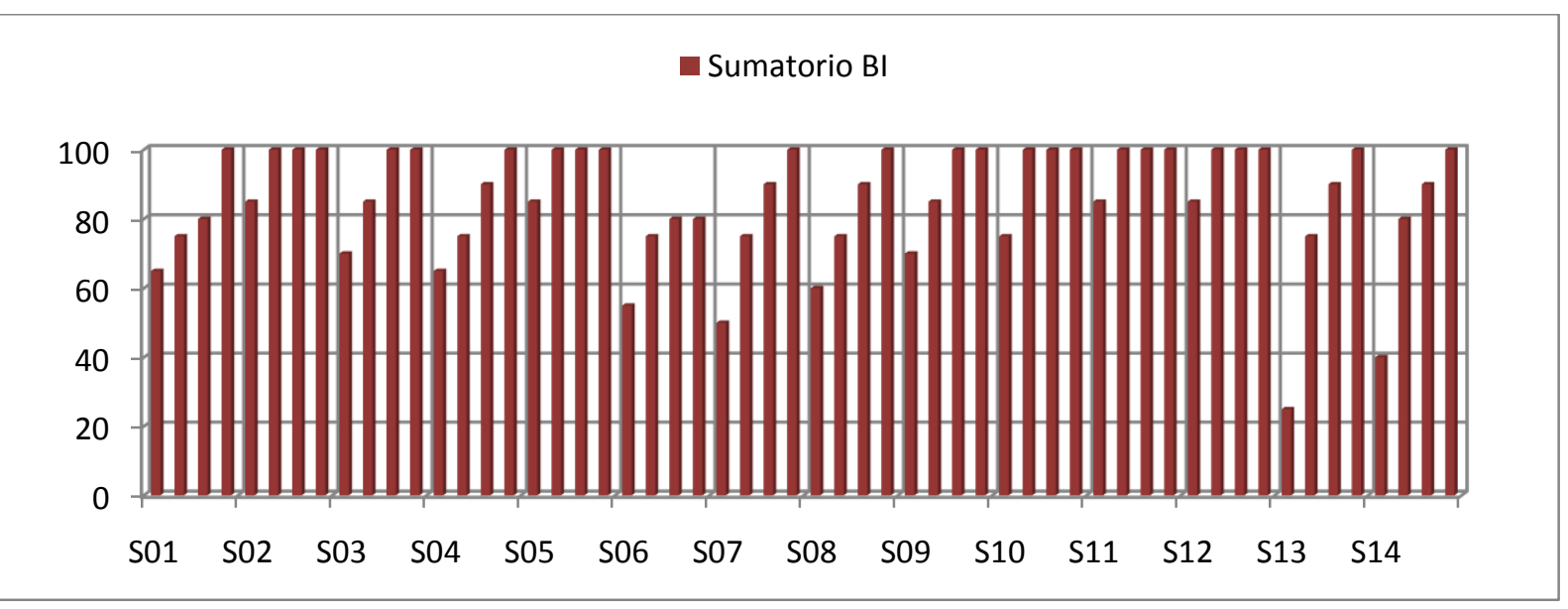

Figura 4.34. Gráfica datos de alumnos BI (\%): 2ํㅡㄹ lecto-escritura (curso 2012/13)

Como muestra la figura 4.34, el ritmo inicial de la clase en relación al indicador BI es aún mayor que el indicador D.122. Su valor inicial de partida se mueve en un rango 
comprendido entre $50-85 \%$; sin embargo, los dos alumnos nuevos (sujeto 13 y 14 ) parten con un nivel inicial inferior al resto de compañeros (del 25\% y el 40\%). La totalidad del grupo, excepto el sujeto 06 , alcanzan el $100 \%$ de los objetivos programados por el $\mathrm{Bl}$; de los 13 alumnos, 5 lo consiguieron en el $1^{\circ}$ trimestre, 2 en el segundo y 6 al finalizar el curso escolar. De nuevo, el sujeto 06 no alcanza la puntuación total de la escala debido a su falta de asistencia continuada. Los alumnos nuevos evolucionan muy rápidamente durante todo el curso, alcanzando el $100 \%$ de los objetivos en el 3ํtrimestre. El avance más rápido se produce al finalizar el $1 \%$ trimestre (mejorando un $50 \%$ el sujeto 13 y un $40 \%$ el sujeto 14 ).

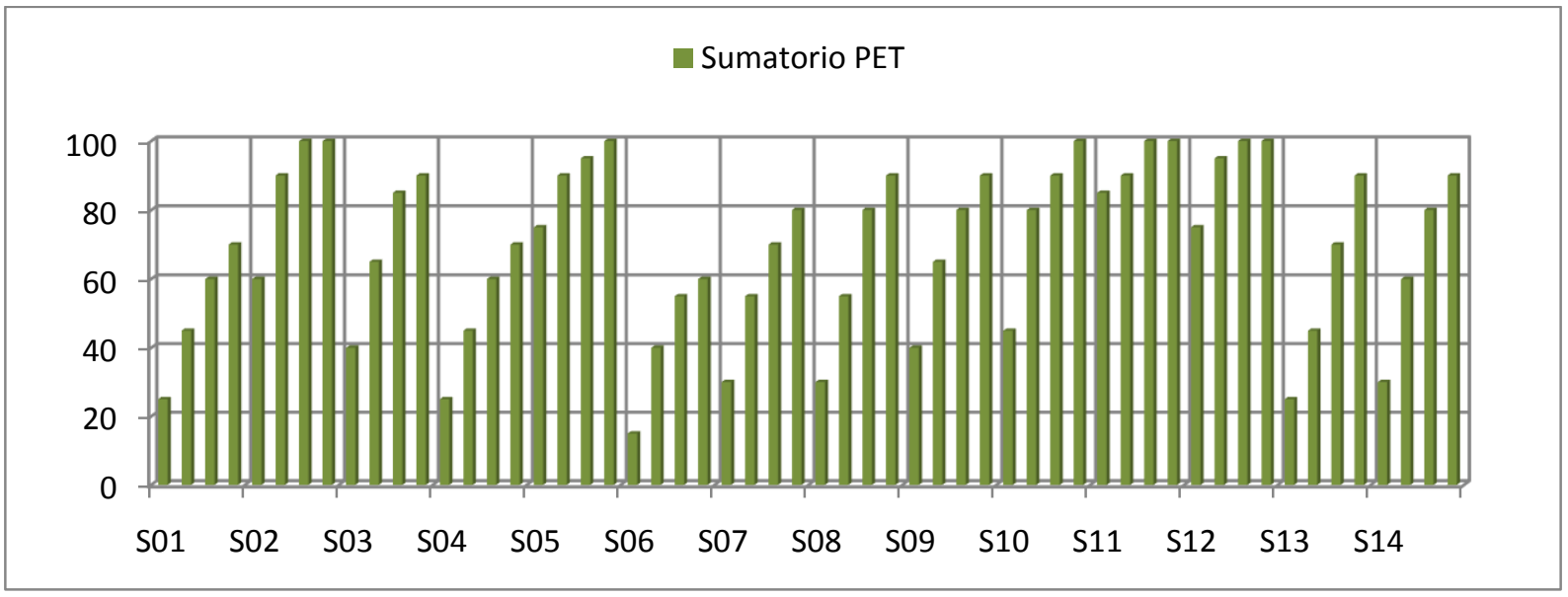

Figura 4.35. Gráfica datos de alumnos PET (\%): 2ํㅡㄹ El lecto-escritura (curso 2012/13)

En la figura 4.35 se pueden ver los valores máximos alcanzados por el grupo en relación al indicador PET. Como ya se ha explicado, el nivel de exigencia de este indicador es superior al del resto. A diferencias de la gráfica 4.33 y 4.34 , no existen diferencias significativas entre los alumnos nuevos y el resto de la clase en relación al valor inicial de partida; el grupo inicia el curso con valores comprendidos entre el 15-45\%. De los 14 alumnos, sólo 5 consiguen alcanzar el valor máximo ( 3 sujetos lo hacen en el $2^{\circ}$ trimestre y 2 en el $3^{\circ}$ ). 4 sujetos se quedan muy cerca de alcanzar la puntuación máxima, entre ellos el sujeto 13 y 14 (alcanzando el $90 \%$ ). El resto de sujetos alcanzan valores medios-altos: $80 \%$ (sujeto 07 ), 60\% (sujeto 06) y $70 \%$ (sujeto 01); de nuevo el sujeto 06 muestra la menor puntuación de la escala, por las mismas razones ya explicadas; sin embargo, a pesar de la falta reiterada de asistencia a clase alcanza valores altos (del 60\%) en la consecución del indicador PET, indicador con un nivel de exigencia muy superior a lo que marca la ley.

La siguiente gráfica (ver figura 4.36) nos permite ver la evolución de todos los alumnos en cada uno de los de indicadores de logro, comparando la respuesta de cada alumno en cada indicador en relación a la lecto-escritura durante todo el curso escolar. 


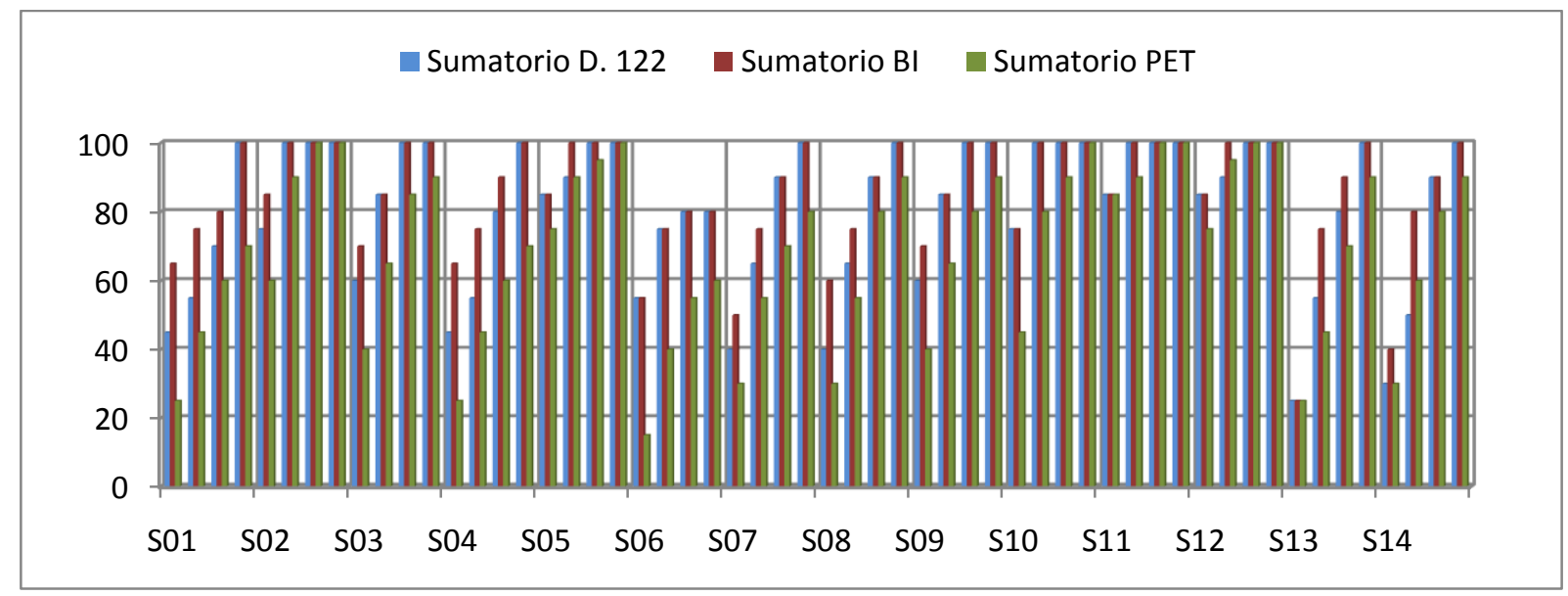

Figura 4.36. Gráfica datos de alumnos comparativa indicadores logro (\%): 2ํㅡㄹ El lecto-escritura (curso 2012/13)

En la gráfica 4.36 se observa que en la clase existe dos ritmos muy diferenciados; encontramos alumnos que poseen un nivel inicial de partida muy alto (especialmente en el indicador Bl y D.122) y evolucionan de forma rápida, alcanzando valores muy altos o del $100 \%$ en todos los indicadores; en cambio, otros alumnos parten de un nivel inicial mucho más bajo, como los sujetos que se incorporan por primera vez al aula en este curso escolar (sujeto 13 y 14) y el alumno con faltas de asistencia continuada (sujeto 06); la evolución de los sujetos 13 y 14 es muy rápida, especialmente en el 1ํy $2^{\circ}$ trimestre, alcanzando valores del $100 \%$ en la consecución de los objetivos propuestos por los indicadores BI y D.122, y quedándose muy cerca de conseguir la puntuación máxima en la escala en el indicador PET (alcanzan el 90\%). El sujeto 06, es el alumno que alcanza los valores más bajos en los tres indicadores (alcanzando el $80 \%$ en los indicadores $\mathrm{BI}$ y $\mathrm{D} .122$, y un $60 \%$ en el indicador PET), registrándose la mayor evolución en el primer trimestre (evoluciona un $20 \%$ en los indicadores BI y D.122 y un $25 \%$ en el indicador PET), durante el segundo y tercer trimestre no existe mejora en la consecución de los objetivos propuestos por el indicador BI y D. 122 (se mantiene en un $80 \%$ en ambos trimestres). No obstante, a pesar de sus repetidas ausencias a lo largo de todo el curso, alcanza unos valores muy positivos en la consecución de los objetivos.

De la totalidad de la clase, 7 alumnos alcanzan el valor máximo en los objetivos programados por el indicador BI y D.122; 5 de ellos lo consiguen al finalizar el $2^{\circ}$ trimestre y los 2 restantes al finalizar el curso. El sujeto 08, 09, 13 y 14 alcanzan el $90 \%$ del valor total en el indicador PET, y los sujetos 07 y 01 el $70 \%$. Otros 6 sujetos alcanzan el $100 \%$ de los objetivos programados por todos los indicadores; 3 de ellos en el segundo trimestre y los tres restantes en el tercero.

Una vez explicada la tabla 4.13 y las 4 gráficas asociadas a esta tabla, pasamos a interpretar los valores hallados por la tabla 4.14 y sus gráficas correspondientes. En la tabla 4.14 se muestran los valores obtenidos a nivel grupal de toda la clase en los tres tipos de 
indicadores, en relación a los 5 objetivos didácticos de referencia para el ámbito lecto-escritor. En las últimas filas encontramos los sumatorios de cada indicador (D. 122, BI y PET) en los 4 periodos evaluados (inicio del curso, primer trimestre, segundo trimestre y final de curso).

Dado que contamos con 14 alumnos y el valor más alto de la escala es 4, el valor máximo que se puede alcanzar en cada indicador será 56 . Por tanto, nos moveremos en un rango entre $0-56$, correspondiendo 52 al $100 \%$ del valor porcentual.

Asociada a la tabla 4.14 se han elaborado 4 gráficas para facilitar la interpretación de los datos, que pueden verse en las figuras $4.37,4.38,4.39$ y 4.40 .

Tabla 4.14. FSG sumatorios lecto-escritura: $2^{\circ}$ EI (curso 2012/13)

\begin{tabular}{|c|c|c|c|c|c|c|c|c|c|}
\hline \multirow{2}{*}{$\begin{array}{c}\text { Curso } \\
\text { escolar:: } \\
\end{array}$} & Alumno: & \multicolumn{4}{|c|}{ SUMATORIO GRUPAL } & \multicolumn{4}{|c|}{ SUMATORIO GRUPAL (\%) } \\
\hline & Indicadores de logro & 1 & $1^{2}$ & $2^{2}$ & $\mathbf{F}$ & $\mathbf{I}$ & $1^{2}$ & $2^{2}$ & $\mathrm{~F}$ \\
\hline \multirow{3}{*}{ 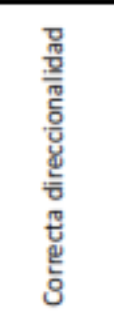 } & $\begin{array}{l}\text { D.122: Correcta dirección en el trazo y } \\
\text { posición adecuada al escribir en } \\
\text { mayúscula }\end{array}$ & 33 & 48 & 56 & 56 & $58,9 \%$ & $85,7 \%$ & $100,0 \%$ & $100,0 \%$ \\
\hline & $\begin{array}{l}\text { BI: Realiza grafias en la direccionalidad } \\
\text { correcta }\end{array}$ & 33 & 48 & 56 & 56 & $58,9 \%$ & $85,7 \%$ & $100,0 \%$ & $100,0 \%$ \\
\hline & $\begin{array}{l}\text { PET: Correcta dirección en el trazo y } \\
\text { posición adecuada al escribir en } \\
\text { mayúscula y minúscula }\end{array}$ & 33 & 48 & 56 & 56 & $58,9 \%$ & $85,7 \%$ & $100,0 \%$ & $100,0 \%$ \\
\hline \multirow{3}{*}{ 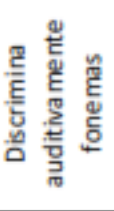 } & $\begin{array}{l}\text { D.122: Discriminación auditiva de } \\
\text { vocales y algunas consonantes }\end{array}$ & 38 & 45 & 53 & 56 & $67,9 \%$ & $80,4 \%$ & $94,6 \%$ & $100,0 \%$ \\
\hline & BI: Identifica las vocales & 51 & 56 & 56 & 56 & $91,1 \%$ & $100,0 \%$ & $100,0 \%$ & $100,0 \%$ \\
\hline & $\begin{array}{l}\text { PET: Discrimina auditivamente todas } \\
\text { las letras del abecedario }\end{array}$ & 30 & 42 & 50 & 53 & $53,6 \%$ & $75,0 \%$ & $89,3 \%$ & $94,6 \%$ \\
\hline \multirow{3}{*}{ 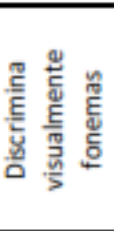 } & $\begin{array}{l}\text { D.122: Discriminación visual de } \\
\text { vocales y algunas consonantes en } \\
\text { mayúscula }\end{array}$ & 38 & 45 & 53 & 56 & $67,9 \%$ & $80,4 \%$ & $94,6 \%$ & $100,0 \%$ \\
\hline & BI: Identifica las vocales & 51 & 56 & 56 & 56 & $91,1 \%$ & $100,0 \%$ & $100,0 \%$ & $100,0 \%$ \\
\hline & $\begin{array}{l}\text { PET: Discrimina visualmente todas las } \\
\text { letras del abecedario }\end{array}$ & 30 & 41 & 50 & 53 & $53,6 \%$ & $73,2 \%$ & $89,3 \%$ & $94,6 \%$ \\
\hline \multirow{3}{*}{ 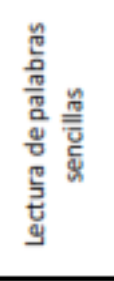 } & $\begin{array}{l}\text { D.122: Iniciarse en la lectura de } \\
\text { palabras sencillas en mayúscula }\end{array}$ & 26 & 38 & 47 & 54 & $46,4 \%$ & $67,9 \%$ & $83,9 \%$ & $96,4 \%$ \\
\hline & $\begin{array}{l}\text { Bl: Lee e interpreta imágenes y } \\
\text { códigos }\end{array}$ & 24 & 40 & 47 & 54 & $42,9 \%$ & $71,4 \%$ & $83,9 \%$ & $96,4 \%$ \\
\hline & $\begin{array}{l}\text { PET: Lectura y comprensión de frases } \\
\text { más complejas en mayúscula y } \\
\text { minúscula }\end{array}$ & 13 & 27 & 35 & 42 & $23,2 \%$ & $48,2 \%$ & $62,5 \%$ & $75,0 \%$ \\
\hline \multirow{6}{*}{ 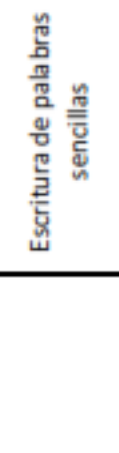 } & $\begin{array}{l}\text { D.122: Iniciarse en la escritura de } \\
\text { palabras sencillas en mayúscula }\end{array}$ & 26 & 38 & 47 & 54 & $46,4 \%$ & $67,9 \%$ & $83,9 \%$ & $96,4 \%$ \\
\hline & $\begin{array}{l}\text { BI: Lee e interpreta imágenes y } \\
\text { códigos }\end{array}$ & 24 & 40 & 47 & 54 & $42,9 \%$ & $71,4 \%$ & $83,9 \%$ & $96,4 \%$ \\
\hline & $\begin{array}{l}\text { PET: Escritura y comprensión de } \\
\text { frases más complejas en mayúscula y } \\
\text { minúscula }\end{array}$ & 14 & 26 & 34 & 42 & $25,0 \%$ & $46,4 \%$ & $60,7 \%$ & $75,0 \%$ \\
\hline & Sumatorio D. 122 & 161 & 214 & 256 & 276 & $57,5 \%$ & $76,4 \%$ & $91,4 \%$ & $98,6 \%$ \\
\hline & Sumatorio BI & 183 & 240 & 262 & 276 & $65,4 \%$ & $85,7 \%$ & $93,6 \%$ & $98,6 \%$ \\
\hline & Sumatorio PET & 120 & 184 & 225 & 246 & $42,9 \%$ & $65,7 \%$ & $80,4 \%$ & $87,9 \%$ \\
\hline
\end{tabular}


En la figura 4.37, se recogen los valores porcentuales hallados por toda la clase en relación al ámbito lecto-escritor para el indicador D.122.

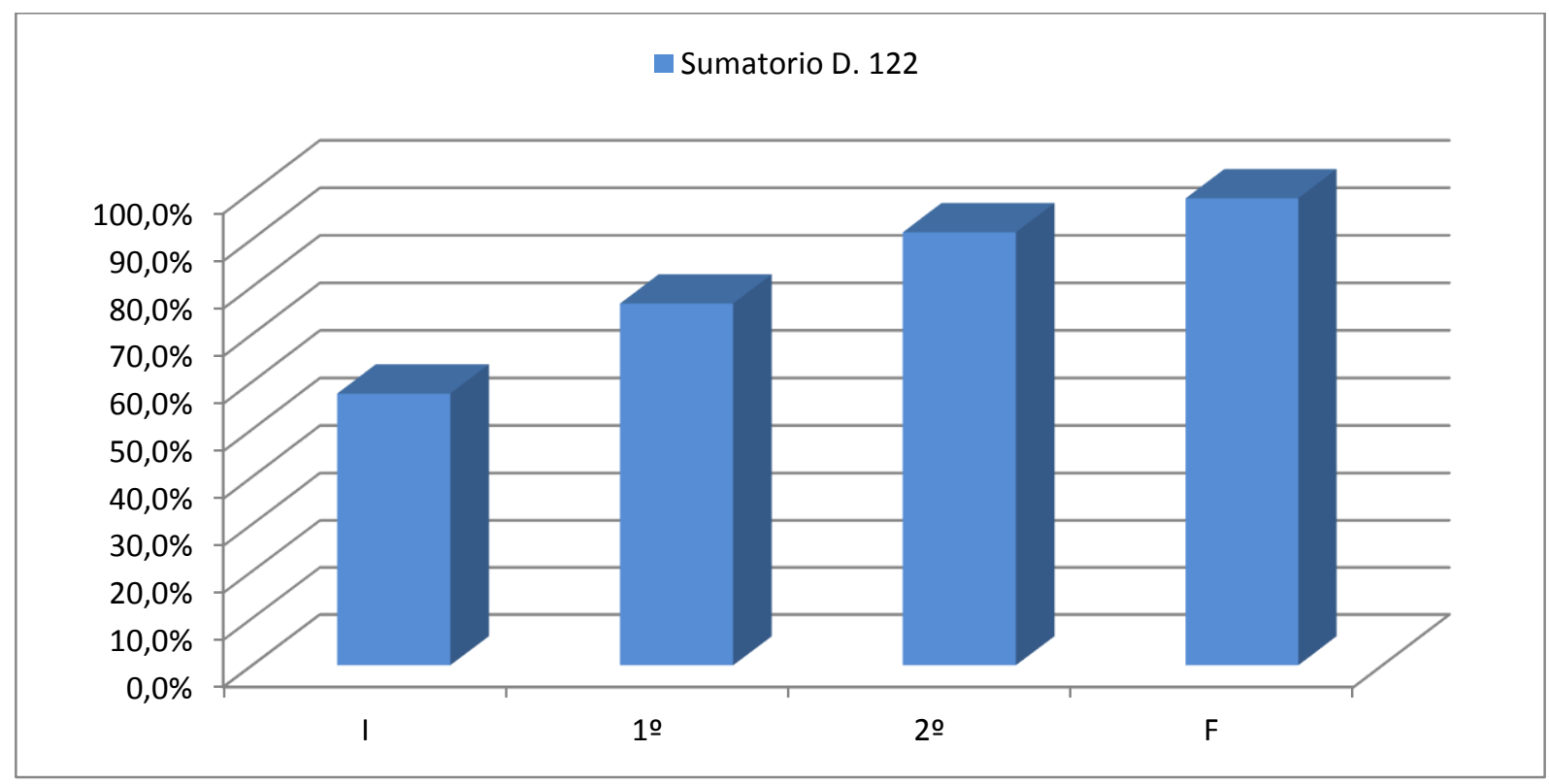

Figura 4.37. Gráfica sumatorio D.122 (\%): 2ํE lecto-escritura (curso 2012/13)

Como se observa en la figura, el grupo parte del valor $57,5 \%$, experimentando una evolución constante a lo largo de todo el curso. Durante el segundo y tercer trimestre también hay evolución, aunque de forma más lenta. Los datos totales porcentuales alcanzados en el segundo trimestre están muy cerca del $92 \%$, consiguiendo un $98,6 \%$ de valor total al finalizar el curso; lo que implica que casi la totalidad del grupo ha conseguido los objetivos del D 122.

En la siguiente gráfica (figura 4.38) podemos observar la evolución obtenida por toda la clase en relación al indicador $\mathrm{BI}$.

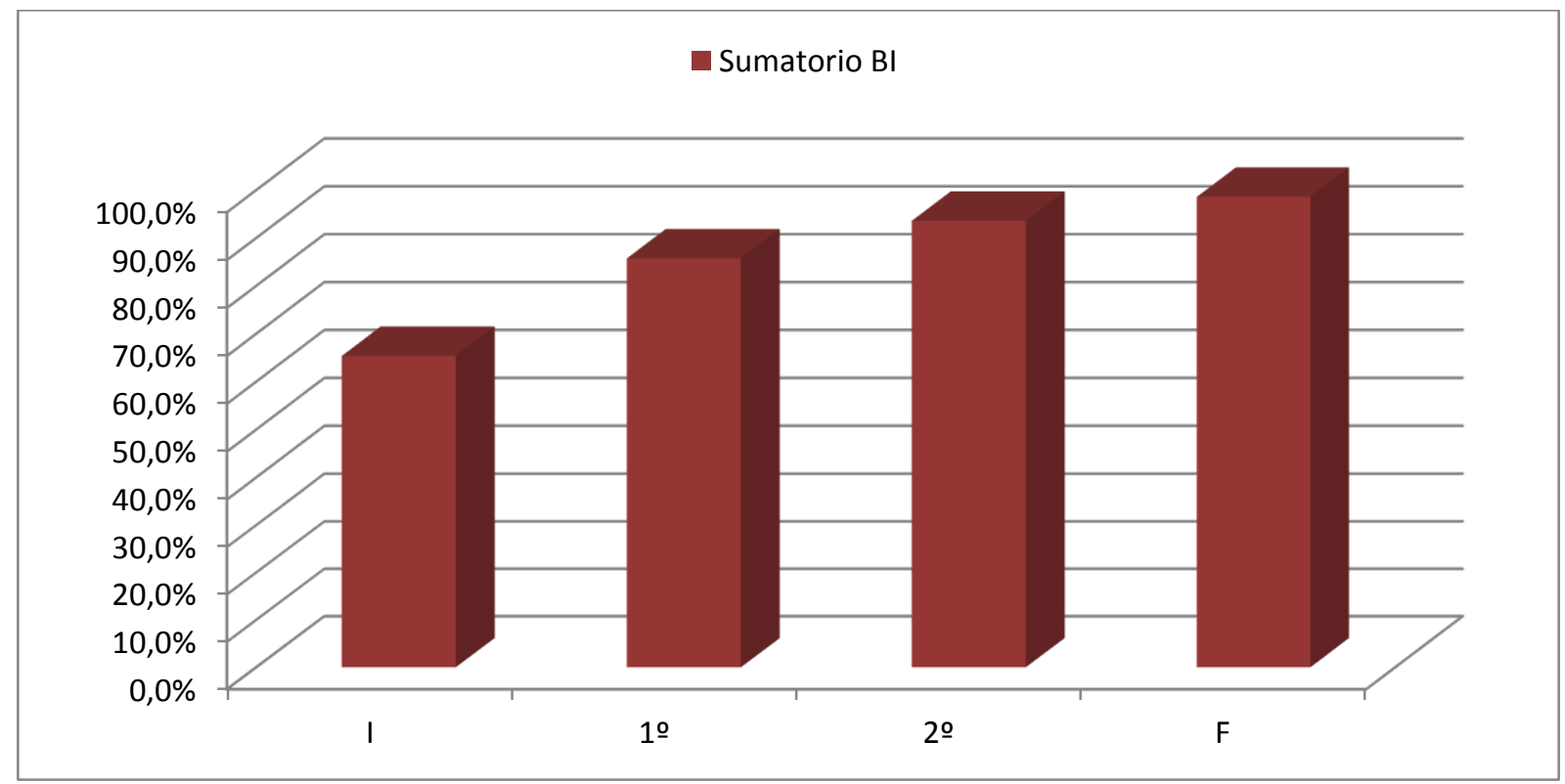


Figura 4.38. Gráfica sumatorio BI (\%): 2ํㅡㄹ lecto-escritura (curso 2012/13)

En la figura puede observarse una evolución muy similar a la vista en la figura anterior, obteniendo el mismo resultado final (del 98,6\%). En este caso partimos de un valor inicial superior a la gráfica anterior (del 65,4\% del indicador BI frente al 57,5\% del indicador D.122). La evolución en la consecución de los objetivos es progresiva durante todo el curso, produciéndose una evolución más rápida a lo largo del primer trimestre. La clase alcanza un $98,6 \%$ de puntuación total al finalizar el curso, lo que implica un nivel casi total en la consecución de este indicador.

En la figura 4.39 mostramos los datos obtenidos por toda la clase en relación al indicador PET.

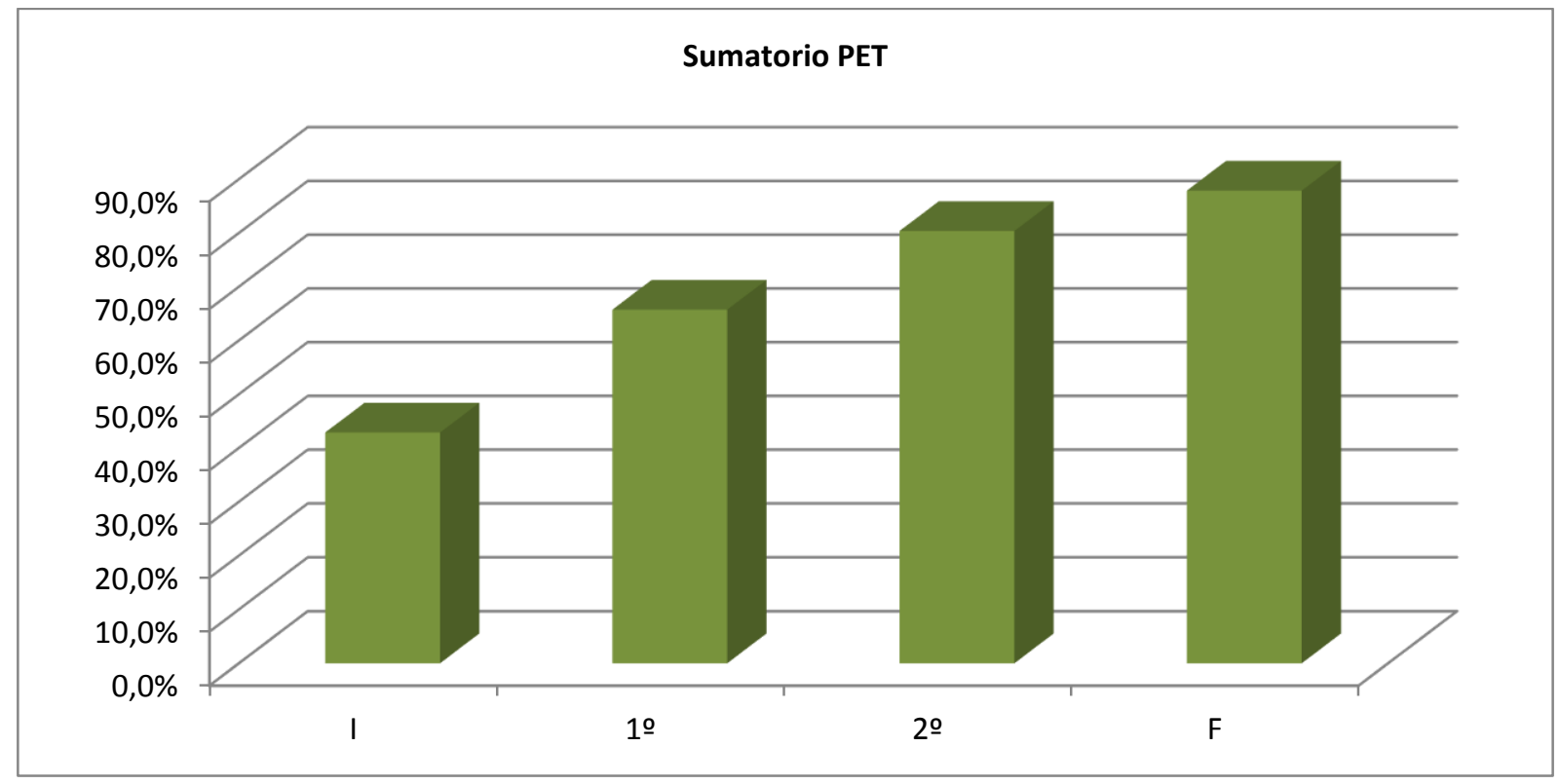

Figura 4.39. Gráfica sumatorio PET (\%): 2º lecto-escritura (curso 2012/13)

La clase parte de un valor inicial inferior a los indicadores BI y D.122 (del 40.7\%). La evolución es constante a lo largo de todo el curso, siendo los progresos más lentos en los dos últimos tramos. Los valores hallados en el primer trimestre alcanzaron una puntuación del $61,4 \%$, del $74,6 \%$ en el segundo trimestre y del $81,4 \%$ al finalizar el curso.

Finalmente, en la siguiente gráfica (figura 4.40) mostramos la evolución conseguida por todos los alumnos, realizando una comparativa de los tres indicadores a lo largo del curso 2012/13. En la gráfica observamos que los indicadores BI y PET parten de valores más altos que el indicador PET. La evolución es constante en los tres indicadores, sufriendo una evolución más rápida en el primer trimestre. El indicador BI y D.122 alcanzan valores muy altos en el segundo y tercer trimestre, quedándose muy cercan de obtener el 100\% (obtienen 


\section{CAPITULO 4: ANÁLISIS DE DATOS}

un $91,4 \%$ del valor total en la escala). El indicador PET, a pesar de partir de un valor inicial más bajo, sufre una evolución paulatina consiguiendo un valor final del 81,4\%.

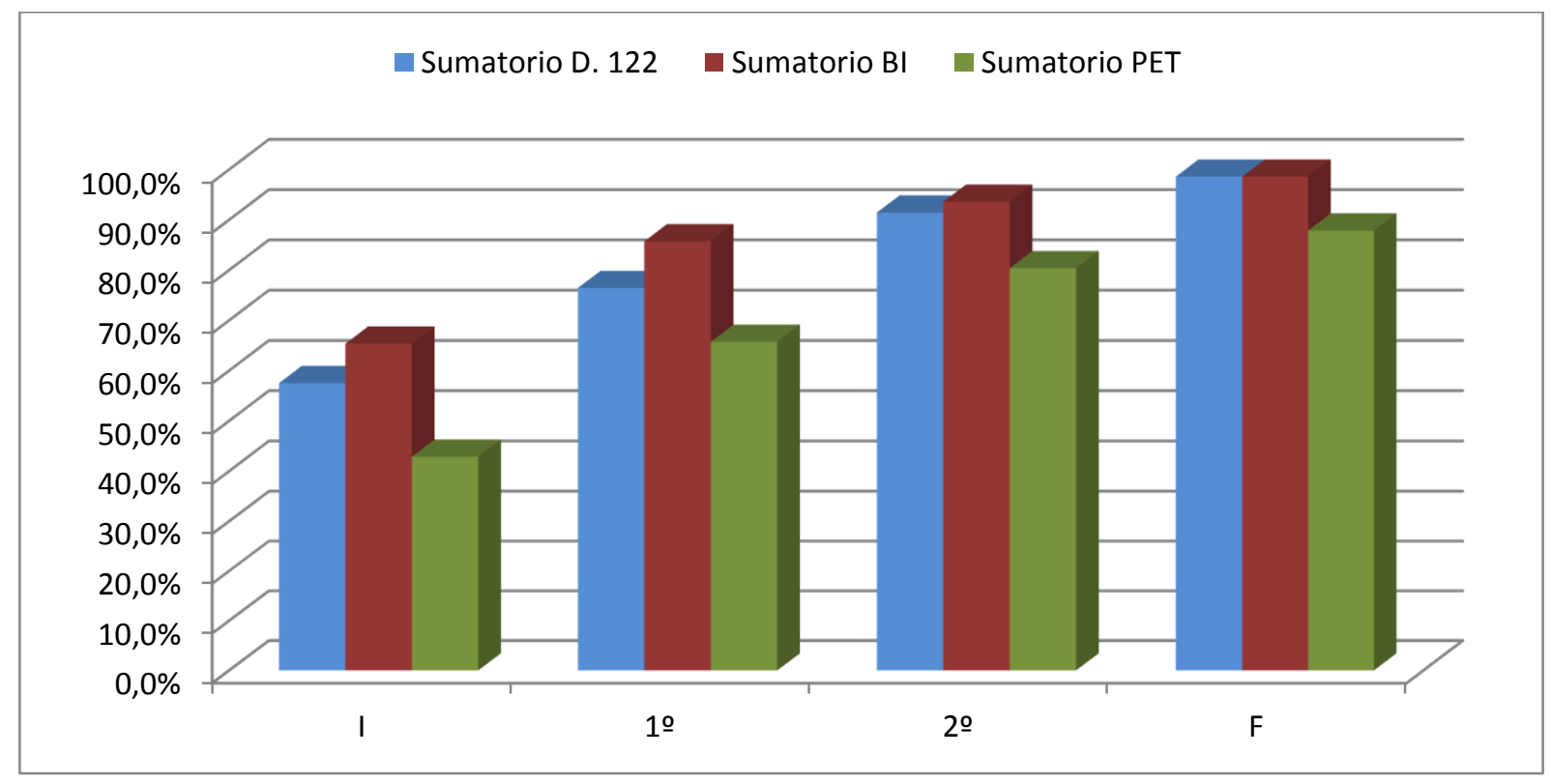

Figura 4.40. Gráfica sumatorio comparativa indicadores logro (\%): 2ํㅡ El (curso 2012/13)

Estos datos indican que el nivel general de la clase es muy alto en referencia a lo que marca y exige la ley para este curso escolar, y además, un porcentaje altísimo de sujetos ha superado con éxito objetivos mucho más exigentes que los que marca el currículo oficial, como son: lectura fluida de cuentos en mayúscula y minúscula y escritura de frases y textos complejos en mayúscula y minúscula (ver anexo 9 y anexo 11).

\subsubsection{Tablas y gráficos de lógico-matemática}

En la tabla 4.7 se muestran los datos obtenidos para el curso 2010/11 en relación al ámbito lógico-matemático. En la primera columna se especifican los 6 objetivos didácticos de referencia para cada alumno durante ese curso escolar. A lo largo de la segunda columna, se concretan los objetivos a alcanzar en cada indicador de logro (D.122, BI y PET). En el caso de $\mathrm{BI}$ existen tres objetivos que no contemplan este indicador (operaciones con sumas, operaciones con restas y operaciones combinadas); por tanto, los valores hallados se moverán en un rango comprendido entre $0-12$, siendo 0 el valor mínimo y 12 el valor máximo. El resto de indicadores de logro (D. 122 y BI) están presentes en todos los objetivos didácticos de la tabla y se moverán en un rango de 0-24, siendo 0 el valor mínimo y 24 el valor máximo. Finalmente, en el resto de columnas se recogen los datos obtenidos por los 14 sujetos durante los 4 periodos de referencia (principio de curso y final de los tres trimestres). 
Tabla 4.15. FSG datos alumnos lógico-matemática: 2º El (curso 2012/13)

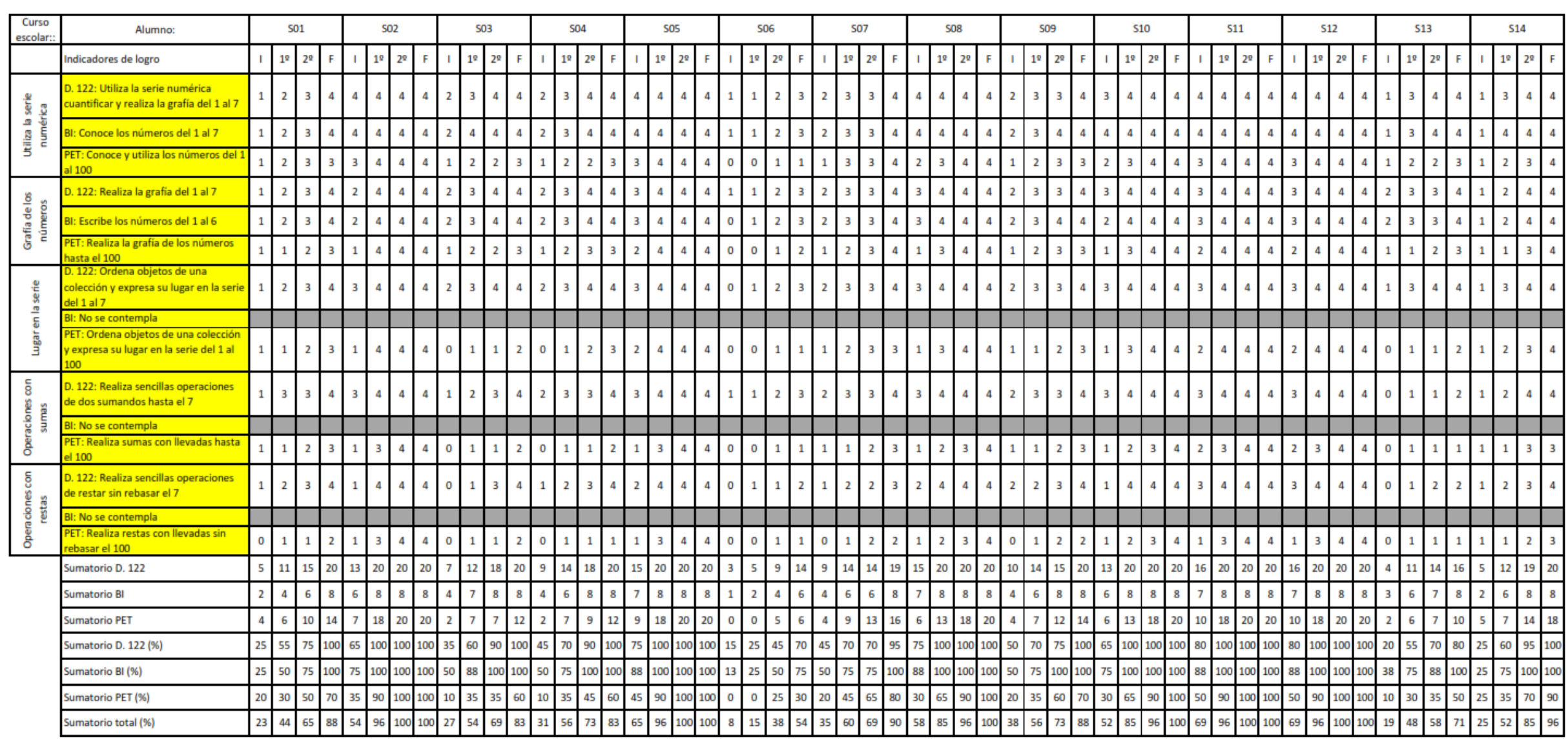


En relación a la tabla 4.15 se han elaborado 4 gráficas para facilitar su interpretación (figuras $4.41,4.42,4.43$ y 4.44 ).

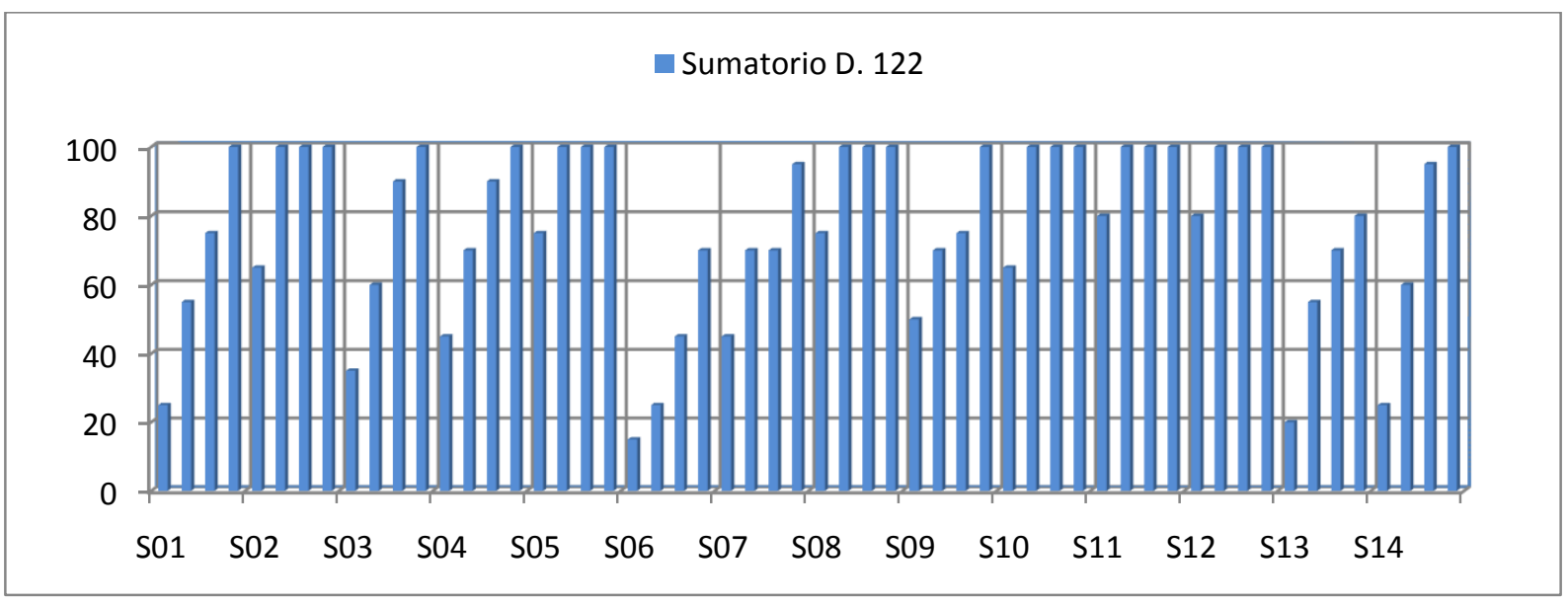

Figura 4.41. Gráfica datos de alumnos D.122 (\%): 2º El lógico-matemática (curso 2012/13)

Como se observa en la figura 4.41, hay dos ritmos diferenciados en relación al nivel inicial de partida del indicador D.122; los sujetos 01, 06, 13 y 14 parten de un nivel inferior al resto del grupo; se mueven en un rango comprendido entre $15 \%$ y el $25 \%$ (estos alumnos se corresponden con los alumnos que han llegado nuevos al aula y el alumno absentista). El resto de alumnos parten con un nivel inicial con valores comprendidos entre el $35 \%$ y el $85 \%$ de la puntuación total en la escala. 11 de los 14 sujetos alcanzan la puntuación máxima en la escala, 6 de ellos lo consiguen al finalizar el segundo trimestre y los otros 5 al finalizar el curso.

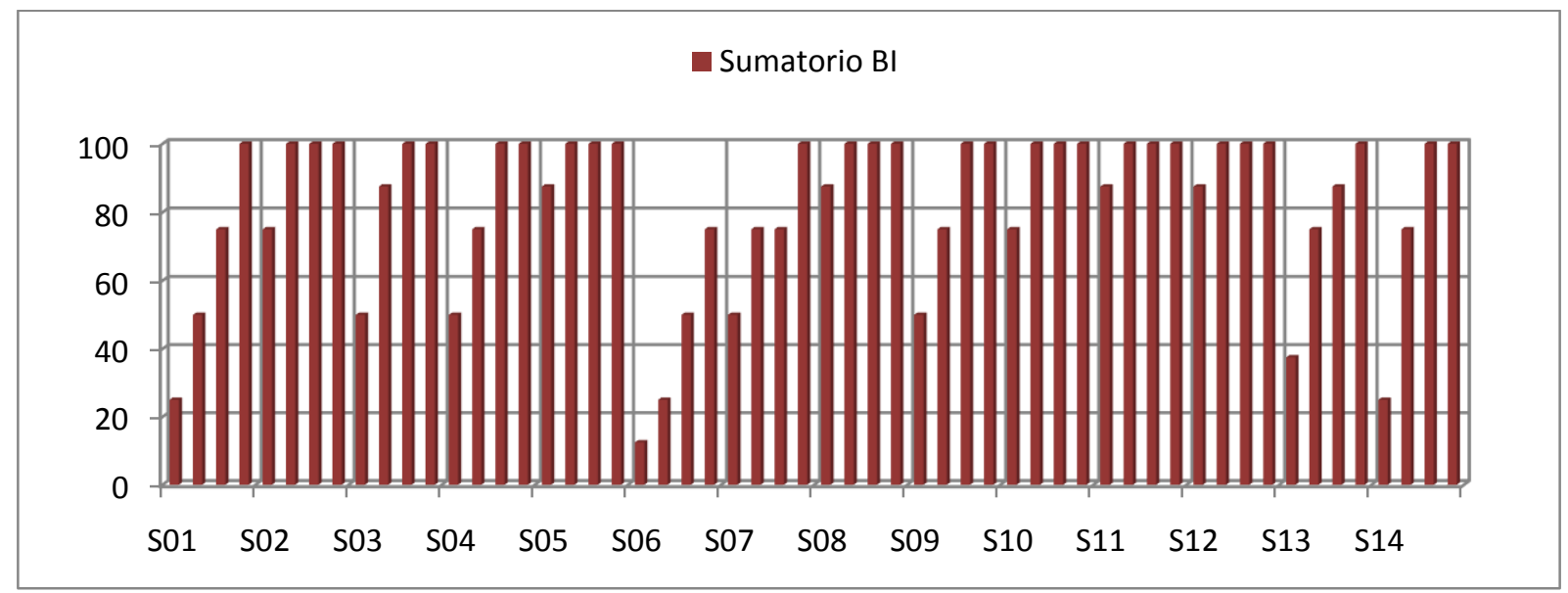

Figura 4.42. Gráfica datos de alumnos BI (\%): 2 El lógico-matemática (curso 2012/13)

De nuevo, en la figura 4.42 observamos la existencia de dos ritmos diferenciados al iniciar el curso escolar en relación al indicador BI. Los sujetos 01, 06, 13 y 14 parten con valores muy similares que se hallan entre el $13-18 \%$, mientras que el resto de la clase parten con valores comprendidos entre el 50-88\%. 13 de los 14 alumnos consiguen la puntuación máxima en el indicador $\mathrm{BI}$; 6 alumnos lo consiguen en el primer trimestre, 4 en el segundo y 
3 en el tercero. El único alumno que no alcanza la valoración máxima es el alumno que falta al aula de forma regular (sujeto 06).

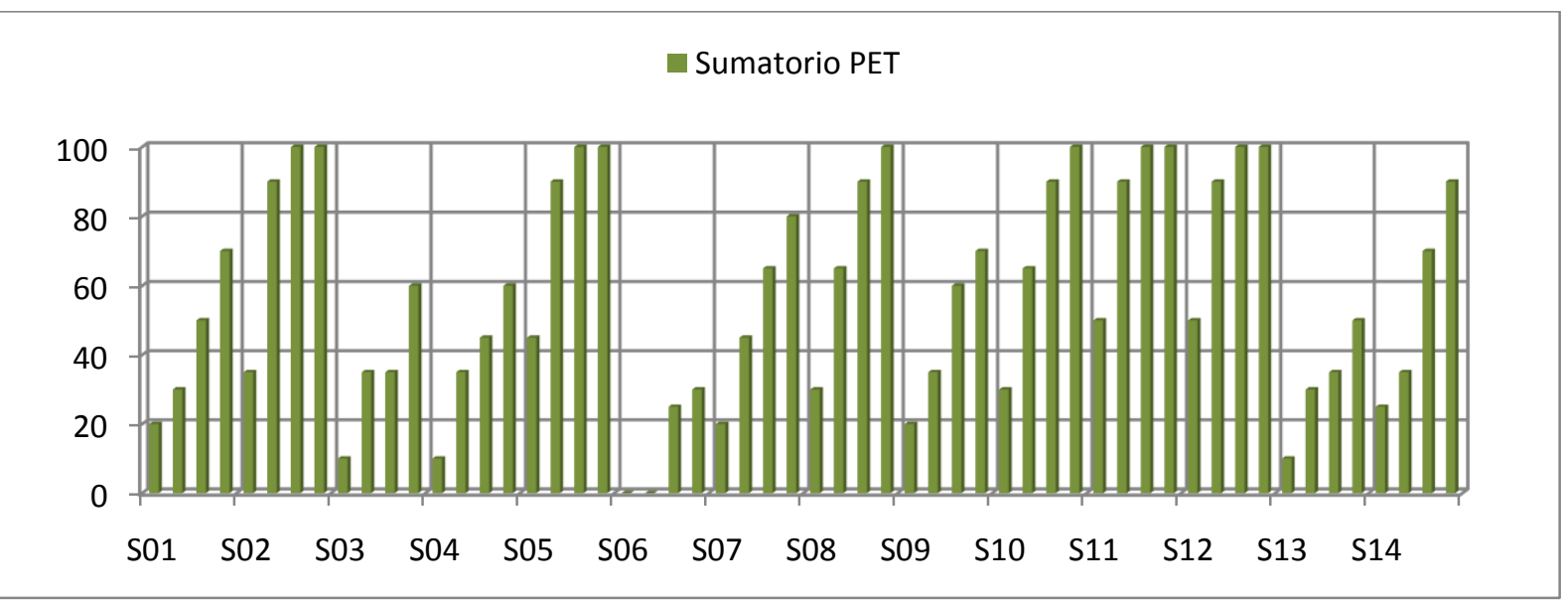

Figura 4.43. Gráfica datos de alumnos PET (\%): 2ํEl lógico-matemática (curso 2012/13)

En la figura 4.43 podemos ver como el nivel inicial de partida del grupo en relación al indicador PET es más bajo que el resto de indicadores y no son tan evidentes los dos ritmos de aprendizaje que se observan en las figuras 4.41 y 4.42 . El grupo parte con un nivel comprendido entre el $10 \%$ y el $55 \%$ de la puntuación total, excepto el sujeto 06 que parte con un nivel inicial del $0 \%$. En el primer trimestre se observa una evolución importante, siendo más evidente a lo largo del segundo trimestre y más lenta en el tercer trimestre. Durante el primer trimestre el nivel de la clase es bastante homogéneo, alcanzando valores comprendidos entre el 38 y el 54\%. Únicamente 6 de los 14 sujetos consiguen la puntuación máxima en la escala en relación al indicador PET, de los cuales 3 alumnos alcanzan en el segundo trimestre y el resto en el tercer trimestre.

La siguiente gráfica (ver figura 4.44) nos permite comparar la evolución de todos los alumnos en cada indicador de logro, comparando los valores hallados por cada alumno en relación al ámbito lógico-matemática durante el curso escolar 2012/13. 


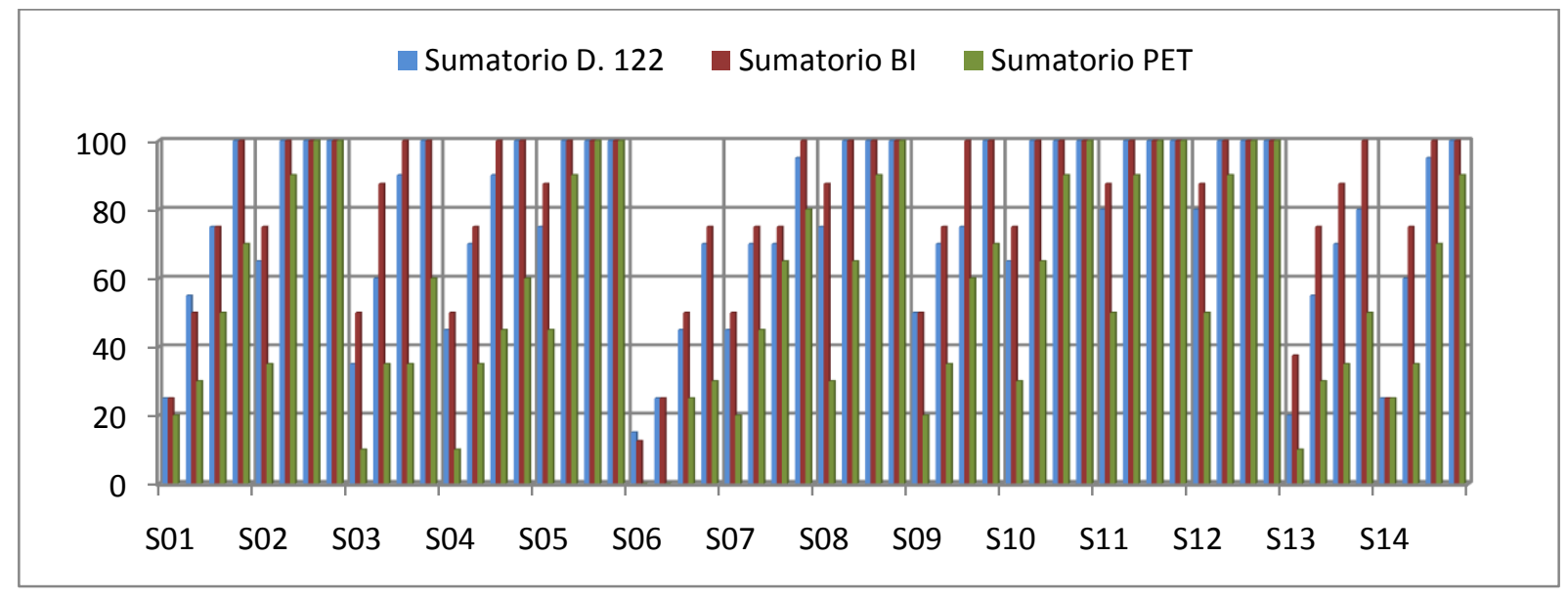

Figura 4.44. Gráfica datos de alumnos comparativa indicadores logro (\%): 2º El lógico-matemática (curso 2012/13)

Debemos tener presente que los objetivos propuestos por PET son mucho más exigentes que el de resto de indicadores, factor determinante en la interpretación de los datos. Como vemos en figura 4.44, se ven claramente dos ritmos de aprendizaje muy marcados durante el periodo inicial de la investigación, que se tienden a equilibrar conforme va evolucionando el curso escolar, obteniendo resultados muy semejantes entre ellos, excepto el sujeto 06, que no consigue alcanzar la puntuación máxima en ninguno de sus indicadores. 6 de los 14 sujetos alcanzan la puntuación máxima en todos los indicadores, incluso 4 de ellos lo consiguen en el segundo trimestre. Otros 5 alumnos obtienen la puntuación máxima en al menos dos de los indicadores de logro (BI y PET) a lo largo del tercer trimestre. El sujeto 06 , 07 y 13 son los alumnos que alcanzan los valores más bajos; no obstante, el sujeto 07 consigue el máximo valor en el indicador BI, el 95\% en el indicador D.122 y el $80 \%$ en el indicador PET; el sujeto 13 consigue el máximo valor en el indicador $\mathrm{BI}$, el $80 \%$ en el indicador D. 122 y $50 \%$ en el indicador PET; el sujeto 06 alcanza valores considerablemente altos en los indicadores $\mathrm{BI}$ y D.122 (alcanzando un $75 \%$ en $\mathrm{BI}$ y un $70 \%$ en $\mathrm{D} .122$ ), a pesar de sus múltiples ausencias, y valores más bajos en el indicador PET (del 30\%).

Una vez explicada la tabla 4.15 y las 4 gráficas asociadas a esta tabla, pasamos a interpretar los valores hallados por última tabla 4.16 y sus gráficas correspondientes. En la 4.16 se muestran los valores obtenidos a nivel grupal de toda la clase en los tres tipos de indicadores, en relación a los 6 objetivos didácticos de referencia para el ámbito lógicomatemático. En las últimas filas encontramos los sumatorios de cada indicador (D. 122, BI y PET) en los 4 periodos evaluados (inicio del curso, primer trimestre, segundo trimestre y final de curso). Al igual que en el ámbito lecto-escritor, contamos con 14 alumnos; por tanto, dado que el valor más alto de la escala es 4 , el valor máximo que se puede alcanzar en cada 
indicador será 56. Por tanto, nos moveremos en un rango entre $0-56$, correspondiendo 56 al $100 \%$ del valor porcentual.

Tabla 4.16. FSG sumatorios lógico-matemática: 2ํE EI (curso 2012/13)

\begin{tabular}{|c|c|c|c|c|c|c|c|c|c|}
\hline \multirow{2}{*}{$\begin{array}{l}\text { Curso } \\
\text { escolar:: }\end{array}$} & Alumno: & \multicolumn{4}{|c|}{ SUMATORIO GRUPAL } & \multicolumn{4}{|c|}{ SUMATORIO GRUPAL (\%) } \\
\hline & Indicadores de logro & 1 & $1^{9}$ & $2^{2}$ & $\mathrm{~F}$ & $\mathbf{I}$ & 19 & $2^{\circ}$ & F \\
\hline \multirow{3}{*}{ 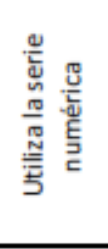 } & $\begin{array}{l}\text { D. 122: Utiliza la serie numérica } \\
\text { cuantificar y realiza la grafia del } 1 \text { al } 7\end{array}$ & 35 & 45 & 51 & 55 & $62,5 \%$ & $80,4 \%$ & $91,1 \%$ & $98,2 \%$ \\
\hline & Bl: Conoce los números del 1 al 7 & 36 & 47 & 52 & 55 & $64,3 \%$ & $83,9 \%$ & $92,9 \%$ & $98,2 \%$ \\
\hline & $\begin{array}{l}\text { PET: Conoce y utiliza los números del } 1 \\
\text { al } 100\end{array}$ & 23 & 37 & 43 & 48 & $41,1 \%$ & $66,1 \%$ & $76,8 \%$ & $85,7 \%$ \\
\hline \multirow{3}{*}{ 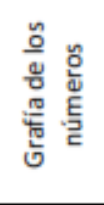 } & D. 122: Realiza la grafia del 1 al 7 & 30 & 44 & 50 & 55 & $53,6 \%$ & $78,6 \%$ & $89,3 \%$ & $98,2 \%$ \\
\hline & Bl: Escribe los números del 1 al 6 & 28 & 44 & 51 & 55 & $50,0 \%$ & $78,6 \%$ & $91,1 \%$ & $98,2 \%$ \\
\hline & $\begin{array}{l}\text { PET: Realiza la grafia de los números } \\
\text { hasta el } 100\end{array}$ & 16 & 33 & 43 & 49 & $28,6 \%$ & $58,9 \%$ & $76,8 \%$ & $87,5 \%$ \\
\hline \multirow{3}{*}{ 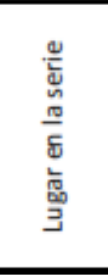 } & $\begin{array}{l}\text { D. 122: Ordena objetos de una } \\
\text { colección y expresa su lugar en la serie } \\
\text { del } 1 \text { al } 7\end{array}$ & 29 & 45 & 51 & 55 & $51,8 \%$ & $80,4 \%$ & $91,1 \%$ & $98,2 \%$ \\
\hline & BI: No se contempla & & & & & & & & \\
\hline & \begin{tabular}{|l|} 
PET: Ordena objetos de una colección \\
y expresa su lugar en la serie del 1 al \\
100
\end{tabular} & 13 & 31 & 39 & 45 & $23,2 \%$ & $55,4 \%$ & $69,6 \%$ & $80,4 \%$ \\
\hline \multirow{3}{*}{ 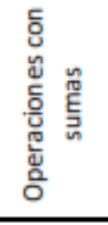 } & $\begin{array}{l}\text { D. 122: Realiza sencillas operaciones } \\
\text { de dos sumandos hasta el } 7\end{array}$ & 28 & 42 & 46 & 53 & $50,0 \%$ & $75,0 \%$ & $82,1 \%$ & $94,6 \%$ \\
\hline & BI: No se contempla & & & & & & & & \\
\hline & $\begin{array}{l}\text { PET: Realiza sumas con llevadas hasta } \\
\text { el } 100\end{array}$ & 12 & 23 & 35 & 42 & $21,4 \%$ & $41,1 \%$ & $62,5 \%$ & $75,0 \%$ \\
\hline \multirow{6}{*}{ 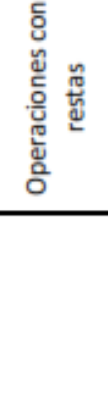 } & $\begin{array}{l}\text { D. 122: Realiza sencillas operaciones } \\
\text { de restar sin rebasar el } 7\end{array}$ & 18 & 37 & 44 & 51 & $32,1 \%$ & $66,1 \%$ & $78,6 \%$ & $91,1 \%$ \\
\hline & BI: No se contempla & & & & & & & & \\
\hline & $\begin{array}{l}\text { PET: Realiza restas con llevadas sin } \\
\text { rebasar el } 100\end{array}$ & 7 & 23 & 33 & 38 & $12,5 \%$ & $41,1 \%$ & $58,9 \%$ & $67,9 \%$ \\
\hline & Sumatorio D. 122 & 140 & 213 & 242 & 269 & $50,0 \%$ & $76,1 \%$ & $86,4 \%$ & $96,1 \%$ \\
\hline & Sumatorio BI & 64 & 91 & 103 & 110 & $57,1 \%$ & $81,3 \%$ & $92,0 \%$ & $98,2 \%$ \\
\hline & Sumatorio PET & 71 & 147 & 193 & 222 & $25,4 \%$ & $52,5 \%$ & $68,9 \%$ & $79,3 \%$ \\
\hline
\end{tabular}

Asociada a la tabla 4.16 se han elaborado 4 gráficas para facilitar la interpretación de los datos; éstas pueden verse en las figuras $4.45,4.46,4.47$ y 4.48 .

Comenzamos con la figura 4.45 , donde se recogen los valores porcentuales hallados por toda la clase en relación a los objetivos lógico-matemáticos del D.122. 


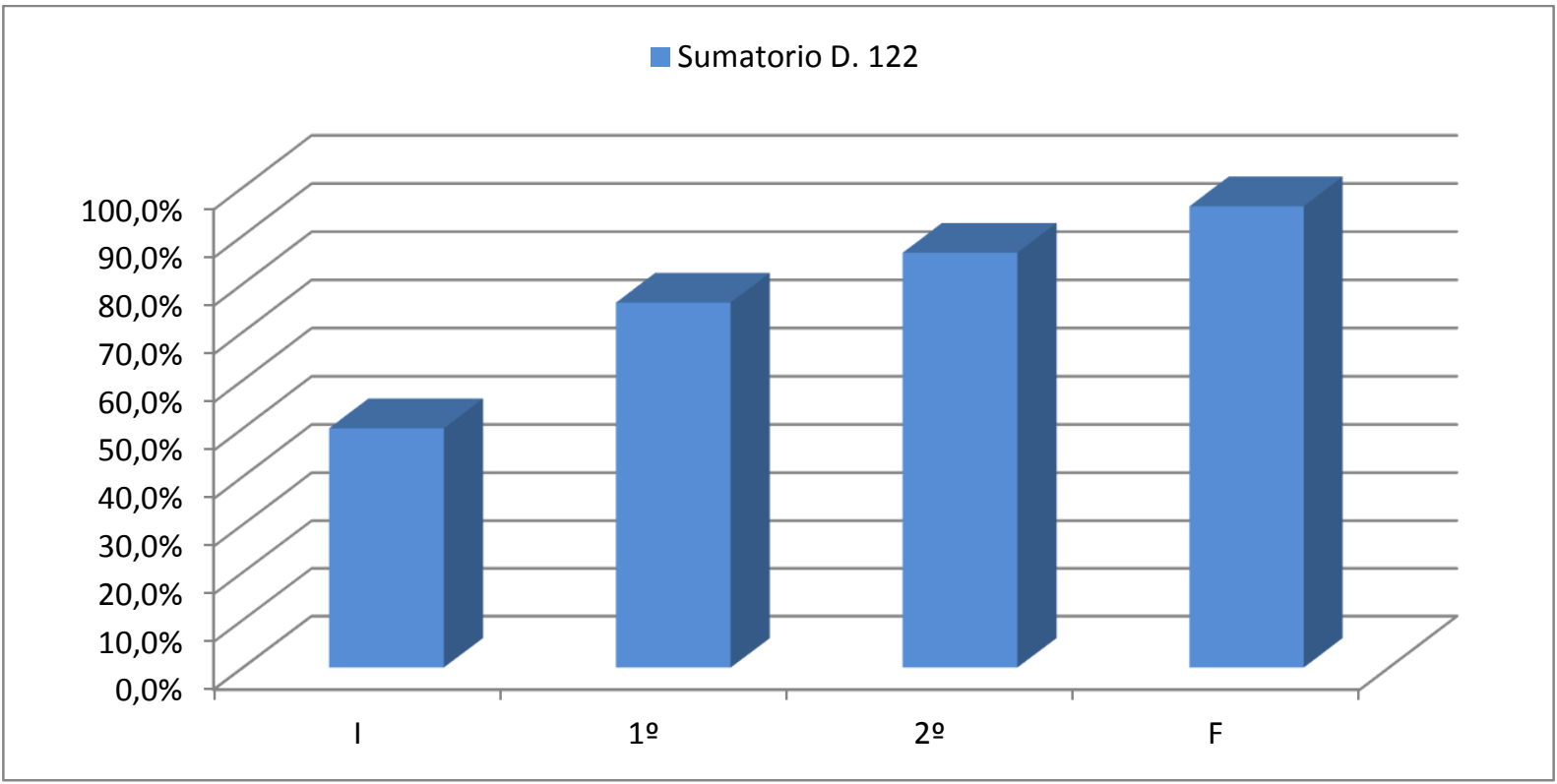

Figura 4.45. Gráfica sumatorio D.122 (\%): 2º El lógico-matemática (curso 2012/13)

Como se observa en la figura, los alumnos parten de un nivel inicial del $50 \%$, experimentando una buena evolución a lo largo del primer trimestre (se pasa de un $50 \%$ a un $76,1 \%)$, y una evolución más lenta a lo largo del resto del curso, consiguiendo un $96,1 \%$ de la puntuación total en la escala al final del curso. No obstante, los objetivos alcanzados por la clase son muy elevados, indicando un alto nivel del grupo en relación a los objetivos exigidos con el currículo oficial

En la siguiente gráfica (véase figura 4.46) podemos observar la evolución obtenida por toda la clase en relación al indicador BI.

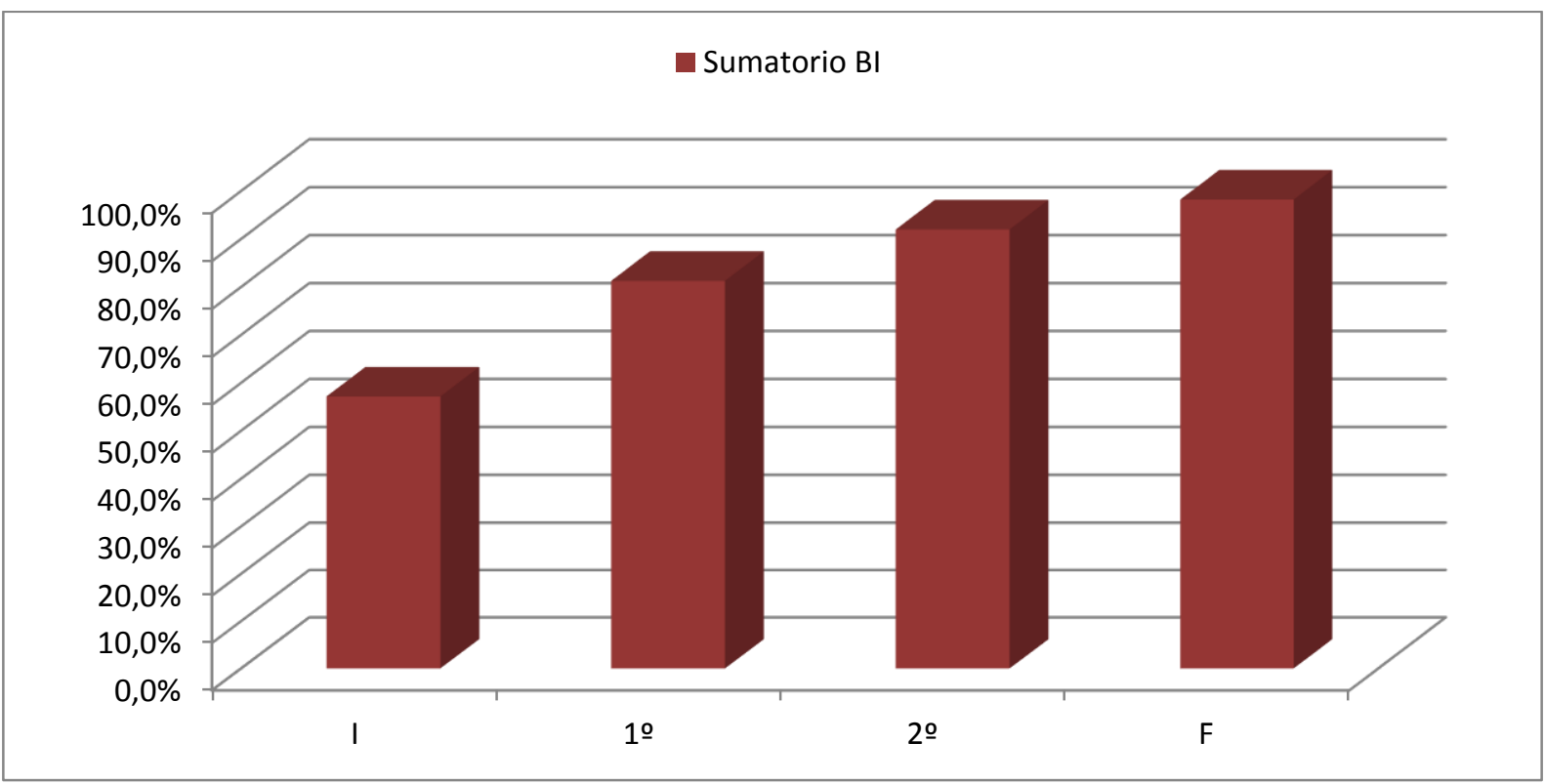

Figura 4.46. Gráfica sumatorio BI (\%): º El lógico matemática (curso 2012/13) 
En relación al indicador $\mathrm{BI}$ se observa una evolución muy similar a la vista en la figura anterior. En este caso el grupo de alumnos parte un valor inicial del 57,1\% de la puntuación total de la escala, experimentando la mayor evolución en el primer trimestre (pasamos del $57,1 \%$ inicial al $81,3 \%$ ); la evolución sigue siendo progresiva, aunque más lenta a lo largo del resto del curso. De nuevo, la puntuación media del grupo al finalizar el curso alcanza valores muy altos en la consecución de los objetivos propuestos por el $\mathrm{BI}$, consiguiendo un valor del $98,2 \%$.

En la siguiente gráfica (véase figura 4.47), recogemos los datos obtenidos por toda la clase en relación al indicador PET.

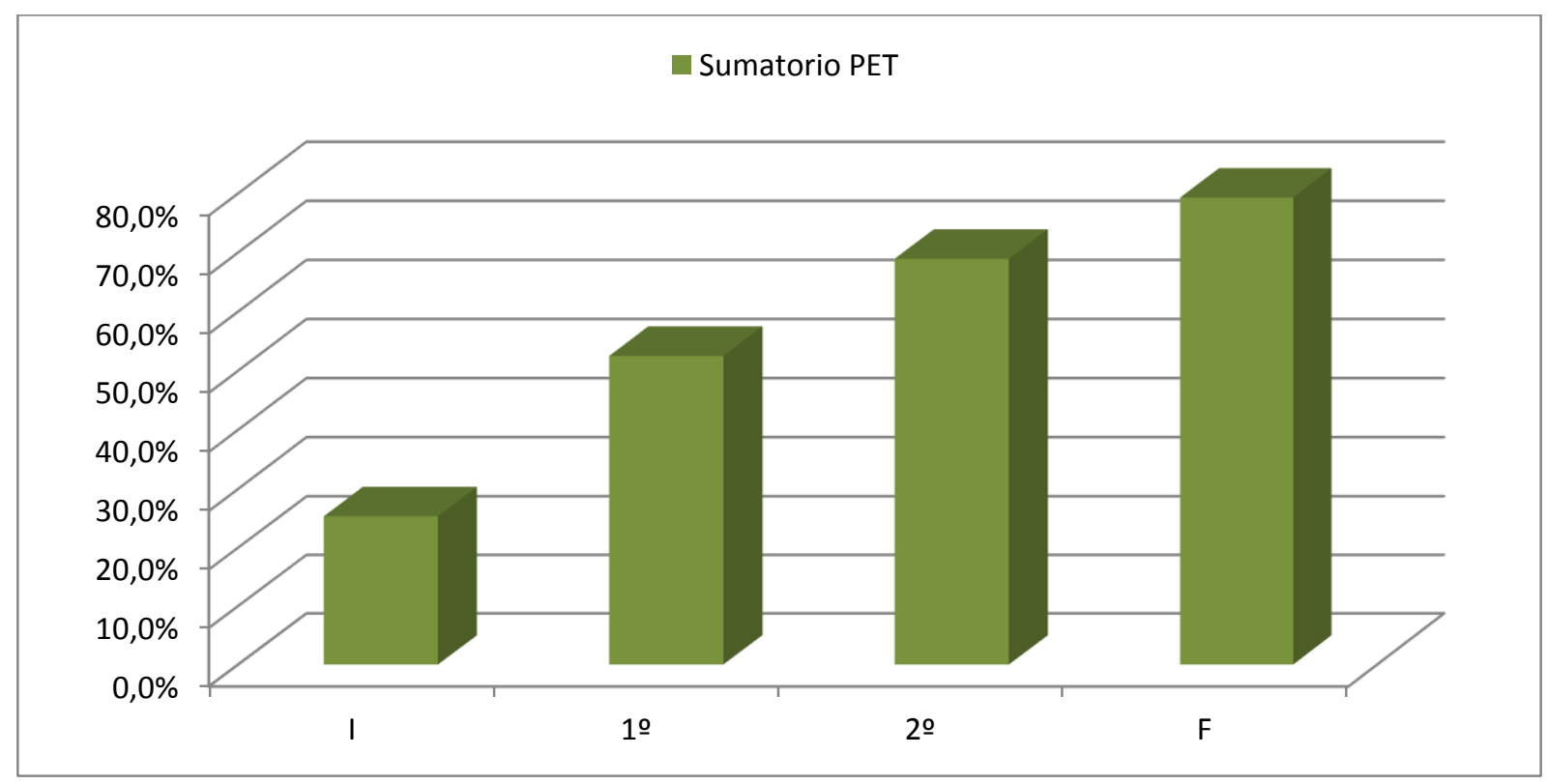

Figura 4.47. Gráfica sumatorio PET (\%): º El lógico-matemática (curso 2012/13)

En el caso del indicador PET partimos de un valor inicial inferior a las gráficas anteriores en la puntuación total de la escala $(25,4 \%)$. Existe una evolución más significativa durante el primer trimestre (pasamos de un 25,4\% inicial a un 52,5\%), produciéndose una mejora continuada a lo largo de todo el curso, aunque más lenta (se pasa de un $68,9 \%$ en el segundo trimestre a un $79,3 \%$ al finalizar el curso). Dado que los objetivos de este indicador son mucho más complejos, se puede considerar que el grupo clase ha alcanzado un nivel muy alto en su aprendizaje en relación al ámbito lógico-matemático.

Por último veremos los resultados obtenidos por toda la clase durante el curso 2012/13 en relación a los tres indicadores de logro en el ámbito lógico-matemático. 


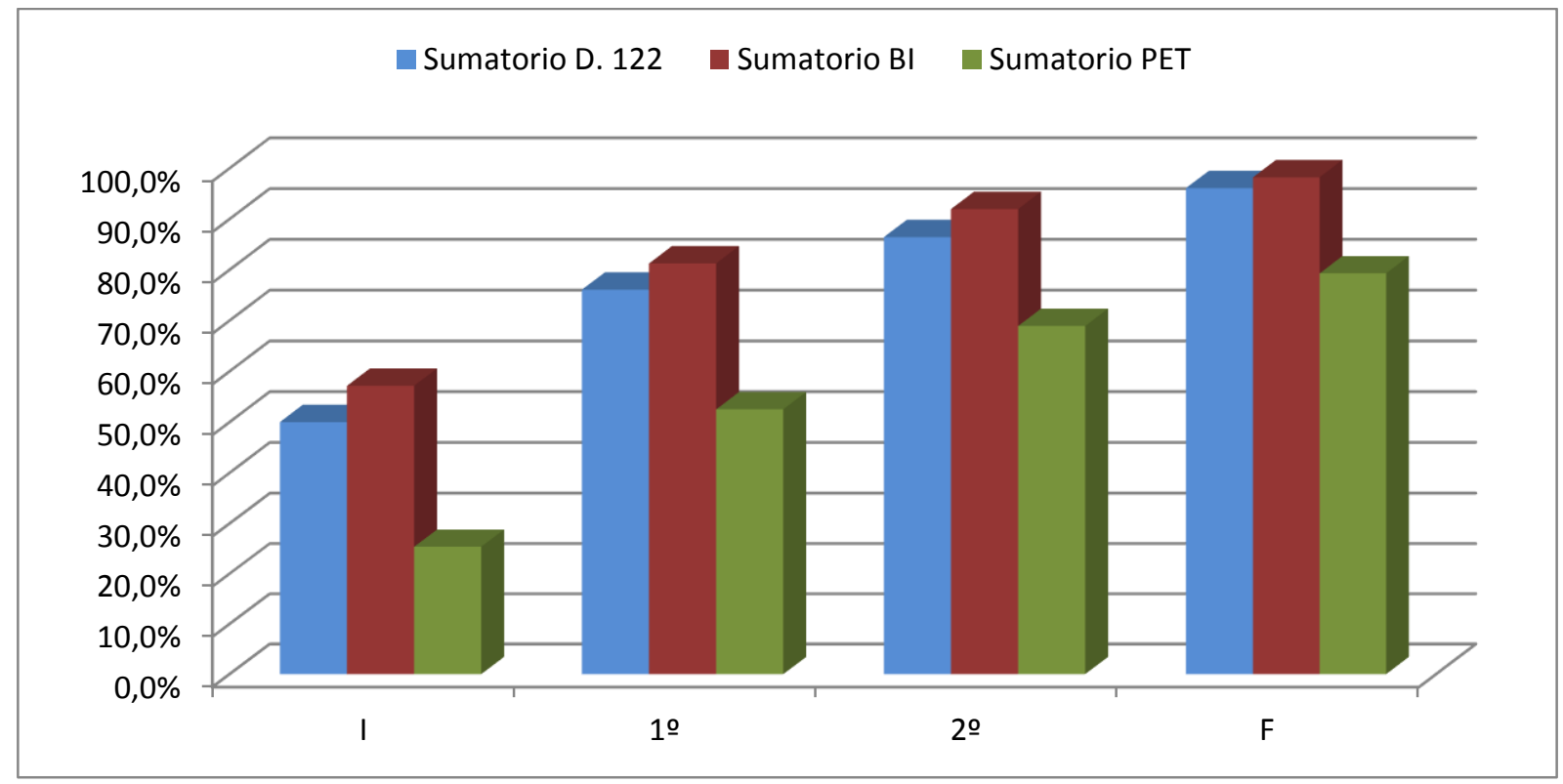

Figura 4.48. Gráfica sumatorio comparativa indicadores logro (\%): 2º El (curso 2012/13)

En la figura 4.48 se observa un nivel de partida por parte del grupo más alto en los indicadores BI y D.122 en comparación al indicador PET. Se produce una evolución progresiva en todos los indicadores, produciéndose una mejora más rápida durante el primer trimestre. Al finalizar el curso la diferencia entre el indicador PET y el resto de indicadores no es tan evidente, obteniendo unos valores muy altos en los indicadores D.122 y BI, y casi del $80 \%$ en el indicador PET.

Estos datos indican que el nivel general de la clase es alto en relación a lo que marca el currículo oficial de El y el boletín oficial del trimestre. Dado que los objetivos propuestos por el PET son mucho más exigentes e implican un nivel mucho más alto que los de los otros dos indicadores, el haber obtenido el grupo un grado de consecución general del 79,3\% muestra un aprendizaje bastante mayor de lo que indican los estándares del currículo oficial para este curso, alcanzando objetivos como: identificar números de 9 cifras, realizar con regletas números hasta el 100, sumas de 4 sumandos, restas con llevadas, etc. (ver anexo 8 y anexo 10). 


\section{DISCUSIÓN}

\section{Capítulo 5}

5.1. Discusión del objetivo

5.2. Discusión de resultados en el ámbito lecto-escritor

5.3. Discusión de resultados en el ámbito lógico-matemático 


\section{CAPITULO 5: DISCUSIÓN}

Esta investigación se ha llevado a cabo con el propósito de evaluar las repercusiones de un PET en el desarrollo de las capacidades lecto-escritoras y lógico-matemáticas, en dos grupos de alumnos a lo largo de tres cursos del segundo ciclo de El. Para ello, se ha utilizado un estudio de caso evaluativo (Stake, 2007) como principal estrategia de recolección de datos. Esto ha permitiendo analizar y describir en cada curso escolar investigado los datos obtenidos por los alumnos, comprobando así: (1) si el programa aplicado permite un mayor desarrollo de la capacidad lectora y escritora en los alumnos, aprendiendo a leer y a escribir de una forma más natural y rápida, en menos tiempo de lo que viene siendo habitual con otros métodos de lecto-escritura; y (2) si el programa aplicado permite un mayor desarrollo de la capacidad lógico-matemática en los niños, de una forma más natural y rápida, en aspectos como por ejemplo, identificar números de dos, tres y cuatro cifras, sumar con y restar llevadas sin utilizar dedos, realización de cálculo mental, etc.

Este estudio parte del supuesto fundamental de que los niños se encuentran en uno de los periodos más importantes para la adquisición de nuevos conocimientos, debido a la gran plasticidad que caracteriza a su desarrollo cerebral; circunstancia que debe ser aprovechada por los docentes en las escuelas a través del diseño de diferentes programas de estimulación, potenciando así el desarrollo óptimo de nuestros alumnos, lo cual coincide con estudios previos que avalan la eficacia de los programas de estimulación (González, 2008; Robles y Sánchez, 2013; Figueroa et. al, 2015, Albornoz y Guzmán, 2016). A lo largo del desarrollo de la investigación, se diseña y evalúa el programa de estimulación y se realiza una descripción detallada de la metodología utilizada y los principales recursos y actividades llevados a cabo con los alumnos para los ámbitos lecto-escritor y lógico-matemático en el transcurso de la investigación.

Se debe destacar investigaciones anteriores en los que se han aplicado diferentes programas de estimulación, como Maquillón (2003), Navarro, Alcalde, Marchena, Gonzalo y Sedeños (2009), Uriarte (2013) y Tellano et al. (2016), los cuales ponen de manifiesto la necesidad de conocer más a fondo la aplicabilidad de los programas de estimulación en la etapa de El, ya que hasta el momento son pocos los trabajos realizados en esta etapa.

Es una queja extendida por parte de los docentes que no haya un tiempo previsto o material idóneo para realizar el trabajo de ET, y esto limita las posibilidades de proporcionar un aprendizaje de calidad en relación al desarrollo de las capacidades lecto-escritoras y lógico-matemáticas. En este sentido, las posibles soluciones pasan por (Pinos, 2013; Barrero, 2012; Vizuete, 2014; Junta, 2016): (a) fomentar en las aulas de El el uso de métodos de estimulación que permitan desarrollar las potencialidades de los alumnos y promuevan aprendizajes significativos; (b) dar a conocer a la comunidad educativa diferentes programas 
de estimulación; y (c) formar a los docentes en este campo, proporcionándoles los fundamentos, requisitos y materiales necesarios para ponerlos en marcha.

\subsection{DISCUSIÓN DEL OBJETIVO}

La evaluación del PET, puesta en práctica a lo largo de todo el segundo ciclo de El, nos ha permitido detectar importantes resultados que deben ser tenidos en consideración tanto en el ámbito lecto-escritor como en el ámbito lógico-matemático.

Para ello analizaremos los hallazgos obtenidos por el indicador PET en los tres curso escolares, en relación a los indicadores D. 122 y BI, para posteriormente reflexionar sobre las razones que han permitido alcanzar estos resultados a través del programa en cada uno de los ámbitos de estudio; pero antes debemos tener presente que: (1) en el indicador $\mathrm{BI}$ se recogen los objetivos mínimos que el ciclo de El considera que deben ser alcanzados por los alumnos a lo largo de la etapa de El; por tanto, estos objetivos parten del D. 122 y son concretados en los boletines informativos para los tres curso escolares investigados. Estos objetivos son la base que sustentarán los conocimientos posteriores que los alumnos deberán alcanzar a lo largo de la Educación Primaria; es por ello, que a pesar de que en El el aprendizaje de la lectura y la escritura, y el aprendizaje de habilidades numéricas básicas no son contenidos propiamente obligatorios, resultan necesarios y muy recomendable ser alcanzados durante esta etapa educativa como base del $1^{\circ}$ curso de primaria (Corral 1997; Flores y Martín, 2006; Zoila, Sazo y Gálvez, 2014); (2) en el indicador D. 122 se recogen los objetivos estipulados por el currículo de la comunidad de Castilla y León, y serán los centros los encargados de adatar estos objetivos al nivel al que van dirigido en referencia al ámbito lecto-escritor y lógico-matemático; es por ello que el nivel de exigencia de estos objetivos, son superiores a los diseñados en $\mathrm{BI}$; (3) los objetivos programados en el indicador PET se han formulado partiendo de los objetivos BI y D.122, siendo objetivos mucho más ambiciosos que los expuestos en los anteriores indicadores. Por tanto, alcanzar un buen nivel de consecución en el indicador PET, repercutirá positivamente en los anteriores.

Retomando los hallazgos más relevantes obtenidos tras la aplicación del programa, procede ahora describir las resultados encontrados que sirvan para consolidar las conclusiones que se describirán posteriormente. Para ello, analizaremos los resultados por cursos escolares y por ámbito de desarrollo. 


\subsection{DISCUSIÓN DE RESULTADOS EN EL ÁMBITO LECTO- ESCRITOR}

La evaluación del PET durante los tres cursos (grupo de alumnos en su último curso del 2 o ciclo de El y grupo de alumnos en su primer y segundo curso de El) nos ha permitido detectar importantes resultados en el ámbito lecto-escritor que deben ser tenidos en consideración.

\subsubsection{CURSO 2010/11: 3 CURSO DEL 2 CICLO DE EI}

Este grupo está constituido por 14 alumnos de los cuales dos son ACNEAE (el sujeto 13 presenta un trastorno de la comunicación no significativo y el sujeto 14 es un alumno con necesidades de compensatoria educativa).

Apoyándonos en la figura 4.4 donde se comparan los hallazgos obtenidos por los tres indicadores en relación al ámbito lecto-escritor, los resultados más destacados son los siguientes:

- 13 alumnos han conseguido el 100\% de los objetivos propuestos por el indicador $\mathrm{BI}$, quedándose el sujeto 14 a 10 puntos en la escala de alcanzar la totalidad de los objetivos propuestos (obteniendo un valor del $90 \%$ en la escala). La clase ha alcanzado un resultado total del $93 \%$ en la adquisición de los objetivos programados por el indicador BI.

- En relación al indicador D 122, vemos que 10 de los sujetos han alcanzado todos los objetivos programados, otros 2 sujetos se quedan a 4 puntos de conseguirlo (alcanzando un valor del $96 \%$ del total en la escala); y los ACNEAE consiguen puntuaciones muy satisfactorias, concretamente del $82 \%$ y del $68 \%$. Debemos puntualizar que el último sujeto, es un alumno con necesidades de compensatorias educativas, y el hecho de obtener una puntuación del 68\%, implica una evolución muy importante en base a sus limitaciones en el ámbito lecto-escritor. La clase ha conseguido un resultado final del $91 \%$ en la adquisición de los objetivos programados por el indicador D 122.

- Para el último indicador, observamos que el nivel inicial de partida del grupo en relación al indicador PET se mueve en valores comprendidos entre el 30-40\% de puntuación total en la escala; estos datos revelan un nivel medio-alto de partida, consecuencia de los resultados experimentados por el programa de estimulación 
puesto en práctica en el curso anterior. Además, se observa que 11 de los 14 alumnos han alcanzado el $100 \%$ de los objetivos marcados por el PET; 2 sujetos han conseguido niveles muy altos (iguales o superiores al $80 \%$ ); y el sujeto 14 , como en el caso anterior, obtiene un valor muy satisfactorio, alcanzando el $68 \%$ de la puntuación total en la escala. La clase ha conseguido un resultado global del 90\% en la adquisición de los objetivos programados por el indicador PET.

Como vemos, los valores hallados por el grupo de alumnos en los tres indicadores son iguales o superiores al 90\%; estos datos revelan que a través del PET se ha conseguido importantes logros que detallamos a continuación:

- Un alto número de alumnos son capaces de leer con bastante fluidez frases sencillas y textos cortos tanto en mayúscula como en minúscula en el primer trimestre. En este sentido, la evolución es muy rápida durante los trimestres siguientes, llegando incluso a adquirir una buena comprensión lectora de textos complejos (por ejemplo, cuentos). En consecuencia, la gran autonomía y facilidad mostrada por los alumnos, desembocó en iniciativas muy interesantes en relación al fomento de la lectura: (1) el encargado del día tenía como función leer el cuento del día a sus compañeros; y (2) era necesario cambiar de forma semanal los cuentos de la biblioteca del aula, puesto que acostumbraban, en su tiempo de juego, a leer los cuentos de la biblioteca.

- La evolución en los dos alumnos ACNEAE y la alumna con un ritmo de aprendizaje más bajo se da de forma más lenta pero progresiva en el tiempo. Durante el primer trimestre son capaces de reconocer la mayoría de las letras en mayúscula y sílabas directas, en incluso leer palabras sencillas; al finalizar el curso, los alumnos consiguen leer frases más complejas en minúscula.

- En el caso de la escritura, la evolución es paralela a la lectura, adquiriendo gran destreza tanto en la direccionalidad del trazo en minúscula, como en la escritura espontánea de frases y textos más largos. En este sentido, algunas de las habilidades adquiridas por los alumnos en relación a este contenido han sido hacer dictados de frases y escribir pequeños relatos y cuentos que exponían en la biblioteca de aula para que el resto de compañeros pudieran leerlos.

Todos estos resultados nos llevan a concretar una serie de conclusiones generales alcanzadas durante este curso que quedan recogido en la tabla 5.1. 
Tabla 5.1. Resultados PET: ámbito lecto-escritor, curso 2010/11 (3ํㅡㄹ)

\begin{tabular}{|c|c|}
\hline № & CONCLUSIONES GENERALES \\
\hline 1 & $\begin{array}{l}\text {-EI PET utiliza estímulos visuales y auditivos que desarrolla una buena capacidad auditiva para oír y } \\
\text { discriminar sonidos, repercutiendo positivamente en el aprendizaje de los fonemas trabajados. }\end{array}$ \\
\hline 2 & $\begin{array}{l}\text {-EI PET desarrolla una buena memoria auditiva y visual para retener los bits de palabras, mejorando los } \\
\text { procesos de escritura y lectura. }\end{array}$ \\
\hline 3 & $\begin{array}{l}\text {-EI PET se diseña en base a los intereses propios del grupo, aumentando la atención y motivación del } \\
\text { alumnado hacia el aprendizaje de la lectura y escritura provocando un aprendizaje más rápido. }\end{array}$ \\
\hline 4 & $\begin{array}{l}\text {-EI PET utiliza el juego como principal herramienta de aprendizaje, ajustándose al ritmo real de todos } \\
\text { los alumnos y favoreciendo un aprendizaje rápido y duradero. }\end{array}$ \\
\hline 5 & $\begin{array}{l}\text {-Las actividades del PET van variando en base a las necesidades de los menores para que integren de } \\
\text { forma significativa estrategias que les permitan aprender a leer, escribir de forma rápida y natural. }\end{array}$ \\
\hline 6 & $\begin{array}{l}\text {-En relación a los logros observados diariamente, cada lunes se planifican y diseñan nuevas categorías } \\
\text { de imágenes, categorías de palabras y actividades relacionadas con la lecto-escritora, que permiten no } \\
\text { sólo afianzar y mejorar los aprendizajes adquiridos con anterioridad, sino ajustarse a las demandas } \\
\text { reales alcanzadas por el grupo en este curso escolar. }\end{array}$ \\
\hline 7 & $\begin{array}{l}\text {-Los propios alumnos toman conciencia de su rápida evolución en relación a lectura lo que despierta en } \\
\text { ellos una fuerte motivación y una actitud idónea que favorece que estén más predispuestos hacia el } \\
\text { aprendizaje de estos contenidos. }\end{array}$ \\
\hline 8 & $\begin{array}{l}\text {-EI PET permite ajustar el diseñar de los bits y los juegos en base a los intereses del docente y } \\
\text { profundizar en contenidos claves para el desarrollo de otros más complejos o que no han sido } \\
\text { alcanzados. }\end{array}$ \\
\hline 9 & $\begin{array}{l}\text {-La rápida evolución por parte de los alumnos motiva a las familias, este hecho provoca que los padres } \\
\text { hayan reforzado desde casa las capacidades adquiridos en base a las pautas dadas en las reuniones } \\
\text { grupales, provocando en consecuencia que el aprendizaje de la lectura y escritura aumentase de forma } \\
\text { rápida y considerable. }\end{array}$ \\
\hline 10 & $\begin{array}{l}\text {-La lectura comprensiva adquirida en este curso a través del PET, permite potenciar el aprendizaje de } \\
\text { la escritura. }\end{array}$ \\
\hline 11 & $\begin{array}{l}\text {-EI PET a través de las actividades y retos planteados en la asamblea, potencia la capacidad de } \\
\text { escritura espontánea. }\end{array}$ \\
\hline
\end{tabular}

\subsubsection{CURSO 2011/12: 1ํ CURSO DEL 2ㅇ CICLO DE EI}

Contamos con 13 alumnos que parten de un nivel inicial nulo. Existen dos ritmos de aprendizaje claramente diferenciado, un grupo de alumno con un nivel más alto y otro grupo de alumnos con un ritmo de aprendizaje más lento condicionado por la barrera idiomática en el sujeto 06 y el sujeto 07 , la falta de absentismo continuada a lo largo de todo el curso por parte del sujeto 06 y los problemas graves de atención del sujeto 03.

Apoyándonos en la figura 4.20 que realiza una comparativa de los valores hallados por todos los indicadores en el ámbito lecto-escritor para este curso escolar, observamos que:

- En relación al indicador BI, son 11 los alumnos que han alcanzado el 100\% de los objetivos propuestos; de los 2 restantes, el sujeto 04 alcanza un valor muy alto (del $80 \%$ ); y es el sujeto absentista, el que consigue un valor del $50 \%$, lo que supone 
un resultado satisfactorio tomando en consideración sus faltas de asistencias reiteradas durante todo el curso escolar. El valor total alcanzado por todo el grupo corresponde al 92,9\%.

- Tomando de referencia el indicador D.122, vemos que son 8 los alumnos que alcanzan la puntuación máxima en la escala; existen 3 alumnos que consiguen resultados muy satisfactorios al alcanzar valores comprendidos entre el 92-96\%; y de nuevo, el sujeto 06, es el que consigue la puntuación más baja con un 54\% del valor total de la escala. El valor total del grupo alcanzado en relación al indicador D. 122 es del $91,1 \%$.

- En el indicador PET, de nuevo son 8 los alumnos que han alcanzado el valor máximo; del resto, 4 sujetos consiguen resultados muy satisfactorios al conseguir valores comprendidos entre el $79-83 \%$; siendo el sujeto 06 , el único alumnos que ha alcanzado una puntuación más baja, concretamente del $46 \%$ del valor total de la escala. El valor total alcanzado por toda la clase corresponde al $90 \%$.

Como se observa, el grupo alcanza valores iguales o superiores al $90 \%$ en todos sus indicadores, estos datos revelan que a través del PET en relación al ámbito lecto-escritor se ha conseguido importantes logros:

- Al finalizar el primer trimestre, la mayoría de alumnos son capaces identifican todas las letras del abecedario en mayúscula (sin incluir las excepciones), establecen correspondencia entre fonema y grafía (sonido y letra), identifican y leen sílabas directas e incluso frases sencillas en mayúscula. Al finalizar el curso, en relación a la lectura, la mayoría de alumnos identifican todas las letras en minúscula (incluidas las excepciones) y leen palabras y frases sencillas en minúscula.

- En referencia a la escritura, al finalizar el curso escolar utilizan una correcta direccionalidad y posición al escribir letras y palabras en mayúscula, son capaces de ubicar espacialmente todas las letras en minúscula del abecedario dentro de la pauta dada y se inician en la escritura de letras en minúscula, existiendo una correcta secuencia en el trazo (trazan toda la letra de una sola vez, sin hacer cortes y realizan el trazo con claridad sobre la línea de base, en la zona media, superior e inferior, haciendo elevaciones y depreciaciones correctamente).

- Resaltar el caso de los alumnos que al finalizar el curso desarrollan una fluidez lectora tan alta, que les permite leer textos más complejos como puede verse en el anexo 5 y anexo 7 y se inician en la escritura espontánea de palabras sencillas. 
Todos estos resultados nos llevan a concretar una serie de conclusiones generales alcanzadas durante este curso, recogidos en la tabla 5.2.

Tabla 5.2. Resultados PET: ámbito lecto-escritor, curso 2011/12 (1ํㅡㄹ)

\begin{tabular}{|l|l|}
\hline № & CONCLUSIONES GENERALES \\
\hline 1 & $\begin{array}{l}\text {-EI PET utiliza estímulos visuales y auditivos, que desarrolla una buena capacidad auditiva para oír y } \\
\text { discriminar sonidos, aspectos muy relevantes para iniciar al grupo en la lectura y posterior escritura. }\end{array}$ \\
\hline 2 & $\begin{array}{l}\text {-EI PET permite una buena memoria auditiva para retener lo escuchado que ha sido clave en la } \\
\text { descodificación de letras, sílabas y palabras sencillas. }\end{array}$ \\
\hline 3 & $\begin{array}{l}\text {-EI PET a través de los bits de imágenes y palabras desarrolla la memoria visual, facilitándoles tanto el } \\
\text { proceso lector, como el escritor. }\end{array}$ \\
\hline 4 & $\begin{array}{l}\text {-El nivel general alcanzado por el grupo que posee un ritmo de aprendizaje más rápido, es muy superior } \\
\text { a lo exigido por el ciclo de El y el currículo oficial en relación al ámbito lecto-escritor. }\end{array}$ \\
\hline 5 & $\begin{array}{l}\text {-El grupo con un ritmo de aprendizaje más lento, alcanzan un nivel similar al grupo anterior y por tanto } \\
\text { el nivel alcanzado por estos alumnos es igual o superior a lo exigido por el ciclo de El y el currículo } \\
\text { oficial. }\end{array}$ \\
\hline 6 & $\begin{array}{l}\text {-EI PET permite que los dos ritmos de aprendizaje del aula tan definidos en el momento inicial de la } \\
\text { investigación, vaya homogeneizándose en el transcurso del curso, mostrando una evolución muy } \\
\text { significativa por parte de todos los alumnos, y especialmente en los ACNEAE. }\end{array}$ \\
\hline 7 & $\begin{array}{l}\text {-El PET permite que el sujeto absentista, alcance un nivel medio al finalizar el curso a pesar de faltar de } \\
\text { forma repetitiva y periódica durante todo el curso escolar, dotándole de estrategias y capacidades que } \\
\text { le permitan mejorar y no estancarse durante este curso escolar, adquiriendo notables competencias } \\
\text { lectoras y escritoras. }\end{array}$ \\
\hline 8 & $\begin{array}{l}\text { - PET desarrolla las potencialidades de todo el alumnado, despertando en los alumnos estrategias que } \\
\text { les permita leer palabras y frases sencillas de forma natural y rápida. }\end{array}$ \\
\hline
\end{tabular}

\subsubsection{CURSO 2012/13: 2 CURSO DEL 2 CICLO DE EI}

Por último, analizaremos los resultados obtenidos por el grupo anterior en su $2^{\circ}$ año de escolaridad en la etapa de El. Antes de comenzar con el análisis, apuntar que en este grupo existe una gran diversidad de ritmos; a pesar que la barrera idiomática de los sujetos 06 y 07 es mínima, contamos con dos alumnos nuevos con un nivel mucho más bajo al del resto del grupo (el sujeto 13 y el sujeto 14, alumno con problemas graves de atención, impulsividad y conductas disruptivas), a todo ello debemos sumar las faltas de asistencias continuadas del sujeto 06 que se han acentuado a lo largo de este año escolar.

Apoyándonos en la figura 4.36 donde se comparan los resultados obtenidos por los tres indicadores en relación al ámbito lecto-escritor, observamos que de los 14 alumnos del aula:

- En referencia al indicador BI, 13 alumnos han alcanzado el 100\% de los objetivos programados; el sujeto 06 ha conseguido un $80 \%$ de puntuación en la escala, este dato es especialmente significativo por los grandes avances obtenidos en su 
segundo año de escolaridad. De forma general, la clase ha alcanzado un $98,6 \%$ en la consecución total de los objetivos.

- En relación al indicador D.122, como en el caso anterior, 13 los alumnos que han alcanzado la máxima puntación en la consecución de los objetivos propuestos por el indicador D.122; siendo el alumno asentista es el que consigue una puntuación del $80 \%$ sobre el total de la escala, de nuevo este dato constata la evolución tan positiva sufrida por él. En consecuencia, el grupo ha alcanzado una puntuación total del $98,6 \%$ en la consecución de los objetivos propuestos por el indicador D.122.

- Finalmente, en referencia al indicador PET, 5 alumnos han conseguido la puntuación máxima; el sujeto 06 ha alcanzado la menor puntuación aunque muy positiva (del 60\%); el resto de alumno han logrado puntuaciones muy altas (con valores comprendidos entre el 70 y el $90 \%$ ). En este caso, el grupo ha conseguido un $87,9 \%$ en la consecución de los objetivos programados por el indicador PET.

Como se observa, los valores hallados por el grupo de alumnos en los indicadores D. 122 y BI rozan la puntuación máxima (98,6\%), siendo el indicador PET el que alcanza una puntuación menor aunque muy satisfactoria (del 87,8\%). Estos datos muestran que a través del PET en relación al ámbito lecto-escritor se ha conseguido importantes logros:

- Durante los primeros meses del curso, el grupo con un nivel más alto son capaces de leer en mayúscula palabras más complejas, frases e incluso pequeños textos; al finalizar el curso estos alumnos leen de forma totalmente autónoma y con gran fluidez tanto en mayúscula como en minúscula, muestra de ello puede observarse el anexo 7 y anexo 9 donde se ve la evolución de este alumno en comparación al curso pasado y en el anexo 11 donde un alumno forma parte de la experiencia del centro "compartir lecturas" (durante todo el curos escolar, un día a la semana, durante $10 \mathrm{~min}$ un miembro de la comunidad educativa leerá un cuento en cada clase del centro, en este caso un alumnos de $2^{\circ}$ de El lee en $5^{\circ}$ de primaria).

- El resto de alumnos con nivel más bajo, al iniciar el curso identifican la mayoría de sílabas directas en mayúscula, experimentando una evolución muy significativa en el segundo y tercer trimestre, reconociendo un gran número de sílabas inversas y mostrando más soltura en la lectura de frases sencillas.

- Cabe una especial mención, los alumnos que se incorporaron este curso por primera vez al grupo, cuyo nivel inicial de partida es tan bajo que no son capaces de escribir su nombre ni reconocer todas las letras del abecedario; ambos sujetos 


\section{CAPITULO 5: DISCUSIÓN}

experimentan una evolución rapidísima ya a lo largo del segundo mes de curso, incluso uno de los sujetos al finalizar el segundo trimestre ha adquirido una competencia lectora fluida.

- En relación a la escritura, durante el primer trimestre un alto número de los alumnos son capaces de escribir todas las letras del abecedario en mayúscula escuchando su sonido, produciéndose una evolución significativa en relación a la autonomía de la escritura espontánea de palabras sencillas en aquellos alumnos con un ritmo menor.

- El paso de la escritura en minúscula se da de forma espontánea a lo largo del segundo trimestre, son los propios alumnos los que por iniciativa propia y siguiendo las pautas dadas (cielos, suelo y centro) comienzan a realizar un trazo correcto en palabras sencillas (como por ejemplo escribiendo su nombre) progresando notablemente a lo largo de todo el curso. La progresión de la escritura en minúscula va paralela a la evolución de la fluidez lectora, de tal manera que aquellos alumnos que son capaces de leer de forma autónoma, comienzan a escribir frases en minúscula de forma rápida y sencilla; a nivel grupal, desde el PET se fortalece este objetivo, a través de los retos planteados en la primera asamblea del día.

- Como se ha mencionado anteriormente, el sujeto absentista es el que presenta más limitaciones en relación a la adquisición de éste ámbito; no obstante, la evolución ha sido mucho más rápida y mayor, que en el curso anterior. Llegando incuso, a alcanzar una tasa de éxito en la consecución de los objetivos muy elevada (del $80 \%$ ).

Consecuencia de estos resultados, se extraen una serie de conclusiones generales recogidas en la tabla 5.3 .

Tabla 5.3. Resultados PET: ámbito lecto-escritor, curso 2012/13 (2ํㅡㄹ)

\begin{tabular}{|l|l|}
\hline № & CONCLUSIONES GENERALES \\
\hline 1 & $\begin{array}{l}\text {-La consecución de los objetivos se produce de forma más progresiva y paulatina, cuando el PET ya ha } \\
\text { sido aplicado con anterioridad, en cursos pasados. }\end{array}$ \\
\hline 2 & $\begin{array}{l}\text {-EI PET permite establecer relaciones entre conceptos, aumentando la facilidad para comenzar a leer y } \\
\text { escribir de forma rápida y sencilla. }\end{array}$ \\
\hline 3 & $\begin{array}{l}\text {-La gran variedad de categorías de bits y actividades utilizadas, próximas a los intereses de los niños, } \\
\text { aumenta la motivación e interés hacia los contenidos trabajados. }\end{array}$ \\
\hline 4 & $\begin{array}{l}\text {-Los diferentes retos planteados en el PET permite que los alumnos establezcan relaciones, } \\
\text { favoreciendo el razonamiento deductivo y el aprendizaje de forma autónoma. }\end{array}$ \\
\hline 5 & $\begin{array}{l}\text {-El diseño de categorías de bits de imágenes y palabras adaptadas a los intereses del grupo, hace que } \\
\text { la atención aumente y los aprendizajes se den de forma temprana y sencilla. }\end{array}$ \\
\hline 6 & $\begin{array}{l}\text {-Utilizar el juego como principal herramienta para la enseñanza de la lectura y la escritura, permite que } \\
\text { los aprendizajes se den de forma espontánea, alcanzando los objetivos de forma temprana. }\end{array}$ \\
\hline
\end{tabular}




\begin{tabular}{|l|l|}
\hline 7 & $\begin{array}{l}\text {-Los bits de palabras presentados en el PET y los juegos relacionados con éstos, permiten que el } \\
\text { aprendizaje de la lectura surja de forma natural y espontáneo. }\end{array}$ \\
\hline 8 & $\begin{array}{l}\text {-Los retos planteados en el PET despiertan en los alumnos las ganas de superación personal, } \\
\text { alcanzando objetivos más complejos. }\end{array}$ \\
\hline 9 & $\begin{array}{l}\text {-La selección de los bits y de las actividades, permiten adaptar los contenidos a trabajar, con el ritmo } \\
\text { real de la clase. }\end{array}$ \\
\hline
\end{tabular}

La valoración global de los resultados conseguidos en este ámbito en los tres cursos indica que el PET logra un aprendizaje en el alumnado mucho más alto que lo que establece la normativa y lo que suele ser habitual en estas edades; desarrollando las potencialidades de todos los alumnos, independientemente de su ritmo de aprendizaje o nivel, homogeneizándose los diferentes ritmos existentes en el grupo. Este hecho da respuesta al principio de inclusión, al poder adaptar el programa a las características personales de todo el alumnado.

Los resultados muestran que los aprendizajes se dan de forma más rápida y temprana que con otros métodos de lecto-escritura más tradicionales, favoreciendo una alta motivación por parte de todos los agentes implicados (alumnos, maestra y padres). La motivación que despierta el PET provoca que los alumnos estén más predispuestos hacia el aprendizaje, favoreciendo un clima de trabajo óptimo. Por su parte, los padres muestran altos niveles de satisfacción con los resultados, reforzando los logros alcanzados por sus hijos y generando que el aprendizaje se asiente y mejore.

Como maestra, la puesta en marcha de este PET despierta en mí una alta motivación al ver a mis alumnos avanzar tan rápidamente y especialmente dar pasos de gigantes a aquellos alumnos que les cuesta más; superación personal, intentando diseñar y crear nuevos materiales que den respuesta a demandas concretas de problemas concretos y una enorme satisfacción personal al observar no solo la evolución de todos mis alumnos, sino como disfrutan aprendiendo.

\subsection{DISCUSIÓN DE RESULTADOS EN EL ÁMBITO LÓGICO- MATEMÁTICO}

De igual modo, y volviendo al objeto de estudio, analizaremos la evaluación del PET durante los tres cursos investigados en relación al ámbito lógico-matemático. 


\subsubsection{CURSO 2010/11: 3 CURSO DEL 2 CICLO DE EI}

La descripción de los resultados alcanzados en la figura 4.12 nos ha permitido analizar los resultados hallados en el ámbito lógico-matemático, donde se recogen los logros obtenidos por los tres indicadores; observamos que en relación al grupo:

- Todos los alumnos alcanzan el $100 \%$ de los objetivos propuestos tanto por el indicador $\mathrm{Bl}$, como por el indicador D. 122.

- Para el último indicador PET, observamos que el nivel inicial de partida del grupo en relación al indicador se mueve en valores comprendidos entre el $25-40 \%$ de puntuación total en la escala; estos datos revelan un nivel medio-alto de partida, consecuencia de los resultados experimentados por el programa de estimulación puesto en práctica en el curso anterior. Además, se observa que 11 de los 14 alumnos alcanzan el $100 \%$ de los objetivos marcados por el PET; otros 2 sujetos muestran niveles altos en su consecución (iguales o superiores al 63\%); y el sujeto 14 , obtiene un valor del $63 \%$ de la puntuación total en la escala. La clase ha conseguido un resultado del $92,6 \%$ en la adquisición de los objetivos programados por el indicador PET.

Como vemos, los datos obtenidos por los indicadores se mueven en valores comprendidos entre el $92,6 \%$ y el $100 \%$; estos datos revelan que a través del PET se ha conseguido logros tan interesantes como:

En el curso pasado se inició al grupo en el cálculo mental; en este curso, se sigue realizando actividades que permiten potenciar esta capacidad, llegando incluso a alcanzar objetivos como:

(3) Dado dos bits de números, averiguar dónde hay más puntos y deducir cuantos puntos le falta a un número para ser igual que el otro.

(4) Realizar sumas con y sin llevadas utilizando más de dos sumandos y en números de 1, 2 y 3 cifras (como por ejemplo 73+3, 201+4, 6+4+4, etc.).

(5) Realizar restas con y sin llevadas en números de 1, 2 y 3 cifras (como por ejemplo 9-5, 62-4, 200-1, etc.).

(6) Deducir relaciones entre números de forma autónoma (por ejemplo: "como el 12 es $10+2$, si quiero sumar al 25 el número 12, debo sumarle primero $10 \mathrm{y}$ luego 2" o "si quiero restar 9 a un número, es más fácil si le quito primero diez y luego le sumo uno"). 
(7) Realizar el juego del 100 que consiste en que todo el grupo y ayudándose entre ellos, realicen de forma mental operaciones hasta el 100 que impliquen sumas y restas (ver anexo 2).

(8) Descodificar símbolos asociados a números mediantes la utilización de números romanos. Inicialmente se comenzó por los 100 primeros, pero dada la gran expectación y motivación que produjo este juego, se aumentó hasta el 3.999 (ver anexo 3).

(9) Manejo con soltura de monedas y billetes de euro, realizando operaciones de sumas y restas para obtener billetes a partir de monedas 1 o 2 euros, y obtener 1 euro a partir de monedas de céntimo (lo que implica sumas sencillas y otras más complejas con llevadas). Todos estos resultados pueden verse en el anexo 3.

Estos logros nos llevan a concretar una serie de conclusiones generales alcanzadas durante este curso escolar, detalladas en la tabla 5.4.

Tabla 5.4. Resultados PET: ámbito lógico-matemático, curso 2010/11 (3ํE)

\begin{tabular}{|l|l|}
\hline No & CONCLUSIONES GENERALES \\
\hline 1 & $\begin{array}{l}\text {-EI PET utiliza estímulos visuales y auditivos, que desarrolla una buena capacidad auditiva para oír y } \\
\text { discriminar los números trabajados a lo largo de este curso. }\end{array}$ \\
\hline 2 & $\begin{array}{l}\text {-EI PET permite una buena memoria auditiva para retener lo escuchado que será clave en la } \\
\text { descodificación los números aprendidos. }\end{array}$ \\
\hline 3 & $\begin{array}{l}\text {-Las experiencias planteadas a través del material manipulativo del PET permiten construir nuevos } \\
\text { conocimientos matemáticos y asentar los ya adquiridos. }\end{array}$ \\
\hline 4 & $\begin{array}{l}\text {-EI PET a través de los materiales utilizados, inicia a los alumnos en el cálculo mental, provocando que } \\
\text { los alumnos no necesiten el uso de dedos para sumar o restar. }\end{array}$ \\
\hline 5 & $\begin{array}{l}\text {-El PET favorece experiencias prácticas para comprender los conceptos de suma y resta de forma } \\
\text { vivenciada. }\end{array}$ \\
\hline 6 & -Las actividades y materiales utilizadas en el PET permite adaptarse al nivel real de cada alumnado. \\
\hline 7 & -Utilizar el juego como principal herramienta de aprendizaje, aumenta la motivación. \\
\hline
\end{tabular}

\subsubsection{CURSO 2011/12: 1ํㅡㄴ CURO DEL 2 CICLO DE EI}

Basándonos en los resultados de la figura 4.32, la cual muestra la evolución de la clase durante este curso escolar en relación a los diferentes indicadores de logros, observamos que:

- La totalidad de los alumnos han alcanzado los objetivos propuestos por el indicador $\mathrm{Bl}$, excepto el sujeto 06 que consigue alcanzar la mitad de los objetivos programados. El grupo alcanza el $92,9 \%$ de los objetivos totales propuestos por el indicador BI. 


\section{CAPITULO 5: DISCUSIÓN}

- 6 de los sujetos han alcanzado el $100 \%$ de los objetivos programados por el D.122; 5 de los 7 sujetos restantes han conseguido valores muy altos (entre el $75 \%$ y el 96\%); siendo el alumno absentista y con barrera idiomática el que alcanza la menor puntuación del grupo (del 42\%). El grupo alcanza el 92,9\% total de los objetivos propuestos por el indicador D.122.

- En relación al indicador PET, sólo 4 sujetos alcanzan todos los objetivos propuestos y otros 3 se han quedado muy cerca de conseguirlo (alcanzando un $96 \%$ de los objetivos); el resto de alumnos se mueven en valores comprendidos entre el $46-70 \%$, excepto el sujeto 06 que de nuevo, obtiene la puntuación más baja (del $25 \%$ ). La clase alcanza el $88,1 \%$ de los objetivos totales propuestos por este indicador.

Como se observa, el grupo alcanza valores muy altos en todos sus indicadores, al adquirir valores comprendidos entre el $88,1 \%$ y el $92,9 \%$, estos datos revelan que a través del PET se ha conseguido importantes logros:

(1) Un alto número de alumnos son capaces de reconocer e identificar los números del 1 al 100.

(2) En relación a dos conjuntos dados (bits de números) identifican dónde hay más o menos elementos

(3) Los alumnos han tenidos experiencias suficientes que les ha permitido iniciarse en la resolución de sumas sencillas de uno y dos sumandos utilizando regletas.

(4) Los alumnos han tenidos experiencias suficientes que les ha permitido iniciarse en la resolución de restas sencillas utilizando regletas.

(5) Se han iniciado en el cálculo mental sin utilizar ningún tipo de soporte material (regletas o dedos), realizando cálculos del tipo 1+8=9, 5+5=10, 1+1+1=3 (ver anexo 5).

(6) Realizan perfectamente la grafía del 1 al 10 utilizando la direccionalidad y trazo correcto.

Todos estos resultados nos llevan a concretar una serie de conclusiones generales alcanzadas durante este curso recogidos en la tabla 5.5:

Tabla 5.5. Resultados PET: ámbito lógico-matemático, curso 2011/12 (1ํㅡㄹ)

\begin{tabular}{|l|l|}
\hline № & CONCLUSIONES GENERALES \\
\hline 1 & $\begin{array}{l}\text {-EI PET utiliza estímulos visuales y auditivos, que desarrolla una buena capacidad auditiva para oír y } \\
\text { discriminar los números trabajados a lo largo de este curso. }\end{array}$ \\
\hline 2 & $\begin{array}{l}\text {-EI PET permite una buena memoria auditiva para retener lo escuchado que será clave en la } \\
\text { descodificación los números aprendidos. }\end{array}$ \\
\hline
\end{tabular}




\begin{tabular}{|l|l|}
\hline 3 & $\begin{array}{l}\text {-Las experiencias planteadas a través del material manipulativo del PET permiten construir nuevos } \\
\text { conocimientos matemáticos y asentar los ya adquiridos. }\end{array}$ \\
\hline 4 & $\begin{array}{l}\text {-EI PET a través de los materiales utilizados, inicia a los alumnos en el cálculo mental, provocando que } \\
\text { los alumnos no necesiten el uso de dedos para sumar o restar. }\end{array}$ \\
\hline 5 & $\begin{array}{l}\text {-EI PET favorece experiencias prácticas para comprender los conceptos de suma y resta de forma } \\
\text { vivenciada. }\end{array}$ \\
\hline 6 & -Las actividades y materiales utilizadas en el PET permite adaptarse al nivel real de cada alumnado. \\
\hline
\end{tabular}

\subsubsection{CURSO 2012/13: 2 CURSO DEL 2 CICLO DE EI}

Tomando de referencia la figura 4.43, analizaremos la evolución de los sujetos en relación al ámbito lógico-matemático para este curso escolar:

- En el indicador BI, todos los alumnos, excepto el sujeto 06, han alcanzado todos los objetivos propuestos por este indicador. El grupo ha logrado el 98,2\% de los objetivos propuestos por este indicador.

- En el indicador D. 122, 11 sujetos han logrado la puntuación máxima y los 3 alumnos restantes, han alcanzado valores iguales o superiores al $70 \%$. El grupo ha obtenido el $96,1 \%$ de los objetivos programados por este indicador.

- En el indicador PET, 6 sujetos han alcanzado los objetivos totales propuestos por este indicador; otros 3 sujetos han logrado valores muy altos (del 96\%); y los sujetos restantes se mueven en valores comprendidos entre el $25 \%$ y el $46 \%$. Al finalizar el curso, el grupo ha alcanzado el $79,3 \%$ de los objetivos propuesto por el indicador PET.

Finalmente, haciendo un balance general de los objetivos conseguidos por el grupo en el ámbito estudiado, observamos que el nivel general del aula es muy satisfactorio al alcanzar valores comprendidos entre el $79,3 \%$ y el $98,2 \%$. Estos datos manifiestan que a través del PET en relación al ámbito lógico-matemático se ha conseguido que:

(1) Los alumnos no sólo identifican números de dos cifras, sino que muestran gran soltura tanto en la identificación, reconocimiento y grafía.

(2) Son capaces de realizar dictados de números de dos cifras, lo que implica una correcta grafía y reconocimiento auditivo de los números, asociando una adecuada correspondencia número-grafía.

(3) Jugar al bingo, identificando y reconociendo de forma ágil números de dos cifras. 


\section{CAPITULO 5: DISCUSIÓN}

(4) Utilizar las estimaciones como práctica habitual en sus juegos diarios (por ejemplo adivinar números dando pistas del tipo "es más grande que 36 y más pequeño que 38 ").

(5) Al finalizar el segundo trimestre, un gran número de alumnos son capaces de reconocer e identificar números de 3 y 4 cifras.

(6) Al finalizar el curso, un alto número de alumnos son capaces de reconocen e identifican números de 9 cifras (ver anexo 11). Lo que muestra una evolución muy rápida de un trimestre a otro.

Todos estos resultados nos llevan a concretar una serie de conclusiones generales alcanzadas durante este curso, detalladas en la tabla 5.6:

Tabla 5.6. Resultados PET: ámbito lógico-matemático, curso 2012/13 (2트)

\begin{tabular}{|l|l|}
\hline № & CONCLUSIONES GENERALES \\
\hline 1 & -EI PET desarrolle las potencialidades de cada alumno en base a su nivel real. \\
\hline 2 & $\begin{array}{l}\text {-EI PET permite que los alumnos con un nivel más bajo de partida, puedan conseguir los } \\
\text { objetivos satisfactoriamente, homogeneizándose los diferentes ritmos existentes en el grupo. }\end{array}$ \\
\hline 3 & $\begin{array}{l}\text {-EI PET da respuesta a las necesidades de los alumnos ACNEAE, permitiendo que mejoren } \\
\text { notablemente a lo largo del curso. }\end{array}$ \\
\hline 4 & $\begin{array}{l}\text {-La evolución en la consecución de los objetivos se da de forma rápida y sencilla, aumentando la } \\
\text { motivación de los alumnos. }\end{array}$ \\
\hline 5 & $\begin{array}{l}\text {-EI PET permita que el alumnado desarrolle nuevas estrategias de cálculo de forma espontánea } \\
\text { y autónoma, estableciendo relaciones entre los números. }\end{array}$ \\
\hline 6 & $\begin{array}{l}\text {-EI PET utiliza el juego como principal herramienta en la construcción de aprendizajes } \\
\text { significativos. }\end{array}$ \\
\hline
\end{tabular}

La valoración global de los resultados conseguidos en este ámbito en los tres cursos indica que el PET logra un aprendizaje en el alumnado mucho más alto que lo que establece la normativa y lo que suele ser habitual en estas edades. Aumentando considerablemente el rendimiento del grupo, dando respuesta a las necesidades de todo el alumnado.

A su vez, los resultados muestran que los aprendizajes se dan de forma mucho más rápida y temprana que con otros métodos más tradicionales, lo que facilita enormemente mi trabajo como maestra, al permitirme dedicar más tiempo a otros contenidos claves en el desarrollo integral de mis alumnos que en otras circunstancias, me veo muy limitada por la falta de tiempo diario: educación emocional, resolución de conflictos, mayor uso de las TIC, etc.

EI PET ha permitido que los alumnos no sólo se inicien en habilidades numéricas básicos, sino que les ha dotado de estrategias para que establezcan sus propias relaciones entre los números, favoreciendo el aprendizaje autónomo y espontáneo, especialmente en el cálculo mental. Las estrategias utilizadas en el programa, hace que los alumnos comprendan 
las matemáticas al favorecer continuamente aprendizajes vivenciados donde los alumnos tengan que manipular, tocar y experimentar. Por ello, este programa resulta una herramienta muy útil, fácil y sencilla de aplicar, en cualquier aula de El independientemente de las características de los alumnos que lo constituyen.

Finalmente apuntar que el programa, ha resultado ser efectivo no sólo en relación a los resultados obtenidos sino en cuanto a la mejora del vínculo maestra-padres-alumnos, favoreciendo una alta motivación por parte de todos los agentes implicados.

A modo de cierre, y teniendo de base los resultados obtenidos a lo largo de los 3 años que duró la investigación, hemos constatado que el PET permite una mayor motivación, participación y satisfacción por parte del alumnado y de la maestra que aplica el programa. En esta misma línea Trianes, De la Morena y Muñoz (1999) señalan la motivación del profesorado como un factor influyente en el proceso de enseñanza-aprendizaje. Así mismo, vemos como el programa de estimulación permite dar respuesta a la diversidad de ritmos, aprendizajes y necesidades educativas de todo el alumnado, componentes que se manifestaron durante toda la investigación al mostrar los logros alcanzados por los sujetos ACNEAE (alumno absentista, alumno con necesidades de compensatoria educativa, alumno con problemas de atención y alumno con conductas disruptivas), sujetos con un ritmo de aprendizaje más bajo y evolución mostrada por los alumnos que se incorporan por primera vez al curso; reforzando esta idea encontramos el estudio de Moya y García (2014), cuyos resultados manifiestan que la aplicación de programas de estimulación a ACEAE no supone un impedimento en la consecución de los objetivos previstos para la actividad, mostrándose plenamente integrado y participando al mismo nivel que el resto de sus compañeros en toda la aplicación de método basado en los bits de inteligencia.

Como hemos defendido, uno de los principales materiales utilizados en el PET han sido los bits de inteligencia, dada sus grandes posibilidades educativas; los estudios de Albornoz y Guzmán (2016), quienes elaborar y desarrollar un programa educativo a través de los bits de inteligencia como prevención de posibles dificultades de aprendizaje en el alumnado de $\mathrm{El}$; muestran que los bits de inteligencia en el aula son un buen recurso para prevenir las dificultades de aprendizaje, ya que atienden a la diversidad en el aula sin que se hagan notables las diferencias socio-culturales, cognitivas y emocionales. Por otra parte, existen numerosos estudios que apoyan el uso de los bits de inteligencia como herramienta potenciadora de aprendizajes, ya que es un material que puedes ser aplicado en cualquier aula de infantil dada la facilidad para ser diseñado y elaborado (Oliva y Acosta, 2015; Albornoz y Guzmán, 2016). Sin embargo, los hallazgos encontrados no concuerdan con los estudios 


\section{CAPITULO 5: DISCUSIÓN}

de L'Ecuyer, (2015), quien afirma que no existen estudios que haya demostrado la eficacia de métodos de estimulación basado en los bits de inteligencia.

Finalmente, y volviendo a los datos procedentes de nuestra investigación, observamos que la aplicación de este PET supone romper con metodologías más tradicionales, apostando por metodologías innovadoras, creativas, cuyo fundamento se sustenta en ofrecer al alumnado experiencias y actividades manipulativas, donde el alumnado tenga que reflexionar, indagar, establecer relaciones como base se su propio aprendizaje. En este sentido, el estudio realizado por Aragón, Delgado, Aguilar, Araújo y Navarro (2013) defiende la necesidad de proporcionar experiencias significativas para el alumnado que faciliten la integración de los conocimientos que ya poseen con otros nuevos, dotando a todo el alumnado, de las estrategias y herramientas necesarias para establecer conexiones entre diferentes campos del saber que promuevan el desarrollo integral del niño. Igualmente, los resultados obtenidos con el PET se han visto fortalecido por la implicación las familias de los alumnos participantes en el estudio. Este hecho demuestra la importancia de dar a conocer tanto el programa de estimulación como las pautas seguidas en el aula, para que las familias dispongan de nociones básicas para reforzarlas en la misma línea que el docente; por su parte, son numerosos los estudios que apoyan esta idea (González, 2005; Vizuete, 2014; Junta, 2016) manifestando que la falta de información limita las posibilidades de brindar una adecuada ET a los niños en el ámbito escolar. 


\title{
6. CONCLUSIONES
}

\author{
Capítulo 6
}

6.1. Resultados conseguidos

6.2. Limitaciones del estudio

6.3. Prospectiva de futuro 


\section{CAPITULO 6: CONCLUSIONES}

La compilación de información del marco teórico, junto los principales hallazgos obtenidos tras el diseño y aplicación del programa de estimulación, nos lleva a concretar una serie de conclusiones en relación al objetivo de la investigación, el cual se organiza en dos apartados, que se corresponden con los objetivos más concretos del mismo: (a) evaluar los resultados obtenidos en el ámbito lecto-escritor en el alumnado del $2^{\circ}$ ciclo de El tras aplicar el PET; y (b) evaluar los resultados obtenidos en el ámbito lógicomatemático en el mismo alumnado tras aplicar el PET; para finalmente dar a conocer los resultados generales del PET. En la misma línea, debemos definir las limitaciones encontradas a lo largo de la investigación y proponer investigaciones futuras.

\subsection{RESULTADOS CONSEGUIDOS}

\subsubsection{RESULTADOS ESPECÍFICO DEL ÁMBITO LECTO-ESCRITORE}

En relación a los tres cursos investigados, se han obtenidos los siguientes resultados específicos en el área lecto-escritor:

El programa de estimulación permite un mayor desarrollo de la capacidad lectora y escritora en los alumnos, aprendiendo a leer y a escribir de una forma más natural y rápida. Permitiendo al docente dedicar más tiempo a reforzar otras áreas del desarrollo del menor, necesarias para su desarrollo integral.

El nivel general alcanzado por los grupos es muy superior a lo exigido por el ciclo de El y el currículo oficial, desarrollando las potencialidades de todos los alumnos ya que el programa se adapta al nivel real del niño; dando respuesta al principio de inclusión, lo que permite que los ACNEAE puedan alcanzar los objetivos satisfactoriamente. Este hecho, aumenta la motivación y participación por parte del alumnado, lo que repercute positivamente en el proceso de enseñanza-aprendizaje.

EI PET mejora los procesos cognitivos básicos de atención, percepción y memoria a través de los bits de palabras y bits de imágenes, aumentando el vocabulario de los alumnos. El uso de bits de palabra, favorece que los alumnos escriban las palabras correctamente sin cometer errores ortográficos.

El PET trabaja la ruta visual, auditiva, sensitiva, táctil y propioceptiva, proporcionando a los alumnos múltiples experiencias que fomentan el aprendizaje significativo. 
El programa de estimulación combina los diferentes métodos tradicionales utilizados en la enseñanza de la lectura y la escritura, adaptándose al ritmo y necesidades del grupo; combina diferentes estrategias partiendo de palabras significativas para el alumnado como unidad generadora, descomponiéndolas en sus unidades mínimas (fonema, letras y sílabas) y en otras ocasiones, parte de estas unidades mínimas del lenguaje, juntándolas una a una hasta formar unidades más complejas con significados propios (palabras o frases).

Los resultados obtenidos de forma rápida y temprana, produce una alta motivación tanto en el profesorado como en los padres, factor influyente en el proceso de enseñanza-aprendizaje.

\subsubsection{RESULTADOS ESPECÍCOS DEL ÁMBITO LÓGICO-MATEMÁTICO}

Los resultados encontrados en el ámbito lógico-matemático, tras la puesta en marcha del programa de estimulación a lo largo de los tres cursos escolares, son:

EI PET permite un mayor desarrollo de la capacidad lógico-matemática en los niños, de una forma más natural y rápida, adquiriendo un aprendizaje en el alumnado mucho más alto que lo que establece la normativa y lo que suele ser habitual en estas edades. En consecuencia, se produce un aumento considerable en el rendimiento del grupo.

EI PET atiende a la diversidad de ritmos, niveles y necesidades de todo el alumnado, favoreciendo un aprendizaje individualizado y personalizado.

Rompe con métodos más tradicionales que fomenta el aprendizaje de manera mecánico y poco individualizado, potenciando experiencias prácticas que tengan sentido para el alumno, experiencias que faciliten la integración de los conocimientos que ya poseen con los nuevos que deben adquirir.

EI PET utiliza estímulos visuales y auditivos, que desarrolla una buena capacidad auditiva para oír y discriminar los números trabajados a lo largo del curso, mejorando la atención, percepción y memoria. Además, el programa de estimulación permite una buena memoria auditiva para retener lo escuchado, clave en la descodificación de los números.

Las experiencias planteadas a través del material manipulativo del PET permiten construir nuevos conocimientos matemáticos y asentar los ya adquiridos. Favoreciendo 


\section{CAPITULO 6: CONCLUSIONES}

estrategias en el que utiliza para resolver los retos planteados y promueve el razonamiento inductivo, generando un aprendizaje autónomo y espontáneo.

EI PET utilizar el juego como principal herramienta de aprendizaje, aumentando la motivación del alumnado y la predisposición hacia los procesos de enseñanzaaprendizaje. Además, las actividades planteadas a lo largo de la estimulación al estar relacionadas con temas que suscitan interés en los niños (números romanos, monedas, etc.) provocan una alta motivación en el alumnado.

EI PET favorece la adquisición del cálculo mental de forma sencilla y natural, sin tener que utilizar materiales de apoyo (como regletas, dedos, palillos, etc.).

Finalmente apuntar que el programa, ha provocado una mejora del vínculo maestra-padres-alumnos, favoreciendo una alta motivación por parte de todos los agentes implicados.

\subsubsection{RESULTADOS GENERALES}

A nivel general, los puntos fuertes encontrados en el programa de estimulación son:

EI PET permite desarrollar las potencialidades individuales de cada alumno; la metodología y materiales utilizados se programan, diseñan y aplican en base al nivel real no sólo del grupo, sino de cada sujeto. Este hecho permite dar una respuesta individualizada tanto a los diferentes ritmos de aprendizaje del grupo (alumnos con nivel alto de aprendizaje, alumnos con nivel medio y alumnos con nivel bajo), como a los alumnos que presentan algún tipo de necesidad educativa por problemas de idioma, atención, absentismo, etc. En consecuencia, este programa es una herramienta más al servicio del docente, de las familias y de los alumnos, que favorece el principio de inclusión.

Siguiendo esta misma línea, a través del PET se consigue equiparar el nivel de los diferentes ritmos de aprendizaje en el aula y, a su vez, mejorar los resultados obtenidos por los alumnos ACNEAE.

En relación a la organización del PET, cada lunes se decide las categorías concretas de bits de imágenes y palabras que se van a utilizar y las actividades grupales que se plantearán en las asambleas teniendo en cuenta los logros alcanzados por cada niño en ese momento. Este hecho provoca que los aprendizajes se den de forma temprana y rápida en todo el alumnado (en mayor o menor medida), aumentando considerablemente la motivación del grupo. Por tanto, otra de las fortalezas encontradas 
es que el PET permite adaptarse al nivel real de cada uno de los alumnos, favoreciendo una educación inclusiva.

De la misma manera, el PET promueve una mejora en la atención del grupo al estar constituido por estímulos rápidos y visuales, que se presentan en un tiempo breve. Este hecho hace que la puesta en práctica del programa implique un tiempo relativamente corto, con mucha variedad en las actividades e imágenes, aumentando la concentración y la atención de los alumnos. EI PET a través de los bits de inteligencia mejora los procesos cognitivos básicos como son la memoria, atención y percepción. $A$ través de las categorías de bits utilizadas, se establecer conexiones entre distintos campos del saber, promoviendo el desarrollo integral en el alumnado y provocando nuevas aficiones en los niños.

EI PET rompe con metodologías más tradicionales, favoreciendo un aprendizaje vivenciado, manipulativo y provocando que el alumno sea el principal responsable en su aprendizaje al formar parte activa del proceso.

Los materiales utilizados en el PET son sencillos de diseñar y construir, permitiendo que cualquier docente pueda elaborar su propio programa de estimulación respetando los principios y fundamentos de la estimulación temprana.

Los rápidos resultados obtenidos con el programa, generan un aumento en la motivación de las familias, provocando una mayor implicación y colaboración en el proceso educativo de sus hijos. Por otro lado, la confianza de las familias depositada en la tutora también se ve reforzada, transmitiendo a sus hijos una actitud muy positiva hacia la escuela, lo que repercute en un clima idónea de trabajo.

\subsection{LIMITACIONES DEL ESTUDIO}

En relación a la aplicación de nuestro programa de estimulación, encontramos dos limitaciones destacadas. La primera está relacionada con el número tan reducido de sujetos de nuestra muestra. En este sentido las posibles soluciones pasan por (1) aplicar el PET en grupos de edades equivalentes, contando con un grupo control y otro experimental que permitan comparar los resultados obtenidos en cada caso; y (2) aplicar el PET en más de un centro educativo, aumentado considerablemente la muestra y resultados para analizar. En segundo lugar, hubiera sido interesante aplicar el PET en aulas que contaran con ACNEAE de diferentes categorías a las de nuestro estudio, para poder comprobar si el programa permite una educación compensatoria e inclusiva en todas las categorías de alumnos con necesidades educativas. 


\subsection{PROSPECTIVA DE FUTURO}

A lo largo de la investigación han surgido numerosas inquietudes sobre cómo dar continuidad a nuestro estudio. Éstas podrían suponer el eje vertebrador de futuros trabajos de investigación.

El éxito y la alta motivación experimentada con la aplicación del PET hacen necesaria la búsqueda de nuevas líneas de investigación que analicen el impacto del programa en otros tramos educativos, como puede ser el primer internivel de primaria $\left(1^{\circ}\right.$ y $\left.2^{\circ}\right)$. Durante los últimos 4 cursos escolares, he sido tutora del primer internivel de primaria, aplicando el PET a mis alumnos, observando que los resultados obtenidos son tan satisfactorios como ocurría en la etapa de El. Sin embargo, los alumnos de primaria requieren de más tiempo para alcanzar los mismos resultados y los alumnos con un ritmo más lento o ACNEAE precisan de otras medidas de refuerzo, además del propio programa, para alcanzar los objetivos programados. Este hecho refuerza lo expuesto en el marco teórico en relación al enorme potencial que poseen los alumnos de El, a consecuencia de su gran plasticidad cerebral, convirtiéndose en un posible nuevo ámbito de estudio.

Por otro lado, la escasa e insuficiente información sobre los fundamentos y requisitos necesarios para crear programas de estimulación ha sido una de las principales dificultades encontradas. Por ello, sería interesante dar a conocer los resultados y actividades descritas en nuestra investigación a través de congresos, grupos de trabajos, conferencias y cursos dirigidos principalmente a estudiantes de magisterios y maestros en activo; intentando dar la máxima difusión posible en la comunidad educativa.

Otra de las perspectivas de futuro que actualmente se está poniendo en marcha es la participación en el proyecto de formación de mi centro, donde se ha creado un grupo de trabajo denominado "neuroestimulación". Las experiencias que se están poniendo en marcha en las diferentes aulas son: (1) PET en el ámbito lecto-escritor y lógico-matemático en el ciclo de El y el primer curso de educación primaria; (2) utilización de pelotas de Pilates en lugar de sillas, para favorecer la integración de reflejos primitivos, dar salida a la demanda motriz requerida por los alumnos, aumentar la concentración a través de movimientos rítmico, favorecer una correcta colocación de la espalda al sentarse y fomentar el equilibrio en primero de primaria; (3) aplicación de gimnasia cerebral al comienzo del día, estimulando los botones cerebrales del cuerpo, realizando ejercicios de marcha cruzada y terminando con un ejercicio denominado "gancho" (ejercicio que combina la posición del cuerpo y la respiración, proporcionando 
calma emocional) en todos los cursos; y (4) estimulación sensorial auditiva a través del método Tomatis en todos los cursos del centro; el método consiste en la escucha dirigida y controlada de sonidos (utilizando cantos gregorianos y música de Mozart) por medio de un aparato electrónico denominado "oído externo".

Otra de las prospectivas de futuro que podría tener una gran acogida sería realizar reuniones periódicas con docentes que actualmente están aplicando el PET para abordar los problemas surgidos, resultados obtenidos y posibles mejoras. Dando una visión más global y completa del programa de estimulación.

Finalmente, podría resultar muy interesante extender el PET a al ámbito de las ciencias naturales y sociales, evaluando los resultados obtenidos en relación a la creación de redes de categorías mediante bits, a través de reconocimiento de imágenes. 
CAPITULO 6: CONCLUSIONES 


\section{BIBLIOGRAFÍA}

Capítulo 7

7.1. Referencias bibliográficas

7.2. Referencias legislativas 


\subsection{REFERENCIAS BIBLIOGRÁFICAS}

Åberg, M., Pedersen, N., Torén, K., Svartengren, M., Bäckstrand, B., Johnsson, T., y Kuhn, H. (2009). Cardiovascular fitness is associated with cognition in young adulthood. Proceedings of the National Academy of Sciences, 106(49), 2090620911.

Albornoz, E., y Guzmán, D. C. (2016). Desarrollo cognitivo mediante estimulación en niños de 3 años. Universidad y Sociedad, 8(4), 186-192. Recuperado de http://scielo.sld.cu/pdf/rus/v8n4/rus25416.pdf

Álvarez, C. (2008). La etnografía como modelo de investigación en educación. Gazeta de Antropología, 24(1), 1-15. Recuperado de http://hdl.handle.net/10481/6998

Álvarez, C., y San Fabián, J. L. (2012). La elección del estudio de caso en investigación educativa. Gazeta de Antropología, 28(1), 1-6. Recuperado de http://www.gazetaantropologia.es/?p=101

Álvarez, M. (2010). Neurociencia y comunidad: la oportunidad del neurodesarrollo. PSIENCIA. Revista Latinoamericana de Ciencia Psicológica, 2(1), 30-33.

Recuperado de http://www.redalyc.org/pdf/3331/333127086007.pdf

Antunes, C. (2014). Estimulación del cerebro infantil : desde el nacimiento hasta los 3 años. Madrid: Narcea.

Aragón, V. (2010). La observación en el campo educativo. Innovación y experiencia $\begin{array}{llll}\text { educativa, } & \text { 1(35), } & \text { Recuperado }\end{array}$ https://archivos.csif.es/archivos/andalucia/ensenanza/revistas/csicsif/revista/pdf/N umero 35/VIRGINIA ARAGON 2.pdf

Aragón, E., Delgado, C., Aguilar, M., Araújo, M., y Navarro, J. (2013). Estudio de la influencia de la inteligencia y el género en la evaluación matemática temprana. European Journal of Education and Psychology, 6(1), 5-18. Recuperado de www.ejep.es

Araque, N., y Barrio, J. L. (2010). Atención a la diversidad y desarrollo de procesos educativos inclusivos. Prisma Social, (4), 1-37.

Arias, M. M. (2000). La triangulación metodológica: sus principios, alcances y limitaciones. Investigación y educación en enfermería, 18(1), 13-26. 
ASPACE. (2001). Terapias alternativas aplicadas a la Parálisis Cerebral. Galicia: ASPACE Galicia

Barrero, N. (2012). Los bits de inteligencia y su influencia en el desarrollo de la memoria visual-auditiva de los niños y niñas del primer ciclo de la escuela república de Alemania del Cantón Mocha, provincia de Tungurahua (Trabajo fin de grado, Universidad Técnica de Ambato). Recuperado de http://repositorio.uta.edu.ec/bitstream/123456789/4083/1/tp 2012 319.pdf

Bautista, S. (2014). Conocimientos de un grupo de docentes de educación inicial sobre Estimulación Temprana (Tesis doctoral, Universidad de Ajusco).

Benarós, S., Lipina, S., Segretin, S., Hermida, J., y Colombo, J. (2010). Neurociencia y educación: hacia la construcción de puentes interactivos. Revista de Neurologia, 50(3), 179-186.

Biddle, B., Good, T., Goodson, I., y Bayo, J. (2000). La enseñanza y los profesores. Barcelona: Paidós.

Blanco, R. (2006). La equidad y la inclusión social: uno de los desafíos de la educación y la escuela hoy. REICE, 4(2), 1-15. Recuperado de http://www.redalyc.org/pdf/551/55140302.pdf

Bloom, B. S. (1964). Técnicas de tratamiento. Buenos Aires: Editorial Panamericana.

Bowlby, J. (1993). El Vínculo afectivo. Barcelona: Paidós.

Bravo, J. (2000). El vídeo educativo. Madrid: ICE de la Universidad Politécnica.

Bricker, D. (1991). Educación temprana de niños en riesgo y disminuidos: de la primera infancia a preescolar. Ciudad de México: Trillas.

Cabrerizo, R., López, P., y Navarro, L. (2013). La realidad actual de la Atención Temprana en España (2 $2^{\text {a }}$ edición). Madrid: POLIBEA.

Calvo, A. (2005). Coeducación en las aulas de Primaria: una experiencia educativa en los centros de Santander. Temática Escuela, (13), 13-15.

Campillo, A., y Díez, I. (2010). Un paso más hacia la inclusión de los deficientes visuales en el aula con las Tics. P. Arnaiz; MD Hurtadoy FJ Soto.(Coords.), 25, 1-8. 


\section{CAPITULO 7: BIBLIOGRAFÍA}

Campos, A. (2010). Neuroeducación: uniendo las neurociencias y la educación en la búsqueda del desarrollo humano. La Educación. Revista Digital, 143, 1-14. https://doi.org/0210-0010

Candel, I. (2007). Atención temprana. Situación actual y perspectivas de futuro. Programa de atención temprana: intervención en niños con Síndrome de Down y otros problemas de desarrollo. Madrid: CEPE.

Clemente, G. (2011). La atención temprana en la etapa de Educación Infantil (Trabajo fin de master, Universidad de Almeria). Recuperado de http://repositorio.ual.es/bitstream/handle/10835/1159/Clemente Villegas Gador.pdf?sequence $=1$

Coriat, L., Waksman, J., y Thelesce, L. (1970). Los efectos de la estimulación psicomotriz sobre el $\mathrm{Cl}$ de los niños trisómicos-21. Buenos Aires: Centro Neuorológico Lydia Coriat.

Corral, A. M. (1997). El aprendizaje de la lectura y escritura en la escuela infantil. Servicios de Publicación UCM, 9(1), 67-94.

Damasio, A. (2011). El error de Descartes: la emoción, la razón y el cerebro humano. Cuadernos de Neuropsicología, 5(2), 173-178.

De La Barrera, M., y Donolo, D. (2009). Neurociencias y su importancia en contextos de aprendizaje. Revista Digital Universitaria, 10(4), 1-18. Recuperado de http://www.ru.tic.unam.mx:8080/bitstream/handle/123456789/1493/843.pdf?seque $\underline{\text { nce }=1 \text { yisAllowed }=y}$

Delacato, C. H. (1990). The treatment and prevention of reading problems: The neuropsychological approach. Springfield, Illinois: Charles C Thomas

Diaz, A., Mendoza, V. M., y Porras, C. M. (2011). Una guía para la elaboración de estudios de caso. Razón y Palabra, 75(1), 1-25. https://doi.org/validez triangulación

Doman, G. y Doman, J. (1998). Cómo multiplicar la inteligencia de su bebé: la revolución pacífica. Madrid: EDAF.

Doman, G. (2008). Cómo enseñar a leer a su bebé: la revolución pacífica. Madrid: EDAF.

Doman, G. (2009). Cómo multiplicar la inteligencia de su bebé. Madrid: EDAF. 
Estalayo, V., y Vega, R. (2001). El método de los Bits de Inteligencia. Madrid: Edelvives.

Estalayo, V., y Vega, R. (2007). Leer bien al alcance de todos: El método Doman adaptado a la escuela. Madrid: Biblioteca Nueva.

Figueroa, M., Campoverde, M., y Calle, S. (2015). Intervención Temprana en Niños con Alteraciones en el Neurodesarrollo. Latin American Journal Os Computing, 2(3), 56-62.

Flores, C., y Martín, M. (2006). El aprendizaje de la lectura y la escritura en Educación Inicial. Revista Universitaria de Investigación, 7(1), 69-79. Recuperado de http://www.redalyc.org/articulo.oa?id=41070106

Flores, J. C., y Ostrosky, F. (2008). Neuropsicología de lóbulos frontales, funciones ejecutivas y conducta humana. Revista neuropsicología, neuropsiquiatría y neurociencias, 8(1), 47-58.

Galeote, M., Soto, P., Sebastián, E., Rey, R., y Checa, E. (2012). La adquisición del vocabulario en niños con síndrome de Down: datos normativos y tendencias de desarrollo. Infancia y aprendizaje, 35(1), 111-122. https://doi.org/10.1174/021037012798977502

García-Herranz, S. (2012). La estimulación cognitiva en Educación Infantil: un programa de intervención en el $2^{\circ}$ ciclo (Trabajo fin de grado, Universidad de Valladolid). Recuperado de http://uvadoc.uva.es/handle/10324/1092

García-Herranz, S., y López, V. (2015). Evaluación Formativa y Compartida en Educación Infantil. Revisión de una Experiencia Didáctica. Qualitative Research in Education, 4(3), 269-298. https://doi.org/10.17583/qre.2015.1269

García-Sánchez, F. A., y Mendieta, P. (1998). Análisis de Atención Temprana. Revista de Atención Temprana, 6(1), 37-43.

García, M., y Benítez, M. (2000). Reconceptualización de la profesión docente mediante el empleo del video. Revista de Medios y Educación, 14, 77-82. Recuperado de https://idus.us.es/xmlui/handle/11441/45498

Gardner, H. (2016). Estructuras de la mente: La teoría de las inteligencias múltiples. Ciudad de Méximo: Fondo de Cultura Económica.

GAT. (2000). Libro Blanco de Atención Temprana. Madrid: Real Patronato sobre 


\section{CAPITULO 7: BIBLIOGRAFÍA}

discapacidad. https://doi.org/214-05-012-9

Ginarte, Y. (2002). Rehabilitación cognitiva. Aspectos teóricos y metodológicos. Revista Neurológica, 34(9), 870-876.

Gliedman, J., y Roth, W. (1980). Unexpected Minirty. New Republic, 3(4), 601-604.

Gómez, A., Viguer, P., y Cantero, M. J. (2007). Intervención Temprana: desarrollo óptimo de 0 a 6 años. Madrid: Ediciones pirámide.

González, A., González, S., y Montero, L. (2010). Estimulación Temprana (Trabajo fin de master, Universidad de Arturo Michelena). Recueprado de https://es.scribd.com/doc/2526604/Estimulacion-Temprana

González, T. (2008). Diversidad e inclusión educativa: algunas reflexiones sobre el liderazgo en el centro escolar. Revista iberoamericana sobre calidad, eficacia y cambio en educación, 6(2), 1-16. Recuperado de http://www.redalyc.org/html/551/55160208/

González, M. (2005). Fisioterapia en neurología: estrategias de intervención en parálisis cerebral. Umbral Científico, 1(7), 24-32.

González-González, M. T. (2008). Diversidad e inclusión educativa: algunas reflexiones sobre el liderazgo en el centro escolar. Revista Iberoamericana sobre calidad, eficacia y cambio en educación, 6(2), 82-99. Recuperado de http://www.redalyc.org/pdf/551/55160208.pdf

Guba, E. G. (2008). Criterios de credibilidad en la investigación naturalista. En Gimeno, J., y Pérez, Á.I. (Eds.). La enseñanza: su teoría y su prática (6ª edición). Madrid: Akal.

Guba, E. G., y Lincoln, Y. (2002). Paradigmas en competencia en la investigación cualitativa. En Denman, C. y, Haro, J. A. (Coords.). Por los rincones. Antología de métodos cualitativos en la investigación social, (pp. 113-145). Sonora (México): Colegio Sonora.

Guralnick, M., y Bennett, F. (2001). Marco para una intervención precoz. In Eficacia de una intervención precoz en niños minusválidos y en situación de riesgo (pp. 3-40). Instituto Nacional de Servicios Sociales.

Gutiez, P., y Ruiz, E. (2012). Orígenes y evolución de la atención temprana. Una 
perspectiva histórica de la génesis de la atención temprana en nuestro país. Psicología Educativa, 18(2), 2012-2107. https://doi.org/10.5093/ed2012a12

Hamodi, C. (2014). La evaluación formativa y compartida en educación superior: un estudio de caso (Tesis doctoral, Universidad de Valladolid). Recuperado de http://uvadoc.uva.es/bitstream/10324/5668/1/TESIS562-140728.pdf

Hebb, D. (2009). The organization of behavior: a neuropsychological theory. Mahaway: Lawrence Erlbaum Associates.

Higgins, M., McLaughlin, T., Derby, K., y Long, J. (2012). The differential effects of direct instruction flashcards on sight-word identification for two preschool students with autism spectrum disorders. Academic Research International, 2(3), 394.

Hundert, J. (1994). The ecobehavioral relationship between teachers' and disabled preschoolers' behaviors before and after supervisor training. Journal of Behavioral Education, 4(1), 75-91.

Junta, A. (2016). Los bits de inteligencia en la etapa de la pre-lectura de los niños y niñas de primer año de educación general básica de la escuela "Glenn Doman" cantón Ambato provincia de Tungurahua (Trabajo fin de grado, Universidad Técnica de Ambato). Recuperado de http://repositorio.uta.edu.ec/bitstream/123456789/24397/1/Junta Chiluisa Ana Cristina.pdf

Kandel, E., Schwartz, J., Jessell, T., y Herreros, P. (1997). Neurociencia y conducta. Madrid: Prentice Hall.

Kawulich, B. (2005). La observación participante como método de recolección de datos. Forum Qualitative Social Research, 6(2), 1-23. Recuperado de http://diverrisa.es/uploads/documentos/LA-OBSERVACION-PARTICIPANTE.pdf

Korzeniowski, C. G. (2011). Desarrollo evolutivo del funcionamiento ejecutivo y su relación con el aprendizaje escolar. Revista de Psicología, 7(13), 7-26. Recuperado de

http://bibliotecadigital.uca.edu.ar/greenstone/collect/Revistas/import/159/13/desarr ollo-evolutivo-funcionamiento-ejecutivo/desarrollo-evolutivo-funcionamientoejecutivo.pdf

L’Ecuyer, C. (2015). La estimulación temprana fundamentada en el método Doman en 


\section{CAPITULO 7: BIBLIOGRAFÍA}

la Educación Infantil: bases teóricas, legado y futuro. Revista de la facultad de educación de Albacete, 30(2), 137-153.

Lazar, R. M. (1986). Second-order control of sequence-class equivalences in children. Behavioural Processes, 13(3), 205-215. Recuperado de https://www.sciencedirect.com/science/article/pii/0376635786900847

Leeber, J., y Rijke, R. (2003). Ecology of development in children with brain impairment. Child: care, health and development, 29(2), 131-140.

Livingston, G., Katona, C., Roch, B., Guilhaume, C., y Rive, B. (2004). A dependency model for patients with Alzheimer's disease: Its validation and relationship to the costs of care. Current medical research and opinion, 20(7), 1007-1016.

López-Arenas, G., y Cabrero, J. (1990). El video en el aula II: el vídeo como instrumento de conocimiento y evaluación. Revista de Educación, 292, 361-376. Recuperado de

https://idus.us.es/xmlui/bitstream/handle/11441/32237/El video en el aula II el video como ins.pdf? sequence $=1$

López, F. (2009). Plasticidad cerebral en la práctica diaria en alumnos y alumnas ciegos/as. Innovación y Experiencia, 20, 1-8.

López, L., y Dario, E. (2015). Hipoterapia como técnica de habilitación y rehabilitación Hippotherapy as a technique of habilitation and rehabilitation. Universidad y Salud, 17(2), 271-273.

López, V. (2009). Evaluación formativa y compartida en Educación Superior: propuestas, técnicas, instrumentos y experiencias. Madrid: Narcea.

Magaly, D. (2007). El Rigor en la Investigación Cualitativa: técnicas de análisis, credibilidad, transferibilidad y confirmabilidad. Revista Venezolana de Investigación, 1(1), 17-26. Recuperado de http://revistas.upel.edu.ve/index.php/sinopsis educativa/article/view/3539/1715

Maquillón, J. (2003). Diseño y evaluación del Diseño de un Programa de Intervención para la mejora de las habilidades de aprendizaje de los estudiantes universitarios (Tesis doctoral, Universidad de Murcia). Recuperado de https://digitum.um.es/xmlui/bitstream/10201/10682/1/MaquilonSanchez.pdf?seque $\underline{\mathrm{nce}=1}$ 
Marina, J. A. (2011). El cerebro infantil: la gran oportunidad. Navarra: Ariel.

Marina, J. A. (2012). Participación educativa: la investigación sobre el cerebro y la mejora de la educación. Neurociencia y educación, 11(11), 7-14. Recuperado de https://sede.educacion.gob.es/publiventa/d/15795/19/0

Martinez, F., Fernández, A., y Chacón, A. (2003). Atención Temprana. Enseñanza, 21(1), 245-274. Recuperado de https://gredos.usal.es/jspui/bitstream/10366/70741/1/Atencion Temprana.pdf

Martínez, L. A. (2007). La observación y el diario de campo en la definición de un tema de investigación. Revista Perfiles Libertadores, 4, 73-80. Recuperado de https://s3.amazonaws.com/academia.edu.documents/34712308/9 La observacio n y el diario de Campo en la Definicion de un Tema de Investigacion.pdf? AWSAccessKeyld=AKIAIWOWYYGZ2Y53UL3A\&Expires=1529526727\&Signatur e=aebuax9\%2BtreUr3\%2FUl8aMNjOcs6Q\%3D\&response-contentdisposition=inline\%3B\%20filename\%3DFecha de Recepcion 300307 Fecha de Ace.pdf

Martínez, M. (2000). La investigación-acción en el aula. Agenda Académica, 7(1). Recuperado de https:/ce16ba11-a-62cb3a1a-ssites.googlegroups.com/site/jesuscamposg19/assignments/investigarparatransfor mar-pnfalara-/MARTINEZ La investigación-acción en el aula.pdf?attachauth=ANoY7cpJGvez8NaKfMhrSnUOW08m3rU1PSz8pAWDKIR UeEbhzugcHK5l-

Martínez, P. C. (2006). El método de estudio de caso: estrategia metodológica de la investigación científica. Pensamiento y gestión, 1(20), 165-196. Recuperado de http://www.redalyc.org/pdf/646/64602005.pdf

Maureira, F. (2010). Neurociencia y Educación. Exemplum, 3, 267-274.

Millá, M. (2016). Armonización del desarrollo en la prematuridad y el bajo peso al nacer mediante programas de Atención Temprana (Tesis doctora, Universidad de Murcia). Recuperado de http://eds.b.ebscohost.com/eds/detail/detail?vid=0ysid=d01e4606-d715-4836acaf400979312950\%40sessionmgr101 ybdata=Jmxhbmc9ZXMmc2I0ZT1|ZHMtbG|2Z Q\%3D\%3D\#AN=edstdx.10803.396109ydb=edstdx 


\section{CAPITULO 7: BIBLIOGRAFÍA}

Millán, M., y Mulas, F. (2009). Atención temprana: qué es y para qué sirve. Summa Neurológica, 1(3), 31-34.

Morales, A., y Rincón, C. (2016). Relación entre madurez neuropsicológica y presenciaausencia de la conducta de gateo. Acta de Investigación Psicológica, 6(2), 24502458. https://doi.org/10.1016/j.aipprr.2016.06.008

Moreno-Torres, I., Cid, M., Santana, R., y Ramos, A. (2011). Estimulación temprana y desarrollo lingüístico en niños sordos con implante coclear: el primer año de experiencia auditiva. Revista de investigación en logopedia, 1(1), 56-75.

Moreno, J., García, M., Godoy, M., y Suárez, Á. (2011). Intervención logopédica en un caso de negligencia infantil con graves repercusiones en el lenguaje. Boletín de AELFA, 11(2), 54-60.

Moya, A., y García, A. (2014). The application of bits of intelligence as prevention of possible learning disabilities in childhood. Journal for Educators, Teachers and Trainers, 5(52), 130-142. Recuperado de http://www.ugr.es/ jett/index.php

Munck, V., y Sobo, E. (1998). Using Methods in the field: a practical introduction and casebook. California: AltaMira Press.

Navarro, J., Alcalde, C., Marchena, E., Gonzalo, I., y Sedeños, M. (2009). Estimación del aprendizaje matemático mediante la versión española del Test de Evaluación Matemática Temprana de Utrecht. European Journal of Education and Psychology, 2(2), 131-143. Recuperado de http://www.redalyc.org/html/1293/129312577004/

Noreña, A. L., Alcaraz-Moreno, N., Rojas, J., y Rebolledo-Malpica, D. (2012). Aplicabilidad de los criterios de rigor y éticos en la investigación. Aquichan, 12(3), 263-274. Recuperado de http://jbposgrado.org/icuali/Criterios de rigor en la Inv cualitativa.pdf

Oliva, J., y Acosta, J. (2015). Aplicación del programa de estimulación temprana con bits de inteligencia en niños del nivel inicia. Revista Científica PAIAN, 5(1), 1-10.

Orcaja, N. (2017). Diseño, aplicación y evaluación del plan de formación de tutores en Atención Temprana (Tesis doctoral, Universidad de Murcia). Recuperado de: https://www.tdx.cat/handle/10803/405575

Ortiz, T. (2009). Neurociencia y educación. Madrid: Alianza Editorial. 
Perez-Serrano, G. (2014). Investigación Cualitativa. Retos e interrogantes. Madrid: La Muralla.

Pérez, J., y Brito, A. (2006). Manual de atención temprana. Madrid: Ediciones Pirámide.

Pérez, J., Martínez, M., Díaz, A., y Brito, A. (2012). Prevención, promoción del desarrollo y atención temprana en la Escuela Infantil. Revista de educación, 43, 17-32.

Pérez, M., y Lorenzo, R. (2001). Inventario de desarrollo de Atención Temprana. Salamanca: AMARÚ Ediciones.

Pineda, D. A. (2000). La función ejecutiva y sus trastornos. Revista de Neurología, 30 (8), 764-768.

Pinos, A. (2013). Estimulación del cerebro con bits de inteligencia y su influencia en el proceso de enseñanza aprendizaje en los niños y niñas de 3 a 4 años del centro de educación general básica "Paulo Freire" de la ciudad de Ambato provincia de Tungurahua en el periodo (Trabajo fin de grado, Universidad Técnica de Ambato). Recuperado de http://repositorio.uta.edu.ec/bitstream/123456789/6396/1/FCHE LEP 456.pdf

Redruello, R. (2004). La organización de la atención temprana en la educación infantil. Tendencias Pedagógicas, 9, 277-249.

Regidor, R. (2003). Las capacidades del niño : guía de estimulación temprana de 0 a 8 años. Madrid: Palabra.

Rivas, S. (2004). Educación temprana en el niño de 0 a 3 años a través de programas. Pamplona: EUNSA.

Robles, M. A., y Sánchez, D. (2013). Atención infantil temprana en España. Papeles del Psicólogo, 34(2), 132-143. Recuperado de http://www.redalyc.org/html/778/77827025005/

Robles, M., y Sánchez, D. (2013). Tratamiento del síndrome del cromosoma X frágil desde la atención infantil temprana en España. Apuntes de Pedagogía, 1, 19-26.

Rodríguez, D. (1993). Programa de atención temprana: intervención con niños con síndrome de Down. Edicación especial y dificultades de aprendizaje, 31, 176. Recuperado de http://eds.b.ebscohost.com/eds/detail/detail?vid=1ysid=79dc79bdOffd-4e08-9b72-2d4f0d5546ff\%40pdc-v- 


\section{CAPITULO 7: BIBLIOGRAFÍA}

sessmgr01ybdata $=J m \times h b m c 9 Z X M m c 2|0 Z T 1| Z H M t b G \mid 2 Z Q \% 3 D \% 3 D \# d b=c a t 0360$ 3ayAN=UVa.b1227492

Romine, C., y Reynolds, C. (2005). A model of the development of frontal lobe functioning: findings from a meta-analysis. Applied Neuropsychology, 12(4), 190201. https://doi.org/10.1207/s15324826an1204_2

Ruiz, J. I. (2012). Metodología de la investigación cualitativa (5ª edición). Bilbao: Deusto.

Salvador, J. (1987). La estimulación precoz en la educación especial. Barcelona: Ceac.

Sánchez-Raya, M., Martínez-Gual, E., Elvira, J., Salas, B., y Cívico, F. (2015). La atención temprana en los trastornos del espectro autista (TEA). Psicología Educativa, 21(1), 55-63. https://doi.org/10.1016/j.pse.2014.04.001

Santos, M. A. (2003). Una flecha en la diana: la evaluación como aprendizaje. Madrid: Narcea.

Santoyo, P. (2010). Driven by data: a practical guide to improve instruction. Nueva Jersey: Jossey-Bass.

Shonkoff, J. P., y Meisels, S. J. (1990). Early childhood intervention: The evolution of a concept. Handbool of Early Childhood Intervention, 1, 1-29.

Simons, H. (2011). El estudio de caso: Teoría y práctica. Madrid: Morata.

Soriano, V. (2000). Intervención temprana en europa: organización de servicios y asistencia a los niños y sus familias tendencias en 17 países europeos agencia europea para el desarrollo de la educación especial. Madrid: Real Patronato de Prevención y de Atención a Personas con Minusvalía.

Stake, R. E. (2007). Investigación con estudio de casos. Madrid: Morata.

Stenhouse, L. (1998). La investigación como base de la enseñanza (5ª edición). Madrid: Morata.

Tarcisio, J. (2012). Neurociencia + pedagogía = neuropedagogía: repercusiones e implicaciones de los avances de la neurociencia para la práctica educativa (Trabajo fin de master, Universidad Internacional de Andalucia). Recuperado de http://repositorio.biblioteca.unia.es/bitstream/handle/10334/2075/0341 Ferreira.pd $\underline{\text { f?sequence }=1}$ 
Tellano, F., Cueli, M., González-Castro, P., Rodríguez, C., Fernández-Vázquez, E., y Álvarez, A. I. (2016). Eficacia del programa EPI.com para la estimulación de las habilidades lectoras en Educación Infantil. Revista de Psicología y Educación, 11(2), 43-64. Recuperado de http://www.revistadepsicologiayeducacion.es/pdf/139.pdf

Tortosa, A., y Reiriz, J. (2010). Sistema nervioso: anatomia. Infermera Virtual, 1-31. Recuperado de https://www.infermeravirtual.com/files/media/file/99/Sistema nervioso.pdf?1358605492

Trianes, M. V; De la Morena, M. L. y Muñoz, A. M. (1999) Relaciones sociales y prevención de la inadaptación social y escolar. Málaga: Aljibe.

UNESCO (2006). Educación para todos. La alfabetización, un factor vital. Paris: Ediciones UNESCO.

Uriarte, R. (2013). Manual de estimulación temprana: esos preciosos primeros años. Madrid: Psimática.

Vázquez, R., y Angulo, F. (2003). Introducción a los estudios de casos: los primeros contactos con la investigación etnográfica. Málaga: Ediciones Aljibe.

Vera, M. J., y Pérez-López, J. (2009). El funcionamiento de un Centro de Desarrollo Infantil y Atención Temprana (CDIAT). Revista interuniversitaria de formación del profesorado, 23(2), 21-38. Recuperado de http://www.redalyc.org/html/274/27419063003/

Velasco, H., y De Rada, Á. D. (1997). La lógica de la investigación etnográfica. Madrid: Trotta.

Vidal, M. (2007). Estimulación temprana de 0 a 6 años: desarrollo de capacidades, valoración y programas de intervención. Madrid: CEPE.

Vizuete, M. J. (2014). El método Glenn Doman en el desarrollo de la atención de niños de 2 a 3 años del centro de desarrollo infantil Los Pecuaritos de la ciudad de Riobamba (Trabajo fin de grado, Universidad Técnica de Ambato). Recuperado de http://repositorio.uta.edu.ec/bitstream/123456789/8403/1/Vizuete Naranjo\%2C María José.pdf

Walker, R. (2002). Case Study, Case Records and MultimediaWalker. Cambridge 
CAPITULO 7: BIBLIOGRAFÍA

Journal of Education, 32(1), 109-127. https://doi.org/10.1080/03057640220116463

White, L. A. (1975). El concepto de cultura: textos fundamentales. Barcelona: Anagrama.

Yin, R. (1989). Case Study Research. Design and Methods. London: SAGE.

Zabalza, M. A. (2004). Diarios de clase: un instrumento de investigación y desarrollo profesional. Madrid: Narcea.

Zoila, M., Sazo, E., y Gálvez, J. A. (2014). El aprendizaje de la lectura y la escritura en los primeros años de escolaridad: experiencias exitosas de Guatemala. Revista Interamericana de Psicología, 48(2), 212-222. Recuperado de http://www.uvg.edu.gt/investigacion/cie/doc/Publicaciones-jun-8-2015.pdf

\subsection{REFERENCIAS LEGISLATIVAS}

Constitución Española. Boletín Oficial del Estado. Madrid, 29 de diciembre de 1978, núm. 311, pp. 29313-29424.

Real Decreto 620/1981, de 5 de febrero, de régimen unificado de ayudas públicas a discapacitados. Boletín Oficial del Estado. Madrid, 6 de abril de 1981, núm. 274, pp. 40133-40134.

Real Decreto 1174/1983, de 27 de abril, sobre educación compensatoria. Boletín Oficial del Estado. Madrid, 27 de abril de 1983, núm. 112, pp. 13109-13110.

Real Decreto 334/1985, de 6 de marzo, de ordenación de la Educación Especial Boletín Oficial del Estado. Madrid, 16 de marzo de 1985, núm. 65, pp. 6917-6920.

Ley Orgánica 1/1991, de 3 de octubre, de Ordenación General del Sistema Educativo. Boletín Oficial del Estado. Madrid, 26 de junio de 1991, núm. 152, pp. 21191 21193

Real Decreto 1344/1991, de 6 de septiembre, por el que se establecen los aspectos básicos del currículo de la Educación Infantil. Boletín Oficial del Estado. Madrid, 7 de septiembre de 1991, núm. 220, pp. 30226-30228.

Orden de 9 de diciembre de 1992, del Ministerio de Educación y Ciencia, por la que se regulan la estructura y funciones de los Equipos de Orientación Educativa y Psicopedagógica. Boletín Oficial del Estado. Madrid, 18 de febrero de 1992, núm. 303, 
Real Decreto 696/1995, de 28 de abril, de ordenación de la educación de los alumnos con necesidades educativas especiales (BOE, 2 de junio, 1995), pp. 4299142993.

Ley Orgánica 1/1996, de 15 de enero, de Protección Jurídica del Menor, de modificación parcial del Código Civil y de la Ley de Enjuiciamiento Civil. Boletín Oficial del Estado. Madrid, 17 de enero de 1996, núm. 15, pp. 1225-1238.

Orden, de 14 de febrero de 1996 por la que se regula el procedimiento para la realización de la evaluación y el dictamen de escolarización y se establecen los criterios para la escolarización de los alumnos con necesidades educativas especiales. Boletín Oficial del Estado. Madrid, 23 de febrero de 1996, pp. 6918-6922.

Real Decreto 1971/1999, de 23 de diciembre, de procedimiento para el reconocimiento, declaración y calificación del grado de minusvalía. Boletín Oficial del Estado. Madrid, 26 de enero de 2000, núm. 22, pp. 3317-3410.

Ley 41/2002, de 14 de noviembre, básica reguladora de la autonomía del paciente y de derechos y obligaciones en materia de información y documentación clínica. Boletín Oficial del Estado. Madrid, 15 de noviembre de 2002, núm. 274, pp. 40126-40132.

Ley Orgánica 10/2002, del 23 de diciembre, de Calidad de la Educación. Boletín Oficial del Estado. Madrid, 24 de diciembre de 2003, núm. 307, pp. 45188-45220.

Ley 16/2003, de 28 de mayo, de cohesión y calidad del Sistema Nacional de Salud. Boletín Oficial del Estado. Madrid, 29 de mayo de 2003, núm. 128, pp. 2056720588.

Real Decreto 828/2003, por el que se establecen los aspectos educativos básicos en Educación Preescolar. Boletín Oficial del Estado. Madrid, 1 de julio de 2003, núm. 156, pp. 25286-25288.

Ley 51/2003, de 2 de diciembre, de igualdad de oportunidades, no discriminación y accesibilidad universal de las personas con discapacidad. Boletín Oficial del Estado. Madrid, 3 de diciembre de 2003, núm. 289, pp. 43187-43195.

Ley Orgánica de Educación, de 3 de mayo, de Educación. Boletín Oficial del Estado. Madrid, 4 de mayo de 2006, núm. 106, pp. 17158-17207. 


\section{CAPITULO 7: BIBLIOGRAFÍA}

Decreto 122/2007, de 27 de diciembre, por el que se establece el currículo del segundo ciclo de la Educación Infantil en la Comunidad de Castilla y León. Boletín Oficial del Castilla y León. Valladolid, 2 de enero de 2007, núm. 191, pp. 19429-19430.

Real Decreto 132/2010, de 12 de febrero, por el que se establecen los requisitos mínimos de los centros que impartan las enseñanzas del segundo ciclo de la Educación Infantil, la Educación Primaria y la Educación Secundaria. Boletín Oficial del Estado. Madrid, 12 de marzo de 2010, núm. 62, pp. 24831-24840.

Orden EDU/1152/2010, de 3 de agosto, por la que se regula la respuesta educativa al alumnado con necesidad específica de apoyo educativo escolarizado en el segundo ciclo de Educación Infantil, Educación Primaria, Educación Secundaria Obligatoria, Bachillerato y Enseñanzas de Educación Especial, en los centros docentes de la Comunidad de Castilla y León. Boletín Oficial del Castilla y León. Valladolid, 13 de agosto, 2010, núm. 156, pp. 64449-64469.

Ley Orgánica 8/2013, de 9 de diciembre, para la mejora de la calidad educativa. Boletín Oficial del Estado. Madrid, 10 de diciembre de 2013, núm. 295, pp. 97858-97921. 


\section{ANEXOS}

Para visualizar los videos de los anexos se pueden utilizar dos procedimientos: (1) presionado "click+control" sobre la dirección url del video, redirigiéndose al enlace youtube; o (2) mediante un lector QR previamente descargado en un dispositivo electrónico (tablet o móvil).

Anexo 1: video $3^{\circ} \mathrm{El}, 2^{\circ}$ trimestre (I)

https://youtu.be/qEKe13vTmT8

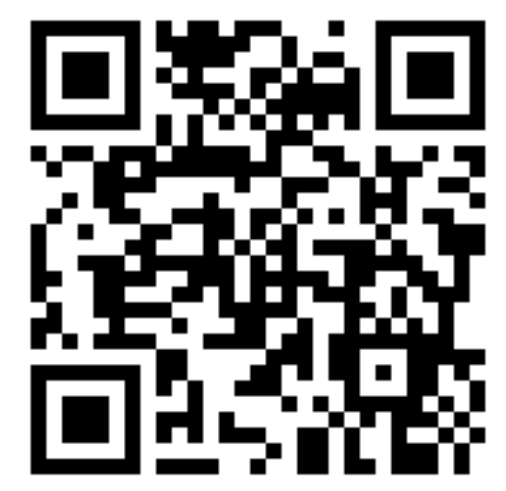

Anexo 2: video 3ํㅡㄹ, 3o trimestre (I)

https://youtu.be/LqRtW XF sM

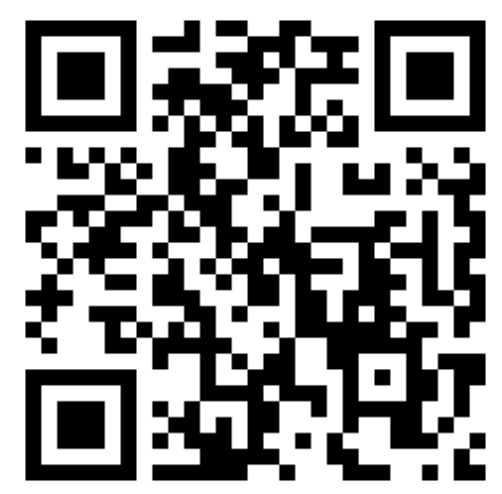


Anexo 3: $3^{\circ} \mathrm{El}, 3^{\circ}$ trimestre (II)

https://youtu.be/zRbLObnCT-o

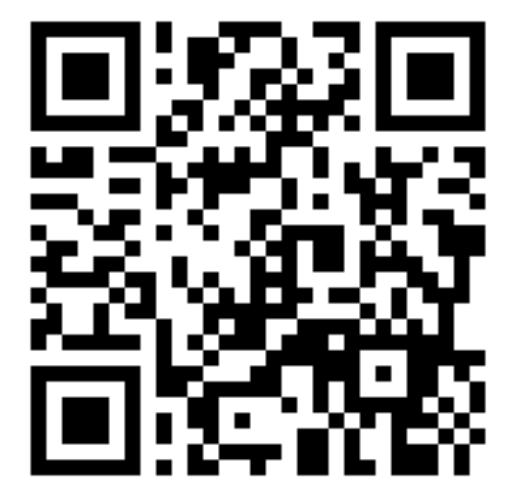

Anexo 4: $1^{\circ} \mathrm{El}, 1^{\circ}$ trimestre $(\mathrm{I})$

https://youtu.be/H6AF2Ao9DrU

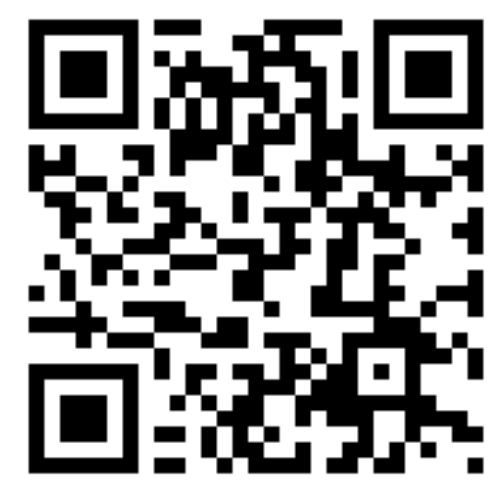


Anexo 5: $1^{\circ} \mathrm{El}, 3^{\circ}$ trimestre (I)

https://youtu.be/GPSPmSKR9j8

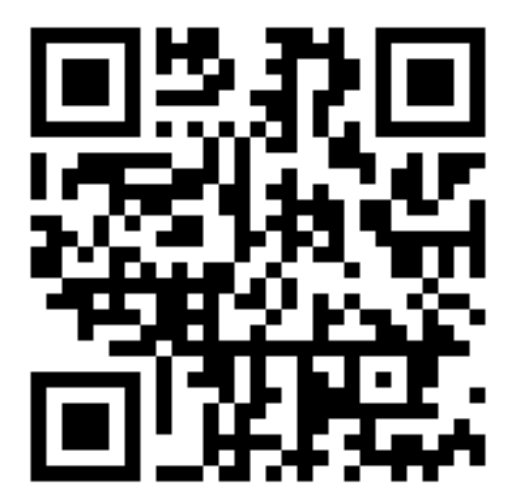

Anexo 6: $1^{\circ} \mathrm{El}, 3^{\circ}$ trimestre (II)

https://www.youtube.com/watch?v=jillCwBwFMtQ\&feature=youtu.be

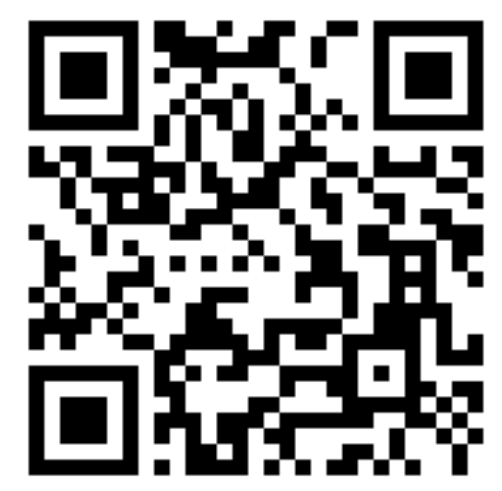


Anexo 7: $1^{\circ} \mathrm{EI}, 3^{\circ}$ trimestre (III)

https://youtu.be/PiiGgOU9Tns

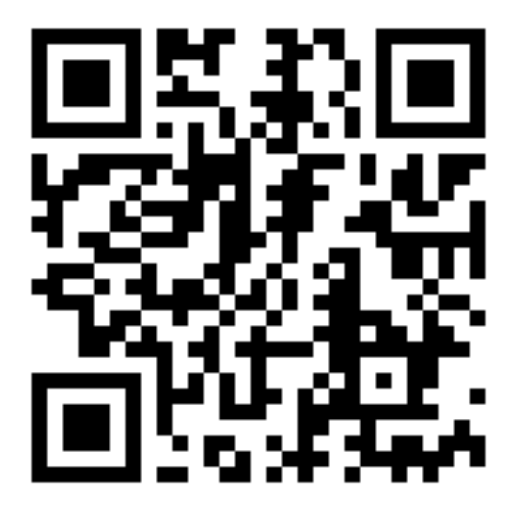

Anexo 8: $2^{\circ} \mathrm{EI}, 1^{\circ}$ trimestre (I)

https://youtu.be/pcqz7bA3SQE

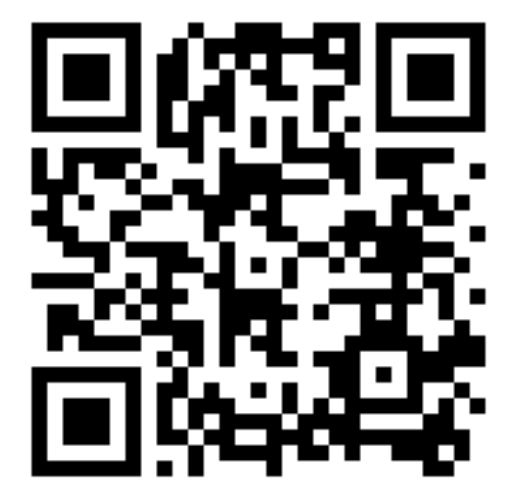


Anexo 9: $2^{\circ} \mathrm{El}, 1^{\circ}$ trimestre (II)

https://youtu.be//RIRAt5tMdc

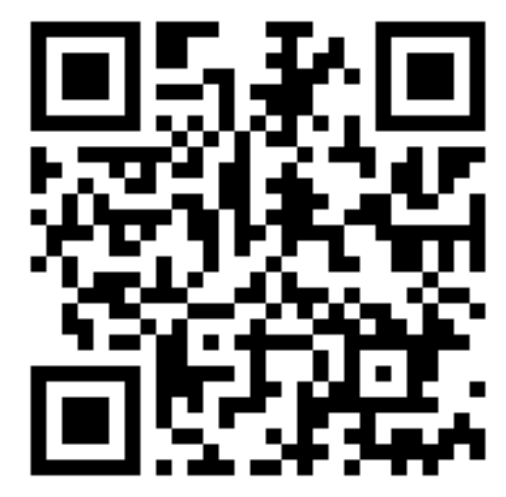

Anexo 10: $2^{\circ} \mathrm{El}, 1^{\circ}$ trimestre (I)

https://youtu.be/hvox6nD3ztl

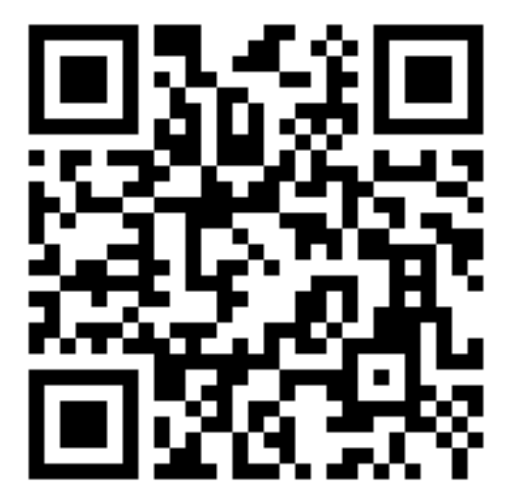


Anexo 11: $2^{\circ} \mathrm{EI}, 3^{\circ}$ trimestre (II)

https://youtu.be/s46c7sdsV5M

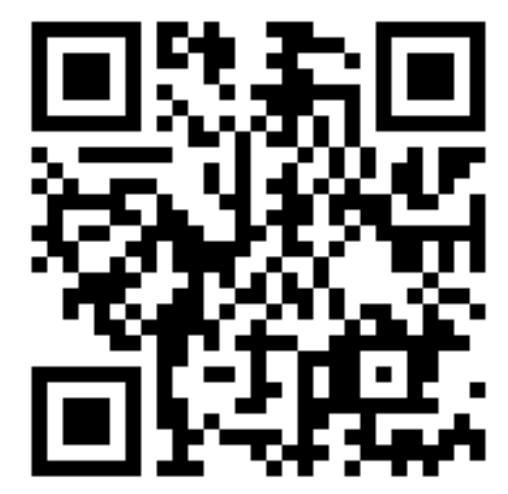

